\title{
TOXICOLOGICAL PROFILE FOR
}

ZINC

U.S. DEPARTMENT OF HEALTH AND HUMAN SERVICES

Public Health Service

Agency for Toxic Substances and Disease Registry

August 2005 


\section{DISCLAIMER}

The use of company or product name(s) is for identification only and does not imply endorsement by the Agency for Toxic Substances and Disease Registry. 


\section{UPDATE STATEMENT}

A Toxicological Profile for Zinc, Draft for Public Comment was released in September 2003. This edition supersedes any previously released draft or final profile.

Toxicological profiles are revised and republished as necessary. For information regarding the update status of previously released profiles, contact ATSDR at:

Agency for Toxic Substances and Disease Registry Division of Toxicology/Toxicology Information Branch 1600 Clifton Road NE

Mailstop F-32

Atlanta, Georgia 30333 



\section{FOREWORD}

This toxicological profile is prepared in accordance with guidelines* developed by the Agency for Toxic Substances and Disease Registry (ATSDR) and the Environmental Protection Agency (EPA). The original guidelines were published in the Federal Register on April 17, 1987. Each profile will be revised and republished as necessary.

The ATSDR toxicological profile succinctly characterizes the toxicologic and adverse health effects information for the hazardous substance described therein. Each peer-reviewed profile identifies and reviews the key literature that describes a hazardous substance's toxicologic properties. Other pertinent literature is also presented, but is described in less detail than the key studies. The profile is not intended to be an exhaustive document; however, more comprehensive sources of specialty information are referenced.

The focus of the profiles is on health and toxicologic information; therefore, each toxicological profile begins with a public health statement that describes, in nontechnical language, a substance's relevant toxicological properties. Following the public health statement is information concerning levels of significant human exposure and, where known, significant health effects. The adequacy of information to determine a substance's health effects is described in a health effects summary. Data needs that are of significance to protection of public health are identified by ATSDR and EPA.

Each profile includes the following:

(A) The examination, summary, and interpretation of available toxicologic information and epidemiologic evaluations on a hazardous substance to ascertain the levels of significant human exposure for the substance and the associated acute, subacute, and chronic health effects;

(B) A determination of whether adequate information on the health effects of each substance is available or in the process of development to determine levels of exposure that present a significant risk to human health of acute, subacute, and chronic health effects; and

(C) Where appropriate, identification of toxicologic testing needed to identify the types or levels of exposure that may present significant risk of adverse health effects in humans.

The principal audiences for the toxicological profiles are health professionals at the Federal, State, and local levels; interested private sector organizations and groups; and members of the public.

This profile reflects ATSDR's assessment of all relevant toxicologic testing and information that has been peer-reviewed. Staff of the Centers for Disease Control and Prevention and other Federal scientists have also reviewed the profile. In addition, this profile has been peer-reviewed by a nongovernmental panel and was made available for public review. Final responsibility for the contents and views expressed in this toxicological profile resides with ATSDR.

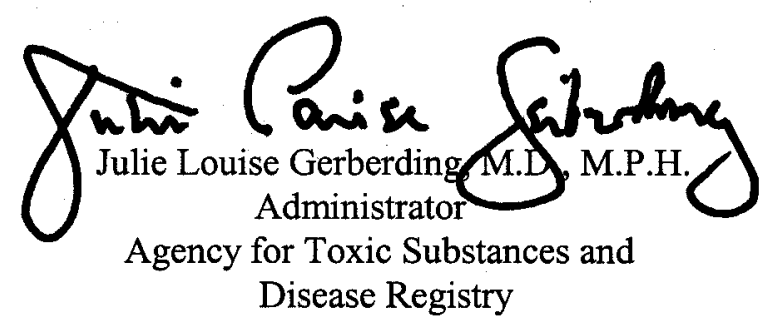




\section{* Legislative Background}

The toxicological profiles are developed in response to the Superfund Amendments and Reauthorization Act (SARA) of 1986 (Public law 99-499) which amended the Comprehensive Environmental Response, Compensation, and Liability Act of 1980 (CERCLA or Superfund). This public law directed ATSDR to prepare toxicological profiles for hazardous substances most commonly found at facilities on the CERCLA National Priorities List and that pose the most significant potential threat to human health, as determined by ATSDR and the EPA. The availability of the revised priority list of 275 hazardous substances was announced in the Federal Register on November 17, 1997 (62 FR 61332). For prior versions of the list of substances, see Federal Register notices dated April 29, 1996 (61 FR 18744); April 17, 1987 (52 FR 12866); October 20, 1988 (53 FR 41280); October 26, 1989 (54 FR 43619); October 17, 1990 (55 FR 42067); October 17, 1991 (56 FR 52166); October 28, 1992 (57 FR 48801); and February 28, 1994 (59 FR 9486). Section 104(i)(3) of CERCLA, as amended, directs the Administrator of ATSDR to prepare a toxicological profile for each substance on the list. 


\section{QUICK REFERENCE FOR HEALTH CARE PROVIDERS}

Toxicological Profiles are a unique compilation of toxicological information on a given hazardous substance. Each profile reflects a comprehensive and extensive evaluation, summary, and interpretation of available toxicologic and epidemiologic information on a substance. Health care providers treating patients potentially exposed to hazardous substances will find the following information helpful for fast answers to often-asked questions.

\section{Primary Chapters/Sections of Interest}

Chapter 1: Public Health Statement: The Public Health Statement can be a useful tool for educating patients about possible exposure to a hazardous substance. It explains a substance's relevant toxicologic properties in a nontechnical, question-and-answer format, and it includes a review of the general health effects observed following exposure.

Chapter 2: Relevance to Public Health: The Relevance to Public Health Section evaluates, interprets, and assesses the significance of toxicity data to human health.

Chapter 3: Health Effects: Specific health effects of a given hazardous compound are reported by type of health effect (death, systemic, immunologic, reproductive), by route of exposure, and by length of exposure (acute, intermediate, and chronic). In addition, both human and animal studies are reported in this section.

NOTE: Not all health effects reported in this section are necessarily observed in the clinical setting. Please refer to the Public Health Statement to identify general health effects observed following exposure.

Pediatrics: Four new sections have been added to each Toxicological Profile to address child health issues:

Section 1.6 How Can (Chemical X) Affect Children?

Section 1.7 How Can Families Reduce the Risk of Exposure to (Chemical X)?

Section 3.7 Children's Susceptibility

Section 6.6 Exposures of Children

Other Sections of Interest:

Section 3.8 Biomarkers of Exposure and Effect

Section 3.11 Methods for Reducing Toxic Effects

\section{ATSDR Information Center}

Phone: 1-888-42-ATSDR or (404) 498-0110 Fax: $\quad$ (770) 488-4178

E-mail: atsdric@cdc.gov Internet: http://www.atsdr.cdc.gov

The following additional material can be ordered through the ATSDR Information Center:

Case Studies in Environmental Medicine: Taking an Exposure History-The importance of taking an exposure history and how to conduct one are described, and an example of a thorough exposure history is provided. Other case studies of interest include Reproductive and Developmental 
Hazards; Skin Lesions and Environmental Exposures; Cholinesterase-Inhibiting Pesticide Toxicity; and numerous chemical-specific case studies.

Managing Hazardous Materials Incidents is a three-volume set of recommendations for on-scene (prehospital) and hospital medical management of patients exposed during a hazardous materials incident. Volumes I and II are planning guides to assist first responders and hospital emergency department personnel in planning for incidents that involve hazardous materials. Volume IIIMedical Management Guidelines for Acute Chemical Exposures-is a guide for health care professionals treating patients exposed to hazardous materials.

Fact Sheets (ToxFAQs) provide answers to frequently asked questions about toxic substances.

\section{Other Agencies and Organizations}

The National Center for Environmental Health (NCEH) focuses on preventing or controlling disease, injury, and disability related to the interactions between people and their environment outside the workplace. Contact: NCEH, Mailstop F-29, 4770 Buford Highway, NE, Atlanta, GA 30341-3724 • Phone: 770-488-7000 • FAX: 770-488-7015.

The National Institute for Occupational Safety and Health (NIOSH) conducts research on occupational diseases and injuries, responds to requests for assistance by investigating problems of health and safety in the workplace, recommends standards to the Occupational Safety and Health Administration (OSHA) and the Mine Safety and Health Administration (MSHA), and trains professionals in occupational safety and health. Contact: NIOSH, 200 Independence Avenue, SW, Washington, DC 20201 • Phone: 800-356-4674 or NIOSH Technical Information Branch, Robert A. Taft Laboratory, Mailstop C-19, 4676 Columbia Parkway, Cincinnati, OH 45226-1998 - Phone: 800-35-NIOSH.

The National Institute of Environmental Health Sciences (NIEHS) is the principal federal agency for biomedical research on the effects of chemical, physical, and biologic environmental agents on human health and well-being. Contact: NIEHS, PO Box 12233, 104 T.W. Alexander Drive, Research Triangle Park, NC 27709 • Phone: 919-541-3212.

\section{Referrals}

The Association of Occupational and Environmental Clinics (AOEC) has developed a network of clinics in the United States to provide expertise in occupational and environmental issues. Contact: AOEC, 1010 Vermont Avenue, NW, \#513, Washington, DC 20005 • Phone: 202-347-4976 •FAX: 202-347-4950•e-mail: AOEC@AOEC.ORG•Web Page: http://www.aoec.org/.

The American College of Occupational and Environmental Medicine (ACOEM) is an association of physicians and other health care providers specializing in the field of occupational and environmental medicine. Contact: ACOEM, 55 West Seegers Road, Arlington Heights, IL 60005 • Phone: 847-818-1800 • FAX: 847-818-9266. 


\section{CONTRIBUTORS}

\section{CHEMICAL MANAGER(S)/AUTHOR(S):}

Nickolette Roney, M.S.

Cassandra V. Smith, M.S.

Malcolm Williams, D.V.M., Ph.D.

Agency for Toxic Substances and Disease Registry, Atlanta, GA

Mark Osier, Ph.D., D.A.B.T.

Sari J. Paikoff, Ph.D.

Syracuse Research Corporation, North Syracuse, NY

\section{THE PROFILE HAS UNDERGONE THE FOLLOWING ATSDR INTERNAL REVIEWS:}

1. Health Effects Review. The Health Effects Review Committee examines the health effects chapter of each profile for consistency and accuracy in interpreting health effects and classifying end points.

2. Minimal Risk Level Review. The Minimal Risk Level Workgroup considers issues relevant to substance-specific Minimal Risk Levels (MRLs), reviews the health effects database of each profile, and makes recommendations for derivation of MRLs.

3. Data Needs Review. The Research Implementation Branch reviews data needs sections to assure consistency across profiles and adherence to instructions in the Guidance.

4. Green Border Review. Green Border review assures the consistency with ATSDR policy. 



\section{PEER REVIEW}

A peer review panel was assembled for zinc. The panel consisted of the following members:

1. Olen Brown, Ph.D., University of Missouri-Columbia, Columbia, Missouri;

2. Robert Michael, Ph.D., RAM TRAC Corporation, Schenectady, New York; and

3. Gary Pascoe, Ph.D., DABT, Pascoe Environmental Consulting, Port Townsend, Washington.

These experts collectively have knowledge of zinc's physical and chemical properties, toxicokinetics, key health end points, mechanisms of action, human and animal exposure, and quantification of risk to humans. All reviewers were selected in conformity with the conditions for peer review specified in Section 104(I)(13) of the Comprehensive Environmental Response, Compensation, and Liability Act, as amended.

Scientists from the Agency for Toxic Substances and Disease Registry (ATSDR) have reviewed the peer reviewers' comments and determined which comments will be included in the profile. A listing of the peer reviewers' comments not incorporated in the profile, with a brief explanation of the rationale for their exclusion, exists as part of the administrative record for this compound.

The citation of the peer review panel should not be understood to imply its approval of the profile's final content. The responsibility for the content of this profile lies with the ATSDR. 



\section{CONTENTS}

DISCLAIMER

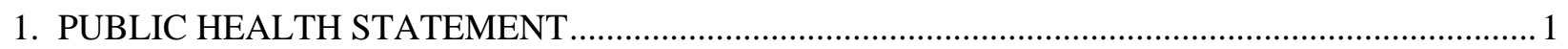

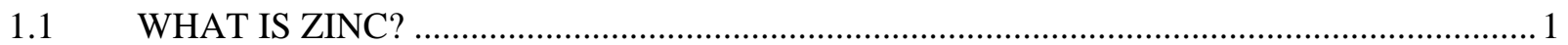

1.2 WHAT HAPPENS TO ZINC WHEN IT ENTERS THE ENVIRONMENT? ............................

1.3 HOW MIGHT I BE EXPOSED TO ZINC? …………………………………………...

1.4 HOW CAN ZINC ENTER AND LEAVE MY BODY? ....................................................... 4

1.5 HOW CAN ZINC AFFECT MY HEALTH? ..................................................................... 4

1.6 HOW CAN ZINC AFFECT CHILDREN? ……………………………………………6

1.7 HOW CAN FAMILIES REDUCE THE RISK OF EXPOSURE TO ZINC................................ 6

1.8 IS THERE A MEDICAL TEST TO DETERMINE WHETHER I HAVE BEEN EXPOSED TO ZINC? .........................................................................................................

1.9 WHAT RECOMMENDATIONS HAS THE FEDERAL GOVERNMENT MADE TO PROTECT HUMAN HEALTH? ....................................................................................

1.10 WHERE CAN I GET MORE INFORMATION? …………………………………….....

2. RELEVANCE TO PUBLIC HEALTH ................................................................................... 11

2.1 BACKGROUND AND ENVIRONMENTAL EXPOSURES TO ZINC IN THE UNITED

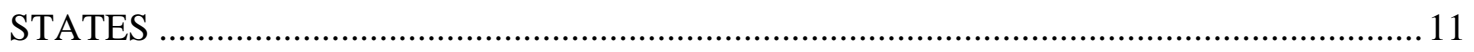

$2.2 \quad$ SUMMARY OF HEALTH EFFECTS ………………………………………………........ 11

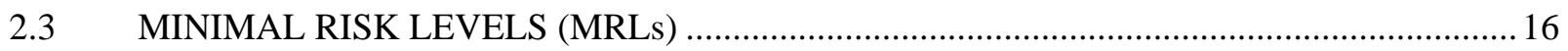

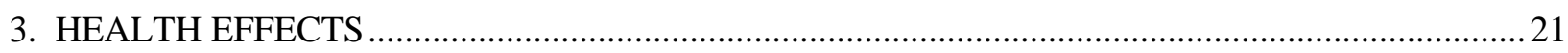

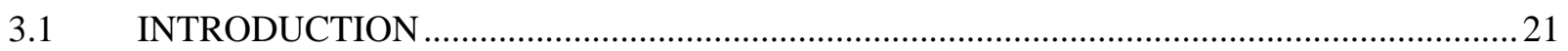

3.2 DISCUSSION OF HEALTH EFFECTS BY ROUTE OF EXPOSURE …………………......22

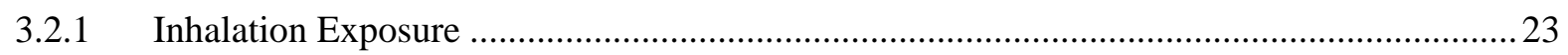

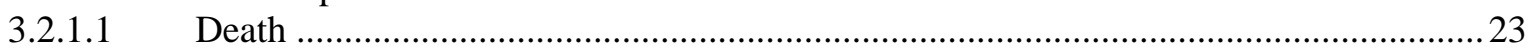

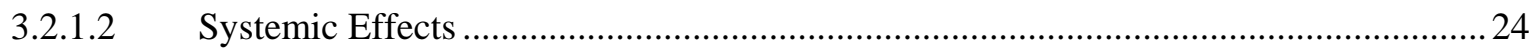

3.2.1.3 Immunological and Lymphoreticular Effects............................................................. 36

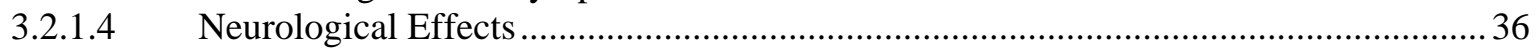

3.2.1.5 Reproductive Effects ………………………………………………………….... 37

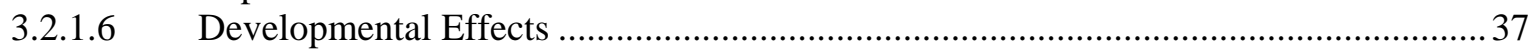

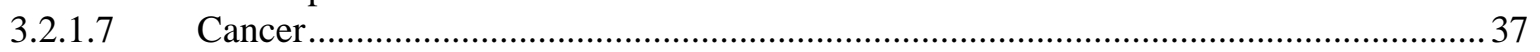

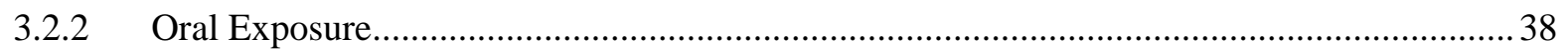

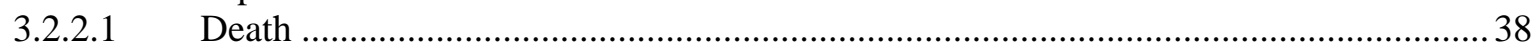

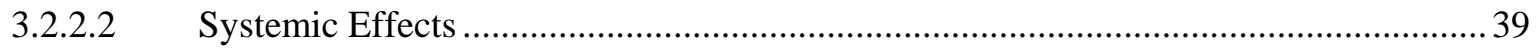

3.2.2.3 Immunological and Lymphoreticular Effects ..........................................................6 63

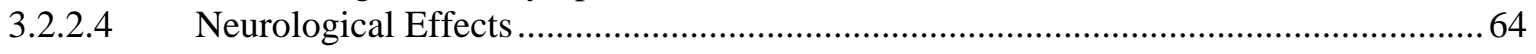

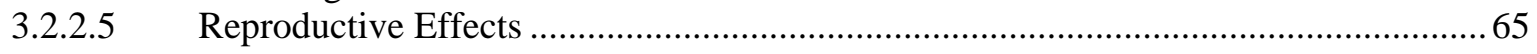




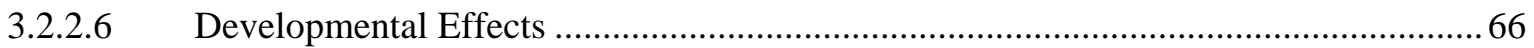

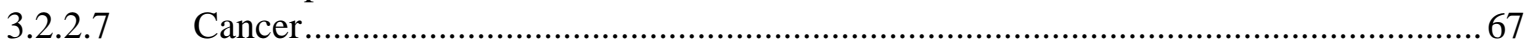

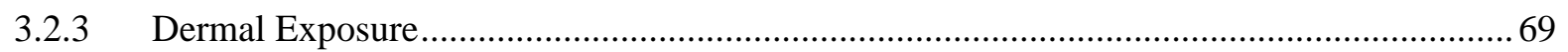

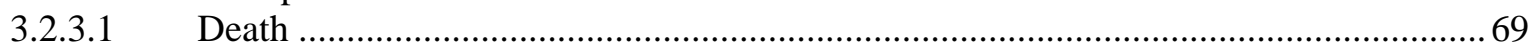

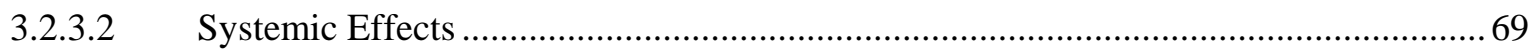

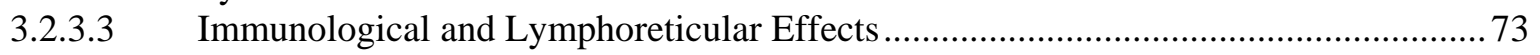

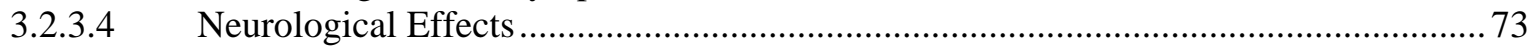

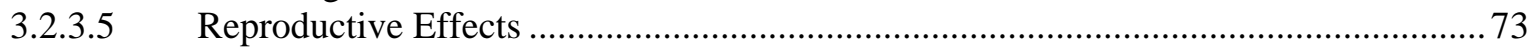

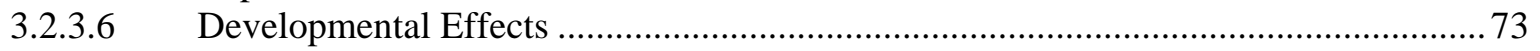

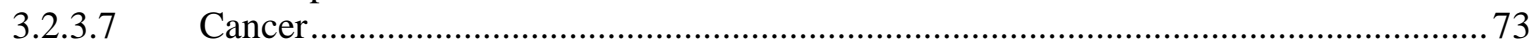

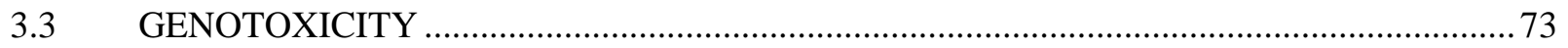

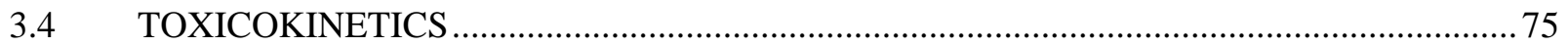

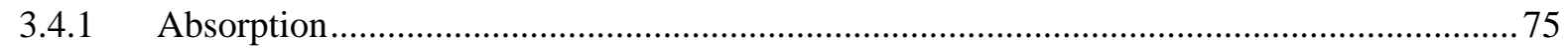

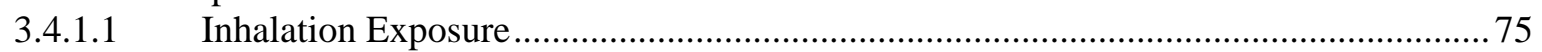

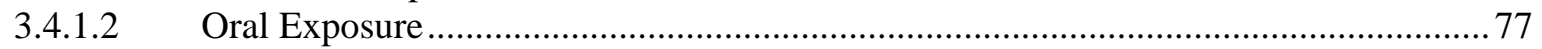

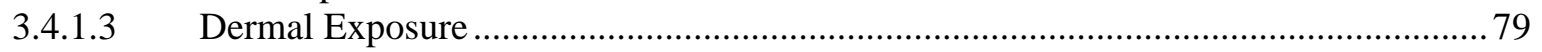

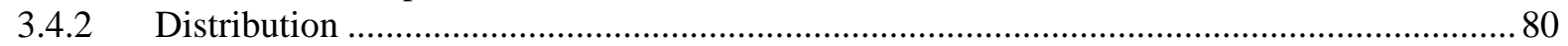

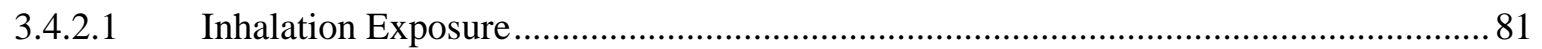

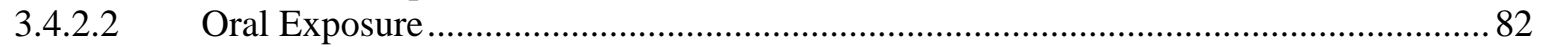

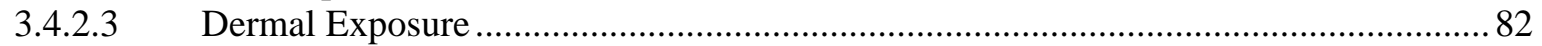

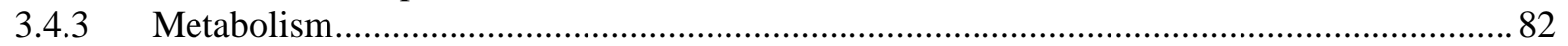

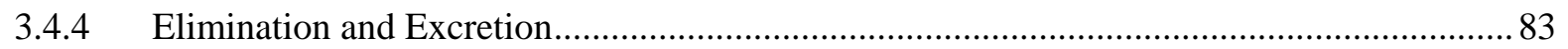

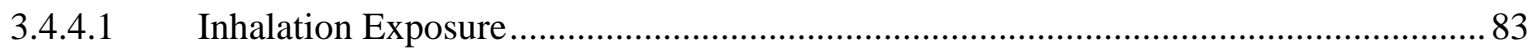

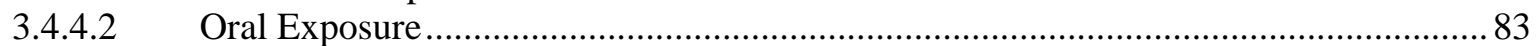

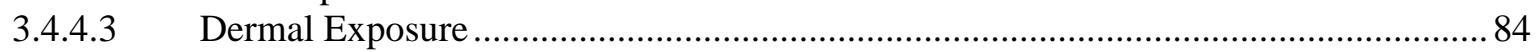

3.4.5 Physiologically Based Pharmacokinetic (PBPK)/Pharmacodynamic (PD) Models ............. 84

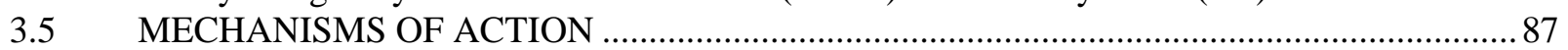

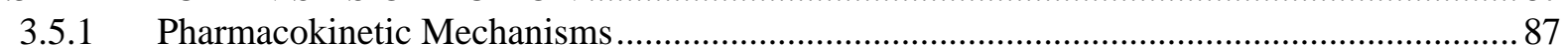

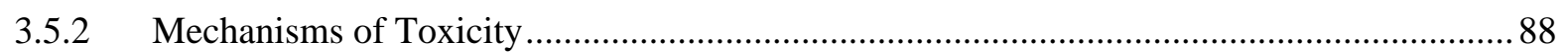

3.6 TOXICITIES MEDIATED THROUGH THE NEUROENDOCRINE AXIS .......................89

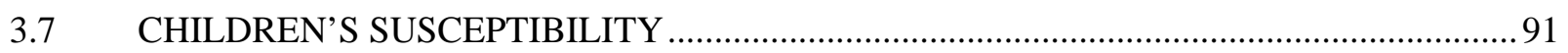

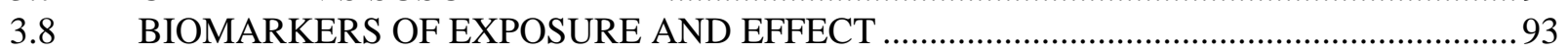

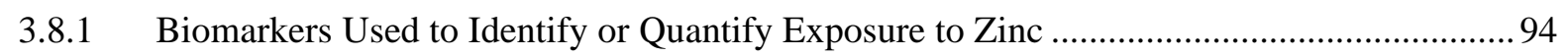

3.8.2 Biomarkers Used to Characterize Effects Caused by Zinc ............................................... 95

3.9 INTERACTIONS WITH OTHER CHEMICALS .......................................................... 96

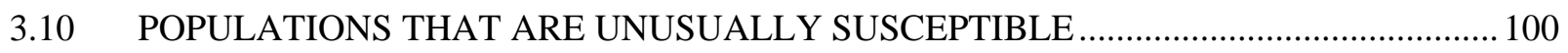

3.11 METHODS FOR REDUCING TOXIC EFFECTS ............................................................ 101

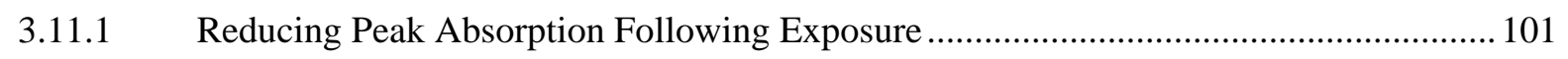

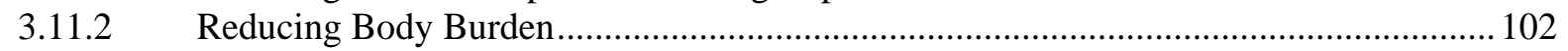

3.11.3 Interfering with the Mechanism of Action for Toxic Effects .................................... 102

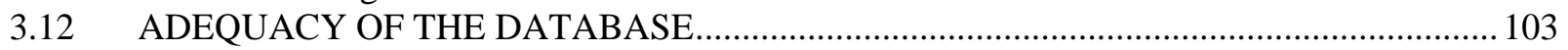

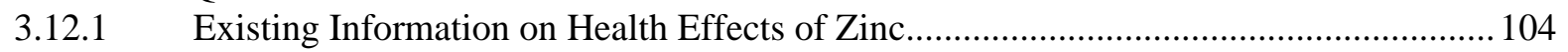

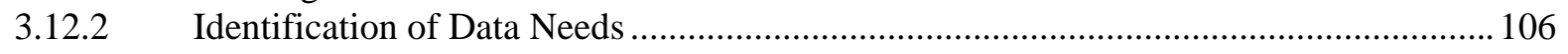

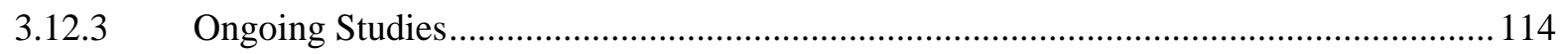

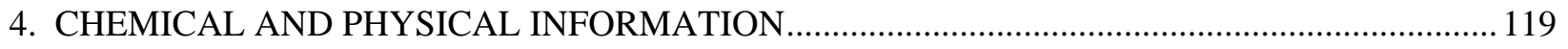

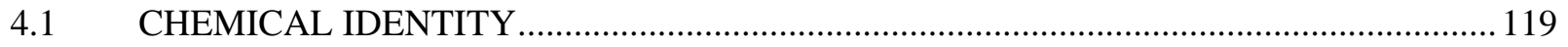

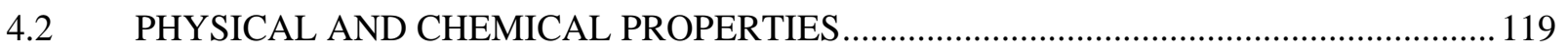

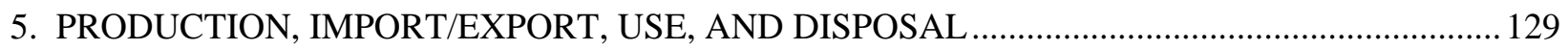

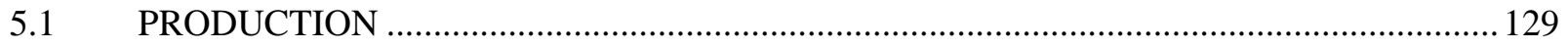




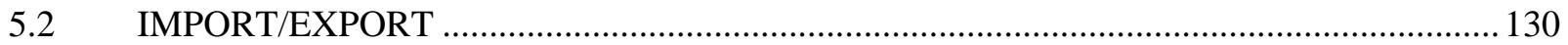

$5.3 \quad$ USE

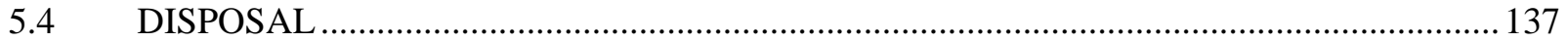

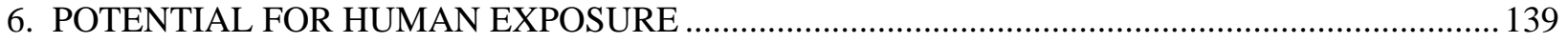

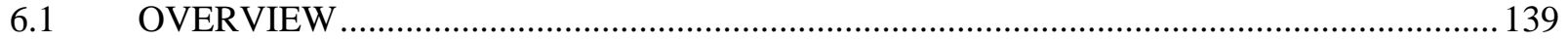

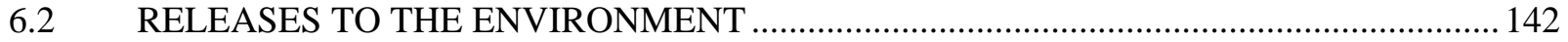

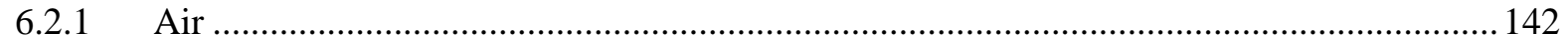

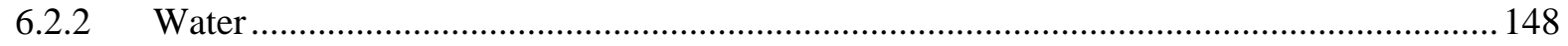

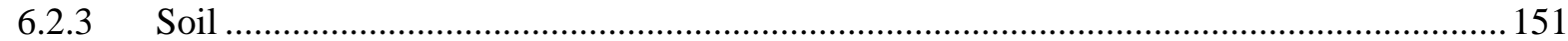

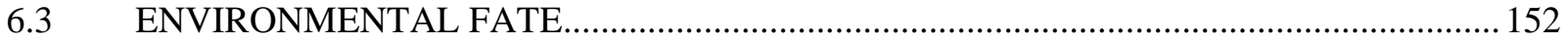

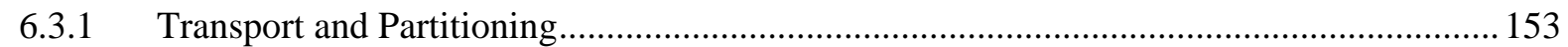

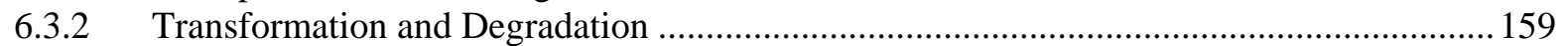

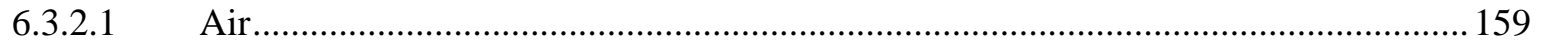

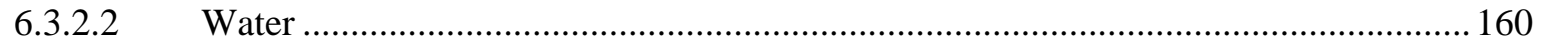

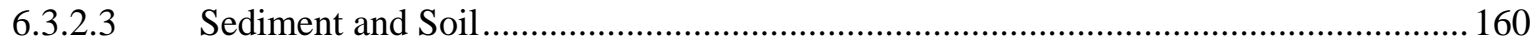

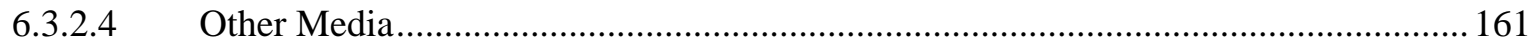

$6.4 \quad$ LEVELS MONITORED OR ESTIMATED IN THE ENVIRONMENT ............................. 161

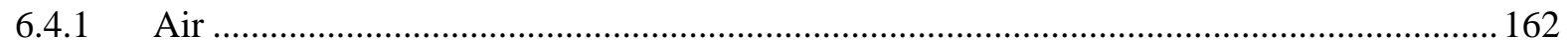

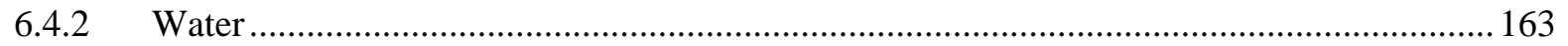

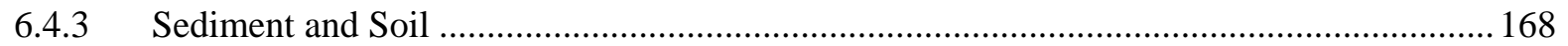

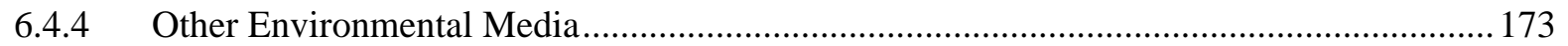

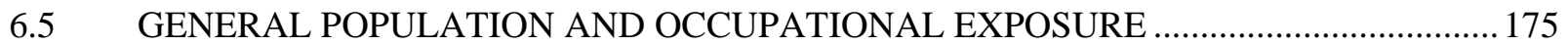

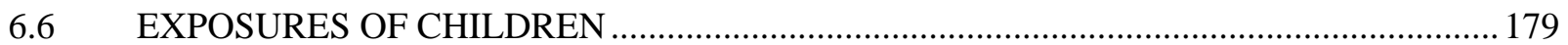

6.7 POPULATIONS WITH POTENTIALLY HIGH EXPOSURES ......................................... 181

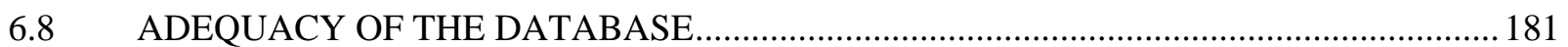

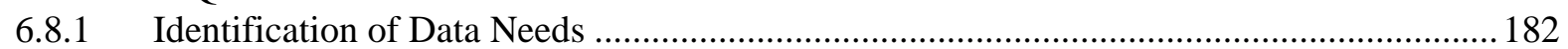

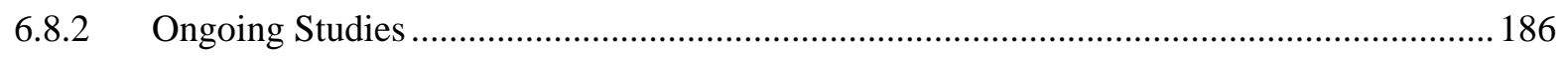

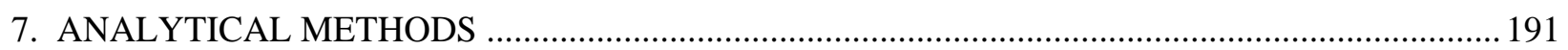

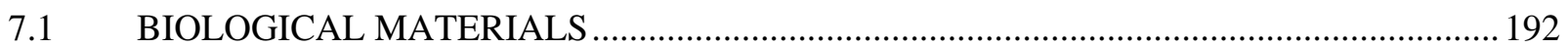

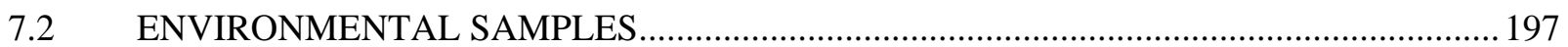

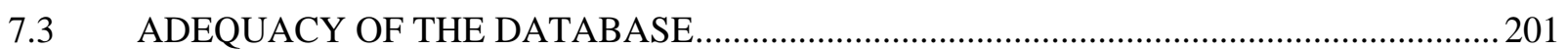

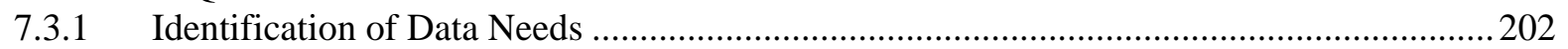

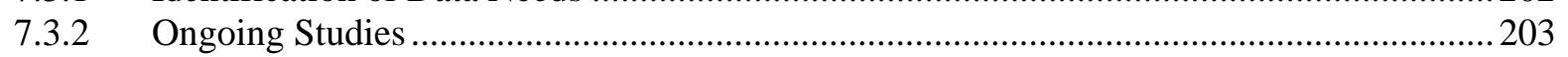

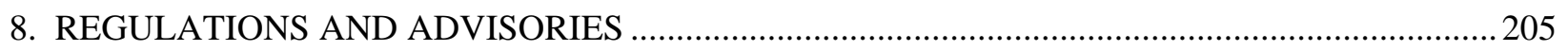

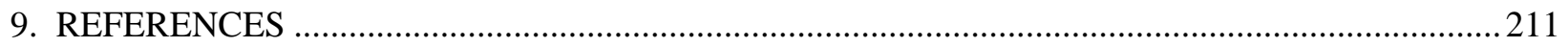

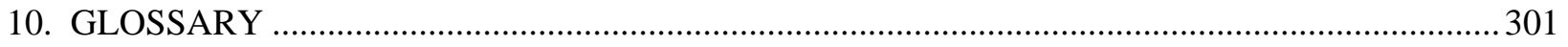

\section{APPENDICES}

A. ATSDR MINIMAL RISK LEVELS AND WORKSHEETS ….....................................................

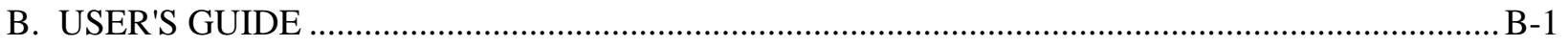

C. ACRONYMS, ABBREVIATIONS, AND SYMBOLS ..............................................................

D. INDEX 



\section{LIST OF FIGURES}

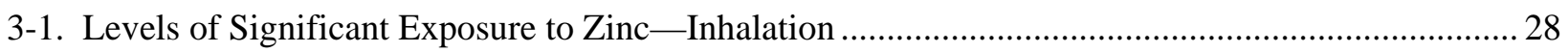

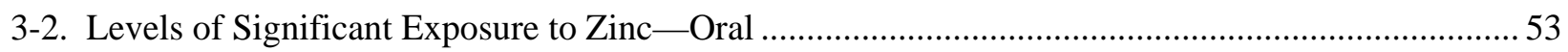

3-3. Conceptual Representation of a Physiologically Based Pharmacokinetic (PBPK) Model for a

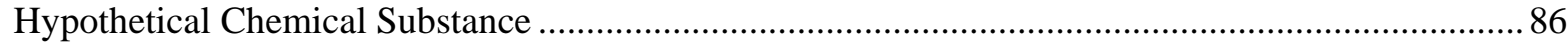

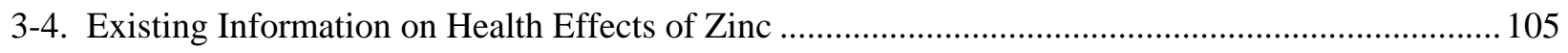

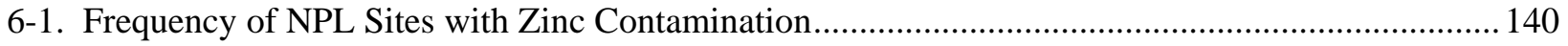





\section{LIST OF TABLES}

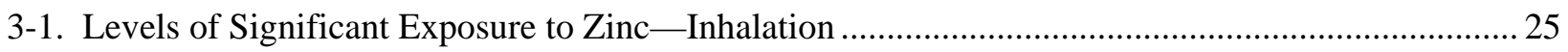

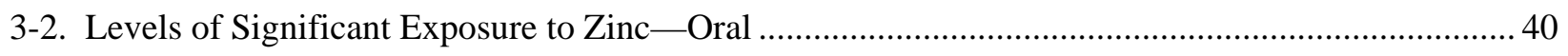

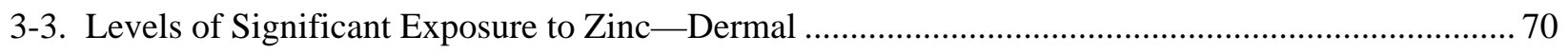

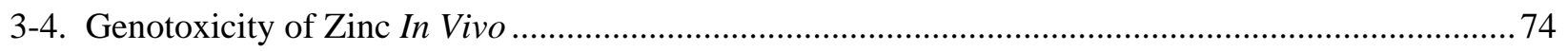

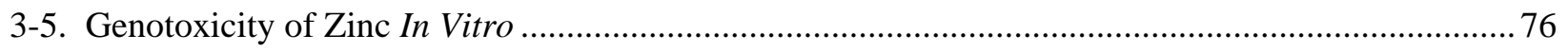

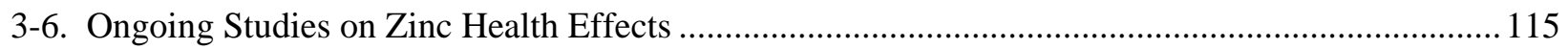

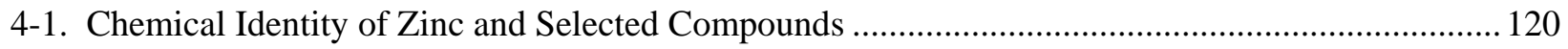

4-2. Physical and Chemical Properties of Zinc and Selected Compounds ......................................... 125

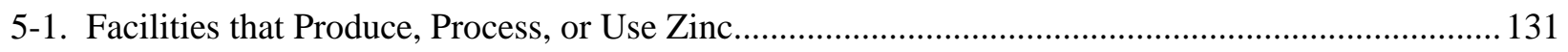

5-2. Facilities that Produce, Process, or Use Zinc Compounds ….................................................... 133

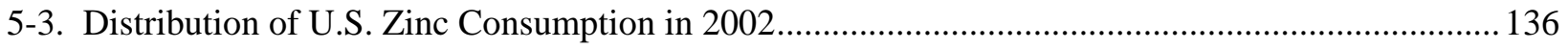

6-1. Releases to the Environment from Facilities that Produce, Process, or Use Zinc ........................... 143

6-2. Releases to the Environment from Facilities that Produce, Process, or Use Zinc Compounds........ 146

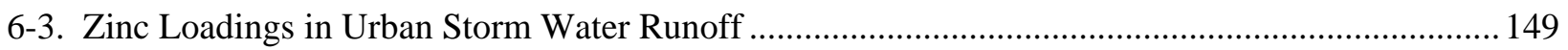

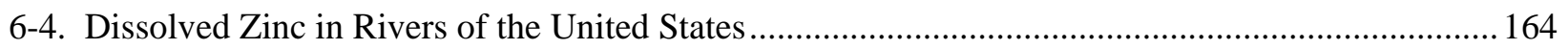

6-5. Median Zinc Levels in Bed Sediment from River Basins of the United States............................. 170

6-6. Ongoing Studies on the Environmental Effects of Zinc .......................................................... 187

7-1. Analytical Methods for Determining Zinc in Biological Materials............................................ 193

7-2. Analytical Methods for Determining Zinc in Environmental Samples ........................................ 198

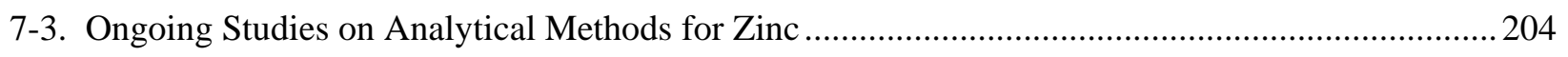

8-1. Regulations and Guidelines Applicable to Zinc and Zinc Compounds ........................................206 



\section{PUBLIC HEALTH STATEMENT}

This public health statement tells you about zinc and the effects of exposure to it. Zinc is an essential element needed by your body and is commonly found in nutritional supplements. However, taking too much zinc into the body can affect your health.

The Environmental Protection Agency (EPA) identifies the most serious hazardous waste sites in the nation. These sites are then placed on the National Priorities List (NPL) and are targeted for long-term federal clean-up activities. Zinc has been found in at least 985 of the 1,662 current or former NPL sites. Although the total number of NPL sites evaluated for zinc is not known, the possibility exists that the number of sites at which zinc is found may increase in the future as more sites are evaluated. This information is important because these sites may be sources of exposure and exposure to zinc may harm you.

When a substance is released either from a large area, such as an industrial plant, or from a container, such as a drum or bottle, it enters the environment. Such a release does not always lead to exposure. You can be exposed to a substance only when you come in contact with it. You may be exposed by breathing, eating, or drinking the substance, or by skin contact.

If you are exposed to zinc, many factors will determine whether you will be harmed. These factors include the dose (how much), the duration (how long), and how you come in contact with it. You must also consider any other chemicals you are exposed to and your age, sex, diet, family traits, lifestyle, and state of health.

\subsection{WHAT IS ZINC?}

Zinc is one of the most common elements in the Earth's crust. Zinc is found in the air, soil, and water and is present in all foods. In its pure elemental (or metallic) form, zinc is a bluish-white, shiny metal. Powdered zinc is explosive and may burst into flames if stored in damp places. Metallic zinc has many uses in industry. A common use for zinc is to coat steel and iron as well 
as other metals to prevent rust and corrosion; this process is called galvanization. Metallic zinc is also mixed with other metals to form alloys such as brass and bronze. A zinc and copper alloy is used to make pennies in the United States. Metallic zinc is also used to make dry cell batteries.

Zinc can also combine with other elements, such as chlorine, oxygen, and sulfur, to form zinc compounds. Zinc compounds that may be found at hazardous waste sites are zinc chloride, zinc oxide, zinc sulfate, and zinc sulfide. Most zinc ore found naturally in the environment is in the form of zinc sulfide. Zinc compounds are widely used in industry. Zinc sulfide and zinc oxide are used to make white paints, ceramics, and other products. Zinc oxide is also used in producing rubber. Zinc compounds, such as zinc acetate, zinc chloride, and zinc sulfate, are used in preserving wood and in manufacturing and dyeing fabrics. Zinc chloride is also the major ingredient in smoke from smoke bombs. Zinc compounds are used by the drug industry as ingredients in some common products, such as vitamin supplements, sun blocks, diaper rash ointments, deodorants, athlete's foot preparations, acne and poison ivy preparations, and antidandruff shampoos. Information can be found on the chemical and physical properties of zinc in Chapter 4 and on its occurrence and fate in the environment in Chapter 6.

\subsection{WHAT HAPPENS TO ZINC WHEN IT ENTERS THE ENVIRONMENT?}

Zinc enters the air, water, and soil as a result of both natural processes and human activities. Most zinc enters the environment as the result of mining, purifying of zinc, lead, and cadmium ores, steel production, coal burning, and burning of wastes. These activities can increase zinc levels in the atmosphere. Waste streams from zinc and other metal manufacturing and zinc chemical industries, domestic waste water, and run-off from soil containing zinc can discharge zinc into waterways. The level of zinc in soil increases mainly from disposal of zinc wastes from metal manufacturing industries and coal ash from electric utilities. Sludge and fertilizer also contribute to increased levels of zinc in the soil. In air, zinc is present mostly as fine dust particles. This dust eventually settles over land and water. Rain and snow aid in removing zinc from air. Most of the zinc in lakes or rivers settles on the bottom. However, a small amount may remain either dissolved in water or as fine suspended particles. The level of dissolved zinc 
in water may increase as the acidity of water increases. Fish can collect zinc in their bodies from the water they swim in and from the food they eat. Most of the zinc in soil is bound to the soil and does not dissolve in water. However, depending on the type of soil, some zinc may reach groundwater, and contamination of groundwater has occurred from hazardous waste sites. Zinc may be taken up by animals eating soil or drinking water containing zinc. Zinc is also a trace mineral nutrient and as such, small amounts of zinc are needed in all animals. For more information about what happens to zinc in the environment, see Chapter 6.

\subsection{HOW MIGHT I BE EXPOSED TO ZINC?}

Zinc is an essential element needed by your body in small amounts. We are exposed to zinc compounds in food. The average daily zinc intake through the diet in this country ranges from 5.2 to 16.2 milligrams (milligram=0.001 gram). Food may contain levels of zinc ranging from approximately 2 parts of zinc per million ( $2 \mathrm{ppm}$ ) parts of foods (e.g., leafy vegetables) to 29 ppm (meats, fish, poultry). Zinc is also present in most drinking water. Drinking water or other beverages may contain high levels of zinc if they are stored in metal containers or flow through pipes that have been coated with zinc to resist rust. If you take more than the recommended daily amount of supplements containing zinc, you may have higher levels of zinc exposure.

In general, levels of zinc in air are relatively low and fairly constant. Average levels of zinc in the air throughout the United States are less than 1 microgram of zinc per cubic meter $\left(\mu \mathrm{g} / \mathrm{m}^{3}\right)$ of air, but range from 0.1 to $1.7 \mu \mathrm{g} / \mathrm{m}^{3}$ in areas near cities. Air near industrial areas may have higher levels of zinc. The average zinc concentration for a 1 -year period was $5 \mu \mathrm{g} / \mathrm{m}^{3}$ in one area near an industrial source.

In addition to background exposure that all of us experience, about 150,000 people also have a source of occupational exposure to zinc that might elevate their total exposure significantly above the average background exposure. Jobs where people are exposed to zinc include zinc mining, smelting, and welding; manufacture of brass, bronze, or other zinc-containing alloys; manufacture of galvanized metals; and manufacture of machine parts, rubber, paint, linoleum, 
oilcloths, batteries, some kinds of glass and ceramics, and dyes. People at construction jobs, automobile mechanics, and painters are also exposed to zinc. For more information on exposure to zinc, see Chapter 6.

\subsection{HOW CAN ZINC ENTER AND LEAVE MY BODY?}

Zinc can enter the body through the digestive tract when you eat food or drink water containing it. Zinc can also enter through your lungs if you inhale zinc dust or fumes from zinc-smelting or zinc-welding operations on your job. The amount of zinc that passes directly through the skin is relatively small. The most likely route of exposure near NPL waste sites is through drinking water containing a high amount of zinc. Zinc is stored throughout the body. Zinc increases in blood and bone most rapidly after exposure. Zinc may stay in the bone for many days after exposure. Normally, zinc leaves the body in urine and feces. More information on how zinc enters and leaves your body can be found in Chapter 3.

\subsection{HOW CAN ZINC AFFECT MY HEALTH?}

Scientists use many tests to protect the public from harmful effects of toxic chemicals and to find ways for treating persons who have been harmed.

One way to learn whether a chemical will harm people is to determine how the body absorbs, uses, and releases the chemical. For some chemicals, animal testing may be necessary. Animal testing may also help identify health effects such as cancer or birth defects. Without laboratory animals, scientists would lose a basic method for getting information needed to make wise decisions that protect public health. Scientists have the responsibility to treat research animals with care and compassion. Scientists must comply with strict animal care guidelines because laws today protect the welfare of research animals.

Inhaling large amounts of zinc (as zinc dust or fumes from smelting or welding) can cause a specific short-term disease called metal fume fever, which is generally reversible once exposure 
to zinc ceases. However, very little is known about the long-term effects of breathing zinc dust or fumes.

Taking too much zinc into the body through food, water, or dietary supplements can also affect health. The levels of zinc that produce adverse health effects are much higher than the Recommended Dietary Allowances (RDAs) for zinc of $11 \mathrm{mg} /$ day for men and $8 \mathrm{mg} /$ day for women. If large doses of zinc (10-15 times higher than the RDA) are taken by mouth even for a short time, stomach cramps, nausea, and vomiting may occur. Ingesting high levels of zinc for several months may cause anemia, damage the pancreas, and decrease levels of high-density lipoprotein (HDL) cholesterol.

Eating food containing very large amounts of zinc (1,000 times higher than the RDA) for several months caused many health effects in rats, mice, and ferrets, including anemia and injury to the pancreas and kidney. Rats that ate very large amounts of zinc became infertile. Rats that ate very large amounts of zinc after becoming pregnant had smaller babies. Putting low levels of certain zinc compounds, such as zinc acetate and zinc chloride, on the skin of rabbits, guinea pigs, and mice caused skin irritation. Skin irritation from exposure to these chemicals would probably occur in humans. EPA has determined that because of lack of information, zinc is not classifiable as to its human carcinogenicity.

Consuming too little zinc is at least as important a health problem as consuming too much zinc. Without enough zinc in the diet, people may experience loss of appetite, decreased sense of taste and smell, decreased immune function, slow wound healing, and skin sores. Too little zinc in the diet may also cause poorly developed sex organs and retarded growth in young men. If a pregnant woman does not get enough zinc, her babies may have birth defects.

More information on the health effects linked with exposure to higher-than-normal levels of zinc is presented in Chapter 3. 


\subsection{HOW CAN ZINC AFFECT CHILDREN?}

This section discusses potential health effects in humans from exposures during the period from conception to maturity at 18 years of age.

Zinc is essential for proper growth and development of young children. Mothers who did not eat enough zinc during pregnancy had a higher frequency of birth defects and gave birth to smaller children (lower birth weight) than mothers whose zinc levels were sufficient. Very young children who did not receive enough zinc in the diet were smaller, both in length and in body weight, than children who ate enough zinc. Some foods, such as soy-based formulas, contain high levels of phytate, which can result in a decreased absorption of zinc in the diet. Too much of these foods may result in effects similar to those that occur when children receive too little zinc in the diet.

Little is known about whether children who eat too much zinc will react differently from adults who have ingested large amounts of zinc. A child who accidentally drank a large amount of a caustic zinc solution was found to have damage to his mouth and stomach, and later to his pancreas, but similar effects have been seen in adults who accidentally drank the same solution.

\subsection{HOW CAN FAMILIES REDUCE THE RISK OF EXPOSURE TO ZINC}

If your doctor finds that you have been exposed to substantial amounts of zinc, ask whether your children might also have been exposed. Your doctor might need to ask your state health department to investigate.

Children living near waste sites containing zinc are likely to be exposed to higher environmental levels of zinc through breathing, drinking contaminated drinking water, touching soil, and eating contaminated soil. It is unlikely that a child would ingest enough zinc from eating soil to cause harmful effects. However, parents should supervise to see that children avoid eating soil and wash their hands frequently, especially before eating. Parents should consult their family 
physicians about whether (and how) hand-to-mouth behaviors in their children might be discouraged. A more complete discussion can be found in Section 3.11 of the profile.

Children and adults require a certain amount of zinc in the diet in order to remain healthy. However, overuse of some medicines or vitamin supplements containing zinc might be harmful; these medicines should always be used appropriately. If you are accidentally exposed to large amounts of zinc, consult a physician immediately.

\subsection{IS THERE A MEDICAL TEST TO DETERMINE WHETHER I HAVE BEEN EXPOSED TO ZINC?}

Medical tests can determine whether your body fluids contain high levels of zinc. Samples of blood or feces can be collected in a doctor's office and sent to a laboratory that can measure zinc levels. It is easier for most laboratories to measure zinc in blood than in feces. The presence of high levels of zinc in the feces can mean recent high zinc exposure. High levels of zinc in the blood can mean high zinc consumption and/or high exposure. High zinc levels in blood or feces reflect the level of exposure to zinc. Measuring zinc levels in urine and saliva also may provide information about zinc exposure. Tests to measure zinc in hair may provide information on long-term zinc exposure; however, no useful correlation has been found between hair zinc levels and zinc exposure and these tests are not routinely used. Since zinc levels can be affected by dietary deficiency and cell stress, these results may not be directly related to current zinc exposure. More information on tests to measure zinc in the body can be found in Chapter 7.

\subsection{WHAT RECOMMENDATIONS HAS THE FEDERAL GOVERNMENT MADE TO PROTECT HUMAN HEALTH?}

The federal government develops regulations and recommendations to protect public health. Regulations can be enforced by law. The EPA, the Occupational Safety and Health Administration (OSHA), and the Food and Drug Administration (FDA) are some federal agencies that develop regulations for toxic substances. Recommendations provide valuable guidelines to protect public health, but cannot be enforced by law. The Agency for Toxic 
Substances and Disease Registry (ATSDR) and the National Institute for Occupational Safety and Health (NIOSH) are two federal organizations that develop recommendations for toxic substances.

Regulations and recommendations can be expressed as "not-to-exceed" levels, that is, levels of a toxic substance in air, water, soil, or food that do not exceed a critical value that is usually based on levels that affect animals; they are then adjusted to levels that will help protect humans. Sometimes these not-to-exceed levels differ among federal organizations because they used different exposure times (an 8-hour workday or a 24-hour day), different animal studies, or other factors.

Recommendations and regulations are also updated periodically as more information becomes available. For the most current information, check with the federal agency or organization that provides it. Some regulations and recommendations for zinc include the following:

The federal government has set standards and guidelines to protect individuals from the potential health effects of excessive zinc. EPA has stated that drinking water should contain no more than $5 \mathrm{mg}$ of zinc per liter of water $(5 \mathrm{mg} / \mathrm{L}$ or $5 \mathrm{ppm})$ because of taste. Furthermore, any release of more than 1,000 pounds (or in some cases 5,000 pounds) of zinc or its compounds into the environment (i.e., water, soil, or air) must be reported to EPA.

The National Academy of Sciences (NAS) estimates an RDA for zinc of $11 \mathrm{mg} /$ day (men). Eleven $\mathrm{mg} /$ day is the same as $0.16 \mathrm{mg}$ per kilogram $(\mathrm{kg})$ of body weight per day for an average adult male $(70 \mathrm{~kg}$ ). An RDA of $8 \mathrm{mg} / \mathrm{day}$, or $0.13 \mathrm{mg}$ per $\mathrm{kg}$ of body weight for an average adult female $(60 \mathrm{~kg})$, was established for women because they usually weigh less than men. Lower zinc intake was recommended for infants (2-3 mg/day) and children (5-9 mg/day) because of their lower average body weights. The RDA provides a level of adequate nutritional status for most of the population. Extra dietary levels of zinc are recommended for women during pregnancy and lactation. An RDA of 11-12 mg/day was set for pregnant women. Women who nurse their babies need $12-13 \mathrm{mg} /$ day. 
To protect workers, OSHA has set an average legal limit of $1 \mathrm{mg} / \mathrm{m}^{3}$ for zinc chloride fumes and $5 \mathrm{mg} / \mathrm{m}^{3}$ for zinc oxide (dusts and fumes) in workplace air during an 8-hour workday, 40-hour work week. This regulation means that the workroom air should contain no more than an average of $1 \mathrm{mg} / \mathrm{m}^{3}$ of zinc chloride over an 8-hour working shift of a 40-hour work week. NIOSH similarly recommends that the level of zinc oxide in workplace air should not exceed an average of $1 \mathrm{mg} / \mathrm{m}^{3}$ over a 10-hour period of a 40-hour work week. For more information on recommendations and standards for zinc exposure, see Chapter 8.

\subsection{WHERE CAN I GET MORE INFORMATION?}

If you have any more questions or concerns, please contact your community or state health or environmental quality department, or contact ATSDR at the address and phone number below.

ATSDR can also tell you the location of occupational and environmental health clinics. These clinics specialize in recognizing, evaluating, and treating illnesses that result from exposure to hazardous substances.

Toxicological profiles are also available on-line at www.atsdr.cdc.gov and on CD-ROM. You may request a copy of the ATSDR ToxProfiles ${ }^{\mathrm{TM}} \mathrm{CD}-\mathrm{ROM}$ by calling the toll-free information and technical assistance number at 1-888-42ATSDR (1-888-422-8737), by e-mail at atsdric@cdc.gov, or by writing to:

Agency for Toxic Substances and Disease Registry Division of Toxicology 1600 Clifton Road NE Mailstop F-32 Atlanta, GA 30333

Fax: 1-770-488-4178 
1. PUBLIC HEALTH STATEMENT

Organizations for-profit may request copies of final Toxicological Profiles from the following:

National Technical Information Service (NTIS)

5285 Port Royal Road

Springfield, VA 22161

Phone: $1-800-553-6847$ or 1-703-605-6000

Web site: http://www.ntis.gov/ 


\section{RELEVANCE TO PUBLIC HEALTH}

\subsection{BACKGROUND AND ENVIRONMENTAL EXPOSURES TO ZINC IN THE UNITED STATES}

Zinc is ubiquitous in the environment, constituting 20-200 ppm (by weight) of the Earth's crust. It is not found as elemental zinc in nature, instead being found mainly as zinc oxide or sphalerite (ZnS). Zinc is released into the environment as the result of mining, smelting of zinc, lead, and cadmium ores, steel production, coal burning, and burning of wastes. Ambient background air concentrations of zinc are generally $<1 \mu \mathrm{g} / \mathrm{m}^{3}$. Zinc is found in soils and surficial materials of the contiguous United States at concentrations between $<5$ and 2,900 mg/kg, with a mean of $60 \mathrm{mg} / \mathrm{kg}$. The zinc background concentrations in surface waters are usually $<0.05 \mathrm{mg} / \mathrm{L}$, but can range from 0.002 to $50 \mathrm{mg} / \mathrm{L}$.

Zinc metal is used most commonly as a protective coating of other metals, such as iron and steel. Zinc is also a component of various alloys including those used for die casting as well as brass and bronze. Many zinc alloys may be found in electrical components of household goods. Alloys containing zinc and copper are used to make U.S. one-cent coins. Zinc metal dust is widely used in paint coatings, as a catalyst, and as a reducing and precipitating agent in organic and analytical chemistry.

Exposure of the general population to zinc is primarily by ingestion. The average daily intake of zinc from food in humans is $5.2-16.2 \mathrm{mg}$ zinc/day; assuming a $70-\mathrm{kg}$ average body weight, this corresponds to $0.07-0.23 \mathrm{mg}$ zinc/kg/day. Zinc is widespread in commonly consumed foods, but tends to be higher in those of animal origin, particularly some sea foods. Meat products contain relatively high concentrations of zinc, whereas fruits and vegetables have relatively low concentrations. Other possible pathways for zinc exposure are water and air. Individuals involved in galvanizing, smelting, welding, or brass foundry operations are exposed to metallic zinc and zinc compounds.

\subsection{SUMMARY OF HEALTH EFFECTS}

Zinc is an essential nutrient for humans and animals that is necessary for the function of a large number of metalloenzymes, including alcohol dehydrogenase, alkaline phosphatase, carbonic anhydrase, leucine aminopeptidase, and superoxide dismutase. Zinc deficiency has been associated with dermatitis, anorexia, growth retardation, poor wound healing, hypogonadism with impaired reproductive capacity, 
impaired immune function, and depressed mental function; an increased incidence of congenital malformations in infants has also been associated with zinc deficiency in the mothers. Zinc deficiency may also have an impact on the carcinogenesis of other chemicals, although the direction of the influence seems to vary with the carcinogenic agent. The recommended dietary allowance (RDA) for zinc is $11 \mathrm{mg} / \mathrm{day}$ in men and $8 \mathrm{mg} /$ day in women; these correspond to approximately $0.16 \mathrm{mg} / \mathrm{kg} / \mathrm{day}$ for men and $0.13 \mathrm{mg} / \mathrm{kg} /$ day for women. Higher RDAs are recommended for women during pregnancy and lactation (12 mg/day).

The effects of inhalation exposure to zinc and zinc compounds vary somewhat with the chemical form of the zinc compound, but the majority of the effects seen will occur within the respiratory tract. Following inhalation of zinc oxide, and to a lesser extent zinc metal and many other zinc compounds, the most commonly reported effect is the development of "metal fume fever." Metal fume fever is characterized by chest pain, cough, dyspnea, reduced lung volumes, nausea, chills, malaise, and leukocytosis. Symptoms generally appear a few hours after exposure, and are reversible 1-4 days following cessation of exposure. Exposure levels associated with the development of metal fume fever have not been identified, though are generally in the range of $77-600 \mathrm{mg} \mathrm{zinc} / \mathrm{m}^{3}$. Acute experimental exposures of humans to lower concentrations of zinc oxide ( $14 \mathrm{mg} / \mathrm{m}^{3}$ for 8 hours or $45 \mathrm{mg}$ zinc/ $/ \mathrm{m}^{3}$ for 20 minutes) and occupational exposures to low concentrations of zinc ( $8-12 \mathrm{mg}$ zinc $/ \mathrm{m}^{3}$ for $1-3$ hours and $0.034 \mathrm{mg}$ zinc $/ \mathrm{m}^{3}$ for $6-8$ hours) did not produce symptoms of metal fume fever.

In contrast, inhalation of high levels of zinc chloride, which is corrosive, generally results in more pronounced damage to the mucous membranes of the respiratory tract without the effects normally seen in metal fume fever. Symptoms of high-concentration zinc chloride exposure include dyspnea, cough, pleuritic chest pain, bilateral diffuse infiltrations, pneumothorax, and acute pneumonitis, resulting from respiratory tract irritation. In many cases, exposure levels for these effects have not been reported, as the exposures were to zinc chloride-containing smoke and were not quantified and the contribution of other components of the smoke cannot be entirely eliminated. However, one study of zinc chloride exposure estimated an exposure level of $1,955 \mathrm{mg}$ zinc $/ \mathrm{m}^{3}$. Similar irritant effects of zinc chloride have been seen in animal studies of lower exposure levels $\left(13-121 \mathrm{mg} / \mathrm{m}^{3}\right)$ and longer duration (5-100 daily exposures). The effects observed after zinc chloride inhalation are likely due to the caustic nature of zinc chloride, rather than a direct action of the zinc ion.

Nausea has been reported by humans exposed to high concentrations of zinc oxide fumes (300$\left.600 \mathrm{mg} / \mathrm{m}^{3}\right)$ and zinc chloride $\left(\sim 120 \mathrm{mg} / \mathrm{m}^{3}\right)$ smoke, as well as following oral exposure to zinc chloride 
and zinc sulfate. Other gastrointestinal symptoms reported in cases of excess zinc exposure include vomiting, abdominal cramps, and diarrhea, in several cases with blood. In general, oral exposure levels associated with gastrointestinal effects of zinc have not been reliably reported, but the limited available data suggest that oral concentrations of $910 \mathrm{mg}$ zinc/L or single-dose exposures of $~ 140-560 \mathrm{mg}$ zinc (acute oral doses of 2-8 mg/kg/day) are sufficient to cause these effects. The noted effects are consistent with gastrointestinal irritation. It is unclear in the majority of human studies whether the gastrointestinal effects seen following zinc inhalation were due to systemic zinc or were the result of direct contact with the gastrointestinal tract following mucociliary clearance of inhaled zinc particles and subsequent swallowing.

Following longer-term exposure to lower doses ( 0.5-2 mg zinc/kg/day) of zinc compounds, the observed symptoms generally result from a decreased absorption of copper from the diet, leading to early symptoms of copper deficiency. The most noticeable manifestation of the decreased copper levels is anemia, manifesting as decreased erythrocyte number or decreased hematocrit. High-dose zinc administration has also resulted in reductions in leukocyte number and function. Some studies have also found decreases in high-density lipoprotein (HDL) levels in humans exposed to increased levels of zinc; however, not all studies have confirmed this observation. Long-term consumption of excess zinc may also result in decreased iron stores, although the mechanism behind this effect is not presently clear.

In most cases, dermal exposure to zinc or zinc compounds does not result in any noticeable toxic effects. Zinc oxide is used routinely in topical applications including sunscreens and creams designed to assist in wound healing. However, dermal exposure to zinc chloride, and to a lesser extent other zinc salts, can result in severe skin irritancy, characterized by parakeratosis, hyperkeratosis, inflammatory changes in the epidermis and superficial dermis, and acanthosis of the follicular epithelia.

Available studies have not presented evidence of reproductive or developmental effects in humans or animals following inhalation of zinc compounds. Effects on reproductive or developmental end points have been noted in oral-exposure animal studies, but generally only at very high doses (>200 mg/kg/day).

Available studies of zinc-induced carcinogenic effects in humans and animals following both oral or inhalation exposure have not adequately demonstrated an increase in cancer incidence following longterm exposure to zinc compounds. The EPA currently classifies zinc and compounds as carcinogenicity group D (not classifiable as to human carcinogenicity). 
The primary effects of zinc are the development of metal fume fever and effects of zinc on copper status; a more detailed discussion of these end points follows. The reader is referred to Section 3.2, Discussion of Health Effects by Route of Exposure, for additional information on other health effects.

Metal Fume Fever. Metal fume fever, a well-documented acute disease induced by inhalation of metal oxides, especially zinc, impairs pulmonary function but does not usually progress to chronic lung disease. Symptoms generally appear within a few hours after acute exposure, usually with dryness of the throat and coughing. The most prominent respiratory effects of metal fume fever are substernal chest pain, cough, and dyspnea. The impairment of pulmonary function is characterized by reduced lung volumes and a decreased diffusing capacity of carbon monoxide. Leukocytosis persisting for approximately 12 hours after the fever dissipates is also a common manifestation of metal fume fever. In general, the symptoms of metal fume fever resolve within 1-4 days after cessation of exposure and do not lead to long-term respiratory effects. Inhalation of "ultrafine" zinc oxide particles may also result in metal fume fever, as well as histologic damage and inflammation of the lung periphery.

Exposure levels leading to the development of metal fume fever have been characterized. Minimal changes in forced expiratory flow were observed 1 hour after a 15-30-minute exposure to $77 \mathrm{mg}$ zinc/ $\mathrm{m}^{3}$ as zinc oxide, while at higher levels (300-600 mg/m $\mathrm{m}^{3}$, from 10 minutes to 3 hours), shortness of breath, nasal passage irritation, cough, substernal chest pain, persistent rales of the lung base, and a decreased vital capacity have been reported. Exposure to lower levels of zinc oxide, either for acute $\left(14 \mathrm{mg} \mathrm{zinc} / \mathrm{m}^{3}\right.$ for 8 hours or $45 \mathrm{mg}$ zinc $/ \mathrm{m}^{3}$ for 20 minutes) or chronic (8-12 mg zinc $/ \mathrm{m}^{3}$ for $1-3$ hours and $0.034 \mathrm{mg}$ zinc $/ \mathrm{m}^{3}$ for 6-8 hours) duration did not result in the symptoms of metal fume fever. However, analysis by bronchoalveolar lavage of volunteers exposed to zinc oxide for up to 2 hours (mean concentration $16.4 \mathrm{mg}$ zinc $/ \mathrm{m}^{3}$ ) revealed an increase in levels of the cytokines TNF, IL-6 and IL- 8 , and increases in the number of polymorphonuclear leukocytes and lymphocytes in the BAL fluid. Thus, it appears that while the precursor events for the development of metal fume fever begin to occur even at very low zinc concentrations, the condition itself does not appear to fully manifest until exposure levels reach much higher $\left(>75 \mathrm{mg} / \mathrm{m}^{3}\right)$ levels. Similar effects, including decreased ventilation, an inflammatory response, and changes in cytokine levels, have also been seen in animal studies of zinc oxide inhalation.

The exact mechanism behind the development of metal fume fever is not known, but it is believed to involve an immune response to the inhaled zinc oxide. It has been suggested that the zinc oxide causes inflammation of the respiratory tract and the release of histamine or histamine-like substances. In response, an allergen-antibody complex is formed that may elicit an allergic reaction upon subsequent 
exposure to the allergen. In response to the allergen-antibody complex, an anti-antibody is formed. The anti-antibody dominates with continued exposure to the zinc oxide, thereby producing a tolerance. When the exposure is interrupted and re-exposure occurs, the allergen-antibody complex dominates, producing an allergic reaction and symptoms of metal fume fever.

Effects on Copper Status. When ingested zinc levels are very high, zinc is believed to inhibit copper absorption through interaction with metallothionein at the brush border of the intestinal lumen. Both copper and zinc appear to bind to the same metallothionein protein; however, copper has a higher affinity for metallothionein than zinc and displaces zinc from metallothionein protein. Copper complexed with metallothionein is retained in the mucosal cell, relatively unavailable for transfer to plasma, and is excreted in the feces when the mucosal cells are sloughed off. Thus, an excess of zinc can result in a decreased availability of dietary copper, and the development of copper deficiency. This fact has been used therapeutically in the treatment of Wilson's Disease. Zinc supplementation is used to substantially decrease the absorption of copper from the diet, which can aggravate the disease.

Copper is incorporated into metalloenzymes involved in hemoglobin formation, carbohydrate metabolism, catecholamine biosynthesis, and cross-linking of collagen, elastin, and hair keratin. The copper-dependent enzymes, which include cytochrome c oxidase, superoxide dismutase, ferroxidases, monoamine oxidase, and dopamine $\beta$-monooxygenase, function mainly to reduce molecular oxygen. Excess zinc may alter the levels or activity of these enzymes before the more severe symptoms of copper deficiency, which include anemia and leucopenia, begin to manifest. Numerous studies in humans receiving 40-50 mg supplemental zinc/day (0.68-0.83 mg zinc/kg/day) have reported decreases in erythrocyte superoxide dismutase, mononuclear white cell 5'-nucleotidase, and plasma 5'-nucleotidase activities. While the results from study to study are not always consistent, the available studies of volunteers identify 40-50 mg supplemental zinc/day as the level at which subtle changes in coppercontaining enzymes begin to be seen. This effect level is supported by other studies that collectively identify a no-observed-adverse-effect level (NOAEL) of $30 \mathrm{mg}$ supplemental zinc/day for changes in copper-containing enzyme levels in adult men.

Long-term administration (1-8 years) of high zinc levels (2-11.6 mg/kg/day) has caused anemia in humans. However, adequate studies of the chronic effects of lower levels of zinc on copper status in humans are not available. Decreased hemoglobin and hematocrit and the development of anemia have also been observed in animals orally exposed to high zinc doses. 


\subsection{MINIMAL RISK LEVELS (MRLS)}

Estimates of exposure levels posing minimal risk to humans (MRLs) have been made for zinc. An MRL is defined as an estimate of daily human exposure to a substance that is likely to be without an appreciable risk of adverse effects (noncarcinogenic) over a specified duration of exposure. MRLs are derived when reliable and sufficient data exist to identify the target organ(s) of effect or the most sensitive health effect(s) for a specific duration within a given route of exposure. MRLs are based on noncancerous health effects only and do not consider carcinogenic effects. MRLs can be derived for acute, intermediate, and chronic duration exposures for inhalation and oral routes. Appropriate methodology does not exist to develop MRLs for dermal exposure.

Although methods have been established to derive these levels (Barnes and Dourson 1988; EPA 1990), uncertainties are associated with these techniques. Furthermore, ATSDR acknowledges additional uncertainties inherent in the application of the procedures to derive less than lifetime MRLs. As an example, acute inhalation MRLs may not be protective for health effects that are delayed in development or are acquired following repeated acute insults, such as hypersensitivity reactions, asthma, or chronic bronchitis. As these kinds of health effects data become available and methods to assess levels of significant human exposure improve, these MRLs will be revised.

\section{Inhalation MRLs}

No inhalation MRLs have been derived for zinc. A number of acute-duration studies of exposed workers have identified metal fume fever as an end point of concern, with effects generally noted at airborne zinc oxide levels of 77-600 mg zinc/m³ (Blanc et al. 1991; Hammond 1944; Sturgis et al. 1927). However, these occupational studies were not able to adequately control or correct for possible exposure to other compounds, and were therefore not suitable for use in MRL derivation. Animal studies (Amdur et al. 1982; Drinker and Drinker 1928) corroborate the effects observed in humans; however, the studies are generally limited in the methods utilized, and other possible targets of toxicity were not examined. Only one chronic-duration inhalation study in humans was located (Ameille et al. 1992). In this study, exposure levels were not reported; thus, the study could not be used as the basis for the derivation of a chronic-duration MRL. Thus, no chronic-duration inhalation MRL could be derived. 


\section{Oral MRLs}

An oral acute MRL was not derived for zinc. A number of case reports involving high-dose acute exposure were located (Brandao-Neto et al. 1990a; Callender and Gentzkow 1937; Lewis and Kokan 1998; Murphy 1970); nausea, vomiting, and other signs of gastrointestinal distress were the primary effects noted. However, a great deal of uncertainty exists for these studies, including a lack of accurate assessment of exposure levels and a minimal evaluation of end points. Animal studies of acute-duration oral exposure to zinc are generally limited to studies of mortality (Domingo et al. 1988a; Straube et al. 1980), with the exception of a study in rats that only evaluated effects on the central nervous system (Kozik et al. 1980). As no studies sufficient for derivation of an acute oral MRL were available, no value was derived.

- An MRL of $0.3 \mathrm{mg}$ zinc/kg/day has been derived for intermediate-duration oral exposure (15364 days) to zinc.

Prolonged oral exposure to zinc has been shown to decrease the absorption of copper from the diet, resulting in the development of copper deficiency. At low doses $(\sim 0.7-0.9 \mathrm{mg}$ zinc/kg/day) and intermediate exposure durations (6-13 weeks), the effect is minor and manifests as subclinical changes in copper-sensitive enzymes, such superoxide dismutase (Davis et al. 2000; Fischer et al. 1984; Milne et al. 2001; Yadrick et al. 1989). At higher exposure levels ( $2 \mathrm{mg}$ zinc/kg/day) for chronic duration, more severe symptoms of copper deficiency, including anemia, have been reported (Broun et al. 1990; Gyorffy and Chan 1992; Hale et al. 1988; Hoffman et al. 1988; Patterson et al. 1985; Porter et al. 1977; Prasad et al. 1978; Ramadurai et al. 1993; Stroud 1991; Summerfield et al. 1992).

Available intermediate-duration studies have examined the effect of zinc supplementation on sensitive biological indices in humans. A series of two studies (Bonham et al. 2003a, 2003b) evaluated a large number of hematological and immunological parameters as well as several copper-sensitive enzymes (e.g., superoxide dismutase) in healthy men exposed to $0.43 \mathrm{mg}$ supplemental zinc/kg/day, and reported no significant changes resulting from zinc exposure. Studies by three other groups have evaluated exposures in the $0.6-0.8 \mathrm{mg}$ zinc/ $\mathrm{kg} /$ day range and identified slight but measurable effects. A study in postmenopausal women receiving a total of $53 \mathrm{mg}$ zinc/day (44 $\mathrm{mg}$ supplemental zinc/day, or $0.68 \mathrm{mg}$ supplemental zinc/kg/day) (Davis et al. 2000; Milne et al. 2001) reported increases in bone-specific alkaline phosphatase ( 25\%) and extracellular superoxide dismutase $(\sim 15 \%)$ levels and decreases in mononuclear white cell 5'-nucleotidase ( $30 \%)$ and plasma 5'-nucleotidase ( 36\%) activity. Another study (Fischer et al. 1984) exposed groups of male volunteers to $0.71 \mathrm{mg}$ supplemental zinc/kg/day for 
6 weeks; erythrocyte superoxide dismutase (ESOD) activity decreased after 4 weeks in the supplement group and was significantly lower than controls by 6 weeks. In women exposed to $0.83 \mathrm{mg}$ supplemental zinc/kg/day for 10 weeks, ESOD activity declined over the supplementation period and was significantly $(\mathrm{p}<0.05)$ lower $(47 \%$ decrease) than pretreatment values at 10 weeks (Yadrick et al. 1989).

While the decrease in ESOD activity reported in the available human studies is noteworthy, it is important to note that other enzymes, including catalase and other forms of superoxide dismutase, also serve to detoxify superoxide within the body. The overall effect of reducing the levels of an isoform of superoxide dismutase on the body's ability to detoxify superoxide radical is therefore uncertain. The subjects in the zinc supplementation studies did not report increased frequencies of clinical signs or symptoms. The other changes in copper status across the studies evaluating zinc supplementation in the $50 \mathrm{mg} /$ day range, such as changes in alkaline phosphatase, mononuclear white cell 5'-nucleotidase, and plasma 5'-nucleotidase activities (Davis et al. 2000; Milne et al. 2001), are generally slight and of questionable clinical and biological significance. The subclinical changes in copper status observed in the intermediate-duration studies of zinc supplementation (Davis et al. 2000; Fischer et al. 1984; Milne et al. 2001; Yadrick et al. 1989) are considered nonadverse effects.

Yadrick et al. (1989) also reported decreased serum ferritin in zinc-supplemented (0.86 mg supplemental zinc/kg/day) premenopausal women. A statistically significant decrease in serum ferritin levels from 36.6 to $28.2 \mu \mathrm{g} / \mathrm{L}$ ( $23 \%$ decrease), was observed. According to the most recent NHANES data (cited in IOM 2000), the median range for serum ferritin levels in menstruating women is $36-40 \mu \mathrm{g} / \mathrm{L}$, while a value of $<12 \mu \mathrm{g} / \mathrm{L}$ represents depleted iron stores. Thus, the subjects in the Yadrick study dropped below the median range for women of their age group, but were still considerably above the level that would represent a depletion of iron stores. This is supported by a lack of reported changes in hemoglobin or hematocrit levels in the study population (Yadrick et al. 1989). In a 90-day study of postmenopausal women exposed to $0.68 \mathrm{mg}$ supplemental zinc/ $\mathrm{kg} / \mathrm{day}$ while living in a metabolic ward (Milne et al. 2001), no changes were reported in serum iron, hematocrit, or percentage of transferrin saturation were observed. However, the study did not evaluate ferritin levels, which are the most sensitive indicator of body iron stores. Other studies that evaluated similar zinc dose levels (Black et al. 1988; Fischer et al. 1984) have not evaluated ferritin levels or other indices of iron status. ATSDR considers the subclinical change in iron stores as indicated by a decrease in serum ferritin levels to be nonadverse.

As it identified the highest NOAEL for effects of zinc exposure, the Yadrick et al. (1989) study was selected as the principal study for MRL derivation. The study identified subclinical changes in copper 
status (decreased ESOD levels) and iron status (decreased ferritin levels) in women exposed to $0.83 \mathrm{mg}$ supplemental zinc/kg/day. This exposure level was designated a NOAEL and selected as the point of departure for the derivation of the MRL. The uncertainty factor for MRL derivation was 3, representing uncertainties involving intrahuman variability; a larger factor for sensitive populations was not believed necessary, as women already represent a sensitive population with regards to changes in iron status. The resulting intermediate-duration MRL is $0.3 \mathrm{mg} / \mathrm{kg} /$ day.

It should be noted that the MRL is calculated based on the assumption of healthy dietary levels of zinc (and copper), and represents the level of exposure above and beyond the normal diet that is believed to be without an appreciable risk of toxic response. The MRL is based on soluble zinc salts; it is less likely that nonsoluble zinc compounds would have these effects at similar exposure levels.

- The intermediate-duration oral MRL of $0.3 \mathrm{mg}$ zinc/kg/day has been accepted as the chronic oral MRL.

The chronic oral MRL is expected to be without adverse effects when consumed on a daily basis over a long period of time; neither inducing nutritional deficiency in healthy, nonpregnant, adult humans ingesting the average American diet nor resulting in adverse effects from excess consumption. The MRL was not based on a chronic-duration oral study due to a lack of adequate long-term studies in humans and animals. Several studies have reported copper deficiency-induced anemia resulting from longer-term exposure to zinc, either via supplements or other sources (Broun et al. 1990; Gyorffy and Chan 1992; Hale et al. 1988; Hoffman et al. 1988; Patterson et al. 1985; Porter et al. 1977; Prasad et al. 1978; Ramadurai et al. 1993; Stroud 1991; Summerfield et al. 1992); effects generally occurred at estimated exposure levels of approximately $2-10 \mathrm{mg}$ zinc/kg/day. However, the available studies are limited by small numbers of subjects evaluated (often a single individual), limited evaluation of end points, and limited reporting of study results, making them unsuitable for use in the derivation of a chronic-duration MRL. 



\section{HEALTH EFFECTS}

\subsection{INTRODUCTION}

The primary purpose of this chapter is to provide public health officials, physicians, toxicologists, and other interested individuals and groups with an overall perspective on the toxicology of zinc. It contains descriptions and evaluations of toxicological studies and epidemiological investigations and provides conclusions, where possible, on the relevance of toxicity and toxicokinetic data to public health.

A glossary and list of acronyms, abbreviations, and symbols can be found at the end of this profile.

Zinc is an essential nutrient in humans and animals that is necessary for the function of a large number of metalloenzymes. These enzymes include alcohol dehydrogenase, alkaline phosphatase, carbonic anhydrase, leucine aminopeptidase, superoxide dismutase, and deoxyribonucleic acid (DNA) and ribonucleic acid (RNA) polymerase. As such, zinc is required for normal nucleic acid, protein, and membrane metabolism, as well as cell growth and division. Zinc also plays an essential role in the maintenance of nucleic acid structure of genes (zinc finger phenomenon). Zinc deficiency has been associated with dermatitis, anorexia, growth retardation, poor wound healing, hypogonadism with impaired reproductive capacity, impaired immune function, and depressed mental function; increased incidence of congenital malformations in infants has also been associated with zinc deficiency in the mothers (Cotran et al. 1989; Elinder 1986; Sandstead 1981). Zinc deficiency may also have an impact on carcinogenesis, though the direction of the influence seems to vary with the agent (Fong et al. 1978; Mathur 1979; Wallenius et al. 1979). Therefore, certain levels of zinc intake are recommended. The RDA for zinc is $11 \mathrm{mg} /$ day in men and $8 \mathrm{mg} /$ day in women (IOM 2002). Higher RDAs are recommended for women during pregnancy and lactation $(12 \mathrm{mg} /$ day for pregnant women and nursing women). While a detailed discussion of zinc deficiency is beyond the scope of this toxicological profile, the subject has been thoroughly reviewed by other agencies (IOM 2002; WHO 1996).

Just as zinc deficiency has been associated with adverse effects in humans and animals, overexposures to zinc also have been associated with toxic effects. This chapter contains a description of the toxic effects that have been associated with exposures to high levels of zinc and selected zinc compounds by the inhalation, oral, and dermal routes. Specifically, zinc chloride, zinc oxide, zinc sulfate, and zinc sulfide will be discussed. Other zinc compounds are discussed in this chapter whenever data regarding these 
compounds add relevant information to the discussion on zinc. Any general comments regarding the lack of data on zinc refer to both zinc and its compounds.

Because there are differences in toxicity between the various zinc compounds following inhalation exposure, these compounds will be discussed under separate subheadings in Section 3.2.1 (Inhalation Exposure). After oral or dermal exposure, the toxicities are comparable for all zinc compounds. Therefore, in Section 3.2.2 (Oral Exposure) and Section 3.2.3 (Dermal Exposure), the discussion will not be subdivided, but the specific zinc compounds will be identified in each case.

\subsection{DISCUSSION OF HEALTH EFFECTS BY ROUTE OF EXPOSURE}

To help public health professionals and others address the needs of persons living or working near hazardous waste sites, the information in this section is organized first by route of exposure (inhalation, oral, and dermal) and then by health effect (death, systemic, immunological, neurological, reproductive, developmental, genotoxic, and carcinogenic effects). These data are discussed in terms of three exposure periods: acute (14 days or less), intermediate (15-364 days), and chronic (365 days or more).

Levels of significant exposure for each route and duration are presented in tables and illustrated in figures. The points in the figures showing no-observed-adverse-effect levels (NOAELs) or lowestobserved-adverse-effect levels (LOAELs) reflect the actual doses (levels of exposure) used in the studies. LOAELs have been classified into "less serious" or "serious" effects. "Serious" effects are those that evoke failure in a biological system and can lead to morbidity or mortality (e.g., acute respiratory distress or death). "Less serious" effects are those that are not expected to cause significant dysfunction or death, or those whose significance to the organism is not entirely clear. ATSDR acknowledges that a considerable amount of judgment may be required in establishing whether an end point should be classified as a NOAEL, "less serious" LOAEL, or "serious" LOAEL, and that in some cases, there will be insufficient data to decide whether the effect is indicative of significant dysfunction. However, the Agency has established guidelines and policies that are used to classify these end points. ATSDR believes that there is sufficient merit in this approach to warrant an attempt at distinguishing between "less serious" and "serious" effects. The distinction between "less serious" effects and "serious" effects is considered to be important because it helps the users of the profiles to identify levels of exposure at which major health effects start to appear. LOAELs or NOAELs should also help in determining whether or not the effects vary with dose and/or duration, and place into perspective the possible significance of these effects to human health. 
The significance of the exposure levels shown in the Levels of Significant Exposure (LSE) tables and figures may differ depending on the user's perspective. Public health officials and others concerned with appropriate actions to take at hazardous waste sites may want information on levels of exposure associated with more subtle effects in humans or animals (LOAELs) or exposure levels below which no adverse effects (NOAELs) have been observed. Estimates of levels posing minimal risk to humans (Minimal Risk Levels or MRLs) may be of interest to health professionals and citizens alike.

A User's Guide has been provided at the end of this profile (see Appendix B). This guide should aid in the interpretation of the tables and figures for Levels of Significant Exposure and the MRLs.

\subsubsection{Inhalation Exposure}

\subsubsection{Death}

In humans, death has resulted from acute exposure to zinc compounds. When a high concentration (estimated at $33,000 \mathrm{mg}$ zinc $/ \mathrm{m}^{3}$ ) of zinc chloride smoke resulted from the explosion of many generators in a tunnel following a bombing raid in World War II, 10 of the 70 exposed people in the tunnel died within 4 days (Evans 1945). The smoke generated contained mainly highly caustic zinc chloride, but exposure to other constituents, namely zinc oxide, hexachloroethane, calcium silicate, and an igniter, was also possible. Therefore, the deaths resulting from the explosion cannot be conclusively attributed to only exposure to zinc chloride. This is the only human study reporting an estimated exposure level that caused death. Another study reported the death of a fireman exposed to the contents of a smoke bomb in a closed environment (Milliken et al. 1963). The man died 18 days after exposure because of respiratory difficulty. Again, exposure to zinc chloride was simultaneous with exposure to other substances in the smoke. Two soldiers exposed without gas masks to zinc chloride smoke during military training developed severe adult respiratory distress syndrome (ARDS) and died 25-32 days after the incident (Hjortso et al. 1988). Diffuse microvascular obliteration, widespread occlusion of the pulmonary arteries, and extensive interstitial and intra-alveolar fibrosis were observed at autopsy. Zinc levels in major organs and tissues obtained during autopsy were within the normal range, and no zinc particles were observed by scanning electron microscopy. According to the authors, the fumes from the smoke bombs consisted mainly of zinc chloride. However, no exposure levels were estimated, and other substances were also present in the smoke. Because of the caustic nature of zinc chloride, it is likely that these effects were the result of severe irritation from the compound, rather than direct actions of the zinc ion. 
A case study presented by Murray (1926) reported on an infant death due to bronchopneumonia resulting from inhalation, and possibly ingestion, of an unspecified amount of zinc stearate powder spilled from a container. However, it is unclear whether the death was due to the zinc content or whether aspiration bronchopneumonia would result from inhalation of similar powders that do not contain zinc.

In mice, the reported $\mathrm{LCT}_{50}$ (product of lethal concentration and time to kill $50 \%$ of animals) of zinc chloride is $11,800 \mathrm{mg} / \mathrm{minute} / \mathrm{m}^{3}$ (Schenker et al. 1981). However, Schenker et al. (1981) did not provide information on how this value was determined. Following exposure to zinc chloride smoke for 320 weeks, mortality was $50 \%$ in mice exposed to $121.7 \mathrm{mg}$ zinc $/ \mathrm{m}^{3}$ (compared to $20 \%$ in controls) and $22 \%$ in guinea pigs exposed to $119.3 \mathrm{mg}$ zinc $/ \mathrm{m}^{3}$ (compared to $8 \%$ in controls) (Marrs et al. 1988). The smoke was similar to that described by Evans (1945) and also contained zinc oxide, hexachloroethane, and other compounds.

\subsubsection{Systemic Effects}

The highest NOAEL values and all LOAEL values from each reliable study for systemic effects in each species and duration category are recorded in Table 3-1 and plotted in Figure 3-1.

No studies were located regarding musculoskeletal, endocrine, dermal, or body weight effects in humans or animals after inhalation exposure to zinc or zinc compounds. The systemic effects observed after inhalation exposure are discussed below. In most cases, the effects of zinc are discussed without separating effects caused by the individual zinc compounds. However, the respiratory effects of the individual zinc compounds are discussed separately because the nature of the respiratory toxicity differs depending on the particular compound to which one is exposed.

\section{Respiratory Effects.}

Zinc Oxide. Metal fume fever, a well-documented acute disease induced by intense inhalation of metal oxides, especially zinc, impairs pulmonary function but does not progress to chronic lung disease (Brown 1988; Drinker and Drinker 1928; Malo et al. 1990). Symptoms generally appear within a few hours after acute exposure, usually with dryness of the throat and coughing (Drinker et al. 1927b). The most 
Table 3-1 Levels of Significant Exposure to Zinc - Inhalation

\begin{tabular}{|c|c|c|c|c|c|c|c|}
\hline \multirow[b]{2}{*}{$\begin{array}{l}\text { Key to } \\
\text { Figure }\end{array}$} & \multirow[b]{2}{*}{$\begin{array}{l}\text { Species } \\
\text { (Strain) }\end{array}$} & \multirow{2}{*}{$\begin{array}{l}\text { Exposure/ } \\
\text { Duration/ } \\
\text { Frequency } \\
\text { (Route) }\end{array}$} & \multirow[b]{2}{*}{ System } & \multirow[b]{2}{*}{$\begin{array}{l}\text { NOAEL } \\
\left(\mathrm{mg} / \mathrm{m}^{3}\right)\end{array}$} & \multicolumn{2}{|c|}{ LOAEL } & \multirow[b]{2}{*}{$\begin{array}{l}\text { Reference } \\
\text { Chemical Form }\end{array}$} \\
\hline & & & & & $\begin{array}{l}\text { Less Serious } \\
\qquad\left(\mathrm{mg} / \mathrm{m}^{3}\right)\end{array}$ & $\begin{array}{l}\text { Serious } \\
\left(\mathrm{mg} / \mathrm{m}^{3}\right)\end{array}$ & \\
\hline
\end{tabular}

ACUTE EXPOSURE

\section{Systemic}

1 Human

$15-30 \mathrm{~min}$

Resp

77 (minimal change in

Blanc et al. 1991

pulmonary function)

Zinc oxide

2 Human

$\begin{array}{ll}1 \mathrm{~d} & \text { Resp }\end{array}$

Other

3.9 (dry or sore throat, chest

tightness)

Gordon et al. 1992

Zinc oxide

3.9 (fever/chills and headache)

3 Human 1x

$1 \mathrm{x}-120$ minutes Resp

$1 \mathrm{x}$

16.4 (Increased indices of

pulmonary inflammation)

Kuschner et al. 1995

Zinc oxide

Kuschner et al. 1997

Zinc oxide

inflammatory cytokines in

bronchoalveolar lavage

Linn et al. 1981

Zinc amm sulfate

Marquart et al. 1989

Zinc oxide 
Table 3-1 Levels of Significant Exposure to Zinc - Inhalation

\begin{tabular}{|c|c|c|c|c|c|c|c|}
\hline \multirow[b]{2}{*}{$\begin{array}{l}\text { Key to } \\
\text { Figure }\end{array}$} & \multirow[b]{2}{*}{$\begin{array}{l}\text { Species } \\
\text { (Strain) }\end{array}$} & \multirow{2}{*}{$\begin{array}{l}\text { Exposure/ } \\
\text { Duration/ } \\
\text { Frequency } \\
\text { (Route) }\end{array}$} & \multirow[b]{2}{*}{ System } & \multirow[b]{2}{*}{$\begin{array}{l}\text { NOAEL } \\
\left(\mathrm{mg} / \mathrm{m}^{3}\right)\end{array}$} & \multicolumn{2}{|c|}{ LOAEL } & \multirow[b]{2}{*}{$\begin{array}{l}\text { Reference } \\
\text { Chemical Form }\end{array}$} \\
\hline & & & & & $\begin{array}{l}\text { Less Serious } \\
\qquad\left(\mathrm{mg} / \mathrm{m}^{3}\right)\end{array}$ & $\begin{array}{l}\text { Serious } \\
\left(\mathrm{mg} / \mathrm{m}^{3}\right)\end{array}$ & \\
\hline
\end{tabular}

$7 \quad$ Human

$10.5-12 \mathrm{~min}$

Resp

Gastro

Hemato

Rat 1 d

(Fischer- 344) 3hr/d

Resp

$9 \quad$ Gn Pig

$1 \mathrm{hr}$

10

Gn Pig $\begin{array}{r}1-3 \mathrm{~d} \\ 3 \mathrm{hr} / \mathrm{d}\end{array}$

Resp

$1.8 \mathrm{M}$

11

$\begin{array}{ll}\text { Gn Pig } & 1 \mathrm{~d} \\ \text { (Hartley) } & 3 \mathrm{hr} / \mathrm{d}\end{array}$

Resp $\mathrm{LDH}$, and protein in
bronchoalveolar lavage

4.7 M (increased neutrophils,

fluid)

$600 \mathrm{M}$ (decreased vital capacity)

$600 \mathrm{M}$ (nausea)

$600 \mathrm{M}$ (increased leukocytes)

2.2 (increased LDH protein in

bronchoalveolar lavage

fluid)

$0.73 \mathrm{M}$ (decrease in lung

compliance)

Amdur et al. 1982

Zinc oxide

Conner et al. 1988

Zinc oxide

Gordon et al. 1992

Zinc oxide 
Table 3-1 Levels of Significant Exposure to Zinc - Inhalation

\begin{tabular}{|c|c|c|c|c|c|c|c|}
\hline \multirow[b]{2}{*}{$\begin{array}{l}\text { Key to } \\
\text { Figure }\end{array}$} & \multirow[b]{2}{*}{$\begin{array}{l}\text { Species } \\
\text { (Strain) }\end{array}$} & \multirow{2}{*}{$\begin{array}{l}\text { Exposure/ } \\
\text { Duration/ } \\
\text { Frequency } \\
\text { (Route) }\end{array}$} & \multirow[b]{2}{*}{ System } & \multirow[b]{2}{*}{$\begin{array}{l}\text { NOAEL } \\
\left(\mathrm{mg} / \mathrm{m}^{3}\right)\end{array}$} & \multicolumn{2}{|c|}{ LOAEL } & \multirow[b]{2}{*}{$\begin{array}{l}\text { Reference } \\
\text { Chemical Form }\end{array}$} \\
\hline & & & & & $\begin{array}{l}\text { Less Serious } \\
\left(\mathrm{mg} / \mathrm{m}^{3}\right)\end{array}$ & $\begin{array}{l}\text { Serious } \\
\left(\mathrm{mg} / \mathrm{m}^{3}\right)\end{array}$ & \\
\hline
\end{tabular}

$12 \quad$ Gn Pig $3 \mathrm{hr}$

(Hartley)

Resp

3 Gn Pig 6d

(Hartley) 3hr/d

Resp

14

Gn Pig $\quad 5 d$

(Hartley) 3hr/d

Resp

$2.2 \mathrm{M}$

15

$\begin{array}{llll}\text { Rabbit } & 1 \mathrm{~d} & & \\ \text { (New } & 2 \mathrm{hr} / \mathrm{d} & \text { Resp } & 4.6 \\ \text { Zealand) } & & & \end{array}$

Zealand)

Immuno/ Lymphoret

16 Human 15-30 min
3.7 (impaired lung function;

inflammation; increased

pulmonary resistance;

increased lung weight)

$6.3 \mathrm{M}$ (decreased functional

residual capacity)

Lam et al. 1982

Zinc oxide

Lam et al. 1985

Zinc oxide

5.6 M (impaired lung function; increased lung weight)

Lam et al. 1988

Zinc oxide

Gordon et al. 1992

Zinc oxide

Blanc et al. 1991

Zinc oxide (increased number of

eukocytes, T cells, T

suppressor cells, and

natural killer cells in

bronchoalveolar lavage

fluid)

amm sulfate = ammonium sulfate; $d$ = day(s); Gastro = gastrointestinal; Gn pig = guinea pig; Hemato = hematological; hr = hour(s); LDH = lactate dehydrogenase; LOAEL = lowest-observed-adverse-effect level; $\min =$ minute(s); NOAEL = no-observed-adverse-effect level; (occup) = occupational; Resp = respiratory 
Figure 3-1 Levels of Significant Exposure to Zinc - Inhalation

Acute ( $\leq 14$ days)

Systemic

$\mathrm{mg} / \mathrm{m} 3$

1000

100

$\Delta 1$

$\Delta 4$

43

10

$\begin{array}{ll}12 \mathrm{~g} & 0_{14 \mathrm{~g}} \\ \mathbf{1} 10 \mathrm{~g} & \Delta 2\end{array}$

O11g $014 \mathrm{~g} 8 \mathrm{r}$

9g

$\triangle 6$

$\triangle 5$

$\Delta 7$

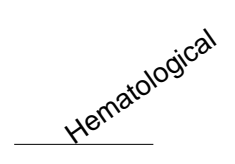

$\Delta 7$

7
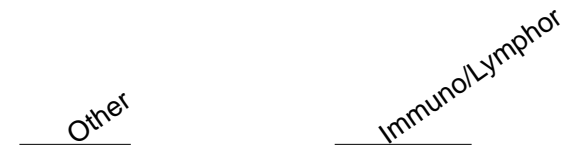

$\mathbf{\Delta} 16$

$\Delta 2$

0.001

\begin{tabular}{|c|c|c|c|c|c|c|}
\hline $\begin{array}{l}\text { c-Cat } \\
\text { d-Dog } \\
\text { r-Rat } \\
\text { p-Pig } \\
\text { q-Cow }\end{array}$ & $\begin{array}{l}\text {-Hymans } \\
\text { k-Monkey } \\
\text { m-Mouse } \\
\text { h-Rabbit } \\
\text { a-Sheep }\end{array}$ & $\begin{array}{l}\text { f-Ferret } \\
\text { j-Pigeon } \\
\text { e-Gerbil } \\
\text { S-Hamster } \\
\text { g-Guinea Pic }\end{array}$ & $\begin{array}{l}\text { n-Mink } \\
\text { o-Other }\end{array}$ & 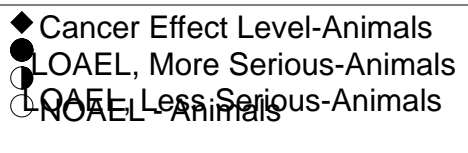 & $\begin{array}{l}\nabla \text { Cancer Effect Level-Humans } \\
\text { AOAEL, More Serious-Humans } \\
\triangle \text { LOAEL, Less Serious-Humans } \\
\triangle \text { NOAEL - Humans }\end{array}$ & $\begin{array}{l}\text { LD50/LC50 } \\
\text { Minimal Risk Level } \\
\text { for effects } \\
\text { other than }\end{array}$ \\
\hline
\end{tabular}


prominent respiratory effects of metal fume fever are substernal chest pain, cough, and dyspnea (Rohrs 1957). The impairment of pulmonary function is characterized by reduced lung volumes and a decreased diffusing capacity of carbon monoxide (Malo et al. 1990; Vogelmeier et al. 1987). The respiratory effects have been shown to be accompanied by an increase in bronchiolar leukocytes (Vogelmeier et al. 1987). The respiratory symptoms generally disappear in the exposed individual within 1-4 days (Brown 1988; Drinker et al. 1927b; Sturgis et al. 1927). Inhalation of zinc oxide is most likely to occur in occupational situations where zinc smelting or welding take place. Ultrafine zinc oxide particles $(0.2-1.0 \mu \mathrm{m})$ originate from heating zinc beyond its boiling point in an oxidizing atmosphere. Upon inhalation, these small particles $(<1 \mu \mathrm{m})$ reach the alveoli and cause inflammation and tissue damage in the lung periphery (Brown 1988; Drinker et al. 1927b; Vogelmeier et al. 1987).

A number of studies have measured exposure levels associated with metal fume fever. Workers involved in pouring molten zinc reported shortness of breath and chest pains 2-12 hours following exposure to $320-580 \mathrm{mg}$ zinc/ $\mathrm{m}^{3}$ as zinc oxide for 1-3 hours (Hammond 1944); the number of workers was not reported. Two volunteers had nasal passage irritation, cough, substernal chest pain, persistent rales of the lung base, and a decreased vital capacity for approximately 3-49 hours following acute inhalation (1012 minutes) of $600 \mathrm{mg} \mathrm{zinc} / \mathrm{m}^{3}$ as zinc oxide (Sturgis et al. 1927). This study is limited due to an inadequate number of subjects, a lack of controls, and a lack of analysis of the final aerosol product. A subject experimentally exposed to zinc oxide fumes reported mild pain when breathing deeply the next day after a 5-hour exposure to $430 \mathrm{mg}$ zinc/ $\mathrm{m}^{3}$ (Drinker et al. 1927a). Minimal changes in forced expiratory flow were observed 1 hour after a 15-30-minute exposure to $77 \mathrm{mg}$ zinc/ $\mathrm{m}^{3}$ as zinc oxide (Blanc et al. 1991).

Acute experimental exposures to lower concentrations of zinc oxide $\left(14 \mathrm{mg} / \mathrm{m}^{3}\right.$ for 8 hours or $45 \mathrm{mg}$ $\mathrm{zinc} / \mathrm{m}^{3}$ for 20 minutes) and occupational exposures to similar concentrations $\left(8-12 \mathrm{mg} \mathrm{zinc} / \mathrm{m}^{3}\right.$ for $1-$ 3 hours and $0.034 \mathrm{mg}$ zinc $/ \mathrm{m}^{3}$ for 6-8 hours) did not produce symptoms of metal fume fever (Drinker et al. 1927b; Hammond 1944; Marquart et al. 1989). In a single-blind experiment, exposure of subjects to $3.9 \mathrm{mg}$ zinc $/ \mathrm{m}^{3}$ as zinc oxide resulted in sore throat and chest tightness but no impairment of pulmonary function (Gordon et al. 1992). It is speculated that subjects in other studies may have been less susceptible because of the development of tolerance to zinc (Gordon et al. 1992). Kuschner et al. (1995) exposed a group of 14 volunteers to a single exposure of varying levels of zinc oxide fume (mean concentration $16.4 \pm 12.5 \mathrm{mg} / \mathrm{m}^{3}$ ) for $15-120$ minutes (mean duration $45 \pm 28$ minutes) and evaluated the response by bronchoalveolar lavage (BAL). Significant increases were reported in the number of polymorphonuclear leukocytes and lymphocytes in the BAL fluid, but not in the number of macrophages or in 
lymphocyte subpopulations; aside from a decrease in $\mathrm{FEV}_{1}$, no changes were reported in pulmonary function tests. In a follow-up study by the same group (Kuschner et al. 1997), single-exposed volunteers showed an increase in levels of the cytokines TNF, IL-6, and IL-8 as a result of zinc oxide inhalation. Recurrent episodes of cough and dyspnea were reported in a former mild smoker 3 years after beginning work in a metal foundry where exposure to zinc oxide presumably occurred (Ameille et al. 1992). This case was distinguishable from metal fume fever because of the lack of tolerance to zinc (as shown by the late emergence of symptoms).

Several animal studies have been conducted to quantify specific effects after acute zinc oxide inhalation. As in human exposure, the respiratory system is the primary site of injury following inhalation exposure. Acute administration of $88-482 \mathrm{mg}$ zinc $/ \mathrm{m}^{3}$ as zinc oxide to rats and rabbits resulted in the following pulmonary changes: grayish areas with pulmonary congestion, various degrees of peribronchial leukocytic infiltration, and bronchial exudate composed almost entirely of polymorphonuclear leukocytes (Drinker and Drinker 1928). Cats similarly exposed exhibited more severe effects including bronchopneumonia, leukocyte infiltration into alveoli, and grayish areas with congestion. During the exposure period, the cats demonstrated labored breathing and evidence of upper respiratory tract obstruction. A minimum effect level could not be determined for any species because the concentration varied widely (88-482 $\mathrm{mg}$ zinc $/ \mathrm{m}^{3}$ ) during exposure.

Guinea pigs administered $0.73 \mathrm{mg}$ zinc/ $\mathrm{m}^{3}$ as zinc oxide for 1 hour had a progressive decrease in lung compliance but no change in air flow resistance. These observations reflect a response in the lung periphery where submicrometer aerosols are likely to deposit (Amdur et al. 1982). The authors postulated that reduced compliance may be associated with human metal fume fever.

In contrast to the results of Amdur et al. (1982), no effects on ventilation, lung mechanics (respiratory frequency, tidal volume, pulmonary resistance, and pulmonary compliance), diffusing capacity of carbon monoxide, or most lung volume parameters were observed by Lam et al. (1982) following the exposure of guinea pigs to $6.3 \mathrm{mg} \mathrm{zinc} / \mathrm{m}^{3}$ as zinc oxide for 3 hours. However, functional residual capacity was significantly decreased. The discrepancy between the results of Amdur et al. (1982) and Lam et al. (1982) may be attributable to the use of anesthetized animals by Lam et al. (1982). In a later study, exposures of guinea pigs to 3.7 or $4.3 \mathrm{mg}$ zinc/ $\mathrm{m}^{3}$ as zinc oxide for 3 hours/day, for 6 days, resulted in transient functional, morphological, and biochemical changes (Lam et al. 1985). Functional changes included increased flow resistance, decreased lung compliance, and decreased diffusing capacity, all of which returned to normal within 24-72 hours following exposure. The morphological changes (increased 
lung weight, inflammation involving the proximal portion of alveolar ducts and adjacent alveoli, interstitial thickening, and increased pulmonary macrophages and neutrophils in adjacent air spaces) were, however, still present at 72 hours. In guinea pigs with evidence of an inflammatory reaction involving the peripheral airways, DNA synthesis increased in bronchiolar cells. Similarly, exposure of guinea pigs to $5.6 \mathrm{mg}$ zinc $/ \mathrm{m}^{3}$ as zinc oxide for 3 hours/day, for 5 days, resulted in gradual decreases in total lung capacity, vital capacity, and decreased carbon monoxide diffusing capacity (Lam et al. 1988); however, no effects were observed in guinea pigs exposed to $2.2 \mathrm{mg} \mathrm{zinc} / \mathrm{m}^{3}$. The reason that effects have been seen in the guinea pig at exposure levels lower than humans may have to do with the structural features of the guinea pig lung. The bronchi and peripheral airways of guinea pigs have a thicker smooth muscle layer and only a small surface area covered by alveolar sacs compared to the bronchi and peripheral airways of other laboratory animals and humans. This makes the guinea pig more susceptible than other laboratory animals to functional impairment of the peripheral airways and should be noted in toxicity comparisons (Lam et al. 1982).

The bronchoalveolar lavage fluid of rats or guinea pigs exposed to $1.8 \mathrm{mg} \mathrm{zinc} / \mathrm{m}^{3}$ as zinc oxide for 3 hours contained increased levels of lactate dehydrogenase and total protein, suggesting effects on cell viability or membrane permeability (Gordon et al. 1992). Rabbits were not affected following a similar exposure to $4.6 \mathrm{mg}$ zinc $/ \mathrm{m}^{3}$ for 2 hours. Guinea pigs had foci of inflammation after exposure to $4.7 \mathrm{mg}$ $\mathrm{zinc} / \mathrm{m}^{3}$ for 3 days, and the bronchoalveolar lavage fluid contained increased levels of protein, angiotensin converting enzyme, and neutrophils (Conner et al. 1988). No significant changes in respiratory effects were observed in this study following exposure to $1.8 \mathrm{mg}$ zinc $/ \mathrm{m}^{3}$ for 3 days.

Zinc Chloride. Zinc chloride, a corrosive inorganic salt, is more damaging than zinc oxide to the mucous membranes of the nasopharynx and respiratory tract upon contact. Zinc chloride is a primary ingredient in smoke bombs used by the military for screening purposes, crowd dispersal, and occasionally in military and civilian fire-fighting exercises. Reports of serious respiratory injury have been reported to result from accidental inhalation of smoke from these bombs. These reports are of limited use in assessing the toxicity of zinc chloride because exposure to other compounds, usually hexachloroethane, zinc oxide, and calcium silicides, also occur. Furthermore, the specific concentrations inhaled are usually unknown. Despite these limitations, several case studies have described similar respiratory effects in humans following acute inhalation exposures. These effects include dyspnea, cough, pleuritic chest pain, bilateral diffuse infiltrations, pneumothorax, and acute pneumonitis from respiratory tract irritation (Johnson and Stonehill 1961; Matarese and Matthews 1966; Schenker et al. 1981; Zerahn et al. 1999). In the study by Johnson and Stonehill (1961), cough, dyspnea, burning throat, diffuse infiltrates throughout the lung, 
chemical pneumonitis, and decreased vital capacity were observed at an estimated zinc chloride exposure level of $4,075 \mathrm{mg} / \mathrm{m}^{3}\left(1,955 \mathrm{mg}\right.$ zinc $\left./ \mathrm{m}^{3}\right)$. In other studies, more severe effects have occurred, including ulcerative and edematous changes in mucous membranes, fibrosis, subpleural hemorrhage, advanced pulmonary fibrosis, and fatal respiratory distress syndrome (Evans 1945; Hjortso et al. 1988; Homma et al. 1992; Milliken et al. 1963).

Focal alveolitis, consolidation, emphysema, infiltration with macrophages, and fibrosis were observed in guinea pigs that died following exposure to $119 \mathrm{mg}$ zinc $/ \mathrm{m}^{3}$ as zinc chloride smoke for 1 hour/day, 5 days/week, for 3-20 weeks (Marrs et al. 1988); no changes were seen in guinea pigs that survived 13 months after the 20-week exposure. Thirteen months after a 20 -week exposure, rats similarly exposed to $12.8 \mathrm{mg}$ zinc/ $\mathrm{m}^{3}$ showed an increase in peribronchial inflammatory cell (lymphocytes and macrophage) infiltration. Mice exposed to $121.7 \mathrm{mg} \mathrm{zinc} / \mathrm{m}^{3}$ as zinc chloride smoke, but not to lower doses, for 1 hour/day, 5 days/week, showed increased macrophages and lymphocytes in the lungs (Marrs et al. 1988). The smoke also contained zinc oxide, hexachloroethane, and other compounds.

Zinc Ammonium Sulfate. Zinc ammonium sulfate is a compound emitted during combustion of fossil fuels and is, therefore, found in the ambient air. Humans acutely exposed to a concentration of $0.0036 \mathrm{mg}$ $\mathrm{zinc} / \mathrm{m}^{3}$ as zinc ammonium sulfate for 2 hours (Linn et al. 1981) exhibited minimal or no short-term respiratory effects (including minimal substernal irritation, throat irritation, and coughing in asthmatic subjects). However, most human exposures to an ambient air pollutant such as zinc ammonium sulfate are chronic, and this study provides little information about the health effects associated with typical exposures.

No studies were located regarding respiratory effects in animals after inhalation exposure to zinc ammonium sulfate.

Zinc Stearate. Inhalation of zinc stearate powder resulted in aspiration bronchopneumonia in an infant (Murray 1926). However, it is unclear whether the bronchopneumonia resulted from the inhalation of zinc stearate powder specifically or from a nonspecific effect of the inhalation of powders.

No studies were located regarding respiratory effects in animals after inhalation exposure to zinc stearate.

Cardiovascular Effects. No atypical heart sounds or blood pressure abnormalities were observed in 24 employees occupationally exposed to concentrations as high as $130 \mathrm{mg} \mathrm{zinc} / \mathrm{m}^{3}$ of metallic zinc dust, 
zinc oxide dust, zinc sulfide dust, or lithophone dust (a combination of barium sulphate and $\approx 30 \%$ zinc sulphide) for 2-35.5 years (Batchelor et al. 1926). However, this study is limited because only selected employees were examined.

Only limited information was located regarding cardiovascular effects in animals following inhalation exposure to zinc. Routine gross and microscopic examination of the hearts of rats and mice revealed no adverse effects 13 months after exposure to $121.7 \mathrm{mg} \mathrm{zinc} / \mathrm{m}^{3}$ as zinc chloride smoke (also containing other compounds) for 1 hour/day, 5 days/week, for 20 weeks (Marrs et al. 1988). Similarly, no changes were observed in the hearts of guinea pigs exposed to $119.3 \mathrm{mg}$ zinc $/ \mathrm{m}^{3}$ as zinc chloride smoke for 1 hour/day, 5 days/week, for 20 weeks, and then observed for an additional 17 months (Marrs et al. 1988).

Gastrointestinal Effects. Nausea was reported by humans exposed to high concentrations of zinc oxide fumes (Hammond 1944; Rohrs 1957; Sturgis et al. 1927) and zinc chloride smoke (Evans 1945; Johnson and Stonehill 1961; Schenker et al. 1981). The zinc chloride smoke also contained zinc oxide, hexachloroethane, and other compounds. In general, exposure levels associated with nausea have not been reported. However, exposures to $320 \mathrm{mg}$ zinc $/ \mathrm{m}^{3}$ as zinc oxide for 1-3 hours (Hammond 1944) or $600 \mathrm{mg}$ zinc/ $\mathrm{m}^{3}$ as zinc oxide for 10-12 minutes (Sturgis et al. 1927) were reported to have resulted in nausea; it should be noted, however, that the zinc used in these studies contained slight impurities (i.e., lead, magnesium). Autopsies of victims who died following exposure to very high concentrations of zinc chloride smoke revealed irritation of the stomach and intestines (Evans 1945). The smoke also contained zinc oxide, hexachloroethane, and other compounds. Workers in the galvanizing industry were found by McCord et al. (1926) to have a higher than expected incidence of gastrointestinal problems; however, these individuals may have been exposed to other chemicals (arsenic, hydrogen sulfide). Of 15 workers examined with 7-20 years of experience, 12 had frequent episodes of epigastric or abdominal pain, nausea, vomiting, ulcers, constipation, tarry stools, and/or gas. It is unclear whether these effects were due to systemic zinc or were the result of direct contact with the gastrointestinal tract following mucociliary clearance of inhaled zinc particles and subsequent swallowing. In contrast, 24 workers with 2-35.5 years of exposure to $\leq 130 \mathrm{mg}$ zinc $/ \mathrm{m}^{3}$ as metallic zinc dust, zinc sulfide dust, zinc oxide, or lithophone dust reported no nausea or vomiting and only occasional mild abdominal discomfort that could not be attributed with certainty to zinc exposure (Batchelor et al. 1926). A study examining the acidity of the stomach contents after stimulation in controls and workers employed in the production of brass alloys showed that stomach acidity was similar in the two groups prior to stimulation but remained elevated for longer periods after stimulation in the exposed workers (Hamdi 1969). This was proposed to account for 
the gastric complaints of workers exposed to zinc fumes. Despite these findings, x-rays showed no lesions in the stomachs or duodenums of exposed workers.

The only information available regarding gastrointestinal effects in animals was found in a study by Marrs et al. (1988) in which rats and mice were exposed to $121.7 \mathrm{mg}$ zinc/ $/ \mathrm{m}^{3}$ as zinc chloride smoke (which also contains zinc oxide, hexachlorophene, and other compounds) for 1 hour/day, 5 days/week, for 20 weeks, and then observed for an additional 13 months. In the same study, guinea pigs were exposed to $119.3 \mathrm{mg} \mathrm{zinc} / \mathrm{m}^{3}$ as zinc chloride smoke for 1 hour/day, 5 days/week, for 3 weeks. All animals were sacrificed at the end of 18 months. Routine gross and microscopic evaluation of the stomach and intestines at 18 months revealed no persistent adverse effects.

Hematological Effects. Leukocytosis persisting for approximately 12 hours after fever dissipates is one of the hallmarks of metal fume fever (Mueller and Seger 1985). Such effects have been observed in a number of case reports of occupational and experimental exposure of humans to zinc oxide fumes (Brown 1988; Drinker et al. 1927a; Malo et al. 1990; Rohrs 1957; Sturgis et al. 1927). Increased leukocyte counts were observed following experimental exposures to $430 \mathrm{mg} \mathrm{zinc} / \mathrm{m}^{3}$ as zinc oxide for 3 hours (Drinker et al. 1927a) or $600 \mathrm{mg}$ zinc $/ \mathrm{m}^{3}$ as zinc oxide for 10-12 minutes (Sturgis et al. 1927). These studies are limited in that they used an inadequate number of subjects, lacked controls, and used impure zinc oxide.

Decreased numbers of red blood cells and hemoglobin were found in several workers with 7-20 years of experience in the galvanizing industry (McCord et al. 1926). However, there were excess tobacco use and alcohol consumption by workers and possible concurrent exposure to other chemicals (chloride, sulfide), which confound the study results. No anemia was detected among 12 workers exposed for 4 21 years to zinc oxide fumes in the production of brass alloys (Hamdi 1969). These workers may have also been exposed to magnesium, copper, and aluminum.

No studies were located regarding hematological effects in animals after inhalation exposure to zinc.

Hepatic Effects. Routine blood chemistries and examinations revealed no liver disease among 12 workers with 4-21 years of exposure to zinc oxide fumes in the production of brass alloys (Hamdi 1969).

No adverse effects were observed during gross and microscopic examination of livers of rats and guinea pigs exposed to $121.7 \mathrm{mg}$ zinc $/ \mathrm{m}^{3}$ or $119.3 \mathrm{mg}$ zinc $/ \mathrm{m}^{3}$, respectively, as zinc chloride smoke for 
1 hour/day, 5 days/week, for 20 weeks, and sacrificed at the end of 18 months (Marrs et al. 1988). Significant increases in the incidence of fatty liver were observed in mice exposed to 12.8 or $121.7 \mathrm{mg}$ $\mathrm{zinc} / \mathrm{m}^{3}$ as zinc chloride smoke using the same exposure paradigm; however, the incidence did not increase with dose (Marrs et al. 1988). The smoke contained other compounds in addition to zinc chloride.

Renal Effects. Urinalyses and histories of urinary function revealed no adverse effects in 24 workers exposed for 2-35.5 years to $\leq 130 \mathrm{mg}$ zinc $/ \mathrm{m}^{3}$ as metallic zinc dust, zinc sulfide dust, zinc oxide, or lithophone dust (Batchelor et al. 1926).

No adverse effects were observed following gross and microscopic examination of kidneys from rats, mice, and guinea pigs exposed for 1 hour/day, 5 days/week, for 20 weeks, to concentrations as high as 121.7 or $119.3 \mathrm{mg} \mathrm{zinc} / \mathrm{m}^{3}$ as zinc chloride smoke (which also contained other compounds) and then sacrificed 13 months later (Marrs et al. 1988).

Ocular Effects. Reddened conjunctiva and corneal burns occurred in individuals exposed to high concentrations of zinc chloride smoke (estimated at 33,000 $\mathrm{mg}$ zinc $/ \mathrm{m}^{3}$ ) when several smoke generators exploded in a tunnel during World War II (Evans 1945). The ocular effects may have been due to direct contact with the smoke.

Homeostatic Effects. A fever appearing 3-10 hours after exposure to zinc oxide fumes and lasting approximately 24-48 hours is characteristic of metal fume fever caused by zinc (Mueller and Seger 1985). Elevated body temperature has been observed in a number of experimental and occupational zinc oxide exposures (Brown 1988; Drinker et al. 1927a; Hammond 1944; Malo et al. 1990; Rohrs 1957; Sturgis et al. 1927; Vogelmeier et al. 1987). Using a number of exposure concentrations for various durations, Drinker et al. (1927b) found that the increase in body temperature was dependent on the exposure duration and concentration. Based on their data, they calculated that the threshold for pyrogenic effects was $45 \mathrm{mg}$ zinc $/ \mathrm{m}^{3}$ for 20 minutes. This study is limited in that impurities were present in the zinc used and no statistical analysis was performed. Exposure to zinc chloride smoke (which also contains other compounds) has also been associated with fever (Hjortso et al. 1988; Matarese and Matthews 1966).

No studies were located regarding other systemic effects in animals following inhalation exposure to zinc. 


\subsubsection{Immunological and Lymphoreticular Effects}

One report described hives and angioedema in a man exposed to zinc fumes at a zinc smelting plant (Farrell 1987). The author suggested that the patient had an immediate or delayed immunoglobulin $\mathrm{E}$ (IgE) response (or both) after a low dose of zinc fumes. Metal fume fever also resulted when the exposure increased. The signs and symptoms of toxicity were repeated in a challenge test conducted at the patient's home.

In a group of 14 welders acutely exposed to $77-153 \mathrm{mg}$ zinc/ $\mathrm{m}^{3}$ as zinc oxide, significant correlations between the concentration of airborne zinc and the proportion of activated $\mathrm{T}$ cells, T helper cells, $\mathrm{T}$ inducer cells, T suppressor cells, and activated killer T cells were observed 20 hours after exposure (Blanc et al. 1991). In addition, significant increases in levels of polymorphonuclear leukocytes, macrophages, and all types of lymphocytes were observed in the bronchoalveolar lavage fluid 20 hours after exposure. Increased levels of lymphocytes, with a predominance of CD8 cells, in the bronchoalveolar lavage fluid were reported in a case study of a smelter exposed to unspecified levels of zinc fumes (Ameille et al. 1992).

The bronchoalveolar lavage fluid of rats or guinea pigs exposed to $2.2 \mathrm{mg}$ zinc $/ \mathrm{m}^{3}$ for 3 hours contained increased levels of $\beta$-glucuronidase, suggesting a change in macrophage function (Gordon et al. 1992).

Rabbits were not affected following a similar exposure to $4.6 \mathrm{mg} \mathrm{zinc} / \mathrm{m}^{3}$ for 2 hours. Rats, mice, and guinea pigs were exposed to concentrations as high as 119.3 or $121.7 \mathrm{mg} \mathrm{zinc} / \mathrm{m}^{3}$ as zinc chloride smoke for 1 hour/day, 5 days/week, for 20 weeks (Marrs et al. 1988). Routine gross and histopathologic examination of the lymph nodes, thymus, and spleen at the end of 18 months revealed no adverse effects. The smoke also contained zinc oxide, hexachlorophene, and other compounds.

\subsubsection{Neurological Effects}

Humans have reported nonspecific neurological effects such as headaches and malaise in association with other symptoms following inhalation of zinc oxide and in metal fume fever (Rohrs 1957; Sturgis et al. 1927). Staggering gait, hallucinations, and hilarity were observed in an individual who intentionally inhaled aerosols of metallic paint containing copper and zinc (Wilde 1975). However, it is most likely that these effects were due to exposure to hydrocarbon propellant rather than zinc. Amr et al. (1997) reported an increase in neuropsychiatric symptoms, including fear of poisoning, headache, nervousness, insomnia, and changes in EEG, in workers who were occupationally-exposed to zinc phosphide for a 
period of many years; however, exposure levels were not reported, and no tests of statistical significance were performed.

No studies were located regarding neurological effects in animals after inhalation exposure to zinc.

\subsubsection{Reproductive Effects}

No studies were located regarding reproductive effects in humans after inhalation exposure to zinc.

Following an initial exposure of rats, mice, and guinea pigs to concentrations as high as 119.3 or $121.7 \mathrm{mg} \mathrm{zinc} / \mathrm{m}^{3}$ as zinc chloride smoke (which also contained other compounds) for 1 hour/day, 5 days/week, for 20 weeks; histological evaluation revealed no adverse effects on the mammary glands, ovaries, fallopian tubes, or uteri were observed at 18 months (Marrs et al. 1988).

\subsubsection{Developmental Effects}

No studies were located regarding developmental effects in humans or animals after inhalation exposure to zinc.

\subsubsection{Cancer}

In two epidemiological studies, workers did not have an increased incidence of cancers associated with occupational exposure (primarily inhalation exposure) to zinc (Logue et al. 1982; Neuberger and Hollowell 1982).

Workers in nine electrolytic zinc and copper refining plants were studied by Logue et al. (1982). The workers at two of these plants were exposed to zinc or zinc and copper; the other workers were exposed to copper. An association between cancer mortality and zinc exposure was not found.

Excess lung cancer mortality associated with residence in an old lead/zinc mining and smelting area of the midwestern United States was studied by Neuberger and Hollowell (1982). The age- and sex-adjusted mortality rates were compared to state and national rates. The analysis determined that lung cancer mortality was elevated in the region but was not found to be associated with exposure to environmental 
levels of lead or zinc. Many confounding factors were not considered in the analysis, such as smoking, occupation, and duration of residence in the area in question.

Female Porton strain mice (98-100/group) exposed to $121.7 \mathrm{mg}$ zinc/ $\mathrm{m}^{3}$ of a zinc oxide/hexachloroethane smoke mixture (which produces zinc chloride), 1 hour/day, 5 days/week, for 20 weeks had a statistically significant increase in the incidence of alveologenic carcinoma (30 versus $8 \%$ in control) thirteen months after the end of exposure (Marrs et al. 1988). No increased tumor incidences were seen in mice exposed to $1,1.3$, or $12.8 \mathrm{mg}$ zinc/ $\mathrm{m}^{3}$. Guinea pigs and rats were also tested with similar dose levels, and no significant carcinogenic response was observed. A number of factors limit the usefulness of this study, including the presence of several compounds in the smoke that may have carcinogenic potential, the use of only female animals, and the short duration of the exposure (20 weeks).

\subsubsection{Oral Exposure}

Zinc has been orally administered in a variety of forms, such as zinc chloride, zinc sulfate, zinc oxide, powdered zinc, and others. Some of these compounds, such as zinc sulfate, have been administered in both hydrated and anhydrous forms. Study authors often do not state definitely which form was used in a particular study. Knowledge of the form used and its molecular weight is necessary to calculate the amount of elemental zinc administered under a given set of circumstances, and is similarly important in that different chemical forms of zinc may be absorbed to differing degrees depending on their in vivo solubility, resulting in differing levels of toxicity. If adequate information was not reported by the study authors, it was assumed that an anhydrous, soluble compound was used.

\subsubsection{Death}

In a case report presented by Murray (1926), an infant died from bronchopneumonia resulting from inhalation and ingestion of an unspecified amount of zinc stearate powder spilled from a container. However, the cause of death (bronchopneumonia) suggests that it resulted from the inhalation exposure, rather than the oral exposure, and it is unclear whether the lung damage resulted from the inhalation of zinc stearate powder specifically or from a general effect of the inhalation of powders.

The $\mathrm{LD}_{50}$ values of several zinc compounds (ranging from 186 to $623 \mathrm{mg}$ zinc/kg/day) have been determined in rats and mice (Domingo et al. 1988a). In general, mice appear to be more sensitive than 
rats to the lethal effects of zinc. In rats, zinc acetate was the most lethal compound tested; zinc nitrate, zinc chloride, and zinc sulfate (in order of decreasing toxicity) were less lethal. In mice, the most lethal compound was zinc acetate followed by zinc nitrate, zinc sulfate, and zinc chloride. Ingestion of $390 \mathrm{mg}$ zinc/kg/day as zinc oxide in the diet for 3-13 days was lethal to 3 of 3 ferrets (Straube et al. 1980). An equivalent dose in humans would be approximately $27 \mathrm{~g}$ zinc/day (which would probably be intolerable to humans because of gastric discomfort). Death was reported in mice that consumed $1,110 \mathrm{mg}$ zinc/kg/day as zinc sulfate in their diet for 13 weeks (Maita et al. 1981). Mortality was also observed in $20 \%$ of rats ingesting $191 \mathrm{mg}$ zinc/kg/day as zinc acetate in drinking water for 3 months (Llobet et al. 1988a).

The $\mathrm{LD}_{50}$ values and all LOAEL values from each reliable study for death in each species and duration category are recorded in Table 3-2 and plotted in Figure 3-2.

\subsubsection{Systemic Effects}

The highest NOAEL values and all LOAEL values from each reliable study for systemic effects in each species and duration category are recorded in Table 3-2 and plotted in Figure 3-2.

Ingestion of zinc or zinc-containing compounds has resulted in a variety of systemic effects in the gastrointestinal and hematological systems and alterations in the blood lipid profile in humans and animals. In addition, lesions have been observed in the liver, pancreas, and kidneys of animals. No studies were located regarding respiratory, ocular, or metabolic effects in humans or animals after oral exposure to zinc.

Observed systemic effects after oral exposure are discussed below. The effects discussed in case reports are not included in Table 3-2 or Figure 3-2 because of the small sample size and lack of control data.

Cardiovascular Effects. A number of studies in humans and animals have examined the effects of zinc on serum cholesterol and triglycerides. However, no studies regarding the direct relationship between excessive zinc intake and cardiac mortality were located. No effects on electrocardiographic results were found in a group of elderly subjects ( $>65$ years of age) taking zinc supplements of up to $2 \mathrm{mg}$ zinc/kg/day (Hale et al. 1988) or $0.71 \mathrm{mg}$ zinc/kg/day (Czerwinski et al. 1974). There was also no effect on the frequency of cardiovascular disease (heart attack, heart failure, hypertension, or angina) in elderly subjects (>67 years of age) taking up to $2 \mathrm{mg}$ zinc/kg/day for a mean of 8 years (Hale et al. 1988). 
Table 3-2 Levels of Significant Exposure to Zinc - Oral

\begin{tabular}{|c|c|c|c|c|c|c|c|}
\hline \multirow[b]{2}{*}{$\begin{array}{l}\text { Key to } \\
\text { Figure }\end{array}$} & \multirow[b]{2}{*}{$\begin{array}{c}\text { Species } \\
\text { (Strain) }\end{array}$} & \multirow{2}{*}{$\begin{array}{l}\text { Exposure/ } \\
\text { Duration/ } \\
\text { Frequency } \\
\text { (Route) }\end{array}$} & \multirow[b]{2}{*}{ System } & \multirow[b]{2}{*}{$\begin{array}{l}\text { NOAEL } \\
\text { (mg/kg/day) }\end{array}$} & \multicolumn{2}{|c|}{ LOAEL } & \multirow[b]{2}{*}{$\begin{array}{l}\text { Reference } \\
\text { Chemical Form }\end{array}$} \\
\hline & & & & & $\begin{array}{r}\text { Less Serious } \\
\text { (mg/kg/day) }\end{array}$ & $\begin{array}{l}\text { Serious } \\
\text { (mg/kg/day) }\end{array}$ & \\
\hline
\end{tabular}

\section{ACUTE EXPOSURE}

Death

1 Rat once

(Sprague- (G)

Dawley)

2 Rat

once

Dawley)

3 Rat

once

(Sprague- (G)

4 Rat

once

(Sprague- (G)

5 Mouse

Mouse once

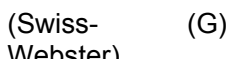

6 Mouse once

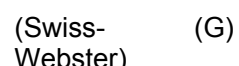

7 Mouse once

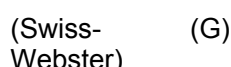

8 Mouse once

(Swiss- (G)

Webster)

237 M (LD50)

$623 \mathrm{M}$ (LD50)

528 M (LD50)

293 M (LD50)

337 M (LD50)

86 M (LD50)

605 M (LD50)

204 M (LD50)
Chemical Form

Domingo et al. 1988a

Zinc acetate

Domingo et al. 1988a

Zinc sulfate

Domingo et al. 1988a

Zinc chloride

Domingo et al. 1988a

Zinc nitrate

Domingo et al. 1988a

Zinc sulfate

Domingo et al. 1988a

Zinc acetate

Domingo et al. 1988a

Zinc chloride

Domingo et al. 1988a

Zinc nitrate 
Table 3-2 Levels of Significant Exposure to Zinc - Oral

\begin{tabular}{|c|c|c|c|c|c|c|c|}
\hline \multirow[b]{2}{*}{$\begin{array}{l}\text { Key to } \\
\text { Figure }\end{array}$} & \multirow[b]{2}{*}{$\begin{array}{l}\text { Species } \\
\text { (Strain) }\end{array}$} & \multirow{2}{*}{$\begin{array}{l}\text { Exposure/ } \\
\text { Duration/ } \\
\text { Frequency } \\
\text { (Route) }\end{array}$} & \multirow[b]{2}{*}{ System } & \multirow[b]{2}{*}{$\begin{array}{l}\text { NOAEL } \\
\text { (mg/kg/day) }\end{array}$} & \multicolumn{2}{|c|}{ LOAEL } & \multirow[b]{2}{*}{$\begin{array}{l}\text { Reference } \\
\text { Chemical Form }\end{array}$} \\
\hline & & & & & $\begin{array}{r}\text { Less Serious } \\
\text { (mg/kg/day) }\end{array}$ & $\begin{array}{l}\text { Serious } \\
\text { (mg/kg/day) }\end{array}$ & \\
\hline
\end{tabular}

$9 \quad$ Ferret $<2 w k$

(F)

Systemic

10 Human

once

(W)

Endocr

0.5 (decreased serum

cortisol levels)

6.7 (gastrointestinal distress; diarrhea)

$390 \quad(3 / 3$ died $)$

once

(W)

Gastro

Single ora exposure

Gastro

(IN)

$2 \mathrm{~d}$

(F)

Gastro

$86 \mathrm{M}$

Endocr

$86 \mathrm{M}$ (increased serum amylase, lipase)

\section{Neurological}

14 Rat

$10 \mathrm{~d}$

(G)
487 (minor neuronal

degeneration; decreased acid phosphatase and acetylchonlinesterase;

increased thiamine

pyrophosphatase)
Straube et al. 1980

Zinc oxide

Brandao-Neto et al. 1990a

Zinc sulfate

Callender and Gentzkow 1937

Zinc oxide

Lewis and Kokan 1998

Zinc gluconate

Murphy 1970

Zinc elemental

Kozik et al. 1980

Zinc oxide 
Table 3-2 Levels of Significant Exposure to Zinc - Oral

(continued)

\begin{tabular}{|c|c|c|c|c|c|c|c|}
\hline \multirow[b]{2}{*}{$\begin{array}{l}\text { Key to } \\
\text { Figure } \\
\end{array}$} & \multirow[b]{2}{*}{$\begin{array}{l}\text { Species } \\
\text { (Strain) }\end{array}$} & \multirow{2}{*}{$\begin{array}{l}\text { Exposure/ } \\
\text { Duration/ } \\
\text { Frequency } \\
\text { (Route) }\end{array}$} & \multirow[b]{2}{*}{ System } & \multirow[b]{2}{*}{$\begin{array}{l}\text { NOAEL } \\
\text { (mg/kg/day) }\end{array}$} & \multicolumn{2}{|c|}{ LOAEL } & \multirow[b]{2}{*}{$\begin{array}{l}\text { Reference } \\
\text { Chemical Form }\end{array}$} \\
\hline & & & & & $\begin{array}{r}\text { Less Serious } \\
(\mathrm{mg} / \mathrm{kg} / \text { day }) \\
\end{array}$ & $\begin{array}{l}\text { Serious } \\
\text { (mg/kg/day) }\end{array}$ & \\
\hline \multicolumn{8}{|c|}{$\begin{array}{l}\text { INTERMEDIATE EXPOSURE } \\
\text { Death }\end{array}$} \\
\hline 15 & Rat & $\begin{array}{l}3 \text { mo } \\
\text { ad lib } \\
\text { (W) }\end{array}$ & & & & $191 \mathrm{~F}(2 / 10 \mathrm{died})$ & $\begin{array}{l}\text { Llobet et al. 1988a } \\
\text { Zinc acetate }\end{array}$ \\
\hline 16 & Mouse & $\begin{array}{l}13 \text { wk } \\
\text { ad lib } \\
(F)\end{array}$ & & & & $1110 \quad(5 / 24$ died $)$ & $\begin{array}{l}\text { Maita et al. } 1981 \\
\text { Zinc sulfate }\end{array}$ \\
\hline \multicolumn{8}{|c|}{ Systemic } \\
\hline 17 & Human & $\begin{array}{l}3 \mathrm{mo} \\
7 \mathrm{~d} / \mathrm{wk} \\
1 \mathrm{x} / \mathrm{d} \\
(\mathrm{C})\end{array}$ & Other & 1.5 & & & $\begin{array}{l}\text { Bogden et al. } 1988 \\
\text { Zinc acetate }\end{array}$ \\
\hline 18 & Human & $\begin{array}{l}14 \mathrm{wk} \\
7 \mathrm{~d} / \mathrm{wk} \\
1 \mathrm{x} / \mathrm{day}\end{array}$ & Hemato & $0.43 \mathrm{M}$ & & & $\begin{array}{l}\text { Bonham et al. 2003b } \\
\text { Zinc glycine chelate }\end{array}$ \\
\hline 19 & Human & $\begin{array}{l}6 w k \\
2 x / d \\
(C)\end{array}$ & Other & & $\begin{array}{l}\text { 4.3 M (increased serum } \\
\text { LDL-cholesterol; } \\
\text { decreased serum } \\
\text { HDL-cholesterol) }\end{array}$ & & $\begin{array}{l}\text { Chandra } 1984 \\
\text { Zinc sulfate }\end{array}$ \\
\hline 20 & Human & $\begin{array}{l}24 \mathrm{wk} \\
7 \mathrm{~d} / \mathrm{wk} \\
3 \mathrm{x} / \mathrm{d} \\
(\mathrm{C})\end{array}$ & Cardio & 0.71 & & & $\begin{array}{l}\text { Czerwinski et al. } 1974 \\
\text { Zinc sulfate }\end{array}$ \\
\hline \multirow[t]{2}{*}{21} & Human & $\begin{array}{l}90 \mathrm{~d} \\
1 \mathrm{x} / \mathrm{d}\end{array}$ & Hemato & $0.68 \mathrm{~F}$ & & & $\begin{array}{l}\text { Davis et al. } 2000 \\
\text { Zinc gluconate }\end{array}$ \\
\hline & & & Endocr & $0.68 \mathrm{~F}$ & & & \\
\hline
\end{tabular}


Table 3-2 Levels of Significant Exposure to Zinc - Oral

\begin{tabular}{|c|c|c|c|c|c|c|c|}
\hline \multirow[b]{2}{*}{$\begin{array}{l}\text { Key to } \\
\text { Figure }\end{array}$} & \multirow[b]{2}{*}{$\begin{array}{l}\text { Species } \\
\text { (Strain) }\end{array}$} & \multirow{2}{*}{$\begin{array}{l}\text { Exposure/ } \\
\text { Duration/ } \\
\text { Frequency } \\
\text { (Route) }\end{array}$} & \multirow[b]{2}{*}{ System } & \multirow[b]{2}{*}{$\begin{array}{l}\text { NOAEL } \\
(\mathrm{mg} / \mathrm{kg} / \text { day })\end{array}$} & \multicolumn{2}{|c|}{ LOAEL } & \multirow[b]{2}{*}{$\begin{array}{l}\text { Reference } \\
\text { Chemical Form }\end{array}$} \\
\hline & & & & & $\begin{array}{r}\text { Less Serious } \\
\text { (mg/kg/day) }\end{array}$ & $\begin{array}{l}\text { Serious } \\
\text { (mg/kg/day) }\end{array}$ & \\
\hline
\end{tabular}

22 Human

6 wk
$7 \mathrm{~d} / w \mathrm{w}$
$2 \mathrm{x} / \mathrm{d}$

0.71

(C)

23 Human

$5 \mathrm{wk} \quad$ Other
$2 \mathrm{x} / \mathrm{d}$

(C)

her

24

Human

$90 \mathrm{~d}$

$1 \mathrm{x} / \mathrm{d}$

Hemato

$0.68 \mathrm{~F}$

25

Human $\quad 6 w k$

(F)

Gastro

$6 \mathrm{wk}$

$7 \mathrm{~d} / \mathrm{wk}$

$3 \mathrm{x} / \mathrm{d}$

(C)

27 Human

\begin{tabular}{|c|c|}
\hline $\begin{array}{l}10 \mathrm{wk} \\
7 \mathrm{~d} / \mathrm{wk} \\
2 \mathrm{x} / \mathrm{d}\end{array}$ & Hemato \\
\hline
\end{tabular}

(C)

28 Rat
Fischer et al. 1984

Zinc gluconate

Hooper et al. 1980

Zinc sulfate

HDL-cholesterol)

Milne et al. 2001

Zinc gluconate

Samman and Roberts 1987

Zinc sulfate

Samman and Roberts 1988

Zinc sulfate

Yadrick et al. 1989

Zinc gluconate

Khan et al. 2001b

Zinc chloride 
Table 3-2 Levels of Significant Exposure to Zinc - Oral

(continued)

\begin{tabular}{|c|c|c|c|c|c|c|c|}
\hline \multirow[b]{2}{*}{$\begin{array}{l}\text { Key to } \\
\text { Figure }\end{array}$} & \multirow[b]{2}{*}{$\begin{array}{l}\text { Species } \\
\text { (Strain) }\end{array}$} & \multirow{2}{*}{$\begin{array}{l}\text { Exposure/ } \\
\text { Duration/ } \\
\text { Frequency } \\
\text { (Route) }\end{array}$} & \multirow[b]{2}{*}{ System } & \multirow[b]{2}{*}{$\begin{array}{l}\text { NOAEL } \\
\text { (mg/kg/day) }\end{array}$} & \multicolumn{2}{|c|}{ LOAEL } & \multirow[b]{2}{*}{$\begin{array}{l}\text { Reference } \\
\text { Chemical Form }\end{array}$} \\
\hline & & & & & $\begin{array}{r}\text { Less Serious } \\
\text { (mg/kg/day) }\end{array}$ & $\begin{array}{l}\text { Serious } \\
\text { (mg/kg/day) }\end{array}$ & \\
\hline
\end{tabular}

crequency

System (mg/kg/day)

(mg/kg/day)

Chemical Form

29 Rat

\begin{tabular}{|c|c|c|}
\hline $\begin{array}{l}6 \mathrm{wk} \\
7 \mathrm{~d} / \mathrm{wk}\end{array}$ & Hemato & $\begin{array}{l}6 \mathrm{M} \text { (ceroplasmin reduced by } \\
28 \% \text { ) }\end{array}$ \\
\hline
\end{tabular}

(F)

$28 \%)$

L'Abbe and Fischer 1984a

Zinc sulfate

Llobet et al. 1988a

Zinc acetate

(Sprague- ad lib $\quad$ Hemato $\quad 191 \mathrm{~F}$

Dawley) (W)

Hepatic $191 \mathrm{~F}$

Renal $\quad 95 \mathrm{~F}$

$191 \mathrm{~F}$ (increased plasma creatine and urea levels; desquamation of

epithelial cells of

proximal tubules)

$\begin{array}{lrr}\text { Hemato } & 53 \mathrm{~F} & 565 \mathrm{~F} \text { (decreased hematocrit } \\ \text { and WBC) }\end{array}$

Maita et al. 1981

Zinc sulfate

$565 \mathrm{~F}$ (acinar cell necrosis and metaplasia in pancreas) 
Table 3-2 Levels of Significant Exposure to Zinc - Oral

\begin{tabular}{|c|c|c|c|c|c|c|c|}
\hline \multirow[b]{2}{*}{$\begin{array}{l}\text { Key to } \\
\text { Figure }\end{array}$} & \multirow[b]{2}{*}{$\begin{array}{l}\text { Species } \\
\text { (Strain) }\end{array}$} & \multirow{2}{*}{$\begin{array}{c}\text { Exposure/ } \\
\text { Duration/ } \\
\text { Frequency } \\
\text { (Route) }\end{array}$} & \multirow[b]{2}{*}{ System } & \multirow[b]{2}{*}{$\begin{array}{c}\text { NOAEL } \\
\text { (mg/kg/day) }\end{array}$} & \multicolumn{2}{|c|}{ LOAEL } & \multirow[b]{2}{*}{$\begin{array}{l}\text { Reference } \\
\text { Chemical Form }\end{array}$} \\
\hline & & & & & $\begin{array}{r}\text { Less Serious } \\
\text { (mg/kg/day) }\end{array}$ & $\begin{array}{l}\text { Serious } \\
\text { (mg/kg/day) }\end{array}$ & \\
\hline
\end{tabular}

32 Rat

$\begin{array}{lll}\text { Rat } & 5 \text { wk } & \text { Hemato } \\ \text { (Sprague- } & \text { ad lib } & \\ \text { Dawley) } & \text { (F) } & \end{array}$

33 Rat $\begin{array}{ll}\text { (Sprague- } & \text { ad lib } \\ \text { Dawley) } & \text { (F) }\end{array}$

34 Rat

$\begin{array}{ll}\text { Rat } & 4 \mathrm{wk} \\ \text { (Wistar) } & 7 \mathrm{~d} / \mathrm{wk} \\ & \text { ad lib } \\ & \text { (W) }\end{array}$

35

Mouse

5-14 mo ad lib

(W)

Other

Hemato

Hemato

lib Hemato

(W)
350 (decreased $\mathrm{Hb}$ )

500 (decreased $\mathrm{Hb}$,

hematocrit, $\mathrm{MCH}, \mathrm{MCHC}$;

slightly increased WBC)

12 (decreased $\mathrm{Hb}$ and erythrocytes)

70 (hypertrophy and

vacuolation of pancreas

islet cells; hypertrophy

and vacuolation of

fasciculata cells in

adrenal cortex)
Smith and Larson 1946

Zinc carbonate

Smith and Larson 1946

Zinc carbonate

Zaporowska and Wasilewsk

1992

Zinc chloride

Aughey et al. 1977

Zinc sulfate 
Table 3-2 Levels of Significant Exposure to Zinc - Oral

\begin{tabular}{|c|c|c|c|c|c|c|c|}
\hline \multirow[b]{2}{*}{$\begin{array}{l}\text { Key to } \\
\text { Figure }\end{array}$} & \multirow[b]{2}{*}{$\begin{array}{l}\text { Species } \\
\text { (Strain) }\end{array}$} & \multirow{2}{*}{$\begin{array}{l}\text { Exposure/ } \\
\text { Duration/ } \\
\text { Frequency } \\
\text { (Route) }\end{array}$} & \multirow[b]{2}{*}{ System } & \multirow[b]{2}{*}{$\begin{array}{l}\text { NOAEL } \\
\text { (mg/kg/day) }\end{array}$} & \multicolumn{2}{|c|}{ LOAEL } & \multirow[b]{2}{*}{$\begin{array}{l}\text { Reference } \\
\text { Chemical Form }\end{array}$} \\
\hline & & & & & $\begin{array}{r}\text { Less Serious } \\
\text { (mg/kg/day) }\end{array}$ & $\begin{array}{l}\text { Serious } \\
\text { (mg/kg/day) }\end{array}$ & \\
\hline
\end{tabular}

$36 \quad$ Mouse 13 wk (ICR) ad lib

Gastro $\quad 104 \mathrm{M}$

$1110 \mathrm{~F}$ (forestomach ulcers)

Maita et al. 1981

(F)

104

Zinc sulfate

Hemato $104 \mathrm{M} \quad 1110 \mathrm{~F} \begin{aligned} & \text { (decreased WBC; } \\ & \text { anemia) }\end{aligned}$

Renal $104 \mathrm{M} \quad 1110 \mathrm{~F}$ (unspecified regressive lesions)

Endocr $\quad 104 \mathrm{M}$

$1110 \mathrm{~F}$ (acinar cell necrosis and metaplasia in pancreas)

$37 \quad$ Mouse

$9 \mathrm{mo}$

Hemato

(F)

Walters and Roe 1965

Zinc oleate

Anderson and Danylchuk 1979

Zinc oxide

ad lib Musc/skel $4 \mathrm{M}$

(W)

Hemato

$174 \mathrm{M}$ (slight decrease in $\mathrm{Hb}$

levels)

Bentley and Grubb 1991

Zinc carbonate

$\mathrm{Bd} \mathrm{Wt}$ 
Table 3-2 Levels of Significant Exposure to Zinc - Oral

\begin{tabular}{|c|c|c|c|c|}
\hline $\begin{array}{l}\text { Key to } \\
\text { Figure }\end{array}$ & $\begin{array}{l}\text { Species } \\
\text { (Strain) }\end{array}$ & $\begin{array}{l}\text { Exposure/ } \\
\text { Duration/ } \\
\text { Frequency } \\
\text { (Route) }\end{array}$ & System & $\begin{array}{r}\text { NOAE } \\
(\mathrm{mg} / \mathrm{kg}\end{array}$ \\
\hline \multirow[t]{4}{*}{40} & Mink & $\begin{array}{l}144 \mathrm{~d} \\
\text { ppd70-214 } \\
\text { (F) }\end{array}$ & Hemato & 323.6 \\
\hline & & & Hepatic & 323.6 \\
\hline & & & Renal & 323.6 \\
\hline & & & $\mathrm{Bd} \mathrm{Wt}$ & 323.6 \\
\hline
\end{tabular}

LOAEL

Reference

41 Cow $\begin{aligned} & 5 w k \\ & 2 x / d\end{aligned}$

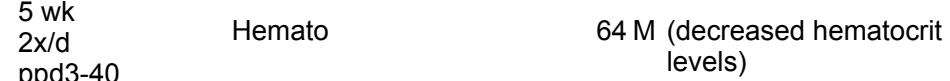

ppd3-40

levels)

Bd Wt $\quad 64 \mathrm{M}$

$42 \quad$ Ferret

$7-97 d$

ad lib

Gastro

195

(F)

$\begin{array}{lr}\text { Hemato } & 65 \\ \text { Renal } & 65 \\ \text { Endocr } & 195\end{array}$

Chemical Form

Aulerich et al. 1991

Zinc sulfate

Serious

(mg/kg/day)

Jenkins and Hidiroglou 1991

Zinc oxide

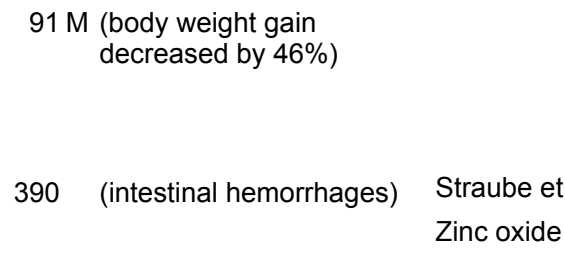

$91 \mathrm{M}$ (body weight gain

decreased by $46 \%$ )

390 (intestinal hemorrhages)

Zinc oxide

Bogden et al. 1988

Zinc acetate

Bonham et al. 2003a

Zinc glycine chelate 
Table 3-2 Levels of Significant Exposure to Zinc - Oral

\begin{tabular}{|c|c|c|c|c|c|c|c|}
\hline \multirow[b]{2}{*}{$\begin{array}{l}\text { Key to } \\
\text { Figure }\end{array}$} & \multirow[b]{2}{*}{$\begin{array}{l}\text { Species } \\
\text { (Strain) }\end{array}$} & \multirow{2}{*}{$\begin{array}{c}\text { Exposure/ } \\
\text { Duration/ } \\
\text { Frequency } \\
\text { (Route) }\end{array}$} & \multirow[b]{2}{*}{ System } & \multirow[b]{2}{*}{$\begin{array}{c}\text { NOAEL } \\
\text { (mg/kg/day) }\end{array}$} & \multicolumn{2}{|c|}{ LOAEL } & \multirow[b]{2}{*}{$\begin{array}{l}\text { Reference } \\
\text { Chemical Form }\end{array}$} \\
\hline & & & & & $\begin{array}{r}\text { Less Serious } \\
\text { (mg/kg/day) }\end{array}$ & $\begin{array}{l}\text { Serious } \\
\text { (mg/kg/day) }\end{array}$ & \\
\hline
\end{tabular}

$45 \quad$ Human $\begin{array}{r}14 \mathrm{wk} \\ 7 \mathrm{~d} / \mathrm{wk}\end{array}$

$7 \mathrm{~d} / \mathrm{wk}$
$1 \mathrm{x} / \mathrm{day}$

46 Human $6 \mathrm{wk}$

$2 \mathrm{x} / \mathrm{d}$

(C)

$47 \quad$ Human $1 \mathrm{mo}$

(C)

$48 \quad$ Mouse

$8 w k$

ad lib

(F)

49 Mouse continuously for

(BALB/c) 42 days

(W)

50 Mouse
$0.43 \mathrm{M}$

4.3 M (impaired lymphocyte
and polymorphonuclear

leukocyte function)

136 (Increases in direct plaque-forming activity of spleen cells and in

lymphyocyte proliferation

in response to mitogen

stimulation)
Bonham et al. 2003b

Zinc glycine chelate

Chandra 1984

Zinc sulfate

Duchateau et al. 1981

Zinc sulfate

Fernandes et al. 1979

ns

Lastra et al. 1997

ns

Schiffer et al. 1991

Zinc sulfate 
Table 3-2 Levels of Significant Exposure to Zinc - Oral

\begin{tabular}{|c|c|c|c|c|c|c|c|}
\hline \multirow[b]{2}{*}{$\begin{array}{l}\text { Key to } \\
\text { Figure }\end{array}$} & \multirow[b]{2}{*}{$\begin{array}{l}\text { Species } \\
\text { (Strain) }\end{array}$} & \multirow{2}{*}{$\begin{array}{c}\text { Exposure/ } \\
\text { Duration/ } \\
\text { Frequency } \\
\text { (Route) }\end{array}$} & \multirow[b]{2}{*}{ System } & \multirow[b]{2}{*}{$\begin{array}{l}\text { NOAEL } \\
\text { (mg/kg/day) }\end{array}$} & \multicolumn{2}{|c|}{ LOAEL } & \multirow[b]{2}{*}{$\begin{array}{l}\text { Reference } \\
\text { Chemical Form }\end{array}$} \\
\hline & & & & & $\begin{array}{l}\text { Less Serious } \\
\text { (mg/kg/day) }\end{array}$ & $\begin{array}{l}\text { Serious } \\
\text { (mg/kg/day) }\end{array}$ & \\
\hline
\end{tabular}

Neurological
51 Mouse drinking water
(Swiss- for 60 days
Webster) (W)

\section{Reproductive}

52 Human

Gwk 20

through

parturition

(C)

53 Rat $8 w k$

$8 \mathrm{wk}$
$7 \mathrm{~d} / \mathrm{wk}$

$7 \mathrm{~d} / \mathrm{wk}$
ad lib

(F)

$54 \quad$ Rat

$14 \mathrm{wk}$ (males)
or $20 \mathrm{wk}$
(females)
$7 \mathrm{~d} / \mathrm{wk}$
$1 \mathrm{x} / \mathrm{d}$
$(\mathrm{GW})$

55

$\begin{array}{ll}\text { Rat } & 18 \mathrm{~d} \\ & \mathrm{Gd0}-18 \\ & \text { ad lib } \\ & (\mathrm{F})\end{array}$

56

Rat $\quad \begin{aligned} & 150 \mathrm{~d} \\ & \text { ad lib }\end{aligned}$

ad lib

(F)

$57 \quad$ Mouse

(BALB/c)

continuously for

42 days

(W)
0.5 (Increase in latency in

inhibitory avoidance test)

$25 \mathrm{M}$ (altered sperm chromatin structure)

$3.5 \mathrm{~F}$
7F (Decreased live pups per
litter in all groups of

treated rats)
Oliveira et al. 2001

Zinc acetate

Mahomed et al. 1989

Zinc sulfate

Evenson et al. 1993

Zinc chloride

Khan et al. 2001b

Zinc chloride

$200 \mathrm{~F}$ (increased pre-implantation loss)

Pal and Pal 1987

Zinc sulfate

Sutton and Nelson 1937

Zinc carbonate

Lastra et al. 1997

ns 
Table 3-2 Levels of Significant Exposure to Zinc - Oral

(continued)

\begin{tabular}{|c|c|c|c|c|c|c|c|}
\hline \multirow[b]{2}{*}{$\begin{array}{l}\text { Key to } \\
\text { Figure }\end{array}$} & \multirow[b]{2}{*}{$\begin{array}{l}\text { Species } \\
\text { (Strain) }\end{array}$} & \multirow{2}{*}{$\begin{array}{l}\text { Exposure/ } \\
\text { Duration/ } \\
\text { Frequency } \\
\text { (Route) }\end{array}$} & \multirow[b]{2}{*}{ System } & \multirow[b]{2}{*}{$\begin{array}{l}\text { NOAEL } \\
\text { (mg/kg/day) }\end{array}$} & \multicolumn{2}{|c|}{ LOAEL } & \multirow[b]{2}{*}{$\begin{array}{l}\text { Reference } \\
\text { Chemical Form }\end{array}$} \\
\hline & & & & & $\begin{array}{r}\text { Less Serious } \\
\text { (mg/kg/day) }\end{array}$ & $\begin{array}{l}\text { Serious } \\
\text { (mg/kg/day) }\end{array}$ & \\
\hline
\end{tabular}

$58 \quad$ Mouse $13 w k$

(ICR) ad lib

(F)

$59 \quad$ Mink approx

$25 \mathrm{wk}$

(F)

Developmental

60 Human
$11 \mathrm{wk}$

$1 \mathrm{x} / \mathrm{d}$

61 Human

Gwk 20

through

parturition

(C)

62 Human

$$
\begin{aligned}
& \text { last } 15- \\
& 25 \mathrm{wk} \\
& \text { of preg- } \\
& \text { nancy } \\
& 1 \times / d
\end{aligned}
$$

(C)

63 Rat

\section{7 wk}

Gd0-17

ad lib

(F)
$0.06 \mathrm{~F}$

1110

20.8

$250 \mathrm{~F}$
Maita et al. 1981

Zinc sulfate

Bleavins et al. 1983

Zinc sulfate

Kynast and Saling 1986

Zinc aspartate

Mahomed et al. 1989

Zinc sulfate

Simmer et al. 1991

Zinc citrate

Kinnamon 1963

Zinc carbonate 
Table 3-2 Levels of Significant Exposure to Zinc - Oral

(continued)

\begin{tabular}{|c|c|c|c|c|c|c|c|}
\hline \multirow[b]{2}{*}{$\begin{array}{l}\text { Key to } \\
\text { Figure }\end{array}$} & \multirow[b]{2}{*}{$\begin{array}{l}\text { Species } \\
\text { (Strain) }\end{array}$} & \multirow{2}{*}{$\begin{array}{c}\text { Exposure/ } \\
\text { Duration/ } \\
\text { Frequency } \\
\text { (Route) }\end{array}$} & \multirow[b]{2}{*}{ System } & \multirow[b]{2}{*}{$\begin{array}{c}\text { NOAEL } \\
\text { (mg/kg/day) }\end{array}$} & \multicolumn{2}{|c|}{ LOAEL } & \multirow[b]{2}{*}{$\begin{array}{l}\text { Reference } \\
\text { Chemical Form }\end{array}$} \\
\hline & & & & & $\begin{array}{r}\text { Less Serious } \\
\text { (mg/kg/day) }\end{array}$ & $\begin{array}{l}\text { Serious } \\
\text { (mg/kg/day) }\end{array}$ & \\
\hline
\end{tabular}

Frequency

System $\quad(\mathrm{mg} / \mathrm{kg} / \mathrm{day}) \quad(\mathrm{mg} / \mathrm{kg} /$ day $)$

(mg/kg/day)

Chemical Form

$64 \quad$ Rat $15 d$

(Sprague- Gd1-15

Dawley) ad lib

(F)

65 Rat

$$
\begin{aligned}
& 36 \text { d } \\
& \text { Gd1-15 } \\
& \text { ad lib }
\end{aligned}
$$

(F)

66 Rat

$\begin{array}{ll}\text { (Sprague- } & \text { Gd1-21 } \\ \text { Dawley) } & \text { ad lib }\end{array}$

Dawley) ad lib

(F)

67 Rat

$150 \mathrm{~d}$

ad lib

(F)

68 Rat

$\begin{array}{ll}\text { (Sprague- } & \text { GdO-20 } \\ & \text { ad lib }\end{array}$

Dawley) ad lib

(F)

69 Mouse 2 gen

(F)
200 F (29\% fetal resorption; decreased fetal weight)

Schlicker and Cox 1968

Zinc oxide

Schlicker and Cox 1968

Zinc oxide

$200 \mathrm{~F}$ (100\% fetal resorption)

Schlicker and Cox 1968

Zinc oxide

Sutton and Nelson 1937

Zinc carbonate

Uriu-Hare et al. 1989

Zinc carbonate

Mulhern et al. 1986

Zinc carbonate 
Table 3-2 Levels of Significant Exposure to Zinc - Oral

\begin{tabular}{|c|c|c|c|c|c|c|c|}
\hline \multirow[b]{2}{*}{$\begin{array}{l}\text { Key to } \\
\text { Figure }\end{array}$} & \multirow[b]{2}{*}{$\begin{array}{l}\text { Species } \\
\text { (Strain) }\end{array}$} & \multirow{2}{*}{$\begin{array}{l}\text { Exposure/ } \\
\text { Duration/ } \\
\text { Frequency } \\
\text { (Route) }\end{array}$} & \multirow[b]{2}{*}{ System } & \multirow[b]{2}{*}{$\begin{array}{l}\text { NOAEL } \\
\text { (mg/kg/day) }\end{array}$} & \multicolumn{2}{|c|}{ LOAEL } & \multirow[b]{2}{*}{$\begin{array}{l}\text { Reference } \\
\text { Chemical Form }\end{array}$} \\
\hline & & & & & $\begin{array}{l}\text { Less Serious } \\
\text { (mg/kg/day) }\end{array}$ & $\begin{array}{l}\text { Serious } \\
\text { (mg/kg/day) }\end{array}$ & \\
\hline
\end{tabular}

Species Frequency

(mg/kg/day)

Chemical Form

$70 \quad$ Mink

\section{approx}

$25 \mathrm{wk}$

(F)

\section{CHRONIC EXPOSURE}

\section{Cancer}

$\begin{array}{ll}71 \text { Human } & 1 \mathrm{x} / \text { day } \\ & 1 \text { or more years }\end{array}$

ns
20.8

Bleavins et al. 1983

Zinc sulfate $\begin{array}{cl}1.43 \mathrm{M} \text { (Increased probability of } & \text { Leitzmann et al. } 2003 \\ \text { advanced prostate } & \text { ns }\end{array}$ cancer)

\section{a The number corresponds to entries in Figure 3-2.}

b Used to derive an intermediate-duration oral minimal risk level (MRL) of $0.3 \mathrm{mg} / \mathrm{kg} / \mathrm{day}$; The MRL was calculated by applying an uncertainty factor of 3 (for uncertainties regarding human variability) to the no-observed-adverse-effect level (NOAEL) of $0.83 \mathrm{mg} / \mathrm{kg} / \mathrm{day}$. The intermediate oral MRL was adopted as the chronic oral MRL.

ad lib = ad libitum; approx = approximately; $(C)$ = capsule; Cardio = cardiovascular; $d$ - day $(\mathrm{s}) ;(F)=$ feed; $(G)$ = gavage; Gastro = gastrointestinal; Gd = gestation day; gen = generation; Gwk = gestation week; $\mathrm{Hb}=$ hemoglobin; $\mathrm{HDL}=$ high density lipoprotein; Hemato = hematological; $\mathrm{LD} 50=$ lethal dose, $50 \%$ kill; $\mathrm{LDL}=$ low density lipoprotein; $\mathrm{LOAEL}=$ lowest-observed-adverse-effect level; $\mathrm{MCH}=$ mean corpuscular hemoglobin; $\mathrm{MCHC}=$ mean corpuscular hemoglobin concentration; $\mathrm{mo}=$ month(s); Musc/skel = musculoskeletal; NOAEL = no-observed-adverse-effect level; $\mathrm{ns}=$ not specificied; $\mathrm{ppd}$ - post partum day; RBC = red blood cell; $(\mathrm{W})=$ drinking water; $\mathrm{WBC}=$ white blood cell; $\mathrm{wk}=$ week $(\mathrm{s}) ; \mathrm{x}=$ time(s); yr = year(s) 
Figure 3-2 Levels of Significant Exposure to Zinc - Oral

Acute ( $\leq 14$ days)
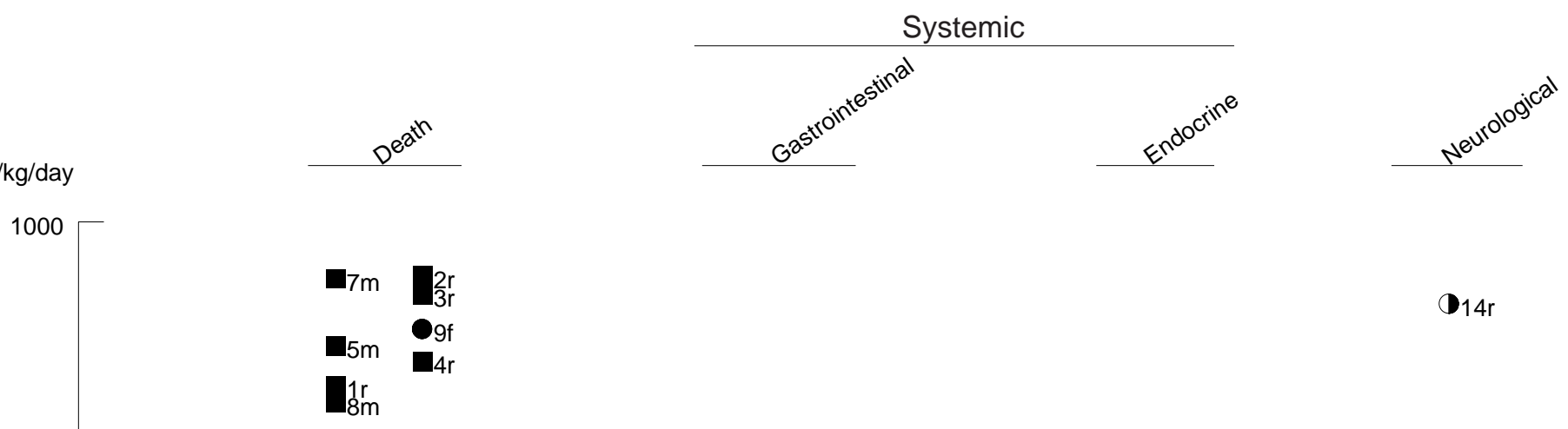

$\Delta 13$

\begin{tabular}{|c|c|c|c|c|c|c|}
\hline $\begin{array}{l}\text { c-Cat } \\
\text { d-Dog } \\
\text { r-Rat } \\
\text { p-Pig } \\
\text { q-Cow }\end{array}$ & $\begin{array}{l}\text { iHymans } \\
\text { k-Monkey } \\
\text { m-Mouse } \\
\text { h-Rabbit } \\
\text { a-Sheep }\end{array}$ & $\begin{array}{l}\text { f-Ferret } \\
\text { j-Pigeon } \\
\text { e-Gerbil } \\
\text { s-Hamster } \\
\text { g-Guinea Pi }\end{array}$ & $\begin{array}{l}\text { n-Mink } \\
\text { o-Other }\end{array}$ & $\begin{array}{l}\text { Cancer Effect Level-Animals } \\
\text { LOAEL, More Serious-Animals } \\
\text { LAOELLLEßfiperilous-Animals }\end{array}$ & $\begin{array}{l}\mathbf{\nabla} \text { Cancer Effect Level-Humans } \\
\text { AOAEL, More Serious-Humans } \\
\Delta \text { LOAEL, Less Serious-Humans } \\
\triangle \text { NOAEL - Humans }\end{array}$ & $\begin{array}{l}\text { LD50/LC50 } \\
\text { Minimal Risk Level } \\
\text { for effects } \\
\text { other than }\end{array}$ \\
\hline
\end{tabular}


Figure 3-2 Levels of Significant Exposure to Zinc - Oral

Intermediate (15-364 days)

Systemic

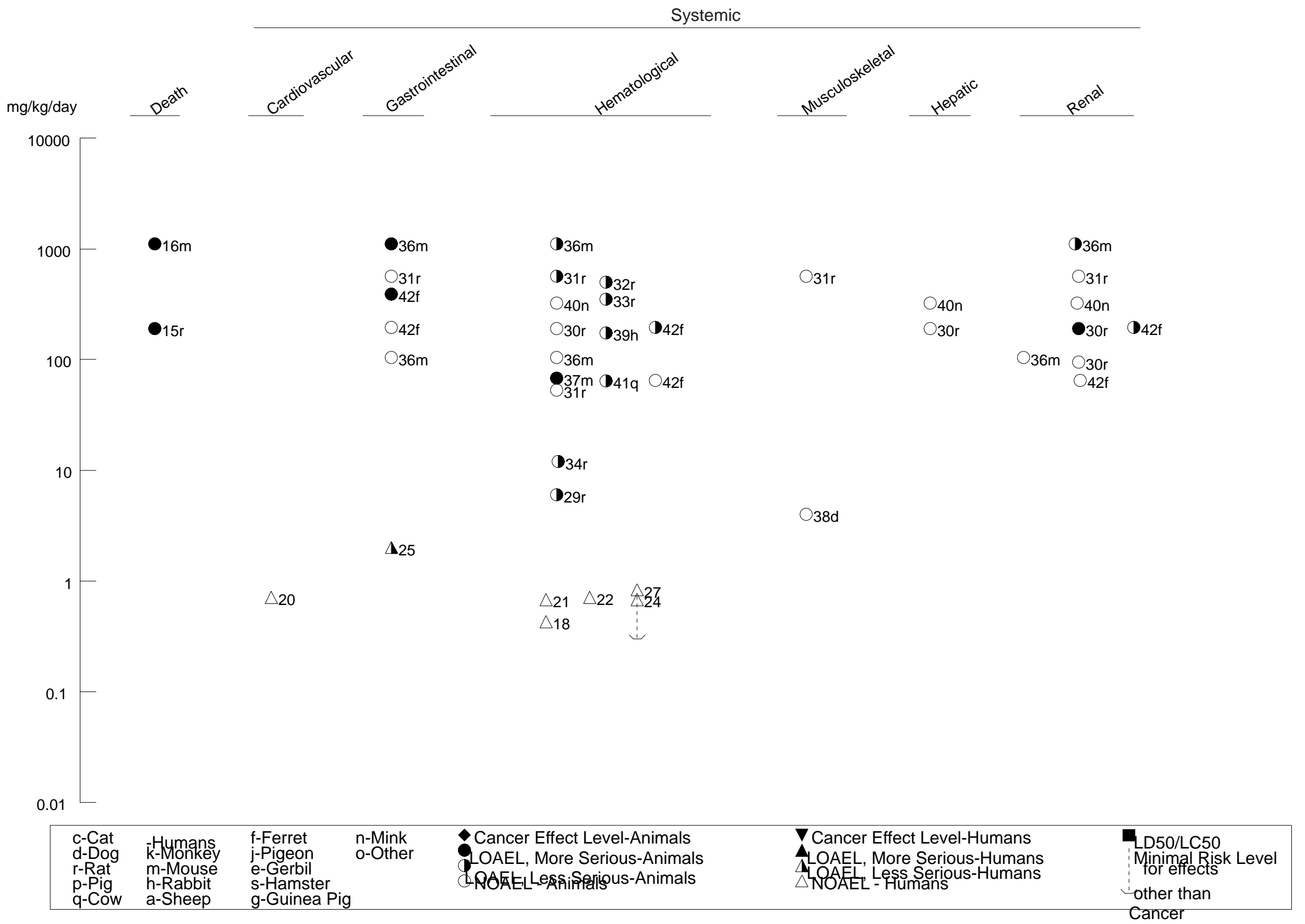


Figure 3-2 Levels of Significant Exposure to Zinc - Oral

Intermediate (15-364 days)

Systemic

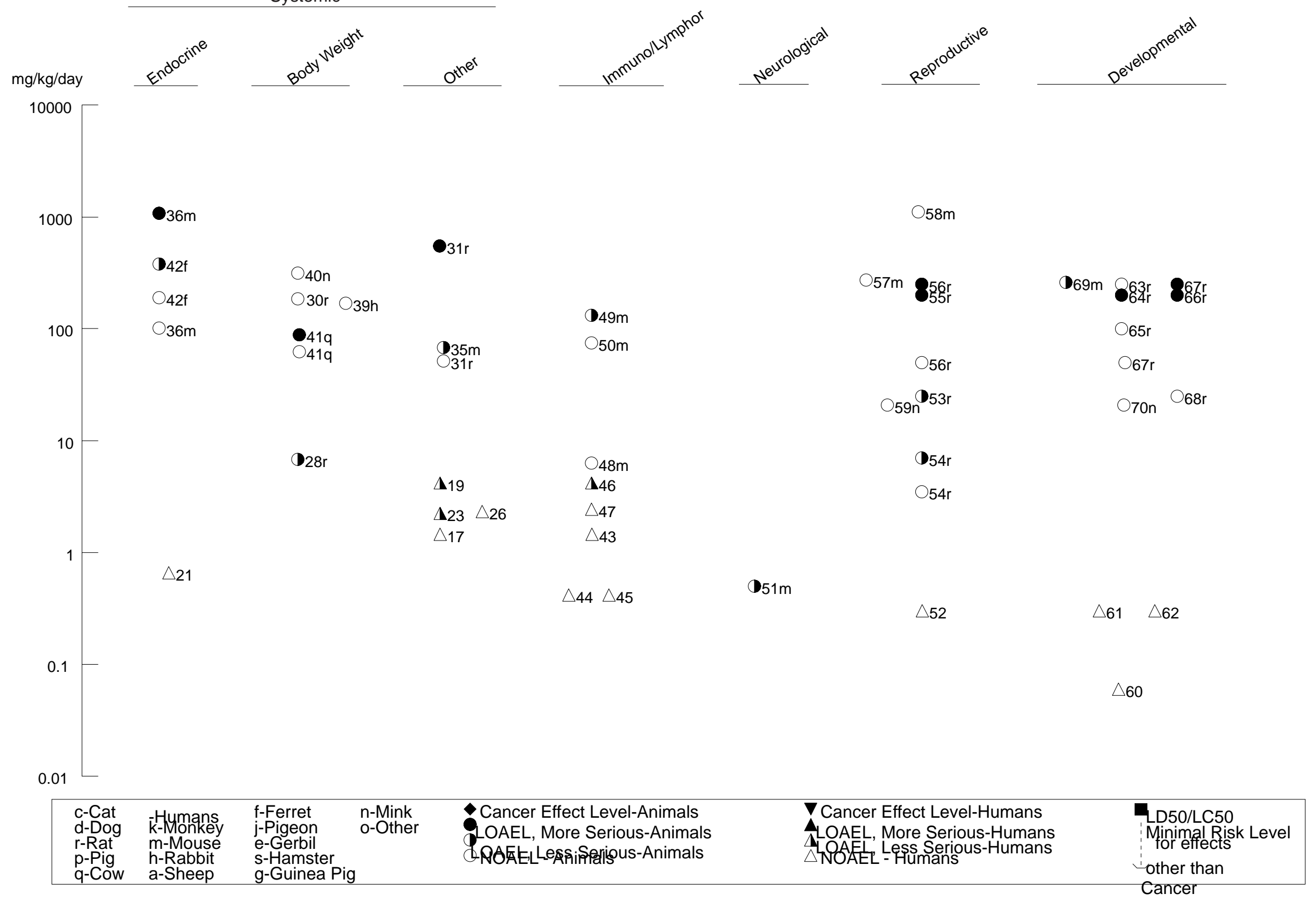

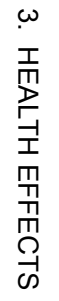


Figure 3-2 Levels of Significant Exposure to Zinc - Oral

Chronic ( $\geq 365$ days)

$\mathrm{mg} / \mathrm{kg} / \mathrm{day}$

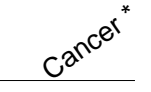

*Doses represent the lowest dose tested per study that produced a tumorigenic response and do not imply the existence of a threshold for the cancer endpoint.

\begin{tabular}{|c|c|c|c|c|c|c|}
\hline $\begin{array}{l}\text { c-Cat } \\
\text { d-Dog } \\
\text { r-Rat } \\
\text { p-Pig } \\
\text { q-Cow }\end{array}$ & $\begin{array}{l}\text { k-Hymans } \\
\text { k-Monkey } \\
\text { m-Mouse } \\
\text { h-Rabbit } \\
\text { a-Sheep }\end{array}$ & $\begin{array}{l}\text { f-Ferret } \\
\text { j-Pigeon } \\
\text { e-Gerbil } \\
\text { s-Hamster } \\
\text { g-Guinea Pig }\end{array}$ & $\begin{array}{l}\text { n-Mink } \\
\text { o-Other }\end{array}$ & $\begin{array}{l}\text { Cancer Effect Level-Animals } \\
\text { LOAEL, More Serious-Animals } \\
\text { LAOELLLEßfiperilous-Animals }\end{array}$ & $\begin{array}{l}\nabla \text { Cancer Effect Level-Humans } \\
\text { ALAEL, More Serious-Humans } \\
\text { LOAELL, Less Serious-Humans } \\
\triangle \text { NOAEL - Humans }\end{array}$ & $\begin{array}{l}\text { LD50/LC50 } \\
\text { Minimal Risk Level } \\
\text { for effects } \\
\text { other than }\end{array}$ \\
\hline
\end{tabular}


In one study, patients having inoperable severe occlusive vascular disease were administered $3.8 \mathrm{mg}$ zinc/kg/day as zinc sulfate for at least 1 year (Henzel et al. 1971). Eighteen of the 24 patients experienced improvement in lower extremity blood flow and unchanged or decreased arterial pressure. Zinc's role in these improvements was not completely understood by the study authors. They hypothesized that when optimal zinc levels are provided to the ischemic limb, the activity of certain zinc enzymes promotes the reversal of tissue-dependent hypoxia and/or lactic acidemia in the muscles. It is also not known if this high dose of zinc was associated with any toxic effects.

No studies were located regarding cardiovascular effects in animals after oral exposure to zinc.

Gastrointestinal Effects. Several studies have suggested that zinc ingestion may cause symptoms of gastrointestinal distress or alterations in gastrointestinal tissues. For example, one individual who ingested about 3 ounces of a zinc chloride solution described acute symptoms that occurred almost immediately following contact with the compound, including burning and pain in the mouth and throat and vomiting (Chobanian 1981). Later, the patient exhibited pharyngitis, esophagitis, hypocalcemia, and elevated levels of amylase; the latter two alterations are suggestive of acute pancreatitis. The patient received intravenous hydration and calcium supplementation and recovered within 5 days. The material ingested was described as a "zinc chloride solution," and its concentration was not reported. Therefore, a dose level could not be established in this case.

Several cases of gastrointestinal disturbances have been reported after ingestion of zinc sulfate (Anonymous 1983; Brown et al. 1964; Moore 1978; Samman and Roberts 1987). Vomiting, abdominal cramps, and diarrhea, in several cases with blood, have been observed after ingestion of zinc sulfate. In one report, an English school girl ingested $440 \mathrm{mg}$ zinc sulfate/day ( $2.6 \mathrm{mg}$ zinc/kg/day) in capsules as a medically prescribed treatment for acne (Moore 1978). After taking each capsule, she experienced epigastric discomfort. A week later, she was admitted to the hospital after a fainting spell. She was diagnosed as anemic and subsequently passed melanic stools, indicative of gastrointestinal bleeding. Gastrointestinal upset (abdominal cramps, vomiting, nausea) occurred in 26 of 47 healthy volunteers following ingestion of zinc sulfate tablets $(150 \mathrm{mg}$ as zinc ion in three divided doses per day, $2 \mathrm{mg}$ zinc/kg/day) for 6 weeks (Samman and Roberts 1987). A 17-year-old boy who ingested approximately $6.8 \mathrm{mg}$ zinc/kg as zinc gluconate showed severe nausea and vomiting, but displayed no other symptoms, and recovered within 7 hours of ingestion (Lewis and Kokan 1998). Ingestion of zinc oxide has also been associated with gastrointestinal distress (Anonymous 1983; Callender and Gentzkow 1937). In one case, $80 \%$ of the personnel of two army companies became ill with gastrointestinal distress and diarrhea after 
consuming limeade prepared in galvanized trash cans (Callender and Gentzkow 1937). The average dose was estimated to be $6.7-7.1 \mathrm{mg} / \mathrm{kg}$. A second example was presented in a case involving school children in New Mexico who experienced nausea and vomiting after accidental excessive zinc intake (Anonymous 1983). These children had consumed punch containing high levels of zinc dissolved from galvanized hinges attached to tanks in which the punch was stored. A 16-year-old boy who ingested $12 \mathrm{~g}$ elemental zinc over a 2-day period ( $86 \mathrm{mg}$ zinc/kg/day) experienced light-headedness, lethargy, staggering gait, and difficulty writing legibly, but no apparent gastrointestinal disturbances (Murphy 1970).

Gastrointestinal effects have also been observed in animals. Intestinal hemorrhages were observed in ferrets that ingested $390 \mathrm{mg}$ zinc/kg/day as zinc oxide for 2 weeks (Straube et al. 1980). These ferrets exhibited a $75 \%$ reduction in food intake. No intestinal hemorrhaging was observed in ferrets fed $195 \mathrm{mg} / \mathrm{kg} / \mathrm{day}$ for up to 21 days. Oral zinc sulfate exposures of intermediate duration in other experimental animals have also resulted in gastrointestinal effects. Mice fed a diet providing 1,110 mg zinc/kg/day for 13 weeks developed ulcers in the forestomach, but gastrointestinal effects were not observed in rats fed $565 \mathrm{mg}$ zinc/kg/day for 13 weeks (Maita et al. 1981).

Hematological Effects. In a case report, acute exposure to $2.6 \mathrm{mg}$ zinc/kg/day as zinc sulfate for 1 week resulted in anemia (Moore 1978). The authors of the report noted that the anemia may have been secondary to the gastrointestinal hemorrhages.

Treatment-related changes in hematological parameters have been observed in humans and animals after intermediate or chronic exposure to zinc or zinc-containing compounds. Long-term administration (18 years) of zinc supplements has caused anemia in humans (Broun et al. 1990; Gyorffy and Chan 1992; Hale et al. 1988; Hoffman et al. 1988; Patterson et al. 1985; Porter et al. 1977; Prasad et al. 1978; Ramadurai et al. 1993; Salzman et al. 2002; Stroud 1991; Summerfield et al. 1992). Exposure of one patient to $2 \mathrm{mg}$ zinc/kg/day as zinc sulfate for 10 months resulted in anemia (Hoffman et al. 1988). A significant reduction in erythrocyte superoxide dismutase activity (47\% decrease), hematocrit, and serum ferritin, compared to pretreatment levels, occurred in female subjects who received supplements (as capsules) of $50 \mathrm{mg}$ zinc/day as zinc gluconate for 10 weeks (Yadrick et al. 1989); this study was selected as the basis for the intermediate-duration oral MRL. A 15\% decrease in erythrocyte superoxide dismutase activity was reported in male volunteers receiving $50 \mathrm{mg}$ zinc/day as zinc gluconate for 6 weeks (Fischer et al. 1984). A more recent study by Davis et al. (2000; Milne et al. 2001) reported increases in bonespecific alkaline phosphatase levels ( 25\%) and extracellular superoxide dismutase ( 15\%), while significant decreases were seen in mononuclear white cell 5'-nucleotidase ( 30\%) and plasma 
5'-nucleotidase activity ( $36 \%)$ following exposure of postmenopausal women to a combined (dietary+supplemental) $53 \mathrm{mg}$ zinc/day as zinc glycine chelate. Healthy men given $200 \mathrm{mg}$ zinc/day as elemental zinc for 6 weeks showed a reduction in lymphocyte stimulation response to phytohemagglutinin as well as chemotaxis and phagocytosis of bacteria by polymorphonuclear leukocytes (Chandra et al. 1984); however, no changes in lymphocyte cell number or in the proportion of lymphocyte populations were noted. Exposure of male volunteers to $0.48 \mathrm{mg}$ zinc $/ \mathrm{kg} /$ day, as zinc glycine chelate, had no effect on markers of coagulation (Bonham et al. 2003b) relative to unexposed subjects. While the changes in hematological end points following long-term zinc exposure in humans are noteworthy, they were subclinical in nature, and therefore, are generally considered to be non-adverse.

In animals, following oral administration of zinc compounds, decreased hemoglobin, hematocrit, erythrocyte, and/or leukocyte levels were observed in rats (Maita et al. 1981; Smith and Larson 1946), mice (Maita et al. 1981; Walters and Roe 1965), rabbits (Bentley and Grubb 1991), dogs (Drinker et al. 1927d; Meurs et al. 1991; Robinson et al. 1991), ferrets (Straube et al. 1980), and preruminant calves (Jenkins and Hidiroglou 1991). In rats, the lowest LOAEL for hematological effects was $4 \mathrm{mg} / \mathrm{kg} / \mathrm{day}$ $(8 \mathrm{mg} / \mathrm{kg}$ every other day) for an increased frequency of basophilic-stippled erythrocytes in rats exposed every other day for 14 days (Piao et al. 2003). The second lowest LOAEL is $12 \mathrm{mg}$ zinc/kg/day as zinc chloride in a 4-week drinking water study with 2-month-old rats (Zaporowska and Wasilewski 1992) that reported decreased hemoglobin (85\% of control values) and erythrocytes (90\% of control values). The highest NOAEL in rats is $191 \mathrm{mg}$ zinc/kg/day as zinc acetate in a 3-month drinking water study (age of rats not specified) (Llobet et al. 1988a). The reason that the lowest LOAEL is less than the highest NOAEL in rats is unclear, but it may be because of the use of different zinc compounds or different rat strains or age. For mice, NOAEL and LOAEL values of 104 and 1,110 $\mathrm{mg}$ zinc/kg/day as zinc sulfate, respectively, were identified by Maita et al. (1981) in a 13-week feeding study. A serious LOAEL of $68 \mathrm{mg}$ zinc/kg/day as zinc oleate was identified for severe anemia in a 9-month feeding study in mice (Walters and Roe 1965). It is not known if the difference in the LOAELs identified in the Maita et al. (1981) and Walters and Roe (1965) studies is due to the use of different zinc compounds, different basic diet formulations, different mouse strains, or different exposure durations. Slight decreases in hemoglobin levels were observed in rabbits fed $174 \mathrm{mg}$ zinc/kg/day as zinc carbonate (Bentley and Grubb 1991). Zinc oxide consumption caused anemia in dogs (76.5 mg zinc/kg/day) (Drinker et al. 1927d), ferrets (195 mg zinc/kg/day) (Straube et al. 1980), and preruminant calves (64 mg zinc/kg/day) (Jenkins and Hidiroglou 1991). Hematological alterations were not observed in cats exposed to up to $83.2 \mathrm{mg}$ zinc/kg/day as zinc oxide (Drinker et al. 1927d) or in adult mink exposed to zinc at up to $297.4 \mathrm{mg}$ zinc/kg/day as zinc oxide (Aulerich et al. 1991; Bleavins et al. 1983) or to rats exposed to $53 \mathrm{mg}$ 
zinc/kg/day as zinc sulfate (Maita et al. 1981). However, decreases in hematocrit and lymphocytes were observed in the offspring of mink females that ingested a time-weighted-average dose of $20.8 \mathrm{mg}$ zinc/kg/day as zinc sulfate for 10 weeks prior to conception and throughout gestation and lactation (Bleavins et al. 1983) indicating that very young mink may be more sensitive to the hematologic effects of zinc than adults. An increased number of weanling rats had low levels of ceruloplasmin, a copper serum protein, after administration of zinc sulfate for 6 weeks (L'Abbe and Fischer 1984a).

Musculoskeletal Effects. No studies were located regarding musculoskeletal effects in humans after oral exposure to zinc.

Rib biopsies revealed no treatment-related effects in dogs given $4 \mathrm{mg}$ zinc $/ \mathrm{kg} / \mathrm{day}$ as zinc oxide in the diet for 9 months (Anderson and Danylchuk 1979). No lesions of the bones were observed in rats exposed to $565 \mathrm{mg}$ zinc/kg/day as zinc sulfate during 13 weeks of exposure in the food (Maita et al. 1981).

Hepatic Effects. Ingestion of $3.5 \mathrm{mg} / \mathrm{kg} /$ day zinc sulfate for 18 weeks by 13 patients being treated for chronic venous leg ulcers was reported to have no effect on the results of liver function tests (Hallbook and Lanner 1972). However, the type of liver function tests was not specified and results were not presented to support this conclusion.

Several reports described changes in the serum lipid profile of humans exposed to zinc sulfate or gluconate for 3-12 months; however, the results are mixed. Ingestion of 2.3-4.3 mg zinc/kg/day for 56 weeks (Chandra 1984; Hooper et al. 1980) or $0.71 \mathrm{mg}$ zinc/kg/day for 12 weeks (Black et al. 1988) reduced levels of high-density lipoprotein (HDL) cholesterol. In the study by Chandra (1984), a slight increase in low-density lipoprotein (LDL) cholesterol was observed in subjects who served as their own controls; measurements were taken prior to zinc supplementation and after a 10-week postexposure period. Serum cholesterol, triglyceride, and LDL cholesterol levels were not affected by zinc supplementation in the study by Black et al. (1988). However, in another study, zinc supplements depressed HDL cholesterol levels and raised LDL cholesterol levels in elderly subjects (>60 years of age), especially in those who exercised. This study was not well controlled, and the wide variation in doses of the supplemented group prevented the determination of a LOAEL (Goodwin et al. 1985). Young women with a total daily intake of $1.6 \mathrm{mg}$ zinc/kg/day in a 2-month study had a transient decrease in HDL cholesterol (Freeland-Graves et al. 1980). In a double-blind crossover study of young men and women receiving 2.0 (men) or 2.4 (women) $\mathrm{mg}$ zinc/kg/day for 6 weeks, total HDL cholesterol was not affected, and LDL cholesterol was significantly decreased in the women (Samman and Roberts 1988). No effect 
on HDL cholesterol was seen in elderly men and women (60-89 years old) with a total daily intake (dietary zinc plus a zinc acetate supplement) of $1.5 \mathrm{mg} / \mathrm{kg} / \mathrm{day}$ for 3 months (Bogden et al. 1988), but the subjects also received copper supplements (about $0.03 \mathrm{mg} / \mathrm{kg}$ ). Bonham et al. (2003b) reported that supplementation of male subjects with $0.43 \mathrm{mg}$ zinc/ $\mathrm{kg} /$ day $(30 \mathrm{mg} / \mathrm{day}$, assuming a reference body weight of $70 \mathrm{~kg}$ ), as zinc glycine chelate, had no effect on LDL, HDL, or triglyceride levels. Another study (Hale et al. 1988) reported no differences in triglycerides and cholesterol levels in subjects ( $\geq 68$ years old) given zinc supplements of up to $2 \mathrm{mg} / \mathrm{kg} / \mathrm{day}$ for an average of 8 years.

No histopathology or changes in serum enzyme levels (serum glutamic oxaloacetic transaminase, serum glutamic pyruvic transaminase, or alkaline phosphatase) were observed in rats receiving $191 \mathrm{mg}$ zinc/kg/day as zinc acetate (Llobet et al. 1988a). Similarly, no histopathology was observed in rats administered $98.3 \mathrm{mg}$ zinc/kg/day as zinc oxide, but an insufficient number of animals were tested (Drinker et al. 1927c). Sheep fed time-weighted-average doses of $19 \mathrm{mg}$ zinc/ $\mathrm{kg} / \mathrm{day}$ as zinc oxide for 49-72 days developed hepatic effects, including necrotic hepatocytes and large quantities of hemosiderin in Kupffer cells (Allen et al. 1983). Because sheep are ruminants, it is not known if they are a good model for predicting human toxicity. No histological damage was observed in adult or young mink fed 327 or $324 \mathrm{mg}$ zinc/kg/day, respectively, as zinc sulfate for 144 days (Aulerich et al. 1991).

Decreased hexobarbital sleeping times were reported by Kadiiska et al. (1985) in rats receiving $40 \mathrm{mg}$ zinc/kg/day as zinc sulfate. This physiological response suggested an induction of microsomal enzymes.

Increases in serum cholesterol levels were observed in two studies where rats were fed either 2.8 or $10 \mathrm{mg}$ zinc/kg/day as zinc acetate for 2-7 months (Katya-Katya et al. 1984; Klevay and Hyg 1973). Other studies have shown no effect on total cholesterol, HDL cholesterol, or serum triglyceride levels in rats ingesting 3 or $25 \mathrm{mg}$ zinc/kg/day of unspecified zinc compounds (Fischer et al. 1980; Woo et al. 1983).

Renal Effects. Thirteen patients treated with zinc sulfate at $3.5 \mathrm{mg}$ zinc/ $\mathrm{kg} /$ day for 18 weeks for chronic venous leg ulcers had normal urinalyses (Hallbook and Lanner 1972). However, neither the specific parameters measured for the urinalysis nor the results were presented to support this conclusion. Furthermore, urinalysis may not be a sensitive indicator of renal function.

A number of intermediate-duration studies have demonstrated renal effects in animals exposed to zinc oxide, zinc sulfate, and zinc acetate. Zinc sulfate caused an increase in the absolute and relative kidney weights and regressive kidney lesions (not specified) in female mice that consumed 1,110 mg zinc/kg/day 
in the diet for 13 weeks, but no effects occurred in rats that consumed $565 \mathrm{mg}$ zinc/ $\mathrm{kg} /$ day or in mice that consumed $104 \mathrm{mg}$ zinc/kg/day under similar conditions (Maita et al. 1981). Severe diffuse nephrosis was observed in ferrets exposed to $195 \mathrm{mg}$ zinc/ $\mathrm{kg} /$ day as zinc oxide in the diet (Straube et al. 1980). In rats exposed to $191 \mathrm{mg}$ zinc/kg/day as zinc acetate for 3 months, epithelial cell damage in the glomerulus and proximal convoluted tubules and increased plasma creatinine and urea levels were observed (Llobet et al. 1988a). The NOAEL for the effects on creatinine and urea was $95 \mathrm{mg}$ zinc/kg/day. It is unclear whether the microscopic changes were observed at lower doses. No histopathological changes in the kidneys were observed in three rats that drank water containing $98.3 \mathrm{mg}$ zinc/ $\mathrm{kg} /$ day as zinc oxide for 35-36 weeks (Drinker et al. 1927c); however, interpretation of the results of this study is severely limited by the small number of rats used. Renal tubular dilation, with proteinaceous casts and hemosiderin deposits, was observed in the kidneys of sheep that ingested $18 \mathrm{mg}$ zinc/kg/day as zinc oxide for 49-72 days (Allen et al. 1983). It is not known if sheep are a good model for human toxicity because they are ruminants. No renal effects were observed in either adult mink consuming $326.7 \mathrm{mg}$ zinc/ $/ \mathrm{kg} / \mathrm{day}$ as zinc sulfate or in young mink consuming $323.6 \mathrm{mg}$ zinc/kg/day as zinc sulfate for 144 days (Aulerich et al. 1991). Minks exposed to $195 \mathrm{mg}$ zinc/kg/day as zinc oxide for 7-97 days in the food developed a diffuse nephrosis, though it did not increase with increasing dose (Straube et al. 1980).

Dermal Effects. No studies were located regarding dermal/ocular effects in humans after oral exposure to zinc.

No dermal effects were seen in adult female minks given a time-weighted dose of $20.8 \mathrm{mg}$ zinc/kg/day as zinc sulfate for 10 weeks prior to mating and then throughout gestation and lactation (Bleavins et al. 1983). However, the offspring of these animals showed graying of the fur around the eyes, ears, jaws, and genitals with a concomitant loss of hair and dermatosis in these areas during the weaning period. These conditions were reversible upon removal of treatment.

Endocrine Effects. Only one human exposure study has evaluated endocrine effects of oral zinc exposure. Davis et al. (2000; Milne et al. 2001) reported a slight $(<10 \%)$ decrease in serum T4 levels in postmenopausal women exposed to $0.68 \mathrm{mg}$ zinc/kg/day as zinc gluconate; the difference did not attain statistical significance, and no changes in free T3 or thyroid stimulating hormone (TSH) levels were reported.

Piao et al. (2003) exposed groups of Wistar rats to 0,4 , or $8 \mathrm{mg}$ zinc $/ \mathrm{kg}$ as zinc acetate every other day for a 14-day period. Levels of T3 were decreased in both groups of exposed rats, relative to controls, but 
levels of T4 and TSH were not significantly altered. Zinc exposure resulted in increased levels of serum cortisol, which was significant from controls at the $8 \mathrm{mg}$ zinc/kg exposure level.

Body Weight Effects. No effects on body weight have been reported in humans following oral exposure to zinc. However, a $46 \%$ decrease in body weight gain was seen in preruminant calves that consumed $91 \mathrm{mg}$ zinc/kg/day as zinc oxide for 5 weeks; there was no effect at $64 \mathrm{mg}$ zinc/kg/day (Jenkins and Hidiroglou 1991). The relevance of this effect to humans is unclear. Body weights of rabbits (Bentley and Grubb 1991), rats (Llobet et al. 1988a), and minks (Aulerich et al. 1991) were unaffected by dosing with 174, 191, and $326.7 \mathrm{mg}$ zinc/kg/day, respectively, for 3-12 months. Decreased postpartum body weights in F0 animals were observed in rats exposed to $7 \mathrm{mg}$ zinc/kg/day as zinc chloride for 20 weeks (Khan et al. 2001b).

\subsubsection{Immunological and Lymphoreticular Effects}

The highest NOAEL values and all LOAEL values from each reliable study for immunological and lymphoreticular effects in each species and duration category are recorded in Table 3-2 and plotted in Figure 3-2.

Zinc plays a role in the normal development and maintenance of the immune system, such as in the lymphocyte response to mitogens and as a cofactor for the thymic hormone thymulin (Delafuente 1991; Fraker et al. 1986). Oral exposure to zinc at levels much higher than the RDA has impaired immune and inflammatory responses. This was observed in in vivo investigations of the immune competence of blood components taken from 11 healthy adult men after ingestion of $4.3 \mathrm{mg}$ zinc/kg/day as zinc sulfate for 6 weeks. The mitogenic response elicited from peripheral blood lymphocytes and the chemotactic and phagocytic responses of polymorphonuclear leukocytes were impaired after zinc ingestion. No effects were seen on total numbers of lymphocytes or relative numbers of T cells, T cell subsets, or B cells (Chandra 1984). The relationship between these observations and decreased levels of immune competence that might lead to increased susceptibility to disease is unknown. Zinc supplements administered to elderly populations at doses up to $1.5 \mathrm{mg}$ zinc/kg/day (Bogden et al. 1988) or $2.5 \mathrm{mg}$ zinc/kg/day (Duchateau et al. 1981) resulted in either no effect or a beneficial effect on immune cell titers or delayed cutaneous hypersensitivity responses to specific antigens. A later study (Bonham et al. 2003) reported no effects of supplementation of male volunteers with $30 \mathrm{mg}$ zinc/day $(0.43 \mathrm{mg}$ zinc/kg/day assuming a reference male body weight of $70 \mathrm{~kg}$ ) as zinc glycine chelate for 14 weeks on levels of peripheral blood leucocytes or on the frequency of lymphocyte subsets. 
Decreased lymphocyte activity (incorporation of ${ }^{3} \mathrm{H}$-thymidine in response to concanavalin A) was reported in mink kits from dams that had ingested a time-weighted-average dose of $20.8 \mathrm{mg}$ zinc/kg/day as zinc sulfate for 10 weeks prior to conception and throughout gestation and lactation (Bleavins et al. 1983). The dose to the kits is unknown. In contrast, no effect was observed on antibody titre (immunoglobulin $\mathrm{G}[\mathrm{IgG}]$ and immunoglobulin $\mathrm{M}[\operatorname{IgM}]$ ) or the mitogenic response of splenic $\mathrm{B}$ cells isolated from mice fed $76.9 \mathrm{mg}$ zinc/kg/day as zinc sulfate for 4 weeks and challenged with B cell antigens either in vivo or in vitro (Schiffer et al. 1991). The in vitro mitogenic response of T cells isolated from these mice was increased. There was no effect of the zinc supplement in the plaque forming cell assay or on cytotoxic T killer cell activity in mice exposed to $6.5 \mathrm{mg}$ zinc/ $\mathrm{kg} /$ day in the diet for 8 weeks (Fernandes et al. 1979). In mice exposed in utero to $136 \mathrm{mg}$ zinc/kg/day, with exposure continuing postnatally, there were increases in direct plaque-forming activity of spleen cells and in lymphocyte proliferation in response to mitogen stimulation (Lastra et al. 1997).

\subsubsection{Neurological Effects}

Zinc appears to be necessary for normal brain function (Sandstead et al. 1983), but excess zinc is toxic. A 16 -year-old boy who ingested $\approx 86 \mathrm{mg}$ zinc/kg/day of metallic zinc over a 2-day period in an attempt to promote wound healing, developed signs and symptoms of lethargy, light-headedness, staggering, and difficulty in writing clearly (Murphy 1970). Lethargy was also observed in a 2-year-old child who ingested a zinc chloride solution $(\approx 1,000 \mathrm{mg}$ zinc $/ \mathrm{kg})$ (Potter 1981). It is not known whether these observations represent direct effects on the nervous system.

Very limited data were located regarding neurological effects in animals. Minor neuron degeneration and proliferation of oligodendroglia occurred in rats dosed with $487 \mathrm{mg} \mathrm{zinc} / \mathrm{kg} /$ day as zinc oxide for 10 days (Kozik et al. 1980). Rats receiving $472 \mathrm{mg}$ zinc/kg/day for 10 days had increased levels of secretory material in the neurosecretory nuclei of the hypothalamus (Kozik et al. 1981). Mice exposed postnatally to $0.5 \mathrm{mg}$ zinc/kg/day as zinc acetate for 28 days showed no changes in memory formation, but showed a gradual decrease in learning extinction throughout the study (de Oliveira et al. 2001). 


\subsubsection{Reproductive Effects}

The highest NOAEL values and all LOAEL values from each reliable study for reproductive effects in each species and duration category are recorded in Table 3-2 and plotted in Figure 3-2.

Pregnant women receiving capsules containing $0.3 \mathrm{mg}$ zinc/ $\mathrm{kg} /$ day as zinc sulfate during the last two trimesters did not exhibit any reproductive effects (no changes in maternal body weight gain, blood pressure, postpartum hemorrhage, or infection) (Mahomed et al. 1989). No other studies were located regarding reproductive effects in humans after oral exposure to zinc.

No measurable effect on gestational length or litter size was observed when female mink ingested a timeweighted average dose of $20.8 \mathrm{mg}$ zinc/kg/day as zinc sulfate (Bleavins et al. 1983). No histological alterations in the testes or ovaries were noted in mice fed zinc sulfate $(1,110 \mathrm{mg}$ zinc/kg/day) for 13 weeks (Maita et al. 1981). Male and female rats exposed by gavage to up to $14 \mathrm{mg}$ zinc/kg/day as zinc chloride resulted in a nonsignificant decrease in fertility index in all groups that was not related to administered dose; in the two highest groups ( 7 and $14 \mathrm{mg}$ zinc/kg/day), decreases in live pups per litter and pup weight at day 21 were also reported (Khan et al. 2001b). Similarly, exposure to up to $8 \mathrm{mg}$ zinc/kg/day every other day for 14 days showed no effects on the levels of abnormal sperm in Wistar rats (Piao et al. 2003). Male and female rats receiving $50 \mathrm{mg}$ zinc/ $\mathrm{kg} / \mathrm{day}$ as zinc carbonate in the diet were reported to reproduce normally for several generations in a poorly documented study by Sutton and Nelson (1937). Rats fed $250 \mathrm{mg}$ zinc/kg/day for 14-17 weeks mated successfully but had a higher than normal percentage of stillborn pups. A subsequent mating of the parental generation fed $250 \mathrm{mg}$ zinc/kg/day for 5 months was unsuccessful. No reproduction occurred in rats fed $500 \mathrm{mg}$ zinc/kg/day for 5 months (Sutton and Nelson 1937). The frequency of sperm with an altered chromatin structure was increased in rats fed $25 \mathrm{mg}$ zinc/kg/day as zinc chloride for 8 weeks (Evenson et al. 1993). Preimplantation loss increased in rats fed diets containing $200 \mathrm{mg}$ zinc/kg/day as zinc sulfate on gestational days 0-18 ( $\mathrm{Pal}$ and $\mathrm{Pal}$ 1987). When the rats received $200 \mathrm{mg}$ zinc/kg/day 21 days prior to mating, no effects on implantation or other adverse reproductive effects were observed (Pal and Pal 1987). Similarly, exposure of up to $372 \mathrm{mg}$ zinc/kg/day in mice prior to and throughout pregnancy did not result in changes in reproductive index (Lastra et al. 1997). 


\subsubsection{Developmental Effects}

The highest NOAEL values and all LOAEL values from each reliable study for developmental effects in each species and duration category are recorded in Table 3-2 and plotted in Figure 3-2.

Zinc is necessary for normal fetal growth and development. Fetal damage may result from zinc deficiency. Only one report in the literature suggested adverse developmental effects in humans due to exposure to excessive levels of zinc (Kumar 1976). Four women were given zinc supplements of $0.6 \mathrm{mg}$ zinc/kg/day as zinc sulfate during the third trimester of pregnancy. Three of the women had premature deliveries, and one delivered a stillborn infant. However, the significance of these results cannot be determined because very few details were given regarding the study protocol, reproductive histories, and the nutritional status of the women. Other human studies have found no developmental effects in the newborns of mothers consuming $0.3 \mathrm{mg}$ zinc/kg/day as zinc sulfate (Mahomed et al. 1989) or zinc citrate (Simmer et al. 1991) or $0.06 \mathrm{mg}$ zinc/kg/day as zinc aspartate (Kynast and Saling 1986) during the last two trimesters. There has been a suggestion that increased serum zinc levels in pregnant women may be associated with an increase in neural tube defects (McMichael et al. 1994), but others have failed to confirm this association (Hambidge et al. 1993).

The developmental toxicity of zinc in experimental animals has been evaluated in a number of investigations. Exposure to high levels of zinc in the diet prior to and/or during gestation has been associated with increased fetal resorptions, reduced fetal weights, altered tissue concentrations of fetal iron and copper, and reduced growth in the offspring.

Administration of zinc in rats at $200 \mathrm{mg}$ zinc/ $\mathrm{kg}$ /day as zinc oxide in the diet for 21 days prior to mating and then throughout gestation resulted in resorption of all fetuses (Schlicker and Cox 1968). Fetal resorptions ranged from 4 to $29 \%$ when $200 \mathrm{mg}$ zinc/kg/day was administered only during gestation (controls had no resorptions). When the dose was reduced to $100 \mathrm{mg} z i n c / \mathrm{kg} / \mathrm{day}$ starting 21 days prior to mating, there were no fetal resorptions, malformations, or growth reduction. In contrast, Kinnamon (1963) reported no resorptions, no difference in the number of offspring per litter, and no change in average wet weight of the fetuses from female rats fed $250 \mathrm{mg}$ zinc/ $\mathrm{kg} / \mathrm{day}$ as zinc carbonate in the diet for 53 days before mating and during gestation. The reason for the differences in the results of these studies is unknown. No effect on fetal viability, size, or malformations was seen in fetuses from female rats fed $25 \mathrm{mg}$ zinc/kg/day as zinc carbonate during gestational days 1-18 (Uriu-Hare et al. 1989). 
Administration of $200 \mathrm{mg}$ zinc/ $\mathrm{kg} /$ day to dams throughout gestation resulted in decreased growth and tissue levels of copper and iron in fetal rats (Cox et al. 1969; Schlicker and Cox 1968). In rats, at both 100 and $200 \mathrm{mg} / \mathrm{kg} /$ day during gestational days 1-18, maternal zinc levels increased. However, zinc tissue levels in the 22-day-old fetuses were not elevated at $100 \mathrm{mg} / \mathrm{kg} /$ day to dams, suggesting that the placenta was able to act as a barrier to zinc at the lower dietary level. In contrast, Ketcheson et al. (1969) showed that newborn and 14-day-old rats from mothers that had consumed $100 \mathrm{mg} / \mathrm{kg} /$ day throughout gestation had elevated levels of total zinc and decreased levels of iron. It is unclear whether the longer exposure to zinc during gestation or the suckling of newborn rats prior to sacrifice may have accounted for these differences.

Animal studies suggest that exposure to very high levels of dietary zinc is associated with reduced fetal weight, alopecia, decreased hematocrit, and copper deficiency in offspring. For example, second generation mice exposed to zinc carbonate during gestation and lactation $(260 \mathrm{mg} / \mathrm{kg} / \mathrm{day}$ in the maternal diet), and then continued on that diet for 8 weeks, had reduced body weight, alopecia, and signs of copper deficiency (e.g., lowered hematocrit and occasional achromotrichia [loss of hair color]) (Mulhern et al. 1986). Similarly, mink kits from dams that ingested a time-weighted-average dose of $20.8 \mathrm{mg}$ zinc/kg/day as zinc sulfate also had alopecia and achromotrichia (Bleavins et al. 1983). It is likely that the alopecia resulted from zinc-induced copper deficiency, which is known to cause alopecia in monkeys (Obeck 1978). However, no adverse effects were observed in parental mice or mink. No effects on reproduction were reported in rats exposed to $50 \mathrm{mg}$ zinc/kg/day as zinc carbonate; however, increased stillbirths were observed in rats exposed to $250 \mathrm{mg}$ zinc/kg/day (Sutton and Nelson 1937).

\subsubsection{Cancer}

Leitzmann et al. (2003) reported on the occurrence of prostate cancer within a cohort of 46,974 men within the United States evaluated between 1986 and 2000. Within the cohort, 2,901 cases of prostate cancer were identified, 434 of which were classified as advanced cancer. Zinc supplementation did not appear to have an effect on the frequency of developing prostate cancer. However, men within the cohort who had taken supplements of $\geq 100 \mathrm{mg}$ zinc/day had a greater probability of developing advanced cancer, if a tumor occurred.

Other studies evaluating the possible carcinogenic effects of zinc in humans are extremely limited. One study reported an association between an excess rate of gastric cancer in the people of North Wales (Great Britain) and the high zinc-to-copper ratio $(\approx 30: 1)$ in the soil of household gardens (Stocks and Davies 
1964). However, the inference that this excess in gastric cancer is causally associated with soil levels of zinc and copper is not consistent with another study. In a survey of cancer registry data (1954-1978) in Shipham, Somerset (Great Britain), an area that also has a high soil zinc-to-copper ratio $(\approx 17: 1)$, the gastric cancer incidence rate was significantly lower than the regional rate (Philipp et al. 1982). It is probable that other factors, not considered by Stocks and Davies (1964), are associated with or coincidental to the high soil zinc-to-copper ratio confounded the results.

The carcinogenicity of zinc in experimental animals following oral exposure was evaluated by Walters and Roe (1965). The incidence of tumors was not increased in mice exposed to $951 \mathrm{mg}$ zinc/kg/day as zinc sulfate in drinking water for 1 year compared to controls. However, important details regarding the study protocol were lacking including the age and sex of the mice, the number of mice at the beginning of the study, the purity of the test material, and a complete list of the organs and tissues examined at necropsy. The control mice developed intercurrent disease (ectromelia), which resulted in a number of deaths; supplementary control mice were added to the study, but they were not concurrent controls. The number of animals in treated and control groups surviving at 1 year (study termination) was small (2228 mice/group). The exposure period (1 year) was less than the standard bioassay period (18-24 months). There were no data in the study (e.g., survival or body weight data) to indicate that a maximum tolerated dose was achieved. These limitations reduce the sensitivity of the study by Walters and Roe (1965) to detect a carcinogenic response.

Halme (1961) exposed tumor-resistant and tumor-susceptible strains of mice to zinc in drinking water. In a 5-generation study, groups of tumor-resistant mice (strain not specified) received 0, 10, 20, 50, 100, or $200 \mathrm{mg}$ zinc/L as zinc chloride in the drinking water. The spontaneous tumor frequency for this strain of mice was $0.0004 \%$. The tumor frequencies were reported as: $\mathrm{F} 0=0.8 \% ; \mathrm{F} 1=3.5 \% ; \mathrm{F} 1$ and $\mathrm{F} 2=7.6 \%$; and $\mathrm{F} 3$ and $\mathrm{F} 4=25.7 \%$. The majority of the tumors were seen in the 10- and 20-mg zinc dose groups. No individual or group tumor incidence data were reported, and a discussion of statistical analysis was not included. In the tumor-susceptible mice, strains $\mathrm{C} 3 \mathrm{H}$ and $\mathrm{A} / \mathrm{Sn}$ received $10-29 \mathrm{mg}$ zinc/L in their drinking water for 2 years; 33/76 tumors were observed in the $\mathrm{C} 3 \mathrm{H}$ strain (31 in females) and 24/74 tumors were observed in the A/Sn strain (20 in females). Most of the tumors were reported to be adenocarcinomas, but the tissues in which they occurred were not reported. The numbers of specific tumor types were not reported. The overall tumor frequencies ( $43.4 \%$ for $\mathrm{C} 3 \mathrm{H}$ and $32.4 \%$ for $\mathrm{A} / \mathrm{Sn}$ ) were higher than the spontaneous frequency (15\% for each strain), but statistical analyses were not reported. 


\subsubsection{Dermal Exposure}

\subsubsection{Death}

No studies were located regarding death in humans or animals after dermal exposure to zinc.

\subsubsection{Systemic Effects}

The dermal toxicity of zinc compounds, particularly effects on the skin, can vary widely with the chemical form of zinc. For example, zinc chloride is caustic and can cause severe irritation at levels $<0.5 \mathrm{mg} / \mathrm{cm} 2$ (Lansdown 1991), while zinc sulfate is irritating but not as caustic as zinc chloride, and zinc oxide does not appear to be a dermal irritant. Zinc oxide is commonly used in topical applications (including sunblock products) without adverse effects.

Zinc has been reported to promote the healing of burns and wounds when topically applied as zinc oxide or calamine lotion (Gordon et al. 1981). The mechanism by which this occurs was not discussed by the authors. Zinc oxide contained in an occlusive zinc tape dressing reduced the inflammatory reactions in the granulation tissue of wounded rats (Wetter et al. 1986). The authors speculated that zinc acted either by a continuous release of zinc ions or by modifying components involved in the tape's adhesive properties.

No studies were located regarding respiratory, cardiovascular, gastrointestinal, musculoskeletal, hepatic, renal, or other systemic effects in humans or animals after dermal exposure to zinc. The systemic effects observed after dermal exposure are discussed below. The NOAEL values and all LOAEL values from each reliable study for dermal effects in each species and duration category are recorded in Table 3-3.

Hematological Effects. A worker who had been employed making up zinc chloride solutions (concentrations not specified) with his hands was found to have microcytic anemia and decreased numbers of platelets (DuBray 1937).

No studies were located regarding hematological effects in animals after dermal exposure to zinc. 
Table 3-3 Levels of Significant Exposure to Zinc - Dermal

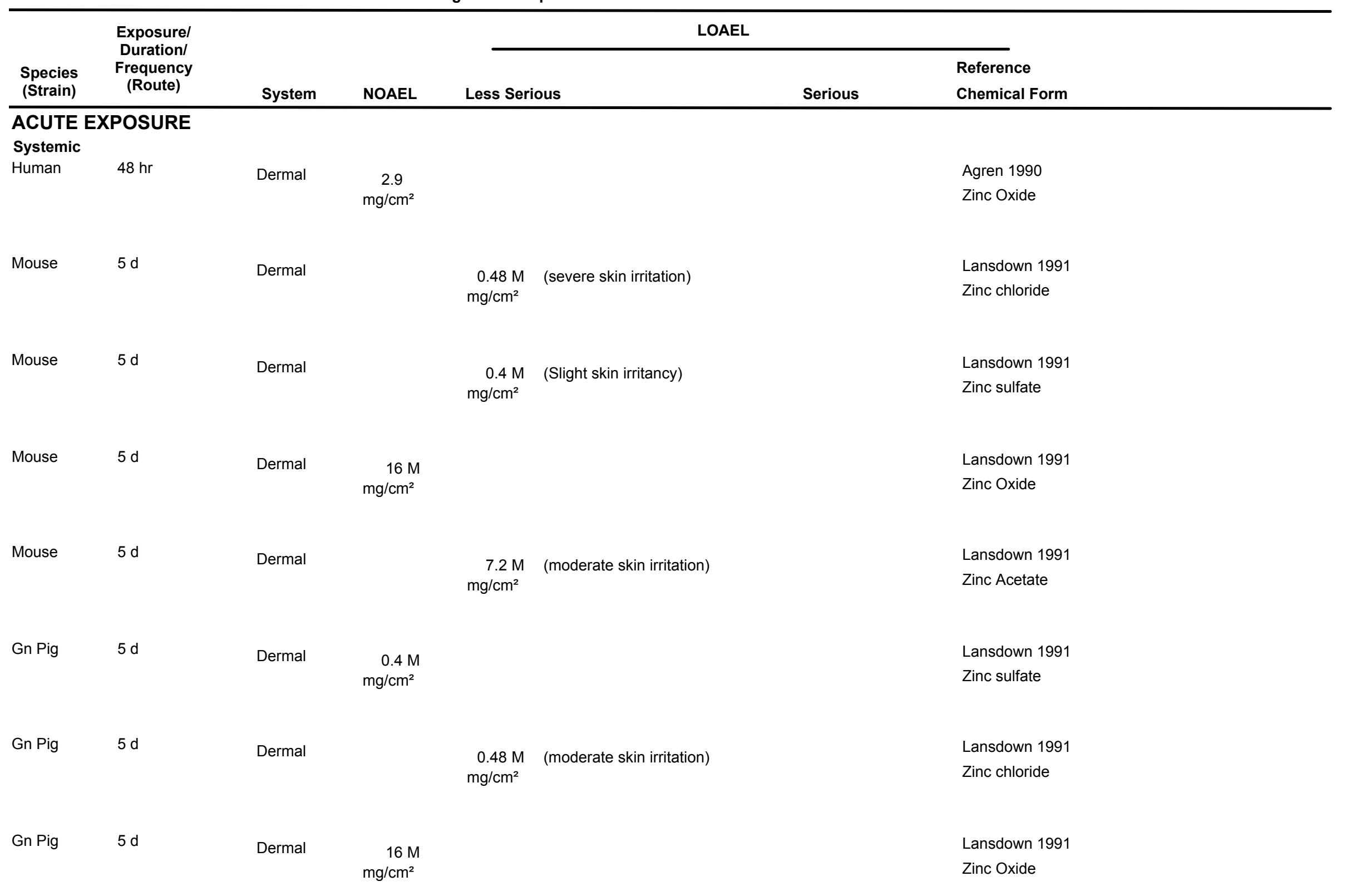


Table 3-3 Levels of Significant Exposure to Zinc - Dermal

(continued)

\begin{tabular}{|c|c|c|c|c|c|c|}
\hline \multirow[b]{2}{*}{$\begin{array}{l}\text { Species } \\
\text { (Strain) }\end{array}$} & \multirow{2}{*}{$\begin{array}{l}\text { Exposure/ } \\
\text { Duration/ } \\
\text { Frequency } \\
\text { (Route) }\end{array}$} & \multirow[b]{2}{*}{ System } & & \multicolumn{2}{|c|}{ LOAEL } & \multirow[b]{2}{*}{$\begin{array}{l}\text { Reference } \\
\text { Chemical Form }\end{array}$} \\
\hline & & & NOAEL & Less Serious & Serious & \\
\hline Gn Pig & $5 \mathrm{~d}$ & Dermal & $\begin{array}{r}7.2 \mathrm{M} \\
\mathrm{mg} / \mathrm{cm}^{2}\end{array}$ & & & $\begin{array}{l}\text { Lansdown } 1991 \\
\text { Zinc Acetate }\end{array}$ \\
\hline Rabbit & $5 d$ & Dermal & $\begin{array}{r}0.4 \mathrm{M} \\
\mathrm{mg} / \mathrm{cm}^{2}\end{array}$ & & & $\begin{array}{l}\text { Lansdown } 1991 \\
\text { Zinc sulfate }\end{array}$ \\
\hline Rabbit & $5 d$ & Dermal & $\begin{array}{r}16 \mathrm{M} \\
\mathrm{mg} / \mathrm{cm}^{2}\end{array}$ & & & $\begin{array}{l}\text { Lansdown } 1991 \\
\text { Zinc Oxide }\end{array}$ \\
\hline Rabbit & $5 \mathrm{~d}$ & Dermal & & $\begin{array}{cl}7.2 \mathrm{M} & \text { (slight skin irritation - } \\
\mathrm{mg} / \mathrm{cm}^{2} & \text { open patch test;severe } \\
& \text { skin irritaiton - occluded } \\
& \text { patch test) }\end{array}$ & & $\begin{array}{l}\text { Lansdown } 1991 \\
\text { Zinc Acetate }\end{array}$ \\
\hline Rabbit & $5 d$ & Dermal & & $\begin{array}{c}0.48 \mathrm{M} \\
\mathrm{mg} / \mathrm{cm}^{2}\end{array}$ (severe skin irritation) & & $\begin{array}{l}\text { Lansdown } 1991 \\
\text { Zinc chloride }\end{array}$ \\
\hline
\end{tabular}


Dermal Effects. No signs of dermal irritation were observed in humans after a $25 \%$ zinc oxide patch $\left(2.9 \mathrm{mg} / \mathrm{cm}^{2}\right)$ was placed on the skin for 48 hours (Agren 1990). However, 14 out of 17 men who were employed in the bagging or packing of zinc oxide and whose skin was frequently covered with zinc oxide dust reported having experienced zinc oxide pox at least once (Turner 1921). The pox appeared as itchy papular-pustular eruptions in the pubic region, scrotum, inner surface of the thigh, and occasionally on the axilla and inner surface of the arms. The study author suggested that these lesions were due to clogging of glands by dust, perspiration, and bacteria when skin surfaces coated with these substances were rubbed together. In contrast, a case study of 24 workers exposed to dusts of either zinc oxide, zinc sulfide, or metallic zinc revealed only 1 worker with papular pustular lesions on the axilla and inner thighs (Batchelor et al. 1926). The difference in the results was attributed to differences in the personal hygiene of the workers in the two studies.

The dermal irritancy of several zinc compounds was compared in mice, rabbits, and guinea pigs (Lansdown 1991). Of the six zinc compounds tested, zinc chloride had the greatest irritancy potential (severe irritation at $0.48 \mathrm{mg} / \mathrm{cm}^{2}$ ), followed by zinc acetate (moderate irritation at $7.2 \mathrm{mg} / \mathrm{cm}^{2}$ ) and zinc sulfate (slight irritation at $0.48 \mathrm{mg} / \mathrm{cm}^{2}$ ); no signs of irritation were observed following exposure to zinc oxide. Although zinc chloride is clearly the most irritating, the relative irritancy of zinc sulfate and zinc acetate was not determined because only one dose was tested and a different dose was used for each compound. The severe skin irritancy observed following application of zinc chloride was characterized by parakeratosis, hyperkeratosis, inflammatory changes in the epidermis and superficial dermis, and acanthosis of the follicular epithelia (Lansdown 1991).

Ocular Effects. In a case report, accidental splashing of a soldering paste containing $30 \%$ zinc chloride into the eye of a plumber produced an immediate reduction in visual acuity, hyperemia, hemorrhaging, conjunctival swelling, corneal opacity, bullous keratopathy, and spotting of the lens (Houle and Grant 1973). Most symptoms disappeared after 6 weeks, but residual lens opacities persisted for over a year after the exposure. Reddened conjunctivae and lacrimation were observed in 34 persons who were exposed to extremely high concentrations of zinc chloride smoke when several smoke generators exploded in a tunnel during World War II (Evans 1945). Two of the exposed persons had corneal burns and four had small vesicular burns on the forehead or wrist. Zinc chloride was the major component of the smoke. However, other components such as zinc oxide, hexachloroethane, calcium silicide, the igniter, or the heat of the explosion may have contributed to the injuries that were observed. 
No studies were located regarding the following health effects in humans or animals after dermal exposure to zinc:

\subsubsection{Immunological and Lymphoreticular Effects}

\subsubsection{Neurological Effects}

\subsubsection{Reproductive Effects}

\subsubsection{Developmental Effects}

\subsubsection{Cancer}

\subsection{GENOTOXICITY}

Genotoxicity studies conducted in a variety of test systems have failed to provide evidence for mutagenicity of zinc. However, there are indications of weak clastogenic effects following zinc exposure.

Chromosome aberrations were observed in the lymphocytes of 24 workers in a zinc smelting plant (Bauchinger et al. 1976). However, the workers had increased blood levels of lead and cadmium, and the clastogenic effect was attributed to cadmium exposure.

Results of in vivo studies are shown in Table 3-4. A dominant lethal study in mice failed to show a mutagenic potential for zinc. However, chromosomal aberrations have been observed in bone marrow cells following in vivo exposure to zinc (Vilkina et al. 1978). This effect was observed in rats exposed to $14.8 \mathrm{mg}$ zinc/kg/day as zinc chlorate in drinking water (Kowalska-Wochna et al. 1988), mice given intraperitoneal injections of $3.6 \mathrm{mg}$ zinc/kg/day as zinc chloride (Gupta et al. 1991), and mice exposed to zinc oxide by inhalation (Voroshilin et al. 1978). Chromosomal aberrations caused by zinc were observed in the bone marrow cells of mice maintained on a low-calcium diet (Deknudt and Gerber 1979). Calcium may be displaced by zinc in calcium-depleted conditions, leading to chromosome breaks and/or interfering in the repair process (Deknudt and Gerber 1979). In vivo exposure to zinc may also result in single-strand breaks, as measured by the Comet assay in mice (Banu et al. 2001). An increased incidence of sister chromatid exchange was observed in bone marrow cells of rats exposed to $17.5 \mathrm{mg}$ zinc/ $\mathrm{kg} / \mathrm{day}$ as zinc chlorate in drinking water (Kowalska-Wochna et al. 1988). 
Table 3-4. Genotoxicity of Zinc In Vivo

\begin{tabular}{|c|c|c|c|}
\hline Species (test system) & End point & Results & Reference \\
\hline \multicolumn{4}{|l|}{ Mammalian systems: } \\
\hline Mouse & Dominant lethal & - & Vilkina et al. 1978 \\
\hline Mouse & $\begin{array}{l}\text { Single-strand DNA } \\
\text { breaks }\end{array}$ & + & Banu et al. 2001 \\
\hline Mouse bone marrow & $\begin{array}{l}\text { Chromosomal } \\
\text { aberrations }\end{array}$ & + & $\begin{array}{l}\text { Deknudt and Gerber } \\
1979\end{array}$ \\
\hline Mouse & $\begin{array}{l}\text { Chromosomal } \\
\text { aberrations }\end{array}$ & + & Voroshilin et al. 1978 \\
\hline Rat bone marrow & $\begin{array}{l}\text { Chromosomal } \\
\text { aberrations }\end{array}$ & + & $\begin{array}{l}\text { Kowalska-Wochna } \\
1988\end{array}$ \\
\hline Mouse bone marrow & $\begin{array}{l}\text { Chromosomal } \\
\text { aberrations }\end{array}$ & + & Gupta et al. 1991 \\
\hline Rat bone marrow & $\begin{array}{l}\text { Sister chromatid } \\
\text { exchange }\end{array}$ & + & $\begin{array}{l}\text { Kowalska-Wochna } \\
1988\end{array}$ \\
\hline Mouse & Micronucleus & - & Gocke et al. 1981 \\
\hline Drosophilia & $\begin{array}{l}\text { Sex-linked recessive } \\
\text { lethal }\end{array}$ & - & Gocke et al. 1981 \\
\hline
\end{tabular}

$-=$ negative result; $+=$ positive result; DNA = deoxyribonucleic acid 
Results of in vitro studies are shown in Table 3-5. Exposure to zinc as zinc sulfate or zinc chloride does not increase mutation frequencies in bacterial or mammalian cell culture test systems (Amacher and Paillet 1980; Gocke et al. 1981; Marzin and Vo Phi 1985; Nishioka 1975; Thompson et al. 1989; Venitt and Levy 1974; Wong 1988). Similarly, there was no convincing evidence of a clastogenic effect in human lymphocytes exposed to 0.0003-0.00003 M zinc chloride (Deknudt and Deminatti 1978).

\subsection{TOXICOKINETICS}

There is limited information on the toxicokinetic properties of zinc following inhalation or dermal exposure. Increased zinc levels in the blood and urine of humans and in the tissue of animals after inhalation and dermal exposure to zinc, respectively, indicate that zinc is absorbed by these routes. The toxicokinetic properties of ingested zinc have been extensively studied. The absorption of zinc from the gastrointestinal tract is homeostatically regulated; under normal physiological conditions, 20-30\% of ingested zinc is absorbed. Zinc uptake from the intestinal lumen involves passive diffusion and a carriermediated process. A number of factors influence the absorption of zinc; these include the solubility of the zinc compound as well as inhibitors, such as calcium, phosphorus, and dietary fiber and phytates (components of dietary fiber that may coprecipitate with zinc in the intestines), and enhancers, such as amino acids, picolinic acid, and prostaglandin $\mathrm{E}_{2}$. Once absorbed, zinc is widely distributed throughout the body. Zinc content is highest in muscle, bone, gastrointestinal tract, kidney, brain, skin, lung, heart, and pancreas. In plasma, two-thirds of the zinc is bound to albumin which represents the metabolically active pool of zinc. This pool of plasma zinc is frequently referred to as loosely bound zinc because albumin has the ability to give up bound zinc to tissues. Zinc is excreted in both urine and feces.

\subsubsection{Absorption}

\subsubsection{Inhalation Exposure}

Quantitative studies regarding absorption of zinc and zinc compounds after inhalation exposure in humans are limited. The absorption of inhaled zinc depends on the particle size and solubility, both of which may greatly influence the deposition and clearance of zinc aerosols, particularly insoluble zinc oxide (a review of the role of particle size in the deposition of particles is found in Witschi and Last 2001). Elevated levels of zinc have been found in the blood and urine of workers exposed to zinc oxide fumes (Hamdi 1969). 
Table 3-5. Genotoxicity of Zinc In Vitro

\begin{tabular}{|c|c|c|c|c|}
\hline \multirow[b]{2}{*}{ Species (test system) } & \multirow[b]{2}{*}{ End point } & \multicolumn{2}{|c|}{ Results } & \multirow[b]{2}{*}{ Reference } \\
\hline & & $\begin{array}{l}\text { With } \\
\text { activation }\end{array}$ & $\begin{array}{l}\text { Without } \\
\text { activation }\end{array}$ & \\
\hline \multicolumn{5}{|l|}{ Prokaryotic organisms: } \\
\hline $\begin{array}{l}\text { Salmonella typhimurium } \\
\text { (TA102) }\end{array}$ & Gene mutation & Not tested & - & $\begin{array}{l}\text { Marzin and Vo Phi } \\
1985\end{array}$ \\
\hline $\begin{array}{l}\text { S. typhimurium (TA98, } \\
\text { TA102, TA1535, TA1537) }\end{array}$ & Gene mutation & - (S9) & - & Wong et al. 1988 \\
\hline $\begin{array}{l}\text { S. typhimurium (TA1538, } \\
\text { TA98, TA100, TA1537) }\end{array}$ & Gene mutation & $-(\mathrm{S} 9)$ & - & $\begin{array}{l}\text { Thompson et al. } \\
1989\end{array}$ \\
\hline $\begin{array}{l}\text { S. typhimurium (TA1535, } \\
\text { TA1537, TA1538, TA98, } \\
\text { TA100) }\end{array}$ & Gene mutation & $-(\mathrm{S} 9)$ & - & Gocke et al. 1981 \\
\hline Escherichia coli & Gene mutation & Not tested & - & Nishioka 1975 \\
\hline E. coli & Gene mutation & Not tested & - & $\begin{array}{l}\text { Venitt and Levy } \\
1974\end{array}$ \\
\hline \multicolumn{5}{|l|}{ Mammalian cells: } \\
\hline Mouse lymphoma & Gene mutation & Not tested & - & $\begin{array}{l}\text { Amacher and } \\
\text { Paillet } 1980\end{array}$ \\
\hline Mouse lymphoma & Gene mutation & $+(\mathrm{S} 9)$ & + & $\begin{array}{l}\text { Thompson et al. } \\
1989\end{array}$ \\
\hline Human lymphocytes & $\begin{array}{l}\text { Chromosomal } \\
\text { aberrations }\end{array}$ & Not tested & + & $\begin{array}{l}\text { Deknudt and } \\
\text { Deminatti } 1978\end{array}$ \\
\hline Chinese hamster ovary cells & $\begin{array}{l}\text { Chromosomal } \\
\text { aberrations }\end{array}$ & $+(\mathrm{S} 9)$ & + & $\begin{array}{l}\text { Thompson et al. } \\
1989\end{array}$ \\
\hline
\end{tabular}

- = negative result; $+=$ positive result 
The rates or percentages of absorption of inhaled zinc in animals are not available; however, studies provide data on zinc retention in the lungs. Zinc retention values were 19.8, 11.5, and 4.7\% in the lungs of guinea pigs, rats, and rabbits, respectively, after inhalation exposure (nose-only) to $3.5-9.1 \mathrm{mg}$ zinc $/ \mathrm{m}^{3}$ as zinc oxide aerosol for 2-3 hours (Gordon et al. 1992). The aerosol had a mass median diameter of $0.17 \mu \mathrm{m}$. The retention of zinc in lungs was dose related in male Wistar rats administered a single intratracheal instillation of $0.07-3.7 \mathrm{mg}$ zinc $/ \mathrm{m}^{3}$ as zinc oxide (Hirano et al. 1989). A half-life of 14 hours was calculated.

The absorption of zinc oxide fumes lead to increased levels of zinc measured in the liver, kidney, and pancreas of cats exposed to zinc oxide fumes for durations ranging from 15 minutes to 3.25 hours (Drinker and Drinker 1928). The usefulness of the study is limited because reporting was inadequate and particle size of the zinc oxide aerosol was not determined. Some inhaled particles of zinc oxide are subject to ciliary clearance and swallowing. Thus, a portion of the inhaled zinc may ultimately be absorbed from the gastrointestinal tract.

\subsubsection{Oral Exposure}

Several studies have measured oral absorption rates of zinc in humans. Absorption ranged from 8 to $81 \%$ following short-term exposures to zinc supplements in the diet; differences in absorption are probably due to the type of diet (amount of zinc ingested, amount and kind of food eaten) (Aamodt et al. 1983; Hunt et al. 1991; Istfan et al. 1983; Reinhold et al. 1991; Sandstrom and Abrahamson 1989; Sandstrom and Cederblad 1980; Sandstrom and Sandberg 1992). For example, dietary protein facilitates zinc absorption; fractional zinc absorption ranged from $8 \%$ for low-protein rolls to $26 \%$ for high-protein rolls 3 days after individuals ingested $0.05 \mathrm{mg}$ zinc/kg (Hunt et al. 1991).

Absorption of labeled zinc was $40.0-48.4 \%$ in male Wistar rats fed a diet containing $0.81 \mathrm{mg}$ zinc/kg as zinc chloride or zinc carbonate (Galvez-Morros et al. 1992). Fractional absorption in immature organisms generally exceeds that in adults. In growing rats, on the basis of indirect calculation from isotope experiments, Weigand and Kirchgessner (1992) suggested surprisingly high absorption values of as much as $94.7 \%$. It is likely that all these results were influenced by isotope exchange and do not provide estimates of net absorption.

The body's natural homeostatic mechanisms control zinc absorption from the gastrointestinal tract (Davies 1980). Persons with adequate nutritional levels of zinc absorb approximately $20-30 \%$ of all 
ingested zinc. Those who are zinc-deficient absorb greater proportions of administered zinc (Johnson et al. 1988; Spencer et al. 1985).

Absorption of zinc occurs from all segments of the intestine, although the largest proportion of zinc absorption occurs from the duodenum (Methfessel and Spencer 1973). The zinc absorption process includes both passive diffusion and a carrier-mediated process (Tacnet et al. 1990). The intestinal absorption of zinc appears to be a saturable carrier-mediated process at low zinc dose levels involving a cysteine-rich intestinal protein (CRIP) (Davies 1980; Gunshin et al. 1991; Hempe and Cousins 1992; Sturniolo et al. 1991). This protein binds zinc entering the intestinal cells from the lumen (Hempe and Cousins 1991). CRIP has a limited binding capacity for zinc and becomes saturated when zinc concentration in the intestine is high. Metallothionein, a metal-binding protein, may contribute to zinc homeostasis at higher zinc absorption. Like several other metals, zinc can induce metallothionein production in intestinal mucosal cells (Richards and Cousins 1975). Zinc binds to metallothionein, which remains in the mucosal cells lining the gastrointestinal tract, and the bound metal is excreted from the body upon sloughing off of these cells. Although the affinity of zinc for metallothionein is relatively low, the protein may serve to prevent absorption of excess zinc in the body (Foulkes and McMullen 1987). Absorption of zinc in rats is increased when metallothionein levels are lower (Flanagan et al. 1983). It is hypothesized that zinc entering luminal cells is associated with CRIP, and a small amount is bound to metallothionein; however, as the luminal zinc concentration increases, the proportion of cytosolic zinc associated with CRIP is decreased with a concomitant increase in zinc binding to metallothionein (Hempe and Cousins 1992). Further details on the influence of CRIP and metallothionein on zinc absorption are provided in Section 3.5, Mechanisms of Action.

Phytate and high phosphorus intakes in animals decrease zinc absorption. In humans, dairy products that contain both calcium and phosphorus decrease zinc absorption and plasma zinc concentration (Pecoud et al. 1975). Zinc binds to phosphate which results in coprecipitation of zinc with calcium phosphate in the intestines (Nelson et al. 1985). Dietary phytate also reduces zinc absorption. The addition of $400 \mu \mathrm{mol}$ phytate to the diet decreased zinc absorption from $43.3 \pm 17.9 \%$ in females fed bread containing $0.02 \mathrm{mg}$ zinc/kg (zinc-65 isotope) to 14.3 $\pm 3.2 \%$ (Sandstrom and Sandberg 1992). Rats given diets supplemented with radiolabeled zinc and phytate excreted significantly more zinc in the feces than rats given diets supplemented with radiolabeled zinc but without phytate (Davies and Nightingale 1975). The study authors suggested that the decrease in absorption was due to the formation of zinc-phytate complexes in the intestines. Phytate also reduced reabsorption of zinc secreted into the gastrointestinal tract of humans (Sandstrom and Sandberg 1992). 
Endogenous substances, such as amino acids, can influence the absorption of zinc. Complexing of zinc with amino acids generally enhances its absorption in all segments of the intestine (Wapnir and Stiel 1986). Although neither zinc nor the amino acid proline are readily absorbed in the colon, complexing of zinc with proline during an in vivo intestinal perfusion in rats resulted in increased zinc absorption.

Acrodermatitis enteropathica is a metabolic disorder that results in the malabsorption of zinc. However, when patients afflicted with this disorder were treated with human milk, zinc absorption was enhanced (Lombeck et al. 1975). It was reported by Evans (1980) that patients with acrodermatitis enteropathica have an impaired tryptophan metabolic pathway. Picolinic acid, a chief metabolite of tryptophan, is also a constituent of human milk. Picolinic acid is secreted by the pancreas into the intestinal lumen. A study by Boosalis et al. (1983) demonstrated that patients with pancreatic insufficiency had difficulty absorbing zinc administered as zinc sulfate. However, when these pancreatic-insufficient patients were given zinc as zinc picolinate, the extent of zinc absorption was similar to that of healthy controls. Zinc absorption may depend on the bioavailability of picolinic acid. Such a mandatory role of picolinic acid in absorption has not been confirmed (Bonewitz et al. 1982).

The addition of prostaglandin $\mathrm{E}_{2}\left(\mathrm{PGE}_{2}\right)$ to the mucosal media of everted jejunal sacs from rats significantly increased zinc transport (Song and Adham 1979). In contrast, similar addition of prostaglandin $\mathrm{F}_{2}\left(\mathrm{PGF}_{2}\right)$ significantly decreased zinc transport. Addition of $\mathrm{PGF}_{2}$ to the serosal side of the jejunal sacs increased the transport of zinc to the mucosal side; $\mathrm{PGE}_{2}$ decreased the serosal to mucosal transport of zinc. The mechanism by which prostaglandins regulate zinc transport has not been established (Song et al. 1992). The limitation of the in vitro study is the absence of vascular perfusion and consequent trapping of metals in the submucosal tissue. Hence, studies of absorption of heavy metals, including zinc, in everted sacs have limited physiological relevance (Foulkes 1984) but may provide information useful for the design of future in vivo experiments.

The presence of other trace metals (e.g., mercury, cadmium, copper) may also diminish zinc transport. Section 3.9 provides detailed information on the interaction of zinc with other metals.

\subsubsection{Dermal Exposure}

Dermal absorption of zinc occurs, but its mechanism is not clearly defined. Studies are very limited regarding the absorption of zinc through the skin. Historically, zinc oxide has been used clinically to 
promote the healing of burns and wounds (Gordon et al. 1981). Absorption has been observed in burn patients treated with gauze dressings containing zinc oxide (Hallmans 1977). The $\mathrm{pH}$ of the skin, the amount of zinc applied, and the vehicle administered with zinc all affect the absorption of zinc (Agren 1990, 1991).

Zinc chloride was also absorbed through the intact skin of the rat (Keen and Hurley 1977). Absorption of zinc sulfate was greater than zinc oxide following 4-48-hour dermal application to open wounds in Sprague-Dawley rats (Agren et al. 1991). About $12 \%$ of zinc oxide $\left(0.25 \mathrm{mg}\right.$ zinc/ $\left.\mathrm{cm}^{2}\right)$ from the dressing

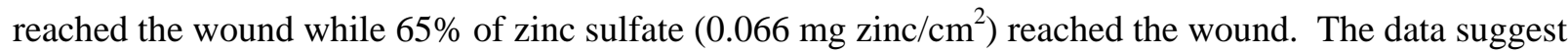
that zinc oxide applied to wounds resulted in sustained delivery of zinc ions causing constant woundtissue zinc levels. In contrast, zinc sulfate, being more water soluble than zinc oxide, is rapidly transferred into the blood and, therefore, caused decreased wound-tissue zinc levels (Agren et al. 1991).

\subsubsection{Distribution}

Zinc is one of the most abundant trace metals in humans. It is found normally in all tissues and tissue fluids and is a cofactor in over 300 enzyme systems. Together, muscle and bone contain approximately $90 \%$ of the total amount of zinc in the body ( $\approx 60$ and 30\%, respectively) (Wastney et al. 1986). Organs containing sizable concentrations of zinc are the liver, gastrointestinal tract, kidney, skin, lung, brain, heart, and pancreas (Bentley and Grubb 1991; Drinker and Drinker 1928; He et al. 1991; Llobet et al. 1988a). High concentrations of zinc were also detected in the prostate (Forssen 1972), retina, and sperm (Bentley and Grubb 1991). Zinc levels may vary considerably from one individual to another (Forssen 1972).

To some degree, the distribution of zinc in some tissues appears to be regulated by age (Schroeder et al. 1967). Zinc concentrations increase in the liver, pancreas, and prostate and decrease in the uterus and aorta with age. Levels in the kidneys and heart peak at approximately 40-50 years of age and then decline.

Zinc is present in blood plasma, erythrocytes, leukocytes, and platelets, but is chiefly localized within erythrocytes (of which $87 \%$ is in carbonic anhydrase, the major binding site) (Ohno et al. 1985). Zinc deficiency has been demonstrated to decrease the ability of erythrocytes to resist hemolysis in vitro. This finding suggests that zinc stabilizes the erythrocyte membrane. In plasma, two-thirds of the zinc is bound to albumin; the remainder is bound primarily to $\alpha 2$-macroglobulin (Bentley and Grubb 1991; Giroux et al. 
1976; Wastney et al. 1986). It appears that the limited number of binding sites for zinc in plasma albumin and macroglobulin regulates the amount of zinc retained by the body (Andermann and Dietz 1982). Albumin-bound zinc has been correlated with plasma zinc levels, whereas $\alpha_{2}$-macroglobulin shows no correlation with plasma zinc levels.

Hormones, such as the adrenocorticotrophic hormone (ACTH), appear to regulate the concentration of zinc in the liver. ACTH, secreted by the anterior pituitary gland, stimulates the secretion of glucocorticoids. Glucocorticoids, or hormones with glucocorticoid activity, have been shown in vitro to stimulate the net zinc uptake in cultured liver cells and at the same time activate the gene that regulates metallothionein synthesis (Failla and Cousins 1978). However, there are no in vivo data to support these in vitro findings. Metallothionein in the cells of the intestinal mucosa binds zinc, thus regulating its release into the blood.

The transfer of zinc across perfused placentas is slow; only $3 \%$ of maternal zinc reached the fetal compartment in 2 hours (Beer et al. 1992). The in vitro transfer of zinc between mother and fetus is bidirectional, with binding in the placenta (Beer et al. 1992). It is proposed that zinc uptake in the placenta involves a potassium/zinc transport system (Aslam and McArdle 1992). Newborns may also be exposed to zinc from their mothers by milk transfer of zinc during lactation (Rossowska and Nakamoto 1992).

\subsubsection{Inhalation Exposure}

No studies were located regarding distribution in humans after inhalation exposure to zinc. However, occupational studies provided indirect evidence that zinc may distribute to tissues to produce systemic effects (Brown 1988; Drinker et al. 1927a; Malo et al. 1990; McCord et al. 1926; Rohrs 1957; Sturgis et al. 1927).

Zinc levels in the lungs of cats peaked immediately after acute exposure to $12-61 \mathrm{mg}$ zinc/kg/day as zinc oxide for approximately 3 hours and remained high for 2 days postexposure, then dropped significantly thereafter (Drinker and Drinker 1928). Levels in pancreas, liver, and kidneys increased slowly. 


\subsubsection{Oral Exposure}

A single oral dose of $0.7 \mathrm{mg}$ zinc/ $/ \mathrm{kg}$ as zinc sulfate given to 11 individuals resulted in peak zinc levels in the plasma at 2-3 hours (Statter et al. 1988; Sturniolo et al. 1991). Similarly, Neve et al. (1991) reported peak serum zinc concentration at 2.3 hours with $0.7 \mathrm{mg}$ zinc/ $\mathrm{kg}$ as zinc sulfate.

Following feeding of $191 \mathrm{mg}$ zinc/kg/day as zinc acetate to rats for 3 months, increased zinc levels were significant in the heart, spleen, kidneys, liver, bone, and blood (Llobet et al. 1988a). The greatest increases were in bone ( $258 \%$ of the control value) and blood ( $520 \%$ of the control value). Elevated zinc levels were found in the kidneys and liver of mice fed $76.9 \mathrm{mg}$ zinc/kg/day as zinc sulfate (Schiffer et al. 1991) or $38 \mathrm{mg}$ zinc/kg/day as zinc nitrate (Cooke et al. 1990) for approximately 1 month. The kidneys and pancreas had higher zinc levels than the liver and carcass of rats fed diets containing $1.1 \mathrm{mg} / \mathrm{kg} / \mathrm{day}$ for an unspecified duration (Weigand and Kirchgessner 1992). Newborn, young, and adult mice receiving a single oral dose of $4.6 \mathrm{mg}$ zinc/ $\mathrm{kg}$ as zinc chloride generally had the highest levels of zinc in the liver, kidneys, lungs, bone, muscle, and carcass 1 day after dosing (He et al. 1991). However, the amount of zinc in the lungs, muscle, and femur decreased with age.

\subsubsection{Dermal Exposure}

No studies were located regarding distribution in humans after dermal exposure to zinc.

Animal data on the distribution of zinc following dermal exposure are limited. Elevated serum zinc levels occurred with the application of zinc oxide or zinc sulfate to skin wounds of Sprague-Dawley rats for 4 48 hours (Agren et al. 1991). Serum zinc level peaked at 4 hours in rats treated with zinc sulfate, while levels were slightly elevated for 48 hours in rats administered zinc oxide. The differences may be attributed to the absorbability of the zinc compounds.

\subsubsection{Metabolism}

Plasma provides a metabolically active transport compartment for zinc (Cousins 1985). Zinc is most often complexed to organic ligands (existing in loosely or firmly bound fractions) rather than free in solution as metallic ion (Gordon et al. 1981). Zinc is found in diffusible or nondiffusible forms in the blood (NAS/NRC 1979). In the diffusible form, approximately two-thirds of plasma zinc is freely 
exchangeable and loosely bound to albumin (Cousins 1985); the zinc-albumin complex has an association constant of about $10^{6}$ (NAS/NRC 1979). The diffusible form of zinc also includes zinc bound to amino acids (primarily histidine and cysteine). The zinc-albumin complex is in equilibrium with the zinc-amino acid complex (Henkin 1974). The zinc-amino acid complex can be transported passively across tissue membranes to bind to proteins. An important binding protein in the kidney and liver is metallothionein, although other tissue-binding proteins may be present.

In the nondiffusible form, a small amount of circulating zinc is tightly bound to $\alpha 2$-macroglobulin in the plasma (Cousins 1985). Zinc is incorporated into and dissociated from $\alpha 2$-macroglobulin only in the liver (Henkin 1974). This zinc-protein complex has an association constant of >1,010 (Henkin 1974;

NAS/NRC 1979). The zinc bound to $\alpha 2$-macroglobulin is not freely exchangeable with other zinc ligands (i.e., zinc-albumin and zinc-amino acid complexes) in serum.

\subsubsection{Elimination and Excretion}

\subsubsection{Inhalation Exposure}

Information was limited regarding zinc excretion following inhalation exposure in humans. Workers exposed to zinc oxide fumes had elevated levels of zinc in the urine (Hamdi 1969) indicating that this is a route of excretion.

No studies were located regarding excretion in animals after inhalation exposure to zinc.

\subsubsection{Oral Exposure}

The principal route of excretion of ingested zinc in humans is through the intestine (Davies and Nightingale 1975; Reinhold et al. 1991; Wastney et al. 1986). Zinc loss in the body is by secretion via the gut, and the remainder occurs in the urine (Wastney et al. 1986). Fecal excretion of zinc increases as intake increases (Spencer et al. 1985). Excretion of zinc in the urine also reflects zinc intake (Wastney et al. 1986). Minor routes of elimination are saliva secretion, hair loss, and sweat (Greger and Sickles 1979; Hambidge et al. 1972; Henkin et al. 1975a; Prasad et al. 1963a; Rivlin 1983).

There was a linear increase in fecal excretion of zinc in proportion to dietary intake in rats fed supplementations of $32 \mathrm{mg}$ zinc/kg/day as zinc oxide for 7-42 days (Ansari et al. 1975) or 50- 
$339 \mathrm{mg} / \mathrm{kg} / \mathrm{day}$ for 21 days (Ansari et al. 1976). No differences in fecal excretion, total excretion, or retention of zinc were found among rats given diets containing different forms of zinc (Seal and Heaton 1983). Rats receiving $2.65 \mathrm{mg}$ zinc/kg/day as zinc chloride, zinc sulfate, zinc phosphate, or zinc citrate, over a 4-day period excreted $87-98 \%$ of intake.

A study by Alexander et al. (1981) demonstrated that zinc is excreted in the bile of rats. Analysis of the bile indicated that the zinc is primarily complexed with reduced glutathione. Treatment of these rats with diethylmaleate, which conjugates with reduced glutathione and restricts its availability, depressed the biliary excretion of zinc. This depression confirms a relationship between zinc and glutathione and suggests that zinc is transferred from liver to bile by a glutathione-dependent process.

Other factors may affect zinc excretion. For example, low dietary intake of zinc or malnutrition can increase the urinary excretion of zinc. This release of zinc is a result of tissue breakdown and catabolism during starvation; and elevated urinary excretion of zinc may persist after intake levels return to normal (Spencer et al. 1976). Administration of histidine or high-protein diet may increase urinary zinc excretion; however, a corresponding increase in zinc absorption may maintain zinc balance in the body (Henkin et al. 1975b; Hunt et al. 1991).

\subsubsection{Dermal Exposure}

No studies were located regarding excretion in humans or animals after dermal exposure to zinc.

\subsubsection{Physiologically Based Pharmacokinetic (PBPK)/Pharmacodynamic (PD) Models}

Physiologically based pharmacokinetic (PBPK) models use mathematical descriptions of the uptake and disposition of chemical substances to quantitatively describe the relationships among critical biological processes (Krishnan et al. 1994). PBPK models are also called biologically based tissue dosimetry models. PBPK models are increasingly used in risk assessments, primarily to predict the concentration of potentially toxic moieties of a chemical that will be delivered to any given target tissue following various combinations of route, dose level, and test species (Clewell and Andersen 1985). Physiologically based pharmacodynamic (PBPD) models use mathematical descriptions of the dose-response function to quantitatively describe the relationship between target tissue dose and toxic end points. 
PBPK/PD models refine our understanding of complex quantitative dose behaviors by helping to delineate and characterize the relationships between: (1) the external/exposure concentration and target tissue dose of the toxic moiety, and (2) the target tissue dose and observed responses (Andersen and Krishnan 1994; Andersen et al. 1987). These models are biologically and mechanistically based and can be used to extrapolate the pharmacokinetic behavior of chemical substances from high to low dose, from route to route, between species, and between subpopulations within a species. The biological basis of PBPK models results in more meaningful extrapolations than those generated with the more conventional use of uncertainty factors.

The PBPK model for a chemical substance is developed in four interconnected steps: (1) model representation, (2) model parametrization, (3) model simulation, and (4) model validation (Krishnan and Andersen 1994). In the early 1990s, validated PBPK models were developed for a number of toxicologically important chemical substances, both volatile and nonvolatile (Krishnan and Andersen 1994; Leung 1993). PBPK models for a particular substance require estimates of the chemical substancespecific physicochemical parameters, and species-specific physiological and biological parameters. The numerical estimates of these model parameters are incorporated within a set of differential and algebraic equations that describe the pharmacokinetic processes. Solving these differential and algebraic equations provides the predictions of tissue dose. Computers then provide process simulations based on these solutions.

The structure and mathematical expressions used in PBPK models significantly simplify the true complexities of biological systems. If the uptake and disposition of the chemical substance(s) are adequately described, however, this simplification is desirable because data are often unavailable for many biological processes. A simplified scheme reduces the magnitude of cumulative uncertainty. The adequacy of the model is, therefore, of great importance, and model validation is essential to the use of PBPK models in risk assessment.

PBPK models improve the pharmacokinetic extrapolations used in risk assessments that identify the maximal (i.e., the safe) levels for human exposure to chemical substances (Andersen and Krishnan 1994). PBPK models provide a scientifically sound means to predict the target tissue dose of chemicals in humans who are exposed to environmental levels (for example, levels that might occur at hazardous waste sites) based on the results of studies where doses were higher or were administered in different species. Figure 3-3 shows a conceptualized representation of a PBPK model. 


\section{Figure 3-3. Conceptual Representation of a Physiologically Based Pharmacokinetic (PBPK) Model for a Hypothetical Chemical Substance}

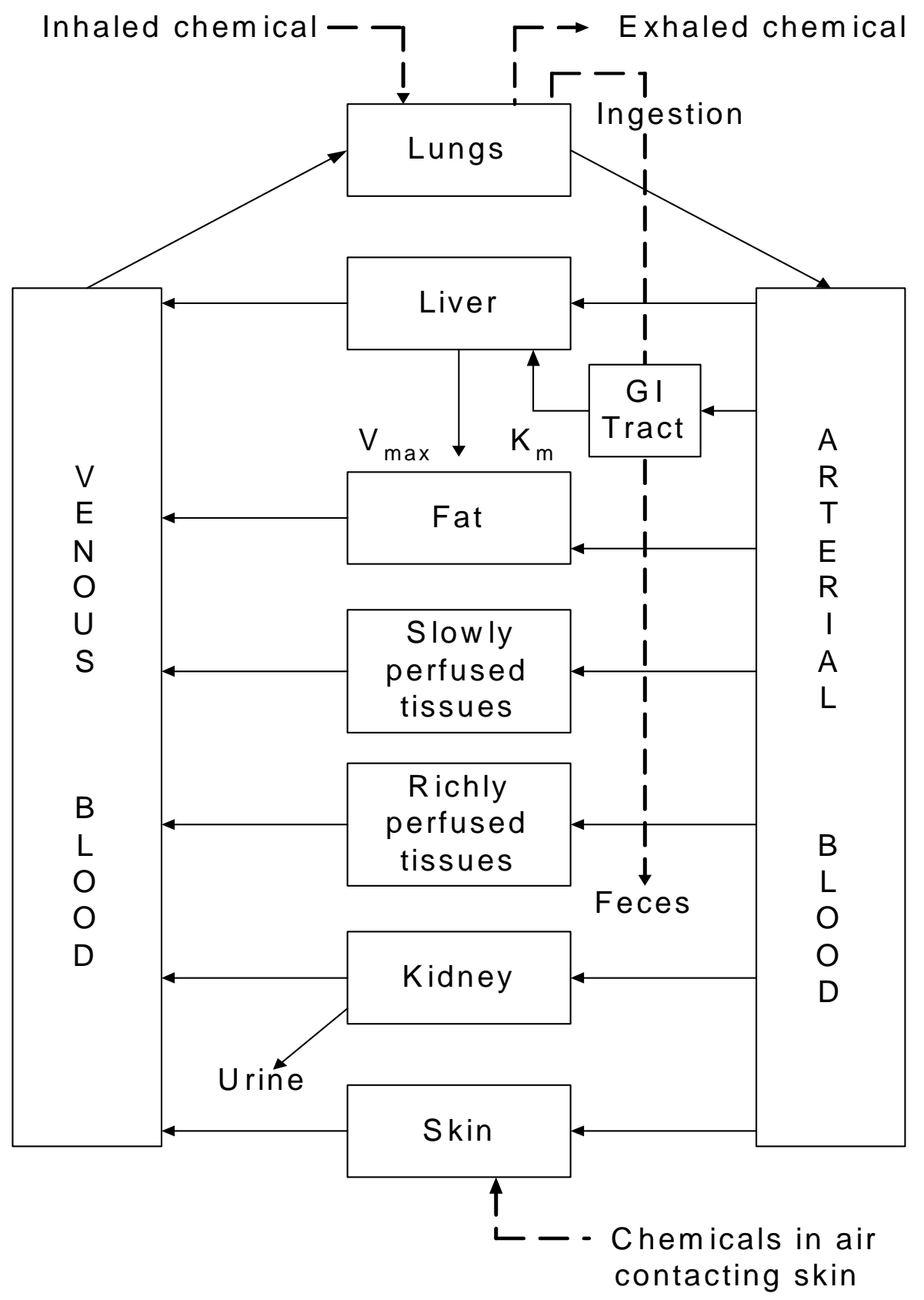

Source: adapted from Krishnan et al. 1994

Note: This is a conceptual representation of a physiologically based pharmacokinetic (PBPK) model for a hypothetical chemical substance. The chemical substance is shown to be absorbed via the skin, by inhalation, or by ingestion, metabolized in the liver, and excreted in the urine or by exhalation. 
If PBPK models for zinc exist, the overall results and individual models are discussed in this section in terms of their use in risk assessment, tissue dosimetry, and dose, route, and species extrapolations.

Validated PBPK models for zinc in animals or humans are not presently available.

\subsection{MECHANISMS OF ACTION}

\subsubsection{Pharmacokinetic Mechanisms}

The absorption of zinc from the intestine is homeostatically controlled. A study by Hempe and Cousins (1992) found that CRIP, a diffusible intracellular zinc carrier, binds zinc in the mucosa during absorption; this process appears to be saturable (Gunshin et al. 1991; Hempe and Cousins 1992; Sturniolo et al. 1991). Zinc transport in the intestinal lumen is also influenced by metallothionein which can inhibit zinc absorption by competing with CRIP for zinc (Hempe and Cousins 1992). CRIP binds about $40 \%$ of radiolabeled zinc entering the intestinal cells from the lumen in ligated loops of the small intestine of anesthetized rats when the zinc concentration is low $(5 \mu \mathrm{M})$, but only $14 \%$ of the radiolabel when the concentration is high $(300 \mu \mathrm{M})($ Hempe and Cousins 1991). These findings suggest that CRIP has a limited binding capacity for zinc and becomes saturated when zinc concentration in the intestine is high (Hempe and Cousins 1992).

High luminal zinc concentrations may damage the brush border membrane, allowing zinc to enter the cell and bind nonspecifically to cell proteins and other ligands (Cousins 1985; Hempe and Cousins 1992). Within the intestinal lumen, a number of factors appear to influence the availability of zinc for absorption. Methionine, histidine, cysteine, reduced glutathione, citrate, and prostaglandin $\mathrm{E}_{2}$ increase the intestinal uptake of zinc (Song et al. 1992), whereas inorganic inhibitors of zinc absorption include cadmium, copper, calcium, and ferrous iron (Hamilton et al. 1978; Harford and Sarkar 1991; Ogiso et al. 1979; Spencer et al. 1992; Yoshida et al. 1993). The mechanism of inhibition has not been clearly elucidated, but it is believed to involve competition for zinc binding sites in the intestinal mucosal cells; an effect on charge distribution on the mucosal membrane has also been suggested (Foulkes 1985). The organic inhibitors, including phytate and some components of dietary fiber, are believed to complex with zinc and decrease its availability. In the mucosal cell, zinc is associated with metalloproteins, including metallothionein. The release of zinc from the intracellular protein ligands and its transfer to the blood may involve diffusion of complexes with glutathione and similar compounds (Foulkes 1993). 
In the plasma, albumin is the primary carrier for zinc, with smaller amounts of zinc bound to a2-macroglobulin and amino acids (Giroux et al. 1976). The albumin-bound zinc represents the metabolically active pool of zinc. Zinc is loosely bound in plasma, and albumin-bound zinc can readily be given up to tissues; however, the mechanisms are not fully elucidated. Zinc is initially concentrated in the liver after ingestion, and is subsequently distributed throughout the body. The liver, pancreas, bone, kidney, and muscle are the major tissue storage sites. When plasma zinc levels are high, liver metallothionein synthesis is stimulated, which facilitates the retention of zinc by hepatocytes (Richards and Cousins 1975). A storage form of zinc has not been identified in soft tissues, with the possible exception of zinc metallothionein. Zinc in bone is relatively unavailable for use by other tissues.

\subsubsection{Mechanisms of Toxicity}

Metal fume fever is the primary effect observed in workers exposed to zinc oxide fumes or dust (Blanc et al. 1991; Brown 1988; Drinker et al. 1927b; Vogelmeier et al. 1987). Metal fume fever usually occurs 310 hours after exposure, and the symptoms persist for $24-48$ hours. The exact pathogenesis of metal fume fever is not known. It is believed to be an immune response to the inhaled zinc oxide (Mueller and Seger 1985). It has been suggested that the zinc oxide causes inflammation of the respiratory tract and the release of histamine or histamine-like substances. In response, an allergen-antibody complex is formed that may elicit an allergic reaction upon subsequent exposure to the allergen. In response to the allergen-antibody complex, an anti-antibody is formed. The anti-antibody dominates with continued exposure to the zinc oxide, thereby producing a tolerance. When the exposure is interrupted and re-exposure occurs, the allergen-antibody complex dominates, producing an allergic reaction and symptoms of metal fume fever (McCord 1960).

Oral exposure to high levels of zinc has caused anemia, decreased levels of HDL cholesterol, and pancreatic damage in humans (Black et al. 1988; Chandra 1984; Chobanian 1981; Hooper et al. 1980; Murphy 1970) and animals (Allen et al. 1983; Aughey et al. 1977; Drinker et al. 1927d; Katya-Katya et al. 1984; Klevay and Hyg 1973; Maita et al. 1981; Straube et al. 1980). The mechanisms involved in the pancreatic damage have not been elucidated. The anemia and possibly the decreased HDL cholesterol levels are thought to be caused by a zinc-induced copper deficiency, although the levels at which this occur have not been well-characterized. Although it is generally accepted that the anemia is the result of copper deficiency, the relationship between zinc and copper levels and HDL cholesterol levels has been extensively debated (Fischer et al. 1980; Katya-Katya et al. 1984; Klevay and Hyg 1973; Murthy and Petering 1976). 


\subsection{TOXICITIES MEDIATED THROUGH THE NEUROENDOCRINE AXIS}

Recently, attention has focused on the potential hazardous effects of certain chemicals on the endocrine system because of the ability of these chemicals to mimic or block endogenous hormones. Chemicals with this type of activity are most commonly referred to as endocrine disruptors. However, appropriate terminology to describe such effects remains controversial. The terminology endocrine disruptors, initially used by Colborn and Clement (1992), was also used in 1996 when Congress mandated the EPA to develop a screening program for “...certain substances [which] may have an effect produced by a naturally occurring estrogen, or other such endocrine effect[s]...”. To meet this mandate, EPA convened a panel called the Endocrine Disruptors Screening and Testing Advisory Committee (EDSTAC), and in 1998, the EDSTAC completed its deliberations and made recommendations to EPA concerning endocrine disruptors. In 1999, the National Academy of Sciences released a report that referred to these same types of chemicals as hormonally active agents. The terminology endocrine modulators has also been used to convey the fact that effects caused by such chemicals may not necessarily be adverse. Many scientists agree that chemicals with the ability to disrupt or modulate the endocrine system are a potential threat to the health of humans, aquatic animals, and wildlife. However, others think that endocrine-active chemicals do not pose a significant health risk, particularly in view of the fact that hormone mimics exist in the natural environment. Examples of natural hormone mimics are the isoflavinoid phytoestrogens (Adlercreutz 1995; Livingston 1978; Mayr et al. 1992). These chemicals are derived from plants and are similar in structure and action to endogenous estrogen. Although the public health significance and descriptive terminology of substances capable of affecting the endocrine system remains controversial, scientists agree that these chemicals may affect the synthesis, secretion, transport, binding, action, or elimination of natural hormones in the body responsible for maintaining homeostasis, reproduction, development, and/or behavior (EPA 1997). Stated differently, such compounds may cause toxicities that are mediated through the neuroendocrine axis. As a result, these chemicals may play a role in altering, for example, metabolic, sexual, immune, and neurobehavioral function. Such chemicals are also thought to be involved in inducing breast, testicular, and prostate cancers, as well as endometriosis (Berger 1994; Giwercman et al. 1993; Hoel et al. 1992).

No in vitro studies were located regarding endocrine disruption of zinc.

Pancreas. Increased levels of serum amylase were observed in a man after accidental ingestion of about 3 ounces of a zinc chloride solution (Chobanian 1981). A 16-year-old boy who ingested an average of 
approximately $86 \mathrm{mg}$ zinc/kg/day as metallic zinc for 2 days $(114 \mathrm{mg} / \mathrm{kg}$ on the 1 st day and $57 \mathrm{mg} / \mathrm{kg}$ on the 2nd day) had increased serum amylase and lipase (Murphy 1970).

In humans receiving a single low dose of zinc sulfate $(0.5 \mathrm{mg}$ zinc $/ \mathrm{kg} /$ day $)$, no changes in blood glucose or insulin levels were observed, and there were no differences in response to a glucose load (BrandaoNeto et al. 1990b).

Pancreatic abnormalities (islet cellular alterations, acinar cell necrosis, metaplasia, fibrosis, pancreatitis) resulting from zinc ingestion have been observed in rats (Maita et al. 1981), mice (Aughey et al. 1977; Maita et al. 1981), cats (Drinker et al. 1927d), ferrets (Straube et al. 1980), sheep (Allen et al. 1983), and birds (Kazacos and Van Vleet 1989; Lu et al. 1990). In dogs (Drinker et al. 1927d) and minks (Aulerich et al. 1991), histological changes in the pancreas have not been observed at doses comparable to or higher than the dose levels that caused abnormalities in rats, mice, cats, ferrets, and sheep. Degeneration of the acinar cells of the pancreas was observed in sheep by Allen et al. (1983) and in rats and mice by Maita et al. (1981). Since the pancreatic acinar cells secrete digestive juices into the small intestine, the increase in serum amylase and lipase observed in the human case reports (Chobanian 1981; Murphy 1970) would correspond to damage in this region of the pancreas.

In 2-month-old $\mathrm{C} 3 \mathrm{H}$ mice exposed to $70 \mathrm{mg}$ zinc/ $\mathrm{kg} /$ day as zinc sulfate, hypertrophy and vacuolation of the $\beta$-cells of the pancreatic islets were observed beginning after 3 months of exposure and become more severe by 12 months (Aughey et al. 1977). The pancreatic islets secrete the hormones glucagon and insulin. No change in plasma levels of insulin and glucose was observed in this study after 6 months of exposure. No effect on islet cells was reported in rats exposed up to $565 \mathrm{mg} / \mathrm{kg} /$ day or mice exposed to $1,110 \mathrm{mg} / \mathrm{kg} /$ day as zinc sulfate in a 13-week study by Maita et al. (1981), and Allen et al. (1983) reported that islet cells in sheep were generally unaffected, although occasional vacuolization occurred. Degeneration of acinar cells, but no effects on the islet cells, were found in ducklings (Kazacos and Van Vleet 1989); however, the relevance of this to humans is unclear. The data are too limited and contradictory to determine whether pancreatic islet cells are a primary target cell of zinc toxicity.

Adrenal Gland. Decreased levels of serum cortisol (a hormone secreted by the adrenal cortex) were observed in humans after a single dose of $0.5 \mathrm{mg}$ zinc/kg/day as zinc sulfate (Brandao-Neto et al. 1990b). No effects on the adrenal gland itself have been reported in humans. 
In mice receiving $70 \mathrm{mg}$ zinc/ $\mathrm{kg} /$ day as zinc sulfate in the drinking water, hypertrophy and increased lipid content of the zona fasciculata cells of the adrenal cortex were observed as early as 3 months after the start of zinc supplementation (Aughey et al. 1977).

Pituitary. No effects on pituitary function have been reported in humans following oral exposure to zinc. However, mice receiving $70 \mathrm{mg}$ zinc/kg/day as zinc sulfate in the drinking water for 5-14 months had hypertrophy and increased granularity suggesting increased activity of the pituitary (Aughey et al. 1977). It is unclear whether the increased activity was a direct effect of the zinc or a reaction to decreased secretion from the adrenal cortex.

\subsection{CHILDREN'S SUSCEPTIBILITY}

This section discusses potential health effects from exposures during the period from conception to maturity at 18 years of age in humans, when all biological systems will have fully developed. Potential effects on offspring resulting from exposures of parental germ cells are considered, as well as any indirect effects on the fetus and neonate resulting from maternal exposure during gestation and lactation. Relevant animal and in vitro models are also discussed.

Children are not small adults. They differ from adults in their exposures and may differ in their susceptibility to hazardous chemicals. Children's unique physiology and behavior can influence the extent of their exposure. Exposures of children are discussed in Section 6.6, Exposures of Children.

Children sometimes differ from adults in their susceptibility to hazardous chemicals, but whether there is a difference depends on the chemical (Guzelian et al. 1992; NRC 1993). Children may be more or less susceptible than adults to health effects, and the relationship may change with developmental age (Guzelian et al. 1992; NRC 1993). Vulnerability often depends on developmental stage. There are critical periods of structural and functional development during both prenatal and postnatal life and a particular structure or function will be most sensitive to disruption during its critical period(s). Damage may not be evident until a later stage of development. There are often differences in pharmacokinetics and metabolism between children and adults. For example, absorption may be different in neonates because of the immaturity of their gastrointestinal tract and their larger skin surface area in proportion to body weight (Morselli et al. 1980; NRC 1993); the gastrointestinal absorption of lead is greatest in infants and young children (Ziegler et al. 1978). Distribution of xenobiotics may be different; for example, infants have a larger proportion of their bodies as extracellular water and their brains and livers are 
proportionately larger (Altman and Dittmer 1974; Fomon 1966; Fomon et al. 1982; Owen and Brozek 1966; Widdowson and Dickerson 1964). The infant also has an immature blood-brain barrier (Adinolfi 1985; Johanson 1980) and probably an immature blood-testis barrier (Setchell and Waites 1975). Many xenobiotic metabolizing enzymes have distinctive developmental patterns. At various stages of growth and development, levels of particular enzymes may be higher or lower than those of adults, and sometimes unique enzymes may exist at particular developmental stages (Komori et al. 1990; Leeder and Kearns 1997; NRC 1993; Vieira et al. 1996). Whether differences in xenobiotic metabolism make the child more or less susceptible also depends on whether the relevant enzymes are involved in activation of the parent compound to its toxic form or in detoxification. There may also be differences in excretion, particularly in newborns who all have a low glomerular filtration rate and have not developed efficient tubular secretion and resorption capacities (Altman and Dittmer 1974; NRC 1993; West et al. 1948). Children and adults may differ in their capacity to repair damage from chemical insults. Children also have a longer remaining lifetime in which to express damage from chemicals; this potential is particularly relevant to cancer.

Certain characteristics of the developing human may increase exposure or susceptibility, whereas others may decrease susceptibility to the same chemical. For example, although infants breathe more air per kilogram of body weight than adults breathe, this difference might be somewhat counterbalanced by their alveoli being less developed, which results in a disproportionately smaller surface area for alveolar absorption (NRC 1993).

While a detailed discussion of zinc deficiency is beyond the scope of this document, there is considerably more information on the effects of zinc deficiency on the developing fetus in pregnant women than exists for the effects of excess zinc during pregnancy. Maternal zinc deficiency can result in intrauterine growth retardation, teratogenesis, or embryonic or fetal death (for review, see King 2000). Zinc supplementation during pregnancy is usually sufficient to prevent these outcomes. Similarly, zinc deficiency during early life can result in adverse effects, including skin rash, diarrhea, anorexia, and growth failure, with more severe instances resulting in detrimental effects on the immune and nervous systems (Krebs 1999). Infants, more than adults, appear to be particularly sensitive to zinc deficiency, possibly the result of their higher zinc requirements on a per body weight basis.

A case study presented by Murray (1926) reported on an infant death due to bronchopneumonia resulting from inhalation, and possibly ingestion, of an unspecified amount of zinc stearate powder spilled from a container. However, it is unclear whether the death was due to the zinc content or whether aspiration 
bronchopneumonia would result from inhalation of similar powders that do not contain zinc. Other data on the effects of zinc inhalation in young children are not available.

The human data on the effects of excess zinc in children consist mainly of reports of acute ingestion. The primary symptoms in these subjects mimic those of adult exposure, consisting mainly of gastrointestinal disturbances (nausea, vomiting, epigastric discomfort), with occasional neurologic symptoms (Anonymous 1983; Lewis and Kokan 1998; Moore 1978; Murphy 1970). Data are not presently sufficient to determine whether children are more sensitive to these effects than adults.

The most sensitive animal model to zinc toxicity in young animals appears to be the mink. Young minks appear to be more sensitive to both the hematologic (decreased hematocrit and lymphocyte number) and dermal effects (graying of the fur and dermatosis) of oral zinc than adults (Bleavins et al. 1983). Other studies have examined the effects of zinc exposure in young animals (Drinker et al. 1927d; L'Abbe and Fischer 1984a; Maita et al. 1981), but have not provided data on adult animals similarly exposed for comparison. Additional data will be required to adequately assess the susceptibility of children to zinc exposure, relative to adults.

\subsection{BIOMARKERS OF EXPOSURE AND EFFECT}

Biomarkers are broadly defined as indicators signaling events in biologic systems or samples. They have been classified as markers of exposure, markers of effect, and markers of susceptibility (NAS/NRC 1989a).

Due to a nascent understanding of the use and interpretation of biomarkers, implementation of biomarkers as tools of exposure in the general population is very limited. A biomarker of exposure is a xenobiotic substance or its metabolite(s) or the product of an interaction between a xenobiotic agent and some target molecule(s) or cell(s) that is measured within a compartment of an organism (NAS/NRC 1989). The preferred biomarkers of exposure are generally the substance itself or substance-specific metabolites in readily obtainable body fluid(s) or excreta. However, several factors can confound the use and interpretation of biomarkers of exposure. The body burden of a substance may be the result of exposures from more than one source. The substance being measured may be a metabolite of another xenobiotic substance (e.g., high urinary levels of phenol can result from exposure to several different aromatic compounds). Depending on the properties of the substance (e.g., biologic half-life) and environmental conditions (e.g., duration and route of exposure), the substance and all of its metabolites may have left the 
body by the time samples can be taken. It may be difficult to identify individuals exposed to hazardous substances that are commonly found in body tissues and fluids (e.g., essential mineral nutrients such as copper, zinc, and selenium). Biomarkers of exposure to zinc are discussed in Section 3.8.1.

Biomarkers of effect are defined as any measurable biochemical, physiologic, or other alteration within an organism that, depending on magnitude, can be recognized as an established or potential health impairment or disease (NAS/NRC 1989). This definition encompasses biochemical or cellular signals of tissue dysfunction (e.g., increased liver enzyme activity or pathologic changes in female genital epithelial cells), as well as physiologic signs of dysfunction such as increased blood pressure or decreased lung capacity. Note that these markers are not often substance specific. They also may not be directly adverse, but can indicate potential health impairment (e.g., DNA adducts). Biomarkers of effects caused by zinc are discussed in Section 3.8.2.

A biomarker of susceptibility is an indicator of an inherent or acquired limitation of an organism's ability to respond to the challenge of exposure to a specific xenobiotic substance. It can be an intrinsic genetic or other characteristic or a preexisting disease that results in an increase in absorbed dose, a decrease in the biologically effective dose, or a target tissue response. If biomarkers of susceptibility exist, they are discussed in Section 3.10 "Populations that are Unusually Susceptible."

\subsubsection{Biomarkers Used to Identify or Quantify Exposure to Zinc}

There is no simple measure of zinc body burden. Under normal physiological conditions, the plasma/serum zinc level is $\approx 1 \mu \mathrm{g} / \mathrm{mL}$ (NAS/NRC 1979) and the urinary level is $0.5 \mathrm{mg} / \mathrm{g}$ creatinine (Elinder 1986). Several studies have reported increased levels of zinc in the serum and urine of humans and animals after inhalation, oral, or dermal exposure to zinc (Agren et al. 1991; Bentley and Grubb 1991; Brandao-Neto et al. 1990a; Hallmans 1977; Hamdi 1969; Keen and Hurley 1977; Neve et al. 1991; Statter et al. 1988; Sturniolo et al. 1991). However, relationships between serum and/or urine levels and zinc exposure levels have not been established.

Hair and nail samples provide a lasting record of long-term metal intake possibly over weeks or months (Hayashi et al. 1993; Wilhelm et al. 1991). Mean zinc concentrations of 129-179 $\mu \mathrm{g} / \mathrm{g}$ have been estimated for nails (Hayashi et al. 1993; Wilhelm et al. 1991) and 102-258 $\mu \mathrm{g} / \mathrm{g}$ for hair (Folin et al. 1991; McBean et al. 1971; Provost et al. 1993; Wilhelm et al. 1991). Most investigators have found a poor correlation between hair and plasma zinc levels since the zinc in hair does not exchange with the 
body zinc pool (McBean et al. 1971; Rivlin 1983). Furthermore, measurements of zinc in hair can be affected by extraneous contamination of hair, contamination by sweat, location of hair sample (distance from scalp), hair coloring, and rate of hair growth (McBean et al. 1971; Rivlin 1983). Although the nail is considered more resistant to washing procedures than hair, external contamination and uncertainties regarding the length and period of exposure reflected by the observed zinc concentration limit this measurement as a biomarker of exposure for zinc (Wilhelm et al. 1991).

\subsubsection{Biomarkers Used to Characterize Effects Caused by Zinc}

The respiratory tract is the most sensitive target organ for zinc following inhalation exposure. Inhalation of zinc oxide results in a syndrome referred to as metal fume fever. Symptoms include fevers, chills, cough, listlessness, and metallic taste. Although oxides of several heavy metals (antimony, aluminum, arsenic, cadmium, cobalt, copper, iron, lead, magnesium, manganese, mercury, nickel, selenium, silver, and tin) and pyrolysis products of fluorocarbon polymers (polytetrafluoroethylene [Teflon] and fluorinated polyethylene propylene) also produce metal fume fever (Ellenhorn and Barceloux 1988), this group of symptoms may be used as a nonspecific biomarker to identify inhalation exposure to zinc oxide.

The target organs associated with oral zinc exposure include the gastrointestinal tract, blood, immune system, and pancreas. The toxic effects observed after oral exposure to zinc include nausea, vomiting, diarrhea, decreased hemoglobin and hematocrit levels, immune suppression, increased serum amylase and lipase, and decreased HDL cholesterol levels (a more detailed discussion of effects associated with exposure to zinc is presented in Section 3.2). However, nausea, vomiting, and diarrhea may be observed following exposure to any gastrointestinal irritant. Increases in serum amylase and lipase are also markers for pancreatic damage; therefore, any condition resulting in pancreatitis (i.e., biliary tract disease [gallstones], alcoholism, trauma, inflammation, blood-borne bacterial infections, viral infections, ischemia, and drugs such as azathioprine, thiazides, sulfonamides, and oral contraceptives) would result in similar increases in these enzymes (Cotran et al. 1989). A hypochromic microcytic anemia that is not responsive to iron supplements may indicate exposure to zinc; however, such anemia may also reflect copper, pyridoxine, or cobalt deficiency, lead intoxication, poor diet, or chronic blood loss (Suber 1989).

Thus, none of the above-mentioned effects observed after exposure to zinc is specific to zinc exposure. However, the combination of these toxic effects may be indicative of zinc overexposure. Additional information on the health effects of zinc may be found in Section 3.2.2. Additional information on 
biomarkers for renal, hepatobiliary, immune, and nervous system effects may be found in the CDC/ATSDR (1990) and OTA (1990) reports listed in Chapter 9.

Increased erythrocyte metallothionein may be an index of zinc exposure in humans (Grider et al. 1990). Daily supplementation of $50 \mathrm{mg}$ zinc/day to subjects for at least 7 days caused a 7-fold increase in metallothionein concentration in erythrocytes. At least 3-4 days are required before an increase in metallothionein is observed. This biomarker of exposure is only useful for recent zinc exposure because the metallothionein levels decreased approximately a week after discontinuation of a 63-week supplementation of zinc (Grider et al. 1990). Fourteen days after discontinuation of zinc supplements, metallothionein levels were reduced by $61 \%$.

\subsection{INTERACTIONS WITH OTHER CHEMICALS}

Zinc is an essential element obtained from the diet. Many different metals and nutrients interact with the absorption, distribution, and excretion of zinc. However, information was not found concerning interactions that increase the toxicity of zinc or other substances in the presence of zinc (i.e., that cause the same amount of zinc to result in a greater toxic response). Zinc administration may increase the toxicity of lead; however, the data are conflicting (Cerklewski and Forbes 1976; Hsu et al. 1975). The toxicity of zinc is believed to be due to its interaction with copper, as explained below.

Metallothionein, a sulfhydryl-rich protein inducible by certain divalent cations and a variety of other agonists, is involved in the interaction between zinc and other metals such as copper (Wapnir and Balkman 1991). Inhibition of intestinal copper absorption by zinc may demonstrate competition between the two metals at the brush border of the lumen (Wapnir and Balkman 1991). Dietary intake of copper $(1,6$, and $36 \mathrm{mg} / \mathrm{kg})$ or zinc $(5,30$, and $180 \mathrm{mg} / \mathrm{kg})$ do not significantly alter the absorption of the other (Oestreicher and Cousins 1985), but when zinc levels are much higher than copper levels, copper absorption is depressed (Fischer et al. 1981). This fact has been used therapeutically in the treatment of Wilson's Disease, in which zinc supplementation is used to prevent the over-absorption of copper caused by the disease (for a brief review, see Brewer 2000). High levels of dietary zinc are known to induce de novo synthesis of metallothionein in the intestinal mucosal cell. Both copper and zinc appear to bind to the same metallothionein protein; however, copper has a higher affinity for metallothionein than zinc and displaces the zinc that is attached to the metallothionein (Ogiso et al. 1979). Copper complexed with metallothionein is retained in the mucosal cell, relatively unavailable for transfer to plasma, and is excreted in the feces when the mucosal cells are sloughed off (Fischer et al. 1981; L'Abbe and Fischer 
1984b). A number of factors influence the effect of dietary zinc on copper metabolism, including the amount of copper and zinc in the diet, the zinc-to-copper ratio, age of the individual, and the duration of exposure to high zinc levels (Johnson and Flagg 1986).

In a study of zinc-supplemented women, Yadrick et al. (1989) reported decreased levels of serum ferritin, a sensitive indicator of iron status. Supplementation of the subjects with iron resulted in a reversal of the diminished iron status, although whether this was due to an interaction with zinc or simply due to additional iron being provided is not clear. Other studies of zinc-exposed subjects have not reported significant changes in copper status (Black et al. 1988; Fischer et al. 1984; Milne et al. 2001); however, these studies have either evaluated male subjects, who are not as sensitive to changes in iron status, or have not evaluated serum ferritin.

Physiological interactions of zinc and cadmium have been discussed in a number of reviews (EPA 1980c; NAS 1980; Underwood 1977). Exposure to cadmium may cause changes in the distribution of zinc, with accumulation of zinc in the liver and kidney. This accumulation in the liver and kidney may result in a deficiency in other organs, particularly if the dietary intake of zinc is marginal. In vitro data demonstrate that zinc and cadmium enter renal proximal cells by a saturable, carrier-mediated process and a nonsaturable pathway (Gachot and Poujeol 1992). At low cadmium doses, cadmium and zinc compete for a common transport carrier system in renal proximal cells. It is hypothesized that, at high doses, the subcellular microtubule system is disrupted by cadmium, which may interfere with changes in carrier configuration that are necessary for transport of the metals (modification of the cytoskeleton), and thereby lead to noncompetitive inhibition between cadmium and zinc (Gachot and Poujeol 1992). Combined treatment with cadmium and zinc in primary cultures of kidney cells resulted in enhanced toxicity of cadmium (Yoshida et al. 1993); however, pretreatment with a nontoxic concentration of zinc caused increased induction of metallothionein synthesis and partial protection against cadmium (Yoshida et al. 1993).

Cadmium is 10 times more efficient than zinc in metallothionein induction in vitro (Harford and Sarkar 1991). Induction by either cadmium or zinc alone is saturable; however, simultaneous administration of cadmium and zinc results in induction of metallothionein in an additive manner. The additive effect on metallothionein induction may involve binding of the metals either to two or more metallothionein promoter binding proteins or separate sites on the same promoter binding protein (Harford and Sarkar 1991). 
Zinc acetate pretreatment in the mouse TRL-1215 cell line reduced single-strand DNA damage associated with cadmium exposure (Coogan et al. 1992). Diminished cadmium-induced DNA damage was not due to decreased cadmium burden in the zinc-pretreated cells. Instead, cadmium levels were actually greater than those in nonpretreated cells (Coogan et al. 1992). Metallothionein levels were elevated in these cells, suggesting that zinc pretreatment affects cadmium genotoxicity by inducing metallothionein which may sequester cadmium from genetic material. In contrast, simultaneous exposure to cadmium and zinc decreased cadmium accumulation in the cells, perhaps because of direct competition for a common transport mechanism (Coogan et al. 1992).

Zinc acetate reduced or prevented cadmium carcinogenesis in the prostate, in the testes, or at the injection site in rats (Gunn et al. 1963a, 1964; Waalkes et al. 1989). The effect of zinc on the cadmium-induced carcinogenesis appeared to be dependent on dose, route, and target site. Sustained levels of zinc inhibited cadmium-induced injection sarcomas but had no effect on the incidence of testicular Leydig cell tumors (Waalkes et al. 1989).

Excessive dietary zinc has been shown to induce a reversible copper deficiency and anemia in experimental animals (Magee and Matrone 1960; Murthy and Petering 1976; O'Dell 1969; Underwood 1977; Wapnir and Balkman 1991). Similar effects have been seen in humans receiving long-term treatment with zinc (Porter et al. 1977; Prasad et al. 1978). However, no significant decreases in plasma copper levels were observed in humans receiving zinc for 6 weeks or 6 months (Henkin et al. 1976; Samman and Roberts 1987) or in mice administered zinc for 1-12 weeks (Sutomo et al. 1992). A reduction in erythrocyte superoxide dismutase (an index of metabolically available copper), without a decrease in plasma copper levels, was exhibited following exposure to high amounts of ingested zinc (Fischer et al. 1984). These findings suggest that superoxide dismutase may be a sensitive indicator of zinc-copper interaction. However, as not all studies of zinc supplementation have noted changes in superoxide dismutase levels, the association is still not completely clear.

Cobalt has been demonstrated to induce seminiferous tubule damage and degeneration (vacuole formation, sloughing of cells, giant cell formation) in the testes of mice following exposure for 13 weeks (Anderson et al. 1993). Coadministration of cobalt and zinc chloride in the drinking water resulted in complete or partial protection in $90 \%$ of the animals. The sites of competitive interaction between zinc and cobalt were not established in the study; however, the authors postulated that the mechanism(s) may be similar to those involved in prevention of cadmium toxicity by zinc. 
The effect of tin on heme biosynthesis appears to be dependent on the concentration of zinc (Chmielnicka et al. 1992). Oral administration of tin can affect the heme synthesis by inhibiting $\delta$-aminolevulinic acid dehydratase (ALAD) activity in blood. Zinc is required for ALAD activity and provides a protective role in heme synthesis by increasing the activity of ALAD. It is postulated that when the tin and zinc are coadministered, these metals are probably attaching to similar binding sites in the ALAD enzyme (Chmielnicka et al. 1992).

Calcium decreases the bioavailability of zinc; the converse is also true (Heth and Hoekstra 1965; Spencer et al. 1992). Oral zinc administration is associated with decreased calcium levels in the serum and in the bone of rats (Yamaguchi et al. 1983). Zinc inhibited calcium uptake in rat brush border membrane vesicles, possibly by competing directly at high-affinity calcium binding sites (Roth-Bassell and Clydesdale 1991). The interaction of calcium and zinc is apparently dose related; intestinal absorption of calcium at a low calcium intake ( $230 \mathrm{mg} /$ day) was inhibited at a high zinc intake of $140 \mathrm{mg} /$ day but not at a lower zinc intake of $100 \mathrm{mg} /$ day (Spencer et al. 1992).

Pretreatment with zinc has been shown to reduce hepatotoxicity induced by xenobiotics such as acetaminophen, bromobenzene, carbon tetrachloride, D-galactosamine, gentamicin, and salicylate (Cagen and Klaassen 1979; Gunther et al. 1991; Hu et al. 1992; Szymanska et al. 1991; Yang et al. 1991). The protective effect of zinc against carbon tetrachloride toxicity is dose dependent at high dose levels of zinc, probably because of sequestering of toxic metabolites of carbon tetrachloride by metallothionein (Cagen and Klaassen 1979). Similarly, the protective action of zinc against bromobenzene and acetaminophen appears to be associated with elevated metallothionein levels (Szymanska et al. 1991). Inhibition of lipid peroxidation may be the basis for the protective effect of zinc against hepatic damage induced by D-galactosamine in rats (Hu et al. 1992). Zinc may be elevating NADPH (nicotinamide adenine dinucleotide phosphate) content in the cell, resulting in regeneration of glutathione, which increases the antioxidative ability of hepatic cells. Salicylate-induced hepatic alterations (increased lipid droplets and iron, reduced glycogen) (Gunther et al. 1991) and gentamicin-induced proximal tubular necrosis (Yang et al. 1991) were diminished in rats pretreated with injections of zinc chloride and zinc sulfate, respectively. This finding corresponded to a dramatic increase in metallothionein content with combined treatment of salicylate and zinc compared to a less significant increase with salicylate alone.

Animal studies suggest that the administration of zinc may also inhibit tumor growth. Forty weeks after exposure, the incidence of injection site sarcomas was 40-60\% in rats receiving simultaneous intramuscular administration of nickel subsulfide and zinc oxide compared to an incidence of $100 \%$ 
following administration of nickel subsulfide alone (Kasprzak et al. 1988). Supplementing drinking water with zinc sulfate reduced the incidence of 9,10-dimethyl-1,2-benzanthracene-induced tumors in the cheek pouches of mice (Poswillo and Cohen 1971). Zinc decreased DNA synthesis in hepatomas induced by 3'-methyl-4-dimethylaminoazobenzene (Duncan and Dreosti 1975). The investigators speculated that the changes were due to inhibited cell division cycle at the level of DNA replication.

\subsection{POPULATIONS THAT ARE UNUSUALLY SUSCEPTIBLE}

A susceptible population will exhibit a different or enhanced response to zinc than will most persons exposed to the same level of zinc in the environment. Reasons may include genetic makeup, age, health and nutritional status, and exposure to other toxic substances (e.g., cigarette smoke). These parameters result in reduced detoxification or excretion of zinc, or compromised function of organs affected by zinc. Populations who are at greater risk due to their unusually high exposure to zinc are discussed in Section 6.7, Populations with Potentially High Exposures.

No specific data regarding human subpopulations that are unusually susceptible to the toxic effects of zinc were located. Healthy elderly people have been shown to have greater daily zinc intake than housebound elderly people (Bunker et al. 1987; Prasad 1988). Data from animal studies indicate that certain human subpopulations may be more susceptible to excess zinc because of zinc's depleting effect on copper (Underwood 1977). People who are malnourished or have a marginal copper status may be more susceptible to the effects of excessive zinc than people who are adequately nourished (Underwood 1977).

Hepatic zinc levels are elevated in patients with hemochromatosis, a genetic disease associated with increased iron absorption from the intestine (Adams et al. 1991). The chronic iron loading that occurs could result in hepatic metallothionein induction leading to the accumulation of zinc because metallothionein has a greater affinity for zinc than iron. These individuals may, therefore, have a greater likelihood of developing toxicity with zinc exposure levels that do not normally result in any symptoms in the general population. However, available studies, including this one, have not correlated increased hepatic zinc with any adverse effects. 


\subsection{METHODS FOR REDUCING TOXIC EFFECTS}

This section will describe clinical practice and research concerning methods for reducing toxic effects of exposure to zinc. However, because some of the treatments discussed may be experimental and unproven, this section should not be used as a guide for treatment of exposures to zinc. When specific exposures have occurred, poison control centers and medical toxicologists should be consulted for medical advice. The following text provides specific information about treatment following exposures to zinc:

Ellenhorn MJ, Barceloux DG. 1988. Medical toxicology: Diagnosis and treatment of human poisoning. New York, NY: Elsevier, 879-880, 1064-1065.

\subsubsection{Reducing Peak Absorption Following Exposure}

General recommendations for the management and treatment of patients following acute exposure to zinc include removal of the victim from the contaminated area and removal and isolation of contaminated clothing, jewelry, and shoes (Bronstein and Currance 1988; Stutz and Janusz 1988). Excess contaminant is gently brushed away and excess liquids blotted with absorbent material. Measures that are appropriate to the route of exposure are taken to remove zinc from the body. Exposed eyes are flushed immediately with water, followed as soon as possible with irrigation of each eye with normal saline. Exposed skin is washed immediately with soapy water. Administration of ipecac to induce emesis, gastric lavage, ingestion of activated charcoal, and cathartics have been recommended to decrease the gastrointestinal absorption of zinc (Burkhart et al. 1990; Ellenhorn and Barceloux 1988). Because zinc causes nausea and vomiting following exposure by the oral route, use of emetic agents may be unnecessary. Ipecac administration may be contraindicated following ingestion of caustic zinc compounds such as zinc chloride. The large amounts of phosphorus and calcium in milk and cheese, and phytate in brown bread, may reduce absorption of zinc from the gastrointestinal tract (Pecoud et al. 1975). Therefore, if vomiting and diarrhea are not prohibitive, ingestion of dairy products or brown bread may also reduce gastrointestinal absorption of zinc. In a study of intestinal absorption of zinc in iron-deficient mice, the uptake of zinc from the gut was inhibited by adding iron to the duodenal loop system. The proposed mechanism was that iron and zinc shared a common gut mucosal binding site (Hamilton et al. 1978). However, it is unknown whether ingestion of iron supplements would be effective in reducing absorption of zinc overdoses. 


\subsubsection{Reducing Body Burden}

Zinc is an essential trace element that is normally found in tissues and fluids throughout the body and is under homeostatic control (NAS/NRC 1989b). Increased levels have been observed in the heart, spleen, kidneys, liver, bone, and blood of animals following subchronic oral exposure to zinc (Llobet et al. 1988a) indicating that some zinc accumulation occurs during excess intakes. The greatest increases were observed in bone and blood.

Administration of the chelating agent, calcium disodium ethylene diaminetetraacetate ( $\left.\mathrm{CaNa}_{2} \mathrm{EDTA}\right)$, is the treatment of choice for reducing the body burden of zinc in humans following exposure to high levels (Ellenhorn and Barceloux 1988). Ethylenediaminetetraacetic acid (EDTA), diethylenetriaminepentaacetic acid (DTPA), and dimercaprol (BAL) are the most common antidotes used in the treatment of human zinc intoxications (Llobet et al. 1989; Murphy 1970; Spencer and Rosoff 1966). Markedly elevated serum zinc levels in a young child who ingested a zinc chloride solution were normalized by intravenously administering a single small dose of $\mathrm{CaNa}_{2}$ EDTA $(11.5 \mathrm{mg} / \mathrm{kg}$ ) (Potter 1981). Use of chelation therapy (administration of BAL) was reported in a case study of a 16-year-old boy who ingested $12 \mathrm{~g}$ of metallic zinc (Murphy 1970). The boy exhibited lethargy and elevated blood zinc levels that were both reversed following intramuscular administration of BAL. Chelation therapy has been demonstrated to increase the urinary excretion of zinc 22-fold (Spencer and Rosoff 1966). Intravenous and nebulized $N$-acetylcysteine (another metal chelating agent) have also been observed to increase urinary zinc excretion and decrease plasma levels following inhalation of zinc chloride smoke (Hjortso et al. 1988).

The efficacy of 16 different chelating agents as possible antidotes for acute oral zinc exposure has been determined in mice (Llobet et al. 1988b). The most efficient chelators were DTPA, cyclohexanediaminetetraacetic acid (CDTA), and EDTA. Increased urinary levels of zinc and decreased bone and liver zinc levels were observed following administration of the chelators. The maximum efficiency of the chelators was observed when they were administered from 10 minutes to 12 hours after zinc exposure (Domingo et al. 1988a, 1988b).

\subsubsection{Interfering with the Mechanism of Action for Toxic Effects}

Anemia has been observed in humans and animals after oral exposure to zinc. It has been postulated that excess zinc intake may result in copper deficiency (mechanisms of action are discussed in Section 3.5). The anemia observed following zinc intake is believed to be caused by the copper deficiency. 
Administration of copper in patients with zinc-related anemia has been shown to be effective in increasing the hemoglobin levels (Porter et al. 1977; Smith and Larson 1946).

The exact mechanism of metal fume fever (a syndrome consisting of a leukocytosis with chills, fever, cough, myalgias, headache, weakness, and dyspnea) is unknown (Ellenhorn and Barceloux 1988), but respiratory tract inflammation and the development of an immune complex reaction have been proposed (McCord 1960). Treatment is supportive (e.g., bed rest, analgesics, and antipyretics) (Mueller and Seger 1985).

In severe cases, inhalation of zinc chloride has resulted in advanced pulmonary fibrosis and fatal respiratory distress syndrome (Evans 1945; Hjortso et al. 1988; Milliken et al. 1963). L-3,4-Dehydroproline was given to two soldiers after inhaling a high concentration of zinc chloride smoke (also contained other chemicals) in an attempt to inhibit collagen deposition in the lungs (Hjortso et al. 1988). This therapy did not prevent respiratory failure.

\subsection{ADEQUACY OF THE DATABASE}

Section 104(i)(5) of CERCLA, as amended, directs the Administrator of ATSDR (in consultation with the Administrator of EPA and agencies and programs of the Public Health Service) to assess whether adequate information on the health effects of zinc is available. Where adequate information is not available, ATSDR, in conjunction with the National Toxicology Program (NTP), is required to assure the initiation of a program of research designed to determine the health effects (and techniques for developing methods to determine such health effects) of zinc.

The following categories of possible data needs have been identified by a joint team of scientists from ATSDR, NTP, and EPA. They are defined as substance-specific informational needs that if met would reduce the uncertainties of human health assessment. This definition should not be interpreted to mean that all data needs discussed in this section must be filled. In the future, the identified data needs will be evaluated and prioritized, and a substance-specific research agenda will be proposed. 


\subsubsection{Existing Information on Health Effects of Zinc}

The existing data on health effects of inhalation, oral, and dermal exposure of humans and animals to zinc are summarized in Figure 3-4. The purpose of this figure is to illustrate the existing information concerning the health effects of zinc. Each dot in the figure indicates that one or more studies provide information associated with that particular effect. The dot does not necessarily imply anything about the quality of the study or studies, nor should missing information in this figure be interpreted as a "data need”. A data need, as defined in ATSDR's Decision Guide for Identifying Substance-Specific Data Needs Related to Toxicological Profiles (Agency for Toxic Substances and Disease Registry 1989), is substance-specific information necessary to conduct comprehensive public health assessments.

Generally, ATSDR defines a data gap more broadly as any substance-specific information missing from the scientific literature.

Figure 3-4 indicates whether a particular health effect end point has been studied for a specific route and duration of exposure. There is little information concerning death in humans after inhalation, oral, or dermal exposure to zinc. However, several case studies report death after exposure to extremely high levels of zinc chloride and other components of zinc chloride smoke (Evans 1945; Hjortso et al. 1988; Milliken et al. 1963).

Systemic effects of acute inhalation exposure to generally unspecified levels of various zinc compounds in humans have been reported in several clinical case studies (Blanc et al. 1991; Brown 1988; Hjortso et al. 1988; Matarese and Matthews 1966; Vogelmeier et al. 1987). Case studies and experimental studies of systemic effects in humans following acute, intermediate, and chronic oral exposures are available (Anonymous 1983; Black et al. 1988; Brandao-Neto et al. 1990a; Chandra 1984; Chobanian 1981; Hale et al. 1988; Hallbook and Lanner 1972; Hoffman et al. 1988; Hooper et al. 1980; Malo et al. 1990; Moore 1978; Patterson et al. 1985; Porter et al. 1977; Potter 1981; Prasad et al. 1978). Experimental studies in humans following acute, intermediate, and chronic dermal exposures were located for hematological, dermal, and ocular effects (Agren 1990; Evans 1945; Fischer et al. 1984; Turner 1921; Yadrick et al. 1989).

Information concerning respiratory effects of acute inhalation exposure to zinc in animals is available (Amdur et al. 1982; Drinker and Drinker 1928; Lam et al. 1982, 1988). One study (Marrs et al. 1988) was located regarding other systemic effects in animals following inhalation exposure to zinc for an intermediate-exposure duration. Information regarding systemic effects of zinc following oral exposure 
Figure 3-4. Existing Information on Health Effects of Zinc
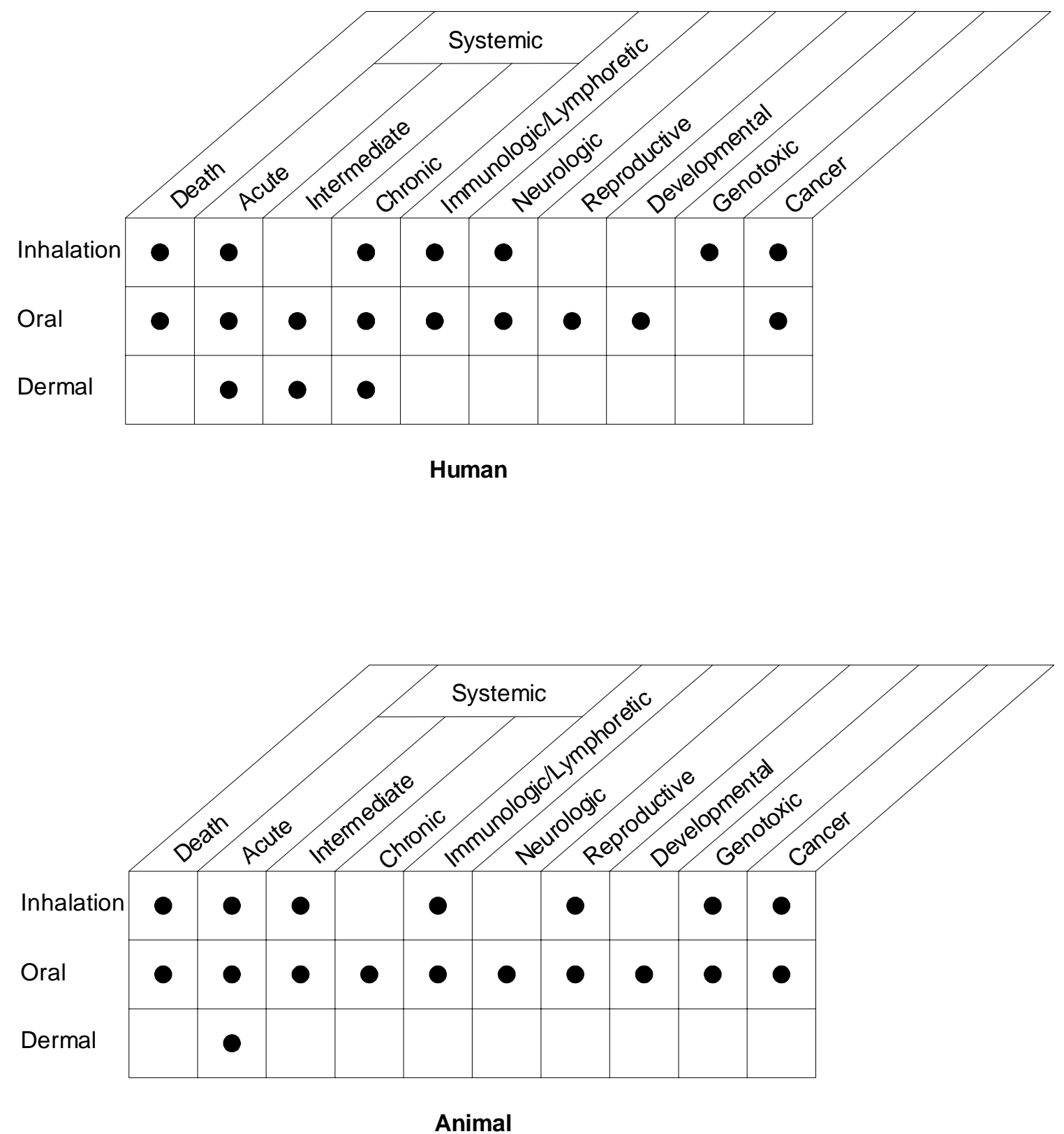

Existing Studies 
in animals is available for acute, intermediate, and chronic exposure durations (Allen et al. 1983; Anderson and Danylchuk 1979; Aughey et al. 1977; Bentley and Grubb 1991; Domingo et al. 1988a; Drinker et al. 1927c; Jenkins and Hidiroglou 1991; Katya-Katya et al. 1984; Klevay and Hyg 1973; Llobet et al. 1988a; Maita et al. 1981; Straube et al. 1980; Walters and Roe 1965). One acute dermal study evaluated dermal irritancy in animals (Lansdown 1991).

Immunological effects were reported in humans following inhalation exposure to zinc oxide (Blanc et al. 1991; Farrell 1987). Another study reported potential adverse immunological effects following oral exposure of humans (Chandra 1984). Clinical symptoms suggestive of neurological effects have been reported by humans following inhalation exposure (Rohrs 1957; Sturgis et al. 1927; Wilde 1975) or oral exposure (Anonymous 1983; Murphy 1970; Potter 1981) to zinc. There were studies that examined reproductive and developmental effects in women orally exposed to zinc during their pregnancies (Kynast and Saling 1986; Mahomed et al. 1989; Simmer et al. 1991).

One study examined immunological and reproductive effects in animals following inhalation exposure to zinc chloride (Marrs et al. 1988). Immunological and neurological end points were evaluated in animals following oral exposure to zinc (Bleavins et al. 1983; Kozik et al. 1980, 1981; Schiffer et al. 1991). Information regarding developmental and reproductive effects in animals after oral exposure to zinc is available (Cox et al. 1969; Ketcheson et al. 1969; Kinnamon 1963; Mulhern et al. 1986; Pal and Pal 1987; Schlicker and Cox 1968; Sutton and Nelson 1937). Studies regarding genotoxicity in animals after inhalation and oral exposures to zinc are limited (Gupta et al. 1991; Kowalska-Wochna et al. 1988; Voroshilin et al. 1978).

Epidemiological studies regarding carcinogenicity after inhalation and oral exposure to zinc are available (Logue et al. 1982; Neuberger and Hollowell 1982; Philipp et al. 1982; Stocks and Davies 1964); however, they were not well controlled and the data are of little significance. Studies are available regarding carcinogenicity in animals after inhalation and oral exposure to zinc (Marrs et al. 1988; Walters and Roe 1965). However, the studies have several deficiencies that limit their usefulness.

\subsubsection{Identification of Data Needs}

Acute-Duration Exposure. Symptoms of metal fume fever (headache, fever, leukocytosis, myalgias) have been observed in humans acutely exposed to airborne zinc oxide (Blanc et al. 1991; Brown 1988; Drinker et al. 1927b; Sturgis et al. 1927). Acute oral exposure to zinc has resulted in 
gastrointestinal disturbances (abdominal pain, nausea, vomiting, esophageal erosion), evidence of pancreatic damage (increased serum amylase and lipase levels), and decreased levels of serum cortisol in humans (Anonymous 1983; Brandao-Neto et al. 1990a; Chobanian 1981; Murphy 1970; Potter 1981). Acute dermal exposure to zinc oxide has not been shown to be irritating to human skin (Agren 1990). Toxic effects similar to those observed for metal fume fever have been observed in guinea pigs (Amdur et al. 1982; Lam et al. 1985). In addition to $\mathrm{LD}_{50}$ data, only one reliable study assessed the acute oral toxicity of zinc compounds in animals. Pancreatic, gastrointestinal, and liver damage were observed in sheep (Allen et al. 1983). It is doubtful that sheep (ruminant animals) are an appropriate model for toxicity of orally administered zinc in humans. The dermal toxicity of several zinc compounds has been tested in rabbits, guinea pigs, and mice (Lansdown 1991). Zinc acetate, zinc chloride, and zinc sulfate have irritating properties. Skin irritation was not observed in rabbits, guinea pigs, or mice after zinc oxide paste application (Lansdown 1991).

The animal data (Amdur et al. 1982; Drinker and Drinker 1928; Lam et al. 1982, 1988) corroborate occupational exposure studies that indicate metal fume fever is an end point of concern. However, other possible targets of toxicity have not been examined. Thus, an acute inhalation MRL cannot be derived. A large amount of the human oral exposure data is in the form of case reports, and a great deal of uncertainty exists regarding the dose levels. The uncertainty about whether sheep are a good model for humans precludes using these data to derive an oral MRL for acute-duration exposure. Additional studies involving acute exposure to zinc compounds by all routes of exposure would be helpful to identify target organ and dose-response relationships. There are groups who may be exposed to zinc at hazardous waste sites for brief periods; therefore, this information is important.

Intermediate-Duration Exposure. Metal fume fever was observed in an individual exposed to zinc fumes and zinc powder for approximately 1 month (Malo et al. 1990). Anemia and decreased levels of HDL cholesterol have been observed in humans taking high doses of zinc supplements (Chandra 1984; Hoffman et al. 1988; Hooper et al. 1980). Intermediate-duration dermal exposure to zinc oxide dust has resulted in pustular lesions, but these lesions were attributed to clogging of the sebaceous glands resulting from poor hygiene (Turner 1921). Rats, mice, and guinea pigs exposed to smoke containing zinc chloride and other compounds had evidence of lung irritation (Marrs et al. 1988). No intermediate-duration animal dermal studies were located. In animals that ingested zinc for an intermediate duration, anemia and kidney and pancreas damage were observed (Bentley and Grubb 1991; Drinker et al. 1927d; Jenkins and Hidiroglou 1991; Llobet et al. 1988a; Maita et al. 1981; Straube et al. 1980). 
Only one case report regarding human intermediate-duration inhalation exposure was located, and this study did not report the exposure level (Malo et al. 1990). Thus, an intermediate-duration inhalation MRL could not be derived. There are less serious LOAELs (decreased serum HDL cholesterol) identified in the Hooper et al. (1980) and Chandra (1984) human oral exposure studies; however, evidence regarding this effect is inconsistent (Bogden et al. 1988; Hale et al. 1988; Samman and Roberts 1988). An intermediate-duration oral MRL was derived for zinc based on hematological effects (decreased hematocrit, serum ferritin, and erythrocyte superoxide dismutase) in women given $50 \mathrm{mg} \mathrm{Zn} /$ day as zinc gluconate supplements for 10 weeks (Yadrick et al. 1989); as these effects were subclinical, they were considered to be non-adverse, and were identified as a NOAEL. Several other studies of zinc supplementation in humans support this NOAEL (Bonham et al. 2003a, 2003b; Davis et al. 2000; Fischer et al. 1984; Milne et al. 2001). The toxic effects of intermediate-duration exposure to zinc compounds are relatively well characterized for the oral route. There are insufficient toxicokinetic data to determine if the toxic effects observed following oral exposure would occur following inhalation or dermal exposure. Inhalation and dermal studies would be useful to determine possible target organs and dose-response relationships. There are populations surrounding hazardous waste sites that might be exposed to zinc compounds for similar durations.

Chronic-Duration Exposure and Cancer. No exposure-related effects on lung function were observed in a group of welders chronically exposed to zinc (Marquart et al. 1989). Anemia has been observed in humans following ingestion of high doses of zinc supplements (Broun et al. 1990; Hale et al. 1988; Porter et al. 1977; Prasad et al. 1978). Chronic-duration dermal exposure to zinc oxide dust has resulted in pustular lesions, but these were attributed to clogging of the sebaceous glands resulting from poor hygiene (Batchelor et al. 1926). No chronic-duration inhalation or dermal studies in animals were located. Pancreatic damage was observed in mice after chronic exposure to zinc sulfate in drinking water (Aughey et al. 1977).

A chronic-duration inhalation MRL could not be derived for zinc because neither of the inhalation studies reported the levels of airborne zinc. Due to a lack of adequate chronic-duration oral studies, the intermediate-duration oral MRL was adopted as the chronic-duration oral MRL, based on hematological effects (decreased hematocrit, serum ferritin, and erythrocyte dismutase) in women given zinc gluconate supplements for 10 weeks (Yadrick et al. 1989). Additional studies involving chronic exposure to zinc compounds by all routes of exposure would be helpful to identify dose-response relationships. 
Although there are several human and animal carcinogenicity studies, the limitations of these studies preclude their use in assessing the carcinogenicity of zinc (Logue et al. 1982; Neuberger and Hollowell 1982; Walters and Roe 1965). Carcinogenicity studies by all routes of exposure would be useful.

Genotoxicity. Several in vitro microbial gene mutation assays were negative (Marzin and Vo Phi 1985; Nishioka 1975; Thompson et al. 1989; Venitt and Levy 1974; Wong 1988), but evidence from gene mutation assays in mammalian cells is mixed (Amacher and Paillet 1980; Thompson et al. 1989). An increase in the occurrence of chromosomal aberrations was observed in vitro in human lymphocytes (Deknudt and Deminatti 1978) and in vivo in rats and mice (Deknudt and Gerber 1979; Gupta et al. 1991; Kowalska-Wochna et al. 1988; Voroshilin et al. 1978). Increased sister chromatid exchange was observed in vivo in rat bone marrow (Kowalska-Wochna et al. 1988). However, while there are sufficient in vivo data establishing the clastogenicity of zinc, data regarding the mutagenicity of zinc are conflicting. Studies designed to assay different types of genotoxicity (i.e., mutagenicity in mammalian cells, effect of excess zinc on DNA replication) would be useful for determining the genotoxic potential of zinc.

Reproductive Toxicity. No complications occurred in the pregnancies of women exposed to daily doses of zinc sulfide during the last two trimesters (Mahomed et al. 1989). No studies were located regarding the reproductive toxicity of zinc in humans after inhalation or dermal exposure. Increased preimplantation loss and reproductive dysfunction in rats were observed in oral exposure studies (Pal and Pal 1987; Sutton and Nelson 1937). No histological changes in reproductive organs were observed in rats, mice, or guinea pigs following inhalation exposure to zinc chloride smoke, but reproductive function was not assessed (Marrs et al. 1988). No dermal reproductive toxicity studies in animals were located. Inhalation and dermal studies assessing reproductive function would be useful to determine whether zinc has the potential to cause reproductive effects by these routes. An oral reproductive toxicity study in a different animal strain as well as a multigeneration study, including reproductive organ pathology, would be useful for determining whether oral zinc exposure is likely to cause reproductive toxicity in humans.

Developmental Toxicity. No studies were located regarding the potential of zinc to cause developmental effects in humans after inhalation or dermal exposure. In a very brief report of a human study in which pregnant women received high-doses of zinc supplements during the last trimester of pregnancy, an increased incidence of stillbirths and one premature delivery were observed (Kumar 1976). This study, however, has many limitations. Increased fetal resorptions were observed in rats after oral exposure to zinc (Schlicker and Cox 1968). No studies were located regarding developmental toxicity in animals after inhalation or dermal exposure to zinc. Additional inhalation, oral, and dermal exposure 
studies in animals would be useful to predict whether developmental effects should be a concern for humans exposed to zinc.

Immunotoxicity. Metal fume fever is believed to be an immune response to zinc oxide. A correlation between the concentration of airborne zinc and the number of all types of T cells (helper, inducer, suppressor, and killer) in the bronchoalveolar lavage fluid of humans, possibly related to the onset of metal fume fever, was observed in an acute-duration inhalation study (Blanc et al. 1991). Impaired immune response in humans has been reported in an intermediate-duration oral study (Chandra 1984). No immune effects were observed in mice after oral exposure to zinc (Schiffer et al. 1991). There is some limited information to suggest that the immune system is a target of zinc toxicity. A battery of immune function tests after inhalation, oral, and dermal exposure to zinc compounds would be useful in determining if zinc is immunotoxic.

Neurotoxicity. Staggering gait and hallucinations were reported in an individual who intentionally inhaled metallic paint aerosols (Wilde 1975). Because there was simultaneous exposure to copper and hydrocarbons, this study cannot be used to assess the neurotoxic potential of zinc. Nonspecific signs and symptoms of neurotoxicity (light-headedness, dizziness, headache, and lethargy) have been reported by humans following acute oral exposure to zinc (Murphy 1970; Potter 1981). Very limited data suggest that high oral doses of zinc can cause minor neuron degeneration and alteration of secretion of the hypothalamus in rats (Kozik et al. 1980, 1981). No studies were located regarding neurotoxic effects in animals after inhalation or dermal exposure to zinc. Additional studies by all routes of exposure would be useful to determine if exposure to zinc compounds would result in neurotoxicity.

Epidemiological and Human Dosimetry Studies. Acute high-level exposure to zinc by inhalation resulted in respiratory irritation and metal fume fever (Blanc et al. 1991; Hjortso et al. 1988; Johnson and Stonehill 1961; Linn et al. 1981; Schenker et al. 1981; Sturgis et al. 1927). Welders are a subpopulation of workers who have a high potential for exposure to zinc oxide. Most of the available studies did not report exposure levels or used a small number of subjects. Studies that correlate occupational exposure to zinc with health effects would be useful. A number of human oral exposure studies have shown that excess levels of zinc can result in anemia, pancreatic damage, decreased serum HDL cholesterol levels, and immunotoxicity (Black et al. 1988; Chandra 1984; Hooper et al. 1980). There are insufficient data for establishing dose-response relationships. Studies designed to establish dose-response relationships would be useful for establishing cause/effect relationships and future monitoring of individuals living near hazardous waste sites. 


\section{Biomarkers of Exposure and Effect.}

Exposure. Increased serum and urine levels of zinc were observed in humans and animals after inhalation, oral, or dermal exposure to zinc (Bentley and Grubb 1991; Brandao-Neto et al. 1990b; Hallmans 1977; Keen and Hurley 1977). However, the relationships between zinc exposure levels and the levels of zinc in biological fluids have not been established. Hair and nail samples may be a potential biomarker for long-term zinc exposure (McBean et al. 1971; Rivlin 1983; Wilhelm et al. 1991); however, no correlation has been demonstrated between these parameters and zinc exposure levels. Development of a biomarker with more exposure and dose data would aid in future medical surveillance that could lead to better detection of zinc exposure.

Effect. Several potential biomarkers for the effects of zinc have been identified. These include increased levels of serum amylases and lipase, indicative of pancreatic damage; non-iron responsive anemia; and decreased HDL cholesterol levels (Suber 1989). However, these biomarkers of effect are not specific for zinc. These biomarkers cannot be used for dosimetry. A potential biomarker of exposure for recent exposures to zinc is increased erythrocyte metallothionein concentrations (Grider et al. 1990). Further investigation of serum biomarkers of effect, particularly for chronic exposure, in zinc-exposed populations would be useful to determine whether exposed populations may be experiencing adverse health effects as the result of zinc exposures.

Absorption, Distribution, Metabolism, and Excretion. Absorption of zinc in humans after oral exposure to high levels has been well described (Aamodt et al. 1983; Hunt et al. 1991; Reinhold et al. 1991; Sandstrom and Abrahamson 1989; Sandstrom and Cederblad 1980; Sandstrom and Sandberg 1992; Spencer et al. 1985). However, quantitative evidence of zinc absorption in humans after inhalation or dermal exposure is very limited. It is known that workers exposed to zinc oxide fumes who experience toxic effects have elevated levels of zinc in plasma and urine (Hamdi 1969). However, it remains to be established whether the elevated levels are the result of the pulmonary absorption or of the swallowing of particles leading to gastrointestinal absorption. Toxic effects have also been observed in humans after dermal exposure (DuBray 1937), indicating dermal absorption.

Information regarding the absorption of zinc in animals following inhalation exposure was limited to lung retention data (Gordon et al. 1992; Hirano et al. 1989). However, there was information to assess the extent of absorption following oral exposure (Davies 1980; Galvez-Morros et al. 1992; Johnson et al. 
1988; Weigand and Kirchgessner 1992). Evidence is limited regarding dermal absorption in animals, but it indicates that zinc sulfate and zinc oxide can penetrate the skin (Agren 1990; Agren et al. 1991; Gordon et al. 1981; Hallmans 1977). Mechanistic data on the oral absorption is reported by Hempe and Cousins (1992); however, there is a lack of information regarding the mechanism of action of inhalation and dermal exposures.

Information on physiological levels and zinc distribution following subtoxic short-term exposures to zinc in humans and animals is abundant (NAS/NRC 1979; Wastney et al. 1986). Blood levels of zinc have been determined in humans following oral exposure to zinc sulfate (Neve et al. 1991; Statter et al. 1988; Sturniolo et al. 1991). Increased zinc tissue content has been seen after short-term oral exposure in humans (Cooke et al. 1990; He et al. 1991; Llobet et al. 1988a; Schiffer et al. 1991; Weigand and Kirchgessner 1992). Studies on tissue distribution in humans following high exposure to zinc for inhalation, oral, and dermal would be useful. There were no studies regarding blood or tissue distribution after acute, high-level exposures to zinc in animals following inhalation or dermal exposure. Additional mechanistic data on the transfer of zinc from respiratory and dermal absorption sites to the blood would be useful.

The principal excretion route of ingested zinc is through the intestines (Davies and Nightingale 1975; Reinhold et al. 1991; Wastney et al. 1986). There is a lack of information regarding the excretion of zinc in both animals and humans following inhalation and dermal exposure.

Therefore, additional studies designed to assess the toxicokinetic properties of zinc following inhalation and dermal exposures would be useful.

Comparative Toxicokinetics. Data suggest that humans and animals have similar target organs of zinc toxicity (Allen et al. 1983; Aughey et al. 1977; Black et al. 1988; Blanc et al. 1991; Brown 1988; Chandra 1984; Chobanian 1981; Drinker et al. 1927b, 1927d; Hoffman et al. 1988; Hooper et al. 1980; Katya-Katya et al. 1984; Klevay and Hyg 1973; Lam et al. 1982, 1985, 1988; Maita et al. 1981; Moore 1978; Murphy 1970; Smith and Larson 1946; Straube et al. 1980; Sturgis et al. 1927). Toxicokinetic studies have been performed in both humans and animals following oral exposure; however, data are limited for inhalation and dermal exposures. The animal model used most often to evaluate the toxicokinetics of zinc are rats (Agren et al. 1991; Alexander et al. 1981; Galvez-Morros et al. 1992; Hirano et al. 1989; Llobet et al. 1988a; Weigand and Kirchgessner 1992) and may be a good model for assessing the kinetics of zinc in humans. 
Methods for Reducing Toxic Effects. No established methods or treatments for reducing the absorption of zinc were located. Studies that examined the effectiveness of emetics and cathartics in the prevention of zinc absorption would be useful. Once absorbed from the gastrointestinal tract, zinc bound to plasma albumin is distributed to the rest of the body. Zinc has a high affinity for proteins, and a number of chelating agents are effective in increasing urinary excretion of zinc following acute- and intermediate-duration administrations (Domingo et al. 1988a, 1988b; Llobet et al. 1989). Studies designed to examine the effectiveness of chelating agents following chronic zinc exposure would be useful in determining treatments to reduce the zinc body burden. Very little information is known about the absorption and distribution of zinc following inhalation or dermal exposure. Studies to determine the mechanisms of absorption and distribution would be useful for developing treatments or methods for reducing the toxic effects of zinc after inhalation or dermal exposure.

Although the exact mechanisms of many of the toxic actions of zinc are not known, the pathogenesis of metal fume fever following inhalation exposure (McCord 1960; Mueller and Seger 1985) and anemia following oral exposure (Prasad et al. 1978) are known. Studies to more clearly elucidate the mechanisms involved in metal fume fever and anemia and to determine the mechanisms involved in pancreatic damage and decreased HDL cholesterol levels would be useful. Therapy for metal fume fever is mainly supportive (Mueller and Seger 1985). Administration of copper has been shown to be effective in alleviating zinc-induced anemia (Porter et al. 1977). Research into methods useful for mitigating metal fume fever and other adverse effects of zinc would be helpful.

Children's Susceptibility. Data needs relating to both prenatal and childhood exposures, and developmental effects expressed either prenatally or during childhood, are discussed in detail in the Developmental Toxicity subsection above.

While a considerable amount of data are available on the effects of zinc deficiency on the growth and development of children, less is known about the effects of excess zinc on children. Accidental acute oral exposures result in mainly gastrointestinal symptoms, including nausea, vomiting, and epigastric discomfort (Anonymous 1983; Lewis and Kokan 1998; Moore 1978; Murphy 1970). Data are not presently available to determine whether children are more susceptible to these effects than adults. Similarly, additional animal studies examining the effects of similar exposure on young and mature animals would be useful to further clarify possible mechanisms of childhood susceptibility, if it exists. 
Child health data needs relating to exposure are discussed in Section 6.8.1, Identification of Data Needs: Exposures of Children.

\subsubsection{Ongoing Studies}

A selection of ongoing studies, located in the Federal Research in Progress database (FEDRIP 2003), is presented in Table 3-6. 
Table 3-6. Ongoing Studies on Zinc Health Effects ${ }^{a}$

\begin{tabular}{|c|c|c|}
\hline Investigator & Institute & Research area \\
\hline Abrams SA & $\begin{array}{l}\text { Baylor College of Medicine, } \\
\text { Houston, Texas }\end{array}$ & $\begin{array}{l}\text { Zinc metabolism in health and chronic } \\
\text { inflammatory bowel disease children }\end{array}$ \\
\hline Black MM & $\begin{array}{l}\text { University of Maryland, } \\
\text { Baltimore, Maryland }\end{array}$ & $\begin{array}{l}\text { Effect of micronutrient supplementation on } \\
\text { children's growth, immune functioning, and } \\
\text { morbidity }\end{array}$ \\
\hline Blanchard K & $\begin{array}{l}\text { Department of Veterans Affairs, } \\
\text { Medical Center, Shreveport, } \\
\text { Louisiana }\end{array}$ & $\begin{array}{l}\text { Efficacy and safety of oral zinc therapy in } \\
\text { patients with Polycythemia Vera }\end{array}$ \\
\hline Blumenthal SS & $\begin{array}{l}\text { Department of Veterans Affairs, } \\
\text { Medical Center, Milwaukee, } \\
\text { Wisconsin }\end{array}$ & $\begin{array}{l}\text { Cadmium, zinc, metallothionein, and kidney } \\
\text { cytotoxicity }\end{array}$ \\
\hline Bobilya DJ & $\begin{array}{l}\text { University of New Hampshire, } \\
\text { Durham, New Hampshire }\end{array}$ & $\begin{array}{l}\text { Evaluation of zinc transport by using an in vitro } \\
\text { model of the blood brain barrier under different } \\
\text { conditions of zinc status }\end{array}$ \\
\hline Bobilya DJ & $\begin{array}{l}\text { University of New Hampshire, } \\
\text { Durham, New Hampshire }\end{array}$ & $\begin{array}{l}\text { Testing to determine whether co-transport with } \\
\text { albumin is a significant route for zinc transport by } \\
\text { endothelial cells }\end{array}$ \\
\hline Brewer GJ & $\begin{array}{l}\text { University of Michigan at Ann } \\
\text { Arbor, Ann Arbor, Michigan }\end{array}$ & $\begin{array}{l}\text { Studies on the treatment of Wilson's disease } \\
\text { with zinc }\end{array}$ \\
\hline Brown $\mathrm{KH}$ & $\begin{array}{l}\text { University of California, } \\
\text { Nutrition, Davis, California }\end{array}$ & $\begin{array}{l}\text { Bioavailability of vitamin A and zinc from } \\
\text { selected foods of potential use for intervention } \\
\text { programs in populations at high risk of deficiency }\end{array}$ \\
\hline Brown KH & $\begin{array}{l}\text { University of California, } \\
\text { Nutrition, Davis, California }\end{array}$ & $\begin{array}{l}\text { Determination of the safety and efficacy of three } \\
\text { levels of zinc supplementation, provided with or } \\
\text { without supplemental copper }\end{array}$ \\
\hline Brown NM & $\begin{array}{l}\text { Northwestern University, } \\
\text { Evanston, Illinois }\end{array}$ & $\begin{array}{l}\text { Combination of fluorescent microscopy studies } \\
\text { with biophysical and proteomic approaches to } \\
\text { identify zinc rich cellular compartments and } \\
\text { isolate the proteins associated with these } \\
\text { vesicles }\end{array}$ \\
\hline Choi DW & $\begin{array}{l}\text { Washington University, St. } \\
\text { Louis, Missouri }\end{array}$ & Zinc and ischemic brain injury \\
\hline Choi DW & $\begin{array}{l}\text { Washington University, St. } \\
\text { Louis, Missouri }\end{array}$ & Study of $\mathrm{Zn}^{2+}$-mediated neurotoxicity \\
\hline Cline TR & $\begin{array}{l}\text { Purdue University, Animal } \\
\text { Science, West Lafayette, } \\
\text { Indiana }\end{array}$ & $\begin{array}{l}\text { Measurement of the effects of fasting, diet } \\
\text { particle size and elevated levels of zinc on } \\
\text { growth and stomach morphology in young pigs }\end{array}$ \\
\hline Disilvestro RA & $\begin{array}{l}\text { Ohio State University, College of } \\
\text { Human Ecology, Columbus, } \\
\text { Ohio }\end{array}$ & $\begin{array}{l}\text { Determine whether stress-induced accumulation } \\
\text { of certain radicals is affected by copper and zinc } \\
\text { consumption in rats }\end{array}$ \\
\hline Disilvestro RA & $\begin{array}{l}\text { Ohio State University, College of } \\
\text { Human Ecology, Columbus, } \\
\text { Ohio }\end{array}$ & $\begin{array}{l}\text { Zinc supplementation in Crohn's disease } \\
\text { patients }\end{array}$ \\
\hline
\end{tabular}


Table 3-6. Ongoing Studies on Zinc Health Effects ${ }^{a}$

\begin{tabular}{|c|c|c|}
\hline Investigator & Institute & Research area \\
\hline Fraker PJ & $\begin{array}{l}\text { Michigan State University, East } \\
\text { Lansing, Michigan }\end{array}$ & $\begin{array}{l}\text { Identification of the underlying mechanisms that } \\
\text { cause the lymphopenia and reduced host } \\
\text { defense that accompanies zinc deficiency in } \\
\text { humans and animals }\end{array}$ \\
\hline Freake HC & $\begin{array}{l}\text { University of Connecticut, } \\
\text { Nutritional Sciences, Storrs, } \\
\text { Connecticut }\end{array}$ & $\begin{array}{l}\text { Effects of zinc on nuclear actions of thyroid } \\
\text { hormone }\end{array}$ \\
\hline Griffiths JK & $\begin{array}{l}\text { Tufts University Boston, Boston, } \\
\text { Massachusetts }\end{array}$ & $\begin{array}{l}\text { Examination of how vitamin A and zinc } \\
\text { supplementation interact in improving immunity, } \\
\text { fostering growth, and preventing infection, in } \\
\text { populations at risk for malnutrition and vitamin A } \\
\text { and zinc deficiency }\end{array}$ \\
\hline Guo MG & $\begin{array}{l}\text { University of Vermont, } \\
\text { Nutritional Sciences, Burlington, } \\
\text { Vermont }\end{array}$ & $\begin{array}{l}\text { Determination of whether the solubility of } \\
\text { minerals added as organic salts of } \mathrm{Zn}, \mathrm{Fe} \text {, and } \\
\mathrm{Cu} \text { is greater than that of formulae prepared } \\
\text { using inorganic ones }\end{array}$ \\
\hline Hennig B & $\begin{array}{l}\text { University of Kentucky, Animal } \\
\text { Science, Lexington, Kentucky }\end{array}$ & $\begin{array}{l}\text { Examination of the antiatherogenic properties of } \\
\text { zinc }\end{array}$ \\
\hline Hennig B & $\begin{array}{l}\text { University of Kentucky, Animal } \\
\text { Science, Lexington, Kentucky }\end{array}$ & $\begin{array}{l}\text { Interference of zinc with the generation of an } \\
\text { oxidative environment mediated by fatty acids }\end{array}$ \\
\hline Johnson MA & $\begin{array}{l}\text { University of Georgia, College of } \\
\text { Family and Consumer Science, } \\
\text { Athens, Georgia }\end{array}$ & $\begin{array}{l}\text { Examination of the influence of supplements of } \\
\text { copper, zinc, and/or manganese on indices of } \\
\text { bone formation and bone resorption in } \\
\text { postmenopausal women }\end{array}$ \\
\hline Keen CL & $\begin{array}{l}\text { University of California Davis, } \\
\text { Davis, California }\end{array}$ & $\begin{array}{l}\text { Examination of potential mechanisms by which } \\
\text { maternal and embryonic zinc deficiency arise, } \\
\text { and how this deficiency results in abnormal } \\
\text { development and growth }\end{array}$ \\
\hline King LM & $\begin{array}{l}\text { ARS, Germplasm and } \\
\text { Physiology Lab, Beltsville, } \\
\text { Maryland }\end{array}$ & $\begin{array}{l}\text { Mechanisms of zinc and calcium regulation of } \\
\text { sperm storage in the turkey }\end{array}$ \\
\hline Lee J-M & $\begin{array}{l}\text { Washington University, St. } \\
\text { Louis, Missouri }\end{array}$ & Role of zinc in focal ischemic brain injury \\
\hline Lei DK & $\begin{array}{l}\text { University of Maryland, Human } \\
\text { Nutrition and Food Science, } \\
\text { College Park, Maryland }\end{array}$ & $\begin{array}{l}\text { Modulation of p53 human tumor suppressor } \\
\text { gene expression by zinc status }\end{array}$ \\
\hline MacDonald RS & $\begin{array}{l}\text { University of Missouri, Food } \\
\text { Science and Engineering, } \\
\text { Columbia, Missouri }\end{array}$ & $\begin{array}{l}\text { Examination of the cellular and molecular } \\
\text { mechanisms that become limiting in humans and } \\
\text { animals when they are deprived of the essential } \\
\text { nutrient zinc }\end{array}$ \\
\hline Mody I & $\begin{array}{l}\text { University of California Los } \\
\text { Angeles, Los Angeles, California }\end{array}$ & $\begin{array}{l}\text { Pathological consequence of the plastic } \\
\text { conversion of zinc }\left(Z n^{2+}\right) \text {-insensitive synaptic } \\
\text { GABA/A receptors into } Z n^{2+} \text {-sensitive ones }\end{array}$ \\
\hline Moser-Veillon PB & $\begin{array}{l}\text { University of Maryland, Nutrition } \\
\text { and Food Science, College } \\
\text { Park, Maryland }\end{array}$ & Zinc needs and homeostasis during lactation \\
\hline
\end{tabular}


Table 3-6. Ongoing Studies on Zinc Health Effects ${ }^{a}$

\begin{tabular}{|c|c|c|}
\hline Investigator & Institute & Research area \\
\hline Onstad CA & $\begin{array}{l}\text { Agricultural Research Service, } \\
\text { Houston, Texas }\end{array}$ & $\begin{array}{l}\text { Assessment of the effects of low zinc intake } \\
\text { compared with a zinc intake consistent with the } \\
\text { RDA on zinc absorption and kinetics in } \\
\text { 9-13-year-old girls }\end{array}$ \\
\hline Onstad CA & $\begin{array}{l}\text { Agricultural Research Service, } \\
\text { Houston, Texas }\end{array}$ & $\begin{array}{l}\text { Measurement of the content of } \mathrm{Ca}, \mathrm{Mg}, \mathrm{Fe} \text {, and } \\
\mathrm{Zn} \text { in existing germ-plasm of selected food crops } \\
\text { to characterize genetic diversity }\end{array}$ \\
\hline Panemangalore M & $\begin{array}{l}\text { Kentucky State University, } \\
\text { Human Nutrition Research } \\
\text { Program, Frankfort, Kentucky }\end{array}$ & $\begin{array}{l}\text { Evaluation of the use of prophyrin profiles, } \\
\text { ceruloplasmin, superoxide dismutase in serum } \\
\text { or blood cells as biomarkers of zinc and copper } \\
\text { status in humans and animals }\end{array}$ \\
\hline Reeves PG & $\begin{array}{l}\text { Agricultural Research Service, } \\
\text { Grand Forks, North Dakota }\end{array}$ & $\begin{array}{l}\text { Studies to determine the correlation between } \\
\text { sperm motility and heavy metals in semen, } \\
\text { blood, urine, plasma, and saliva }\end{array}$ \\
\hline Sazawal S & $\begin{array}{l}\text { Johns Hopkins University, } \\
\text { Baltimore, Maryland }\end{array}$ & $\begin{array}{l}\text { Role of zinc in childhood growth and } \\
\text { development and the effects of zinc deficiency } \\
\text { on childhood morbidity }\end{array}$ \\
\hline Spears JW & $\begin{array}{l}\text { North Carolina State University, } \\
\text { Animal Science, Raleigh, North } \\
\text { Carolina }\end{array}$ & $\begin{array}{l}\text { Determination of the effect of dietary level and } \\
\text { source of zinc and copper on growth, } \\
\text { reproduction, mineral status, and mineral } \\
\text { excretion during the productive life span of } \\
\text { female swine }\end{array}$ \\
\hline Tankanow RM & $\begin{array}{l}\text { University of Michigan at Ann } \\
\text { Arbor, Ann Arbor, Michigan }\end{array}$ & $\begin{array}{l}\text { Zinc gluconate glycine lozenges and vitamin c } \\
\text { effects on common cold }\end{array}$ \\
\hline Thompson RB & $\begin{array}{l}\text { University of Maryland, } \\
\text { Baltimore, Maryland }\end{array}$ & $\begin{array}{l}\text { Development of a group of optical probes for } \\
\text { studying zinc in neural tissue by fluorescence } \\
\text { microscopy }\end{array}$ \\
\hline Tielsch JM & $\begin{array}{l}\text { Johns Hopkins University, } \\
\text { Baltimore, Maryland }\end{array}$ & $\begin{array}{l}\text { Examination of the role of micronutrient } \\
\text { deficiency on the health and well-being of } \\
\text { women and children in underdeveloped areas of } \\
\text { the world }\end{array}$ \\
\hline Wagner GJ & $\begin{array}{l}\text { University of Kentucky, } \\
\text { Agronomy, Lexington, Kentucky }\end{array}$ & $\begin{array}{l}\text { Study of the mechanisms for vacuolar } \\
\text { storage/sequestration of } \mathrm{Cd}, \mathrm{Zn}, \mathrm{Mn} \text {, and } \mathrm{Ni}\end{array}$ \\
\hline Weiss $\mathrm{JH}$ & $\begin{array}{l}\text { University of California Irvine, } \\
\text { Irvine, California }\end{array}$ & $\begin{array}{l}\mathrm{Ca}^{2+}, \mathrm{Zn}^{2+}, \text { and selective excitotoxic } \\
\text { neurodegeneration }\end{array}$ \\
\hline
\end{tabular}

${ }^{\mathrm{a} S o u r c e: ~ F E D R I P ~} 2003$

FEDRIP $=$ Federal Research in Progress 



\section{CHEMICAL AND PHYSICAL INFORMATION}

\subsection{CHEMICAL IDENTITY}

Information concerning the chemical identity of elemental zinc and zinc compounds is listed in Table 4-1.

Zinc is a naturally occurring element found in the earth's surface rocks. Because of its reactivity, zinc metal is not found as the free element in nature. There are approximately 55 mineralized forms of zinc. The most important zinc minerals in the world are sphalerite $(\mathrm{ZnS})$, smithsonite $\left(\mathrm{ZnCO}_{3}\right)$, and hemimorphite $\left(\mathrm{Zn}_{4} \mathrm{Si}_{2} \mathrm{O}_{7}\left(\mathrm{OH}_{2}\right) \mathrm{H}_{2} \mathrm{O}\right)$. Zinc appears in Group IIB of the periodic table and has two common oxidation states, $\mathrm{Zn}(0)$ and $\mathrm{Zn}(+2)$. Zinc forms a variety of different compounds, such as zinc chloride, zinc oxide, and zinc sulfate (Goodwin 1998; Ohnesorge and Wilhelm 1991; WHO 2001).

\subsection{PHYSICAL AND CHEMICAL PROPERTIES}

Information regarding the physical and chemical properties of elemental zinc and zinc compounds is located in Table 4-2.

Zinc is a lustrous, blue-white metal that burns in air with a bluish-green flame. It is stable in dry air, but upon exposure to moist air, it becomes covered with a film of zinc oxide or basic carbonate (e.g., $\left.2 \mathrm{ZnCO}_{3} \cdot 3 \mathrm{Zn}(\mathrm{OH})_{2}\right)$ isolating the underlying metal and retarding further corrosion. Bonding in zinc compounds tends to be covalent, as in the sulfide and oxide (Goodwin 1998). In solution, four to six ligands can be coordinated with the zinc ion. Zinc has a strong tendency to react with acidic, alkaline, and inorganic compounds. Since zinc is amphoteric (i.e., capable of reacting chemically either as an acid or a base), it also forms zincates (e.g., $\left[\mathrm{Zn}(\mathrm{OH})_{3} \mathrm{H}_{2} \mathrm{O}\right]-$ and $\left.\left[\mathrm{Zn}(\mathrm{OH})_{4}\right]^{2-}\right)(\mathrm{Goodwin} 1998$; Ohnesorge and Wilhelm 1991; WHO 2001).

In humans and animals, zinc is an essential nutrient that plays a role in membrane stability, in over 300 enzymes, and in the metabolism of proteins and nucleic acids (WHO 2001). 
Table 4-1. Chemical Identity of Zinc and Selected Compounds ${ }^{a}$

\begin{tabular}{|c|c|c|c|}
\hline Characteristic & Zinc & Zinc acetate & Zinc chloride \\
\hline Synonyms & Zinc dust; zinc powder & $\begin{array}{l}\text { Acetic acid, zinc salt; } \\
\text { acetic acid, zinc(II) salt; } \\
\text { dicarbomethoxyzinc; } \\
\text { octan zinecnaty [Czech]; } \\
\text { zinc diacetate; zinc(II) } \\
\text { acetate }\end{array}$ & $\begin{array}{l}\text { Butter of zinc; chlorure de zinc } \\
\text { (French); zinc (Chlorure de) } \\
\text { (French); zinc butter; zinc } \\
\text { chloride ( } \mathrm{ZnCl}_{2} \text { ); zinc } \\
\text { dichloride; zinco (cloruro di) } \\
\text { (Italian); zinkchlorid (German); } \\
\text { zinkchloride (Dutch) }\end{array}$ \\
\hline $\begin{array}{l}\text { Registered trade } \\
\text { name(s) }\end{array}$ & $\begin{array}{l}\text { Asarco; L 15; Blue } \\
\text { powder; CI 77945; CI } \\
\text { pigment Metal 6; } \\
\text { Emanay zinc dust; } \\
\text { Granular zinc; JASAD; } \\
\text { Merrillite; PASCO }\end{array}$ & No data & $\begin{array}{l}\text { Tinning flux (DOT) }{ }^{\mathrm{b}} \text {; Al3-0440; } \\
\text { Zintrace }\end{array}$ \\
\hline Chemical formula & $\mathrm{Zn}$ & $\mathrm{Zn}\left(\mathrm{C}_{2} \mathrm{H}_{3} \mathrm{O}_{2}\right)_{2}$ & $\mathrm{ZnCl}_{2}$ \\
\hline Chemical structure & $\mathrm{Zn}$ & $\left.\int_{0^{-}} \mathrm{Zn}^{2+}\right\rangle^{\mathrm{O}^{-}}$ & $\mathrm{Cl}-\mathrm{Zn}-\mathrm{Cl}$ \\
\hline \multicolumn{4}{|c|}{ Identification numbers: } \\
\hline CAS registry & $7440-66-6$ & $\begin{array}{l}\text { 557-34-6 (anhydrous) } \\
\text { 5970-45-6 (dihydrate) }\end{array}$ & $7646-85-7$ \\
\hline NIOSH RTECS & ZG8600000 & $\begin{array}{l}\text { AK1500000 (anhydrous) } \\
\text { ZG8750000 (dihydrate) }\end{array}$ & ZH1400000 \\
\hline $\begin{array}{l}\text { EPA hazardous } \\
\text { waste }\end{array}$ & No data & No data & No data \\
\hline OHM/TADS & 7216955 & No data & 7216957 \\
\hline $\begin{array}{l}\text { DOT/UN/NA/ } \\
\text { IMCO shipping }\end{array}$ & $\begin{array}{l}\text { Zinc, powder or dust, } \\
\text { UN 1436; zinc, powder } \\
\text { or dust, zinc ashes, } \\
\text { IMO4.3; zinc ashes, } \\
\text { UN 1435 }\end{array}$ & $\begin{array}{l}\text { Zinc acetate, } \\
\text { environmental hazardous } \\
\text { substance, solid, NOS, } \\
\text { UN } 3077\end{array}$ & $\begin{array}{l}\text { Zinc chloride, anhydrous, UN } \\
2331 \text {; zinc chloride, solution, } \\
\text { UN 1840; zinc chloride, } \\
\text { anhydrous, solution, IMO } 8.3\end{array}$ \\
\hline HSDB & 1344 & 1043 & 1050 \\
\hline $\mathrm{NCl}$ & No data & No data & No data \\
\hline
\end{tabular}


Table 4-1. Chemical Identity of Zinc and Selected Compounds ${ }^{a}$

\begin{tabular}{|c|c|c|}
\hline Characteristic & Zinc chromate & Zinc cyanide \\
\hline Synonyms & $\begin{array}{l}\text { Basic zinc chromate; chromic acid, } \\
\text { zinc salt(1:1); chromic acid, zinc salt; } \\
\text { chromium zinc oxide; zinc chrome } \\
\text { yellow; zinc chromate; zinc chromate } \\
\text { AM; zinc chromate C; zinc chromate } \\
\text { O; zinc chromate Z; zinc chromate(VI) } \\
\text { hydroxide; zinc chrome; zinc chrome } \\
\text { (anti-corrosion); zinc chromium oxide; } \\
\text { zinc hydroxychromate; zinc } \\
\text { tetraoxychromate }\end{array}$ & $\begin{array}{l}\text { Cyanure de zinc (French); zinc } \\
\text { dicyanide }\end{array}$ \\
\hline $\begin{array}{l}\text { Registered trade } \\
\text { name(s) }\end{array}$ & $\begin{array}{l}\text { Pigment yellow 36; buttercup yellow; } \\
\text { zinc tetraoxychromate } 76 \mathrm{~A} \text {; zinc } \\
\text { tetraoxychromate } 780 \mathrm{~B} \text {; zinc yellow; } \\
\text { ZTO; zincro ZTO }\end{array}$ & No data \\
\hline $\begin{array}{l}\text { Chemical formula } \\
\text { Chemical structure }\end{array}$ & $\mathrm{ZnCrO}_{4}$ & $\mathrm{Zn}(\mathrm{CN})_{2}$ \\
\hline \multicolumn{3}{|l|}{ Identification numbers: } \\
\hline CAS registry & $13530-65-9$ & $557-21-1$ \\
\hline NIOSH RTECS & GB3290000 & ZH1575000 \\
\hline EPA hazardous waste & No data & $\begin{array}{l}\text { P121; an acute hazardous waste when } \\
\text { a discarded commercial chemical } \\
\text { product or manufacturing chemical } \\
\text { intermediate or an off-specification } \\
\text { commercial chemical product or a } \\
\text { manufacturing chemical intermediate. } \\
\text { D003; a waste containing zinc cyanide } \\
\text { may (or may not) be characterized a } \\
\text { hazardous waste following testing for } \\
\text { the reactivity characteristics as } \\
\text { prescribed by RCRA regulations }\end{array}$ \\
\hline $\mathrm{OHM} / \mathrm{TADS}$ & No data & No data \\
\hline $\begin{array}{l}\text { DOT/UN/NA/IMCO } \\
\text { shipping }\end{array}$ & No data & $\begin{array}{l}\text { Zinc cyanide, UN 1713; Zinc cyanide, } \\
\text { IMO } 6.1\end{array}$ \\
\hline HSDB & 6188 & 1051 \\
\hline $\mathrm{NCl}$ & 77955 & No data \\
\hline
\end{tabular}


Table 4-1. Chemical Identity of Zinc and Selected Compounds ${ }^{a}$

\begin{tabular}{|c|c|c|}
\hline Characteristic & Zinc hydroxide & Zinc oxide \\
\hline Synonyms & Zinc dihydroxide & $\begin{array}{l}\text { Zinc monoxide; zincum oxydatum; zinci oxydum; zinci } \\
\text { oxicum; cynku tlenek (Polish) }\end{array}$ \\
\hline $\begin{array}{l}\text { Registered trade } \\
\text { name(s) }\end{array}$ & No data & $\begin{array}{l}\text { Actox 14; Actox 16; Actox 216; Al3-00277; Akro-Zinc } \\
\text { Bar85'; Amalox; Amaloz; Azo 22; Azodox; Blanc de } \\
\text { Zinc; Cadox XX 78; Caswell No 920; Chinese White; } \\
\text { Cl 77947; CI Pigment White 4; Electrox 2500; Emanay } \\
\text { Zinc Oxide; Emar; Felling Zinc Oxide; Flores de Zinci; } \\
\text { Flowers of Zinc; GIAP 10; Green Seal-8; Hubbuck's } \\
\text { White; Kadox 15; Kadox-25; Kadox 72; Outmine; } \\
\text { Ozide; Ozlo; Permanent White; Philosopher's Wool; } \\
\text { Powder Base 900; Protox 166; Protox 168; Protox 169; } \\
\text { Protox Type 166; Protox Type 167; Protox Type 168; } \\
\text { Protox Type 169; Protox Type 267; Protox Type 268; } \\
\text { Red Seal; Red seal-9; Snow White; Unichem ZO; } \\
\text { Vandem VAC; Vandem VOC; Vandem VPC; C-Weiss } \\
8 \text { (German); White Seal-7; XX 78; XX 203; XX 601; } \\
\text { Zinca 20; Zinc White; Zincoid; Zn 0701T; Calamine } \\
\text { Zincite }\end{array}$ \\
\hline Chemical formula & $\mathrm{Zn}(\mathrm{OH})_{2}$ & $\mathrm{ZnO}$ \\
\hline Chemical structure & $\mathrm{HO}-\mathrm{Zn}-\mathrm{OH}$ & $\mathrm{Zn}=\mathrm{O}$ \\
\hline \multicolumn{3}{|l|}{ Identification numbers: } \\
\hline CAS registry & 20427-58-1 & $1314-13-2$ \\
\hline NIOSH RTECS & ZH3853000 & ZH4810000 \\
\hline EPA hazardous waste & No data & No data \\
\hline OHM/TADS & No data & No data \\
\hline $\begin{array}{l}\text { DOT/UN/NA/IMCO } \\
\text { shipping }\end{array}$ & No data & No data \\
\hline HSDB & No data & 5024 \\
\hline $\mathrm{NCl}$ & No data & No data \\
\hline
\end{tabular}


Table 4-1. Chemical Identity of Zinc and Selected Compounds ${ }^{a}$

\begin{tabular}{|c|c|c|}
\hline Characteristic & Zinc phosphate & Zinc sulfate \\
\hline Synonyms & $\begin{array}{l}\text { Zinc ortho-phosphate; neutral zinc } \\
\text { phosphate; tribasic zinc phosphate; } \\
\text { trizinc diphosphate; zinc acid } \\
\text { phosphate; zinc phosphate }(3: 2)\end{array}$ & $\begin{array}{l}\text { Sulfate de zinc (French); sulfuric acid zinc } \\
\text { salt; sulfuric acid, zinc salt (1:1); white } \\
\text { copperas; white vitriol; zinc sulfate; zinc } \\
\text { vitriol; zinci sulfas; zincum sulfuricum }\end{array}$ \\
\hline $\begin{array}{l}\text { Registered trade } \\
\text { name(s) }\end{array}$ & $\begin{array}{l}\text { Bonderite 181; Bonderite 40; } \\
\text { Bonderite 880; C.I. Pigment White } \\
\text { 32; Delaphos; Delaphos 2M; } \\
\text { Fleck's Extraordinary; Fleck's } \\
\text { Extraordinary cement; Granodine } \\
\text { 16NC; Granodine 80; Heucophos } \\
\text { ZP 10; LF Bowsei PW 2; Man-Gill } \\
\text { 51339; Man-Gill 51355; Microphos } \\
\text { 90; Phoshinox PZ 06; Pigment } \\
\text { White 32; Sicor ZNP/M; ZPF; Sicor } \\
\text { ZNP/S; Virchem 931; Weather coat } \\
\text { 1000; ZP-DL; ZP-SB }\end{array}$ & $\begin{array}{l}\text { Bonazen }^{\text {b}} \text {; Medizinc; Bufopto Zinc sulfate; } \\
\text { Op-thal-zin; Optraex; Solvenzink; } \\
\text { Verazinc; zincate; Zincomed; Zinkosite; } \\
\text { Al3-03967; Orazinc; Zinc-200; Zinklet; } \\
\text { Neozin; Optised; Prefrin-Z; Visine-AC; } \\
\text { Zincfrin; Zink-Gro }\end{array}$ \\
\hline $\begin{array}{l}\text { Chemical formula } \\
\text { Chemical structure }\end{array}$ & 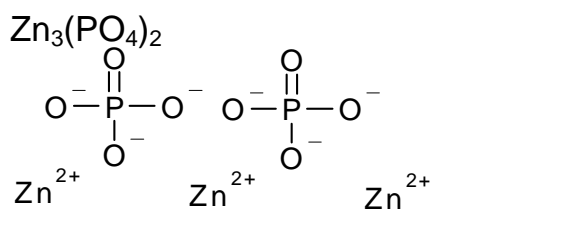 & $\mathrm{Zn}_{1}^{\prime}, \mathrm{S}^{\prime}$ \\
\hline \multicolumn{3}{|l|}{ Identification numbers: } \\
\hline CAS registry & $7779-90-0$ & $7733-02-0$ \\
\hline NIOSH RTECS & TD0590000 & ZH5260000 \\
\hline EPA hazardous waste & No data & No data \\
\hline $\mathrm{OHM} / \mathrm{TADS}$ & No data & 7216958 \\
\hline $\begin{array}{l}\text { DOT/UN/NA/IMCO } \\
\text { shipping }\end{array}$ & No data & NA 9161 \\
\hline HSDB & No data & 1063 \\
\hline $\mathrm{NCl}$ & No data & No data \\
\hline
\end{tabular}




\section{Table 4-1. Chemical Identity of Zinc and Selected Compounds ${ }^{a}$}

\begin{tabular}{|c|c|}
\hline Charactersitic & Zinc sulfide \\
\hline Synonyms & $\begin{array}{l}\text { Wurtzite (alpha) })^{\text {b }} \text {; sphalerite (beta) }{ }^{\text {b }} \text {; zinc monosulfide; zinc blende; zinc } \\
\text { sulphide }\end{array}$ \\
\hline $\begin{array}{l}\text { Registered trade } \\
\text { name(s) }\end{array}$ & $\begin{array}{l}\text { Albalith; Irtran Z; Irtran 2; CI Pigment White 7; Sachtolith; Sachtolith HD-S; } \\
\text { Cleartran }\end{array}$ \\
\hline Chemical formula & ZnS \\
\hline Chemical structure & $\mathrm{Zn}=\mathrm{S}$ \\
\hline \multicolumn{2}{|l|}{ Identification numbers: } \\
\hline CAS registry & $1314-98-3$ \\
\hline NIOSH RTECS & ZH5400000 \\
\hline \multicolumn{2}{|c|}{ EPA hazardous waste D003 } \\
\hline OHM/TADS & No data \\
\hline $\begin{array}{l}\text { DOT/UN/NA/IMCO } \\
\text { shipping }\end{array}$ & $\begin{array}{l}\text { UN 3077; Zinc sulfide, environmentally hazardous substance, solid, NO; } \\
\text { UN 3082; zinc sulfide, environmentally hazardous substance, liquid, NOS }\end{array}$ \\
\hline HSDB & 5802 \\
\hline $\mathrm{NCl}$ & No data \\
\hline
\end{tabular}

aUnless otherwise specified, all data from Chemfinder 2003; ChemID 2003; HSDB 2003; NIOSH 1990; and RTECS 2003

${ }^{\mathrm{b}}$ HSDB 1990

${ }^{\mathrm{C} O}$ 'Neil et al. 2001

CAS = Chemical Abstracts Service; DOT/UN/NA/IMCO = Department of Transportation/United Nations/North America/International Maritime Dangerous Goods Code; EPA = Environmental Protection Agency; HSDB = Hazardous Substances Data Bank; NCI = National Cancer Institute; NIOSH = National Institute for Occupational Safety and Health; OHM/TADS = Oil and Hazardous Materials/Technical Assistance Data System; RCRA = Resource Conservation and Recovery Act; RTECS = Registry of Toxic Effects of Chemical Substances 


\section{Table 4-2. Physical and Chemical Properties of Zinc and Selected Compounds ${ }^{a}$}

\begin{tabular}{|c|c|c|c|}
\hline Property & Zinc & Zinc acetate & Zinc chloride \\
\hline $\begin{array}{l}\text { Molecular } \\
\text { weight }\end{array}$ & 65.38 & 183.48 & 136.29 \\
\hline Color & Bluish-white, lustrous & White granules & White granules ${ }^{b}$ \\
\hline Physical state & Solid metal & Solid & Solid \\
\hline Melting point & $419.5^{\circ} \mathrm{C}$ & $237^{\circ} \mathrm{C}$ (decomposes) & $290^{\circ} \mathrm{C}$ \\
\hline Boiling point & $908^{\circ} \mathrm{C}$ & No applicable & $732{ }^{\circ} \mathrm{C}$ \\
\hline Density $\left(\mathrm{g} / \mathrm{cm}^{3}\right)$ & 7.14 at $25^{\circ} \mathrm{C}$ & 1.735 & 2.907 at $25^{\circ} \mathrm{C}$ \\
\hline Odor & No data & Faint acetous odor ${ }^{\mathrm{c}}$ & Odorless; fume has acrid odor ${ }^{c}$ \\
\hline \multicolumn{4}{|l|}{ Odor threshold: } \\
\hline Water & No data & No data & No data \\
\hline Air & No data & No data & No data \\
\hline \multicolumn{4}{|l|}{ Solubility: } \\
\hline Water & Insoluble $^{d}$ & $\begin{array}{l}4.0 \times 10^{4} \mathrm{mg} / \mathrm{L} \text { at } 25^{\circ} \mathrm{C} ; \\
6.7 \times 10^{4} \mathrm{mg} / \mathrm{L} \text { at } 100^{\circ} \mathrm{C}^{\mathrm{c}}\end{array}$ & $\begin{array}{l}4.32 \times 10^{6} \mathrm{mg} / \mathrm{L} \text { at } 25^{\circ} \mathrm{C} ; \\
6.14 \times 10^{6} \mathrm{mg} / \mathrm{L} \text { at } 100^{\circ} \mathrm{C}\end{array}$ \\
\hline $\begin{array}{l}\text { Other } \\
\text { solvent(s) }\end{array}$ & $\begin{array}{l}\text { Soluble in acetic acid and } \\
\text { alkali }\end{array}$ & $33 \mathrm{mg} / \mathrm{L}$ in alcohol & $\begin{array}{l}1 \mathrm{~g} / 1.3 \mathrm{~mL} \text { alcohol; } 1 \mathrm{~g} / 2 \mathrm{~mL} \\
\text { glyderol; } 1 \mathrm{~g} / 0.25 \mathrm{~mL} 2 \% \text { hydro- } \\
\text { chloroacetic acid }\end{array}$ \\
\hline \multicolumn{4}{|c|}{ Partition coefficients: } \\
\hline $\mathrm{K}_{\mathrm{d}}(\mathrm{mL} / \mathrm{g})$ & $\begin{array}{l}0.1-8,000^{\mathrm{e}} ; 40 \text { (average }^{\mathrm{f}} \\
39 \text { in sandy loam soil; } \\
12.2 \text { in sandy soil }\end{array}$ & No data & No data \\
\hline $\mathrm{K}_{\mathrm{ow}}$ & No data & No data & No data \\
\hline $\mathrm{K}_{\mathrm{oc}}$ & No data & No data & No data \\
\hline Vapor pressure & $1 \mathrm{~mm} \mathrm{Hg}$ at $487^{\circ} \mathrm{C}$ & Not data & Not data \\
\hline $\begin{array}{l}\text { Henry's law } \\
\text { constant }\end{array}$ & Not applicable & Not applicable & Not applicable \\
\hline $\begin{array}{l}\text { Autoignition } \\
\text { temperature }\end{array}$ & No data & No data & Not flammable ${ }^{h}$ \\
\hline Flashpoint & No data & No data & Not flammable ${ }^{\mathrm{h}}$ \\
\hline $\begin{array}{l}\text { Flammability } \\
\text { limits }\end{array}$ & No data & No data & Not flammable ${ }^{\mathrm{h}}$ \\
\hline $\begin{array}{l}\text { Conversion } \\
\text { factor }\end{array}$ & Not applicable & $\begin{array}{l}\mathrm{mg} \mathrm{Zn}\left(\mathrm{C}_{2} \mathrm{H}_{3} \mathrm{O}_{2}\right)_{2} \times 0.36 \\
=\mathrm{mg} \mathrm{Zn}\end{array}$ & $\mathrm{mg} \mathrm{ZnSO}_{4} \times 0.40=\mathrm{mg} \mathrm{Zn}$ \\
\hline Explosive limits & No data & No data & No data \\
\hline
\end{tabular}


Table 4-2. Physical and Chemical Properties of Zinc and Selected Compounds ${ }^{a}$

\begin{tabular}{|c|c|c|c|}
\hline Property & Zinc chromate & Zinc cyanide & Zinc hydroxide \\
\hline Molecular weight & 181.37 & 117.42 & 99.40 \\
\hline Color & Lemon-yellow & White $^{c}$ & Colorless $^{c}$ \\
\hline Physical state & Solid & Powder ${ }^{c}$ & Solid $^{c}$ \\
\hline Melting point & No data & $800^{\circ} \mathrm{C}$ (decomposes) ${ }^{\mathrm{c}}$ & $\begin{array}{l}\text { Decomposes at } 125 \\
{ }^{\circ} \mathrm{C}^{\mathrm{C}}\end{array}$ \\
\hline Boiling point & No data & Not applicable & Not applicable \\
\hline Density $\left(\mathrm{g} / \mathrm{cm}^{3}\right)$ & 3.40 & $1.852^{\mathrm{c}}$ & $3.053^{\mathrm{C}}$ \\
\hline Odor & Odorless & No data & No data \\
\hline \multicolumn{4}{|l|}{ Odor threshold: } \\
\hline Water & No data & No data & No data \\
\hline Air & No data & No data & No data \\
\hline \multicolumn{4}{|l|}{ Solubility: } \\
\hline Water & $\begin{array}{l}\text { Insoluble in cold water; sparingly } \\
\text { soluble }\end{array}$ & $\begin{array}{l}\text { Insoluble } \\
50 \mathrm{mg} / \mathrm{L} \text { at } 20{ }^{\circ} \mathrm{C}^{\mathrm{c}}\end{array}$ & Almost insoluble ${ }^{c}$ \\
\hline Other solvent(s) & $\begin{array}{l}\text { Soluble in acids, liquid ammonia; } \\
\text { insoluble in acetone }\end{array}$ & $\begin{array}{l}\text { Soluble in dilute mineral } \\
\text { acids }\end{array}$ & No data \\
\hline \multicolumn{4}{|l|}{ Partition coefficients: } \\
\hline $\mathrm{K}_{\mathrm{d}}(\mathrm{mL} / \mathrm{g})$ & No data & No data & No data \\
\hline $\mathrm{K}_{\mathrm{ow}}$ & No data & No data & No data \\
\hline $\mathrm{K}_{\mathrm{oc}}$ & No data & No data & No data \\
\hline Vapor pressure & No data & No data & No data \\
\hline $\begin{array}{l}\text { Henry's law } \\
\text { constant }\end{array}$ & Not applicable & Not applicable & Not applicable \\
\hline $\begin{array}{l}\text { Autoignition } \\
\text { temperature }\end{array}$ & No data & No data & No data \\
\hline Flashpoint & No data & No data & No data \\
\hline Flammability limits & No data & No data & No data \\
\hline Conversion factor & $\mathrm{mg} \mathrm{ZnCrO}_{4} \times 0.36=\mathrm{mg} \mathrm{Zn}$ & $\begin{array}{l}\mathrm{mg} Z \mathrm{Zn}(\mathrm{CN})_{2} \times 0.56= \\
\mathrm{mg} \mathrm{Zn}\end{array}$ & $\begin{array}{l}\mathrm{mg} \mathrm{Zn}(\mathrm{OH})_{2} \times 0.66= \\
\mathrm{mg} \mathrm{Zn}\end{array}$ \\
\hline Explosive limits & No data & No data & No data \\
\hline
\end{tabular}


Table 4-2. Physical and Chemical Properties of Zinc and Selected Compounds ${ }^{a}$

\begin{tabular}{|c|c|c|c|}
\hline Property & Zinc oxide & Zinc phosphate & Zinc sulfate \\
\hline $\begin{array}{l}\text { Molecular } \\
\text { weight }\end{array}$ & 81.38 & 386.11 & 161.44 \\
\hline Color & White/yellowish-white & White $^{c}$ & Colorless $^{i}$ \\
\hline Physical state & Solid & Powder ${ }^{c}$ & Solid \\
\hline Melting point & $1975^{\circ} \mathrm{C}$ & $900^{\circ} \mathrm{C}^{\mathrm{c}}$ & $680^{\circ} \mathrm{C}$ (decomposes) \\
\hline Boiling point & Sublimes & No data & No applicable \\
\hline $\begin{array}{l}\text { Density } \\
\left(\mathrm{g} / \mathrm{cm}^{3}\right)\end{array}$ & 5.607 at $20^{\circ} \mathrm{C}$ & 3.998 at $15^{\circ} \mathrm{C}^{\mathrm{c}}$ & 3.54 at $25^{\circ} \mathrm{C}$ \\
\hline Odor & Odorless & Odorless & Not determined \\
\hline \multicolumn{4}{|l|}{$\begin{array}{l}\text { Odor } \\
\text { threshold: }\end{array}$} \\
\hline Water & No data & No data & No data \\
\hline Air & No data & No data & No data \\
\hline \multicolumn{4}{|l|}{ Solubility: } \\
\hline Water & $1.6 \mathrm{mg} / \mathrm{L}$ at $29^{\circ} \mathrm{C}^{\mathrm{i}}$ & Insoluble ${ }^{j}$ & $\begin{array}{l}\text { Soluble in cold and hot } \\
\text { wateri; } 4.19 \times 10^{5} \mathrm{mg} / \mathrm{L} \text { at } \\
0^{\circ} \mathrm{C} ; 9.1 \times 10^{5} \mathrm{mg} / \mathrm{L} \text { at } 70 \\
{ }^{\circ} \mathrm{C}\end{array}$ \\
\hline $\begin{array}{l}\text { Other } \\
\text { solvent(s) }\end{array}$ & $\begin{array}{l}\text { Soluble in dilute acetic or mineral } \\
\text { acids, ammonia, ammonium } \\
\text { carbonate, fixed alkali hydroxide } \\
\text { solution, and ammonium chloride; } \\
\text { insoluble in alcohol }\end{array}$ & $\begin{array}{l}\text { Soluble in dilute mineral } \\
\text { acids, ammonium } \\
\text { hydroxide and alkali } \\
\text { hydroxide solutions; } \\
\text { insoluble in alcohol }\end{array}$ & $\begin{array}{l}\text { Slightly soluble in } \\
\text { alcohol; soluble in } \\
\text { methanol and glycerol'; } \\
1 \mathrm{~g} / 2.5 \mathrm{~mL} \text { glycerol }\end{array}$ \\
\hline \multicolumn{4}{|c|}{ Partition coefficients: } \\
\hline $\mathrm{K}_{\mathrm{d}}$ & No data & No data & No data \\
\hline $\mathrm{K}_{\mathrm{ow}}$ & No data & No data & No data \\
\hline $\mathrm{K}_{\mathrm{oc}}$ & No data & No data & No data \\
\hline $\begin{array}{l}\text { Vapor } \\
\text { pressure }\end{array}$ & Not data & No data & No data \\
\hline $\begin{array}{l}\text { Henry's law } \\
\text { constant }\end{array}$ & Not applicable & No data & Not applicable \\
\hline $\begin{array}{l}\text { Autoignition } \\
\text { temperature }\end{array}$ & Not flammable ${ }^{h}$ & No data & Not flammable ${ }^{\mathrm{h}}$ \\
\hline Flashpoint & Not flammable $^{\text {h }}$ & No data & Not flammable ${ }^{\mathrm{h}}$ \\
\hline $\begin{array}{l}\text { Flammability } \\
\text { limits }\end{array}$ & Not flammable $^{h}$ & No data & Not flammable ${ }^{h}$ \\
\hline $\begin{array}{l}\text { Conversion } \\
\text { factor }\end{array}$ & $\mathrm{mg} \mathrm{ZnO} \times 0.80=\mathrm{mg} Z \mathrm{n}$ & \multicolumn{2}{|c|}{$\begin{array}{l}\mathrm{mg} \mathrm{Zn}_{3}\left(\mathrm{PO}_{4}\right)_{2} \times 0.51={\mathrm{mg} \mathrm{mg} \mathrm{ZnSO}_{4}}_{\mathrm{Zn}} \times 0.40=\mathrm{mg} \\
\mathrm{Zn}\end{array}$} \\
\hline $\begin{array}{l}\text { Explosive } \\
\text { limits }\end{array}$ & No data & No data & No data \\
\hline
\end{tabular}


Table 4-2. Physical and Chemical Properties of Zinc and Selected Compounds ${ }^{a}$

\begin{tabular}{|c|c|c|}
\hline Property & Zinc sulfide $(\alpha)$ & Zinc sulfide $(\mathrm{\gamma})$ \\
\hline Molecular weight & 97.45 & 97.45 \\
\hline Color & Colorless ${ }^{i}$ & Colorless \\
\hline Physical state & Solid & Solid \\
\hline Melting point & $1,700 \pm 20^{\circ} \mathrm{C}$ & No data \\
\hline Boiling point & $1,185^{\circ} \mathrm{C}$ at $1 \mathrm{~atm}$ & $1,185^{\circ} \mathrm{C}$ at $1 \mathrm{~atm}$ \\
\hline Density $\left(\mathrm{g} / \mathrm{cm}^{3}\right)$ & 3.98 at $20^{\circ} \mathrm{C}^{\mathrm{i}} ; 4.087$ at $25^{\circ} \mathrm{C}$ & 4.102 at $25^{\circ} \mathrm{C}$ \\
\hline Odor & No data & No data \\
\hline \multicolumn{3}{|l|}{ Odor threshold: } \\
\hline Water & No data & No data \\
\hline Air & No data & No data \\
\hline \multicolumn{3}{|l|}{ Solubility: } \\
\hline Water & $6.9 \mathrm{mg} / \mathrm{L}$ at $18{ }^{\circ} \mathrm{C}^{\mathrm{i}}$ & $6.5 \mathrm{mg} / \mathrm{L}$ at $18{ }^{\circ} \mathrm{C}^{\mathrm{i}}$ \\
\hline Organic solvents & $\begin{array}{l}\text { Very soluble in alcohol; soluble in dilute mineral } \\
\text { acids; insoluble in acetic acid; insoluble in } \\
\text { alkalis }\end{array}$ & $\begin{array}{l}\text { Very soluble in alcohol; soluble in } \\
\text { dilute mineral acids; insoluble in } \\
\text { alkalis }\end{array}$ \\
\hline \multicolumn{3}{|c|}{ Partition coefficients: } \\
\hline $\mathrm{K}_{\mathrm{d}}$ & No data & No data \\
\hline $\mathrm{K}_{\mathrm{ow}}$ & No data & No data \\
\hline $\mathrm{K}_{\mathrm{oc}}$ & No data & No data \\
\hline Vapor pressure & No data & No data \\
\hline $\begin{array}{l}\text { Henry's law } \\
\text { constant }\end{array}$ & Not applicable & Not applicable \\
\hline $\begin{array}{l}\text { Autoignition } \\
\text { temperature }\end{array}$ & No data & No data \\
\hline Flashpoint & No data & No data \\
\hline $\begin{array}{l}\text { Flammability } \\
\text { limits }\end{array}$ & No data & No data \\
\hline Conversion factor & $\mathrm{mg} \mathrm{ZnS} \times 0.67=\mathrm{mg} \mathrm{Zn}$ & $\mathrm{mg} Z \mathrm{nS} \times 0.67=\mathrm{mg} Z \mathrm{n}$ \\
\hline Explosive limits & No data & No data \\
\hline
\end{tabular}

'Information obtained from O'Neil et al. (2001) except where noted.

${ }^{\mathrm{b}}$ ACGIH 1991

'Lewis 1997

dHSDB 2003

e Baes and Sharp 1983

f Baes et al. 1984

${ }^{\mathrm{g}}$ Gerritse et al. 1982

${ }^{\mathrm{h}}$ Weiss 1986

'Weast 1988

jGoodwin 1998

$\mathrm{Zn}=$ zinc; $\mathrm{Zn}\left(\mathrm{C}_{2} \mathrm{H}_{3} \mathrm{O}_{2}\right)_{2}=$ zinc acetate; $\mathrm{ZnCl}_{2}=$ zinc chloride; $\mathrm{ZnCrO}_{4}=$ zinc chromate; $\mathrm{Zn}(\mathrm{CN})_{2}=$ zinc cyanide; $\mathrm{Zn}(\mathrm{OH})_{2}=$ zinc hydroxide; $\mathrm{ZnO}=$ zinc oxide; $\mathrm{Zn}_{3}\left(\mathrm{PO}_{4}\right)_{2}=$ zinc phosphate; $\mathrm{ZnS}=$ zinc sulfide; $\mathrm{ZnSO}_{4}=\mathrm{Zinc}$ sulfate 


\section{PRODUCTION, IMPORT/EXPORT, USE, AND DISPOSAL}

\subsection{PRODUCTION}

No information is available in the TRI database on facilities that manufacture or process zinc because this chemical is not required to be reported under Section 313 of the Emergency Planning and Community Right-to-Know Act (Title III of the Superfund Amendments and Reauthorization Act of 1986) (EPA 1997).

Zinc is widely distributed in nature, constituting 20-200 ppm (by weight) of the Earth's crust (Goodwin 1998), but it is not found as elemental zinc in nature (Lloyd and Showak 1984). The procedure used to mine zinc varies with the composition of the ore. The mineral sphalerite $(\mathrm{ZnS})$ provides ca. $90 \%$ of the zinc produced today (Goodwin 1998). Zinc ore is mined using both underground mining and open pit mining (Stokinger 1981). The mined zinc ores are too low in zinc content for direct reduction to refined metal; thus, they are first concentrated. Production of concentrates requires crushing and grinding followed by gravity or magnetic methods of separation or flotation. These processes may be combined, depending on the complexity of the ore. A caustic-leach process is used to decrease the extent of metal loss during the concentration process. In this process, the metal is leached by caustic soda, the resulting electrolyte is purified with zinc dust and lime, and the zinc is electrodeposited. The crude zinc may be dissolved in sulfuric acid and purified by electrodeposition. Two processes are used to produce metallic zinc from the ore concentrates that are not subjected to caustic soda leaching. In one process, the ore concentrate containing zinc sulfide is roasted in the presence of air to produce zinc oxide, which is combined with coke or coal and retorted to approximately $1,100{ }^{\circ} \mathrm{C}$ to produce metallic zinc. In the other process, the roasted zinc oxide is leached with sulfuric acid, and the solution is electrolyzed to produce zinc of $>99.9 \%$ purity. The electrolytic processing of zinc is replacing smelting as the most commonly used process (Lloyd and Showak 1984; Stokinger 1981).

Continued low zinc prices in 2001 have resulted in operation reductions and facility closures across the United States. By the end of 2001, 12 mines in 5 states were in operation in the United States. Alaska was the leading zinc-mining state, followed by (in descending order) Tennessee, Missouri, New York, and Montana. Alaska also had the largest production of recoverable zinc in the United States in 2001, followed by Missouri, Montana, and New York. In 2001, three companies operated three primary zinc refineries (Zinc Corporation of America, Monaco, Pennsylvania; Big River Zinc Corporation, Sauget, 
Illinois; and Pasminco Ltd., Clarksville, Tennessee) (USGS 2001). Tables 5-1 and 5-2 summarize the facilities that manufacture or process zinc and zinc compounds, respectively, in the United States. The information in this table was obtained from the Toxics Release Inventory (TRI), and it summarizes the reported release data for 2002 (TRI02 2004). However, this list does not include all facilities that manufacture or process zinc and zinc compounds. Tables 5-1 and 5-2 also list the maximum amounts of zinc and zinc compounds, respectively, that are present at these sites and the end uses of zinc. In 2001, approximately 799,000 metric tons of zinc was produced in the United States from domestic ores. The estimated world production from mines in 2001 was $8,850,000$ metric tons. The world production of zinc has increased from 1997 to 2001 (USGS 2001).

Zinc is available in many commercial forms, including ingots, lumps, sheets, wire, shot, strips, sticks, granules, granulated zinc (obtained when molten metal is poured into cold water), and powder (O'Neil et al. 2001).

\subsection{IMPORT/EXPORT}

In 2002, approximately 874,000 metric tons of zinc were imported to the United States as refined slab zinc, 122,000 metric tons were imported as ores and concentrates, and 7,240 metric tons were imported as rolled zinc. In 2002, the United States imported more refined slab and rolled zinc than in 2001, going against the trend observed in the previous 4 years. More ores and concentrate were imported in 2002 than in the previous 4 years (USGS 2003).

In 2002, an estimated 822,000 metric tons of ores and concentrates, 1,160 metric tons of slab zinc, and 7,200 metric tons of rolled zinc were exported from the United States. In contrast, exports of ores and concentrates reached approximately 23,000 metric tons in 1985 and 461,000 in 1997 (DOI 1988, 1991; USGS 2002). In 2001, the United States exported the largest amounts of zinc ores and concentrates to Japan (210,000 metric tons), Canada (171,000 metric tons) and Spain (122,000 metric tons) (USGS 2002).

\subsection{USE}

Zinc metal is used most commonly as a protective coating of other metals, such as iron and steel. Methods, in general, include hot-dip galvanizing, continuous-line galvanizing, electro-galvanizing, zinc 
Table 5-1. Facilities that Produce, Process, or Use Zinc

\begin{tabular}{|c|c|c|c|c|}
\hline State $^{a}$ & $\begin{array}{l}\text { Number of } \\
\text { facilities }\end{array}$ & $\begin{array}{l}\text { Minimum amount } \\
\text { on site in pounds }\end{array}$ & $\begin{array}{l}\text { Maximum } \\
\text { amount on site in } \\
\text { pounds }{ }^{b}\end{array}$ & Activities and uses ${ }^{c}$ \\
\hline$\overline{\mathrm{AK}}$ & 1 & 0 & 99 & 1,5 \\
\hline$A L$ & 64 & 0 & $499,999,999$ & $1,2,3,4,5,6,7,8,9,10,11,12,13$ \\
\hline AR & 57 & 0 & $499,999,999$ & $1,2,3,4,5,6,7,8,9,10,11,12,14$ \\
\hline$A Z$ & 23 & 0 & 999,999 & $1,2,3,4,5,6,7,8,10,12,13$ \\
\hline CA & 112 & 0 & $499,999,999$ & $1,2,3,4,5,6,7,8,9,10,11,12,13,14$ \\
\hline $\mathrm{CO}$ & 25 & 0 & $9,999,999$ & $1,2,3,4,5,6,7,8,9,10,11,12,13,14$ \\
\hline $\mathrm{CT}$ & 25 & 0 & $49,999,999$ & $1,2,3,4,5,6,7,8,9,10,12$ \\
\hline FL & 27 & 100 & $499,999,999$ & $1,2,3,4,5,6,7,8,9,10,12,13$ \\
\hline GA & 43 & 0 & $499,999,999$ & $1,2,3,4,5,6,7,8,9,10,11,12$ \\
\hline IA & 34 & 0 & $49,999,999$ & $1,2,3,4,5,6,7,8,9,10,11,12,13$ \\
\hline ID & 10 & 0 & $49,999,999$ & $1,3,5,8,12,13$ \\
\hline IL & 128 & 0 & $999,999,999$ & $1,2,3,4,5,6,7,8,9,10,11,12,13$ \\
\hline IN & 64 & 0 & $9,999,999$ & $1,2,3,4,5,6,7,8,9,10,11,12,13$ \\
\hline KS & 16 & 0 & 999,999 & $1,3,4,5,6,7,8,9,11,12,13$ \\
\hline KY & 59 & 0 & $99,999,999$ & $1,2,3,4,5,6,7,8,9,10,11,12,13$ \\
\hline LA & 55 & 0 & $99,999,999$ & $1,2,3,4,5,6,7,8,9,10,11,12,13$ \\
\hline MA & 30 & 0 & 999,999 & $1,2,3,4,5,6,7,8,9,10,11,12,13$ \\
\hline MD & 16 & 0 & 999,999 & $1,2,3,4,5,7,8,9,10,11$ \\
\hline ME & 7 & 100 & $49,999,999$ & 8,11 \\
\hline MI & 88 & 0 & $49,999,999$ & $1,2,3,4,5,6,7,8,9,10,11,12,13$ \\
\hline MN & 23 & 100 & 999,999 & $1,3,4,5,7,8,9,10,11,12,13$ \\
\hline MO & 52 & 0 & $499,999,999$ & $1,2,3,4,5,6,7,8,9,10,11,12,13$ \\
\hline MS & 19 & 0 & $99,999,999$ & $2,3,5,7,8,9,10,11,12$ \\
\hline NC & 44 & 0 & $9,999,999$ & $1,2,3,4,5,6,7,8,9,10,11,12,13,14$ \\
\hline ND & 1 & 100 & 999 & 12 \\
\hline NE & 18 & 100 & $49,999,999$ & $1,2,3,4,5,7,8,9,10,11,13$ \\
\hline $\mathrm{NH}$ & 7 & 0 & 99,999 & $1,5,7,8,12$ \\
\hline NJ & 64 & 0 & $99,999,999$ & $1,2,3,4,5,6,7,8,9,10,11,12,13$ \\
\hline NM & 4 & 1,000 & $9,999,999$ & $1,5,8,12$ \\
\hline NV & 6 & 10,000 & $9,999,999$ & $1,2,3,5,6,7,8,10,11,12$ \\
\hline NY & 55 & 0 & $49,999,999$ & $1,2,3,4,5,6,7,8,9,10,11,12,13$ \\
\hline $\mathrm{OH}$ & 115 & 0 & $499,999,999$ & $1,2,3,4,5,6,7,8,9,10,11,12,13$ \\
\hline OK & 40 & 0 & $499,999,999$ & $1,2,3,4,5,6,7,8,9,10,11,12,13$ \\
\hline OR & 19 & 100 & 999,999 & $1,2,3,4,5,7,8,9,11,12$ \\
\hline PA & 112 & 0 & $99,999,999$ & $1,2,3,4,5,6,7,8,9,10,11,12,13,14$ \\
\hline PR & 11 & 100 & 999,999 & $1,2,3,5,7,8,10$ \\
\hline RI & 11 & 100 & 999,999 & $1,3,4,5,8,9,10$ \\
\hline SC & 44 & 0 & $49,999,999$ & $1,2,3,4,5,6,7,8,9,10,11,12,13$ \\
\hline
\end{tabular}


Table 5-1. Facilities that Produce, Process, or Use Zinc

\begin{tabular}{|c|c|c|c|c|}
\hline State $^{a}$ & $\begin{array}{l}\text { Number of } \\
\text { facilities }\end{array}$ & $\begin{array}{l}\text { Minimum amount } \\
\text { on site in pounds }\end{array}$ & $\begin{array}{l}\text { Maximum } \\
\text { amount on site in } \\
\text { pounds }^{b}\end{array}$ & Activities and uses ${ }^{c}$ \\
\hline SD & 6 & 1,000 & 99,999 & $1,2,3,5,7,8,12,14$ \\
\hline $\mathrm{TN}$ & 66 & 0 & $49,999,999$ & $1,2,3,4,5,6,7,8,9,10,11,12,13,14$ \\
\hline $\mathrm{TX}$ & 97 & 0 & $499,999,999$ & $1,2,3,4,5,6,7,8,9,10,11,12,13,14$ \\
\hline UT & 18 & 100 & $99,999,999$ & $1,2,3,4,5,6,7,8,9,10,12,13$ \\
\hline VA & 42 & 0 & $49,999,999$ & $1,2,3,4,5,6,7,8,9,10,11,12,13$ \\
\hline VT & 2 & 10,000 & 99,999 & $1,5,8$ \\
\hline WA & 21 & 100 & $499,999,999$ & $1,2,3,4,5,6,7,8,9,12,13$ \\
\hline WI & 57 & 0 & $99,999,999$ & $1,2,3,4,5,6,7,8,9,10,11,12,13$ \\
\hline WV & 34 & 0 & 49,999,999 & $1,2,3,4,5,6,7,8,9,11,12,13$ \\
\hline WY & 6 & 1,000 & 999,999 & $1,4,6,9,10,12$ \\
\hline
\end{tabular}

Source: TRI02 2004 (Data are from 2002)

${ }^{\mathrm{a}}$ Post office state abbreviations used

${ }^{\mathrm{b}}$ Amounts on site reported by facilities in each state

${ }^{\mathrm{c} A c t i v i t i e s / \text { Uses: }}$
1. Produce
6. Impurity
2. Import
7. Reactant
11. Chemical Processing Aid
3. Onsite use/processing
8. Formulation Component
12. Manufacturing Aid
4. Sale/Distribution
9. Article Component
13. Ancillary/Other Uses
5. Byproduct
10. Repackaging
14. Process Impurity 
Table 5-2. Facilities that Produce, Process, or Use Zinc Compounds

\begin{tabular}{|c|c|c|c|c|}
\hline & Number & f Minimum amount & Maximum amount & \\
\hline State $^{a}$ & facilities & on site in pounds ${ }^{b}$ & on site in pounds ${ }^{b}$ & Activities and uses ${ }^{c}$ \\
\hline$\overline{\mathrm{AK}}$ & 12 & 10,000 & $10,000,000,000$ & $1,2,3,4,5,6,7,9,10,12,13$ \\
\hline$A L$ & 166 & 0 & $99,999,999$ & $1,2,3,4,5,6,7,8,9,10,11,12,13,14$ \\
\hline AR & 146 & 0 & $499,999,999$ & $1,2,3,4,5,6,7,8,9,10,11,12,13,14$ \\
\hline$A Z$ & 66 & 100 & $10,000,000,000$ & $1,2,3,4,5,6,7,8,9,10,11,12,13,14$ \\
\hline CA & 237 & 0 & $499,999,999$ & $1,2,3,4,5,6,7,8,9,10,11,12,13,14$ \\
\hline $\mathrm{CO}$ & 47 & 0 & $49,999,999$ & $1,2,3,4,5,6,7,8,9,10,11,12,13,14$ \\
\hline CT & 97 & 0 & $99,999,999$ & $1,2,3,4,5,6,7,8,9,10,11,12,13$ \\
\hline DE & 36 & 100 & 999,999 & $1,2,3,4,5,6,7,8,9,10,11,12,13,14$ \\
\hline FL & 97 & 0 & $9,999,999$ & $1,2,3,4,5,6,7,8,9,10,11,12,13,14$ \\
\hline GA & 182 & 0 & $49,999,999$ & $1,2,3,4,5,6,7,8,9,10,11,12,13,14$ \\
\hline $\mathrm{HI}$ & 13 & 100 & 999,999 & $1,2,3,4,5,7,9,10,12$ \\
\hline IA & 127 & 0 & $499,999,999$ & $1,2,3,4,5,6,7,8,9,10,11,12,13,14$ \\
\hline ID & 25 & 0 & $49,999,999$ & $1,2,3,5,6,7,8,10,11,12,13$ \\
\hline IL & 348 & 0 & $499,999,999$ & $1,2,3,4,5,6,7,8,9,10,11,12,13,14$ \\
\hline IN & 241 & 0 & $499,999,999$ & $1,2,3,4,5,6,7,8,9,10,11,12,13,14$ \\
\hline KS & 81 & 0 & $99,999,999$ & $1,2,3,4,5,6,7,8,9,10,11,12,13,14$ \\
\hline KY & 134 & 0 & $49,999,999$ & $1,2,3,4,5,6,7,8,9,10,11,12,13,14$ \\
\hline LA & 153 & 0 & $99,999,999$ & $1,2,3,4,5,6,7,8,9,10,11,12,13,14$ \\
\hline MA & 114 & 0 & $99,999,999$ & $1,2,3,4,5,6,7,8,9,10,11,12,13,14$ \\
\hline MD & 75 & 0 & $99,999,999$ & $1,2,3,4,5,6,7,8,9,10,11,12,13$ \\
\hline ME & 31 & 0 & 999,999 & $1,3,5,6,7,8,10,11,12,13$ \\
\hline MI & 314 & 0 & $999,999,999$ & $1,2,3,4,5,6,7,8,9,10,11,12,13,14$ \\
\hline MN & 79 & 0 & $9,999,999$ & $1,2,3,4,5,6,7,8,9,10,11,12,13,14$ \\
\hline $\mathrm{MO}$ & 164 & 0 & $499,999,999$ & $1,2,3,4,5,6,7,8,9,10,11,12,13,14$ \\
\hline MS & 94 & 0 & $99,999,999$ & $1,2,3,4,5,6,7,8,9,10,11,12,13,14$ \\
\hline MT & 16 & 100 & $10,000,000,000$ & $1,2,3,4,5,6,7,8,9,10,11,12,13,14$ \\
\hline NC & 139 & 0 & $9,999,999$ & $1,2,3,4,5,6,7,8,9,10,11,12,13,14$ \\
\hline ND & 9 & 1,000 & 99,999 & $1,5,7,9,12,13$ \\
\hline NE & 84 & 0 & $49,999,999$ & $1,2,3,4,5,6,7,8,9,10,11,12,13$ \\
\hline $\mathrm{NH}$ & 18 & 0 & 999,999 & $1,5,6,7,8,9,10,12$ \\
\hline NJ & 173 & 0 & $499,999,999$ & $1,2,3,4,5,6,7,8,9,10,11,12,13$ \\
\hline NM & 22 & 0 & $10,000,000,000$ & $1,3,4,5,7,8,9,10,11,12,13,14$ \\
\hline NV & 61 & 0 & $999,999,999$ & $1,2,3,4,5,6,7,8,9,10,11,12,13,14$ \\
\hline NY & 180 & 0 & $10,000,000,000$ & $1,2,3,4,5,6,7,8,9,10,11,12,13,14$ \\
\hline $\mathrm{OH}$ & 405 & 0 & $999,999,999$ & $1,2,3,4,5,6,7,8,9,10,11,12,13,14$ \\
\hline OK & 105 & 0 & $499,999,999$ & $1,2,3,4,5,6,7,8,9,10,11,12,13,14$ \\
\hline OR & 55 & 0 & $9,999,999$ & $1,2,3,4,5,6,7,8,9,10,11,12,13,14$ \\
\hline PA & 279 & 0 & $499,999,999$ & $1,2,3,4,5,6,7,8,9,10,11,12,13,14$ \\
\hline PR & 52 & 0 & $999,999,999$ & $1,2,3,4,5,6,7,8,9,10,11,12$ \\
\hline
\end{tabular}




\section{Table 5-2. Facilities that Produce, Process, or Use Zinc Compounds}

\begin{tabular}{|c|c|c|c|c|}
\hline State $^{a}$ & $\begin{array}{l}\text { Number } \\
\text { facilities }\end{array}$ & $\begin{array}{l}\text { f Minimum amount } \\
\text { on site in pounds }\end{array}$ & $\begin{array}{l}\text { Maximum amount } \\
\text { on site in pounds }\end{array}$ & Activities and uses ${ }^{c}$ \\
\hline $\mathrm{RI}$ & 35 & 100 & 999,999 & $1,2,3,4,5,6,7,8,10,11,12$ \\
\hline SC & 136 & 0 & $499,999,999$ & $1,2,3,4,5,6,7,8,9,10,11,12,13,14$ \\
\hline SD & 15 & 100 & $9,999,999$ & $1,5,7,8,9,10,11,12,13$ \\
\hline TN & 209 & 0 & $499,999,999$ & $1,2,3,4,5,6,7,8,9,10,11,12,13,14$ \\
\hline TX & 336 & 0 & $499,999,999$ & $1,2,3,4,5,6,7,8,9,10,11,12,13,14$ \\
\hline UT & 68 & 0 & $499,999,999$ & $1,2,3,4,5,6,7,8,9,10,11,12,13,14$ \\
\hline VA & 112 & 0 & $49,999,999$ & $1,2,3,4,5,6,7,8,9,10,11,12,13,14$ \\
\hline VT & 6 & 1,000 & 99,999 & 6,7 \\
\hline WA & 56 & 0 & $9,999,999$ & $1,2,3,4,5,6,7,8,9,10,11,12,13,14$ \\
\hline WI & 156 & 0 & $499,999,999$ & $1,2,3,4,5,6,7,8,9,10,11,12,13,14$ \\
\hline WV & 76 & 0 & $499,999,999$ & $1,2,3,4,5,6,7,8,9,10,11,12,13,14$ \\
\hline WY & 15 & 0 & $9,999,999$ & $1,3,4,5,6,7,9,12,13$ \\
\hline
\end{tabular}

Source: TRI02 2004 (Data are from 2002)

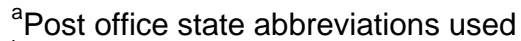

${ }^{\mathrm{b}}$ Amounts on site reported by facilities in each state

${ }^{\mathrm{c} A c t i v i t i e s / U s e s:}$
1. Produce
6. Impurity
2. Import
7. Reactant
11. Chemical Processing Aid
3. Onsite use/processing
8. Formulation Component
12. Manufacturing Aid
4. Sale/Distribution
9. Article Component
13. Ancillary/Other Uses
5. Byproduct
10. Repackaging
14. Process Impurity 
plating, zinc spraying, and painting with zinc-bearing paints. Some examples of galvanized materials include nails, water towers, and electrical transmission towers. Because zinc metal lacks strength, it is frequently alloyed with other metals (e.g., aluminum, copper, titanium, and magnesium) to impart a range of properties. When zinc metal is the primary component of the alloy, it is called a 'zinc-base' alloy, which is primarily used for casting and wrought applications. Other important applications of zinc alloys are in dye-casting, construction, and in other alloys (e.g., brass and bronze) which may be found in electrical components of many household goods. Also, alloys containing zinc and copper are used to make U.S. one-cent coins. Zinc metal dust is widely used in paint coatings, as a catalyst, and as a reducing and precipitating agent in organic and analytical chemistry (Goodwin 1998). As shown in Table 5-3, in 2002, the reported consumption of zinc by industry was 265,000 metric tons $(53.4 \%$ of total consumption) for galvanizing; 103,000 metric tons (20.8\% of total consumption) for zinc-based alloys; and 86,800 metric tons (17.5\% of total consumption) for bass and bronze (USGS 2002).

Zinc compounds have dental, medical, and household applications. In pharmaceuticals, zinc salts are used as solubilizing agents in many drugs, including insulin (Lloyd 1984; Lloyd and Showak 1984; Windholz 1983). Zinc compounds are utilized therapeutically in human medicine in the treatment of zinc deficiency (Keen and Hurley 1977). Zinc oxide accounts for the largest use of zinc compounds, and is used primarily by the rubber industry as a vulcanization activator and accelerator and to slow rubber aging by neutralizing sulfur and organic acids formed by oxidation. It also acts in rubber as a reinforcing agent, a heat conductor, a white pigment, and an absorber of UV light. In paints, zinc oxide serves as a mildewstat, acid buffer, and a pigment. It is used in animal feed as a zinc supplement and as a fertilizeradditive for zinc-deficient soils. Zinc oxide is used in cosmetics and drugs primarily for its fungicide properties, and in dentistry in dental cements. It is also used in ceramics, in glass manufacture, as a catalyst in organic synthesis, and in coated photocopy paper (Goodwin 1998). The largest uses of zinc chloride in the United States are in wood preservation, solder fluxes, and batteries. Solutions of zinc chloride are widely used in mercerizing cotton and as a mordant in dying. In medicine, zinc chloride is used as an antiseptic, disinfectant, deodorant, and in dental cements. Other uses are in organic synthesis, as a dehydrant, in rubber vulcanization, and in oil refining (Goodwin 1998). Zinc chloride is a primary ingredient in smoke bombs used for crowd dispersal, in fire-fighting exercises (by both military and civilian communities), and by the military for screening purposes (WHO 2001). Zinc sulfate is used in fertilizers, sprays, and animal feed as a trace element and disease-control agent. It is used in the manufacture of rayon (as crenulating agent), as a starting material for many zinc chemicals, in textile dying and printing, in flotation reagents, for electrogalvanizing, in paper bleaching, and in glue (Goodwin 1998). Zinc sulfide is used as a phosphor (watches, TV screens), a white pigment, and in dental materials 
Table 5-3. Distribution of U.S. Zinc Consumption in 2002

\begin{tabular}{lcc}
\hline Use & Total (metric tons) & Percent of total \\
\hline Galvanizing & 265,000 & 53.4 \\
Zinc-based alloys & 103,000 & 20.8 \\
Brass and bronze $_{\text {Total }^{\mathrm{a}}}$ & 86,800 & 17.5 \\
\hline
\end{tabular}

Source: USGS 2002

${ }^{\text {a }}$ The data were rounded off to three significant figures and therefore the sum of the total may not equal the total amount reported. A small unspecified amount of zinc was consumed for "other" uses. 
(especially in form of lithopone) (O’Neil et al. 2001). Uses for zinc acetate are as a wood preservative, a mordant for antiseptics, a catalyst, and a waterproofing agent. Zinc cyanide has two uses: electroplating and gold extraction. The primary uses of zinc phosphate are in preparation of metal coatings and as a dental cement (Goodwin 1998). Zinc chromate is used in pigments. Zinc hydroxide uses are as an intermediate, as an absorbent in surgical dressings, and in rubber compounding (Lewis 1997).

\subsection{DISPOSAL}

Zinc processing plants have attempted to limit releases to the environment by using techniques such as water reuse, control of particulate emissions, and filtration thickener overflow. In addition, liquid effluents are limed and allowed to settle so that zinc can precipitate out as the hydroxide (Lloyd and Showak 1984). Waste products containing zinc are also being used as a source of zinc for electrogalvanizing (Jolly 1988). Disposal procedures for spills include ferric hydroxide precipitation and cement-based fixation processes; the latter method is very effective in rendering zinc contaminants insoluble (Dawson and Mercer 1986). Unsalvageable zinc waste may be buried in an approved landfill while salvageable zinc is typically recycled. In 2003, an estimated 370,000 tons of zinc were recovered from waste and scrap in the United States; about 30\% was recovered in the form of slab zinc and the remainder was recovered in alloys, oxide, and chemicals. Of the total amount of scrap recycled, in 2002, 319,000 tons was derived from new scrap and 47,300 tons were derived from old scrap. About 25,000 tons of scrap in the United States were exported mainly to China, India, and Taiwan. Most of this scrap (95\%) came from Canada (USGS 2003).

In 1989, EPA applied its revised interpretation of the Bevill Amendment (exclusion) to solid waste from the extraction, beneficiation, and processing of ores and minerals. The slag from the primary zinc processing is the only zinc-related waste remaining in the Bevill exclusion (DOI 1991). 



\section{POTENTIAL FOR HUMAN EXPOSURE}

\subsection{OVERVIEW}

Zinc has been identified in at least 985 of the 1,662 hazardous waste sites that have been proposed for inclusion on the EPA National Priorities List (NPL) (HazDat 2005). However, the number of sites evaluated for zinc is not known. The frequency of these sites can be seen in Figure 6-1. Of these sites, 969 are located within the United States, and 2, 12, and 2 sites are located in the Commonwealth of Guam, Puerto Rico, and the Virgin Islands, respectively.

Zinc is an element commonly found in the Earth's crust. It is released to the environment from both natural and anthropogenic sources; however, releases from anthropogenic sources are greater than those from natural sources. The primary anthropogenic sources of zinc in the environment (air, water, soil) are related to mining and metallurgic operations involving zinc and use of commercial products containing zinc. Worldwide, releases to soil are probably the greatest source of zinc in the environment. The most important sources of anthropogenic zinc in soil come from discharges of smelter slags and wastes, mine tailings, coal and bottom fly ash, and the use of commercial products such as fertilizers and wood preservatives that contain zinc. Zinc does not volatilize from soil. Although zinc usually remains adsorbed to soil, leaching has been reported at waste disposal sites. Zinc does not volatilize from water but is deposited primarily in sediments through adsorption and precipitation. Severe zinc contamination tends to be confined to areas near emission sources. Large amounts of contaminated soil would need to be ingested in order to reach the registered dietary index value of 3.3-3.8 $\mathrm{mg}$ of zinc a day. It is therefore unlikely that the zinc found in the contaminated soil would pose a health risk if ingested.

Zinc is capable of forming complexes with a variety of organic and inorganic groups (ligands).

Biological activity can affect the mobility of zinc in the aquatic environment, although the biota contains relatively little zinc compared to the sediments. Zinc bioconcentrates moderately in aquatic organisms; bioconcentration is higher in crustaceans and bivalve species than in fish. Zinc does not concentrate in plants, and it does not biomagnify through terrestrial food chains.

In some fish, it has been observed that the level of zinc found in their bodies did not directly relate to the exposure concentrations. A recent study shows that bioaccumulation of zinc in fish is inversely related to 
Figure 6-1. Frequency of NPL Sites with Zinc Contamination

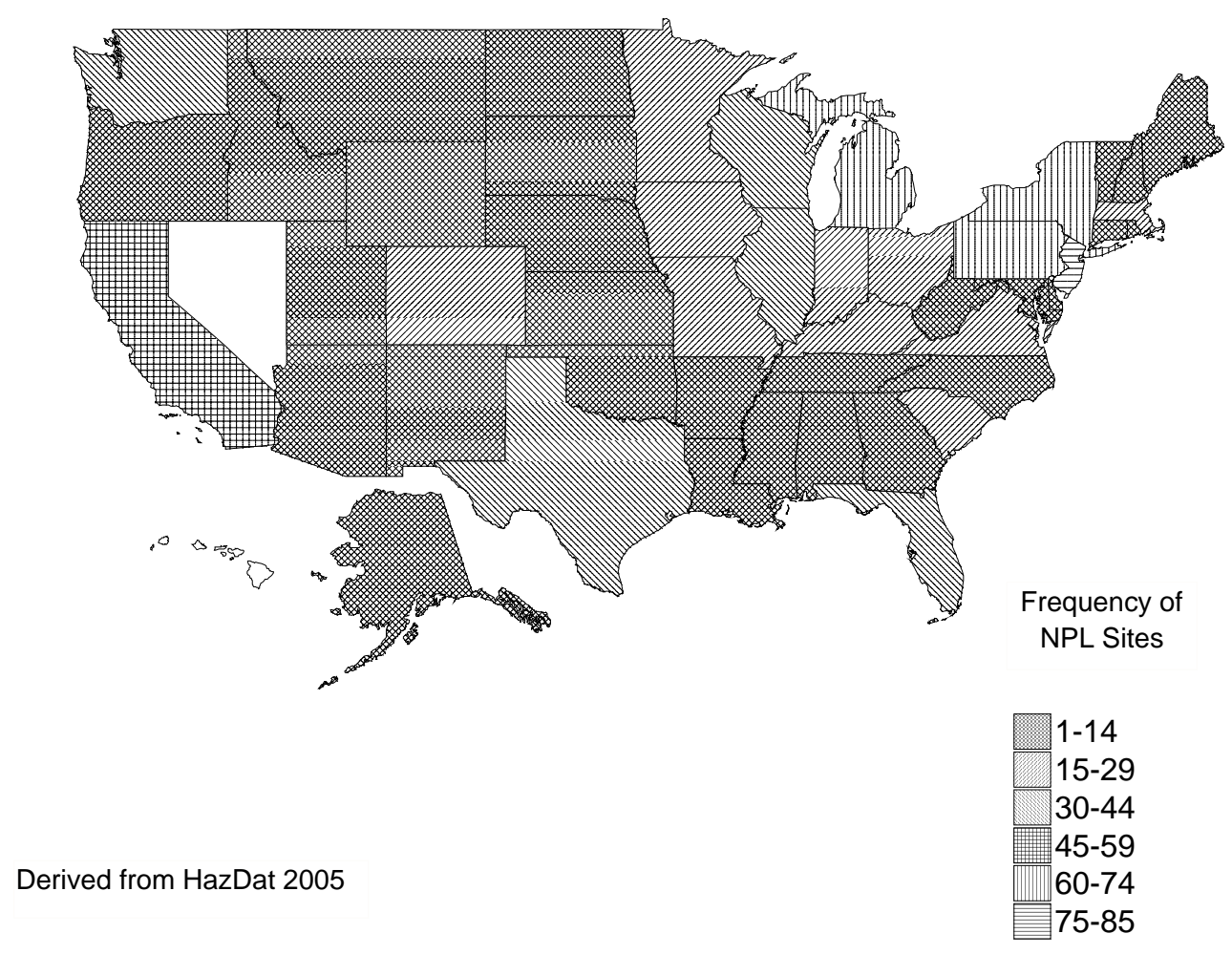


the aqueous exposure (McGeer et al. 2003). This evidence suggests that fish placed in environments with lower zinc concentrations can sequester zinc in their bodies.

There are few data regarding the speciation of zinc released to the atmosphere. Zinc is removed from the air by dry and wet deposition, but zinc particles with small diameters and low densities suspended in the atmosphere travel long distances from emission sources.

Zinc has been detected in air, surface water, groundwater, and soil; the frequency of detection and the concentrations are greatest near source areas (e.g., hazardous waste sites and industrial areas such as lead smelters). In a survey by the National Air Surveillance Network, the mean concentration of zinc in the air in the United States in $1977-1979$ was $0.02-0.16 \mu \mathrm{g} / \mathrm{m}^{3}$ for urban air compared to $0.01-0.05 \mu \mathrm{g} / \mathrm{m}^{3}$ for rural air. The concentrations of zinc in the air of remote areas range from $<0.003$ to $0.027 \mu \mathrm{g} / \mathrm{m}^{3}$. The mean concentrations of zinc in ambient water and drinking water range from 0.02 to $0.05 \mathrm{mg} / \mathrm{L}$ and from 0.01 to $0.1 \mathrm{mg} / \mathrm{L}$, respectively. The concentration of zinc in drinking water can often be higher than the concentration in the raw water from which the drinking water was obtained because zinc may leach from transmission and distribution pipes. The concentration of zinc in standing water from galvanized household water pipes was $\leq 1.3 \mathrm{mg} / \mathrm{L}$ (Sharrett et al. 1982a). The concentration of zinc in cultivated soils in the United States ranged from $<5$ to $400 \mathrm{mg} / \mathrm{kg}$, with a mean of $36 \mathrm{mg} / \mathrm{kg}$, compared to a range of $<10$ $2,000 \mathrm{mg} / \mathrm{kg}$, with a mean of $51 \mathrm{mg} / \mathrm{kg}$, in uncultivated soils; this probably results from the differences in soils used for farming rather than the use of zinc in agriculture. Concentrations of zinc can be high in soils from contaminated sites, such as waste dumps.

The concentrations of zinc in various foods and human tissues have also been determined. Certain population groups may be exposed to higher concentrations of zinc than the general population. People who work in coal mines, people who work with the refining and smelting of nonferrous metals, and people who live near waste sites and metal smelting operations may be exposed to high levels of zinc. A study of the tissue of deceased copper smelter workers in Sweden showed that they had, on average, 58.9 and $31.5 \mathrm{mg} / \mathrm{kg}$ wet weight of zinc in the liver and kidney, respectively, as compared to the controls, who had 47.2 and $23.3 \mathrm{mg} / \mathrm{kg}$ wet weight of zinc in the liver and kidney, respectively. The controls, however, had a higher concentration of zinc in the hair $(233 \mathrm{mg} / \mathrm{kg}$ as opposed to the smelter workers who had $212 \mathrm{mg} / \mathrm{kg}$ ) (Gerhardsson et al. 2002). People who consume large amounts of foods high in zinc content, such as oysters and mussels, may also be exposed to elevated levels of zinc. The zinc body burdens of the copper smelter workers were not significantly different than that of the controls. Higher exposure may or may not be manifested as increased body burden in the exposed individuals. 
According to NHANES 1999-2000 dietary data, a large portion of obese people over the age of 50 are not getting the recommended amount of zinc (Bermudez et al. 2003). The RDA for zinc is $11 \mathrm{mg} /$ day for men and $8 \mathrm{mg} /$ day for women (see Section 3.1). Much of the human zinc intake comes from eating meat and meat products. A typical Italian diet contains about $10.6 \mathrm{mg}$ of dietary zinc per day, where $4.3 \mathrm{mg}$ of zinc comes from meat and meat products (Lombardi-Boccia et al. 2003). Nonvegetarians absorb a higher percentage of zinc (3.7 mg/day) than vegetarians (2.4 mg/day) (Hunt 2003; Hunt et al. 1998). Infants also need zinc, and the RDA for zinc in pregnant and nursing mothers is $12 \mathrm{mg} / \mathrm{day}$. A recent study of breast milk in lactating mothers showed an average zinc concentration of about $5.65 \mathrm{mg} / \mathrm{L}$. This average did not vary much depending on the age of the mother (Honda et al. 2003).

\subsection{RELEASES TO THE ENVIRONMENT}

The TRI data should be used with caution because only certain types of facilities are required to report (EPA 1997). This is not an exhaustive list. Manufacturing and processing facilities are required to report information to the Toxics Release Inventory only if they employ 10 or more full-time employees; if their facility is classified under Standard Industrial Classification (SIC) codes 20-39; and if their facility produces, imports, or processes $\geq 25,000$ pounds of any TRI chemical or otherwise uses $>10,000$ pounds of a TRI chemical in a calendar year (EPA 1997).

Zinc is commonly found in the earth's crust, and natural releases to the environment can be significant. In addition, zinc is one of the most widely used metals in the world. The major industrial sources of zinc include electroplating, smelting and ore processing, and drainage from both active and inactive mining operations (Mirenda 1986). Furthermore, zinc is an important component of brass, bronze, die casting metal, other alloys, rubber, and paints. The environmental releases of zinc from sources of human origin far exceed the releases from natural sources (Fishbein 1981).

\subsubsection{Air}

Estimated releases of 0.91 million pounds ( 413 metric tons) of zinc to the atmosphere from 389 domestic manufacturing and processing facilities in 2002, accounted for about $1.9 \%$ of the estimated total environmental releases from facilities required to report to the TRI (TRI02 2004). These releases are summarized in Table 6-1. 
Table 6-1. Releases to the Environment from Facilities that Produce, Process, or Use Zinc ${ }^{a}$

\begin{tabular}{|c|c|c|c|c|c|c|c|c|c|}
\hline \multirow[b]{3}{*}{ State $^{c}$} & \multirow[b]{3}{*}{$R F^{d}$} & \multicolumn{8}{|c|}{ Reported amounts released in pounds per year ${ }^{b}$} \\
\hline & & \multirow[b]{2}{*}{$\mathrm{Air}^{\mathrm{e}}$} & \multirow[b]{2}{*}{ Water $^{f}$} & \multirow[b]{2}{*}{$\mathrm{UI}^{\mathrm{g}}$} & \multirow[b]{2}{*}{ Land $^{\mathrm{h}}$} & \multirow[b]{2}{*}{ Other ${ }^{i}$} & \multicolumn{3}{|c|}{ Total release } \\
\hline & & & & & & & On-site & Off-site & $\begin{array}{l}\text { On- and } \\
\text { off-site }\end{array}$ \\
\hline$\overline{\mathrm{AL}}$ & 9 & 25,166 & 26,199 & 0 & 98,857 & 18,716 & 51,365 & 117,573 & 168,938 \\
\hline AR & 8 & 12,295 & 5 & 0 & 141,993 & 7,440 & 154,293 & 7,440 & 161,733 \\
\hline$A Z$ & 2 & 500 & 0 & 0 & 0 & 0 & 500 & 0 & 500 \\
\hline CA & 21 & 4,853 & 19,219 & 0 & $1,155,909$ & 339 & $1,161,251$ & 19,069 & $1,180,320$ \\
\hline $\mathrm{CO}$ & 5 & 1,385 & 383 & 0 & 13,847 & 5,808 & 12,978 & 8,445 & 21,423 \\
\hline CT & 3 & 500 & 0 & 0 & 0 & 0 & 500 & 0 & 500 \\
\hline $\mathrm{DE}$ & 1 & No data & No data & No data & No data & No data & No data & No data & No data \\
\hline $\mathrm{FL}$ & 5 & 1,277 & 5 & 0 & 0 & 3,800 & 1,282 & 3,800 & 5,082 \\
\hline GA & 9 & 521 & 0 & 0 & 28,010 & 420 & 521 & 28,430 & 28,951 \\
\hline IA & 11 & 15,806 & 82 & 0 & 48,666 & 0 & 15,887 & 48,666 & 64,553 \\
\hline ID & 3 & 6,863 & 0 & 0 & $21,957,330$ & 520 & $21,964,193$ & 520 & $21,964,713$ \\
\hline IL & 24 & 134,748 & 750 & 0 & 680,474 & 30,373 & 134,748 & 711,597 & 846,345 \\
\hline IN & 20 & 12,445 & 267 & 0 & 44,651 & 40,370 & 36,473 & 61,261 & 97,734 \\
\hline KS & 4 & 4,541 & 0 & 0 & 36,921 & 4 & 4,541 & 36,925 & 41,466 \\
\hline KY & 15 & 16,266 & 0 & 0 & 35,572 & 618 & 17,866 & 34,590 & 52,456 \\
\hline LA & 13 & 12,382 & 0 & 0 & 54,683 & 0 & 12,382 & 54,683 & 67,065 \\
\hline MA & 6 & 270 & 178 & 0 & 0 & 468 & 270 & 646 & 916 \\
\hline MD & 3 & 122 & 0 & 0 & 5,537 & 0 & 122 & 5,537 & 5,659 \\
\hline ME & 1 & 0 & 0 & 0 & 5,569 & 1,646 & 0 & 7,215 & 7,215 \\
\hline MI & 15 & 4,927 & 9 & 0 & 660,702 & 10,912 & 114,609 & 561,941 & 676,550 \\
\hline MN & 4 & 249 & 0 & 0 & 0 & 0 & 249 & 0 & 249 \\
\hline MO & 9 & 5,391 & 0 & 0 & 77,964 & 0 & 73,772 & 9,583 & 83,355 \\
\hline MS & 6 & 720 & 251 & 0 & 9,025 & 0 & 9,746 & 250 & 9,996 \\
\hline NC & 19 & 1,203 & 0 & 0 & 342,077 & $2,487,306$ & 1,203 & $2,829,383$ & $2,830,586$ \\
\hline NE & 2 & 3,194 & 0 & 0 & 5 & 10 & 3,199 & 10 & 3,209 \\
\hline $\mathrm{NH}$ & 1 & 950 & 0 & 0 & 0 & 5 & 950 & 5 & 955 \\
\hline $\mathrm{NJ}$ & 7 & 10,681 & 0 & 0 & 5,700 & 14,623 & 10,681 & 20,323 & 31,004 \\
\hline NM & 1 & 0 & 0 & 0 & 252,500 & 0 & 252,500 & 0 & 252,500 \\
\hline NV & 2 & 972 & 0 & 0 & 70,226 & 0 & 71,198 & 0 & 71,198 \\
\hline NY & 10 & 8,103 & 0 & 0 & 11,278 & 525 & 18,203 & 1,703 & 19,906 \\
\hline $\mathrm{OH}$ & 32 & 85,004 & 6,334 & 0 & $9,415,075$ & $6,165,482$ & $9,389,168$ & $6,282,727$ & $15,671,896$ \\
\hline OK & 8 & 17,406 & 50 & 0 & 0 & 42,403 & 17,456 & 42,403 & 59,859 \\
\hline
\end{tabular}




\section{Table 6-1. Releases to the Environment from Facilities that Produce, Process, or Use Zinc ${ }^{a}$}

\begin{tabular}{|c|c|c|c|c|c|c|c|c|c|}
\hline \multirow[b]{3}{*}{ State $^{c}$} & \multirow[b]{3}{*}{$\mathrm{RF}^{\mathrm{d}}$} & \multicolumn{8}{|c|}{ Reported amounts released in pounds per year ${ }^{b}$} \\
\hline & & \multirow[b]{2}{*}{ Air $^{\mathrm{e}}$} & \multirow[b]{2}{*}{ Water ${ }^{f}$} & \multirow[b]{2}{*}{$\mathrm{UI}^{\mathrm{g}}$} & \multirow[b]{2}{*}{ Land $^{\text {h }}$} & \multirow[b]{2}{*}{ Other ${ }^{\mathrm{i}}$} & \multicolumn{3}{|c|}{ Total release } \\
\hline & & & & & & & On-site ${ }^{j}$ & Off-site & $\begin{array}{l}\text { On- and } \\
\text { off-site }\end{array}$ \\
\hline$\overline{\mathrm{OR}}$ & 1 & 0 & 0 & 0 & 37,960 & 0 & 37,960 & 0 & 37,960 \\
\hline PA & 20 & 64,389 & 144 & 0 & 353,840 & 58,168 & 64,709 & 411,832 & 476,541 \\
\hline PR & 2 & 0 & 0 & 0 & 0 & 5 & 0 & 5 & 5 \\
\hline $\mathrm{RI}$ & 3 & 930 & 0 & 0 & 0 & 5 & 930 & 5 & 935 \\
\hline SC & 8 & 27,976 & 168 & 0 & 20,724 & 7,596 & 35,372 & 21,092 & 56,464 \\
\hline SD & 2 & 1,085 & 0 & 0 & 3,218 & 0 & 1,335 & 2,968 & 4,303 \\
\hline $\mathrm{TN}$ & 12 & 9,000 & 705 & 0 & 164,297 & 22,208 & 23,431 & 172,779 & 196,210 \\
\hline $\mathrm{TX}$ & 19 & 46,875 & 2,211 & 0 & 63,988 & 121,879 & 73,195 & 161,758 & 234,953 \\
\hline UT & 4 & 119 & 0 & 0 & 8,009 & 8 & 6,613 & 1,523 & 8,136 \\
\hline VA & 9 & 340,253 & 1,316 & 0 & 38,919 & 2,986 & 369,093 & 14,381 & 383,474 \\
\hline WA & 1 & No data & No data & No data & No data & No data & No data & No data & No data \\
\hline WI & 17 & 4,738 & 250 & 0 & O $1,228,914$ & 4,607 & 4,988 & $1,233,521$ & $1,238,509$ \\
\hline WV & 9 & 26,652 & 0 & 0 & 52,674 & 6,111 & 79,326 & 6,111 & 85,437 \\
\hline WY & 3 & 208 & 0 & 0 & 42,767 & 0 & 39,672 & 3,303 & 42,975 \\
\hline Total & 389 & 910,964 & 58,525 & 0 & 37,167,881 & $9,055,361$ & $34,268,728$ & $12,924,002$ & $47,192,731$ \\
\hline
\end{tabular}

Source: TRI02 2004 (Data are from 2002)

${ }^{a}$ The TRI data should be used with caution since only certain types of facilities are required to report. This is not an exhaustive list. Data are rounded to nearest whole number.

${ }^{\mathrm{b}}$ Data in TRI are maximum amounts released by each facility.

${ }^{\mathrm{C}}$ Post office state abbreviations are used.

${ }^{\mathrm{d}}$ Number of reporting facilities.

${ }^{\mathrm{e}}$ The sum of fugitive and point source releases are included in releases to air by a given facility.

'S urface water discharges, wastewater treatment-(metals only), and publicly owned treatment works (POTWs) (metal and metal compounds).

${ }^{9}$ Class I wells, Class II-V wells, and underground injection.

${ }^{\mathrm{h}}$ Resource Conservation and Recovery Act (RCRA) subtitle C landfills; other on-site landfills, land treatment, surface impoundments, other land disposal, other landfills.

'Storage only, solidification/stabilization (metals only), other off-site management, transfers to waste broker for disposal, unknown

'The sum of all releases of the chemical to air, land, water, and underground injection wells.

${ }^{\mathrm{k}}$ Total amount of chemical transferred off-site, including to POTWs.

$\mathrm{RF}=$ reporting facilities; $\mathrm{UI}=$ underground injection 
Natural emissions of zinc and its compounds to air are mainly due to windborne soil particles, volcanic emissions, and forest fires. The global flux of zinc due to erosion is estimated to be 915,000 tonnes/year; of this total, 681,000 tonnes comes from high-temperature thermal vents in mid-ocean ridges (WHO 2001). Volcanic release of zinc has been estimated to be around 35,800 tonnes/year (Lantzy 1979). The eruption of Mt. Pinatubo alone released an estimated 800,000 tonnes of zinc into the atmosphere in 1991 (Garrett 2000). Other natural sources of zinc in air are biogenic emissions and sea salt sprays with annual amounts estimated to be 8,100 and 440 metric tons, respectively (Nriagu 1989).

Anthropogenic releases of zinc and its compounds to the atmosphere are from dust and fumes from mining, zinc production facilities, processing of zinc-bearing raw materials (e.g., lead smelters), brass works, coal and fuel combustion, refuse incineration, and iron and steel production (EPA 1980d; Ragaini et al. 1977). In urban East St. Louis, Illinois, industrial complexes, such as smelters, accounted for about $86 \%$ of fine and course particulate matter emitted into air. In southeastern Chicago, Illinois, incinerator emissions accounted for $86 \%$ of fine particulate in the atmosphere while urban dust account for $93 \%$ of the course particulate emissions (Sweet et al. 1993). Estimated atmospheric zinc loss is $100 \mathrm{~g} / \mathrm{ton}$ of zinc mined, and most of the loss comes from handling raw and concentrated ore and wind erosion of tailing piles (Lloyd and Showak 1984). Average zinc emissions to the atmosphere from stationary sources in the United States were 151,000 tons/year (137,000 metric tons/year) for 1969-1971 (Fishbein 1981). Based on emission studies in Western Europe, the United States, Canada, and the former Soviet Union, total worldwide zinc emissions to air were calculated to range from 70,250 to 193,500 metric tons in 1983 . Emissions from the nonferrous metal industry account for the largest fraction of zinc emitted (50-70\%) (Nriagu and Pacyna 1988). However, emissions have decreased considerably since the 1970s and 1980s as a result of improvements in contemporary zinc production facilities. Zinc emissions decreased $73 \%$ for air and 83\% for water during the years 1985-1995 (WHO 2001).

According to the TRI, estimated totals of 910,964 pounds (413 metric tons) of zinc (dust and fume) and $6,415,067$ pounds (2,909 metric tons) of zinc compounds, amounting to about 1.9 and $0.92 \%$, respectively, of the total environmental on-site releases, were discharged into the atmosphere in the United States in 2001 from mining, manufacturing, processing, and electrical power generation industries listed in Tables 6-1 and 6-2 (TRI02 2004). Data for stack/point source emissions indicate releases of 495,206 pounds ( 224 metric tons) of zinc (dust and fume) and 4,617,457 pounds (2,094 metric tons) of zinc compounds, while data for fugitive source emission indicate a release of 375,586 pounds (170 metric tons) of zinc (dust and fume) and 1,542,235 pounds (700 metric tons) of zinc compounds. The TRI data 
Table 6-2. Releases to the Environment from Facilities that Produce, Process, or Use Zinc Compounds ${ }^{a}$

\begin{tabular}{|c|c|c|c|c|c|c|c|c|c|}
\hline \multirow[b]{3}{*}{ State $^{c}$} & \multirow[b]{3}{*}{$\mathrm{RF}^{\mathrm{d}}$} & \multicolumn{8}{|c|}{ Reported amounts released in pounds per year ${ }^{b}$} \\
\hline & & \multirow[b]{2}{*}{$\mathrm{Air}^{\mathrm{e}}$} & \multirow[b]{2}{*}{ Water $^{f}$} & \multirow[b]{2}{*}{$\mathrm{UI}^{\mathrm{g}}$} & \multirow[b]{2}{*}{ Land $^{\text {h }}$} & \multirow[b]{2}{*}{ Other $^{i}$} & \multicolumn{3}{|c|}{ Total release } \\
\hline & & & & & & & On-site & Off-site ${ }^{k}$ & $\begin{array}{l}\text { On- and } \\
\text { off-site }\end{array}$ \\
\hline$\overline{\mathrm{AK}}$ & 5 & 57,736 & 892 & $10,000,000$ & $295,817,343$ & 0 & $305,875,971$ & 0 & $305,875,971$ \\
\hline AL & 91 & 146,282 & 73,856 & 77,052 & $5,220,635$ & $7,077,255$ & $4,908,757$ & $7,686,323$ & $12,595,081$ \\
\hline AR & 78 & 81,410 & 102,806 & 6,991 & 696,606 & $2,389,162$ & 336,042 & $2,940,934$ & $3,276,976$ \\
\hline$A Z$ & 21 & 32,825 & 20,160 & 144,780 & $25,217,086$ & 2,004 & $25,376,638$ & 40,217 & $25,416,855$ \\
\hline $\mathrm{CA}$ & 119 & 63,649 & 19,734 & 9,665 & 595,116 & 20,349 & 398,970 & 309,543 & 708,513 \\
\hline $\mathrm{CO}$ & 19 & 57,253 & 344 & 25,996 & 198,087 & 10,270 & 176,373 & 115,577 & 291,950 \\
\hline CT & 32 & 5,722 & 28,075 & 0 & 133,452 & 134,880 & 7,120 & 295,010 & 302,129 \\
\hline $\mathrm{DE}$ & 13 & 10,020 & 17,921 & 0 & 107,926 & 17,708 & 58,714 & 94,861 & 153,575 \\
\hline $\mathrm{FL}$ & 66 & 72,363 & 93,297 & 48,570 & $2,000,003$ & 88,270 & $1,937,933$ & 364,570 & $2,302,503$ \\
\hline GA & 114 & 244,067 & 98,139 & 0 & $1,233,070$ & 210,195 & $1,099,676$ & 685,796 & $1,785,472$ \\
\hline $\mathrm{HI}$ & 1 & 20 & 0 & 0 & 37,942 & 0 & 20 & 37,942 & 37,962 \\
\hline IA & 95 & 77,263 & 117,986 & 31,317 & $1,768,665$ & 95,611 & 488,463 & $1,602,378$ & $2,090,841$ \\
\hline ID & 12 & 41,585 & 2,108 & 0 & $3,669,321$ & 95 & $3,700,829$ & 12,280 & $3,713,109$ \\
\hline IL & 221 & 395,491 & 149,295 & 163,316 & $27,247,648$ & $1,294,295$ & $22,947,032$ & $6,303,014$ & $29,250,046$ \\
\hline IN & 157 & 723,924 & 286,946 & 15,177 & $37,744,073$ & $24,151,185$ & $8,875,522$ & $54,045,784$ & $62,921,306$ \\
\hline KS & 42 & 97,372 & 1,625 & 1,685 & 450,609 & 101,544 & 304,823 & 348,012 & 652,835 \\
\hline KY & 92 & 83,843 & 125,476 & 4,375 & $2,453,652$ & 183,585 & $2,167,004$ & 683,927 & $2,850,931$ \\
\hline LA & 77 & 147,835 & 81,079 & 167,914 & $4,761,318$ & 340,895 & $3,238,709$ & $2,260,332$ & $5,499,041$ \\
\hline MA & 50 & 9,766 & 2,381 & 0 & 363,863 & 136,582 & 35,580 & 477,012 & 512,592 \\
\hline MD & 34 & 17,599 & 23,384 & 10,389 & 205,405 & 149,224 & 178,885 & 227,116 & 406,001 \\
\hline ME & 8 & 16,887 & 16,090 & 0 & 449,015 & 450 & 174,943 & 312,499 & 487,442 \\
\hline MI & 159 & 213,987 & 286,754 & 16,000 & $43,809,978$ & 423,988 & 909,641 & $43,841,066$ & $44,750,707$ \\
\hline MN & 55 & 19,108 & 49,405 & 0 & $1,393,144$ & 329,519 & 507,238 & $1,283,938$ & $1,791,176$ \\
\hline MO & 97 & 565,546 & 27,386 & 20,266 & $31,884,266$ & 142,655 & $32,046,061$ & 594,058 & $32,640,118$ \\
\hline MS & 54 & 256,284 & 98,069 & 375,083 & 311,418 & 174,217 & 709,670 & 505,401 & $1,215,070$ \\
\hline MT & 6 & 6,244 & 21 & 0 & $10,787,188$ & 1,745 & $10,775,448$ & 19,750 & $10,795,198$ \\
\hline NC & 99 & 45,630 & 24,744 & 39,813 & $1,600,363$ & 305,408 & 827,882 & $1,188,075$ & $2,015,958$ \\
\hline ND & 4 & 760 & 23 & 0 & 180,026 & 0 & 77,783 & 103,026 & 180,809 \\
\hline$N E$ & 42 & 237,066 & 6,864 & 0 & 635,674 & $3,396,549$ & 566,918 & $3,709,235$ & $4,276,152$ \\
\hline $\mathrm{NH}$ & 10 & 333 & 825 & 0 & 5,165 & 5,467 & 2,148 & 9,642 & 11,791 \\
\hline NJ & 80 & 20,689 & 64,099 & 6,287 & 512,445 & $1,109,971$ & 131,391 & $1,582,100$ & $1,713,491$ \\
\hline NM & 11 & 2,660 & 670 & 0 & 515,365 & 0 & 367,346 & 151,349 & 518,695 \\
\hline NV & 21 & 6,904 & 1,006 & 0 & $13,889,325$ & 26,367 & $13,893,110$ & 30,492 & $13,923,602$ \\
\hline NY & 76 & 86,776 & 64,436 & 0 & $1,089,648$ & 113,112 & 495,131 & 858,840 & $1,353,971$ \\
\hline $\mathrm{OH}$ & 298 & 216,289 & 305,502 & 180,784 & $13,434,185$ & $1,583,235$ & $2,138,108$ & $13,881,887$ & $16,019,995$ \\
\hline
\end{tabular}




\section{Table 6-2. Releases to the Environment from Facilities that Produce, Process, or Use Zinc Compounds ${ }^{a}$}

\begin{tabular}{|c|c|c|c|c|c|c|c|c|c|}
\hline \multirow[b]{3}{*}{ State $^{C}$} & \multirow[b]{3}{*}{${ }^{c} R^{d}$} & \multicolumn{8}{|c|}{ Reported amounts released in pounds per year ${ }^{b}$} \\
\hline & & \multirow[b]{2}{*}{ Air ${ }^{\mathrm{e}}$} & \multirow[b]{2}{*}{ Water $^{f}$} & \multirow[b]{2}{*}{$\mathrm{UI}^{\mathrm{g}}$} & \multirow[b]{2}{*}{ Land $^{\mathrm{h}}$} & \multirow[b]{2}{*}{ Other } & \multicolumn{3}{|c|}{ Total release } \\
\hline & & & & & & & On-site & Off-site ${ }^{k}$ & $\begin{array}{l}\text { On- and } \\
\text { off-site }\end{array}$ \\
\hline$\overline{\mathrm{OK}}$ & 50 & 24,320 & 14,242 & 88,407 & $1,035,166$ & 665,664 & 489,512 & $1,338,287$ & $1,827,799$ \\
\hline OR & 31 & 17,533 & 19,513 & 0 & 262,676 & 267,398 & 54,083 & 513,037 & 567,120 \\
\hline PA & 187 & $1,452,852$ & 198,276 & 73,781 & $11,446,276$ & $22,981,774$ & $2,213,480$ & $33,939,479$ & $36,152,959$ \\
\hline PR & 15 & 3,800 & 463 & 0 & 31,944 & 272,783 & 35,858 & 273,133 & 308,991 \\
\hline RI & 6 & 217 & 45 & 0 & 65,720 & 3,314 & 217 & 69,079 & 69,296 \\
\hline SC & 76 & 213,093 & 47,512 & 14,331 & $1,823,765$ & $13,098,684$ & $1,644,194$ & $13,553,191$ & $15,197,385$ \\
\hline SD & 12 & 5,521 & 59 & 5 & $1,067,005$ & 0 & $1,053,460$ & 19,130 & $1,072,590$ \\
\hline TN & 118 & 229,905 & 90,647 & 12,856 & $24,051,495$ & 479,494 & $22,909,614$ & $1,954,784$ & $24,864,397$ \\
\hline TX & 211 & 201,120 & 344,154 & $2,103,302$ & $2,913,177$ & 344,478 & $2,118,673$ & $3,787,557$ & $5,906,230$ \\
\hline UT & 24 & 12,446 & 3,747 & 0 & $6,728,264$ & 270,481 & $6,738,249$ & 276,689 & $7,014,938$ \\
\hline VA & 62 & 95,445 & 70,786 & 3,429 & $4,932,625$ & 679,941 & 848,684 & $4,933,543$ & $5,782,227$ \\
\hline VT & 3 & 0 & 0 & 0 & 46,117 & 0 & 0 & 46,117 & 46,117 \\
\hline WA & 25 & 15,956 & 12,218 & 0 & 299,308 & 27,754 & 120,295 & 234,941 & 355,236 \\
\hline WI & 108 & 62,409 & 17,693 & 4,857 & $3,218,796$ & 168,323 & 110,208 & $3,361,870$ & $3,472,078$ \\
\hline WV & 34 & 14,267 & 95,866 & 0 & $1,323,140$ & 192,671 & $1,132,148$ & 493,795 & $1,625,944$ \\
\hline WY & 7 & 4,993 & 2,410 & 0 & 140,640 & 9,543 & 119,725 & 37,861 & 157,586 \\
\hline Total & 3,328 & $6,415,067$ & $3,109,033$ & $13,946,427$ & $9,805,136$ & $83,483,093$ & $485,324,282$ & $211,434,474$ & $696,758,756$ \\
\hline
\end{tabular}

Source: TRI02 2004 (Data are from 2002)

${ }^{a}$ The TRI data should be used with caution since only certain types of facilities are required to report. This is not an exhaustive list. Data are rounded to nearest whole number.

${ }^{\mathrm{b}}$ Data in TRI are maximum amounts released by each facility.

${ }^{\mathrm{c}}$ Post office state abbreviations are used.

${ }^{\mathrm{d}}$ Number of reporting facilities.

${ }^{\mathrm{e}}$ The sum of fugitive and point source releases are included in releases to air by a given facility.

'Surface water discharges, wastewater treatment-(metals only), and publicly owned treatment works (POTWs) (metal and metal compounds).

${ }^{9}$ Class I wells, Class II-V wells, and underground injection.

${ }^{\mathrm{h}}$ Resource Conservation and Recovery Act (RCRA) subtitle C landfills; other on-site landfills, land treatment, surface impoundments, other land disposal, other landfills.

'Storage only, solidification/stabilization (metals only), other off-site management, transfers to waste broker for disposal, unknown

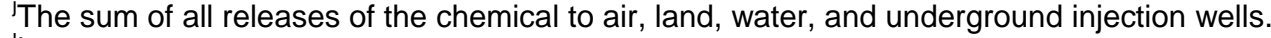

${ }^{\mathrm{k}}$ Total amount of chemical transferred off-site, including to POTWs.

$\mathrm{RF}=$ reporting facilities; $\mathrm{UI}=$ underground injection 
should be used with caution since only certain facilities are required to report. This is not an exhaustive list.

Zinc has been identified in air at 37 sites collected from the 985 NPL hazardous waste sites where it was detected in some environmental media (HazDat 2005).

\subsubsection{Water}

Estimated releases of 0.059 million pounds of zinc to surface water from 389 domestic manufacturing and processing facilities in 2002, accounted for about $0.1 \%$ of the estimated total environmental releases (TRI02 2004). This value includes the amount that was released to publicly owned treatment works (POTWs) (TRI02 2004). These releases are summarized in Table 6-1.

Zinc and its compounds are found in the earth's crust and are present in most rocks, certain minerals, and some carbonate sediments. As a result of weathering of these materials, soluble compounds of zinc are formed and may be released to water (NAS 1977). The largest input of zinc to water results from erosion of soil particles containing natural traces of zinc (45,400 metric tons/year) (EPA 1980d). Erosion resulting from human activities accounts for $70 \%$ of this soil loss; geologic or natural erosion constitutes the other 30\% (EPA 1980d). However, this source of low levels of zinc is widely dispersed and is, therefore, unlikely to elevate aquatic concentrations significantly. Zinc flux to the oceans from high temperature hydrothermal fluids in mid-ocean ridges has been estimated to be approximately 681,000 metric tons/year (WHO 2001).

Urban runoff, mine drainage, and municipal and industrial effluents are smaller but more concentrated sources of zinc in water. Davis et al. (2001) estimated the zinc loadings in urban storm water runoff. In this study, buildings and automobiles were found to contribute $95 \%$ of loadings $(0.646 \mathrm{~kg} / \mathrm{ha} / \mathrm{year})$ to storm water runoff in urban environments. Data from this study are summarized in Table 6-3. The Nationwide Urban Runoff Program (NURP), initiated to evaluate the significance of priority pollutants in urban storm water runoff, reports a frequency of detection for zinc of 95\%, with a concentration range of 0.01-2.4 mg/L (Cole et al. 1984). Industries that discharge large quantities of zinc directly to water include iron and steel, zinc smelting, plastics, and electroplating (EPA 1980d). The arithmetic mean concentration of zinc in influents of 239 waste water treatment plants in the United States was $0.7 \mathrm{mg} / \mathrm{L}$, with minimum and maximum concentrations of 0.0001 and $28.7 \mathrm{mg} / \mathrm{L}$, respectively (Minear et al. 1981). Accidental zinc discharges to water are most often associated with smelting and refining operations. Zinc 
Table 6-3. Zinc Loadings in Urban Storm Water Runoff ${ }^{\mathrm{a}}$

\begin{tabular}{|c|c|c|c|c|}
\hline & Rate & Unit value & $\begin{array}{l}\text { Loading } \\
\text { (kg/ha/year) }\end{array}$ & Percent of total \\
\hline \multicolumn{5}{|l|}{ Buildings } \\
\hline Siding & $180,000 \mathrm{~m}^{2} / \mathrm{ha} /$ year & $2,100 \mu \mathrm{g} / \mathrm{m}^{2}$ & & 58 \\
\hline Roof & 450,000 L/ha/year & $100 \mu \mathrm{g} / \mathrm{L}$ & & 7 \\
\hline Total & & & 0.423 & 65 \\
\hline \multicolumn{5}{|l|}{ Autos } \\
\hline Brakes & 240,000 km/ha/year & $88 \mu \mathrm{g} / \mathrm{km}$ & 0.021 & 3 \\
\hline Tires & $48,000 \mathrm{~g}$ tire/ha/year & $3,400 \mu \mathrm{g} / \mathrm{g}$ & 0.163 & 25 \\
\hline Oil leakage & 48 L-oil/ha/year & $1.25 \times 10^{5} \mathrm{mg} / \mathrm{L}$ & 0.006 & 1 \\
\hline Total & & & 0.190 & 29 \\
\hline \multicolumn{3}{|c|}{ Total buildings and autos } & 0.613 & 95 \\
\hline \multicolumn{3}{|l|}{ Wet deposition } & 0.013 & 2 \\
\hline \multicolumn{3}{|l|}{ Dry deposition } & 0.020 & 3 \\
\hline \multicolumn{3}{|l|}{ Total } & 0.646 & 100 \\
\hline
\end{tabular}

${ }^{a}$ Source: Davis et al. 2001 
is present with cadmium and lead in these processes (NAS 1977). Urban runoff and drainage from inactive mines account for approximately 5,250 and 4,060 metric tons/year, respectively, of the total releases of zinc to water (EPA 1980d). Drainage from active mining areas is considerably less than from inactive areas because of the disposal methods currently employed. Hazardous waste sites, in which zinc has been improperly disposed of, are additional sources of the element.

Metals, such as zinc, also enter estuaries from many natural and manufactured sources. Three important sources of zinc input into surface water are metal manufacturing (33,000-178,000 metric tons/year), domestic waste water (21,000-58,000 metric tons/year), and atmospheric fallout (2,600-31,000 metric tons/year). On an annual worldwide basis, an estimated 77,000-375,000 metric tons of zinc are discharged into water from anthropogenic sources (Nriagu and Pacyna 1988). Publicly owned treatment works are the largest total point source for zinc discharges. Publicly owned treatment works receive zinc contributions from the water supply and distribution system corrosion, combined sewer area runoff, industrial wastes, and human excrement (EPA 1980d). Crawford et al. (1995) reported the direct inputs of zinc contamination to the Newark Bay Estuary as follows ( $\mathrm{kg} /$ day): municipal treatment systems, 272.0; industry, 14.34; combined sewer overflows, 141.5; storm water runoff, 164.6; and tributary flow, 307. Indirect inputs were $934.7 \mathrm{~kg} / \mathrm{day}$. The flux of zinc into the Hudson River Estuary from sewage has decreased from $924 \mathrm{~kg} /$ day in 1974 to $285 \mathrm{~kg} /$ day in 1997 as a result of improvements in controlling discharges from municipal and industrial waste water treatment plants since the Clean Water Act was enacted in 1972 (Sanudo-Wilhelmy and Gill 1999).

According to the TRI, estimated totals of 58,525 pounds (26.5 metric tons) of zinc (dust and fume) and $3,109,033$ pounds (1,410 metric tons) of zinc compounds, amounting to about 0.1 and $0.44 \%$, respectively, of the total environmental on-site releases, were discharged into surface water in the United States in 2002 from mining, manufacturing, processing, and electrical power generation industries listed in Tables 6-1 and 6-2. Estimated totals of 0 pounds (0 metric tons) of zinc (dust and fume) and $13,946,427$ pounds ( 6,325 metric tons) of zinc compounds, amounting to about 0.0 and $2 \%$ of the total environmental on-site releases, respectively, were injected underground in the United States in 2001 from mining, manufacturing, processing, and Resource Conservation and Recovery Act (RCRA)/Solvent Recovery industries listed in Tables 6-1 and 6-2 (TRI02 2004). The TRI data should be used with caution since only certain facilities are required to report. This is not an exhaustive list.

The concentration of zinc in drinking water may increase as a result of the distribution system and household plumbing (EPA 1987c). Common piping materials used in distribution systems often contain 
zinc, as well as other metals and alloys. Trace metals may enter the water through corrosion products or simply by the dissolution of small amounts of metals with which the water comes in contact. Reactions with materials of the distribution system, particularly in soft low-pH waters, very often have produced concentrations of zinc in tap water much greater than those in the raw or treated waters at the plant of origin (NAS 1977). The total quantity of annual releases of zinc from these sources has not been estimated. Environmental toxicity of zinc in water is dependent upon the concentration of other minerals and the $\mathrm{pH}$ of the solution, which affect the ligands that associate with zinc (Heijerick et al. 2002a; Paquin et al. 2002; Santore 2002).

Zinc has been identified in surface water and groundwater at 393 and 685 sites, respectively, collected from the 985 NPL hazardous waste sites where it was detected in some environmental media (HazDat 2005).

\subsubsection{Soil}

Estimated releases of 37 million pounds (16,856 metric tons) of zinc to soils from 389 domestic manufacturing and processing facilities in 2002, accounted for about $79 \%$ of the estimated total environmental releases from facilities required to report to the TRI (TRI02 2004). No material was released via underground injection (TRI02 2004). These releases are summarized in Table 6-1.

Limited information is available on total releases of zinc to soil. Zinc is often present in soils and grasses as a result of atmospheric deposition. Furthermore, approximately 22,000 tons (20,000 metric tons) of zinc is used in fertilizers each year in the United States (NAS 1977). The extent to which zinc may run off into soil, rivers, and streams has not been evaluated. Hazardous waste sites are additional sources of zinc in soil. Municipal sludges applied to cropland soils can also be an important source of trace metals, including zinc (Chang et al. 1987).

On a worldwide basis, an estimated 1,193,000-3,294,000 metric tons of zinc per year are released to soil from anthropogenic sources (Nriagu and Pacyna 1988). The four most important sources of zinc in soil were estimated to be smelter slugs and wastes, mine tailings, coal and bottom fly ash, and the discharge of commercial products such as fertilizers.

Tire debris contains significant quantities of zinc, which may contaminate soils near roads. For example, snow collected on soil near an expressway in Montréal, Québec (Canada) contained higher levels zinc 
near the expressway. At $15 \mathrm{~m}$ from expressway, a snow pack concentration of $0.143 \mathrm{mg} / \mathrm{L}$ was measured, while at $150 \mathrm{~m}$ from the expressway, the concentration of zinc in snow was $0.029 \mathrm{mg} / \mathrm{L}$ (Loranger et al. 1996). Laboratory experiments indicated that a significant fraction of zinc may be released from tire rubber debris. Soil $\mathrm{pH}$ limits the mobilization of zinc in soil. Thus, zinc from tire debris will be less available and become immobile with soil interactions (Smolders and Degryse 2002).

Metallic zinc may yield soluble zinc compounds under acidic conditions where the zinc hydroxidecarbonate layer is attacked from pollutants such as sulfur dioxide. Metallic zinc is washed off slowly and forms a diffuse source of zinc release to soils. Other releases of zinc include the use of sacrificial anodes in soil to protect steel structures from corrosion (WHO 2001).

According to the TRI, estimated totals of $37,167,881$ pounds (16,856 metric tons) of zinc (dust and fume) and $589,805,136$ pounds (267,485 metric tons) of zinc compounds, amounting to about 79 and $85 \%$, respectively, of the total environmental on-site releases, were released to land in the United States in 2001 from mining, manufacturing, processing, and electrical power generation industries (Tables 6-1 and 6-2) (TRI02 2004). Another 12,924,002 pounds (5,861 metric tons) of zinc (dust and fume) and $211,434,474$ pounds $(95,889$ metric tons) of zinc compounds were transferred to off-site treatment, storage, and disposal facilities. The TRI data should be used with caution since only certain types of facilities are required to report. This is not an exhaustive list.

Zinc has been identified in soil and sediment at 522 and 370 sites, respectively, collected from the 985 NPL hazardous waste sites where it was detected in some environmental media (HazDat 2005).

\subsection{ENVIRONMENTAL FATE}

Zinc occurs in the environment mainly in the +2 oxidation state (Lindsay 1979). Sorption is the dominant reaction, resulting in the enrichment of zinc in suspended and bed sediments (EPA 1979d). Zinc in aerobic waters is partitioned into sediments through sorption onto hydrous iron and manganese oxides, clay minerals, and organic material. The efficiency of these materials in removing zinc from solution varies according to their concentrations, $\mathrm{pH}$, redox potential $(\mathrm{Eh})$, salinity, nature and concentrations of complexing ligands, cation exchange capacity, and the concentration of zinc. Precipitation of soluble zinc compounds appears to be significant only under reducing conditions in highly polluted water. Generally, at lower $\mathrm{pH}$ values, zinc remains as the free ion. The free ion $\left(\mathrm{Zn}^{+2}\right)$ tends to be adsorbed and transported by suspended solids in unpolluted waters. In polluted waters in which the concentration of zinc is high, 
removal of zinc by precipitation of the hydroxide is possible, particularly when the $\mathrm{pH}$ is $>8$ (EPA 1979d). In anaerobic environments and in the presence of sulfide ions, precipitation of zinc sulfide limits the mobility of zinc. The relative mobility of zinc in soil is determined by the same factors that affect its transport in aquatic systems (i.e., solubility of the compound, pH, and salinity) (Clement 1985).

Zinc is an essential nutrient that is present in all organisms. Although biota appears to be a minor reservoir of zinc relative to soils and sediments, microbial decomposition of biota in water can produce ligands, such as humic acids, that can affect the mobility of zinc in the aquatic environment through zinc precipitation and adsorption (EPA 1979d).

Zinc concentrations in the air are relatively low, except near industrial sources such as smelters. No estimate for the atmospheric lifetime of zinc is available at this time, but the fact that zinc is transported long distances in air indicates that its lifetime in air is at least on the order of days.

\subsubsection{Transport and Partitioning}

Air. In the atmosphere, zinc exists primarily in an oxidized form bound to aerosols, with the size of zinc particulates determined by the source of zinc emission (Nriagu and Davidson 1980; Sweet et al. 1993). A major proportion of zinc released from industrial processes is adsorbed on particulates that are small enough to be in the respirable range (Dorn et al. 1976). Wind-blown dust transports zinc bound to soil particulates into the atmosphere (EPA 1980d). The particulates may also contain other materials (Pacyna et al. 1989; Saltzman et al. 1985).

Zinc-bearing particles in the atmosphere are transported to soil and water by wet deposition (rain and snow) and dry deposition (gravitational settling and deposition on water and soil surfaces). Zinc particles with low dry deposition velocities (i.e., particles with small diameters and low densities) can be transported from their emission source to distant regions (Pacyna et al. 1989). The atmospheric wet deposition of zinc (and other trace metals) was examined at two Maryland Chesapeake Bay sites from June 1990 to July 1991 as part of the Chesapeake Bay Atmospheric Deposition Study (Scudlark et al. 1994). The average annual wet deposition at these two sites was $1,335 \mu \mathrm{g} / \mathrm{m}^{2} /$ year with $99 \%$ attributed to anthropogenic sources. As part of the Atmospheric Exchange over Lakes and Oceans Study (AEOLOS), dry deposition fluxes of zinc were measured over the southern basin of Lake Michigan near the urban area of Chicago and the nonurban area of South Haven, Michigan (Paode et al. 1998). In 1993, the average measured zinc fluxes were $200 \mu \mathrm{g} / \mathrm{m}^{2} /$ day in Chicago; $10 \mu \mathrm{g} / \mathrm{m}^{2} /$ day over southern Lake 
Michigan; and $4 \mu \mathrm{g} / \mathrm{m}^{2} /$ day in South Haven, Michigan. Between 1993 and 1995, Shahin et al. (2000) estimated the dry deposition flux of zinc in Chicago to be $4.4 \times 10^{4} \mu \mathrm{g} / \mathrm{m}^{2} /$ year. Atmospheric deposition rates of zinc for Lakes Superior, Erie, and Ontario were reported to be 3,310, 2,180, and $5,650 \mu \mathrm{g} / \mathrm{m}^{2} /$ year, respectively (Nriagu et al. 1996). Detection of zinc in rain waters confirms the importance of wet precipitation in the removal of zinc particles from the atmosphere (Aten et al. 1983; Colin et al. 1990; Dasch and Wolff 1989; Golomb et al. 1997; Heaton et al. 1990). Golomb et al. (1997) measured the atmospheric deposition of zinc at Nahant, Massachusetts (near urban area of Boston) and at Truro, Massachusetts (on Cape Cod) for the years 1992-1993. Results indicated that wet deposition was a significant fraction of the total atmospheric deposition of zinc for Nahant (28\%) and Truro (40\%).

Water. In water, zinc occurs in the environment primarily in the +2 oxidation state. It dissolves in acids to form hydrated $\mathrm{Zn}^{+2}$ cations and in strong bases to form zincate anions, which are hydroxo complexes, e.g., $\left(\mathrm{Zn}[\mathrm{OH}]_{3}\right)^{-},\left(\mathrm{Zn}[\mathrm{OH}]_{4}\right)^{2-}$, and $\left(\mathrm{Zn}[\mathrm{OH}]_{4}\left[\mathrm{H}_{2} \mathrm{O}\right]_{2}\right)^{2-}\left(\mathrm{O}^{\prime} \mathrm{Neil}\right.$ et al. 2001). In most waters, zinc exists primarily as the hydrated form of the divalent cation. However, the metal often forms complexes with a variety of organic and inorganic ligands (EPA 1979d, 1984b, 1987c).

Zinc can occur in both suspended and dissolved forms in surface water. Dissolved zinc may occur as the free (hydrated) zinc ion or as dissolved complexes and compounds with varying degrees of stability. Suspended (i.e., undissolved) zinc may be dissolved with changes in water conditions (e.g., pH, redox potential, solution speciation) or may sorb on to suspended matter. Gundersen and Steinnes (2003) reported that $<10 \%$ of zinc was sorbed on particles or colloids in river water from two rivers with average pHs of 3.1 and 5.1 (rivers with mining activity near Roes, Norway), whereas $21 \%$ of zinc occurred in sorbed form in six $\mathrm{pH}$ neutral rivers.

In the aquatic environment, zinc partitions to sediments or suspended solids in surface waters through sorption onto hydrous iron and manganese oxides, clay minerals, and organic material. Reservoirs located downstream from lead-zinc mining and milling areas were found to contain higher concentrations of zinc than reservoirs in other areas, and the zinc was more highly concentrated in reservoir bottom sediments than in the surrounding soils (Pita and Hyne 1975). In addition, the zinc content in sediment closely correlated with the depth, organic content, and clay content of the sediments. Phosphates and iron hydroxides affect the transfer of metals (including zinc) from river water to the sediments, according to a study by Houba et al. (1983). In this study, zinc was bound predominantly to carbonate and amorphous matter (iron, aluminum, and manganese hydroxides). In addition, mobile components of naturally occurring organic matter contributed to the increase in the metal hydroxide-bound fraction. 
The transport of zinc in the aquatic environment is controlled by anion species. In natural waters, complexing agents, such as humic acid, can bind zinc. The stability of zinc complexes depends on the $\mathrm{pH}$ of the water and the nature of the complex. The dissociation of the complex may determine the amount of free zinc ions in solution. Zinc-humic acid complexes may be 50\% dissociated at pH 5.5 and the dissociation rate may be higher as the $\mathrm{pH}$ decreases (Guy and Chakrabarti 1976). Therefore, as the $\mathrm{pH}$ of the water decreases, the concentration of zinc ions in the water phase increases at the same rate as that of the release of zinc from the sediment. The magnesium found in the silicate minerals of igneous rocks is often replaced with the divalent zinc ion; consequently, weathering of this zinc-containing bedrock gives rise to $\mathrm{Zn}^{+2}$ in solution. The hydrated cation is the dominant form when the $\mathrm{pH}$ is $\leq 9$ (EPA 1979d).

The tendency of zinc to be sorbed is affected not only by the nature and concentration of the sorbent but also by $\mathrm{pH}$ and salinity (EPA 1979d). Zinc tends to sorb more readily at a high $\mathrm{pH}(\mathrm{pH}>7)$ than at a low pH (EPA 1979d). Desorption of zinc from sediments occurs as salinity increases (Helz et al. 1975), apparently because of displacement of the adsorbed zinc ions by alkali and alkaline earth cations, which are abundant in brackish and saline waters (EPA 1979d). In column leaching tests with sediment collected from the banks of the Rhone River, the presence of dissolved organic matter and $\mathrm{pH}$ was found to be the factors controlling the adsorption and mobility of zinc (Bourg and Darmendrail 1992).

A small fraction of zinc will exist in the aquatic phase as soluble inorganic zinc compounds (e.g., zinc chloride, zinc sulfate). Soluble inorganic zinc compounds hydrolyze in solution, forming zinc hydroxide precipitates. Hydrolysis may lower $\mathrm{pH}$, but the buffering action present in most natural water prevents a significant alteration in $\mathrm{pH}$. The precipitation of zinc hydroxide and zinc carbonate was studied by Patterson et al. (1977), who found that zinc hydroxide precipitates faster than zinc carbonate. Zinc carbonate is soluble in pure water at $25^{\circ} \mathrm{C}$ at concentrations of $\leq 107 \mathrm{mg}$ zinc/L. The hydroxide is soluble only at concentrations of $\leq 0.2 \mathrm{mg}$ zinc/L. As a result, some of the inorganic forms of zinc that are expected to be present in water are basic carbonate $\left(\mathrm{Zn}_{2}[\mathrm{OH}]_{2} \mathrm{CO}_{3}\right)$, hydroxide $\left(\mathrm{Zn}[\mathrm{OH}]_{2}\right)$, and silicate ( $\left.\mathrm{Zn}_{2} \mathrm{SiO}_{4}\right)$ (Florence 1980; NAS 1977). When the $\mathrm{pH}$ is $\geq 8$, most of these compounds will precipitate; however, as the $\mathrm{pH}$ decreases, more and more of these compounds will dissolve and remain in the water phase (EPA 1979d).

The effect of $\mathrm{pH}$ on the mobilization of zinc in a few highly acidic clean lakes has been studied (Sprenger et al. 1987; White and Driscoll 1987). In these lakes, in which the $\mathrm{pH}$ was $\leq 3.6$, concentrations of zinc were elevated in the water column, and the concentration of zinc in the upper layer of sediment was 
substantially lower than values reported for other lakes at higher $\mathrm{pH}$ values. The relatively higher concentration of zinc in the water column compared to the sediment may be the result of lower adsorption of zinc on oxide surfaces due to low $\mathrm{pH}$, solubilization of inorganic zinc from the sediment layer, and the dissociation of bound organic complexes of zinc present in the sediment and their subsequent release into the water phase.

The precipitation of zinc sulfide affects the mobility of zinc in reducing environments, especially when hydrogen sulfide is formed. The precipitation of the hydroxide, carbonate, or basic sulfate may become more significant at high concentrations of zinc. Hesterberg et al. (1997) reports that zinc (hydr)oxides and not sulfides are the dominant species in aquifers solids under reducing conditions. The hydroxides and hydrous oxides of iron and manganese are often components of the clay fraction of sediments and often exist as coatings on the surfaces of other minerals (NAS 1977). Zinc may coprecipitate with hydrous oxides when reduced iron or manganese oxides are oxidized. As the new solids are formed, they can trap various ions in their crystal lattices (EPA 1979d).

Soil. The redox status of the soil may shift zinc partitioning. Reductive dissolution of iron and manganese (hydr)oxides under suboxic conditions release zinc into the aqueous phase; the persistence of suboxic conditions may then lead to a repartitioning of zinc into sulfide and carbonate solids. Bostick et al. (2001) describe zinc speciation in contaminated wetland soil that undergoes seasonal flooding. In dry oxidized soils, the authors found that zinc was associated with (hydr)oxide phases, while in flooded systems, zinc was associated with sulfides and carbonates. Reversible change occurred with flooding from dry soil. However, a small fraction of zinc became recalcitrant with (hydr)oxides fraction.

Zinc sorbs strongly onto soil particulates. Little water-soluble and exchangeable heavy metals were found in soil irrigated with raw waste water (Schalscha et al. 1982). Although considerable amounts of metals were added to the soil in soluble and exchangeable forms during waste-water irrigation, they were converted into the less chemically active forms (i.e., organically bonded and inorganic precipitates). Further examination showed that zinc accumulation in soil resulting from waste disposal occurred primarily as inorganic precipitates.

The mobility of zinc in soil depends on the solubility of the speciated forms of the element and on soil properties such as cation exchange capacity, $\mathrm{pH}$, redox potential, and chemical species present in soil; under anaerobic conditions, zinc sulfide is the controlling species (EPA 1980d; Kalbasi et al. 1978). Since zinc sulfide is insoluble, the mobility of zinc in anaerobic soil is low. In a study of the effect of $\mathrm{pH}$ 
on zinc solubility, Saeed and Fox (1977) showed that, when the pH is <7, an inverse relationship exists between the $\mathrm{pH}$ and the amount of zinc in solution. As negative charges on soil surfaces increase with increasing $\mathrm{pH}$, additional sites for zinc adsorption are activated and the amount of zinc in solution decreases. The active zinc species in the adsorbed state is the singly charged zinc hydroxide species (i.e., $\left.\mathrm{Zn}[\mathrm{OH}]^{+}\right)($Sanders and Kherbawy 1987). Other investigators have also shown that the mobility of zinc in soil increases at lower soil $\mathrm{pH}$ under oxidizing conditions and at a lower cation exchange capacity of soil (Bergkvist et al. 1989; Hermann and Neumann-Mahlkau 1985; Tyler and McBride 1982). On the other hand, the amount of zinc in solution generally increases when the $\mathrm{pH}$ is $>7$ in soils high in organic matter. This is a result of the release of organically complexed zinc, reduced zinc adsorption at higher $\mathrm{pH}$, or an increase in the concentration of chelating agents in soil (Saeed and Fox 1977). For calcareous soils, the relationship between zinc solubility and $\mathrm{pH}$ is nonlinear. At a high $\mathrm{pH}$, zinc in solution is precipitated as $\mathrm{Zn}(\mathrm{OH})_{2}$, zinc carbonate $\left(\mathrm{ZnCO}_{3}\right)$, or calcium zincate (Saeed and Fox 1977). Clay and metal oxides are capable of sorbing zinc and tend to retard its mobility in soil. Warwick et al. (1998) studied the mobility of zinc ions in sand. Zinc was more mobile at $\mathrm{pH} 4$ than at $\mathrm{pH} 6.5$ as a consequence of sorption. Goethite (i.e., iron oxyhydroxide) caused a greater decrease in mobility, and increased retardation was also observed with humic acid.

Distribution constants $\left(\mathrm{K}_{\mathrm{d}}=\right.$ concentration of sorbed zinc/concentration of zinc in solution) for zinc in soil range widely from 0.1 to 8,000 L/kg (or mL/g) (Baes and Sharp 1983; Bunzl and Schimmack 1989; Gao et al. 1997; Gerritse et al. 1982; Janssen et al. 1997). $\mathrm{K}_{\mathrm{d}}$ values of $100 \pm 770 \mathrm{~mL} / \mathrm{g}$ for sandy loam soil and $0.2 \pm 4 \mathrm{~mL} / \mathrm{g}$ for sandy soils were reported by Gerritse et al. (1982). $\mathrm{K}_{\mathrm{d}}$ values ranging from 0.1 to $8,000 \mathrm{~mL} / \mathrm{g}$ were reported by Baes and Sharp (1983). $\mathrm{K}_{\mathrm{d}}$ values for zinc of 140 and $41 \mathrm{~L} / \mathrm{kg}$ were determined for the O-horizon (organic layer) and E-horizon (silty sand), respectively, of a podzol forest soil (Bunzl and Schimmack 1989). Field-based $\mathrm{K}_{\mathrm{p}}$ ranged from 6 to 6,762 L/kg for 20 Dutch agricultural soils (Janssen et al. 1997). $K_{d}$ values for nine soils treated with sewage sludge supernatant ranged from 0.034 to $1.359 \mathrm{~L} / \mathrm{g}$ at $\mathrm{pH} 4.5$ while at $\mathrm{pH} 6.5, \mathrm{~K}_{\mathrm{d}}$ values ranged from 0.425 to $2.896 \mathrm{~L} / \mathrm{g}$ (Gao et al. 1997).

Zinc in a soluble form (e.g., zinc sulfate) is moderately mobile in most soils. However, relatively little land-disposed zinc at waste sites is in the soluble form. Thus, mobility is limited by a slow rate of dissolution. Consequently, movement towards groundwater is expected to be slow unless zinc is applied to soil in soluble form (such as in agricultural applications) or accompanied by corrosive substances (such as in mine tailings) (EPA 1980d). Yet, soil conditions not suitable for zinc sorption may lead to leaching. Low $\mathrm{pH}(\mathrm{pH}<7)$ and high ionic strength of the leaching solution favor desorption (EPA 1987c; Saeed and Fox 1977). 
Consequently, zinc primarily remains in recalcitrant, immobile forms in contaminated soils (Chlopecka et al. 1996; Kabala and Singh 2001; Kaminiski and Landsberger 2000b; Ma and Rao 1997a). Ma and Rao (1997) studied the chemical fractionation of zinc in nine soils from various U.S. locations contaminated by agriculture and industrial activities. Zinc was found to be concentrated in the residual (or recalcitrant) fraction (range, 55.8-97.6\%), which reflected greater tendency of zinc to become unavailable once in soils. However, some zinc was found in exchangeable and carbonate fractions at levels ranging from 0.73 to $25 \%$, which suggests that some zinc may be available to plants. In soil from East St. Louis, Illinois, an area heavily contaminated with metals, sequential extraction analysis of soil revealed that the largest fraction of zinc was partitioned in the iron-manganese oxide fraction (47.2\%) followed by carbonate $(37.9 \%)$ and organic $(14.1 \%)$ and exchangeable $(0.8 \%)$ fractions (Kaminiski and Landsberger 2000b). Kabala and Singh (2001) reported that water-soluble zinc was present in only very small amounts $(<1 \%)$ in most contaminated soils. However, concentrations of exchangeable zinc were significantly higher in surface horizons (4-19\% of total zinc) than in subsurface layers. In subsurface horizons of the studied soils, zinc was concentrated in the residual (or recalcitrant) fraction. The percentage of residual zinc ranged from $45 \%$ in silty soils to $94 \%$ in clay-loam soil. The nonresidual fractions prevailed only in the surface horizons in both contaminated and uncontaminated soil (65-91\% of total zinc) (Kabala and Singh 2001). Soils from Southwestern Poland subjected to severe metal contamination contained zinc at concentrations ranging from 20 to 10,000 mg/kg (Chlopecka et al. 1996). Acidic soils $(\mathrm{pH}<5.6)$ contained a greater fraction of exchangeable zinc, while for other soils $(\mathrm{pH}>5.6)$, zinc was found primarily in the oxide and residual (or recalcitrant) fractions with moderate amounts in the organic, carbonate, and exchangeable forms.

Zinc is an essential nutrient and occurs in the tissues of organisms, even at normal ambient water and soil concentrations. Zinc can accumulate in freshwater animals at 51-1,130 times the concentration present in the water (EPA 1987c). Microcosm studies indicate, in general, that zinc does not biomagnify through food chains (Biddinger and Gloss 1984; EPA 1979d; Hegstrom and West 1989). Furthermore, although zinc actively bioaccumulates in aquatic systems, biota appears to represent a relatively minor sink compared to sediments. Steady-state zinc bioconcentration factors (BCFs) for 12 aquatic species range from 4 to 24,000 (EPA 1987c). Crustaceans and fish can accumulate zinc from both water and food. A $\mathrm{BCF}$ of 1,000 was reported for both aquatic plants and fish, and a value of 10,000 was reported for aquatic invertebrates (Fishbein 1981). The order of enrichment of zinc in different aquatic organisms was as follows (zinc concentrations in $\mu \mathrm{g} / \mathrm{g}$ dry weight appear in parentheses): fish (25), shrimp (50), mussel (60), periphyton (260), zooplankton (330), and oyster (3,300) (Ramelow et al. 1989). The high 
enrichment in oysters may be due to their ingestion of particulate matter containing higher concentrations of zinc than ambient water. Other investigators have also indicated that organisms associated with sediments have higher zinc concentrations than organisms living in the aqueous layer (Biddinger and Gloss 1984). With respect to bioconcentration from soil by terrestrial plants, invertebrates, and mammals, BCFs of $0.4,8$, and 0.6 , respectively, have been reported. The concentration of zinc in plants depends on the plant species, soil pH, and the composition of the soil (Dudka and Chlopecka 1990; Rudd et al. 1988). Plant species do not concentrate zinc above the levels present in soil (Levine et al. 1989).

\subsubsection{Transformation and Degradation}

As an element, zinc does not degrade in the environment. Degradation of an element is a nuclear process by definition, and stable elements, such as zinc, typically undergo such processes only at insignificant rates in the environment. Zinc can change from one form to another, sometimes reversibly, in numerous chemical reactions that can proceed under a wide range of common environmental conditions.

\subsubsection{Air}

The chemical interaction of zinc compounds in the atmosphere may change the anionic speciation of the compound. Atmospheric interactions are greatest for particles with small aerodynamic diameters (Fishbein 1981). Zinc is found in the atmosphere at the highest concentrations in the smallest particles (Fishbein 1981). Atmospheric emissions of zinc, consisting primarily of zinc sorbed to submicron particulate matter in the form of zinc oxide $(\mathrm{ZnO})$, are expected to dissipate quickly as a result of deposition to soil and surface waters (EPA 1980d).

In the atmosphere, zinc-bearing particles may undergo chemical transformation before deposition. The association of zinc particles in aerosols in Arizona was studied, and five zinc-bearing particles were identified with an automated scanning electron microscope (Anderson et al. 1988). These particles, in decreasing order of concentration in the aerosol, were zinc sulfide $(\mathrm{ZnS})$, ferrous zinc $\left(\mathrm{Fe}_{\mathrm{x}} \mathrm{Zn}_{\mathrm{y}}\right)$, zinc phosphides $\left(\mathrm{Zn}_{3} \mathrm{P}_{2}\right)$, zinc chloride $\left(\mathrm{ZnCl}_{2}\right)$, and metallic zinc $(\mathrm{Zn})$. The presence of zinc sulfide in an area adjacent to mining and smelting activities was not unanticipated, but no conclusion regarding the speciation of zinc in the atmosphere could be drawn from this investigation. However, the relative concentration of zinc ions in rainwater from a rural area was approximately 10 times higher than in 
airborne particulates (Aten et al. 1983). This finding suggests that zinc sulfide in the atmosphere is oxidized to a more water-soluble form, zinc sulfate.

\subsubsection{Water}

Zinc is in the +2 form in aqueous solution and exhibits amphoteric properties; zinc metal and compounds dissolve in acids to form hydrated $\mathrm{Zn}^{+2}$ cations and in strong bases to form zincate anions, which are hydroxo complexes, such as $\left[\mathrm{Zn}(\mathrm{OH})_{3}\right]^{-},\left[\mathrm{Zn}(\mathrm{OH})_{4}\right]^{2-}$, and $\left[\mathrm{Zn}(\mathrm{OH})_{4}\left(\mathrm{H}_{2} \mathrm{O}\right)_{2}\right]^{2-}($ EPA 1979d; O'Neil et al. 2001). However, at the $\mathrm{pH}$ of most natural waters, the formation of anionic zinc species is not likely.

A small part of the available zinc may partition into the aquatic phase through the formation of soluble zinc chloride and sulfate compounds. These compounds hydrolyze in solution to form the hydroxide or hydrated zinc oxide precipitate with a resultant decrease in $\mathrm{pH}$. The decrease in $\mathrm{pH}$ can increase the solubility of zinc hydroxide and increase the zinc concentration in water. However, the buffering action of most natural waters prevents any significant change of $\mathrm{pH}$ due to the hydrolysis reactions. As a result, in the water phase, the solubility of its carbonate and hydroxide is likely to control the availability of zinc. It was reported by Patterson et al. (1977) that $\mathrm{Zn}(\mathrm{OH})_{2}$ precipitates faster than $\mathrm{ZnCO}_{3}$. $\mathrm{Zinc}$ is not directly affected by changes in Eh; however, the valences and reactivity of ligands reacting with zinc are affected by Eh. Zinc is an active reducing agent for many metal ions such as iron $\left(\mathrm{Fe}^{+3}\right)$ and permanganate $\left(\mathrm{MnO}_{4}{ }^{-2}\right)$ ions (Stokinger 1981). As a result of the reducing reactions, the manganese oxides and ferric salts may precipitate and, in the process, may entrap soluble zinc in the precipitate, thereby reducing the zinc concentration in the water phase.

Because alkyl zinc compounds are unstable in water and oxygen, biomethylation of zinc compounds in aquatic ecosystems probably does not occur (EPA 1979d). Insoluble zinc compounds (e.g., zinc oxide) are solubilized indirectly under anaerobic conditions with reduction of iron sulfides, which reduces the solution pH (Couillard et al. 1994; Francis and Dodge 1988). No evidence was found that photolysis in the aquatic environment significantly affects the fate of zinc compounds.

\subsubsection{Sediment and Soil}

Zinc undergoes reactions in sediment and soil involving precipitation/dissolution, complexation/dissociation, and adsorption/desorption. These reactions are controlled by the $\mathrm{pH}$, redox potential (Eh), the 
concentration of zinc ions and other ions in the soil pore water, the number and type of adsorption sites associated with the solid phase, and the organic ligands present that are capable of forming complexes with zinc. In acidic sediments and soils, more zinc is available in ionic forms, and cation exchange processes influence its fate. Depending on the nature and concentrations of other mobile metals in sediments and soils, competition for the binding sites probably occurs. In the absence of suitable binding sites, zinc may be mobilized (ICF 1986). In alkaline soils, the chemistry of zinc is dominated by interactions with organic ligands. The ecological toxicity of sediment is complex and appears to be correlated to the ratio of zinc to acid volatile sulfide (Berry et al. 1996; Di Toro et al. 1992; Sibley et al. 1996).

Biological degradation of zinc complexes in soil is necessary for the normal operation of ecosystems to facilitate the recycling of zinc from litter, feces, and dead organisms. In some environments, bacteria and fungi are able to oxidize zinc sulfide producing zinc sulfate, which will solubilize in the soil solution (WHO 2001).

\subsubsection{Other Media}

During composting of organic wastes, zinc remains in mobile and bioavailable forms. Zinc carbonates are formed, although not at the expense of zinc sulfide levels, which remain unaltered during the composing process (Ciba et al. 1997). No further data were located in the literature for the transformation and degradation of zinc in other media.

\subsection{LEVELS MONITORED OR ESTIMATED IN THE ENVIRONMENT}

Reliable evaluation of the potential for human exposure to zinc depends in part on the reliability of supporting analytical data from environmental samples and biological specimens. Concentrations of zinc in unpolluted atmospheres and in pristine surface waters are often so low as to be near the limits of current analytical methods. In reviewing data on zinc levels monitored or estimated in the environment, it should also be noted that the amount of chemical identified analytically is not necessarily equivalent to the amount that is bioavailable. The analytical methods available for monitoring zinc in a variety of environmental media are detailed in Chapter 7. 


\subsubsection{Air}

Zinc concentrations in air are relatively low and fairly constant except near sources such as smelters. Average atmospheric concentrations of zinc resulting from releases from automobiles, fuel combustion, incineration, soil erosion, and industrial, commercial, and construction activity throughout the United States generally are $<1 \mu \mathrm{g} / \mathrm{m}^{3}$ (EPA 1980d; Lloyd and Showak 1984). In 1990, the median concentration of zinc in air samples collected across Minnesota was $0.012 \mu \mathrm{g} / \mathrm{m}^{3}$ (maximum, $0.187 \mu \mathrm{g} / \mathrm{m}^{3}$ ) (Pratt et al. 2000). At six measurement sites in Columbus, Ohio, the mean atmospheric particulate concentration of zinc for samples collected in 1989 was $0.01 \pm 0.01 \mu \mathrm{g} / \mathrm{m}^{3}$ (Spicer et al. 1996). Data on zinc concentrations in New York City during 1972-1975 show that the average atmospheric zinc concentration ranged from 0.293 to $0.380 \mu \mathrm{g} / \mathrm{m}^{3}$ annually (Lioy et al. 1978). An average ambient zinc concentration of $0.127 \mu \mathrm{g} / \mathrm{m}^{3}$ (concentration range, $0.027-0.500 \mu \mathrm{g} / \mathrm{m}^{3}$ ) was determined from analyses of particulate samples collected at nine air monitoring sites in the San Francisco Bay area (John et al. 1973). The concentrations of zinc in atmospheric samples collected from seven cities in the United States during 1968-1971 ranged from 0.17 to $0.67 \mu \mathrm{g} / \mathrm{m}^{3}$, whereas the concentrations at two rural sites ranged from 0.02 to $0.16 \mu \mathrm{g} / \mathrm{m}^{3}$ (Saltzman et al. 1985). The concentrations of zinc during 1977-1979 from the National Air Surveillance Networks were reported by Evans et al. (1984). The arithmetic mean zinc concentrations in urban areas in the United States ranged from 0.02 to $0.16 \mu \mathrm{g} / \mathrm{m}^{3}$, whereas the concentrations in nonurban areas ranged from 0.01 to $0.05 \mu \mathrm{g} / \mathrm{m}^{3}$. The geometric mean concentrations of zinc from three urban areas in New Jersey monitored in 1981-1982 ranged from 0.07 to $0.59 \mu \mathrm{g} / \mathrm{m}^{3}$, whereas the concentrations at a rural site ranged from 0.02 to $0.06 \mu \mathrm{g} / \mathrm{m}^{3}$ (Daisey 1987). Davidson et al. (1988) measured the atmospheric zinc concentrations at Great Smoky Mountains and Olympic National Parks where crustal weathering, sea spray, and long-range transport of zinc were likely to influence concentrations. The average atmospheric concentrations of zinc were 0.0033 and $0.0089 \mu \mathrm{g} / \mathrm{m}^{3}$ for Great Smoky Mountains in 1979 and Olympic National Parks in 1980, respectively. The reported concentration range of zinc in air at remote sites (arctic) was $<0.003-0.027 \mu \mathrm{g} / \mathrm{m}^{3}$ (Barrie and Hoff 1985; Duce et al. 1975; Zoller et al. 1974). In aerosol samples of the lower troposphere collected over the Southern Bight of the North Sea between September 1988 and October 1989, the average zinc concentration was $0.067 \mu \mathrm{g} / \mathrm{m}^{3}$ (standard deviation, $0.054 \mu \mathrm{g} / \mathrm{m}^{3}$; range, $0.003-0.22 \mu \mathrm{g} / \mathrm{m}^{3} ; \mathrm{n}=108$ samples) (Injuk et al. 1992). The concentration of atmospheric zinc is usually lower in winter than in summer (Barrie and Hoff 1985; Daisey 1987).

Indoor air from other regions of the world has been reported to contain zinc in particulate matter at low levels. In 1991, household dust sampled from Bahrain in Persian Gulf region contained zinc at a concentration of $64.4 \mu \mathrm{g} / \mathrm{g}$ (Akhter and Madany 1993). As part of the Southeastern Brazil Indoor Air 
Quality Study (SEBIAQS) in the summer of 1993, indoor and outdoor air samples were collected at 12 sites in the cities of São Paulo and Rio de Janeiro, Brazil. Indoor air particulate samples had higher levels of zinc than outdoor samples. The concentration of zinc in indoor air particulates from São Paulo and Rio de Janeiro, Brazil were 0.046-0.30 and 0.036-0.38 $\mu \mathrm{g} / \mathrm{m}^{3}$, respectively, while outdoor samples ranged from not detected to 0.23 and from 0.05 to $0.29 \mu \mathrm{g} / \mathrm{m}^{3}$, respectively (Miguel et al. 1995).

Although data are sparse, higher-than-background concentrations have been reported near iron- and steelproducing factories and zinc, lead, and copper smelters. During zinc smelting operations, concentrated zinc ore goes through a roasting procedure to convert zinc sulfide to zinc oxide. This process accounts for a large portion of the total atmospheric zinc emission during primary production (EPA 1980d). About 1.5 miles from a smelter in Kellogg, Idaho, Ragaini et al. (1977) detected high annual mean concentrations of zinc in ambient air of $5 \mu \mathrm{g} / \mathrm{m}^{3}$. The 24-hour values for zinc ranged from 0.27 to $15.7 \mu \mathrm{g} / \mathrm{m}^{3}$; the average lead and cadmium concentrations at this smelter site were 11 and $0.8 \mu \mathrm{g} / \mathrm{m}^{3}$, respectively, indicating severe environmental pollution. Higher concentrations of zinc in the vicinity of a copper smelter than in reference areas were also reported by Patterson et al. (1977).

\subsubsection{Water}

In general, zinc is more concentrated in the sediments of streams and rivers than in the water column. It is reported by NAS (1977) that zinc is probably detectable in $75 \%$ of all water samples from various locations. The zinc background concentrations in surface waters are usually $<50 \mu \mathrm{g} / \mathrm{L}$ (EPA 1980d), but concentrations in surface waters and groundwater can range from 0.002 to $50 \mathrm{mg} / \mathrm{L}$ (NAS 1977). Table 6-4 summarizes the typical concentrations of dissolved zinc in rivers of the United States (Shiller and Boyle 1985). The concentration of dissolved zinc in water from three Adirondack lakes was highest for low $\mathrm{pH}$ waters (Heit et al. 1989). Lake water from Darts Lake (pH 5.1-5.4) contained $7.9 \mathrm{ng}$ zinc/mL while Moss Lake, a lake with variable acidity ( $\mathrm{pH} 5.8-6.7$ ), contained zinc at $2.9 \mathrm{ng} / \mathrm{mL}$ and Rondoxe Lake, a neutral lake (pH 6.5-6.8), contained $2.5 \mathrm{ng}$ zinc/mL.

In many locations (e.g., New England, the southeast, the Missouri River basin, the Rio Grande River basin, and the Upper Colorado River basin), higher-than-background concentrations of zinc are common and appear to be correlated with mining activities in these areas and/or geological areas rich in zinc (EPA 1980d). However, in all river basins, there are some locations with zinc concentrations of 0.1-1.0 mg/L (EPA 1980d). In the Upper Rio Grande River, the dissolved zinc concentration upriver of Willow Creek, which drains a metal mining district, was approximately $2-3 \mu \mathrm{g} / \mathrm{L}$. Immediately downstream of the 
Table 6-4. Dissolved Zinc in Rivers of the United States ${ }^{a}$

\begin{tabular}{|c|c|c|c|}
\hline River $^{\text {b }}$ & Date $^{\mathrm{c}}$ & $\mathrm{pH}$ & $\operatorname{Zinc}\left(\mu \mathrm{g} / \mathrm{L} \text { at } 20^{\circ} \mathrm{C}\right)^{\mathrm{d}}$ \\
\hline \multicolumn{4}{|l|}{ Ohio Valley } \\
\hline Allegheny (Pittsburgh, PA) & May 1984 & 6.86 & $1.89,2.02$ \\
\hline Monongahela (Pittsburgh, PA) & May 1984 & 7.22 & $2.54,2.87$ \\
\hline Ohio (Wheeling, WV) & May 1984 & 7.34 & $3.19,3.19$ \\
\hline Muskingum (Zanesville, $\mathrm{OH}$ ) & May 1984 & 7.55 & $1.04,1.24$ \\
\hline Muskingum (Marietta, OH) & May 1984 & 7.66 & $0.63,0.63$ \\
\hline Kanawha (Winfield, WV) & May 1984 & 7.4 & $0.33,0.35$ \\
\hline Big Sandy (Louisa, KY) & May 1984 & 7.15 & $0.33,0.33$ \\
\hline Ohio (Greenup Dam) & May 1984 & 7.42 & $0.78,0.91$ \\
\hline Sciotto (Portsmouth, OH) & May 1984 & 7.87 & $1.30,1.43$ \\
\hline Little Miami (Milford, OH) & May 1984 & 8.1 & $0.85,1.04$ \\
\hline Licking (Alexandria, KY) & May 1984 & 7.63 & 0.07 \\
\hline Great Miami (Cleves, OH) & May 1984 & 8.0 & $4.24,4.30$ \\
\hline Whitewater (Elizabethtown, OH) & May 1984 & 7.95 & 0.16 \\
\hline Ohio (Warsaw, KY) & May 1984 & 7.45 & $0.39,0.42$ \\
\hline Kentucky (Lockport, KY) & May 1984 & 7.28 & $0.12,0.15$ \\
\hline Ohio (Cannelton Dam) & May 1984 & 7.27 & 0.61 \\
\hline Green (Beach Grove, KY) & May 1984 & 7.32 & $0.16,0.16$ \\
\hline Wabash (New Harmony, IN) & May 1984 & 8.1 & 0.49 \\
\hline Cumberland (Barkley Dam) & May 1984 & 7.44 & $0.10,0.10$ \\
\hline Tennessee (Kentucky Dam) & May 1984 & 7.10 & $0.12,0.12$ \\
\hline Ohio (Mound City, IL) & May 1984 & 7.49 & $0.29,0.29$ \\
\hline \multicolumn{4}{|l|}{ Mississippi River } \\
\hline Mississippi (Cape Girardeau, MO) & May 1984 & 7.70 & $0.19,0.23$ \\
\hline Mississippi (Baton Rouge, LA) & Sept 1983 & 8.1 & $0.10,0.12$ \\
\hline Mississippi (Baton Rouge, LA) & Apr 1984 & 7.72 & $0.18,0.19$ \\
\hline Atchafalaya (Krotz Springs, LA) & Apr 1984 & 7.6 & 0.18 \\
\hline \multicolumn{4}{|l|}{ Other U.S. rivers } \\
\hline Connecticut (Old Saybrook, CT) & Apr 1983 & 7.1 & $0.91,1.04$ \\
\hline Mullica & Aug 1983 & 5.81 & $2.54,2.61$ \\
\hline Merrimack (West Newbury, MA) & Feb 1983 & 6.73 & 13.04. 13.04 \\
\hline Vermilion, (Lafayette, LA) & Apr 1984 & 7.1 & $0.25,0.27$ \\
\hline Delaware (West Trenton, NJ) & Apr 1984 & 7.38 & $3.91,3.98$ \\
\hline Delaware (Philadelphia, PA) & Apr 1984 & 7.05 & $13.04,15.65$ \\
\hline Schuykill (Philadelphia, PA) & Apr 1984 & 7.58 & $4.56,4.89$ \\
\hline
\end{tabular}


6. POTENTIAL FOR HUMAN EXPOSURE

Table 6-4. Dissolved Zinc in Rivers of the United States ${ }^{a}$

\begin{tabular}{clll}
\hline River $^{\mathrm{b}}$ & Date $^{\mathrm{c}}$ & $\mathrm{pH}$ & Zinc $\left(\mu \mathrm{g} / \mathrm{L} \text { at } 20^{\circ} \mathrm{C}\right)^{\mathrm{d}}$ \\
\hline Susquehanna (Holtwood, PA) & Apr 1984 & 7.54 & $0.78,0.85$ \\
Potomac (Great Falls, MD) & Apr 1984 & 7.75 & $0.54,0.55$ \\
\hline
\end{tabular}

${ }^{\mathrm{a}}$ Source: Shiller and Boyle 1985

${ }^{\mathrm{b}}$ Post office state abbreviations are used.

${ }^{\mathrm{c}} \mathrm{Apr}=$ April; Aug = August; Feb = February; Sept $=$ September

${ }^{\mathrm{d}}$ Calculated from nmol $/ \mathrm{kg}$ using density of water at $20^{\circ} \mathrm{C}(0.99707 \mathrm{~g} / \mathrm{mL})$ and zinc molecular weight of $65.39 \mathrm{~g} / \mathrm{mole}$. 
Willow Creek confluence, zinc concentrations were $>20 \mu \mathrm{g} / \mathrm{L}$ and elevated concentrations occurred for the next $100 \mathrm{~km}$ (Taylor et al. 2001). The concentrations of zinc in water samples from Whitewood Creek, South Dakota, were measured by Hale (1977). The samples were collected upstream from the discharge of a local mining company. In 42 analyses, zinc concentrations ranged from $<0.004$ to $0.048 \mathrm{mg} / \mathrm{L}$ with a mean concentration of $0.018 \mathrm{mg} / \mathrm{L}$. May et al. (2001) reported that water samples analyzed in 1996 from this contaminated watershed contained zinc at concentrations of 2.4-21 and 3.8$30 \mu \mathrm{g} / \mathrm{L}$ for filtered and unfiltered samples, respectively.

The average levels of dissolved zinc in water from Lakes Superior, Erie, and Ontario were 277, 87, and 160 ng/L, respectively, for samples collected between 1991 (Lake Superior) and 1993 (Lakes Ontario and Erie) (Nriagu et al. 1996). Coale and Flegal (1989) reported that concentration of dissolved zinc in water from Lakes Erie and Ontario ranged from $3 \times 10^{-6}$ to $1.1 \times 10^{-4} \mathrm{mg} / \mathrm{L}$. In summer, there is a marked depletion of zinc in the epilimnion (i.e., area of warmest water) of Great Lakes off-shore waters, which may be attributed to biological processes (Nriagu et al. 1996). Groundwater from a shallow alluvial aquifer beneath a major urban center (Denver, Colorado) contained dissolved zinc at a median concentration of $3 \mu \mathrm{g} / \mathrm{L}$ (range, 2-28 $\mu \mathrm{g} / \mathrm{L}$ ) (Bruce and McMahon 1996).

Scudlark et al. (1994) reported that the average concentration of zinc in water from the Chesapeake Bay was $1.21 \pm 0.95 \mu \mathrm{g} / \mathrm{L}(\mathrm{n}=5)$ for samples collected from 1990 to 1991 . The median concentration of zinc in the Hudson River estuary decreased from $200 \mathrm{nM}(1.6 \mathrm{ng} / \mathrm{L})$ in 1974 to approximately $25 \mathrm{nM}(13 \mathrm{ng} / \mathrm{L})$ in 1997 (Sañudo-Wilhelmy and Gill 1999). The declining levels of zinc and other metals is a result of the decreased metal flux to the estuary from sewage effluents. Zinc concentrations in remote regions of the Atlantic Ocean ranged from 0.023 to $0.097 \mu \mathrm{g} / \mathrm{L}$ in the Northeast region and averaged $0.004 \mu \mathrm{g} / \mathrm{L}$ in the Northwest region (Helmers and Schrens 1995). Yeats (1988) reported that the concentrations of dissolved zinc in ocean water from the Sargasso Sea and Northeast Pacific were 0.3-3.0 nM (20$200 \mathrm{ng} / \mathrm{L})$ in 1984 and 3.6-9.2 nM (240-600 ng/L) in 1981, respectively. Seawater from lagoons of the Gulf of Mexico contained average dissolved zinc concentrations of 2.37, 5.12, and $9.76 \mu \mathrm{g} / \mathrm{L}$ for locations at Alvarado, San Andres, and Sedue (in Mexico), respectively (Vazquez et al. 1995). The concentration of zinc in surficial seawater from the Indian River lagoon (Florida) ranged from 0.01 to $6.6 \mu \mathrm{g} / \mathrm{L}$ (average, $0.8 \pm 1.4 \mu \mathrm{g} / \mathrm{L}$ ) in 1992 (Trocine and Trefry 1996).

Zinc concentration in precipitation from remote regions of the Atlantic Ocean ranged from 0.359 to $3.93 \mu \mathrm{g} / \mathrm{L}$ (Helmers and Schrens 1995). Heaton et al. (1990) reported that precipitation collected from three locations Rhode Island between 1985 and 1988 contained zinc at median concentration of $4.5 \mathrm{ppb}$ 
$(n=269)$. Levels of zinc were higher in samples collected in warm periods (5.8 ppb) versus cold periods (3.7 ppb). Nearly all zinc was dissolved in these samples. Trace amounts of zinc were measured in cloud water ( $\mathrm{n}=3$; range, $<10-43 \mu \mathrm{g} / \mathrm{L}$ ) collected from Whiteface Mountain (Adirondacks Region, New York) in the summer of 1987 (Khwaja et al. 1995). Municipal waste incineration was the primary source of zinc in these wet deposition samples. Snow near an expressway in Montréal, Québec, Canada, contained zinc at average concentrations of $0.143,0.33,0.034$, and $0.029 \mathrm{mg} / \mathrm{L}$ at $15,20,125$, and 150 meters from the roadway, respectively (Loranger et al. 1996). Higher zinc concentrations near expressway were the result of road dust from tire abrasion.

Available data suggest that zinc concentrations in drinking water are far less than levels required to meet a daily intake level of $11 \mathrm{mg} /$ day (assuming an adult water consumption of 2 L/day) (IOM 2002). Concentrations of zinc in drinking water can be higher than levels in surface waters. Concentrations of $0.002-1.2 \mathrm{mg} / \mathrm{L}$ were detected in $77 \%$ of 1,577 surface water samples while levels of $0.003-2.0 \mathrm{mg} / \mathrm{L}$ were found in 380 drinking water samples (NAS 1977). Higher concentrations in drinking waters are a result of water treatment and of contamination from plumbing of the water distribution system.

Zinc was found in drinking water at levels as great as several $\mathrm{mg} / \mathrm{L}$ as a result of galvanized pipes and tanks in alkaline-water distribution systems. Drinking water samples from galvanized pipe plumbing systems in Seattle, Washington, contained zinc concentrations of $0.128-1.279 \mathrm{mg} / \mathrm{L}$; these levels were $>10$ times higher than those in homes with copper pipe plumbing systems (Sharrett et al. 1982a). Fortythree tap-water samples collected from homes in Dallas, Texas and analyzed for trace metals reported maximum, minimum, median, and average zinc concentrations of 0.049, 0.005, 0.011, and $0.0124 \mathrm{mg}$ zinc/L, respectively (NAS 1977). High zinc concentrations in these water samples were believed to be due to the household plumbing. In a study investigating associations between inorganic constituents of drinking water and cardiovascular diseases, Greathouse and Osborne (1980) collected and analyzed tap water samples in 35 geographic areas in the United States; 100-110 tap-water samples were collected from each area. The maximum, minimum, and mean concentrations were $1.447,0.025$, and $0.144 \mathrm{mg}$ zinc/L, respectively. Seventy-five percent of the zinc values were below $0.236 \mathrm{mg} / \mathrm{L}$. Other investigators have attributed the higher concentrations of zinc in household tap waters, compared to finished drinking water, to distribution and transmission lines (Maessen et al. 1985; Ohanian 1986; Schock and Neff 1988).

The median concentration of zinc in leachate from municipal landfills in the United States ranged from 0.68 to $1.7 \mathrm{mg} / \mathrm{L}$ with a high concentration of $250 \mathrm{mg} / \mathrm{L}$ (Roy 1994). 


\subsubsection{Sediment and Soil}

Zinc is found in soils and surficial materials of the conterminous United States at concentrations between $<5$ and 2,900 mg/kg, with a mean of $60 \mathrm{mg} / \mathrm{kg}$ (Schacklette and Boerngen 1984). Zinc concentrations measured across the United Stated ranged from $<5$ to $400 \mathrm{mg} / \mathrm{kg}$ and from $<10$ to 2,000 mg/kg, with corresponding means of 36 and $51 \mathrm{mg} / \mathrm{kg}$ in cultivated and uncultivated subsurface soils, respectively (Connor and Shacklette 1975); however, these differences in zinc concentration may be attributed to differences in the soils prior to use (and not to cultivation). The sampling survey was designed to determine zinc concentrations of surficial materials unaltered from their natural condition. Chen et al. (1999) determined the baseline concentration of zinc in 448 representative Florida surface soils as part of the Florida Cooperative Soil Survey Program. Baseline soil samples represent natural elemental concentrations without human influence. The mean concentration of zinc was $8.35 \pm 13.8 \mathrm{mg} / \mathrm{kg}$ (range, $0.9-169 \mathrm{mg} / \mathrm{kg}$ ) in archived soil samples from this study.

Soils near highways and smelters contained high zinc concentrations as a result of deposition of zinc released in tire abrasion and stack emissions (EPA 1980d; Norrström and Jacks 1999). Urban alluvial soils from New Orleans, Louisiana had higher levels of zinc as a result of highway traffic $(130 \mu \mathrm{g} / \mathrm{g})$ than freshly deposited lower Mississippi River delta spillway alluvium (11.1 $\mu \mathrm{g} / \mathrm{g}$ ) (Mielke et al. 1999, 2000).

A study was designed by Hutchinson and Wai (1979) to investigate the distribution of cadmium, lead, and zinc in the soil and vegetation at two reclaimed waste dumps from phosphate ore mines in southeastern Idaho. Zinc concentrations in the soil of the waste dumps averaged from $443 \pm 210$ to $1,112 \pm 124 \mathrm{mg} / \mathrm{kg}$. These values were high compared to those found in the control plot $(54 \pm 16 \mathrm{mg} / \mathrm{kg})$. Zinc concentrations in vegetation from the reclaimed waste dumps were also high compared to the control plot. Moderate-tohigh levels of zinc contamination were found in leafy vegetables (lettuce) and their supporting soil in a zone with a 0-5-km radius around a copper smelter (Beavington 1975). The mean concentrations of zinc in 17 soil samples and 12 lettuce samples collected in this zone were $229 \pm 17$ and $316 \pm 64 \mathrm{mg} / \mathrm{kg}$ dry weight, respectively. Significant relationships were found between the distance from the smelter and the levels of easily extractable zinc in the soil, and between the distance from the smelter and the content of zinc in herbage. The concentration of zinc in soil at the Palmerton zinc smelter site in eastern Pennsylvania was determined 6 years after zinc smelting was terminated in 1980 (Storm et al. 1994). Levels in soils were highest $(4,160 \mathrm{mg} / \mathrm{kg})$ at sites close to the former smelter and decreased with distance. Zinc concentrations in urban top soils from the western half of East St. Louis, Illinois (a city with historical industrial activities such as smelting of nonferrous metals) ranged from 79 to $10,360 \mu \mathrm{g} / \mathrm{g}$ 
with an average concentration of $1,034 \mu \mathrm{g} / \mathrm{g}$ (Kaminski and Landsberger 2000). Concentrations of zinc in soil irrigated with waste water or river water were measured by Schalscha et al. (1982). The total concentration of zinc in waste water-treated soils was $228 \mathrm{mg} / \mathrm{kg}$. The total concentration of zinc in soils irrigated with river water ranged from 103 to $136 \mathrm{mg} / \mathrm{kg}$.

Soils around galvanized water and electrical transmission towers have been reported to have elevated levels of zinc (Jones and Burgess 1984). Near Peterborough, Ontario, Canada, soil nearest to a galvanized water tower contained zinc at a concentration of $11,480 \pm 2,966 \mu \mathrm{g} / \mathrm{g}$ dry weight, while the concentration of zinc in soil 50 meters from the tower was $54 \pm 16 \mu \mathrm{g} / \mathrm{g}$ dry weight.

Municipal sludge and municipal incineration ash contain considerably higher levels of zinc than uncontaminated soils (Mumma et al. 1984, 1990, 1991). Therefore, application of sludge and municipal ash to soil will elevate the levels of zinc in these soils. The mean concentrations ( $\mathrm{mg} / \mathrm{kg}$ ) of zinc according to four land use types were as follows: agricultural, 25; suburban residential, 75; mixed industrial/residential, 157; and industrial inner urban area, 360 (Haines 1984).

Zinc in water is transported to the sediment in the adsorbed or precipitated phase; the concentration of zinc in sediments of most waters is higher than the zinc concentration in aqueous phase. From 1992 to 1996, streambed sediments samples were collected from 541 locations at more than 50 river basins across the conterminous United States (illustrated in Table 6-5) as part of the National Water-Quality Assessment Program (Rice 1999; USGS 2002). The median zinc concentration in these sediments was $110 \mu \mathrm{g} / \mathrm{g}$ dry weight (range, $<4.0-9,000 \mu \mathrm{g} / \mathrm{g}$ dry weight). Samples collected from urban settings were enriched in zinc relative to agricultural or forest settings. The highest median concentration was observed in the Upper Colorado River Basin while the lowest was observed in Central Nebraska Basins (USGS 2002). Bed sediments from the South Platte River basin sampled from 1992 to 1993 contained zinc at concentrations ranging from 82 to $3,700 \mu \mathrm{g} / \mathrm{g}$ dry weight (average, $454 \mu \mathrm{g} / \mathrm{g}$ dry weight) (Heiny and Tat 1997). The highest concentrations were observed near the urban region around Denver, Colorado and in the Rocky Mountains. In 1979-1980, as part of the Apalachicola River Quality Assessment, fine grained sediment ( $<20 \mu \mathrm{m}$ particle size) of the Apalachicola River was reported to contain zinc at a median concentration of $70 \mu \mathrm{g} / \mathrm{g}$ dry weight ( $\mathrm{n}=15$; range, 20-150 $\mu \mathrm{g} / \mathrm{g}$ dry weight) (Elder and Mattraw 1984). Surficial lake sediments from four locations in Rock Mountain National Park contained zinc at mean concentrations ranging from $72 \pm 4$ to $125 \pm 3 \mu \mathrm{g} / \mathrm{g}$ dry weight (Heit et al. 1984). The geometric mean and range of zinc levels in lake sediment from 189 sites in 52 Quebec and Ontario, Canada lakes were 125.2 and 3.0-559.9 $\mu \mathrm{g} / \mathrm{g}$ dry weight, respectively (Rowan and Kalff 1993). The concentrations of zinc 


\section{Table 6-5. Median Zinc Levels in Bed Sediment from River Basins of the United States $^{\mathrm{a}}$}

\begin{tabular}{|c|c|}
\hline NAWQA study unit ${ }^{\mathrm{b}}$ & $\begin{array}{l}\text { Median concentration of zinc } \\
\text { ( } \mu \mathrm{g} / \mathrm{g} \text { dry weight) }\end{array}$ \\
\hline Acadian-Ponchartrain (ACAD) & 120 \\
\hline Albemarle-Pamlico Drainage (ALBE) & 99 \\
\hline Allegheny and Monongahela River Basins (ALMN) & 195 \\
\hline Apalachicola-Chattahoochee-Flint River Basin (ACFB) & 130 \\
\hline Central Arizona Basins (CAZB) & 160 \\
\hline Central Columbia Plateau (CCPT) & 82 \\
\hline Central Nebraska Basins (CNBR) & 69 \\
\hline Connecticut, Housatonic, and Thames River Basins (CONN) & 200 \\
\hline Cook Inlet Basin (COOK) & 110 \\
\hline Delaware River Basin (DELR) & 290 \\
\hline Eastern lowa Basins (EIWA) & 72.5 \\
\hline Georgia-Florida Coastal Plain (GAFL) & 100 \\
\hline Great and Little Miami River Basins (MIAM) & 130 \\
\hline Hudson River Basin (HDSN) & 180 \\
\hline Kanawha-New River Basin (KANA) & 200 \\
\hline Lake Erie-Lake St. Clair Drainage (LERI) & 120 \\
\hline Long Island and New Jersey Coastal Drainages (LINJ) & 245 \\
\hline Lower Illinois River Basin (LIRB) & 88 \\
\hline Lower Susquehanna River Basin (LSUS) & 300 \\
\hline Lower Tennessee River Basin (LTEN) & 84 \\
\hline Mississippi Embayment (MISE) & 91.5 \\
\hline Mobile River and Tributaries (MOBL) & 110 \\
\hline Nevada Basin and Range (NVBR) & 100 \\
\hline New England Coastal Basins (NECB) & 295 \\
\hline Northern Rockies Intermontane Basins (NROK) & 108 \\
\hline Oahu (OAHU) & 375 \\
\hline Ozark Plateaus (OZRK) & 90 \\
\hline Potomac River Basin (POTO) & 130 \\
\hline Puget Sound Basin (PUGT) & 130 \\
\hline Red River of the North (REDN) & 95 \\
\hline Rio Grande Valley (RIOG) & 82.5 \\
\hline Sacramento River Basin (SACR) & 120 \\
\hline San Joaquin-Tulare Basin (SANJ) & 110 \\
\hline Santa Ana Basin (SANA) & 160 \\
\hline Santee Basin and Costal Drainages (SANT) & 94 \\
\hline South Central Texas (SCTX) & 77 \\
\hline South Platte River Basin (SPLT) & 180 \\
\hline Trinity River Basin (TRIN) & 77.5 \\
\hline
\end{tabular}


Table 6-5. Median Zinc Levels in Bed Sediment from River Basins of the United States $^{\mathrm{a}}$

\begin{tabular}{lc} 
NAWQA study unit & $\begin{array}{c}\text { Median concentration of zinc } \\
(\mu \mathrm{g} / \mathrm{g} \text { dry weight })\end{array}$ \\
\hline Upper Colorado River Basin (UCOL) & 940 \\
Upper Illinois River Basin (UIRB) & 110 \\
Upper Mississippi Basin (UMIS) & 110 \\
Upper Snake River Basin (USNK) & 81 \\
Upper Tennessee River Basin (UTEN) & 140 \\
Western Lake Michigan Drainage (WMIC) & 98 \\
White River Basin (WHIT) & 100 \\
Willamette River Basin (WILL) & 120 \\
National median & 110 \\
\hline
\end{tabular}

${ }^{a}$ Source: USGS 2000

${ }^{\mathrm{b}}()=$ acronym for study unit 
in sediments of the upper Columbia River, British Columbia, ranged from 45 to $51 \mathrm{mg} / \mathrm{kg}$, while zinc concentrations in sediments from Lake Roosevelt, Washington were 60-26,840 mg/kg (Johnson et al. 1990). The higher zinc concentrations in lake sediments were due to discharges from a lead-zinc smelter and a refinery. Contaminated sediments in the West Branch of the Grand Calumet River (Indiana/ Illinois), a river system heavily impacted by various industrial activities for many years, were found to contain zinc at concentrations ranging from 325 to 9,281 ppm (mean, 1,270 $\pm 1,097 \mathrm{ppm}$ ) (Cahill and Unger 1993). Sediment samples collected from streams in the Black Hills, South Dakota, an area impacted by gold mining operations, contained zinc at levels ranging from 3.8 to $250 \mu \mathrm{g} / \mathrm{g}$ dry weight (May et al. 2001).

Marine sediments also contain elevated concentrations of zinc with respect to concentrations of zinc in seawater. The concentration of zinc in Hamilton Harbor sediments ranged from 1,050 to 2,900 mg/kg, compared to zinc concentrations of 6-48 $\mu \mathrm{g} / \mathrm{L}$ in the aqueous phase (Mayer and Manning 1990). Surficial sediments from the Newark Bay Estuary, Hackensack River, Newark Bay, Arthur Kill, and Kill van Kull contained zinc at mean concentrations of $739.5 \pm 243.9,426 \pm 600.5,489.8 \pm 238.1,769.1 \pm 715.2$, and $331.3 \pm 213.7$ ppm, respectively (Crawford et al. 1995). Sediment samples collected from the Hudson River Estuary in 1991 contained zinc at levels of 27-215 and 400-2,500 mg/kg in bottom and suspended sediment, respectively (Gibbs 1994). Marine sediment samples from the border region of Baja California (Mexico) and California (United States) contained zinc at concentration levels ranging from 39 to $188 \mu \mathrm{g} / \mathrm{g}$ dry weight (mean, $68.3 \mu \mathrm{g} / \mathrm{g}$ dry weight) in the fine fraction $(<63 \mu \mathrm{m})$ of sediment. A relative enrichment of $>350 \%$ was observed with respect to nonpolluted sediments of the region (VillascusaCelaya et al. 2000). Marine sediment in coastal areas of Mexico (Pacific Ocean and Gulf of Mexico) was found to contain zinc at mean concentrations ranging from 4.0 to $227.0 \mu \mathrm{g} / \mathrm{g}$ dry weight (Villanueva and Botello 1998). Soto-Jimenez and Páez-Osuna (2001) reported mean concentrations of zinc ranging from $84.3 \pm 38.7$ to $359 \pm 76.5 \mathrm{mg} / \mathrm{kg}$ dry weight for marine sediments collected in November 1994 from Mazatlán Harbor, Mexico (southeastern Gulf of California). This harbor receives land runoff and untreated or partially treated industrial, shipping, and domestic effluents from local point sources. During the period of 1984-1985, marine sediment samples were collected from the San Andres lagoon of the Gulf of Mexico, which is located near two industrial ports and industrial effluent is discharged into the lagoon year round. Sediments from this region were found to contain zinc at a concentration of $10.1 \mathrm{mg} / \mathrm{kg}$ dry weight (Vasquez et al. 1994). 


\subsubsection{Other Environmental Media}

As part of the National Water Quality Assessment (NAWQA) Program, the concentration of zinc in various species of fish was measured (USGS 2000a, 2000b, 2001). The concentration of zinc in fish fillet sampled from the Lower Tennessee River Basin ranged from 3.0 to $46.0 \mu \mathrm{g} / \mathrm{g}$ dry weight for 79 of 102 positive detections from 1980 to 1998 (USGS 2001). Fish fillets collected from the Clark Fork-Pend Oreille and Spokane River Basins (Washington, Idaho, and Montana) contained zinc at concentrations ranging from 11 to $36 \mu \mathrm{g} / \mathrm{g}$ dry weight ( $\mathrm{n}=15$; median $16 \mu \mathrm{g} / \mathrm{g}$ dry weight) in 1998 (USGS 2000b). In the National Contaminant Biomonitoring Program, the geometric mean concentration of zinc in various whole fish was $21.7 \mathrm{mg} / \mathrm{kg}$ wet weight (Schmitt and Brumbaugh 1990). Of all fish tested (e.g., bloater, sucker, white perch, bass, catfish, etc.), common carp showed the highest level of zinc. No significant trend in the level of zinc in whole fish was observed during 1978-1984. Blevens and Pancorbo (1986) determined the zinc concentrations in muscle tissue of fish from aquatic systems in east Tennessee, from 1980 to 1984. Mean levels of zinc in fish from Nolichucky and Little Chucky Creeks ranged from 12 to 19 ppm wet weight. Fish from Watauga and Boone Lakes had a range of mean zinc concentrations of 8.3-12 ppm wet weight; in the Holston River Basin, the range of mean concentrations of zinc was 4.628 ppm wet weight. The mean concentration of zinc in muscle tissue of tuna (Thunnus thynnus) collected from the northwest Atlantic Ocean was $17 \mu \mathrm{g} / \mathrm{g}$ dry weight (range, 12-25 $\mu \mathrm{g} / \mathrm{g}$ dry weight) in 1990 (Hellou et al. 1992).

Zinc will not concentrate in fish tissues with exposure to elevated concentrations. The concentration of zinc in yellow perch (Perca flavescens) from six acidic lakes in northwestern New Jersey ranged from 26.1 to $66.2 \mathrm{mg} / \mathrm{kg}$ dry weight (Sprenger et al. 1988). Although the concentrations of mercury and lead in fish from acidic lakes were higher compared to fish collected from nonacidic lakes, the concentrations of zinc showed no significant difference. Similarly, high concentrations of zinc were not found in white suckers (Catostomus commersoni) and brown bullheads (Ictalurus nebulosus) collected from two acidic Adirondack lakes in New York (Heit and Klusek 1985). Fish from the Milltown Reservoir Superfund Site in Montana (characterized by elevated concentrations of metals in wetland soils, surface water, and groundwater) contained zinc in whole body tissues at a concentration of $26.3 \mathrm{mg} / \mathrm{kg}$ wet weight (Pascoe et al. 1996). Redear sunfish (Lepomis microlophus), largemouth bass (Micropterus salmoides), and bluegill sunfish (Lepomis macrochirus) were collected from storm water ponds and natural lakes and ponds in Orlando, Florida between 1991 and 1992 (Campbell 1994). The mean concentrations of zinc in whole fish collected from storm water ponds were 42.2, 29.99, and $36.1 \mathrm{mg} / \mathrm{kg}$ wet weight for redear sunfish, largemouth bass, and bluegill sunfish, respectively. At natural lakes and ponds (controls sites), 
the mean concentrations of zinc were $24.83,21.18$, and $30.72 \mathrm{mg} / \mathrm{kg}$ wet weight for redear sunfish, largemouth bass, and bluegill sunfish, respectively.

Bivalves and other sessile estuarine organisms are often used as a measure of contamination of estuarine water because they usually contain higher levels of metals than fish. The arithmetic mean concentration of zinc in oysters (Crassostrea virginica) from the Mississippi Sound collected in 1988 was $640 \mathrm{mg} / \mathrm{kg}$ wet weight (Lytle and Lytle 1990). Oysters collected from the San Andres lagoon (Gulf of Mexico) from 1984 to 1985 contained zinc at a concentration of 3,180 mg/kg dry weight (Vazquez et al. 1994). The mean concentration of zinc in oysters (C. virginica) collected from the U.S. coastline of the Gulf of Mexico during 1986-1988 was 2,150 mg/kg dry weight (Presley et al. 1990). In a nationwide mussel watch program, the mean concentrations of zinc in molluscs (Mytilus edulis) around the coast of the United States during 1976-1988 ranged from 67 to 3,700 mg/kg dry weight (Lauenstein et al. 1990). Although the concentration on a nationwide basis varied depending on sampling sites, the level of zinc showed little evidence of statistically significant change during 1976-1988. Clams endevors (Corbicula manilmsis) collected as part of the Apalachicola River Quality Assessment between 1979 and 1980 contained zinc at a median concentration of $20 \mu \mathrm{g} / \mathrm{g}$ dry weight (range, 2.1-26 $\mu \mathrm{g} / \mathrm{g}$ dry weight) (Elder and Mattraw 1984). Blue crabs (Callinectes sapidus) from the Quinnipac and Connecticut Rivers (Connecticut), which are mostly harvested for personal consumption, contained zinc in muscle and heltopancreas tissues at concentrations of $31-33$ and $27-28 \mathrm{mg} / \mathrm{kg}$ wet weight, respectively (Jop et al. 1997).

Vegetation may accumulate higher levels zinc if grown on contaminated soils. Jones et al. (1988) found that corn plants and young corn plants (Zea mays) grown beneath and close to a galvanized electrical transmission tower had elevated concentrations of zinc due to corrosion of the zinc protective layer on the steel. Corn seedlings grown in a highly contaminated soil $(1,425 \mu \mathrm{g}$ zinc/g soil $)$ a meter from the tower had zinc concentration in shoots and roots of $484 \pm 103$ and $1,330 \pm 250 \mu \mathrm{g} / \mathrm{g}$ dry weight, respectively. In contrast, seedlings grown in soil 50 meters from tower $(67.3 \mu \mathrm{g}$ zinc/g soil) had zinc concentrations in shoots and roots of $25.3 \pm 4.2$ and $21.0 \pm 2.6 \mu \mathrm{g} / \mathrm{g}$ dry weight, respectively. Bache et al. (1991) found concentrations of zinc were highest in grass samples (Phleum pratense L.; Agropyron repens L.; Bromus inermis L; Phalaris arundinacea L.) collected immediately adjacent to the a municipal waste incinerator (135.7 $\mu \mathrm{g} / \mathrm{g}$ dry weight) compared to grass samples collected upwind or a distance from the incinerator (17.82-73.78 $\mu \mathrm{g} / \mathrm{g}$ dry weight). Grasses collected from the Milltown Reservoir Superfund Site in Montana contained zinc at concentrations of 153.7 and $882.1 \mathrm{mg} / \mathrm{kg}$ for above- and below-ground samples, respectively (Pascoe et al. 1996). In contrast, control samples from a reference area contained 
zinc at concentrations of 71.8 and $36.2 \mathrm{mg} / \mathrm{kg}$ for above- and below-ground samples, respectively. Other studies have not shown significant correlations between zinc concentrations in soils and vegetation (Fytianos et al. 2001; Schuhmacher et al. 1998).

Sewage sludge and compost, which may be used in agriculture as a soil amendment, have high levels of zinc. The average concentrations of zinc in municipal solid waste compost and sewage from the United States were found to be 609 and 1,202 mg/kg dry weight, respectively (He et al. 1995). The median concentration of zinc found in residential compost from Toronto, Canada was $190 \mathrm{mg} / \mathrm{kg}$ dry weight (range, 100-410 mg/kg dry weight) (Evans and Tan 1998). Biowaste, composed of organic waste products from indoors and outdoors, contained zinc at concentrations of $120 \pm 25,129 \pm 13$, and $338 \pm 58 \mathrm{mg} / \mathrm{kg}$ dry matter in the $>5 \mathrm{~mm}, 1-5 \mathrm{~mm}$, and $<0.05 \mathrm{~mm}$ fractions, respectively (Veeken and Hamelers 2002).

Other environmental concentrations of significance include coal and paint. Coal from the United States was found to contain zinc at a mean concentration of $53 \pm 440 \mathrm{ppm}(\mathrm{n}=7,908$; maximum=19,000 ppm) (Finkelman 1999). Zinc was present at a median concentration of $31,101 \mu \mathrm{g} / \mathrm{g}$ (n=31; range, 52$98,056 \mu \mathrm{g} / \mathrm{g}$ ) in paint from historic old homes of New Orleans, Louisiana (Mielke et al. 2001).

\subsection{GENERAL POPULATION AND OCCUPATIONAL EXPOSURE}

General Population. Zinc is essential element needed by the body in small amounts and ranks as one of the most abundant trace metals in humans. Sources of exposure to zinc include ingestion of food, drinking water, food, polluted air, tobacco products, and occupational exposure, with ingestion of food being the primary route of exposure. NAS established the RDA for zinc at $11 \mathrm{mg} /$ day for men and $8 \mathrm{mg} /$ day for women (IOM 2002).

The average daily intake (AVDI) of zinc in humans is on the order of 5.2-16.2 $\mathrm{mg}$ zinc/day (Pennington et al. 1986). The dietary intake of an average teenage male has been estimated to be $0.27 \mathrm{mg}$ zinc/(kg/day). Dietary supplements may provide up to an additional $1 \mathrm{mg}$ zinc/(kg/day) (EPA 1980d). In an extensive survey of foods in the total diets of individuals in the United States, conducted by FDA during 1982-1984, the following values for daily zinc intakes (mg/day) were estimated in eight age and sex groups: 6-11-month-old infants, 5.24; 2-year-old children, 7.37; 14-16-year-old girls, 9.90; 1416-year-old boys, 15.61; 25-30-year-old women, 9.56; 25-30-year-old men, 16.15; 60-65-year-old women, 8.51; and 60-85-year-old men, 12.64 (Pennington et al. 1986). FDA included drinking water in 
the total diet. In 1986, the average daily intakes of 40 African-Americans (age 21-65 years old living in Washington D.C. area) were $7.7 \pm 0.4 \mathrm{mg}$ for men and $9.1 \pm 0.7 \mathrm{mg}$ for women (Ellis et al. 1997). These results are comparable with data from the USDA's Continuing Survey of Food Intakes by Individuals (CSFII) and the National Health and Nutrition Examination Survey (NHANES) III, which reported average daily intakes as follows: NHANES III, 40-49 year old value, male (12.3 mg/day), female ( $8.5 \mathrm{mg} /$ day); CSFII, >20-year-old value, male (12.9 mg/day), female, $(8.3 \mathrm{mg} /$ day $)$. The estimated average daily intakes of zinc were reported to be 14,11, 14, and $13.2 \mathrm{mg} /$ day in France, Spain, Sweden, and Belgium, respectively (Biego et al. 1998). Using a market basket method, the average daily intakes of zinc for residents of Japan were estimated as 8,700 and 8,500 $\mu \mathrm{g} /$ day for the years 1991 and 1992, respectively (Tsuda et al. 1995).

After a review of the literature, the National Research Council concluded that zinc concentrations in drinking water are generally well below $5 \mathrm{mg} / \mathrm{L}$ (NAS 1977). Assuming a daily intake of $2 \mathrm{~L}$ of water and an average body weight of $70 \mathrm{~kg}$, a daily intake of $<0.14 \mathrm{mg} \mathrm{zinc} / \mathrm{kg} / \mathrm{day}$ from drinking water can be estimated. Based on a body weight of $70 \mathrm{~kg}$, the mean daily intakes of zinc in drinking water for residents of homes with galvanized and copper pipe plumbing systems in Seattle, Washington, were estimated to be $0.017-0.028$ and $0.002-0.006 \mathrm{mg} / \mathrm{kg} / \mathrm{day}$, respectively (Sharrett et al. 1982b).

Food is the major source of zinc for the general population (EPA 1987c). Zinc is widespread in commonly consumed foods but tends to be higher in those of animal origin, particularly some seafoods (e.g., one serving of oysters will more than meet the daily dietary requirements of zinc) (NAS/NRC 1979). Meat products contain relatively high concentrations of zinc, whereas fruits and vegetables have relatively low concentrations. Meats, fish, and poultry contained an average of $24.5 \mathrm{mg}$ zinc/ $\mathrm{kg}$, whereas grains (or cereal products) and potatoes contained 8 and $6 \mathrm{mg} / \mathrm{kg}$, respectively (Mahaffey et al. 1975). Zinc was present in all of the examined food classes. A diet of dairy products, meat, fish, poultry, grains, and cereals provides approximately $77 \%$ of the daily zinc intake. Data reported by the Food Safety and Inspection Service of the U.S. Department of Agriculture indicate that zinc was detected in $99.4-100 \%$ of the samples of healthy livestock and poultry randomly selected from among the specimens presented for slaughter in 1985-1986. Zinc concentrations in muscle tissue ranged from $0.20 \mathrm{ppm}$ in young turkeys $(\mathrm{n}=61)$ to $1.92 \mathrm{ppm}$ in heifers/steers $(\mathrm{n}=287)$ (Coleman et al. 1992). In a review of zinc levels in vegetables and other foods and beverages of plant origin, Weigert (1991) reported the following average concentrations $(\mathrm{mg} / \mathrm{kg})$ : wheat, 41 ; rye, 13 ; rice, $8-20$; potatoes, 3.51 ; vegetables, 4.31 ; fruit, 1.66 ; mushrooms, 9.7; cocoa, 35; tea, 35; and coffee, 6.7. Zinc is found in onions, peas, and potatoes from Denmark at mean concentrations of 3.4,3.3-5.5, and $7.9 \mathrm{mg} / \mathrm{kg}$ fresh weight, respectively (Bibak et al. 
1998a, 1998b; 1999). Zinc has also been detected in wines from Seville, Spain, at concentrations of 0.3$5.40 \mu \mathrm{g} / \mathrm{mL}$, while concentrations of zinc in sherry wines ranged from 0.12 to $5.08 \mathrm{mg} / \mathrm{L}$ (López-Artiguez et al. 1990, 1996). As part of the U.S. FDA's Total Diet Study (TDS), market basket food items from locations in United States were sampled from 1991 through 1999 (FDA 2000). Results from this survey showed the highest amounts of zinc in cereals ranging from a mean of $147 \mathrm{mg} / \mathrm{kg}$ for fruit-sweetened cereals to $8.2 \mathrm{mg} / \mathrm{kg}$ for corn flakes. Beef and other meat products also included a large amount of zinc, with the highest meat product mean being $81 \mathrm{mg} / \mathrm{kg}$ for baked beef chuck roast. In France, the estimated dietary intake of zinc from different foods were determined as follows ( $\mu \mathrm{g} / \mathrm{day})$ : vegetables, 807; fruits, 143; beverages, 143; cereals, 2,572; fish-crustaceans, 795; meat-poultry-eggs, 8,318; milk-dairy products, 1,127; condiments-sugar-oils, 140; canned foods, 383; and total, 14,429 (Biego et al. 1998). The largest percentage of zinc is from meat-poultry-eggs $(58 \%)$ followed by cereals $(18 \%)$ and milk-dairy products $(8 \%)$.

Federal regulations permit the use of zinc acetate, zinc oxide, and zinc sulfide as components of adhesives, coatings, or rubber packaging materials intended for food contact (FDA 1987b, 1987c, 1987d). Federal regulations also permit the use of zinc chloride, zinc oxide, zinc stearate, and zinc sulfate as GRAS (Generally Recognized As Safe) food additives when they are used "in accordance with good manufacturing practices" (FDA 1987e, 1987f, 1987g, 1987h, 1987i, 1987j). In addition, the use of zinc oxide as a color additive in drugs and cosmetics is also permitted with certain restrictions (FDA 1987a).

Negligible quantities of zinc are inhaled in ambient air. Exposure to airborne zinc is largely occupational through the inhalation of industrial dusts or fumes. Individuals occupationally exposed to metallic zinc and zinc compounds are those involved in galvanizing, smelting, welding, or brass foundry operations. In such operations, zinc as ore or metal and its alloys are often exposed in an oxidizing atmosphere to temperatures near the metal's boiling point of $907^{\circ} \mathrm{C}$. This heating results in the formation of fresh zinc oxide particles $(0.2-1.0 \mu \mathrm{m})$, which may subsequently be inhaled. Inhalation of zinc oxide particles and fumes by workers can result in metal fume fever (Martin et al. 1999). Inhalation was reported to be the most probable route of exposure to zinc for 26 lead smelter workers found to have significantly $(\mathrm{p}<0.01)$ elevated blood plasma levels of zinc. Mean plasma zinc concentrations were $12.9 \mathrm{mmol} / \mathrm{L}$ (range, 9.8 16.7) for the workers versus $10.9 \mathrm{mmol} / \mathrm{L}$ (range, 8.1-14.6) for a nonlead-exposed control group (Vasikaran et al. 1992). Twenty workers in a zinc foundry in Baiyin, China were investigated for exposure to zinc oxide fumes (Martin et al. 1999). Eighteen of the workers had worked at the foundry since its opening 6 years earlier. Thirteen of the subjects reported at least one of the symptoms associated with metal fume fever during their tenure at the foundry. Workers were examined before the start of the 
shift, in the middle of the shift, and after the shift. Despite zinc exposures as high as $36.3 \mathrm{mg} / \mathrm{m}^{3}$ over $<4$ hours and a mean air sample concentration of $3.16 \mathrm{mg} / \mathrm{m}^{3}$, no cases of metal fume fever were observed for these workers. Concentrations of zinc in serum and urine for these workers averaged $11.515 \mu \mathrm{mol} / \mathrm{L}$ $(752.85 \mu \mathrm{g} / \mathrm{L})$ and $3.6705 \mu \mathrm{mol} / \mathrm{L}(239.98 \mu \mathrm{g} / \mathrm{L})$, respectively, during the period of an 8-hour shift.

Zinc is found in human tissues and body fluids. As part of the 1982 National Human Adipose Tissue Survey (NHATS) conducted in the United States, the concentration of zinc in adipose tissue ranged from 1.1 to $6.0 \mu \mathrm{g} / \mathrm{g}$ (EPA 1986). The mean concentration of zinc was $6.95 \pm 1.08 \mu \mathrm{g} / \mathrm{mL}$ in whole blood samples from residents of Baajoz, Spain (a region with low environmental pollution) with zinc levels increasing with age (Moreno et al. 1999). Individuals <30, 30-45, and $>45$ years old had whole blood zinc concentrations of $4.85,6.85$, and $7.32 \mu \mathrm{g} / \mathrm{mL}$, respectively. Blood and serum collected from 372 adolescents (15 years old) from the Swedish cities of Uppsala and Trollhättan contained zinc at median concentrations of 6.1 and $0.99 \mathrm{mg} / \mathrm{L}$, respectively (Bárány et al. 2002). The mean concentration of zinc in the fingernails and toenails of populations from the United States, Canada, and Japan were 105, 109, and $94 \mathrm{mg} / \mathrm{kg}$, respectively (Takagi et al. 1988). Hayashi et al. (1993) reported that human fingernail samples from Japanese individuals had higher mean levels of zinc in the spring (145-149 $\mu \mathrm{g} / \mathrm{g}$ ) compared to winter $(122-136 \mu \mathrm{g} / \mathrm{g})$. The geometric mean concentrations of zinc in toenails $(129 \mathrm{mg} / \mathrm{kg})$ and scalp hair $(108 \mathrm{mg} / \mathrm{kg})$ of pre-school children in Germany were about the same (Wilhelm et al. 1991). The total concentrations of zinc in 29 body tissues of 55 human cadavers were measured (Saltzman et al. 1990). The lowest concentration (mean of $1.5 \pm 2.2 \mathrm{mg} / \mathrm{kg}$ wet weight) of zinc in both males and females was found in adipose tissues, while the highest concentrations were detected in the skull of males (mean of $54.3 \mathrm{mg} / \mathrm{kg}$ wet weight) and in the skeletal muscle of females (mean of $59.0 \mathrm{mg} / \mathrm{kg}$ wet weight). The mean concentrations of zinc in the feces of low-income urban Hispanics and rural Blacks in the United States were 75 and $94 \mathrm{mg} / \mathrm{kg}$ wet weight, respectively (Prevost et al. 1985). Body tissue and fluid samples were collected from two nonoccupationally exposed individuals living in the Los Angeles, California area (Krishnan and Que Hee 1992). Ear wax, blood plasma, sweat, and skin from these individuals contained zinc at levels of 88-103, 0.79-1.7, 0.50-1.58, and 15.6-1,000 $\mu \mathrm{g} / \mathrm{g}$ dry weight, respectively.

Concentrations of zinc in human milk are affected by the stages lactation. Arnaud and Favier (1995) found that the level of zinc in human milk will rise to a peak 2-days postpartum $(183 \pm 70 \mu \mathrm{mol} / \mathrm{L}$ or $12.0 \pm 4 \mathrm{mg} / \mathrm{L}$ ) and then decline during the duration of lactation (e.g., at 6-days postpartum, $77 \pm 22 \mu \mathrm{mol} / \mathrm{L}$ or $5.0 \pm 1.4 \mathrm{mg} / \mathrm{L}$ ). At 6 -months, the concentration of zinc in human milk is only $12 \%$ of its initial levels (Dórea 2002). Wasowicz et al. (2001) observed an inverse relationship between zinc levels in blood 
plasma and human milk for lactating women from Poland. Mean levels of zinc in blood plasma increased from $0.51 \pm 0.13 \mathrm{mg} / \mathrm{L}$ ( $0-4$ days postpartum) to $0.76 \pm 0.20 \mathrm{mg} / \mathrm{L}$ (10-30 days postpartum), while mean levels of zinc in human milk decreased from $8.2 \pm 2.8 \mathrm{mg} / \mathrm{L}$ ( $0-4$ days postpartum) to $1.4 \pm 0.7 \mathrm{mg} / \mathrm{L}$ (10-30 days postpartum).

Zinc levels in maternal blood are normally higher than levels in cord blood. Maternal and cord blood of 56 mothers living in Singapore were analyzed for zinc (Ong et al. 1993). For these mothers, the mean concentrations of zinc were $4.97 \pm 1.15$ and $1.58 \pm 0.45 \mathrm{mg} / \mathrm{L}$ in maternal and cord blood, respectively. During the period of 1993-1997, Raghunath et al. (2000) determined the concentration of zinc in maternal and cord blood for 148 mothers (20-25 years old) living Mumbai City, India. The mean concentrations of zinc were 6.335 and $2.527 \mathrm{mg} / \mathrm{L}$ in maternal and cord blood, respectively.

Occupational. As part of the National Occupational Exposure Survey (NOES) conducted from 1980 to 1983, NIOSH statistically estimated that 269 workers (including 22 women) in 22 plants were potentially exposed to elemental zinc in the workplace; also, 133,608 workers (including 17,586 women) in 6,157 plants were potentially exposed to other forms of zinc (of undefined composition) in the workplace (NIOSH 1984b). All of the workers exposed to elemental zinc were employed in the fabricated metal products industry as millwrights or assemblers. The largest numbers of workers exposed to other forms of zinc worked in the primary metal industries, with fabricated metal products, with transportation equipment, with stone, clay, and glass products, and in special trade contractors industries. Occupational groups with the largest numbers of exposed workers were miscellaneous machine operators (not elsewhere classified or not specified), molding and casting machine operators, janitors and cleaners, and machinists. Exposure estimates were derived from observations of the actual use of the compound and the use of trade name products known to contain the compound.

\subsection{EXPOSURES OF CHILDREN}

This section focuses on exposures from conception to maturity at 18 years in humans. Differences from adults in susceptibility to hazardous substances are discussed in Section 3.7, Children's Susceptibility.

Children are not small adults. A child's exposure may differ from an adult's exposure in many ways. Children drink more fluids, eat more food, breathe more air per kilogram of body weight, and have a larger skin surface in proportion to their body volume. A child's diet often differs from that of adults. The developing human's source of nutrition changes with age: from placental nourishment to breast milk 
or formula to the diet of older children who eat more of certain types of foods than adults. A child's behavior and lifestyle also influence exposure. Children crawl on the floor, put things in their mouths, sometimes eat inappropriate things (such as dirt or paint chips), and spend more time outdoors. Children also are closer to the ground, and they do not use the judgment of adults to avoid hazards (NRC 1993).

As for adults, sources of exposure for children to zinc include ingestion of food, drinking water, and polluted air, with ingestion of food being the primary route of exposure. In an extensive survey of foods in the total diets of children in the United States, conducted by FDA during 1982-1984, the following values for daily zinc intakes (mg/day) were estimated: 6-11-month-old infants, 5.24; 2-year-old children, 7.37; 14-16-year-old girls, 9.90; and 14-16-year-old boys, 15.61 (Pennington et al. 1986). The FDA also included drinking water in the total diet. Hair samples collected from children (10-12 years old) living rural and industrial areas of southern Poland and analyzed for zinc (Zachwieja et al. 1995). Hair samples of children from Kraków-Shakina (urban areas), Tarnów-Czechowice-Dziedzice (industrial areas), and rural areas contained zinc at concentrations of 171.5, 185.0, and $244.6 \mathrm{ppm}$, respectively (Zachwieja et al. 1995). Whole blood samples from children (3-6 years old) living in Mumbai and Hyderabad, industrialized urban areas of India, contained zinc at mean concentrations of 398.9 and $483.4 \mu \mathrm{g} / \mathrm{dL}$, respectively (Tripathi et al. 2001).

At waste sites, zinc that is found in excess of natural background levels is most likely to be in soil, and presents a special hazard for young children. Hand-to-mouth activity and eating contaminated dirt will result in oral exposure to zinc. The hazard in this case depends on the form of zinc that is present at the waste site. Zinc in soil at waste sites is in both soluble and insoluble forms; zinc in insoluble forms would be expected to be less available than more soluble forms.

Zinc exposure to children from parents' work clothes, skin, hair, tools, or other objects from the workplace is possible if the parent uses zinc or its compounds at work. Household products or products used in crafts, hobbies, or cottage industries which contain galvanized materials (e.g., nails) or zinccontaining paint will have significant amounts of zinc. Hand-to-mouth activity, chewing, and eating these materials may result in higher exposure to zinc. However, no cases of home exposure to zinc were located in the literature. 


\subsection{POPULATIONS WITH POTENTIALLY HIGH EXPOSURES}

Certain populations receive greater-than-average exposures to zinc from environmental sources. For example, higher levels of zinc have been reported in soil and water near waste sites, metal smelters, and areas exposed to untreated waste water (Hutchinson and Wai 1979; Ragaini et al. 1977; Schalscha et al. 1982). Other populations at risk of high exposure are those that have galvanized plumbing in their residences, and those that intentionally consume large doses of zinc as a dietary supplement. Patients who receive chronic treatment with drugs containing zinc salts (such as injectable insulin) are exposed to higher zinc levels than the general population. Allergic reactions to the zinc in insulin have been reported (Bruni et al. 1986). People in certain occupations (e.g., nonferrous metal smelting) are likely to be exposed to higher concentrations of zinc than the general population (see Section 6.5). However, the higher exposure may not be indicative of a long-term increase in body burden. For example, the median zinc concentration in the lung tissues of 21 Swedish workers previously employed in the refining and smelting of nonferrous metals was about the same as in a control group (11.0 versus $10.7 \mathrm{mg} / \mathrm{kg}$ wet weight) (Hewitt 1988). On the other hand, the median concentration of zinc in lung tissues of eight deceased coal miners from England was $72 \mathrm{mg} / \mathrm{kg}$ wet weight compared to a median value of $54 \mathrm{mg} / \mathrm{kg}$ wet weight for a control group (Hewitt 1988); however, the study author did not provide any evidence that the difference in zinc concentrations in the lungs of unexposed controls is statistically significant.

Individuals who smoke or who use zinc supplementation will have greater exposure to zinc. Zinc was measured in samples of cigarette tobacco from the United States at concentrations ranging from 30 to $69 \mu \mathrm{g} / \mathrm{g}$ (Jenkins 1986). Levels of zinc in smoke from these cigarettes ranged from 0.34 to $1.21 \mu \mathrm{g} /$ cigarette. Individuals, who use high-dose zinc supplementation as a potential treatment for agerelated macular degeneration, will have higher exposures to zinc. Hiller et al. (1995) reported that zinc supplements will have an effect on the concentration of serum zinc in the body.

\subsection{ADEQUACY OF THE DATABASE}

Section 104(i)(5) of CERCLA, as amended, directs the Administrator of ATSDR (in consultation with the Administrator of EPA and agencies and programs of the Public Health Service) to assess whether adequate information on the health effects of zinc is available. Where adequate information is not available, ATSDR, in conjunction with NTP, is required to assure the initiation of a program of research designed to determine the health effects (and techniques for developing methods to determine such health effects) of zinc. 
The following categories of possible data needs have been identified by a joint team of scientists from ATSDR, NTP, and EPA. They are defined as substance-specific informational needs that if met would reduce the uncertainties of human health assessment. This definition should not be interpreted to mean that all data needs discussed in this section must be filled. In the future, the identified data needs will be evaluated and prioritized, and a substance-specific research agenda will be proposed.

\subsubsection{Identification of Data Needs}

Physical and Chemical Properties. Data are available that adequately characterize the physical and chemical properties of the various forms of zinc to permit estimation of their environmental fate (ACGIH 1991; Baes and Sharp 1983; Baes et al. 1984; Gerritse et al. 1982; HSDB 1986, 1990; NIOSH 1990; Weast 1988; Weiss 1986; Windholz 1983).

Production, Import/Export, Use, Release, and Disposal. According to the Emergency Planning and Community Right-to-Know Act of 1986, 42 U.S.C. Section 11023, industries are required to submit substance release and off-site transfer information to the EPA. The TRI, which contains this information for 2002, became available in May of 2004. This database is updated yearly and should provide a list of industrial production facilities and emissions.

Information about current and future production of zinc and zinc compounds is available. Zinc is also one of the most widely used metals in the world (Mirenda 1986). In 2001, approximately 799,000 metric tons of zinc were produced in the United States from domestic ores. The estimated world production from mines in 2001 was $8,850,000$ metric tons (USGS 2001). Information on the use of zinc and its compounds in the home, environment, and workplace is available. Zinc is most commonly used as a protective coating for other metals. It is also used in alloys such as bronze and brass, for electrical apparatus, and in organic chemical extractions. Zinc salts have numerous applications, including wood preservation. Zinc chloride is a primary ingredient in smoke bombs. In pharmaceuticals, zinc salts are used as solubilizing agents in drugs, including insulin (Lloyd 1984; Lloyd and Showak 1984; Windholz 1983). Zinc oxide is found in ointments used to treat burns and infectious and skin diseases (EPA 1987d). Zinc is also utilized therapeutically in human medicine in the treatment of zinc deficiency (Elinder 1986). Information on typical releases of zinc and its compounds in the home, environment, and workplace, and which environmental media are likely to be contaminated with significant quantities of zinc are available. Zinc is ubiquitous in the environment. Both natural releases and releases of human 
origin to the environment can be significant (EPA 1980d; Fishbein 1981; Mirenda 1986; NAS 1977; Nriagu 1989; Ragaini et al. 1977; TRI02 2004). Soils and sediments are likely to contain significant quantities of zinc and its compounds (Connor and Shacklette 1975; Rice 1999; Shacklette and Boerngen 1984; USGS 2002). Current disposal methods are efficient (Dawson and Mercer 1986; Lloyd and Showak 1984). No data were located regarding the amount of zinc being disposed. Rules and regulations regarding the disposal of zinc are available (Dawson and Mercer 1986; DOI 1991). According to the Emergency Planning and Community Right-to-Know Act of 1986, 42 U.S.C. Section 11023, industries are required to submit chemical release and off-site transfer information to EPA. The Toxics Release Inventory (TRI) contains this information for 2001. Environmental releases of zinc and zinc compounds from manufacturing and processing facilities required to report their releases are listed in Tables 6-1 and 6-2. This database is updated yearly and should provide a list of industrial production facilities and emissions.

Environmental Fate. Zinc partitions to the air, water, and soil (EPA 1979d; Guy and Chakrabarti 1976; Houba et al. 1983; Pita and Hyne 1975). Zinc occurs in the environment mainly in the +2 oxidation state (Lindsey 1979). Adsorption is the dominant fate of zinc, resulting in enrichment of zinc in suspended and bed sediments (EPA 1979d). The mobility of zinc in soil has been characterized (Baes and Sharp 1983; Bergkvist et al. 1989; EPA 1980d; Hermann and Neumann-Mahlkau 1985; Kalbasi et al. 1978; Saeed and Fox 1977; Tyler and McBride 1982). No estimate for the atmospheric lifetime of zinc is available. Development of pertinent data on the atmospheric processes important for zinc speciation in the atmosphere would be helpful. Development of this information would permit construction of a comprehensive model for the transport and interaction of zinc not only in air but in other media as well. Transformation in air and water can occur as a result of changes in chemical speciation (Anderson et al. 1988; EPA 1979d, 1980d; Stokinger 1981). Data that describe the transformation processes for zinc in soil or the fate of zinc in soil are needed. A model of zinc flux from all environmental compartments would be useful for providing information on the overall environmental fate of zinc.

The primary anthropogenic sources of zinc in the environment (i.e., air, water, soil) are related to mining and metallurgic operations involving zinc and use of commercial products containing zinc (EPA 1980d; NAS 1977; Nriagu and Pacyna 1988; Ragaini et al. 1977; TRI02 2004). Zinc has been detected in air, surface water, groundwater, and soil, with the frequency of detection and the concentrations greatest near source areas (e.g., hazardous waste sites and industrial areas such as lead smelters) (EPA 1980d; HazDat 2005; Lioy et al. 1978; Lloyd and Showak 1984; Mumma et al. 1984, 1990, 1991; NAS 1977). 
Bioavailability from Environmental Media. Zinc can be absorbed following inhalation (Drinker and Drinker 1928; Hamdi 1969), ingestion (Aamodt et al. 1983; Davies 1980; Johnson et al. 1988; Methfessel and Spencer 1973; NAS/NRC 1979; Spencer et al. 1985), or dermal contact (Agren 1990; Gordon et al. 1981; Hallmans 1977; Keen and Hurley 1977). No estimates of the bioavailability of zinc after inhalation of zinc particles in air, ingestion from water and soil, or skin contact with bath water or soil were located. The bioavailability of zinc is higher in media with a low $\mathrm{pH}$, as a result of increased zinc solubility and ionization. If zinc is partly present in an irreversibly adsorbed state in soil, this part is not available for skin absorption. It would be useful to develop quantitative data on the bioavailability of zinc from various environmental media.

Food Chain Bioaccumulation. Zinc bioconcentrates moderately in aquatic organisms, and this bioconcentration is higher in crustaceans and bivalve species than in fish (EPA 1987c; Ramelow et al. 1989). Zinc may concentrate in plants grown on contaminated soils. However, it does not biomagnify through the terrestrial food chain (Biddinger and Gloss 1984; EPA 1979d; Hegstrom and West 1989; Levine et al. 1989).

Exposure Levels in Environmental Media. Reliable monitoring data for the levels of zinc in contaminated media at hazardous waste sites are needed so that the information obtained on levels of zinc in the environment can be used in combination with the known body burden of zinc to assess the potential risk of adverse health effects in populations living in the vicinity of hazardous waste sites.

Zinc has been detected in air (Barrie and Hoff 1985; Duce et al. 1975; EPA 1980d; Evans et al. 1984; John et al. 1973; Lioy et al. 1978; Lloyd and Showak 1984; Patterson et al. 1977; Pratt et al. 2000; Ragaini et al. 1977; Saltzman et al. 1985; Spicer et al. 1996; Zoller et al. 1974), water (Bruce and McMahon 1996; Coale and Flegal 1989; Cole et al. 1984; EPA 1980d; Hale 1977; HazDat 2005; Heit et al. 1989; Maessen et al. 1985; Minear et al. 1981; NAS 1977; Nriagu et al. 1996; Ohanian 1986; SañudoWilhelmy and Gill 1999; Schock and Neff 1988; Scudlark et al. 1994; Shiller and Boyle 1985; Taylor et al. 2001; Windom et al. 1991), soil (Beavington 1975; Chen et al. 1999; Connor and Shacklette 1975; EPA 1980d; Haines 1984; HazDat 2005; Johnson et al. 1990; Mayer and Manning 1990; Mielke et al. 1999, 2000; Mumma et al. 1984, 1990, 1991; Norrström and Jacks 1999; Schalscha et al. 1982; Storm et al. 1994), and food (Coleman et al. 1992; FDA 2001; Gartrell et al. 1986a; Mahaffey et al. 1975; Weigert 1991). However, since most of the data are not current, i.e., within the last 3 years, additional data would be useful to provide a more complete characterization of human exposure and the trend in zinc concentrations in various environmental media. Estimates have been made for human intake of zinc from 
food and drinking water (EPA 1980d; Gartrell et al. 1986a; IOM 2002; Pennington et al. 1986; Sharrett et al. 1982a, 1982b). Further data are needed on estimated daily intakes from inhalation resulting from occupational exposures.

Reliable monitoring data for the levels of zinc in contaminated media at hazardous waste sites are needed so that the information obtained on levels of zinc in the environment can be used in combination with the known body burden of zinc to assess the potential risk of adverse health effects in populations living in the vicinity of hazardous waste sites.

Exposure Levels in Humans. Zinc has been detected in fingernails, toenails, hair, all tissues, organs, skull and skeletal muscle, blood, feces, urine, sweat, and saliva (Greger and Sickles 1979; Hambidge et al. 1972; Henkin et al. 1975a; Llobet et al. 1988a; NAS/NRC 1979; Prasad et al. 1963a; Prevost et al. 1985; Saltzman et al. 1990; Schroeder et al. 1967; Takagi et al. 1988; Wastney et al. 1986; Wilhelm et al. 1991). Most of the data on occupational exposure levels of zinc are outdated (NIOSH 1976, 1984b). Additional information on potentially exposed workers and exposure levels would provide a more accurate characterization of occupational exposures in the United States. Current biological monitoring data on zinc are needed for populations surrounding hazardous waste sites. This information is necessary for assessing the need to conduct health studies on these populations.

This information is necessary for assessing the need to conduct health studies on these populations.

Exposures of Children. Limited data are available regarding the exposure and body burdens of children to zinc. Children, like adults, are primarily exposed to zinc through the diet. Zinc was identified in the postpartum human milk of women at concentrations of 5 to $12 \mathrm{mg} / \mathrm{L}$ (Arnaud and Favier 1995). In an extensive survey of foods in the total diets of individuals in the United States, conducted by FDA during 1982-1984, the following values for daily zinc intakes (mg/day) were estimated for children: 611-month-old infants, 5.24; 2-year-old children, 7.37; 14-16-year-old girls, 9.90; and 14-16-year-old boys, 15.61 (Pennington et al. 1986). Since zinc is found in soil and children ingest soil either intentionally through pica or unintentionally through hand-to-mouth activity, pica is a unique exposure pathway for children. While zinc is found in home products such as paint, ointments, galvanized metals, coins, and dietary supplements, this exposure route should be low and will not disproportionally affect children. Continued monitoring data are necessary to understand potentially dangerous routes of childhood exposure. 
Child health data needs relating to susceptibility are discussed in Section 3.12.2, Identification of Data Needs: Children's Susceptibility.

Exposure Registries. No exposure registries for zinc were located. This substance is not currently one of the compounds for which a sub-registry has been established in the National Exposure Registry. The substance will be considered in the future when chemical selection is made for sub-registries to be established. The information that is amassed in the National Exposure Registry facilitates the epidemiological research needed to assess adverse health outcomes that may be related to exposure to this substance.

\subsubsection{Ongoing Studies}

The Federal Research in Progress (FEDRIP 2004) database provides additional information obtainable from a few ongoing studies that may fill in some of the data needs identified in Section 6.8.1. These studies are summarized in Table 6-6. 
Table 6-6. Ongoing Studies on the Environmental Effects of Zinc ${ }^{a}$

\begin{tabular}{|c|c|c|c|}
\hline Investigator & Affiliation & Study & Sponsor \\
\hline Ahner BA & $\begin{array}{l}\text { Cornell University, } \\
\text { Biological and } \\
\text { Environmental Engineering }\end{array}$ & $\begin{array}{l}\text { Monitoring the bioavailability of toxic } \\
\text { metals in soil }\end{array}$ & USDA \\
\hline Basta N, Raun WR & $\begin{array}{l}\text { Oklahoma State University, } \\
\text { Agronomy }\end{array}$ & $\begin{array}{l}\text { Chemistry and bioavailability of waste } \\
\text { constituents in soils }\end{array}$ & USDA \\
\hline Basta NT & $\begin{array}{l}\text { Oklahoma State University, } \\
\text { Agronomy }\end{array}$ & $\begin{array}{l}\text { Heavy metal and trace element } \\
\text { chemistry in soils: Chemical speciation } \\
\text { and bioavailability }\end{array}$ & USDA \\
\hline $\begin{array}{l}\text { Bleam WF, Helmke } \\
\text { PA }\end{array}$ & $\begin{array}{l}\text { University of Wisconsin } \\
\text { Soil Science }\end{array}$ & $\begin{array}{l}\text { Verifying and quantifying the specific } \\
\text { complexation of metals to humic } \\
\text { substances }\end{array}$ & USDA \\
\hline Chaney RL & $\begin{array}{l}\text { Beltsville Agricultural } \\
\text { Research Center }\end{array}$ & $\begin{array}{l}\text { Characterization and remediation of } \\
\text { potential trace element and phosphate } \\
\text { risks from contaminated soils }\end{array}$ & USDA \\
\hline Chaney RL & $\begin{array}{l}\text { Beltsville Agricultural } \\
\text { Research Center }\end{array}$ & $\begin{array}{l}\text { Development of methods to control } \\
\text { heavy metal contents in soils at benign } \\
\text { or beneficial levels }\end{array}$ & USDA \\
\hline Chaney RL & $\begin{array}{l}\text { Beltsville Agricultural } \\
\text { Research Center }\end{array}$ & $\begin{array}{l}\text { Long-term phytoavailability and } \\
\text { bioavailability of soil metals }\end{array}$ & USDA \\
\hline $\begin{array}{l}\text { Chaney RL, Angle } \\
\text { JS }\end{array}$ & $\begin{array}{l}\text { University of Maryland, } \\
\text { Agronomy }\end{array}$ & $\begin{array}{l}\text { Phytoavailability and bioavailability of } \\
\text { heavy metals from heavy metal } \\
\text { contaminated soil }\end{array}$ & USDA \\
\hline Cox FR & $\begin{array}{l}\text { North Carolina State } \\
\text { University, Soil Science }\end{array}$ & $\begin{array}{l}\text { Effects of } \mathrm{P}, \mathrm{Cu} \text {, and } \mathrm{Zn} \text { from animal } \\
\text { waste and fertilizer on crop responses } \\
\text { and soil test interpretations }\end{array}$ & USDA \\
\hline Fish RH & $\begin{array}{l}\text { Lawrence Berkeley } \\
\text { Laboratory, University of } \\
\text { California }\end{array}$ & $\begin{array}{l}\text { Removal and recovery of toxic metal ions } \\
\text { from aqueous streams by utilization of } \\
\text { polymer pendant ligands }\end{array}$ & DOE \\
\hline Guo MG, Tyzbir R & $\begin{array}{l}\text { University Of Vermont, } \\
\text { Nutritional Sciences }\end{array}$ & $\begin{array}{l}\text { Solubility and distribution of trace } \\
\text { elements in milk based infant formula }\end{array}$ & USDA \\
\hline $\begin{array}{l}\text { Harsh JB, Zamora } \\
\text { BA, Kuo S, Pan W, } \\
\text { Stevens RG, Flury M }\end{array}$ & $\begin{array}{l}\text { Washington State } \\
\text { University, Crop and Soil } \\
\text { Sciences }\end{array}$ & $\begin{array}{l}\text { Physical chemical state and plant } \\
\text { availability of uranium, lead, cadmium, } \\
\text { zinc, and arsenic in selected Washington } \\
\text { soils }\end{array}$ & USDA \\
\hline Heil D & $\begin{array}{l}\text { Colorado State University, } \\
\text { Soil and Crop Science }\end{array}$ & $\begin{array}{l}\text { Biogeochemistry and management of } \\
\text { salts and potentially toxic trace elements } \\
\text { in arid-zone soils, sediments, and water }\end{array}$ & USDA \\
\hline $\begin{array}{l}\text { Helmke PA, Bleam } \\
\text { WF }\end{array}$ & $\begin{array}{l}\text { University of Wisconsin Soil } \\
\text { Science }\end{array}$ & $\begin{array}{l}\text { Reactions controlling free ion activities } \\
\text { and solubility of soil trace elements }\end{array}$ & USDA \\
\hline Hesterberg DL & $\begin{array}{l}\text { North Carolina State } \\
\text { University, Soil Science }\end{array}$ & $\begin{array}{l}\text { Molecular-scale characterization and fate } \\
\text { of soil contaminants }\end{array}$ & USDA \\
\hline Kinraide TB & $\begin{array}{l}\text { Agricultural Research } \\
\text { Service }\end{array}$ & $\begin{array}{l}\text { The role of binding and electrostatic } \\
\text { attraction to roots in the uptake of heavy } \\
\text { metals by plants }\end{array}$ & USDA \\
\hline $\begin{array}{l}\text { Kochian LV, Paolillo } \\
\text { DJ }\end{array}$ & $\begin{array}{l}\text { Cornell University, Plant } \\
\text { Biology }\end{array}$ & $\begin{array}{l}\text { Mechanisms of aluminum tolerance and } \\
\text { heavy metal accumulation in plants }\end{array}$ & USDA \\
\hline
\end{tabular}


Table 6-6. Ongoing Studies on the Environmental Effects of Zinc ${ }^{a}$

\begin{tabular}{|c|c|c|c|}
\hline Investigator & Affiliation & Study & Sponsor \\
\hline Kochian LV & $\begin{array}{l}\text { Agricultural Research } \\
\text { Service }\end{array}$ & $\begin{array}{l}\text { Investigation of heavy metal } \\
\text { bioaccumulation in plants grown on } \\
\text { metal-polluted soils }\end{array}$ & USDA \\
\hline Kochian LV & $\begin{array}{l}\text { Agricultural Research } \\
\text { Service }\end{array}$ & $\begin{array}{l}\text { Mechanisms of heavy metal and } \\
\text { radionuclide hyper-accumulation and } \\
\text { bioavailability in higher plants }\end{array}$ & USDA \\
\hline $\begin{array}{l}\text { Kpomblekou- } \\
\text { Ademawou K, } \\
\text { Ankumah RO }\end{array}$ & $\begin{array}{l}\text { Tuskegee University, } \\
\text { Agriculture and Home } \\
\text { Economics }\end{array}$ & $\begin{array}{l}\text { Trace elements in broiler littered soils: } \\
\text { fate and effects on nitrogen } \\
\text { transformation }\end{array}$ & USDA \\
\hline Kuo S & $\begin{array}{l}\text { Washington State } \\
\text { University, Puyallup } \\
\text { Research and Extension } \\
\text { Center }\end{array}$ & $\begin{array}{l}\text { Chemistry and bioavailability of waste } \\
\text { constituents in soils }\end{array}$ & USDA \\
\hline Little RE & $\begin{array}{l}\text { NIEHS, National Institutes } \\
\text { of Health }\end{array}$ & $\begin{array}{l}\text { Environmental pollution in eastern and } \\
\text { central Europe }\end{array}$ & $\mathrm{NIH}$ \\
\hline McBride MB & $\begin{array}{l}\text { Cornell University, Soil, } \\
\text { Crop and Atmospheric } \\
\text { Science }\end{array}$ & $\begin{array}{l}\text { Heavy metal solubility in contaminated } \\
\text { soils }\end{array}$ & USDA \\
\hline McBride MB & $\begin{array}{l}\text { Cornell University, Soil, } \\
\text { Crop and Atmospheric } \\
\text { Science }\end{array}$ & $\begin{array}{l}\text { Reaction and availability of toxic metals } \\
\text { in soils }\end{array}$ & USDA \\
\hline $\begin{array}{l}\text { Norvell WA, Duxbury } \\
\text { JM }\end{array}$ & Cornell University & $\begin{array}{l}\text { Plant availability and geographical } \\
\text { distribution of essential and toxic } \\
\text { elements }\end{array}$ & USDA \\
\hline $\begin{array}{l}\text { Norvell WA, Welch } \\
\text { RM, Degloria SD }\end{array}$ & Cornell University & $\begin{array}{l}\text { Bioavailability and geographic } \\
\text { distribution of nutritionally important } \\
\text { elements in crops and soils }\end{array}$ & USDA \\
\hline Odom JW & $\begin{array}{l}\text { Auburn University, } \\
\text { Agronomy and Soils }\end{array}$ & $\begin{array}{l}\text { Occurrence, measurement and mapping } \\
\text { of plant micronutrient and trace elements } \\
\text { in Alabama soils }\end{array}$ & USDA \\
\hline Parker DR & $\begin{array}{l}\text { University of California, } \\
\text { Environmental Sciences }\end{array}$ & $\begin{array}{l}\text { Predicting trace-metal bioavailability from } \\
\text { soil solution speciation: can it be done }\end{array}$ & USDA \\
\hline Pierzynski GM & $\begin{array}{l}\text { Kansas State University, } \\
\text { Agronomy }\end{array}$ & $\begin{array}{l}\text { Chemistry and bioavailability of waste } \\
\text { constituents in soils }\end{array}$ & USDA \\
\hline Ross DS & $\begin{array}{l}\text { University of Vermont, } \\
\text { Plant and Soil Science }\end{array}$ & $\begin{array}{l}\text { Soil manganese oxides: Oxidation and } \\
\text { retention of contaminant metals and } \\
\text { organics }\end{array}$ & USDA \\
\hline Salt DE & $\begin{array}{l}\text { Purdue University, } \\
\text { Horticulture }\end{array}$ & $\begin{array}{l}\text { A dissection of the molecular } \\
\text { mechanisms underlying metal } \\
\text { hyperaccumulation in plants }\end{array}$ & USDA \\
\hline Slaton NA & $\begin{array}{l}\text { University of Arkansas, } \\
\text { Crop, Soil and } \\
\text { Environmental Sciences }\end{array}$ & $\begin{array}{l}\text { Evaluation of fertilization practices, soil } \\
\text { fertility, and plant nutrition for crops } \\
\text { produced in Arkansas }\end{array}$ & USDA \\
\hline Sparks DL, Ford RG & $\begin{array}{l}\text { University of Delaware, } \\
\text { Plant and Soil Sciences }\end{array}$ & $\begin{array}{l}\text { Influence of aging and competitive } \\
\text { sorption on stabilization of metals via } \\
\text { surface precipitation in soils }\end{array}$ & USDA \\
\hline Thompson ML & $\begin{array}{l}\text { Iowa State University, } \\
\text { Agronomy }\end{array}$ & $\begin{array}{l}\text { Co-migration of metals and dissolved } \\
\text { humic substances in aquifer material }\end{array}$ & USDA \\
\hline
\end{tabular}


Table 6-6. Ongoing Studies on the Environmental Effects of Zinc ${ }^{a}$

\begin{tabular}{llll}
\hline Investigator & Affiliation & Study & Sponsor \\
\hline Thompson ML & $\begin{array}{l}\text { lowa State University, } \\
\text { Agronomy }\end{array}$ & $\begin{array}{l}\text { Sustainable and environmentally safe } \\
\text { management of soil resources }\end{array}$ & USDA \\
$\begin{array}{l}\text { Welch RM, Norvell } \\
\text { WA, Kochian LV }\end{array}$ & $\begin{array}{l}\text { Agricultural Research } \\
\text { Service }\end{array}$ & $\begin{array}{l}\text { Agricultural approaches to human health } \\
\text { through understanding soil-plant- } \\
\text { human/animal food systems }\end{array}$ & USDA \\
Zelazny LW & $\begin{array}{l}\text { Virginia Polytechnic } \\
\text { Institute, Crop and Soil } \\
\text { Environmental Sciences }\end{array}$ & $\begin{array}{l}\text { Soil mineralogical controls on nutrient } \\
\text { availability and mobility }\end{array}$ & USDA \\
& & & \\
\hline
\end{tabular}

${ }^{\mathrm{a}}$ Source: FEDRIP 2004

DOE = Department of Energy; FEDRIP = Federal Research in Progress Database; NIEHS = National Institute of Environmental Health Services; $\mathrm{NIH}=$ National Institute of Health; USDA = United Stated Department of Agriculture 



\section{ANALYTICAL METHODS}

The purpose of this chapter is to describe the analytical methods that are available for detecting, measuring, and/or monitoring zinc, its metabolites, and other biomarkers of exposure and effect to zinc. The intent is not to provide an exhaustive list of analytical methods. Rather, the intention is to identify well-established methods that are used as the standard methods of analysis. Many of the analytical methods used for environmental samples are the methods approved by federal agencies and organizations such as EPA and the National Institute for Occupational Safety and Health (NIOSH). Other methods presented in this chapter are those that are approved by groups such as the Association of Official Analytical Chemists (AOAC) and the American Public Health Association (APHA). Additionally, analytical methods are included that modify previously used methods to obtain lower detection limits and/or to improve accuracy and precision.

Zinc is ubiquitous in both the environment and the laboratory. Since many biological and environmental samples contain low levels of zinc, it is easy to contaminate samples. Thus, it is imperative that special precautions be taken to avoid sample contamination in order to obtain accurate results and ensure the integrity of samples. Precautions must be taken to avoid contamination during sample collection and analysis from sources such as sampling and filtration equipment, inadequate reagent purity, and atmospheric deposition. For ultratrace analysis, the use of a clean-room laboratory with a laminar flow work station is highly recommended to avoid contamination of samples and standards with airborne particulates. In blood analysis, collection tubes are potential sources of zinc contamination (Delves 1981). An example of failure to institute proper measures to control sample contamination, which led to inaccuracies in reported data, was described by Windom et al. (1991). Methods that can be used to avoid reporting erroneous results include interlaboratory data comparison (Galloway et al. 1983) or use of standard reference materials, such as certified SRM 1549 (nonfat powdered milk) available from the National Institute of Standards and Technology (Perry 1990).

Zinc concentrations are typically quantified using instrumental methods such as atomic absorption, emission, or mass spectroscopies; x-ray fluorescence; electro-analytical techniques (e.g., stripping voltammetry); and neutron activation analysis. 


\subsection{BIOLOGICAL MATERIALS}

Table 7-1 lists the applicable analytical methods used for determining zinc in biological fluids and tissues.

Inductively coupled plasma-atomic emission spectroscopy (ICP-AES) is used for zinc determinations in blood and tissue samples (NIOSH Method 8005) and in urine (NIOSH Method 8310). Detection limits in blood and tissue are $1 \mu \mathrm{g} / 100 \mathrm{~g}$ and $0.2 \mu \mathrm{g} / \mathrm{g}$, respectively, with recoveries of 100\% (NIOSH 1994). Sample preparation involves acid digestion with concentrated acids. Detection of zinc in urine samples requires extraction of the metals with a polydithiocarbamate resin prior to digestion and analysis (NIOSH 1984). Detection limits in urine are $0.1 \mu \mathrm{g} / \mathrm{sample.} \mathrm{Inductively} \mathrm{coupled} \mathrm{plasma-mass} \mathrm{spectroscopy} \mathrm{(ICP-}$ MS) has been used to determine the concentration of zinc in milk samples and brain tissue (Panayi et al. 2002; Patterson et al. 1992). Detection limits are $0.06 \mu \mathrm{g} / \mathrm{sample}$ for milk and $10.7 \mathrm{ng} / \mathrm{g}$ (for a $150 \mathrm{mg}$ sample) for brain tissue samples. Recoveries ranged from 99-111\% for brain tissue samples (Panayi et al. 2002).

Atomic absorption spectrometry (AAS) is a common and simple laboratory technique capable of routine zinc analysis of biological samples including bone, liver, hair, blood, and urine. Graphite furnace AAS (GF-AAS) is more sensitive than flame AAS and has been used to determine very low levels of zinc (detection limit, $0.052 \mu \mathrm{mol} / \mathrm{L}$ ) in human milk (Arnaud et al. 1991). GF-AAS has been used to determine zinc in human semen. Recovery (96-104\%) was good, and preparation by microwave wet acid dissolution was more accurate than the standard water dilution method (Alvarado et al. 1991). Zinc concentrations in liver have been accurately quantified by flame AAS. Homogenization of tissue samples coupled with flame AAS resulted in $100 \%$ recoveries, accuracies of $0-3 \%$, and a detection limit of $0.04 \mathrm{mg} / \mathrm{L}$ (Luterotti et al. 1992). AAS has also been used to determine zinc in bloodstains on filter paper. This method is accurate, reproducible, and acceptable for routine clinical testing using both dry ashing and direct extraction sample preparation (Fan et al. 1991).

The use of stable isotopes or tracers to study zinc absorption in humans with subsequent analysis by mass spectrometry has been reported in the literature. Analysis of fecal samples obtained 3 and 6 days after the administration of zinc-65 isotope in food showed that between 45 and $75 \%$ of zinc isotope was absorbed (Johnson 1982). The results indicated satisfactory detection of the zinc-67 isotope in human feces, while the zinc-70 isotope was not as detectable. Better precision and recovery were obtained for the zinc-67 isotope $(2.4 \% \mathrm{CV}$ [coefficient of variation]; >95\% recovery) than for the zinc-70 isotope (38\% 
Table 7-1. Analytical Methods for Determining Zinc in Biological Materials

\begin{tabular}{|c|c|c|c|c|c|}
\hline $\begin{array}{l}\text { Sample } \\
\text { matrix }\end{array}$ & Preparation method & $\begin{array}{l}\text { Analytical } \\
\text { method }\end{array}$ & $\begin{array}{l}\text { Sample } \\
\text { detection limit }\end{array}$ & $\begin{array}{l}\text { Percent } \\
\text { recovery }\end{array}$ & Reference \\
\hline Blood or tissue & $\begin{array}{l}\text { Acid digestion with } \\
\mathrm{HNO}_{3} / \mathrm{HClO}_{4}, \mathrm{H}_{2} \mathrm{SO}_{4} \text {, measure } \\
\text { at } 213.9 \mathrm{~nm}\end{array}$ & ICP-AES & $\begin{array}{l}1 \mu \mathrm{g} / 100 \mathrm{~g} \\
\text { (blood); } \\
0.2 \mu \mathrm{g} / \mathrm{g} \\
\text { (tissue) }\end{array}$ & 103 & $\begin{array}{l}\text { NIOSH } 1994 \\
\text { (method } \\
8005 \text { ) }\end{array}$ \\
\hline Urine & $\begin{array}{l}\text { Acid digestion of oxygen } \\
\text { plasma ashing; extract with } \\
\text { polydithiocarbamate resin; } \\
\text { measure at } 213.9 \mathrm{~nm}\end{array}$ & ICP-AES & $0.1 \mu \mathrm{g} /$ sample & 100 & $\begin{array}{l}\text { NIOSH } 1994 \\
\text { (method } \\
8310 \text { ) }\end{array}$ \\
\hline Semen & Microwave wet acid digestion & GF-AAS & $400 \mu \mathrm{g} / \mathrm{L}$ & 96-104 & $\begin{array}{l}\text { Alvarado et } \\
\text { al. } 1991\end{array}$ \\
\hline Fingernails & $\begin{array}{l}\text { Digest nail samples with } \\
\text { concentrated nitric acid; heat at } \\
65^{\circ} \mathrm{C} \text { for } 1 \text { hour; cool and dilute } \\
\text { with deionized water }\end{array}$ & GF-AAS & No data & No data & $\begin{array}{l}\text { Sohler et al. } \\
1976\end{array}$ \\
\hline Liver & $\begin{array}{l}\text { Acid digestion with mixtures of } \\
\text { different acids; distill volatile } \\
\text { elements }\end{array}$ & $\begin{array}{l}\text { Radio- } \\
\text { chemical NAA }\end{array}$ & No data & 98 & $\begin{array}{l}\text { Lievens et al. } \\
1977\end{array}$ \\
\hline Liver & $\begin{array}{l}\text { Homogenize sample with water; } \\
\text { add } \mathrm{HCl} \text {; shake; centrifuge; } \\
\text { dilute }\end{array}$ & Flame AAS & $40 \mu \mathrm{g} / \mathrm{L}$ & 100 & $\begin{array}{l}\text { Luterotti et al. } \\
1992\end{array}$ \\
\hline Muscle tissue & $\begin{array}{l}\text { Mineralize sample in muffle } \\
\text { furnace; dissolve in } \mathrm{HNO}_{3}\end{array}$ & FIA & $3 \mu \mathrm{g} / \mathrm{L}$ & No data & $\begin{array}{l}\text { Fernandez et } \\
\text { al. 1992b }\end{array}$ \\
\hline Blood & $\begin{array}{l}\text { Separate serum from blood by } \\
\text { centrifugation; transfer a portion } \\
\text { of serum into an ampule of } \\
\text { highly pure silica and dry; } \\
\text { irradiate capsules at a thermal } \\
\text { neutron density of } \\
5 \times 10^{3} \mathrm{n} / \mathrm{cm}^{-2} / \mathrm{second}^{-1}\end{array}$ & $\begin{array}{l}\text { Instrumental } \\
\text { NAA }\end{array}$ & No data & $>100$ & $\begin{array}{l}\text { Jurgensen } \\
\text { and Behne } \\
1977\end{array}$ \\
\hline Blood & $\begin{array}{l}\text { Feed radiotracer }{ }^{65} \text { zinc; } \\
\text { measure zinc activity in blood at } \\
14 \text { days }\end{array}$ & $\begin{array}{l}\text { Tracer } \\
\text { technique }\end{array}$ & No data & 88 & $\begin{array}{l}\text { Watson et al. } \\
1987\end{array}$ \\
\hline $\begin{array}{l}\text { Blood serum } \\
\text { and red blood } \\
\text { cells }\end{array}$ & $\begin{array}{l}\text { Feed }{ }^{68} \text { zinc and }{ }^{70} \text { zinc and } \\
\text { measure blood levels in a } \\
\text { 24-hour sample and a sample } \\
\text { taken immediately after zinc } \\
\text { administration; wet ash sample; } \\
\text { add APDC precipitant; dissolve } \\
\text { precipitate in } \mathrm{HNO}_{3} \text { irradiate }\end{array}$ & $\begin{array}{l}\text { Isotope tracer } \\
\text { technique }\end{array}$ & No data & No data & $\begin{array}{l}\text { Janghorbani } \\
\text { et al. } 1981\end{array}$ \\
\hline Blood & $\begin{array}{l}\text { Feed }{ }^{65} \mathrm{ZnCl}_{2} \text { orally; measure } \\
\text { zinc blood levels and whole } \\
\text { blood count }\end{array}$ & $\begin{array}{l}\text { Radiotracer } \\
\text { technique- } \\
\text { whole blood } \\
\text { count and } \\
\text { blood level } \\
\text { measurement }\end{array}$ & No data & 88 & $\begin{array}{l}\text { Watson et al. } \\
1987\end{array}$ \\
\hline
\end{tabular}




\section{Table 7-1. Analytical Methods for Determining Zinc in Biological Materials}

\begin{tabular}{|c|c|c|c|c|c|}
\hline $\begin{array}{l}\text { Sample } \\
\text { matrix }\end{array}$ & Preparation method & $\begin{array}{l}\text { Analytical } \\
\text { method }\end{array}$ & $\begin{array}{l}\text { Sample } \\
\text { detection limit }\end{array}$ & $\begin{array}{l}\text { Percent } \\
\text { recovery }\end{array}$ & Reference \\
\hline Bloodstain & $\begin{array}{l}\text { Place drop of blood on filter } \\
\text { paper; cut away excess paper; } \\
\text { optional dry ash; add } \mathrm{HCl} \text {; } \\
\text { shake }\end{array}$ & Flame AAS & No data & No data & $\begin{array}{l}\text { Fan et al. } \\
1991\end{array}$ \\
\hline $\begin{array}{l}\text { Thoracic } \\
\text { aorta, lung, } \\
\text { myocardium, } \\
\text { spleen }\end{array}$ & $\begin{array}{l}\text { Homogenize sample; complete } \\
\text { wet ashing with } \mathrm{HNO}_{3}\end{array}$ & Flame AAS & No data & No data & $\begin{array}{l}\text { Marks et al. } \\
1972\end{array}$ \\
\hline Brain tissue & $\begin{array}{l}\text { Digest with } \mathrm{HNO}_{3} \text { using } \\
\text { microwave digestion; dilute }\end{array}$ & ICP-MS & $\begin{array}{l}32 \mathrm{mg} / \mathrm{L} \\
(10.7 \mathrm{ng} / \mathrm{g} \text { for } \\
150 \mathrm{mg} \\
\text { sample) }\end{array}$ & 99-111 & $\begin{array}{l}\text { Panayi et al. } \\
2002\end{array}$ \\
\hline Feces & $\begin{array}{l}\text { Give }{ }^{67} \mathrm{Zn} \text { through diet; treat } \\
\text { fecal samples with } \mathrm{H}_{2} \mathrm{O}_{2} ; \\
\text { prepare chelates }\end{array}$ & $\begin{array}{l}\text { Isotope tracer } \\
\text { technique }\end{array}$ & No data & $\begin{array}{l}>95 \\
\left({ }^{67} Z n\right) \\
71\left({ }^{70} Z n\right)\end{array}$ & $\begin{array}{l}\text { Johnson } \\
1982\end{array}$ \\
\hline Feces & $\begin{array}{l}\text { Feed }{ }^{70} \mathrm{Zn},{ }^{68} \mathrm{Zn} \text {, and }{ }^{64} \mathrm{Zn} \text { orally; } \\
\text { homogenize sample; evaporate; } \\
\text { ash; } \mathrm{HNO}_{3} \text { digestion; boil; } \\
\text { evaporate; add } \mathrm{HCl} \text {; transfer to } \\
\text { anion exchange column; } \\
\text { prepare eluate; irradiate }\end{array}$ & $\begin{array}{l}\text { Isotope tracer } \\
\text { technique; } \\
\text { NAA }\end{array}$ & No data & No data & Ni et al. 1991 \\
\hline Bone & $\begin{array}{l}\text { Acid digestion of dried bone ash } \\
\text { with concentrated } \mathrm{HNO}_{3} ; \\
\text { evaporate to dryness and add } \\
\text { more concentrated } \mathrm{HNO}_{3} ; \\
\text { remove silica residue by } \\
\text { filtration; transfer samples to } \\
\text { polyethylene bottles }\end{array}$ & Flame AAS & No data & No data & $\begin{array}{l}\text { Szpunar et } \\
\text { al. } 1978\end{array}$ \\
\hline Hair & $\begin{array}{l}\text { Digest clean sample in acid } \\
\text { mixture }\end{array}$ & Flame AAS & $20 \mu \mathrm{g} / \mathrm{g}$ & No data & $\begin{array}{l}\text { Wilhelm et al. } \\
1991\end{array}$ \\
\hline Hair & $\begin{array}{l}\text { Rinse sample with hexane; wet } \\
\text { or dry ash with } \mathrm{HNO}_{3}\end{array}$ & EDXRF & $0.001 \mu \mathrm{g} / \mathrm{L}$ & No data & $\begin{array}{l}\text { Folin et al. } \\
1991\end{array}$ \\
\hline Hair & $\begin{array}{l}\text { Rinse sample with hexane; wet } \\
\text { or dry ash with } \mathrm{HNO}_{3}\end{array}$ & Flame AAS & $0.001 \mu \mathrm{g} / \mathrm{L}$ & No data & $\begin{array}{l}\text { Folin et al. } \\
1991\end{array}$ \\
\hline Hair & $\begin{array}{l}\text { Digest clean sample in acid } \\
\text { mixture }\end{array}$ & ICP-AES & No data & 81-102 & $\begin{array}{l}\text { Takagi et al. } \\
1988\end{array}$ \\
\hline $\begin{array}{l}\text { Serum } \\
\text { (animal) }\end{array}$ & Add Brij 35 to sample; mix & Flame AAS & $\sim 0.6 \mu \mathrm{g} / \mathrm{mL}$ & No data & $\begin{array}{l}\text { AOAC } 1990 \\
\text { (method } \\
\text { 991.11) }\end{array}$ \\
\hline $\begin{array}{l}\text { Serum and } \\
\text { plasma }\end{array}$ & $\begin{array}{l}\text { Separate serum and plasma by } \\
\text { centrifugation; keep stored in } \\
\text { glass tubes at }-20^{\circ} \mathrm{C} \text { until } \\
\text { analysis; thaw to room } \\
\text { temperature prior to analysis }\end{array}$ & Flame AAS & No data & No data & $\begin{array}{l}\text { Shaw et al. } \\
1982\end{array}$ \\
\hline
\end{tabular}




\section{Table 7-1. Analytical Methods for Determining Zinc in Biological Materials}

\begin{tabular}{llllll}
\hline $\begin{array}{l}\text { Sample } \\
\text { matrix }\end{array}$ & Preparation method & $\begin{array}{l}\text { Analytical } \\
\text { method }\end{array}$ & $\begin{array}{l}\text { Sample } \\
\text { detection limit }\end{array}$ & $\begin{array}{l}\text { Percent } \\
\text { recovery }\end{array}$ & Reference \\
\hline Milk & $\begin{array}{l}\text { Ash; lyophilize; wet-ash with } \\
\mathrm{HNO}_{3} ; \text { add } \mathrm{H}_{2} \mathrm{O}_{2} ; \text { dry; dissolve } \\
\text { in } \mathrm{HCl} \text { and } \mathrm{NH}_{4} \mathrm{Cl} \text {; extract with } \\
\text { DDDC }\end{array}$ & ICP-MS & $0.06 \mu \mathrm{g} / \mathrm{sample}$ No data & $\begin{array}{l}\text { Patterson et } \\
\text { al. } 1992\end{array}$ \\
& $\begin{array}{l}\text { Dilute sample with Triton X-100 } \\
\text { Milk }\end{array}$ & GF-AAS & $0.052 \mu \mathrm{mol} / \mathrm{L}$ & $86-106$ & $\begin{array}{l}\text { Arnaud et al. } \\
\text { Saliva }\end{array}$ \\
& $\begin{array}{l}\text { Lashley cup place over one of } \\
\text { the Stenson's ducts; secretion } \\
\text { stimulated with lemon candies; } \\
\text { discard first 5-10 mL; collect }\end{array}$ & GF-AAS & No data & No data & $\begin{array}{l}\text { Langmyhr et } \\
\text { al. 1979 }\end{array}$ \\
& $\approx 120 \mathrm{~mL}$ & & & \\
& & & & \\
\hline
\end{tabular}

AAS = atomic absorption spectroscopy; AES = atomic emission spectroscopy; APDC = ammonium pyrolidine dithiocarbamate; Brij 35 = polyoxyethylene (35) lauryl ether; DDDC = diethylammonium diethyldithiocarbamate; EDXRF = energy dispersive $x$-ray fluorescence; FIA = flow injection analysis; GF = graphite furnace;

$\mathrm{HCl}=$ hydrochloric acid; $\mathrm{HClO}_{4}=$ perchloric acid; $\mathrm{HNO}_{3}=$ nitric acid; $\mathrm{H}_{2} \mathrm{O}_{2}=$ hydrogen peroxide; $\mathrm{H}_{2} \mathrm{SO}_{4}=$ sulfuric acid; ICP = inductively coupled plasma spectroscopy; $\mathrm{MS}=$ mass spectrometry; NAA = neutron activation analysis; $\mathrm{NH}_{4} \mathrm{Cl}=$ ammonium chloride; $\mathrm{Zn}=$ zinc; $\mathrm{ZnCl}_{2}=$ zinc chloride 
$\mathrm{CV} ; 71 \%$ recovery). Sample detection limits were not reported. Total reported sample preparation time was $<2$ hours, and it took only 5-10 minutes to analyze each sample on the mass spectrometer.

Multi-elemental analysis has been used to detect zinc and other trace metals in biological fluids and tissues. For determination of metallic constituents in biological samples, such as liver, samples were digested with mixtures of different acids, volatile elements were distilled by selective distillation, and a cleanup step was performed using ion exchange chromatography prior to assay by neutron activation analysis (NAA) (Lievens et al. 1977). Recovery (98\%) and precision (<10\% CV) were excellent. Although the limit of detection for zinc was not reported, based on the reported results, this method can detect levels ranging from the low- to the sub-ppm range (Lievens et al. 1977). The NAA technique has also been used to detect zinc in urine and blood samples. Jurgensen and Behne (1977) used the technique to measure human serum levels of trace elements including zinc. Recovery and precision for this method are very good. Sensitivity was not reported.

A practical method, based on NAA, was developed for accurate measurement of the stable isotopes zinc-68 and zinc-70 in human plasma and red blood cells (Janghorbani et al. 1981). This method can provide an alternative to the use of radiolabeled zinc. It is more complex and time consuming than those used to measure radiolabeled zinc levels. As with any isotopic method, isotope exchange may invalidate calculation of net absorption, but this potential problem was not investigated. Precision was very good $(<10 \%)$. Sensitivity and accuracy were not reported.

Radionuclide studies offer an additional method to investigate the factors that affect trace element absorption. Radioactivity emitted by the radionuclide was measured in blood 14 days after the oral ingestion of zinc- 65 and compared with the amount of radioactivity emission determined by whole-body counting (Watson et al. 1987). The results indicated that, where whole-body counting facilities were not available, measurement of radioactivity emitted in blood was a reasonable alternative for the prediction of zinc absorption. Recovery for this method was adequate ( $88 \%)$; precision was acceptable $(<17 \% \mathrm{CV})$. The limit of detection for zinc was not reported.

Other analytical methods include flow injection analysis (FIA). FIA has been used to determine very low levels of zinc in muscle tissue. This method provides very high sensitivity, low detection limits (3 ng/mL), good precision, and high selectivity at trace levels (Fernandez et al. 1992b). 
Animal and human tissues samples are usually analyzed without drying and concentrations are reported as wet weight. For some samples, freeze-drying has been used. Care should be taken during the acid dissolution of blood and urine samples as frothing of natural surfactants during digestion can lead to losses. This problem can be prevented by allowing the sample to stand overnight after the addition of acid (WHO 2001).

\subsection{ENVIRONMENTAL SAMPLES}

Table 7-2 lists the methods used for analyzing zinc in environmental samples.

ICP-AES is used to determine concentrations of zinc in air (NIOSH method 7300), water (EPA methods 3120 B, 6010 C, 200.7; APHA methods 3120B, 3125B, 3130B), solid wastes (AOAC method 990.08), and soil (EPA methods 6010, 3050) (AOAC 1998; APHA 1998; EPA 1986a, 1994; NIOSH 1994). Detection limits in air, water, and solid wastes are 0.6, 2, and, $2 \mu \mathrm{g} / \mathrm{L}$, respectively (AOAC 1998; EPA 1994; NIOSH 1994). Preparation for water samples typically involves acid digestion with concentrated acids. The concentration of zinc in soil was determined by ICP-AES coupled with an ammonium bicarbonate-diethylenetriaminepentaacetic acid (NH4HCO3-DTPA) extraction procedure. This method can be used to screen soils for zinc (Boon and Soltanpour 1991). ICP-MS has been used to determine the concentration of zinc in water (EPA methods 200.8, 1638; APHA method 3125 B), (APHA 1998; EPA 1994, 1996). Detection limits have been reported to be as low as $0.017 \mu \mathrm{g} / \mathrm{L}$ using 66Zn isotope. Recoveries range from 99 to $117 \%$ (APHA 1998).

Flame AAS has been used to determine zinc concentrations in natural waters (Fishman 1966). AAS is a rapid method of measuring zinc, with a detection limit of 0.005 ppm. Brooks et al. (1967) demonstrated a simple extraction system consisting of two reagents, ammonium pyrollidine dithiocarbamate (APDC) and methyl isobutylketone (MIBK), with subsequent analysis by flame AAS to measure particulate and "soluble" zinc in seawater. Sensitivity was in the sub-ppm range, and precision was good (3\% CV). Flame AAS, coupled with microwave digestion and GF-AAS, has been used to determine the concentration of zinc in food and shellfish samples. Limits of detection ranged from 0.12 to $0.24 \mathrm{ppm}$, with recoveries ranging from 80 to $113 \%$. Precision and recovery using microwave digestion were comparable to traditional wet ashing and superior to dry ashing in shellfish samples (AOAC 1984; McCarthy and Ellis 1991; Morales-Rubio et al. 1992). GF-AAS was also used to determine low levels of zinc in beer. Recovery (94-106\%) and precision (4.2\% CV) were excellent. Sensitivity was not reported (Wagner et al. 1991). Flame AAS has been used to measure heavy metals, including zinc, in various oil 


\section{Table 7-2. Analytical Methods for Determining Zinc in Environmental Samples}

\begin{tabular}{|c|c|c|c|c|c|}
\hline $\begin{array}{l}\text { Sample } \\
\text { matrix }\end{array}$ & Preparation method & $\begin{array}{l}\text { Analytical } \\
\text { method }\end{array}$ & $\begin{array}{l}\text { Sample } \\
\text { detection limit }\end{array}$ & $\begin{array}{l}\text { Percent } \\
\text { recovery }\end{array}$ & Reference \\
\hline Air & $\begin{array}{l}\text { Collect air particulates on } \\
\text { Teflon filters; digest with } \\
\mathrm{HNO}_{3}\end{array}$ & $\begin{array}{l}\text { NAA (non- } \\
\text { destructive) }\end{array}$ & No data & No data & Zoller et al. 1974 \\
\hline Air & $\begin{array}{l}\text { Collect sample on cellulose } \\
\text { filter; wet ash filter with } \\
\mathrm{HNO}_{3} / \mathrm{HClO}_{4} \text {; dilute }\end{array}$ & ICP-AES & $0.6 \mathrm{ng} / \mathrm{mL}$ & 94-101 & $\begin{array}{l}\text { NIOSH } 1994 \\
\text { (method 7300) }\end{array}$ \\
\hline Air & $\begin{array}{l}\text { Collect sample on cellulose } \\
\text { filter; wet ash with } \mathrm{HNO}_{3} ; \\
\text { dilute }\end{array}$ & Flame AAS & $3 \mu \mathrm{g} / \mathrm{sample}$ & No data & $\begin{array}{l}\text { NIOSH } 1994 \\
\text { (method 7030) }\end{array}$ \\
\hline $\begin{array}{l}\text { Air (as zinc } \\
\text { oxide) }\end{array}$ & $\begin{array}{l}\text { Collect sample on PVC- } \\
\text { acrylonitrile filter }\end{array}$ & XRD & $5 \mu \mathrm{g} /$ sample & No data & $\begin{array}{l}\text { NIOSH } 1994 \\
\text { (method 7502) }\end{array}$ \\
\hline $\begin{array}{l}\text { Atmospheric } \\
\text { aerosols }\end{array}$ & $\begin{array}{l}\text { Collect sample on cellulose } \\
\text { filter; digest with } \mathrm{HNO}_{3} \text {; filter; } \\
\text { dry; add } \mathrm{HNO}_{3} \text {; adjust } \mathrm{pH} \text {; } \\
\text { add } \mathrm{KNO}_{3}\end{array}$ & $\begin{array}{l}\text { Anodic } \\
\text { stripping } \\
\text { voltammetry }\end{array}$ & $13.7 \mu \mathrm{g} / \mathrm{L}$ & No data & $\begin{array}{l}\text { Casassas et al. } \\
1991\end{array}$ \\
\hline Water & Acidify; dilute & ICP-MS & $0.14 \mu \mathrm{g} / \mathrm{L}$ & No data & $\begin{array}{l}\text { EPA } 1996 \\
\text { (method 1638) }\end{array}$ \\
\hline Water & Reflux with $\mathrm{HNO}_{3} / \mathrm{HCl}$; dilute & GF-AAS & $0.14 \mu \mathrm{g} / \mathrm{L}$ & No data & $\begin{array}{l}\text { EPA } 1996 \\
\text { (method 1639) }\end{array}$ \\
\hline Water & $\begin{array}{l}\text { Acidify (digest if necessary); } \\
\text { dilute }\end{array}$ & ICP-AES & $2 \mu \mathrm{g} / \mathrm{L}$ & No data & $\begin{array}{l}\text { EPA } 1994 \\
\text { (method 200.7) }\end{array}$ \\
\hline Water & $\begin{array}{l}\text { Acidify (digest if necessary); } \\
\text { dilute }\end{array}$ & ICP-MS & $1.8 \mu \mathrm{g} / \mathrm{L}$ & No data & $\begin{array}{l}\text { EPA } 1994 \\
\text { (method 200.8) }\end{array}$ \\
\hline Water & Acid digestion; dilute & ICP-AES & $1.2 \mu \mathrm{g} / \mathrm{L}$ & No data & $\begin{array}{l}\text { EPA } 2000 \\
\text { (method } 6010 \mathrm{C} \text { ) }\end{array}$ \\
\hline Water & Dissolve in $\mathrm{HCl}$; dilute & Flame AAS & $5 \mu \mathrm{g} / \mathrm{L}$ & No data & $\begin{array}{l}\text { APHA } 1998 \\
\text { (method } 3111 \text { B) }\end{array}$ \\
\hline Water & $\begin{array}{l}\text { Chelation with ammonium } \\
\text { pyrrolidine dithiocarbamate } \\
\text { and extraction into MIBK }\end{array}$ & Flame AAS & No data & No data & $\begin{array}{l}\text { APHA } 1998 \\
\text { (method 3111C) }\end{array}$ \\
\hline Water & Acidify; dilute & ICP-AES & $2 \mu \mathrm{g} / \mathrm{L}$ & No data & $\begin{array}{l}\text { APHA } 1998 \\
\text { (method } 3120 \text { B) }\end{array}$ \\
\hline Water & Acidify; dilute & ICP-MS & $\begin{array}{l}0.017 \mu \mathrm{g} / \mathrm{L} \\
\left({ }^{66} \mathrm{Zn}\right) \\
0.020 \mu \mathrm{g} / \mathrm{L} \\
\left({ }^{68} \mathrm{Zn}\right)\end{array}$ & $\begin{array}{l}99-117 \\
\left({ }^{66} \mathrm{Zn}\right) \\
98-116 \\
\left({ }^{66} \mathrm{Zn}\right)\end{array}$ & $\begin{array}{l}\text { APHA } 1998 \\
\text { (method } 3125 \text { B) }\end{array}$ \\
\hline Water & Dilute with $\mathrm{HNO}_{3}$ & $\begin{array}{l}\text { Anodic } \\
\text { stripping } \\
\text { voltammetry }\end{array}$ & $<1 \mu \mathrm{g} / \mathrm{L}$ & No data & $\begin{array}{l}\text { APHA } 1998 \\
\text { (method } 3130 \text { B) }\end{array}$ \\
\hline Water & $\begin{array}{l}\text { Add sodium ascorbate; KCN; } \\
\text { zircon (2-carboxy- } \\
\text { 2'-hydroxy-5'-sulfoformazyl } \\
\text { benzene) }\end{array}$ & Colormetry & No data & No data & $\begin{array}{l}\text { APHA } 1998 \\
\text { (method } \\
3500-Z n \text { B) }\end{array}$ \\
\hline $\begin{array}{l}\text { Water and } \\
\text { waste water }\end{array}$ & Acid digestion & Flame AAS & $5 \mu \mathrm{g} / \mathrm{L}$ & No data & $\begin{array}{l}\text { EPA } 1979 \\
\text { (method 289.1) }\end{array}$ \\
\hline
\end{tabular}




\section{Table 7-2. Analytical Methods for Determining Zinc in Environmental Samples}

\begin{tabular}{|c|c|c|c|c|c|}
\hline $\begin{array}{l}\text { Sample } \\
\text { matrix }\end{array}$ & Preparation method & $\begin{array}{l}\text { Analytical } \\
\text { method }\end{array}$ & $\begin{array}{l}\text { Sample } \\
\text { detection limit }\end{array}$ & $\begin{array}{l}\text { Percent } \\
\text { recovery }\end{array}$ & Reference \\
\hline $\begin{array}{l}\text { Water and } \\
\text { waste water }\end{array}$ & Acidify; dilute & GF-AAS & $0.05 \mu \mathrm{g} / \mathrm{L}$ & No data & $\begin{array}{l}\text { EPA 1979 } \\
\text { (method 289.2) }\end{array}$ \\
\hline Water & $\begin{array}{l}\text { Mineralize sample in muffle } \\
\text { furnace; dissolve in } \mathrm{HNO}_{3}\end{array}$ & FIA & $3 \mu \mathrm{g} / \mathrm{L}$ & No data & $\begin{array}{l}\text { Fernandez et al. } \\
\text { 1992b }\end{array}$ \\
\hline Seawater & APDC-MIBK extraction & Flame AAS & $0.05 \mathrm{ppb}$ & No data & $\begin{array}{l}\text { Brooks et al. } \\
1967\end{array}$ \\
\hline Seawater & $\begin{array}{l}\text { Take a sample digest in the } \\
\text { electrochemical cell; adjust } \\
\text { pH; add chelating agent and } \\
\text { aerate }\end{array}$ & $\begin{array}{l}\text { Cathodic } \\
\text { stripping } \\
\text { voltammetry }\end{array}$ & $7 \times 10^{-11} \mathrm{M}$ & No data & $\begin{array}{l}\text { van den Berg } \\
1986\end{array}$ \\
\hline Crude oil & $\begin{array}{l}\text { Digest sample with } \mathrm{HNO}_{3} \text {; } \\
\text { extract with MIBK or dilute } \\
\text { with MIBK }\end{array}$ & Flame AAS & $0.8 \mu \mathrm{g} / \mathrm{g}$ & No data & Elson et al. 1981 \\
\hline $\begin{array}{l}\text { Soil, solid } \\
\text { waste, } \\
\text { sludges }\end{array}$ & Acid digestion & $\begin{array}{l}\text { ICP-AES or } \\
\text { flame AAS }\end{array}$ & $\begin{array}{l}2 \mu \mathrm{g} / \mathrm{L} \text { (in } \\
\text { solution) }\end{array}$ & $\begin{array}{l}102.5 \text { at } \\
80 \mu \mathrm{g} / \mathrm{L}\end{array}$ & $\begin{array}{l}\text { EPA 1986a } \\
\text { (methods 6010 } \\
\text { and 3050) }\end{array}$ \\
\hline $\begin{array}{l}\text { Soil, solid } \\
\text { waste and } \\
\text { sludges }\end{array}$ & None & Flame AAS & $0.005 \mu \mathrm{g} / \mathrm{L}$ & No data & $\begin{array}{l}\text { EPA 1986a } \\
\text { (method 7950) }\end{array}$ \\
\hline Solid wastes & No data & ICP-AES & $2 \mu \mathrm{g} / \mathrm{L}$ & No data & $\begin{array}{l}\text { AOAC } 1998 \\
\text { (method 990.08) }\end{array}$ \\
\hline Soil & $\begin{array}{l}\text { Extract with DTPA and } \\
\mathrm{NH}_{4} \mathrm{HCO}_{3} \text {-DTPA }\end{array}$ & ICP-AES & No data & No data & $\begin{array}{l}\text { Boon and } \\
\text { Soltanpour } 1991\end{array}$ \\
\hline Plants & Digest samples with acids & Flame AAS & No data & No data & $\begin{array}{l}\text { AOAC 1984 } \\
\text { (method 3.013) }\end{array}$ \\
\hline Plants & $\begin{array}{l}\text { Digest samples with acid; } \\
\text { extract with dithiozone } \\
\text { reagent and } \mathrm{CCl}_{4} ; \text { add } \mathrm{HCl} \\
\text { and } \mathrm{CCl}_{4} ; \text { read at } 525 \mathrm{~nm} \text { for } \\
\text { mixed-color method and at } \\
535 \mathrm{~nm} \text { for single-color } \\
\text { method }\end{array}$ & $\begin{array}{l}\text { Mixed and } \\
\text { single color } \\
\text { methods - } \\
\text { spectrophoto- } \\
\text { metric analysis }\end{array}$ & No data & No data & $\begin{array}{l}\text { AOAC } 1984 \\
\text { (methods } 3.054 \\
\text { and 3.061) }\end{array}$ \\
\hline Food & $\begin{array}{l}\text { Digest sample with acid } \\
\text { mixtures; remove sulfide, } \\
\text { nickel, and cobalt; add } \\
\text { dithioxone and } \mathrm{CCl}_{4} ; \\
\text { measure transmission at } \\
540 \mathrm{~nm}\end{array}$ & Colorimetry & No data & No data & $\begin{array}{l}\text { AOAC } 1984 \\
\text { (method 25.168) }\end{array}$ \\
\hline Food & $\begin{array}{l}\text { Wet ash using Kjeldahl } \\
\text { digestion } \mathrm{HNO}_{3} / \mathrm{H}_{2} \mathrm{SO}_{4} \text { with } \\
\text { heat; dilute; alternatively, dry } \\
\text { ash; dissolve in } \mathrm{HCl} \text { with } \\
\text { heat }\end{array}$ & Flame AAS & No data & No data & $\begin{array}{l}\text { AOAC } 1990 \\
\text { (method 969.32) }\end{array}$ \\
\hline Food & $\begin{array}{l}\text { Digest samples with acid } \\
\text { mixtures; dilute }\end{array}$ & Flame AAS & No data & No data & $\begin{array}{l}\text { AOAC } 1990 \\
\text { (method 986.15) }\end{array}$ \\
\hline Food & $\begin{array}{l}\text { Dry ash sample in muffle } \\
\text { oven; dilute with } \mathrm{HNO}_{3}\end{array}$ & $\begin{array}{l}\text { Flame AAS; } \\
\text { Flame AES }\end{array}$ & $0.24 \mu \mathrm{g} / \mathrm{g}$ & $97-100$ & $\begin{array}{l}\text { Morales-Rubio et } \\
\text { al. } 1992\end{array}$ \\
\hline
\end{tabular}




\section{Table 7-2. Analytical Methods for Determining Zinc in Environmental Samples}

\begin{tabular}{llllll}
\hline $\begin{array}{l}\text { Sample } \\
\text { matrix }\end{array}$ & Preparation method & $\begin{array}{l}\text { Analytical } \\
\text { method }\end{array}$ & $\begin{array}{l}\text { Sample } \\
\text { detection limit }\end{array}$ & $\begin{array}{l}\text { Percent } \\
\text { recovery }\end{array}$ & Reference \\
\hline Food & $\begin{array}{l}\text { Clarify; de-gas; dilute with } \\
\text { deionized water; add } \mathrm{HNO}_{3} \\
\text { to solid samples }\end{array}$ & GF-AAS & No data & $90-113$ & $\begin{array}{l}\text { Wagner et al. } \\
1991\end{array}$ \\
Food & $\begin{array}{l}\text { Blend; lyophilize; grind; } \\
\text { oven-dry; press into pellets } \\
\mathrm{HNO}_{3} \text { digestion in } \\
\text { microwave; dilute }\end{array}$ & EDXRF & $0.8 \mathrm{ppm}$ & No data & $\begin{array}{l}\text { Nielson et al. } \\
1991\end{array}$ \\
Shellfish & Flame AAS & $0.12 \mathrm{ppm}$ & 80 & $\begin{array}{l}\text { McCarthy and } \\
\text { Ellis 1991 }\end{array}$ \\
\hline
\end{tabular}

AAS = atomic absorption spectroscopy; AES = atomic emission spectrometry; APDC = ammonium pyrolidine dithiocarbamate; $\mathrm{CCl}_{4}=$ carbon tetrachloride; DTPA = diethylenetriaminepentaacetic acid; EDXRF = energy dispersive x-ray fluorescence; FIA = flow-injection analysis; GF = graphite furnace; $\mathrm{HCl}=$ hydrochloric acid; $\mathrm{HClO}_{4}=$ perchloric acid; $\mathrm{HNO}_{3}=$ nitric acid; $\mathrm{H}_{2} \mathrm{SO}_{4}=$ sulfuric acid; ICP = inductively coupled plasma spectroscopy; $\mathrm{KCN}=$ potassium cyanide; $\mathrm{KNO}_{3}=$ potassium nitrite; $\mathrm{MIBK}=$ methyl isobutyl ketone; $\mathrm{NAA}=$ neutron activation analysis; $\mathrm{NH}_{4} \mathrm{HCO}_{3}$-DTPA = ammonium bicarbonate-diethlyenetriaminepentaacetic acid; PVC = polyvinyl chloride; $\mathrm{XRD}=\mathrm{x}$-ray diffraction; $\mathrm{Zn}=\mathrm{zinc}$ 
samples collected at different stages of oil refining (Elson et al. 1981). These samples were prepared using three techniques (digestion, extraction, and dilution) prior to AAS analysis; recovery from crude oil was higher with wet digestion. Sensitivity for zinc was in the low-ppm range.

Cathodic stripping voltammetry, also known as adsorption voltammetry, has been used to detect various metal ions in a 10-10-10-11 M range in seawater (van den Berg 1986). APDC was used as a chelating agent for zinc. Because of the great sensitivity and specificity of APDC for zinc, it can be detected directly in the unaltered sample. Similarly, differential pulse cathodic stripping voltammetry (DPCSV) and differential pulse anodic stripping voltammetry (DPASV) after complexation with APDC have been used for determining zinc speciation at nanomolar concentrations in ocean waters (Donat and Bruland 1990). Anodic stripping voltammetry (ASV) has been used to detect zinc and other metal ions simultaneously at trace levels in atmospheric aerosols. This method is primarily used for small samples with very low concentrations of zinc. The limit of detection was $13.7 \mathrm{ng} / \mathrm{L}$ (Casassas et al. 1991).

An ion chromatographic method has been proposed for simultaneous determination of several elements including zinc in soil (Basta and Tabatabai 1990). In this method, after preliminary sample treatment, the metals are separated by ion chromatography, and the separated elements are quantified by ultravioletvisible detection of zinc-PAR (4-[2-pyridylazo] resorcinol) colored complexes. The limit of detection for zinc by this method was $5 \mathrm{ppb}$ in soil extract. Precision was $\leq 2.5 \% \mathrm{CV}$.

Other analytical methods include energy dispersive $\mathrm{x}$-ray fluorescence (EDXRF). This technique has been used to detect zinc in dried food samples with better precision (e.g., detection limit, $0.8 \mathrm{ppm}$ ) than AAS methods (Nielson et al. 1991).

\subsection{ADEQUACY OF THE DATABASE}

Section 104(i)(5) of CERCLA, as amended, directs the Administrator of ATSDR (in consultation with the Administrator of EPA and agencies and programs of the Public Health Service) to assess whether adequate information on the health effects of zinc is available. Where adequate information is not available, ATSDR, in conjunction with NTP, is required to assure the initiation of a program of research designed to determine the health effects (and techniques for developing methods to determine such health effects) of zinc. 
The following categories of possible data needs have been identified by a joint team of scientists from ATSDR, NTP, and EPA. They are defined as substance-specific informational needs that if met would reduce the uncertainties of human health assessment. This definition should not be interpreted to mean that all data needs discussed in this section must be filled. In the future, the identified data needs will be evaluated and prioritized, and a substance-specific research agenda will be proposed.

\subsubsection{Identification of Data Needs}

\section{Methods for Determining Biomarkers of Exposure and Effect.}

Exposure. ICP-AES, ICP-MS, and AAS are the most commonly used analytical methods to determine zinc levels in plasma, bone, fingernails, hair, and other biological tissues and body fluids (Alvarado et al. 1991; AOAC 1990; Arnaud et al. 1991; Fan et al. 1991; Folin et al. 1991; Langmyhr et al. 1979; Luterotti et al. 1992; Marks et al. 1972; NIOSH 1984a, 1994; Panayi et al. 2002; Patterson et al. 1992; Shaw et al. 1982; Sohler et al. 1976; Szpunar et al. 1978; Takagi et al. 1988; Wilhelm et al. 1991). These methods generally are sensitive enough to measure background levels in the population and levels at which biological effects occur. However, improved sensitivity and recovery data are needed in order to better evaluate the relationship between body and environmental exposure levels of zinc. Other methods that are specific for measuring zinc in biological fluids and tissues include NAA, FIA, and isotope tracers techniques (Fernandez et al. 1992b; Janghorbani et al. 1981; Johnson 1982; Lievens et al. 1977; NIOSH 1984a; Watson et al. 1987). Sensitivity and/or recovery data for these methods are needed to more fully evaluate the reliability of these methods as predictors of environmental exposure.

Effect. Although several biomarkers for the effects of zinc have been identified (increased levels of serum amylases and lipase, noniron responsive anemia, and decreased HDL cholesterol levels), these biomarkers of effect are not specific for zinc (Cotran et al. 1989; Suber 1989). Standard laboratory tests are available that can measure these biomarkers (Henry 1984). These methods are sensitive, accurate, and reliable enough to measure background levels in the population and levels at which biological effects occur. The development of methods for determining biomarkers of effect specific for zinc would be beneficial in assessing whether an individual has been exposed to elevated levels of zinc.

\section{Methods for Determining Parent Compounds and Degradation Products in Environmental}

Media. Methods of adequate sensitivity and specificity are available for determining levels of zinc in 
environmental media (AOAC 1984; APHA 1998; Basta and Tabatabai 1990; Brooks et al. 1967; Casassas et al. 1991; Donat and Bruland 1990; Elson et al. 1981; EPA 1979c, 1986a, 1994, 1996, 2000; Fishman 1966; McCarthy and Ellis 1991; Morales-Rubio et al. 1992; Nielson et al. 1991; NIOSH 1994; van den Berg 1986; Wagner et al. 1991; Zoller et al. 1974). Most of these methods are precise and sensitive enough to measure background levels in the environment and levels at which health effects occur. Some methods can distinguish between soluble zinc, insoluble zinc, and chelated zinc in water (Donat and Bruland 1990).

\subsubsection{Ongoing Studies}

The information in Table 7-3 was found as a result of a search of the Federal Research in Progress database (FEDRIP 2004) 
Table 7-3. Ongoing Studies on Analytical Methods for Zinc ${ }^{a}$

\begin{tabular}{llll}
\hline Investigator & Affiliation & Study & Sponsor \\
\hline $\begin{array}{l}\text { Michel RG, Freake } \\
\text { HC, Zinn SA et al. }\end{array}$ & University of Connecticut & $\begin{array}{l}\text { Capillary electrophoresis to enable } \\
\text { zinc speciation for studies of zinc } \\
\text { homeostasis }\end{array}$ & USDA \\
Panemangalore M & $\begin{array}{l}\text { Kentucky State University, } \\
\text { Human Nutrition Research } \\
\text { Program }\end{array}$ & $\begin{array}{l}\text { Evaluation of biomarkers of zinc and } \\
\text { copper status in animals and humans }\end{array}$ & USDA \\
\hline
\end{tabular}

${ }^{\mathrm{a} S}$ Source: FEDRIP 2004

FEDRIP = Federal Research in Progress Database; USDA = United States Department of Agriculture 



\section{REGULATIONS AND ADVISORIES}

Zinc (fume and dust) and its compounds are on the list of chemicals appearing in "Toxic Chemicals Subject to Section 313 of the Emergency Planning and Community Right-to-Know Act of 1986" (EPA 2003j).

The national and state regulations and guidelines pertaining to zinc and compounds in air, water, food, and other media are summarized in Table 8-1. No international regulations or guidelines applicable to zinc or its compounds were found.

ATSDR has derived an intermediate-duration oral MRL of $0.3 \mathrm{mg} \mathrm{Zn/kg/day} \mathrm{for} \mathrm{zinc} \mathrm{based} \mathrm{on} \mathrm{decreased}$ erythrocyte superoxide dismutase, a sensitive indicator of body copper status, and changes in serum ferritin in women given supplements containing zinc gluconate for 10 weeks (Yadrick et al. 1989). It should be noted that the MRL is calculated based on the assumption of healthy dietary levels of zinc (and copper), and represents the level of exposure above and beyond the normal diet that is believed to be without an appreciable risk of toxic response. The MRL is based on soluble zinc salts; it is less likely that nonsoluble zinc compounds would have these effects at similar exposure levels. The intermediate oral MRL has been adopted as the chronic oral MRL.

EPA has derived an oral reference dose (RfD) of $0.3 \mathrm{mg} / \mathrm{kg} /$ day for zinc (IRIS 2005). EPA has not derived an inhalation reference concentration (RfC) for zinc. 
Table 8-1. Regulations and Guidelines Applicable to Zinc and Zinc Compounds

\begin{tabular}{|c|c|c|c|}
\hline Agency & Description & Information & Reference \\
\hline \multicolumn{4}{|c|}{$\begin{array}{l}\text { INTERNATIONAL } \\
\text { Guidelines: }\end{array}$} \\
\hline IARC & Carcinogenicity classification & No data & \\
\hline WHO & $\begin{array}{l}\text { Drinking water and air quality } \\
\text { guidelines }\end{array}$ & No data & \\
\hline \multicolumn{4}{|c|}{$\begin{array}{l}\text { NATIONAL } \\
\text { Regulations and } \\
\text { Guidelines: }\end{array}$} \\
\hline \multicolumn{4}{|l|}{ a. Air } \\
\hline ACGIH & TLV (8-hour TWA) & No data & \\
\hline EPA & $\begin{array}{l}\text { Hazardous air pollutant pursuant } \\
\text { to Section } 112 \text { of the Clean Air } \\
\text { Act }\end{array}$ & Zinc and zinc oxide & $\begin{array}{l}\text { EPA } 2003 e \\
40 \text { CFR } 61.01\end{array}$ \\
\hline $\mathrm{NIOSH}$ & $\begin{array}{l}\text { REL (10-hour TWA) } \\
\text { Zinc chloride (fume) } \\
\text { Zinc oxide (dust and fume) } \\
\text { STEL (15-minute TWA) } \\
\text { Zinc chloride (fume) } \\
\text { Zinc oxide (fume) } \\
\text { Ceiling } \\
\text { Zinc oxide (dust) } \\
\text { IDLH } \\
\text { Zinc chloride (fume) } \\
\text { Zinc oxide }\end{array}$ & $\begin{array}{l}1 \mathrm{mg} / \mathrm{m}^{3} \\
5 \mathrm{mg} / \mathrm{m}^{3} \\
2 \mathrm{mg} / \mathrm{m}^{3} \\
10 \mathrm{mg} / \mathrm{m}^{3} \\
\\
15 \mathrm{mg} / \mathrm{m}^{3} \\
50 \mathrm{mg} / \mathrm{m}^{3} \\
500 \mathrm{mg} / \mathrm{m}^{3}\end{array}$ & NIOSH 2003a, 2003b \\
\hline \multirow[t]{5}{*}{ OSHA } & $\begin{array}{l}\text { PEL (8-hour TWA) for general } \\
\text { industry } \\
\text { Zinc chloride (fume) } \\
\text { Zinc oxide (fume and } \\
\text { respirable } \\
\text { fraction of dust) } \\
\text { Zinc oxide (total dust) }\end{array}$ & $\begin{array}{l}1 \mathrm{mg} / \mathrm{m}^{3} \\
5 \mathrm{mg} / \mathrm{m}^{3} \\
15 \mathrm{mg} / \mathrm{m}^{3}\end{array}$ & $\begin{array}{l}\text { OSHA 2003a } \\
29 \text { CFR 1910.1000, } \\
\text { Table Z-1 }\end{array}$ \\
\hline & $\begin{array}{l}\text { PEL (8-hour TWA) for construction } \\
\text { industry } \\
\text { Zinc chloride (fume) } \\
\text { Zinc oxide (fume and }\end{array}$ & $\begin{array}{l}1 \mathrm{mg} / \mathrm{m}^{3} \\
5 \mathrm{mg} / \mathrm{m}^{3}\end{array}$ & $\begin{array}{l}\text { OSHA 2003c } \\
29 \text { CFR } 1926.55, \\
\text { Appendix A }\end{array}$ \\
\hline & $\begin{array}{l}\text { respirable } \\
\text { fraction of dust) } \\
\text { Zinc oxide (total dust) }\end{array}$ & $15 \mathrm{mg} / \mathrm{m}^{3}$ & \\
\hline & $\begin{array}{l}\text { PEL (8-hour TWA) for shipyard } \\
\text { industry } \\
\text { Zinc chloride (fume) } \\
\text { Zinc oxide (fume and }\end{array}$ & $\begin{array}{l}1 \mathrm{mg} / \mathrm{m}^{3} \\
5 \mathrm{mg} / \mathrm{m}^{3}\end{array}$ & $\begin{array}{l}\text { OSHA 2003b } \\
29 \text { CFR } 1915.1000\end{array}$ \\
\hline & $\begin{array}{l}\text { fraction of dust) } \\
\text { Zinc oxide (total dust) }\end{array}$ & $15 \mathrm{mg} / \mathrm{m}^{3}$ & \\
\hline
\end{tabular}


Table 8-1. Regulations and Guidelines Applicable to Zinc and Zinc Compounds

\begin{tabular}{|c|c|c|c|}
\hline Agency & Description & Information & Reference \\
\hline \multicolumn{4}{|c|}{ NATIONAL (cont.) } \\
\hline \multicolumn{4}{|l|}{ b. Water } \\
\hline EPA & $\begin{array}{l}\text { Drinking water health advisories } \\
\text { 1-day (10-kg child) } \\
\text { 10-day (10-kg child) } \\
\text { DWEL }^{\mathrm{a}} \\
\text { Lifetime }^{\mathrm{b}}\end{array}$ & $\begin{array}{l}6 \mathrm{mg} / \mathrm{L} \\
6 \mathrm{mg} / \mathrm{L} \\
10 \mathrm{mg} / \mathrm{L} \\
2 \mathrm{mg} / \mathrm{L}\end{array}$ & EPA 2002 \\
\hline \multirow[t]{9}{*}{ EPA } & $\begin{array}{l}\text { Hazardous substance in } \\
\text { accordance with Section } 311 \\
\text { (b)(2)(A) of the Clean Water Act }\end{array}$ & $\begin{array}{l}\text { Zinc chloride } \\
\text { Zinc sulfate }\end{array}$ & $\begin{array}{l}\text { EPA 2003k } \\
40 \text { CFR } 116.4\end{array}$ \\
\hline & $\begin{array}{l}\text { Hazardous substance in } \\
\text { accordance with Section } 311 \text { of } \\
\text { the Clean Water Act; reportable } \\
\text { quantities }\end{array}$ & & $\begin{array}{l}\text { EPA } 2003 \mathrm{~g} \\
40 \text { CFR } 117.3\end{array}$ \\
\hline & $\begin{array}{l}\text { Zinc chloride } \\
\text { Zinc sulfate }\end{array}$ & $\begin{array}{l}1,000 \text { pounds } \\
1,000 \text { pounds }\end{array}$ & \\
\hline & $\begin{array}{l}\text { National secondary drinking water } \\
\text { regulations; secondary MCL for } \\
\text { zinc }\end{array}$ & $5 \mathrm{mg} / \mathrm{L}$ & $\begin{array}{l}\text { EPA } 2003 f \\
40 \text { CFR } 143.3\end{array}$ \\
\hline & $\begin{array}{l}\text { Pollutants of initial focus in the } \\
\text { Great Lakes Water Quality } \\
\text { Initiative }\end{array}$ & Zinc & $\begin{array}{l}\text { EPA } 20031 \\
40 \text { CFR } 132 \\
\text { Table } 6\end{array}$ \\
\hline & $\begin{array}{l}\text { Reportable quantities of hazard- } \\
\text { ous substances designated } \\
\text { pursuant to Section } 311 \text { of the } \\
\text { Clean Water Act }\end{array}$ & & \\
\hline & Zinc chloride & 1,000 pounds & \\
\hline & Zinc sulfate & 1,000 pounds & \\
\hline & $\begin{array}{l}\text { Toxic pollutant designation } \\
\text { pursuant to Section } 307(a)(1) \text { of } \\
\text { the Clean Water Act }\end{array}$ & Zinc and compounds & $\begin{array}{l}\text { EPA 2003c } \\
40 \text { CFR } 401.15\end{array}$ \\
\hline \multicolumn{4}{|l|}{ c. Food } \\
\hline EPA & $\begin{array}{l}\text { Tolerances for residues (ppm) of a } \\
\text { fungicide (mancozeb), which } \\
\text { contains } 20 \% \text { manganese, } \\
2.5 \% \text { zinc, and } 77.5 \% \text { ethylene- } \\
\text { bisdithiocarbamate }\end{array}$ & & $\begin{array}{l}\text { EPA 2003i } \\
40 \text { CFR } 180.176\end{array}$ \\
\hline
\end{tabular}


Table 8-1. Regulations and Guidelines Applicable to Zinc and Zinc Compounds

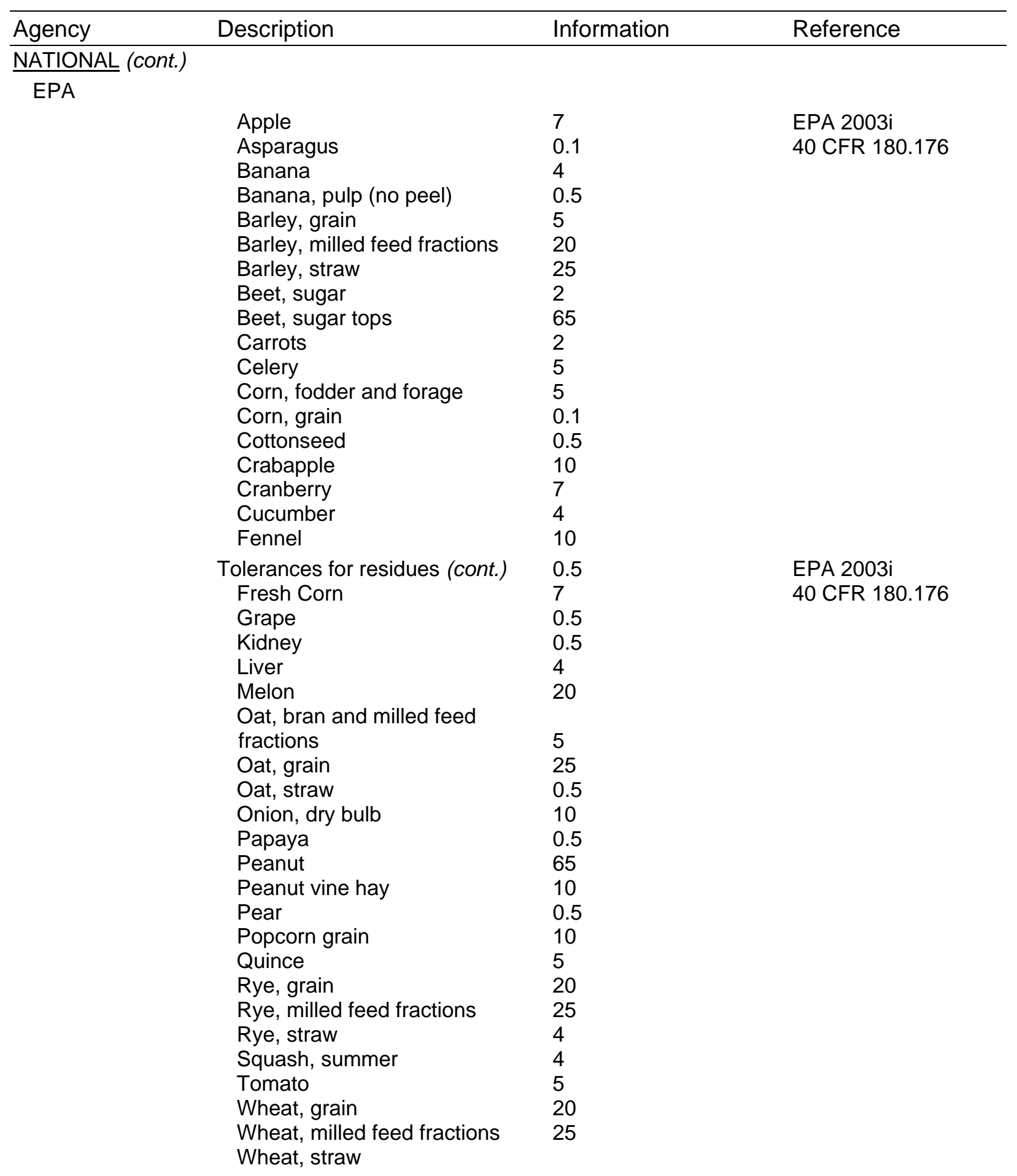


Table 8-1. Regulations and Guidelines Applicable to Zinc and Zinc Compounds

\begin{tabular}{|c|c|c|c|}
\hline Agency & Description & Information & Reference \\
\hline \multicolumn{4}{|c|}{ NATIONAL (cont.) } \\
\hline \multirow[t]{5}{*}{ FDA } & $\begin{array}{l}\text { Bottled drinking water (allowable } \\
\text { concentration of zinc); mineral } \\
\text { water is exempt based on } \\
\text { aesthetically allowable levels } \\
\text { and do not relate to health } \\
\text { concern }\end{array}$ & $5.0 \mathrm{mg} / \mathrm{L}$ & $\begin{array}{l}\text { FDA } 2003 a \\
21 \text { CFR } 165.110\end{array}$ \\
\hline & $\begin{array}{l}\text { Drug products containing certain } \\
\text { active ingredients offered over- } \\
\text { the-counter (OTC) for certain } \\
\text { uses; ingredients used in skin } \\
\text { protectant drug products }\end{array}$ & $\begin{array}{l}\text { Zinc chloride } \\
\text { Zinc oxide } \\
\text { Zinc sulfate }\end{array}$ & $\begin{array}{l}\text { FDA 2003c } \\
21 \text { CFR 310.545 }\end{array}$ \\
\hline & $\begin{array}{l}\text { Nutrition labeling of food; } \\
\text { statement of the amount per } \\
\text { serving of zinc calculated as a } \\
\text { percent of the RDI and } \\
\text { expressed as percent of Daily } \\
\text { Value }\end{array}$ & $15 \mathrm{mg}$ & $\begin{array}{l}\text { FDA 2003b } \\
21 \text { CFR } 101.9\end{array}$ \\
\hline & $\begin{array}{l}\text { Substances generally recognized } \\
\text { as safe; trace minerals added to } \\
\text { animal feeds as nutritional } \\
\text { dietary supplements when } \\
\text { added at levels consistent with } \\
\text { good feeding practices }\end{array}$ & $\begin{array}{l}\text { Zinc chloride } \\
\text { Zinc oxide } \\
\text { Zinc sulfate }\end{array}$ & $\begin{array}{l}\text { FDA 2003d } \\
21 \text { CFR 582.80 }\end{array}$ \\
\hline & $\begin{array}{l}\text { Substances generally recognized } \\
\text { as safe when used in accord- } \\
\text { ance with good manufacturing } \\
\text { practices }\end{array}$ & $\begin{array}{l}\text { Zinc oxide and zinc } \\
\text { sulfate }\end{array}$ & $\begin{array}{l}\text { FDA 2003e } \\
21 \text { CFR 182.8991; } \\
21 \text { CFR 182.8997 }\end{array}$ \\
\hline \multicolumn{4}{|l|}{ d. Other } \\
\hline \multirow[t]{7}{*}{ EPA } & Carcinogenicity classification & $D^{c}$ & IRIS 2003 \\
\hline & $\mathrm{RfC}$ & No data & IRIS 2003 \\
\hline & $\mathrm{RfD}$ & $3 \times 10^{-1} \mathrm{mg} / \mathrm{kg} / \mathrm{day}$ & IRIS 2003 \\
\hline & $\begin{array}{l}\text { Community right-to-know; release } \\
\text { reporting; effective date of } \\
\text { reporting for zinc (fume and } \\
\text { dust) }\end{array}$ & 01/01/87 & $\begin{array}{l}\text { EPA 2003j } \\
40 \text { CFR 372.65 }\end{array}$ \\
\hline & $\begin{array}{l}\text { Designated as a hazardous } \\
\text { substance pursuant to } \\
\text { Section } 311(b)(2) \text { of the Clean } \\
\text { Water Act; reportable quantity } \\
\text { Zinc and compounds }\end{array}$ & Not assigned & $\begin{array}{l}\text { EPA } 2003 \mathrm{~b} \\
40 \text { CFR } 302.4\end{array}$ \\
\hline & $\begin{array}{l}\text { Designated as a hazardous } \\
\text { substance pursuant to } \\
\text { Section } 307(a) \text { of the Clean } \\
\text { Water Act; reportable quantities }\end{array}$ & & $\begin{array}{l}\text { EPA 2003b } \\
40 \text { CFR } 302.4\end{array}$ \\
\hline & Zinc chloride & 1,000 pounds & \\
\hline
\end{tabular}




\section{Table 8-1. Regulations and Guidelines Applicable to Zinc and Zinc Compounds}

\begin{tabular}{|c|c|c|c|c|}
\hline Agency & Description & \multicolumn{2}{|l|}{ Information } & Reference \\
\hline \multicolumn{5}{|c|}{ NATIONAL (cont.) } \\
\hline \multicolumn{5}{|c|}{ d. Other } \\
\hline \multirow[t]{4}{*}{ EPA } & $\begin{array}{l}\text { Hazardous constituent for } \\
\text { municipal solid waste landfills }\end{array}$ & Zinc & & $\begin{array}{l}\text { EPA 2003a } \\
40 \text { CFR 258, } \\
\text { Appendix II }\end{array}$ \\
\hline & $\begin{array}{l}\text { Land disposal restrictions; } \\
\text { universal treatment standards } \\
\text { for zinc }\end{array}$ & & & $\begin{array}{l}\text { EPA 2003d } \\
40 \text { CFR } 268.48\end{array}$ \\
\hline & $\begin{array}{l}\text { Waste water standard } \\
\text { Non-waste water standard }\end{array}$ & $\begin{array}{l}2.61 \mathrm{mg} / \mathrm{L} \\
4.3 \mathrm{mg} / \mathrm{L} \mathrm{TCL}\end{array}$ & & \\
\hline & $\begin{array}{l}\text { Standards for owners and } \\
\text { operators of hazardous waste } \\
\text { TSD facilities; groundwater } \\
\text { monitoring for zinc }\end{array}$ & $\begin{array}{l}\begin{array}{l}\text { Suggested } \\
\text { method }\end{array} \\
\frac{6010}{7950} \\
7951\end{array}$ & $\begin{array}{l}\text { PQL } \\
20 \mu \mathrm{g} / \mathrm{L} \\
50 \mu \mathrm{g} / \mathrm{L} \\
0.5 \mu \mathrm{g} / \mathrm{L}\end{array}$ & $\begin{array}{l}\text { EPA } 2003 h \\
40 \text { CFR 264, } \\
\text { Appendix IX }\end{array}$ \\
\hline \multicolumn{5}{|l|}{ STATE } \\
\hline a. Air & No data & & & \\
\hline \multicolumn{5}{|l|}{ b. Water } \\
\hline Arizona & $\begin{array}{l}\text { Drinking water guideline (zinc and } \\
\text { zinc compounds) }\end{array}$ & $5 \mathrm{mg} / \mathrm{L}$ & & HSDB 2003 \\
\hline Illinois & $\begin{array}{l}\text { Drinking water standard (zinc and } \\
\text { zinc compounds) }\end{array}$ & $5 \mathrm{mg} / \mathrm{L}$ & & HSDB 2003 \\
\hline Minnesota & $\begin{array}{l}\text { Drinking water guideline (zinc and } \\
\text { zinc compounds) }\end{array}$ & $2 \mathrm{mg} / \mathrm{L}$ & & HSDB 2003 \\
\hline c. Food & No data & & & \\
\hline d. Other & No data & & & \\
\hline
\end{tabular}

aDWEL: a lifetime exposure concentration protective of adverse, non-cancer health effects, that assumes all of the exposure to a contaminant is from drinking water.

bifetime: the concentration of a chemical in drinking water that is not expected to cause any adverse noncarcinogenic effects for a lifetime of exposure. The lifetime HA is based on exposure of a 70-kg adult consuming $2 \mathrm{~L}$ water/day.

${ }^{\mathrm{C} D}$ : not classifiable as to human carcinogenicity

ACGIH = American Conference of Governmental Industrial Hygienists; CFR = Code of Federal Regulations; DWEL = drinking water equivalent level; EPA = Environmental Protection Agency; FDA = Food and Drug Administration; HA = health advisory; HSDB = Hazardous Substances Data Bank; IARC = International Agency for Research on Cancer; IDLH = immediately dangerous to life or health; IRIS = Integrated Risk Information System; $\mathrm{MCL}=$ maximum contaminant level; NIOSH = National Institute for Occupational Safety and Health; OSHA = Occupational Safety and Health Administration; OTC = over-the-counter; PEL = permissible exposure limit; $\mathrm{PQL}$ = practical quantitation level; RDI = recommended daily intake; $\mathrm{REL}$ = recommended exposure limit; $\mathrm{RfC}=$ inhalation reference concentration; RfD = oral reference dose; STEL = short-term exposure limit; TCLP = toxicity characteristic leachate procedure; TLV = threshold limit values; TSD = treatment, storage, and disposal; TWA = time-weighted average; $\mathrm{WHO}=$ World Health Organization 


\section{REFERENCES}

Aamodt RL, Rumble WF, Babcock AK, et al. 1982. Effects of oral zinc loading on zinc metabolism in humans: I. Experimental studies. Metabolism 31:326-334.

*Aamodt RL, Rumble WF, Henkin RI. 1983. Zinc absorption in humans: Effects of age, sex, and food. In: Inglett G, ed. The nutritional bioavailability of zinc. Washington, DC: The American Chemical Society, 61-82.

Aamodt RL, Rumble WF, Johnston GS, et al. 1981. Absorption of orally administered ${ }^{65} \mathrm{Zn}$ by normal human subjects. Am J Clin Nutr 34:2648-2652.

Aastrup P, Riget F, Dietz R, et al. 2000. Lead, zinc, cadmium, mercury, selenium, and copper in Greenland caribou and reindeer (Rangerifer tarandus). Sci Total Environ 245:149-159.

Abdelmageed AB, Oehme FW. 1991. The effect of various dietary zinc concentrations on the biological interactions of zinc, copper, and iron in rats. Biol Trace Elem Res 29(3):239-256.

Abrams SA, Zavaleta N, Lonnerdal B. 2002. Absorption of iron (Fe) and Zinc (Zn) by 1-yr-old Peruvian children consuming a diet based on wheat flour fortified with $\mathrm{Fe}$ with or without $\mathrm{Zn}$ and/or vitamin $\mathrm{A}$. Pediatr Res 51:189A.

Abshire MK, Buzard GS, Shiraishi MPW. 1996. Induction of c-myc and c-jun proto-oncogene expression in rat L6 myoblasts by cadmium is inhibited by zinc preinduction of the metallothionein gene. J Toxicol Environ Health 48:359-377.

Absil MCP, van Scheppingen Y. 1996. Concentrations of selected heavy metals in benthic diatoms and sediment in the Westerschelde estuary. Bull Environ Contam Toxicol 56:1008-1015.

*ACGIH. 1991. Threshold limit values for chemical substances and physical agents and biological exposure indices - 1991-1992. Cincinnati, OH: American Conference of Governmental Industrial Hygienists.

Acuff-Smith KD, Rogers JM, Keen CL, et al. 1995. Toxicant-induced maternal-embryonic Zn deficiency causes excess cell death in rat embryos. Teratology 51:171.

Adachi A, Okiayu M, Nishikawa A, et al. 1998. Metal levels in rain water from Kobe City in Japan. Bull Environ Contam Toxicol 60:892-897.

*Adams PC, Bradley C, Frei JV. 1991. Hepatic zinc in hemochromatosis. Clin Invest Med 14(1):16-20.

Adamson IYR, Prieditis H, Hedgecock C, et al. 2000. Zinc is the toxic factor in the lung response to an atmospheric particulate sample. Toxicol Appl Pharmacol 166:111-119.

Adarve MJ, Hernandez AJ, Gil A, et al. 1998. Boron, zinc, iron, and manganese content in four grassland species. J Environ Qual 27:1286-1293.

* Cited in text 
9. REFERENCES

*Adinolfi M. 1985. The development of the human blood-CSF-brain barrier. Dev Med Child Neurol 27:532-537.

*Adlercreutz H. 1995. Phytoestrogens: Epidemiology and a possible role in cancer protection. Environ Health Perspect Suppl 103(7):103-112.

*Agency for Toxic Substances and Disease Registry. 1989. Agency for Toxic Substances and Disease Registry. Fed Regist 54:37618-37634.

Agency for Toxic Substances and Disease Registry. 1995. Toxicological profile for zinc. Public Health Service. Atlanta, GA: U.S. Department of Health and Human Services.

*Agren MS. 1990. Percutaneous absorption of zinc from zinc oxide applied topically to intact skin in man. Dermatologica 180:36-39.

*Agren MS. 1991. Influence of 2 vehicles for zinc oxide on zinc absorption through intact skin and wounds. Acta Derm Venereol (Stockh) 71(2):153-156.

*Agren MS, Krusell M, Franzen L. 1991. Release and absorption of zinc from zinc oxide and zinc sulfate in open wounds. Acta Derm Venereol 71(4):330-333.

Ahmad S, Waheed S, Mannan A, et al. 1993. Evaluation of trace elements in wheat and wheat byproducts. J AOAC Int 77:11-17.

Ahmed KO, Al-Swaidan HM, Davies BE. 1993. Simultaneous elemental analysis in dust of the city of Riyadh, Saudi Arabia by inductively coupled plasma-mass spectrometry (ICP/MS). Sci Total Environ 138:207-212.

Aiken SP, Horn NM, Saunders NR. 1992a. Effects of amino acids on zinc transport in rat erythrocytes. J Physiol 445:69-80.

Aiken SP, Horn NM, Saunders NR. 1992b. Effects of histidine on tissue zinc distribution in rats. BioMetals 5(4):235-243.

Ajmal M, Khan MK, Normani AA. 1985. Distribution of heavy metal in water and sediments of selected sites of Yamuna River (India). Environ Monit Assess 5:205-214.

*Akhter MS, Madany IM. 1993. Heavy metals in street and house dust in Bahrain. Water Air Soil Pollut 66:111-119.

Alabdula'aly AI, Khan MA. 2000. Chemistry of rain water in Riyadh, Saudi Arabia. Arch Environ Contam Toxicol 39:66-73.

Alam MGM, Tanaka A, Allinson G, et al. 2002. A comparison of trace element concentrations in cultured and wild carp (Cyprinus carpio) of Lake Kasumigaura, Japan. Ecotoxicol Environ Saf 53:348354.

Alam SM, Gupta A, Kumar S, et al. 1986. The role of zinc in renal diseases. J Indian Med Assoc 84:233-236. 
9. REFERENCES

Albering HJ, Vanleusen SM, Moonen EJC, et al. 1999. Human health risk assessment: A case study involving heavy metal soil contamination after the flooding of the river Meuse during the winter of 19931994. Environ Health Perspect 107:37-43.

*Alexander J, Aaseth J, Refsvik T. 1981. Excretion of zinc in rat bile--a role of glutathione. Acta Pharmacol Toxicol 49:190-194.

Alexandre S, Rast C, Maire MA, et al. 2003. $\mathrm{ZnCl}_{2}$ induces Syrian hamster embryo (SHE) cell transformation. Toxicol Lett 142(1-2):77-87.

*Allen JG, Masters HG, Peet RL, et al. 1983. Zinc toxicity in ruminants. J Comp Pathol 93:363-377.

Allen JRL, Rae JE, Zanin PE. 1990. Metal speciation $(\mathrm{Cu}, \mathrm{Zn}, \mathrm{Pb})$ and organic matter in an oxic salt marsh, Severn Estuary, Southwest Britain. Mar Pollut Bull 21:574-580.

Alliot A, Piron-Frenet M. 1990. Relationship between metals in seawater and metal accumulation in shrimps. Mar Pollut Bull 21(1):30-33.

Almas A, Singh BR, Salbu B. 1999. Mobility of cadmium-109 and zinc-65 in soil influenced by equilibration time, temperature, and organic matter. J Environ Qual 28:1742-1750.

Al-saleh IA. 1996. Trace elements in drinking water coolers collected from primary schools, Riyadh, Saudi Arabia. Sci Total Environ 181:215-221.

*Altman PL, Dittmer DS. 1974. In: Biological handbooks: Biology data book. Vol. III. $2^{\text {nd }}$ ed. Bethesda, MD: Federation of American Societies for Experimental Biology, 1987-2008, 2041.

*Alvarado J, Moreno R, Cristiano AR. 1991. Determination of cadmium, chromium, copper, lead and zinc in human semen by graphite-furnace atomic absorption spectrometry after microwave sample dissolution. J Trace Elem Electrolytes Health Dis 5(3):173-180.

Alvarez JM, Novillo J, Obrador A, et al. 2001. Mobility and leachability of zinc in two soils treated with six organic zinc complexes. J Agric Food Chem 49:3833-3840.

*Amacher DI, Paillet SC. 1980. Induction of trifluorothymidene-resistant mutants by metal ions in L5178Y/TK ${ }^{+/-}$cells. Mutat Res 78:279-288.

*Amdur M, McCarthy J, Gill M. 1982. Respiratory response of guinea pigs to zinc oxide fume. Am Ind Hyg Assoc J 43:887-889.

*Ameille J, Brechot JM, Brochard P, et al. 1992. Occupational hypersensitivity in a smelter exposed to zinc fumes. Chest 101(3):862-863.

*Amr MM, Abbas EZ, El-Samra GM, et al. 1997. Neuropsychiatric syndromes and occupational exposure to zinc phosphide in Egypt. Environ Res 73:200-206.

Amundsen CE, Hanssen JE, Semb A, et al. 1992. Long-range atmospheric transport of trace elements to southern Norway. Atmos Environ 26, Part A:1309-1324.

*Andermann G, Dietz M. 1982. The bioavailability and pharmacokinetics of three zinc salts: Zinc pantothenate, zinc sulfate, and zinc orotate. Eur J Drug Metab Pharmacokinet 7:233-239. 
9. REFERENCES

Andersen O. 1984. Chelation of cadmium. Environ Health Perspect 54:249-266.

*Andersen ME, Clewell HJ III, Gargas ML, et al. 1987. Physiologically based pharmacokinetics and the risk assessment process for methylene chloride. Toxicol Appl Pharmacol 87:185-205.

*Andersen ME, Krishnan K. 1994. Relating in vitro to in vivo exposures with physiologically based tissue dosimetry and tissue response models. In: Salem H, ed. Animal test alternatives: Refinement, reduction, replacement. New York: Marcel Dekker, Inc., 9-25.

Andersen O, Nielsen JB, Sorensen JA, et al. 1994. Experimental localization of intestinal uptake sites for metals (Cd, Hg, Zn, Se) in vivo in mice. Environ Health Perspect 102:199-206.

*Anderson C, Danylchuk KD. 1979. The effect of chronic excess zinc administration on the haversian bone remodelling system and its possible relationship to "Itai-Itai" disease. Environ Res 20:351-357.

Anderson D, Blowers SD, Marrs TC, et al. 1996. An in vitro and an in vivo unscheduled DNA synthesis assay with a zinc oxide/hexachloroethane (Zn/HCE) smoke. Hum Exp Toxicol 15:38-44.

*Anderson JR, Aggett FJ, Buseck PR, et al. 1988. Chemistry of individual aerosol particles from Chandler, Arizona, an arid urban environment. Environ Sci Technol 22:811-818.

*Anderson MB, Lepak K, Farinas V, et al. 1993. Protective action of zinc against cobalt induced testicular damage in the mouse. Reprod Toxicol 7(1):49-54.

Anderson PR, Christensen TH. 1988. Distribution coefficients of Cd, Co, Ni and Zn in soils. J Soil Sci 39:15-22.

Andrews S, Sutherland RA. 2004. Cu, Pb and Zn contamination in Nuuanu watershed, Oahu, Hawaii. Sci Total Environ 324(1-3):173-182.

Angelidis MO, Aloupi M. 1995. Metals in sediments of Rhodes Harbor, Greece. Mar Pollut Bull 31:276-276.

Anonymous. 1982. Hair zinc in normal populations. Nutr Rev 40:74-76.

*Anonymous. 1983. Illness associated with elevated levels of zinc in fruit punch--New Mexico. Morb Mortal Wkly Rep 32:257-258.

Anonymous. 1989. Secondary prevention of coronary disease with lipid lowering drugs. Lancet i:473474.

Anonymous. 2004. Large doses of zinc may increase risk of prostate cancer. Mayo Clinic Health Letter 22(5):4.

*Ansari MS, Miller WJ, Lassiter JW, et al. 1975. Effects of high but nontoxic dietary zinc on zinc metabolism and adaptations in rats. Proc Soc Exp Biol Med 150:534-536.

*Ansari MS, Miller WJ, Neathery MW, et al. 1976. Zinc metabolism and homeostasis in rats fed a wide range of high dietary zinc levels. Proc Soc Exp Biol Med 152:192-194. 
*AOAC. 1984. Official methods of analysis of the Association of Official Analytical Chemists. Alexandria, VA: Association of Official Analytical Chemists.

*AOAC. 1990. Official methods of analysis of the Association of Official Analytical Chemists. Alexandria, VA: Association of Official Analytical Chemists.

*AOAC. 1998. Official methods of analysis of the Association of Official Analytical Chemists. Alexandria, VA: Association of Official Analytical Chemists.

*APHA. 1998. Standard methods for the examination of water and wastewater. Washington, DC: American Public Health Association.

Araki S, Murata K, Uchida E, et al. 1993. Radial and median nerve conduction velocities in workers exposed to lead, copper, and zinc: A follow-up study for 2 years. Environ Res 61(2):308-316.

Araki S, Murata K, Yokoyama K, et al. 1992. Auditory event-related potential (P300) in relation to peripheral nerve conduction in workers exposed to lead, zinc, and copper: Effects of lead on cognitive function and central nervous system. Am J Ind Med 21(4):539-547.

AREDS. 2002. The effect of five-year zinc supplementation on serum zinc, serum cholesterol and hematocrit in persons randomly assigned to treatment group in the age-related eye disease study: AREDS report no. 7. J Nutr 132:697-702.

Argiratos V, Samman S. 1994. The effect of calcium carbonate and calcium citrate on the absorption of zinc in health female subjects. Eur J Clin Nutr 48:198-204.

*Arnaud J, Favier A. 1995. Copper, iron, manganese and zinc contents in human colostrum and transitory milk of French women. Sci Total Environ 159:9-15.

*Arnaud J, Favier A, Alary J. 1991. Determination of zinc in human milk by electrothermal atomicabsorption spectrometry. J Anal Atom Spectrom 6(8):647-652.

Arnaud J, Favier A, Herrmann MA, et al. 1992. Effect of folic and folinic acids on zinc intestinal absorption. Ann Nutr Metab 36(3):157-161.

Arnaud J, Preziosi P, Mashako L, et al. 1994. Serum trace elements in Zairian mothers and their newborns. Eur J Clin Nutr 48:341-348.

Artola A, Rigola M. 1992. Selection of optimum biological sludge for zinc removal from wastewater by a biosorption process. Biotechnol Lett 14(12):1199-1204.

ASBC. 1992. American Society of Brewing Chemists, Inc. Zinc in wort and beer by graphite furnace atomic absorption spectroscopy. Journal of the American Society of Brewing Chemists 50(4):158-159.

Aschner M, Conklin DR, Yao CP, et al. 1998. Induction of astrocyte metallothioneins (MTs) by zinc confers resistance against the acute cytotoxic effects of methylmercury on cell swelling, $\mathrm{Na}^{+}$uptake, and $\mathrm{K}^{+}$release. Brain Res 813:254-261.

Ashraf W, Jaffar M, Mohammad D. 1995. Levels of selected trace metals in hair of urban and rural adult male population of Pakistan. Bull Environ Contam Toxicol 54:207-213. 
9. REFERENCES

*Aslam N, McArdle HJ. 1992. Mechanism of zinc uptake by microvilli isolated from human term placenta. J Cell Physiol 151(3):533-538.

*Aten CF, Bourke JB, Walton JC. 1983. Heavy metal content of rainwater in Geneva, New York during late 1982. Bull Environ Contam Toxicol 31:574-581.

Atik OS. 1983. Zinc and senile osteoporosis. J Am Geriatr Soc 31:790-791.

Attrill MJ, Thomes RM. 1995. Heavy metal concentrations in sediment from the Thames estuary, UK. Mar Pollut Bull 30(11):742-744.

*Aughey E, Grant L, Furman BL, et al. 1977. The effects of oral zinc supplementation in the mouse. J Comp Pathol 87:1-14.

*Aulerich RJ, Bursian SJ, Poppenga RH, et al. 1991. Toleration of high concentrations of dietary zinc by mink. J Vet Diagn Invest 3:232-237.

Ayalon O, Nishri A, Avnimelech Y. 1991. Distribution of soluble iron and zinc in leachates of municipal wastes. In: Chen Y, Hadar Y, eds. Iron nutrition and interactions in plants. Netherlands: Kluwer Academic Publishers, 53-56.

Azcue JMP, Pfeiffer WC, Donangelo CM, et al. 1988. Heavy metals in foods from the Paraiba do Sul River Valley, Brazil. J Food Comp Anal 1(3):250-258.

Azizi MR, Rezvan N, Dehpour AR, et al. 2003. Changes in concentration of zinc in urine, serum, and saliva as indices of gentamicin nephotoxicity in male Wistar rats. Toxicol Lett 144(suppl 1):s84.

Babcock AK, Henkin RI, Aamodt RL, et al. 1982. Effects of oral zinc loading on zinc metabolism in humans: II. In vivo kinetics. Metabolism 31:335-347

*Bache CA, Gutenmann WH, Rutske M, et al. 1991. Concentrations of metals in grasses in the vicinity of a municipal refuse incinerator. Arch Environ Contam Toxicol 20:538-542.

Bache CA, Lisk DJ. 1990. Heavy-metal absorption by perennial ryegrass and swiss chard grown in potted soils amended with ashes from 18 municipal refuse incinerators. J Agric Food Chem 38:190-194.

Badsha K, Eduljee G, Scudamore N. 1986. Environmental monitoring for PCB and trace metals in the vicinity of a chemical waste disposal facility: Part III. Chemosphere 15:947-957.

Badsha KS, Goldspink CR. 1988. Heavy metal levels in three species of fish in Tjeukemeer, a Dutch Polder Lake. Chemosphere 17:459-463.

*Baes CF, Sharp RD. 1983. A proposal for estimation of soil leaching and leaching constants for use in assessment models. J of Environ Qual 12:17-28.

*Baes CF, Sharp RD, Sjoreen AL, et al. 1984. A review and analysis of parameters for assessing transport of environmentally released radionuclides through agriculture. U.S. Department of Energy, Washington, DC. ORNL-5786, 53-64.

Bajraktari, Ismet D, Alija, et al. 2004. The effect of zinc chloride and cadmium chloride on genetic loads of Drosophila melanogaster viability. FASEB J 18(4-5):A1195. 
9. REFERENCES

Baker DE, Bowers ME. 1988. Health effects of cadmium predicted from growth and composition of lettuce grown in gardens contaminated by emissions from zinc smelters. Preprint of paper presented at the $22^{\text {nd }}$ Annual Conference on Trace Substances in Environmental Health, St. Louis, MO, May 23-26. University Park, PA: The Pennsylvania State University Department of Agronomy, Paper No. 7908, 115.

*Banu BS, Devi KD, Mahboob M, et al. 2001. In vivo genotoxic effect of zinc sulfate in mouse peripheral blood leukocytes using Comet assay. Drug Chem Toxicol 24(1):63-73.

Baranowski J, Norska-Borówka I, Baranowska I. 2002. Determination of heavy metals in the bones and livers of deceased neonatal humans. Bull Environ Contam Toxicol 69:1-7.

*Barany E, Bergdahl IA, Bratteby L-E, et al. 2002. Relationships between trace element concentrations in human blood and serum. Toxicol Lett 134:177-184.

Barany E, Bergdahl IA, Schutz A, et al. 1997. Inductively coupled plasma mass spectrometry for direct multi-element analysis of diluted human blood and serum. J Anal Atom Spectrom 12:1005-1009.

Barbera R, Farre R, Mesado D. 1991. Determination of cadmium, cobalt, copper, iron, lead, manganese, nickel and zinc in diets: Development of a method. Nahrung 35(7):683-687.

Barceloux DG. 1999. Zinc. Clin Toxicol 37(2):279-292.

Barclay DV, Mauron J, Blondel A, et al. 2003. Micronutrient intake and status in rural Democratic Republic of Congo. Nutr Res 23(5):659-671.

Bargagli R. 2001. Trace metals in Antarctic organisms and the development of circumpolar biomonitoring network. Rev Environ Contam Toxicol 171:53-110.

Bargagli R, Barghigiani C, Siegel BZ, et al. 1991. Trace metal anomalies in surface soils and vegetation on two active island volcanoes. Sci Total Environ 102:209-222.

*Barnes DG, Dourson M. 1988. Reference dose (RfD): Description and use in health risk assessments. Regul Toxicol Pharmacol 8:471-486.

Barrett HM, Cunningham JG, Johnston JH. 1939. A study of the fate in the organism of some chlorinated hydrocarbons. J Ind Hyg Toxicol 21:479-490.

*Barrie LA, Hoff RM. 1985. Five years of air chemistry observations in the Canadian Arctic. Atmos Environ 19:1995-2010.

*Basta NT, Tabatabai MA. 1990. Ion-chromatographic determination of total metals in soils. Soil Sci Soc Am J 54:1289-1297.

*Batchelor RP, Fehnel JW, Thomson RM, et al. 1926. A clinical and laboratory investigation of the effect of metallic zinc, of zinc oxide, and of zinc sulphide upon the health of workmen. J Ind Hyg 8:322363.

Batra N, Nehru B, Bansal MP. 1998. The effect of zinc supplementation on the effects of lead on the rat testis. Reprod Toxicol 12(5):535-540. 
*Bauchinger M, Schmid E, Einbrodt HJ, et al. 1976. Chromosome aberrations in lymphocytes after occupational exposure to lead and cadmium. Mutat Res 40:57-62.

Bay BH, Sit KH. 1992. Coarse to fine hair conversion induced by zinc in C57 6J mice. Tohoku J Exp Med 168(1):63-66.

Bay BH, Tan BKH, Sit KH, et al. 1996. Cytochrome P450 content and ultrastructural changes in liver of zinc-treated C57/6J mice. Pharmacol Res 34:93-97.

*Beavington F. 1975. Heavy metal contamination of vegetables and soil in domestic gardens around a smelting complex. Environ Pollut 9:211-217.

Bebe FN. 2004. Pesticides in the diet modify the retention of calcium, zinc and copper metals in the small intestines. FASEB J 18(4-5):A527.

Bebe FN, Panamangalore M. 1996. Modulation of tissue trace metal concentrations in weanling rats fed different levels of zinc and exposed to oral lead and cadmium. Nutr Res 16:1369-1380.

Beceiro-Gonzalez E, Andrade-Garda JM, Serrano-Velasco E, et al. 1997. Metals in airborne particulate matter in La Coruna (NW Spain). Sci Total Environ 196:131-139.

*Bedwal RS, Nair N, Mathur RS. 1991. Effects of zinc-deficiency and toxicity on reproductive-organs, pregnancy and lactation - a review. Trace Elements in Medicine 8(2):89-100.

*Beer WH, Johnson RF, Guentzel MN, et al. 1992. Human placental transfer of zinc: Normal characteristics and role of ethanol. Alcoholism: Clinical and Experimental Research 16(1):98-105.

Belmonte NM, Rivera OE, Herkovits J. 1989. Zinc protection against cadmium effects of preimplantation mice embryos. Bull Environ Contam Toxicol 43:107-110.

Bennett DR, Baird CJ, Chan KM, et al. 1997. Zinc toxicity following massive coin ingestion. Am J Forensic Med Pathol 18(2):148-153.

*Bentley PJ, Grubb BR. 1991. Experimental dietary hyperzincemia tissue disposition of excess zinc in rabbits. Trace Elements in Medicine 8:202-207.

*Berger GS. 1994. Epidemiology of endometriosis. In: Berger GS, ed. Endometriosis: Advanced management and surgical techniques. New York, NY: Springer-Verlag.

*Bergkvist B, Folkeson L, Berggren D. 1989. Fluxes of $\mathrm{Cu}, \mathrm{Zn}, \mathrm{Pb}, \mathrm{Cd}, \mathrm{Cr}$, and $\mathrm{Ni}$ in temperate forest ecosystems. Water Air Soil Pollut 47:217-286.

*Bermudez OI, Maras J, Tucker KL. 2003. Differences in food intake of NHANES older adults, by ethnicity and obesity status. FASEB J 17(4-5):A284.

*Berry WJ, Cantwell MG, Edwards PA, et al. 1999. Predicting toxicity of sediments spiked with silver. Environ Toxicol Chem 18(1):40-48.

*Berry WJ, Hansen DJ, Mahoney JD, et al. 1996. Predicting the toxicity of metal-spiked laboratory sediments using acid-volatile sulfide and interstitial water normalizations. Environ Toxicol Chem 15(12):2067-2079. 
Berti WR, Jacobs LW. 1998. Distribution of trace elements in soil from repeated sewage sludge applications. J Environ Qual 27:1280-1286.

Bervoets L, Intpanis L, Verheyen R. 1994. Trace metal levels in water, sediments and chironomus gr. Thumni, from different water courses in Flanders (Belgium). Chemosphere 29:1591-1601.

Beyer WN. 1983. The smoke that settled over Palmerton. N J Audubon 9:14-16.

Beyer WN. 1986. A reexamination of biomagnification of metals in terrestrial food chains. Environ Toxicol Chem 5:863-864.

Beyer WN, Cromartie EJ. 1987. A survey of $\mathrm{Pb}, \mathrm{Cu}, \mathrm{Zn}, \mathrm{Cd}, \mathrm{Cr}, \mathrm{As}$, and $\mathrm{Se}$ in earthworms and soil from diverse sites. Environ Monit Assess 8:27-36.

Beyer WN, Miller GW, Cromartie EJ. 1984. Contamination of the 02 soil horizon by zinc smelting and its effect on woodlouse survival. J Environ Qual 13:247-251.

*Bibak A, Behrens A, Sturup S, et al. 1998a. Concentration of 55 major trace elements in Danish agricultural crops measured by inductively coupled plasma mass spectometry. 2. Pea (Pisum sativum ping pong). J Agric Food Chem 46:3146-3149.

*Bibak A, Behrens A, Sturup S, et al. 1998b. Concentrations of 63 major and trace elements in Danish agricultural crops measured by inductively coupled plasma mass spectometry. 1. Onion (Allium cepa Hysam). J Agric Food Chem 46:3139-3145.

*Bibak A, Sturup S, Haahr V, et al. 1999. Concentrations of 50 major and trace elements in Danish agricultural crops measured by inductively coupled plasma mass spectrometry. 3. Potato (Solanum tuberosum Folva). J Agric Food Chem 47:2678-2684.

*Biddinger GR, Gloss SP. 1984. The importance of trophic transfer in the bioaccumulation of chemical contaminants in aquatic ecosystems. Residue Rev 91:103-145.

*Biego GH, Joyeux M, Hartemann P, et al. 1998. Daily intake of essential minerals and metallic micropollutants form foods in France. Sci Total Environ 217:27-36.

Bilici M, Yildirim F, Kandil S, et al. 2004. Double-blind, placebo-controlled study of zinc sulfate in the treatment of attention deficit hyperactivity disorder. Prog Neuro-Psychopharmacol Biol Psychiat 28(1):181-190.

Bilski JJ, Alva AK. 1995. Transport of heavy metals and cations in a fly ash amended soil. Bull Environ Contam Toxicol 55:502-509.

Birch G, Siaka M, Owens C. 2001. The source of anthropogenic heavy metals in fluvial sediments of a rural catchment: Coxs River, Australia. Water Air Soil Pollut 125:13-35.

*Black MR, Medeiros DM, Brunett E, et al. 1988. Zinc supplements and serum lipids in young adult white males. Am J Clin Nutr 47:970-975.

Blain D, Chan HM, Kubow S. 1996. Metallothionein pre-induction by zinc and isotretinoin teratogenicity in CD-1 mice. Toxicologist 30:195. 
9. REFERENCES

Blain D, Kubow S, Chan HM. 1998. Zinc pretreatment inhibits isotretinoin teratogenicity and induces embryonic metallothionein in CD-1 mice. J Nutr 128:1239-1246.

*Blanc P, Wong H, Bernstein MS, et al. 1991. An experimental human model of metal fume fever. Ann Intern Med 114:930-936.

Blanusa M, Ivicic N, Simeon V. 1990. Lead, iron, copper, zinc and ash in deciduous teeth in relation to age and distance from a lead smelter. Bull Environ Contam Toxicol 45:478-485.

Blanusa M, Kucak A, Varnai VM, et al. 2001. Uptake of cadmium, copper, iron, manganese, and zinc in mushrooms (Boletaceae) from Croatian forest soil. J AOAC Int 84:1964-1971.

Blanusa M, Prester L, Matek M, et al. 1999. Trace elements in soil and coniferous needles. Bull Environ Contam Toxicol 62:700-707.

Bleavins MR, Aulerich RJ. 1981. Feed consumption and food passage time in mink (Mustela vison) and European ferrets (Mustela putomus furo). Lab Anim Sci 31:268.

*Bleavins MR, Aulerich RJ, Hochstein JR, et al. 1983. Effects of excessive dietary zinc on the intrauterine and postnatal development of mink. J Nutr 113:2360-2367.

*Blevins RD, Pancorbo OC. 1986. Metal concentrations in muscle of fish from aquatic systems in east Tennessee, U.S.A. Water Air Soil Pollut 29:361-371.

Blume HP, Brummer G. 1991. Prediction of heavy metal behaviour in soil by means of simple field tests. Ecotoxicol Environ Safety 22:164-174.

*Bogden JD, Oleske JM, Lavenhar MA, et al. 1988. Zinc and immunocompetence in elderly people: Effects of zinc supplementation for 3 months. Am J Clin Nutr 48:655-663.

*Bonewitz RF, Voner C, Foulkes EC. 1982. Uptake and absorption of zinc in perfused rat jejunum: The role of endogenous factors in the lumen. Nutr Res 2:301-307.

*Bonham M, O'Connor JM, Alender HD, et al. 2003a. Zinc supplementation has no effect on circulating levels of peripheral blood leucocytes and lymphocyte subsets in healthy adult men. Br J Nutr 89(5):695703.

*Bonham M, O'Connor JM, McAnena LB, et al. 2003b. Zinc supplementation has no effect on lipoprotein metabolism, hemostasis, and putative indices of copper status in healthy men. Biol Trace Elem Res 93:2003.

Boodles D, Burger IH, Whyte AL, et al. 1991. Effects of two levels of zinc intake on growth and trace element status in Labrador puppies. J Nutr 121(11):S79-S80.

*Boon DY, Soltanpour PN. 1991. Estimating total lead, cadmium and zinc in contaminated soils from ammonium hydrogen carbonate - DTPA-extractable levels. Commun Soil Science Plant Anal 22(5):369378.

Boon DY, Soltanpour PN. 1992. Lead, cadmium, and zinc contamination of aspen and garden soils and vegetation. J Environ Qual 21:82-86. 
*Boosalis MG, Evans GW, McClain CJ. 1983. Impaired handling of orally administered zinc in pancreatic insufficiency. Am J Clin Nutr 37:268-271.

Bos LP, Van Volten WA, Smit AFD, et al. 1977. Zinc deficiency with skin lesions as seen in acrodermatitis enteropathica and intoxication with Zn during parenteral nutrition. Neth J Med 20:263.

*Bostick BC, Hansel CM, Laforce MJ, et al. 2001. Seasonal fluctuations in zinc speciation within a contaminated wetland. Environ Sci Technol 35:3823-3829.

Bothwell DN, Mair EA, Cable BB. 2003. Chronic ingestion of a zinc-based penny. Pediatrics 111(3):176-177.

Bougle D, Isfaoun A, Bureau F, et al. 1999. Long-term effects of iron: Zinc interactions on growth in rats. Biol Trace Elem Res 67:37-48.

Boukaiba N, Flament C, Archer S, et al. 1993. A physiological amount of zinc supplementation: Effects on nutritional, lipid, and thymic status in an elderly population. Am J Clin Nutr 57(4):566-572.

*Bourg ACM, Darmendrail D. 1992. Effect of dissolved organic matter and pH on the migration of zinc through river bank sediments. Environ Technol 13(7):695-700.

Boutron CF, Candelone JP, Hong S. 1994. The changing occurrence of natural and man-derived heavy metals in antarctic and Greenland ancient ice and recent snow. Int J Environ Anal Chem 55:203-209.

Boutron CF, Ducroz FM, Gorlach U, et al. 1993. Variations in heavy metal concentrations in fresh Greenland snow from January to August 1989. Atmos Environ 27 (Part 1):2773-2779.

Bowers LJ, Melhuish JH. 1988. Comparison of elemental concentrations in the wood of three tree species growing adjacent to an inactive chromium smelter. Bull Environ Contam Toxicol 40:457-461.

Bradley SB, Cox JJ. 1988. The potential availability of cadmium, copper, iron, lead, manganese, nickel and zinc in standard river sediment (NBS 1645). Environ Technol Lett 9:733-739.

*Brandao-Neto J, deMendon CA, Shuhama T, et al. 1990a. Zinc acutely and temporarily inhibits adrenal cortisol secretion in humans: A preliminary report. Biol Trace Elem Res 24:83-89.

*Brandao-Neto J, Vieira JG, Shuhama T, et al. 1990b. Interrelationships of zinc with glucose and insulin metabolism in humans. Biol Trace Elem Res 24:73-82.

Brandao-Neto J, Vieira JG, Shuhama T, et al. 1991. Interaction among zinc, glucose, and insulin in normal individuals during glucose and tolbutamid perfusion. Biol Trace Elem Res 28:123-133.

Bremner I. 1979. The toxicity of cadmium, zinc, and molybdenum and their effects on copper metabolism. Proc Nutr Soc 38:235-42.

*Brewer GJ. 2000. Recognition, diagnosis, and management of Wilson's disease. Proc Soc Exp Biol Med 223:39-46.

Brewer GJ, Johnson VD, Dick RD, et al. 2000. Treatment of Wilson's disease with zinc. XVII: treatment during pregnancy. Hepatology 31:364-370. 
9. REFERENCES

Bridges $\mathrm{CH}$, Womack JE, Harris ED, et al. 1984. Considerations of copper metabolism in osteochondrosis of suckling foals. J Am Vet Med Assoc 185:173-178.

Brightwell J, Magaha J, Flinn J, et al. 1999. Enhanced levels of zinc in drinking water adversely affect spatial learning in rats. Abstr Soc Neurosci 25:1829.

Brito G, Diaz C, Galindo L, et al. 1990. Levels of metals in canned meat products: Intermetallic correlations. Bull Environ Contam Toxicol 44:309-316.

Broderick M, Birnbaum K. 2002. Fatal ingestion of zinc phosphide rodenticide. J Toxicol Clin Toxicol 40:684.

*Bronstein AC, Currance PL, eds. 1988. Emergency care for hazardous materials exposure. St. Louis, MO: CV Mosby Company, 111-112, 147-148.

*Brooks RR, Presley BJ, Kaplan IR. 1967. APDC-MIBK extraction system for the determination of trace elements in saline waters by atomic-absorption spectrophotometry. Talanta 14:809-816.

Broomhall J, Kovar IZ. 1986. Environmental pollutants in breast milk. Rev Environ Health 6(1-4):311337.

*Broun ER, Greist A, Tricot G, et al. 1990. Excessive zinc ingestion: A reversible cause of sideroblastic anemia and bone marrow depression. JAMA 264:1441-1443.

*Brown JJ. 1988. Zinc fume fever. Br J Radiol 61:327-329.

*Brown MA, Thom JV, Orth GL, et al. 1964. Food poisoning involving zinc contamination. Arch Environ Health 8:657-660.

Brown S, Chaney R, Hallfrisch J, et al. 2004. In sita soil treatments to reduce the phyto- and bioavailability of lead, zinc, and cadmium. J Environ Qual 33(2):522-531.

*Bruce BW, McMahon PB. 1996. Shallow ground-water quality beneath a major urban center: Denver, Colorado, USA. J Hydrol 186:129-151.

Bruehler G, Depeyster AD. 1999. Selenium and other trace metals in pelicans dying at the Salton Sea. Bull Environ Contam Toxicol 63:590-597.

Brugmann L. 1988. Some peculiarities of the trace-metal distribution in Baltic waters and sediments. Mar Chem 23:425-440.

Brumas V, Hacht B, Filella M, et al. 1992. Can N-acetyl-L-cysteine affect zinc metabolism when used as a paracetamol antidote. Agents Actions 36(3-4):278-288.

*Bruni B, Barolo P, Gamba S, et al. 1986. Case of generalized allergy due to zinc and protamine in insulin preparation. Diabetes Care 9:552.

Brzóska MM, Moniuszko-Jakoniuk J, Jurczuk M, et al. 2001. The effect of zinc supply on cadmiuminduced changes in the tibia of rats. Food Chem Toxicol 39:729-737. 
9. REFERENCES

Buchauer MJ. 1973. Contamination of soil and vegetation near a zinc smelter by zinc, cadmium, copper, and lead. Environ Sci Technol 7:131-135.

Buchter B, Davidoff B, Amacher MC, et al. 1989. Correlation of freundlich Kd and retention parameters with soils and elements. Soil Sci 148(5):370-379.

Bui LM, Taubeneck MW, Commisso JF, et al. 1998. Altered zinc metabolism contributes to the developmental toxicity of 2-ethylhexanoic acid, 2-ethylhexanol and valproic acid. Toxicology 126(1):921.

Bui L, Taubeneck M, Faber W, et al. 1997a. Multiple dosing of 2-ethylhexanoic acid alters maternal zinc $(\mathrm{Zn})$ metabolism and is teratogenic in the rat. FASEB J 11:A194.

Bui LM, Taubeneck MW, Faber WD, et al. 1997b. Altered zinc ( $\mathrm{Zn})$ metabolism contributes to the developmental toxicity of 2-ethylhexanoic acid (EHXA) in Sprague-Dawley rats. Teratology 55:60.

*Bunker VW, Hinks LJ, Stansfield MF, et al. 1987. Metabolic balance studies for zinc and copper in housebound elderly people and the relationship between zinc balance and leukocyte zinc concentrations. Am J Clin Nutr 46:353-359.

*Bunzl K, Schimmack W. 1989. Association between the fluctuations of the distribution coefficients of $\mathrm{Cs}, \mathrm{Zn}, \mathrm{Sr}, \mathrm{Co}, \mathrm{Cd}, \mathrm{Ce}, \mathrm{Ru}, \mathrm{Tc}$ and I in the upper two horizons of a Podzol forest soil. Chemosphere 18:2109-2120.

Bunzl K, Trautmannsheimer M, Schramel P. 1999. Partitioning of heavy metals in a soil contaminated by slag: A redistribution study. J Environ Qual 28:1168-1173.

Burd GD. 1993. Morphological study of the effects of intranasal zinc sulfate irrigation on the mouse olfactory epithelium and olfactory bulb. Microsc Res Tech 24(3):195-213.

Burggraaf S, Wilkins AL, Langdon AG, et al. 1997. Heavy metals and organic hydrocarbons in sediments from the Waikareao Estuary, Tauranga Harbour, New Zealand. Bull Environ Contam Toxicol 58:871-878.

*Burke DM, DeMicco FJ, Taper LJ, et al. 1981. Copper and zinc utilization in elderly adults. J Gerontol 36:558-563.

*Burkhart KK, Kulig KW, Rumack B. 1990. Whole-bowel irrigation as treatment for zinc sulfate overdose. Ann Emerg Med 19:1167-1170.

Burns LV, Parker GH. 1988. Metal burdens in two species of fiddleheads growing near the ore smelters at Sudbury, Ontario, Canada. Bull Environ Contam Toxicol 40:717-723.

Bury NR, Walker PA, Glover CN. 2003. Nutritive metal uptake in teleost fish. J Exp Biol 206(1):11-23

Butte W, Heinzow B. 2002. Pollutants in house dust as indicators of indoor contamination. Rev Environ Contam Toxicol 175:1-46.

Byerley JJ, Scharer JM. 1992. Natural release of copper and zinc into the aquatic environment. Hydrometallurgy 30(1-3):107-126. 
*Cagen SZ, Klaassen CD. 1979. Protection of carbon tetrachloride-induced hepatotoxicity by zinc: Role of metallothionein. Toxicol Appl Pharmacol 51:107-116.

*Cahill RA, Unger MT. 1993. Evaluation of the extent of contaminated sediments in the west branch of the Grand Calumet River, Indiana-Illinois, USA. Water Sci Technol 28:53-58.

Cai L, Cherian MG. 1996. Adaptive response to ionizing radiation-induced chromosome aberrations in rabbit lymphocytes: Effect of pre-exposure to zinc, and copper salts. Mutat Res 369:233-241.

*Callender GR, Gentzkow CJ. 1937. Acute poisoning by the zinc and antimony content of limeade prepared in a galvanized iron can. Military Surgeon 80:67-71

Calvery HO. 1941. Trace elements in foods. Food Research 7:313-331.

*Campbell KR. 1994. Concentrations of heavy metals associated with urban runoff in fish living in stormwater treatment ponds. Arch Environ Contam Toxicol 27:352-356.

Camps J, Bargallo T, Gimenez A, et al. 1992. Relationship between hepatic lipid peroxidation and fiberogenesis in carbon tetrachloride treated rats: Effects of zinc administration. Clin Sci 83(6):695-700.

Camusso M, Vigano L, Balestrini R. 1995. Bioconcentration of trace metals in rainbow trout: a field study. Ecotoxicol Environ Saf 31:133-141.

Cao GH, Chen JD. 1991. Effects of dietary zinc on free-radical generation, lipid-peroxidation, and superoxide dismutase in trained mice. Arch Biochem Biophys 291(1):147-153.

Capar SG, Cunningham WC. 2000. Element and radionuclide concentrations in food: FDA Total Diet Study 1991-1996. J AOAC Int 83:157-177.

Carbery JT. 1978. Osteodysgenesis in a foal associated with copper deficiency. New Zealand Veterinary Journal 26:279.

Carey LC, Berbee PL, Coyle P, et al. 2003. Zinc treatment prevents lipopolysaccharide-induced teratogenicity in mice. Birth Defects Research Part A 67(4):240-245.

Carey LC, Coyle P, Philcox JC, et al. 2003 Zinc supplementation at the time of ethanol exposure ameliorates teratogenicity in mice. Alcohol Clin Exp Res 27(1):107-110.

*Casassas E, Perez-Vendrell AM, Puignou L. 1991. Improved voltammetric procedure for the determination of zinc, lead cadmium and copper in atmospheric aerosols. Int J Environ Anal Chem 45(1):55-63.

Cassel GH. 1978. Zinc: A review of current trends in therapy and our knowledge of its toxicity. Del Med J 50:323-328.

Castaneda SS. 1999. Simultaneous determination of lead, cadmium and zinc in metro manila air particulates by anodic stripping voltammetry. INIS-PH-004.

Castet D, Bouillard J. 1992. Acute lung reaction to zinc oxide. Rev Mal Respir 9(6):632-633. 
9. REFERENCES

Castillo-Duran C, Hertrampf ED, Ruz MO, et al. 2002. Controlled trial of zinc supplementation on growth and body composition in Chilean children from low income groups. Pediatr Res 51:188A.

*CDC/ATSDR. 1990. Biomarkers of organ damage or dysfunction for the renal, hepatobiliary and immune systems. Atlanta, GA: CDC/ATSDR Subcommittee on Biomarkers of Organ Damage and Dysfunction, Centers for Disease Control, Agency for Toxic Substances and Disease Registry. Summary report, August 27, 1990.

CELDS. 1993. Computer-aided Environmental Legislative Data Systems. University of Illinois, Urbana, IL. June 23, 1993.

Celentano JJ, Gyenes M, Gibbs TT, et al. 1991. Negative modulation of the $\gamma$-aminobutyric acid response by extracellular zinc. Mol Pharmacol 40:766-773.

Cerklewski FL. 1979. Influence of dietary zinc on lead toxicity during gestation and lactation in the female rat. J Nutr 109:1703-1709.

*Cerklewski FL, Forbes RM. 1976. Influence of dietary zinc on lead toxicity in the rat. J Nutr 106:689696.

Chambers JC, Sidle RC. 1991. Fate of heavy metals in an abandoned lead-zinc tailings pond: I. Vegetation. J Environ Qual 20:745-751.

Chan KM. 1995. Concentrations of copper, zinc, cadmium, and lead in rabbitfish (Siganus oramin) collected in Victoria Harbour, Hong Kong. Mar Pollut Bull 31:277-280.

*Chandra RK. 1984. Excessive intake of zinc impairs immune responses. JAMA 252:1443-1446.

Chaney RL. 1985. Potential effects of sludge-borne heavy metals and toxic organics on soils, plants, and animals, and related regulatory guidelines. Annex 3, workshop paper. Vol. 9: Final Report of the Workshop on the International Transportation, Utilization or Disposal of Sewage Sludge Including Recommendations. Washington, DC: Pan American Health Organization. PSNP/85-01.

Chaney RL. 1988. Metal speciation and interaction among elements affect trace element transfer in agricultural and environmental food-chains. In: Kramer JR, Allen HE, eds. Metal speciation: Theory, analysis, and application. Chelsea, MI: Lewis Publishers, 219-260.

Chaney RL, Bruins RJF, Baker DE, et al. 1987. Transfer of sludge-applied trace elements to the foodchain. In: Page AL, Logan TJ, Ryan JA, eds. Land application of sludge -- food chain implications. Ann Arbor, MI: Lewis Publishers Inc., 67-99.

Chaney RL, Sterrett SB, Mielke HW. 1984. The potential for heavy metal exposure from urban gardens and soils. In: Preer JR, ed. Proceedings of the Symposium on Heavy Metals in Urban Gardens. Washington, DC: University of D.C. Extension Service, 37-84.

Chaney RL, Stoewsand GS, Bache CA, et al. 1978a. Cadmium deposition and hepatic microsomal induction in mice fed lettuce grown on municipal sludge-amended soil. J Agric Food Chem 26:992-994.

Chaney RL, Stoewsand GS, Furr AK, et al. 1978b. Elemental content of tissues of guinea pigs fed Swiss chard grown on municipal sewage sludge-amended soil. J Agric Food Chem 26:994-997. 
9. REFERENCES

Chang AC, Granato TC, Page AL. 1992. A methodology for establishing phytotoxicity criteria for chromium, copper, nickel, and zinc in agricultural land application of municipal sewage sludges. J Environ Qual 21(4):521-536.

*Chang AC, Hinesly TD, Bates TE, et al. 1987. Effects of long-term sludge application on accumulation of trace elements by crops. In: Page AL, Logan TJ, Ryan JA, eds. Land application of sludge -- food chain implications. Chelsea, MI: Lewis Publishers Inc., 53-66.

*Chang CH, Mann DE, Gautieri RF. 1977. Teratogenicity of zinc chloride, 1,10-phenanthroline and zinc-1,10-phenanthroline complex in mice. J Pharm Sci 66:1755-1758.

Chang CY, Chien HF, Jiangshieh YF, et al. 2003. Microglia in the olfactory bulb of rats during postnatal development and olfactory nerve injury with zinc sulfate: A lectin labeling and ultrastructural study. Neurosci Res 45(3):325-333.

Chapman PM, Allen HE, Godtfredsen K, et al. 1996. Evaluation of bioaccumulation factors in regulating metals. Environ Sci Technol 30:449a-452a.

Charelsworth M, Service M, Mitchell SH, et al. 1999. Metals in surficial sediments of the north-west Irish Sea. Bull Environ Contam Toxicol 62:40-47.

Chattopadhyay G, Lin KC-P, Feitz AJ. 2003. Household dust metal levels in the Sydney metropolitan area. Environ Res 93:301-307.

Chelani AB, Gajghate DG, Hasan MZ. 2001. Airborne toxic metals in air of Mumbai City, India. Bull Environ Contam Toxicol 66:196-205.

Chen C-J, Liao S-L. 2003a. Neurotrophic and neurotoxic effects of zinc on neonatal cortical neurons. Neurochem Int 42(6):471-479.

Chen C-J, Liao S-L. 2003b. Zinc toxicity on neonatal cortical neurons: involvement of glutathione chelation. J Neurochem 85(2):443-453.

*Chen M, Ma LQ, Harris WG. 1999. Baseline concentrations of 15 trace elements in Florida surface soils. J Environ Qual 28(4):1173-1181.

Cherian L, Gupta VK. 1992. Spectrophotometric determination of zinc using 4-carboxyphenyldiazoaminoazobenzene and its application in complex materials. Chem Anal (Warsaw) 37(1):69-72.

Chevalier P. 1995. Zinc and duration of treatment of severe malnutrition. Lancet 345:1046-1047.

Chevreuil M, Carru AM, Chesterikoff A, et al. 1995. Contamination of fish from different areas of the River Seine (France) by organic (PCB and pesticides) and metallic ( $\mathrm{Cd}, \mathrm{Cr}, \mathrm{Cu}, \mathrm{Fe}, \mathrm{Mn}, \mathrm{Pb}$, and $\mathrm{Zn}$ ) micropollutants. Sci Total Environ 162:31-42.

Chillrud SN, Bopp RF, Simpson HJ, et al. 1999. Twentieth century atmospheric metal fluxes into Central Park Lake, New York City. Environ Sci Technol 33(5):657-662.

*Chlopecka A, Bacon JR, Wilson MJ, et al. 1996. Heavy metals in the environment. J Environ Qual 25:69-79. 
9. REFERENCES

Chmielewski J, Jaremin B, Bartnicki C, et al. 1974. Evaluation of occupational exposure to zinc oxide in the marine production shipyard: II. Examination of the state of health of the workers exposed to zinc oxide. Bull Inst Marit Trop Med Gdynia 25(1):53-65.

Chmielnicka J, Sowa B. 1996. Cadmium interaction with essential metals ( $\mathrm{Zn}, \mathrm{Cu}, \mathrm{Fe}$ ), metabolism metallothionein, and ceruloplasmin in pregnant rats and fetuses. Ecotoxicol Environ Saf 35:277-281.

*Chmielnicka J, Zareba G, Grabowska U. 1992. Protective effect of zinc on heme-biosynthesis disturbances in rabbits after administration per os of tin. Ecotoxicol Environ Safety 24(3):266-274.

Cho CH, Teh GW. 1991. The inhibitory action of zinc sulfate on the contractile activity of guinea-pig ileum. J Pharm Pharmacol 43(4):294-296.

*Chobanian SJ. 1981. Accidental ingestion of liquid zinc chloride: Local and systemic effects. Ann Emerg Med 10:91-93.

*Choi DW, Yokoyama M, Koh J. 1988. Zinc neurotoxicity in cortical cell culture. Neuroscience 24:6779.

Chovanec A, Vogel WR, Lorbeer G, et al. 1994. Chlorinated organic compounds, PAHs and heavy metals in sediments and aquatic mosses of two upper Austrian rivers. Chemosphere 29:2117-2133.

Christensen JB, Jensen DL, Christensen TH. 1996. Effect of dissolved organic carbon on the mobility of cadmium, nickel and zinc in leachate polluted groundwater. Water Res 30:3037-3049.

Christian P, Katz J, Dominici F, et al. 2004a. Treatment effects of maternal micronutrient supplementation vary by percentiles of the birth weight distribution in Nepal. FASEB J 18(4-5):A512.

Christian P, Shrestha J, LeClerq SC, et al. 2004b. Supplementation with micronutrients in addition to iron and folic acid does not further improve the hematologic status of pregnant women in rural Nepal. J Nutr 133(11):3492-3498.

Chung CS, Nagey DA, Veillon C, et al. 2002. A single 60-mg iron dose decreases zinc absorption in lactating women. J Nutr 132:1903-1905.

*Ciba J, Zolotajkin M, Cebula J. 1997. Changes of chemical forms of zinc and zinc sulfide during the composting process of municipal solid waste. Water Air Soil Pollut 93:167-173.

*Clement. 1985. Chemical, physical, and biological properties of compounds present at hazardous waste sites. Final Report to the Office of Waste Programs Enforcement, Office of Solid Waste and Emergency Response, Environmental Protection Agency, Washington, DC, by Clement Associates, Arlington, VA.

*Clewell HJ III, Andersen ME. 1985. Risk assessment extrapolations and physiological modeling. Toxicol Ind Health 1(4):111-131.

*Coale KH, Flegal AR. 1989. Copper, zinc, cadmium and lead in surface waters of lakes Erie and Ontario. Sci Total Environ 87/88:297-304.

Cohen HJ, Powers BJ. 1994. A study of respirable versus nonrespirable copper and zinc oxide exposures at a nonferrous foundry. Am Ind Hyg Assoc J 55(11):1047-1050. 
9. REFERENCES

Cohen NL, Shulte MJ, Laus MJ. 2004. Dietary intake and nutritional risk in food secure and insecure older food pantry recipients. FASEB J 18(4-5):A106.

Cole KL, Engstrom DR, Futyama RP, et al. 1990. Past atmospheric deposition of metals in northern Indiana measured in a peat core from Cowles Bog. Environ Sci Technol 24:543-549.

*Cole RH, Frederick RE, Healy RP, et al. 1984. Preliminary findings of the Priority Pollutant Monitoring Project of the Nationwide Urban Runoff Program. J Water Pollut Control Fed 56:898-908.

*Coleman ME, Elder RS, Basu P. 1992. Trace metals in edible tissues of livestock and poultry. J Assoc Analyt Chem Int 75:615-625.

*Colin JL, Jaffrezo JL, Gros JM. 1990. Solubility of major species in precipitation: Factors of variation. Atmos Environ 24A:537-544.

*Colin MA, Taper LJ, Ritchey SJ. 1983. Effect of dietary zinc and protein levels on the utilization of zinc and copper by adult females. J Nutr 113:1480-1488.

Collins RN, Merrington G, McLaughlin MJ, et al. 2002. Uptake of intact zincethylenediaminetetraacetic acid from soil is dependent on plant species and complex concentration. Environ Toxicol Chem 21(9):1940-1945.

Colvin RA, Davis N, Nipper RW, et al. 2000. Zinc transport in the brain: Routes of zinc influx and efflux in neurons. J Nutr 130:1484S-1487S.

*Connor JJ, Shacklette HT. 1975. Background geochemistry of some rocks, soils, plants, and vegetables in the conterminous United States. Geological Survey Professional Paper 574-F. Washington, DC: U.S. Department of the Interior. F9, F11, F160-161.

*Conner MW, Flood WH, Rogers AE, et al. 1988. Lung injury in guinea pigs caused by multiple exposures to ultrafine zinc oxide: Changes in pulmonary lavage fluid. J Toxicol Environ Health 25:5769.

Conner M, Lam H, Rogers A, et al. 1985. Lung injury in guinea pigs caused by multiple exposures to submicron zinc oxide mixed with sulfur dioxide in a humidified furnace. J Toxicol Environ Health 16:101-114.

*Coogan TP, Bare RM, Waalkes MP. 1992. Cadmium-induced DNA strand damage in cultured liver cells: Reduction in cadmium genotoxicity following zinc pretreatment. Toxicol Appl Pharmacol 113:227-233.

*Cooke JA, Andrews SM, Johnson MS. 1990. The accumulation of lead, zinc, cadmium and fluoride in the wood mouse (Apodemus sylvaticus L.). Water Air Soil Pollut 51:55-63.

Cosma G, Fulton H, Defeo T, et al. 1992. Rat lung metallothionein and heme oxygenase gene expression following ozone and zinc oxide exposure. Toxicol Appl Pharmacol 117(1):75-80.

Cossack ZT, Rojhani A, Musaiger AO. 1992. The effects of sugar beet fiber supplementation for 5 weeks on zinc, iron and copper status in human subjects. Eur J Clin Nutr 46(3):221-225. 
9. REFERENCES

Costello LC, Franklin RB, Feng P, et al. 2004. Re: Zinc supplement use and risk of prostate cancer. J Natl Cancer Inst 96(3):239-241.

*Cotran RS, Kumar V, Robbins SL. 1989. Robbins pathologic basis of disease. 4th ed. Philadelphia, PA: W.B. Saunders Company, 461.

*Couillard D, Chartier M, Mercier G. 1994. Major factors influencing bacterial leaching of heavy metals $(\mathrm{Cu}$ and $\mathrm{Zn})$ from anaerobic sludge. Environ Pollut 85:175-184.

*Cousins RJ. 1985. Absorption, transport, and hepatic metabolism of copper and zinc: Special reference to metallothionein and ceruloplasmin. Physiol Rev 65:238-309.

Couzy F, Mansourian R, Labate A, et al. 1998. Effect of dietary phytic acid on zinc absorption in the healthy elderly, as assessed by serum concentration curve tests. Br J Nutr 80:177-182.

Cox D, Harris D. 1960. Effect of excess dietary zinc on iron and copper in the rat. J Nutr 70:514-520.

*Cox DH, Schlicker SA, Chu RC. 1969. Excess dietary zinc for the maternal rat, and zinc, iron, copper, calcium and magnesium content and enzyme activity in maternal and fetal tissues. J Nutr 98:459-466.

*Crawford DW, Bonnevie NL, Wenning RJ. 1995. Sources of pollution and sediment contamination in Newark Bay, New Jersey. Ecotoxicol Environ Saf 30:85-100.

Crebelli R, Paoletti A, Falcone E, et al. 1985. Mutagenicity studies in a tyre plant: In vitro activity of workers' urinary concentrates and raw materials. Br J Ind Med 42:481-487.

Cuajungco MP, Lees GJ. 1997. Zinc metabolism in the brain: Relevance to human neurodegenerative disorders. Neurobiol Dis 4:137-169.

Cullumbine H. 1957. The toxicity of screening smokes. J Army Med Corps 103:109-122.

Culshaw C, Newton LC, Weir I, et al. 2002. Concentrations of Cd, $\mathrm{Zn}$ and $\mathrm{Cu}$ in sediments and brown shrimp (Crangon crangon L.) from the Severn Estuary and Bristol Channel, UK. Mar Environ Res 54:331-334.

*Cunningham-Rundles S, Bockman RS, Lin A, et al. 1990. Physiological and pharmacological effects of zinc on immune response. Ann NY Acad Sci 587:113-122.

Cyr F, Mehra MC, Mallet VN. 1987. Leaching of chemical contaminants from a municipal landfill site. Bull Environ Contam Toxicol 38:775-782.

*Czerwinski AW, Clark M, Serafetinides EA, et al. 1974. Safety and efficacy of zinc sulfate in geriatric patients. Clin Pharmacol Ther 15:436-441.

*Daisey JM. 1987. Chemical composition of inhalable particulate matter- seasonal and intersite comparisons. In: Lioy PJ, Daisey JM, eds. Toxic air pollution: A comprehensive study of non-criteria air pollutants. Chelsea, MI: Lewis Publishing Inc., 47-63.

Dannecker W, Schroeder B, Stechmann H. 1990. Organic and inorganic substances in highway tunnel exhaust air. Sci Total Environ 93:293-300. 
9. REFERENCES

*Dasch JM, Wolff GT. 1989. Trace inorganic species in precipitation and their potential use in source apportionment studies. Water Air Soil Pollut 43:401-412.

Dassenakis M, Degaita A, Scoullos M. 1995. Trace metals in sediments of a Mediterranean estuary affected by human activities (Acheloos River Estuary, Greece). Sci Total Environ 168:19-31.

*Davidson CI, Goold WD, Mathison TP, et al. 1985. Airborne trace elements in Great Smoky Mountains, Olympic, and Glacier National Parks. Environ Sci Technol 19(1):27-34.

Davidson CI, Lin S, Osborn JF, et al. 1986. Indoor and outdoor air pollution in the Himalayas. Environ Sci Technol 20:561-567.

Davidsson L, Almgren A, Sandstrom B, et al. 1996. Zinc absorption in adult humans: The effect of protein sources added to liquid test meals. Br J Nutr 75:607-613.

Davies J. 1984. Lung cancer mortality among workers making lead chromate and zinc chromate pigments at three English factories. Br J Ind Med 41:158-169.

*Davies NT. 1980. Studies on the absorption of zinc by rat intestine. Br J Nutr 43:189-203.

*Davies NT, Nightingale R. 1975. The effects of phytate on intestinal absorption and secretion of zinc, and whole body retention of $\mathrm{Zn}$, copper, iron and manganese in rats. Br J Nutr 34:243-258.

*Davis AP, Shokouhian M, Ni S. 2001. Loading estimates of lead, copper, cadmium, and zinc in urban runoff from specific sources. Chemosphere 44:997-1009.

*Davis CD, Milne DB, Nielsen FH. 2000. Changes in dietary zinc and copper affect zinc-status indicators of postmenopausal women, notably, extracellular superoxide dismutase and amyloid precursor proteins. Am J Clin Nutr 71:781-788.

*Dawson GW, Mercer BW. 1986. Hazardous waste management. New York, NY: John Wiley \& Sons, $328-412$.

Dean CE, Hargis BM, Hargis PS. 1991. Effects of zinc toxicity on thyroid function and histology in broiler chicks. Toxicol Lett 57(3):309-318.

Deknudt GH. 1982. [Clastogenic effects of zinc in mammals.] C R Seances Soc Biol Fil 176:563-567. (French)

*Deknudt GH, Deminatti M. 1978. Chromosome studies in human lymphocytes after in vitro exposure to metal salts. Toxicology 10:67-75.

*Deknudt G, Gerber GB. 1979. Chromosomal aberrations in bone-marrow cells of mice given a normal or a calcium-deficient diet supplemented with various heavy metals. Mutat Res 68:163-168.

*Delafuente JC. 1991. Nutrients and immune responses. Rheum Dis Clin North Am 17(2):203-212.

*Delves HT. 1981. The analysis of biological and clinical materials. Progress in Analytical Atomic Spectroscopy 4:1-48. 
*de Oliveira FS, Viana MR, Antoniolli AR, et al. 2001. Differential effects of lead and zinc on inhibitory avoidance learning in mice. Braz J Med Biol Res 34:117-120.

De Schrijver R, Conrad S. 1992. Availability of calcium, magnesium, phosphorus, iron, and zinc in rats fed oat bran containing diets. J Agric Food Chem 40(7):1166-1171.

Deverel SJ, Millard SP. 1988. Distribution and mobility of selenium and other trace elements in shallow groundwater of the western San Joaquin Valley, California. Environ Sci Technol 22(6):697-702.

Devevey E, Bitton G, Rossel D, et al. 1993. Concentration and bioavailability of heavy metals in sediments in Lake Yojoa (Honduras). Bull Environ Contam Toxicol 50:253-259.

Dewet LPD, Schoonbee HJ, Pretorius J, et al. 1990. Bioaccumulation of selected heavy metals by the water fern, Azolia filiculoides Lam. in a wetland ecosystem affected by sewage, mine and industrial pollution. Water South Africa 16(4):281-286.

Dhawan D, Goel A. 1995. Further evidence for zinc as a hepatoprotective agent in rat liver toxicity. Exp Mol Pathol 63:110-117.

DHHS. 1986. Nutrition monitoring in the United States: A progress report from the Joint Nutrition Monitoring Evaluation Committee. U.S. Department of Health and Human Services, Public Health Service. DHHS publication No. (PHS) 86-1255.

Dho NY, Lee SR. 2003. Effect of temperature on single and competitive adsorptions of $\mathrm{Cu}$ (II) and $\mathrm{Zn}$ (II) onto natural clays. Environ Monit Assess 83(2):117-203.

Diaz C, Galindo L, Garciamontelongo F. 1994. Distribution of metals in some fishes from Santa Cruz De Tenerife, Canary Islands. Bull Environ Contam Toxicol 52:374-381

Diaz C, Galido L, Montelongo FG, et al. 1990. Metals in coastal waters of Santa Cruz De Tenerife, Canary Islands. Mar Pollut Bull 13:217-218.

Diaz-Gomez NM, Domenech E, Barroso F, et al. 2003. The effect of zinc supplementation on linear growth, body composition, and growth factors in preterm infants. Pediatrics 111(5):1002-1009.

Dineley KE, Malaiyandi LM, Filiano AJ, et al. 2004. Evidence for a bidirectional relationship between intracellular zinc and reactive oxygen species. J Neurochem 85(1):64.

Dineley KE, Scanlon JM, Kress GJ, et al. 2000. Astrocytes are more resistant than neurons to the cytotoxic effects of increased $\left[\mathrm{Zn}^{2+}\right]_{i}$. Neurobiol Dis 7:310-320.

Dineley KE, Votyakova TV, Reynolds IJ. 2003. Zinc inhibition of cellular energy production: implications for mitochondria and neurogeneration. J Neurochem 85(3):563-570.

*Di Toro DM, Mahoney JD, Hansen DJ, et al. 1992. Acid volatile sulfide predicts the acute toxicity of cadmium and nickel in sediments. Environ Sci Technol 26:96-101.

*DOI. 1988. The mineral commodity summaries. Washington, DC: Department of the Interior, Bureau of Mines, 180-181. 
9. REFERENCES

*DOI. 1991. U.S. Department of the Interior Minerals Yearbook. Washington, DC: Bureau of Mines, 1145-1174.

Doganoc DZ. 1996. Distribution of lead, cadmium, and zinc in tissues of hens and chickens from Slovenia. Bull Environ Contam Toxicol 57:932-937.

Doherty CP, Sarkar MAK, Shakur MS, et al. 1998. Zinc and rehabilitation from severe protein-energy malnutrition: Higher-dose regimens are associated with increased mortality. Am J Clin Nutr 68:742-748.

Domingo JL. 1994. Metal-induced development toxicity in mammals: A review. J Toxicol Environ Health 42:123-141.

*Domingo JL, Llobet JM, Colomina MT, et al. 1988b. The removal of zinc from the mouse by polyamincarboxylic acids (CDTA and DTPA) following semichronic zinc ingestion. Vet Hum Toxicol 30:524-527.

*Domingo JL, Llobet JM, Paternain JL, et al. 1988a. Acute zinc intoxication: Comparison of the antidotal efficacy of several chelating agents. Vet Hum Toxicol 30:224-228.

Donaldson J, St. Pierre T, Minnich J, et al. 1971. Seizures in rats associated with divalent cation inhibition of Na+-K+-ATPase. Can J Biochem 49:1217-1224.

Donangelo CM, Woodhouse LR, King SM, et al. 2002. Supplemental zinc lowers measures of iron status in young women with low iron reserves. J Nutr 132:1860-1864.

*Donat JR, Bruland KW. 1990. A comparison of two voltammetric techniques for determining zinc speciation in Northeast Pacific ocean waters. Mar Chem 28:301-323.

*Dorea JG. 2002. Zinc and copper in breast-milk and home-prepared milk fed to urban infants from lowincome families. J Trace Elem Exp Med 15:123-129.

*Dorn CR, Pierce JO, Phillips PE, et al. 1976. Airborne Pb, Cd, Zn and Cu concentration by particle size near a $\mathrm{Pb}$ smelter. Atmos Environ 10:443-446.

Dowdy RH, Latterell JJ, Hinesly TD, et al. 1991. Trace metal movement in an aeric ochraqualf following 14 years of annual sludge applications. J Environ Qual 20:119-123.

Dragnev K, Yanchev I, Angelov L. 1991. Use of some indicative fodder plants and animal organs as a criterion for evaluation of the degree of pollution with copper and zinc in industrial regions. Proc Int Congr Meat Sci Technol 37th, 1244-1247.

*Drinker K, Drinker P. 1928. Metal fume fever: V. Results of the inhalation by animals of zinc and magnesium oxide fumes. J Ind Hyg 10:56-70.

*Drinker P, Thomson RM, Finn JL. 1927a. Metal fume fever: II. Resistance acquired by inhalation of zinc oxide on two successive days. J Ind Hyg 9:98-105.

*Drinker P, Thomson RM, Finn JL. 1927b. Metal fume fever: IV. Threshold doses of zinc oxide, preventive measures, and the chronic effects of repeated exposures. J Ind Hyg 9:331-345. 
9. REFERENCES

*Drinker KR, Thompson PK, Marsh M. 1927c. An investigation of the effect upon rats of longcontinued ingestion of zinc compounds, with especial reference to the relation of zinc excretion to zinc intake. Am J Physiol 81:284-306.

*Drinker KR, Thompson PK, Marsh M. 1927d. An investigation of the effect of long-continued ingestion of zinc, in the form of zinc oxide, by cats and dogs, together with observations upon the excretion and the storage of zinc. Am J Physiol 80:31-64.

*DuBray ES. 1937. Chronic zinc intoxication: An instance of chronic zinc poisoning from zinc chloride used in the pillow manufacturing industry. JAMA 108:383-385.

*Duce RA, Hoffman GL, Zoller WH. 1975. Atmospheric trace metals at remote northern and southern hemisphere sites: Pollution or natural? Science 187:59-61.

*Duchateau J, Delepesse G, Vrijens R, et al. 1981. Beneficial effects of oral zinc supplementation on the immune response of old people. Am J Med 70:1001-1004.

*Dudka S, Chlopecka A. 1990. Effect of solid-phase speciation on metal mobility and phytoavailability in sludge-amended soil. Water Air Soil Pollut 51:153-160.

Dudka S, Ponce-Hernandez R, Tate G, et al. 1996. Forms of $\mathrm{Cu}, \mathrm{Ni}$, and $\mathrm{Zn}$ in soils of Sudbury, Ontario and the metal concentrations in plants. Water Air Soil Pollut 90:531-542.

Duffy JY, Baines D, Keen CL, et al. 1997. Developmental outcome of metallothionein-null mice fed various levels of zinc during gestation. Teratology 55:54.

*Duncan JR, Dreosti IE. 1975. Zinc intake, neoplastic DNA synthesis and chemical carcinogenesis in rats and mice. J Natl Cancer Inst 55:195-196.

Dybczynski R, Boboli K. 1976. Forensic and environmental aspects of neutron activation analysis of single human hairs. J Radioanal Chem 31:267-289.

Eamens GJ, Macadam JF, Laing EA. 1984. Skeletal abnormalities in young horses associated with zinc toxicity and hypocuprosis. Aust Vet J 61:205-207.

Eary LE, Rai D, Mattigod SV, et al. 1990. Geochemical factors controlling the mobilization of inorganic constituents from fossil fuel combustion residues: II. Review of the minor elements. J Environ Qual 19:202-214.

Ecker FJ, Hirai E, Chohji T. 1990. Airborne trace metals in snow on the Japan sea side of Japan. Atmos Environ 24a:2593-2600.

Eduljee G, Badsha K, Price L. 1985. Environmental monitoring for PCB and heavy metals in the vicinity of a chemical waste disposal facility: Part I. Chemosphere 14:1371-1382.

Eduljee G, Badsha K, Scudamore N. 1986. Environmental monitoring for PCB and heavy metals in the vicinity of a chemical waste disposal: Part II. Chemosphere 15:81-93.

Eisenberg M, Topping JJ. 1986. Trace metal residues in fin fish from Maryland waters, 1978-1979. J Environ Sci Health B 21:87-102. 
9. REFERENCES

*Elder JF, Mattraw HC Jr. 1984. Accumulation of trace elements, pesticides, and polychlorinated biphenyls in sediments and the clam Corbicula manilensis of the Apalachicola River, Florida. Arch Environ Contam Toxicol 13:453-470.

El-Gazzar RM, Finelli VN, Boiano J, et al. 1978. Influence of dietary zinc on lead toxiicty in rats. Toxicol Lett 1:227-234.

*Elinder CG. 1986. Zinc. In: Friberg L, Nordberg FF, Vouk V, eds. Handbook on the toxicology of metals. Vol. II. New York, NY: Elsevier Science Publishers B.V., 664-679.

Elkin BT, Bethke RW. 1995. Environmental contaminants in caribou in the Northwest Territories, Canada. Sci Total Environ 161:307-321.

*Ellenhorn MJ, Barceloux DG. 1988. Medical toxicology: Diagnosis and treatment of human poisoning. New York, NY: Elsevier, 879-880, 1064-1065.

Elliott JE, Scheuhammer AM. 1997. Heavy metal and metallothionein concentrations in seabirds from the Pacific coast of Canada. Mar Pollut Bull 34:794-800.

Elliot JE, Scheuhammer AM, Leighton FA, et al. 1992. Heavy metal and metallothionein concentrations in Atlantic Canadian seabirds. Arch Environ Contam Toxicol 22:63-73.

*Ellis R, Morris ER, Hill AD, et al. 1997. Selected mineral intakes of adult African-Americans in the Washington, DC area. J Food Comp Anal 10:334-342.

Ellis TM, Masters HG, Mayberry C. 1984. Examination of the susceptibility of different breeds of sheep to zinc intoxication. Aust Vet J 61:296-298.

El-Sammak A. 2001. Heavy metal pollution in bottom sediment, Dubai, United Arab Emirates. Bull Environ Contam Toxicol 67:295-302.

El-Sammak AA, Aboul-Kassim TA. 1999. Metal pollution in the sediments of Alexandria region, southeastern Mediterranean, Egypt. Bull Environ Contam Toxicol 63:263-270.

*Elson CM, Bem EM, Ackman RG. 1981. Determination of heavy metals in a menhaden oil after refining and hydrogenation using several analytical methods. J Am Oil Chem Soc 58:1024-1026.

Ely JC, Neal CR, Kulpa CF, et al. 2001. Implications of platinum-group element accumulation along U.S. roads from catalytic-converter attrition. Environ Sci Technol 35:3816-3822.

Endo T, Kimura O, Hatakeyama M, et al. 1997. Effects of zinc and copper on cadmium uptake by brush border membrane vesicles. Toxicol Lett 91:111-120.

EPA. 1973. Basic zinc sulfate; tolerances for residues. U.S. Environmental Protection Agency. Code of Federal Regulations. 40 CFR 180.244.

EPA. 1979a. National secondary drinking water regulations. U.S. Environmental Protection Agency. Fed Regist 44:42198. 40 CFR 143.

EPA. 1979b. Criteria and standards for the National Pollutant Discharge Elimination System. U.S. Environmental Protection Agency. Fed Regist 44:32948-32956. 40 CFR 125. 
9. REFERENCES

*EPA. 1979c. Methods for chemical analysis of water and wastes. Cincinnati, OH: U.S. Environmental Protection Agency, Environmental Monitoring and Support Laboratory. EPA600479020.

*EPA. 1979d. Water-related environmental fate of 129 priority pollutants. Washington, DC: U.S. Environmental Protection Agency, Office of Water Planning and Standards. EPA440479029a.

EPA. 1980a. Identification and listing of hazardous waste; discarded commercial chemical products, offspecification species, container residues, and spill residues thereof. U.S. Environmental Protection Agency. Fed Regist 45:33125. 40 CFR 261.33(e).

EPA. 1980b. Identification and listing of hazardous waste: Appendix VIII. Hazardous constituents. U.S. Environmental Protection Agency. Fed Regist 45:33133 40 CFR 261.

*EPA. 1980c. Ambient water quality criteria for zinc. Washington, DC: U.S. Environmental Protection Agency, Office of Water Regulations and Standards. EPA440580079. PB81117897.

*EPA. 1980d. Exposure and risk assessment for zinc. Washington, DC: U.S. Environmental Protection Agency, Office of Water Regulations and Standards (WH-553). EPA440481016. PB85212009.

EPA. 1980e. Guidelines and methodology used in the preparation of health effect assessment chapters of the consent decree water criteria documents. U.S. Environmental Protection Agency. Fed Regist 45:79347-79357.

EPA. 1981. Toxic pollutants. U.S. Environmental Protection Agency. Code of Federal Regulations. 40 CFR 401.15.

EPA. 1982. Compilation of and commentary on existing methodologies and guidelines relating to "risk assessments for complex mixtures." Cincinnati, OH: U.S. Environmental Protection Agency, Environmental Criteria and Assessment Office. SRC TR-82-544.

EPA. 1983. EPA administered permit programs: The National Pollutant Discharge Elimination System. General permits. U.S. Environmental Protection Agency. Fed Regist 48:14153-14178.

EPA. 1984a. Identification and listing of hazardous waste; discarded commercial chemical products, offspecification species, container residues, and spill residues thereof. U.S. Environmental Protection Agency. Fed Regist 49:19923. 40 CFR 261.33(f).

*EPA. 1984b. Health effects assessment for zinc (and compounds). Washington, DC: U.S. Environmental Protection Agency, Office of Emergency and Remedial Response. EPA540186048.

EPA. 1984c. Contract laboratory program statement of work--inorganic analysis. Washington, DC: U.S. Environmental Protection Agency, Contract Laboratory Program. SOW 784.

EPA. 1984d. Air quality data for metals 1977 through 1979 from the National Air Surveillance Networks. Research Triangle Park, NC: U.S. Environmental Protection Agency. EPA600S483053.

EPA. 1985a. Designation, reportable quantities and notification; designation of hazardous substances. U.S. Environmental Protection Agency. Fed Regist 50:13500 40. CFR 302.4. 
9. REFERENCES

EPA 1985b. Measurement of cadmium, lead, zinc, and calcium in selected populations in the United States. Research Triangle Park, NC: U.S. Environmental Protection Agency. EPA600184021.

*EPA. 1986a. General pretreatment regulations for existing and new sources. U.S. Environmental Protection Agency. Fed Regist 51:20429. 40 CFR 403.

EPA. 1986b. Designation, reportable quantities, and notification; designation of hazardous substances. U.S. Environmental Protection Agency. Fed Regist 51:34533. 40 CFR 302.4.

EPA. 1986c. Inventory reporting regulations, partial updating of the inventory data base. U.S. Environmental Protection Agency. Fed Regist 51:21447-21450. 40 CFR 710.

EPA. 1986d. Test methods for evaluating solid waste. Washington, DC: U.S. Environmental Protection Agency, Office of Solid Waste and Emergency Response. SW-846.

EPA. 1987a. Toxic chemical release reporting; community right-to-know. U.S. Environmental Protection Agency. Fed Regist 52:21152-21208.

EPA. 1987b. Emergency planning and notification: Appendix A. The list of extremely hazardous substances and their threshold planning quantities. U.S. Environmental Protection Agency. Fed Regist 52:13403 40 CFR 355.

*EPA. 1987c. Ambient water quality criteria for zinc--1987. Washington, DC: U.S. Environmental Protection Agency, Office of Water Regulations and Standards. EPA440587003. PB87153581.

*EPA. 1987d. Summary review of the health effects associated with zinc and zinc oxide: Health issue assessment. Research Triangle Park, NC: U.S. Environmental Protection Agency, Environmental Criteria and Assessment Office. EPA600887022F.

EPA. 1988a. General pretreatment regulations for existing and new sources of pollution. U.S. Environmental Protection Agency. Code of Federal Regulations. 40 CFR 403.

EPA. 1988b. National Priorities Listing Technical Data Base. Washington, DC: U.S. Environmental Protection Agency, National Priorities Listing.

EPA. 1988c. Recommendations for and documentation of biological values for use in risk assessment. Cincinnati, OH: U.S. Environmental Protection Agency. EPA600687008. PB88179874.

EPA. 1989a. Designation of hazardous substances. U.S. Environmental Protection Agency. Code of Federal Regulations. 40 CFR 116.4.

EPA. 1989b. Designation of hazardous substances. U.S. Environmental Protection Agency. Code of Federal Regulations. 40 CFR 302.4.

EPA. 1989c. Health effects assessment summary tables: Second quarter FY 1989. Washington, DC: U.S. Environmental Protection Agency, Office of Solid Waste and Emergency Response, Office of Emergency and Remedial Response.

*EPA. 1990a. Interim methods for development of inhalation reference concentrations. Washington, DC: U.S. Environmental Protection Agency. EPA600890066A. 
9. REFERENCES

EPA. 1990b. Emergency planning and notification: Appendix A - The list of extremely hazardous substances and their threshold planning quantities. U.S. Environmental Protection Agency. Code of Federal Regulations. 40 CFR 355, Appendix A.

EPA. 1991a. Hazardous constituents. U.S. Environmental Protection Agency. Code of Federal Regulations. 40 CFR 261, Appendix VIII.

EPA. 1991b. National secondary drinking water regulations. U.S. Environmental Protection Agency. Code of Federal Regulations. 40 CFR 143.

EPA. 1991c. Pesticide tolerances for zinc phosphide. U.S. Environmental Protection Agency. Fed Regist 56(233):63467-63468.

EPA. 1991d. Toxic chemical release reporting: Community right-to-know. U.S. Environmental Protection Agency. Code of Federal Regulations. 40 CFR 372.

*EPA. 1994. Methods for the determination of metals in environmental samples: Supplement 1. U.S. Environment Protection Agency. EPA600R94111. http://www.nemi.gov. August 5, 2003.

EPA. 1995. Engineering Forum Issue: Determination of background concentrations of inorganics in soils and sediments at hazardous waste sites. Office of Research and Development, Office of Solid Waste and Emergency Response. EPA540S96500.

*EPA. 1996. EPA method guidance CD-ROM: Includes MCAWW methods and most current EPA methods. U.S. Environment Protection Agency. http://www.nemi.gov. August 5, 2003.

*EPA. 1997. Special report on environmental endocrine disruption: An effects assessment and analysis. Washington, DC: U.S. Environmental Protection Agency, Risk Assessment Forum. EPA630R96012.

*EPA. 2000. Test methods for evaluating solid waste, physical/chemical methods, online EPA publication SW-846. http://www.epa.gov/epaoswer/hazwaste/test/main.htm. July 25, 2003.

*EPA. 2002. 2002 edition of the drinking water standards and health advisories. Washington, DC: EPA822R02038.

*EPA. 2003a. Criteria for municipal solid waste landfills. List of hazardous inorganic and organic constituents. Washington, DC: U.S. Environmental Protection Agency. 40 CFR 258, Appendix II. http://www.epa.gov/epahome/cfr40.htm. June 6, 2003.

*EPA. 2003b. Designation, reportable quantities, and notification. Designation of hazardous substance. Washington, DC: U.S. Environmental Protection Agency. 40 CFR 302.4. http://www.epa.gov/epahome/cfr40.htm. June 6, 2003.

*EPA. 2003c. Effluent guidelines and standards. General provisions. Toxic pollutants. Washington, DC: U.S. Environmental Protection Agency. 40 CFR 401.15. http://www.epa.gov/epahome/cfr40.htm. June 6, 2003.

*EPA. 2003d. Land disposal restrictions. Universal treatment standards. Washington, DC: U.S. Environmental Protection Agency. 40 CFR 268.48. http://www.epa.gov/epahome/cfr40.htm. June 6, 2003. 
*EPA. 2003e. National emission standards for hazardous air pollutants. List of pollutants. Washington, DC: U.S. Environmental Protection Agency. 40 CFR 61.01. http://www.epa.gov/epahome/cfr40.htm. June 6, 2003.

*EPA. 2003f. National secondary drinking water regulations. Secondary maximum contaminant levels. Washington, DC: U.S. Environmental Protection Agency. 40 CFR 143.3.

http://www.epa.gov/epahome/cfr40.htm. June 6, 2003.

*EPA. 2003g. Reportable quantities of hazardous substances designated pursuant to Section 311 of the Clean Water Act. Washington, DC: U.S. Environmental Protection Agency. 40 CFR 117.3.

http://www.epa.gov/epahome/cfr40.htm. June 6, 2003.

*EPA. 2003h. Standards for owners and operators of hazardous waste treatment, storage, and disposal facilities. Ground-water monitoring list. Washington, DC: U.S. Environmental Protection Agency. 40 CFR 264, Appendix IX. http://www.epa.gov/epahome/cfr40.htm. June 6, 2003.

*EPA. 2003i. Tolerance and exemptions from tolerance for pesticide chemicals in food. Mancozeb; tolerances for residues. Washington, DC: U.S. Environmental Protection Agency. 40 CFR 180.176. http://www.epa.gov/epahome/cfr40.htm. June 6, 2003.

*EPA. 2003j. Toxic chemical release reporting: Community right-to-know. Chemicals and chemical categories to which this part applies. Washington, DC: U.S. Environmental Protection Agency. 40 CFR 372.65. http://www.epa.gov/epahome/cfr40.htm. June 6, 2003.

*EPA. 2003k. Water programs. Designation of hazardous substances. Washington, DC: U.S. Environmental Protection Agency. 40 CFR 116.4. http://www.epa.gov/epahome/cfr40.htm. June 6, 2003.

*EPA. 20031. Water quality guidance for the Great Lakes system. Pollutants of initial focus in the Great Lakes water quality initiative. Washington, DC: U.S. Environmental Protection Agency. 40 CFR 132, Table 6. http://www.epa.gov/epahome/cfr40.htm. June 6, 2003.

Ertekin MV, Koc M, Karslioglu I, et al. 2004. Zinc sulfate in the prevention of radiation-induced oropharyngeal mucositis: A prospective, placebo-controlled, randomized study. Int J Radiat Oncol Biol Phys 58(1):167-174.

Esenin AV, Ma WC. 2000. Heavy metals (Cd, Cu, Zn) in wood and wood-feeding insects and other invertebrates associated with decaying pine trees. Bull Environ Contam Toxicol 64:242-249.

Esparza-Gonzalez BP, Nino-Fong R, Fuentealba I, et al. 2003. Zinc supplementation may decrease hepatic copper accumulation in LEC rat: A model of Wilson's disease. Toxicol Sci 72(S-1):402.

Evangelou A, Kalfakakou V. 1993. Electrocardiographic alterations induced by zinc ions on isolated guinea pig heart preparations. Biol Trace Elem Res 36(2):203-208.

*Evans EH. 1945. Casualties following exposure to zinc chloride smoke. Lancet 249:368-370.

*Evans GW. 1980. Normal and abnormal zinc absorption in man and animals: The tryptophan connection. Nutr Rev 38:137-141. 
9. REFERENCES

*Evans GJ, Tan PV. 1998. The fate of elements in residential composters. Arch Environ Contam Toxicol 34:323-329.

*Evenson DP, Emerick RJ, Jost LK, et al. 1993. Zinc-silicon interactions influencing sperm chromatin integrity and testicular cell-development in the rat as measured by flow cytometry. J Anim Sci 71(4):955962.

Ewing CI, Gibbs ACC, Ashcroft C, et al. 1991. Failure of oral zinc supplementation in atopic eczema. Eur J Clin Nutr 45(10):507-510.

Fahim MS, Wang M, Sutcu MF, et al. 1993. Sterilization of dogs with intraepididymal injection of zinc arginine. Contraception 47(1):107-122.

*Failla ML, Cousins RJ. 1978. Zinc accumulation and metabolism in primary cultures of adult rat liver cells: Regulation by glucocorticoids. Biochem Biophys Acta 543:293-304.

Fairweather-Tait SJ. 1995. Iron-zinc and calcium-Fe interactions in relation to $\mathrm{Zn}$ and Fe absorption. Proc Nutr Soc 54:465-473.

*Falin LI, Gromzewa KE. 1939. Experimental teratoma testis in fowl produced by injection of zinc sulphate solution. Am J Cancer 36:233-236.

*Fan J, Luo C, Wang S. 1991. Determination of zinc in bloodstain by atomic-absorption spectrometry. Atomic Spectroscopy 12(6):212-214.

Fan W, Wang W, Chen J. 2002. Geochemistry of Cd, Cr, and Zn in highly contaminated sediments and its influences on assimilation by marine bivalves. Environ Sci Technol 36:5164-5171.

Farinati F, Cardin R, D'Inca R, et al. 2003. Zinc treatment prevents lipid peroxidation and increases glutathione availability in Wilson's disease. J Lab Clin Med 141(6):372-377.

Farrah H, Pickering WF. 1993. Factors influencing the potential mobility and bioavailability of metals in dried lake sediments. Chem Speciat Bioavail 5(3):81-96.

*Farrell FJ. 1987. Angioedema and urticaria as acute and late phase reactions to zinc fume exposure, with associated metal fume fever-like symptoms. Am J Ind Med 12:331-337.

*FDA. 1987a. U.S. Food and Drug Administration. Code of Federal Regulations. 21 CFR 73.1991.21 CFR 73.2991.

*FDA. 1987b. Indirect food additives: Adhesives and components of coatings. U.S. Food and Drug Administration. Code of Federal Regulations. 21 CFR 175.105.

*FDA. 1987c. Resinous and polymeric coatings. U.S. Food and Drug Administration. Code of Federal Regulations. 21 CFR 175.300.

*FDA. 1987d. Rubber articles intended for repeated use. U.S. Food and Drug Administration. Code of Federal Regulations. 21 CFR 177.2600.

*FDA. 1987e. Substances migrating from cotton and cotton fabrics used in dry food packaging. U.S. Food and Drug Administration. Code of Federal Regulations. 21 CFR 182.70. 
9. REFERENCES

*FDA. 1987f. Substances migrating to food from paper and paperboard products. U.S. Food and Drug Administration. Code of Federal Regulations. 21 CFR 182.90.

*FDA. 1987g. Zinc chloride. U.S. Food and Drug Administration. Code of Federal Regulations. 21 CFR 182.5985.

*FDA. 1987h. Zinc oxide. U.S. Food and Drug Administration. Code of Federal Regulations. 21 CFR 182.5991.

*FDA. 1987i. Zinc stearate. U.S. Food and Drug Administration. Code of Federal Regulations. 21 CFR 182.5994.

*FDA. 1987j. Zinc sulfate. U.S. Food and Drug Administration. Code of Federal Regulations. 21 CFR 182.5997.

FDA. 1989. Quality standards for foods with no identity standards: Bottled water. U.S. Food and Drug Administration. Code of Federal Regulations. 21 CFR 103.35.

*FDA. 2000. Total diet study statistics on element results. Washington, DC: U.S. Food and Drug Administration.

*FDA. 2001. Beverages. Bottled water. U.S. Food and Drug Administration. Code of Federal Regulations. 21 CFR 165.110.

*FDA. 2003a. Beverages. Bottled water. Washington, DC: U.S. Food and Drug Administration. 21 CFR 165.110. http://www.access.gpo.gov/cgi-bin/cfrassemble.cgi?title=200321. June 6, 2003.

*FDA. 2003b. Food labeling. Nutrition labeling of food. Washington, DC: U.S. Food and Drug Administration. 21 CFR 101.9. http://www.access.gpo.gov/cgi-bin/cfrassemble.cgi?title=200321. June 6, 2003.

*FDA. 2003c. New drugs. Drug products containing certain active ingredients offered over-the-counter (OTC) for certain uses. Washington, DC: U.S. Food and Drug Administration. 21 CFR 310.545. http://www.access.gpo.gov/cgi-bin/cfrassemble.cgi?title=200321. June 6, 2003.

*FDA. 2003d. Substances generally recognized as safe. Trace minerals added to animal feeds. Washington, DC: U.S. Food and Drug Administration. 21 CFR 582.80. http://www.access.gpo.gov/cgibin/cfrassemble.cgi?title=200321. June 6, 2003.

*FDA. 2003e. Substances generally recognized as safe. Zinc oxide. Zinc sulfate. Washington, DC: U.S. Food and Drug Administration. 21 CFR 182.8991 and 21 CFR 182.8997. http://www.access.gpo.gov/cgi-bin/cfrassemble.cgi?title=200321. June 6, 2003.

*FEDRIP. 2003. Federal Research in Progress. Dialog Information Services, Inc.

*FEDRIP. 2004. Federal Research in Progress. Dialog Information Services, Inc.

Fergusson JE, Stewart C. 1992. The transport of airborne trace elements copper, lead, calcium, zinc, and manganese from a city into rural areas. Sci Total Environ 121:247-269. 
9. REFERENCES

*Ferm VH, Carpenter SJ. 1968. The relationship of cadmium and zinc in experimental mammalian teratogenesis. Lab Invest 18:429-432.

*Fernandes G, Nair M, Onoc K, et al. 1979. Impairment of cell-mediated immunity functions by dietary zinc deficiency in mice. Proc Natl Acad Sci USA 76:457-461.

Fernandez A, Davis SB, Wendt JOL, et al. 2001. Particulate emission from biomass combustion. Nature 409:998.

Fernandez MA, Martinez L, Segarra M, et al. 1992a. Behavior of heavy metals in the combustion gases of urban waste incinerators. Environ Sci Technol 26(5):1040-1047.

*Fernandez P, Perez Conde C, Gutierrez A, et al. 1992b. Selective spectrofluorimetric determination of zinc in biological samples by flow injection analysis (FIA). Fresenius J Anal Chem 342(7):597-600.

*Festa MD, Anderson HL, Dowdy RP, et al. 1985. Effect of zinc intake on copper excretion and retention in men. Am J Clin Nutr 41:285-292.

Fine JM, Gordon T, Chen LC, et al. 1997. Metal fume fever: Characterization of clinical and plasma IL6 responses in controlled human exposures to zinc oxide fume at and below the threshold limit value. J Occup Environ Med 39:722-726.

Fine JM, Gordon T, Chen LC, et al. 2000. Characterization of clinical tolerance to inhaled zinc oxide in naive subjects and sheet metal workers. J Occup Environ Med 42:1085-1091.

Finelli VN, Klauder DS, Karaffa MA, et al. 1975. Interaction of zinc and lead and $\alpha$-aminolevulinate dehydratase. Biochem Biophys Res Commun 65(1):303-311.

*Finkelman RB. 1999. Trace elements in coal. Environmental and heath significance. Biol Trace Elem Res 67:197-204.

Fischer PWF, Campbell JS, Giroux A. 1991. Effects of low copper and high zinc intakes and related changes in $\mathrm{Cu}, \mathrm{Zn}$-superoxide dismutase activity on DMBA-induced mammary tumorigenesis. Biol Trace Elem Res 30(1):65-79.

*Fischer PWF, Giroux A, Belonje B, et al. 1980. The effect of dietary copper and zinc on cholesterol metabolism. Am J Clin Nutr 33:1019-1025.

*Fischer PWF, Giroux A, L'Abbe AR. 1984. Effect of zinc supplementation on copper status in adult man. Am J Clin Nutr 40:743-746.

*Fischer PWF, Giroux A, L'Abbe MR. 1981. The effect of dietary zinc on intestinal copper absorption. Am J Clin Nutr 34:1670-1675.

*Fishbein L. 1981. Sources, transport, and alterations of metal compounds: An overview: 1. Arsenic, beryllium, cadmium, chromium, and nickel. Environ Health Perspect 40:43-64.

*Fishman MJ. 1966. The use of atomic absorption for analysis of natural waters. Atomic Absorption Newsletter 5:102-106. 
9. REFERENCES

Fiske DN, McCoy HE, Kitchens CS. 1994. Zinc-induced sideroblastic anemia: Report of a case, review of the literature, and description of the hematologic syndrome. Am J Hematol 46:147-150.

*Flanagan PR, Haist J, Valberg LS. 1983. Zinc absorption, intraluminal zinc and intestinal metallothionein levels in zinc-deficient and zinc-repleted rodents. J Nutr 113:962-972.

Fliss H, Menard M, Desai M. 1991. Hypochlorous acid mobilizes cellular zinc. Can J Physiol Pharmacol 69(11):1686-1691.

Flora SJS. 1991. Influence of simultaneous supplementation of zinc and copper during chelation of lead in rats. Hum Exp Toxicol 10(5):331-336.

Flora SJS, Kumar D, Dasgupta S. 1991. Interaction of zinc, methionine or their combination with lead at gastrointestinal or post-absorptive level in rats. Pharmacol Toxicol 68(1):3-7.

*Florence TM. 1980. Speciation of zinc in natural waters. In: Nriagu JO, ed. Zinc in the environment: Part I. Ecological cycling. New York, NY: John Wiley and Sons, 199-227.

*Folin M, Cotiero E, Calliari I. 1991. Quantitative determination of copper and zinc in biological samples (human hair): Comparison between atomic-absorption spectrometry and X-ray fluorescence spectrometry. Ann Chim (Rome) 81(1-2):39-49.

*Fomon SJ. 1966. Body composition of the infant: Part I: The male "reference infant." In: Falkner F, ed. Human development. Philadelphia, PA: WB Saunders, 239-246.

*Fomon SJ, Haschke F, Ziegler EE, et al. 1982. Body composition of reference children from birth to age 10 years. Am J Clin Nutr 35:1169-1175.

*Fong LYY, Sivak A, Newberne PM. 1978. Zinc deficiency and methylbenzylnitrosoamine-induced esophageal cancer in rats. J Natl Cancer Inst 61:145-150.

*Forssen A. 1972. Inorganic elements in the human body: I. Occurrence of $\mathrm{Ba}, \mathrm{Br}, \mathrm{Ca}, \mathrm{Cd}, \mathrm{Cs}, \mathrm{Cu}, \mathrm{K}$, Mn, Ni, Sn, Sr, Y, and Zn in the human body. Ann Med Exp Biol Fenn 50:99-162.

Foster DM, Aamodt RL, Henkin RI, et al. 1979. Zinc metabolism in humans: A kinetic model. Am J Physiol 237:R340-R349.

*Foulkes EC. 1984. Intestinal absorption of heavy metals. In: Csaky TZ, ed. Handbook of experimental pharmacology. Berlin, Germany: Springer Verlag, I: 543-565.

*Foulkes EC. 1985. Interactions between metals in rat jejunum: Implications on the nature of cadmium uptake. Toxicology 37:117-125.

*Foulkes EC. 1993. Metallothionein and glutathione as determinants of cellular retention and extrusion of cadmium and mercury. Life Sci 52:1617-1620.

*Foulkes EC, McMullen DM. 1987. Kinetics of transepithelial movement of heavy metals in rat jejunum. Am J Physiol 253:G134-G138.

Fraker PJ, DePasquale-Jardien P, Zwickl CM, et al. 1978. Regeneration of T cell helper function in zinc deficient adult mice. Proc Nat Acad Sci 75:5660-5664. 
9. REFERENCES

Fraker PJ, Gershwin ME, Good RA, et al. 1986. Interrelationships between zinc and immune function. Fed Proc 45:1474-1479.

*Francis AJ, Dodge CJ. 1988. Anaerobic microbial dissolution of transitions and heavy metal oxides. Appl Environ Microbiol 54:1009-1014.

Francis AJ, Dodge CJ. 1990. Anaerobic microbial remobilization of toxic metals coprecipitated with iron oxide. Environ Sci Technol 24(3):373-378.

Frangides CY, Pneumatikos IA. 2002. Persistent severe hypoglycemia in acute zinc phosphide poisoning. Intensive Care Med 28:223.

Fraser JD, Urban RG, Strominger JL, et al. 1992. Zinc regulates the function of two superantigens. Proc Natl Acad Sci USA 89(12):5507-5511.

Freeland-Graves JH, Friedman BJ, Han W, et al. 1982. Effect of zinc supplementation on plasma highdensity lipoprotein and zinc. Am J Clin Nutr 35:988-992.

*Freeland-Graves JH, Han WH, Friedman BJ, et al. 1980. Effect of dietary $\mathrm{Zn} / \mathrm{Cu}$ ratios on cholesterol and HDL cholesterol levels in women. Nutr Rep Int 22:285-293.

Freeland-Graves JH, Lin PH. 1991. Plasma uptake of manganese as affected by oral loads of manganese, calcium, milk, phosphorus, copper, and zinc. J Am Coll Nutr 10(1):38-43.

Frenzel RW, Witmer GW, Starkey EE. 1990. Heavy metal concentrations in a lichen of Mt. Rainier and Olympic National Parks, Washington, USA. Bull Environ Contam Toxicol 44:158-164.

Frias-Espericueta MG, Osuna-Lopez JI, Sandoval-Salazar G, et al. 1999. Distribution of trace metals in different tissues in the rock oyster Crassostrea iridescens: Seasonal variation. Bull Environ Contam Toxicol 63:73-79.

Friel JK, Naake VL, Miller LV, et al. 1992. The analysis of stable isotopes in urine to determine the fractional absorption of zinc. Am J Clin Nutr 55(2):473-477.

FSTRAC. 1990. Summary of state and federal drinking water standards and guidelines. Federal-State Toxicology and Regulatory Alliance Committee, Washington, DC.

Fujiwara Y, Watanabe S, Sakamoto M, et al. 1998. Repair of wounded monolayers of cultured vascular endothelial cells after simultaneous exposure to lead and zinc. Toxicol Lett 94:181-188.

*Fytianos K, Katsianis G, Triantafyllou P, et al. 2001. Accumulation of heavy metals in vegetables grown in an industrial area in relation to soil. Bull Environ Contam Toxicol 67:423-430.

*Gachot T, Poujeol P. 1992. Effects of cadmium and copper on zinc transport kinetics by isolated renal proximal cells. Biol Trace Elem Res 35(2):93-103.

Gaither LA, Eide DJ. 2000. Functional expression of the human hZIP2 zinc transporter. J Biol Chem 275:5560-5564.

Gallery EDM, Blomfield J, Dixon SR. 1972. Acute zinc toxicity in haemodialysis. Br Med J 4:331-333. 
9. REFERENCES

Gallorini M, Pesavento M, Profumo A, et al. 1993. Analytical related problems in metal and trace elements determination in industrial waste landfill leachates. Sci Total Environ 133:285-298.

*Galloway WB, Lake JL, Phelps DK, et al. 1983. The mussel watch: Intercomparison of trace level constituent determinations. Environ Toxicol Chem 2:395-410.

*Galvez-Morros M, Garcia-Martinez O, Wright AJA, et al. 1992. Bioavailability in the rat of zinc and iron from the basic salts $\mathrm{Zn}_{5}(\mathrm{OH}) 8 \mathrm{Cl}_{2} \cdot \mathrm{H}_{2} \mathrm{O}, \mathrm{Fe}(\mathrm{OH}) \mathrm{SO}_{4}$ and $\mathrm{Fe}_{4}(\mathrm{OH}) 11 \mathrm{NO}_{3} \cdot 2 \mathrm{H}_{2} \mathrm{O}$. Food Chemistry 43(5):377-381.

Gamberg M, Braune BM. 1999. Contaminant residue levels in Artic wolves (Canis lupus) from the Yukon Territory, Canada. Sci Total Environ 243/244:329-338.

Gambrell RP. 1994. Trace and toxic metals in wetlands - a review. J Environ Qual 23:883-891.

*Gao S, Walker WJ, Dahlgren RA. 1997. Simultaneous sorption of Cd, Cu, Ni, Zn, Pb, and Cr on soils treated with sewage sludge supernatant. Water Air Soil Pollut 93:331-345.

Garcia R, Millan E. 1998. Assessment of $\mathrm{Cd}, \mathrm{Pb}$ and $\mathrm{Zn}$ contamination in roadside soils and grasses from Gipuzkoa (Spain). Chemosphere 37:1615-1625.

Gardner M. 1999. Dissolved phase speciation of zinc in the Humber Estuary. Chemosphere 38:21172124.

*Garrett RG. 2000. Natural sources of metals to the environment. Hum Ecol Risk Assess 6(6):945-963.

*Gartrell MJ, Craun JC, Podrebarac DS, et al. 1986a. Pesticides, selected elements, and other chemicals in adult total diet samples, October 1980 - March 1982. J Assoc Off Anal Chem 68:146-161.

Gartrell MJ, Craun JC, Podrebarac DS, et al. 1986b. Pesticides, selected elements, and other chemicals in infant and toddler total diet samples, October 1980 - March 1982. J Assoc Off Anal Chem 68:11841197.

Gasiorek K, Bauchinger M. 1981. Chromosome changes in human lymphocytes after separate and combined treatment with divalent salts of lead, cadmium and zinc. Environ Mutagen 3:513-518.

Gerhardsson L, Brune D, Nordberg GF, et al. 1988. Multielemental assay of tissues of deceased smelter workers and controls. Sci Total Environ 74:97-110.

*Gerhardsson L, Englyst V, Lundstrom NG, et al. 2002. Cadmium, copper and zinc in tissues of deceased copper smelter workers. J Trace Elem Med Biol 16(4):261-266.

*Gerritse RG, Vriesema R, Dalenberg JW, et al. 1982. Effect of sewage sludge on trace element mobility in soils. J Environ Qual 11:359-363.

Ghosh PB, Choudhury A. 1989. Copper, zinc and lead in the sediments of Hooghly Estuary. Environ Ecol 7:427-430.

*Gibbs RJ. 1994. Metals in the sediments along the Hudson River estuary. Environ Int 20:507-516. 
9. REFERENCES

Gibson RS, Ferguson EL. 1998. Nutrition intervention strategies to combat zinc deficiency in developing countries. Nutr Res Rev 11:115-131.

Giesy JP, Bowling JW, Kania HJ. 1980. Cadmium and zinc accumulation and elimination by freshwater crayfish. Arch Environ Contam Toxicol 9:637-697.

Gil MN, Harvey MA, Esteves JL. 1999. Heavy metals in intertidal surface sediments from the Patagonian Coast, Argentina. Bull Environ Contam Toxicol 63:52-58.

Gimenez A, Caballeria J, Pares A, et al. 1992. Influence of dietary zinc on hepatic collagen and prolyl hydroxylase activity in alcoholic rats. Hepatology 16(3):815-819.

*Giroux EL, Durieux M, Schechter PJ. 1976. A study of zinc distribution in human serum. Bioinorg Chem 5:211-218.

Giusquiani PL, Gigliotti G, Businelli D. 1992. Mobility of heavy metals in urban waste-amended soils. J Environ Qual 21:330-335.

*Giwercman A, Carlsen E, Keiding N, et al. 1993. Evidence for increasing incidence of abnormalities of the human testis: A review. Environ Health Perspect Suppl 101(2):65-71.

*Gocke E, King MT, Echardt K, et al. 1981. Mutagenicity of cosmetics ingredients licensed by the European Communities. Mutat Res 90:91-109.

Godfrey JC, Sloane BC, Smith DS, et al. 1992. Zinc gluconate and the common cold: A controlled clinical study. J Int Med Res 20(3):234-246.

Goering PL, Fowler BA. 1987. Kidney zinc-thionein regulation of delta-aminolevulinic acid dehydratase inhibition by lead. Arch Biochem Biophys 253(1):48-55.

Gokayama M, Koh J, Choi DW. 1986. Brief exposure to zinc is toxic to cortical neurons. Neurosci Lett 71:351-355.

Goldin A, Bigelow C, Veneman PLM. 1992. Concentrations of metals in ash from municipal solid waste combusters. Chemosphere 24(3):271-280.

*Golomb D, Ryan D, Eby N, et al. 1997. Atmospheric deposition of toxics onto Massachusetts Bay-I. Metals. Atmos Environ 31(9):1349-1359.

Gonsior SJ, Sorci JJ, Zoellner MJ, et al. 1997. The effects of EDTA on metal solubilization in river sediment/water systems. J Environ Qual 26:957-966.

Gonzalez H, Pomares M, Ramirez M, et al. 1999. Heavy metals in organisms and sediments from the discharge zone of the submarine sewage outfall of Havana City, Cuba. Mar Pollut Bull 38:1048-1051.

Gonzalez H, Ramirez M, Ablanedo N. 1991. Heavy metals in fish (Micropogonias furnieri) from Cienfuegos Bay, Cuba. Mar Pollut Bull 22:469-471.

Gonzalez J, Hernandez LM, Hernan A, et al. 1985. Multivariate analysis of water contamination by heavy metals at Donana National Park. Bull Environ Contam Toxicol 35:266-271. 
9. REFERENCES

*Goodwin FE. 1998. Zinc compounds. In: Kroschwitz J, Howe-Grant M, eds. Kirk-Othmer encyclopedia of chemical technology. New York, NY: John Wiley \& Sons, Inc., 840-853.

*Goodwin JS, Hunt WC, Hooper P, et al. 1985. Relationship between zinc intake, physical activity, and blood levels of high density lipoprotein cholesterol in a healthy elderly population. Metabolism 34(6):519-523.

*Gordon EF, Gordon RC, Passal DB. 1981. Zinc metabolism: Basic, clinical, and behavioral aspects. J Pediatr 99:341-349.

*Gordon T, Chen LC, Fine JM, et al. 1992. Pulmonary effects of inhaled zinc oxide in human subjects, guinea-pigs, rats, and rabbits. Am Ind Hyg Assoc J 53(8):503-509.

Gorlach U, Boutron CF. 1992. Variations in heavy metals concentrations in Antarctic snows from 1940 to 1980. J Atmos Chem 14:205-222.

Goyer RA. 1986. Toxic effects of metals. In: Klaassen CD, Amdur MD, Doull J, eds. Casarett and Doull's toxicology--the basic science of poisons. 3rd ed. New York, NY: Macmillan Publishing Co., 617-619.

*Greathouse DG, Osborne RH. 1980. Preliminary report on nationwide study of drinking water and cardiovascular diseases. J Environ Pathol Toxicol Oncol 4:65-76.

Greaves MW, Skillen AW. 1970. Effects of long-continued ingestion of zinc sulphate in patients with venous leg ulceration. Lancet ii:889-891.

*Greger JL, Baligar P, Abernathy RP, et al. 1978b. Calcium, magnesium, phosphorus, copper, and manganese balance in adolescent females. Am J Clin Nutr 31:117-121.

*Greger JL, Sickles VS. 1979. Saliva zinc levels: Potential indicators of zinc status. Am J Clin Nutr 32:1859-1866.

*Greger JL, Zaikis SC, Abernathy RP, et al. 1978a. Zinc, nitrogen, copper, iron and manganese balance in adolescent females fed two levels of zinc. J Nutr 108:1449-1456.

*Grider A, Bailey LB, Cousins RJ. 1990. Erythrocyte metallothionein as an index of zinc status in humans. Proc Natl Acad Sci USA 87:1259-1262.

Grimshaw DL, Lewin J, Fuge R. 1976. Seasonal and short-term variations in the concentration and supply of dissolved zinc to polluted aquatic environments. Environ Pollut 11:1-7.

Guenther K, Waldner H. 1992. Speciation of zinc and cadmium in ordinary vegetable foodstuffs. Anal Chim Acta 259(1):165-173.

Guidolin D, Polato P, Venturin G, et al. 1992. Correlation between zinc level in hippocampal mossy fibers and spatial memory in aged rats. Ann NY Acad Sci 673:187-193.

Gulmini M, Zelano V, Gastaldi D, et al. 1999. Cd, Cr, Cu, Fe, Mn, $\mathrm{Pb}$ and $\mathrm{Zn}$ content in sediments from the Venice lagoon. Ann Chim 89:267-277. 
Gumgum B, Unlu E, Tez Z, et al. 1994. Heavy metal pollution in water, sediment and fish from the Tigris River in Turkey. Chemosphere 29(1):111-116.

*Gundersen P, Steinnes E. 2003. Influence of $\mathrm{pH}$ and TOC concentration on $\mathrm{Cu}, \mathrm{Zn}, \mathrm{Cd}$, and $\mathrm{Al}$ speciation in rivers. Water Res 37:307-318.

*Gunn S, Gould TC, Anderson WAD. 1963a. Cadmium-induced interstitial cell tumors in rats and mice and their prevention by zinc. J Natl Cancer Inst 31:745-759.

Gunn SA, Gould TC, Anderson WAD. 1963b. The selective injurious response of testicular and epididymal blood vessels to cadmium and its prevention by zinc. Am J Pathol 42:685-702.

*Gunn S, Gould TC, Anderson WAD. 1964. Effect of zinc on cancerogenesis by cadmium. Proc Soc Exp Biol Med 115:653-657.

Gunshin H, Mackenzie B, Berger U, et al. 1997. Cloning and characterization of a mammalian protoncoupled metal-ion transporter. Nature 388:482-488.

*Gunshin H, Noguchi T, Naito H. 1991. Effect of calcium on the zinc uptake by brush-border membrane vesicles isolated from the rat small intestine. Agric Biol Chem 35(11):2813-2816.

Gunson DE, Kowalczyk DF, Shoop CR, et al. 1982. Environmental zinc and cadmium pollution associated with generalized osteochondrosis, osteoporosis, and nephrocalcinosis in horses. J Am Vet Med Assoc 180:295-299.

*Gunther T, Gossrau R, Vormann J, et al. 1991. Protection against salicylate-induced hepatic injury by zinc: A histochemical and biochemical study. Histochem J 23(2):75-82.

Gupta S, Pandey S, Misra V, et al. 1986. Effect of intratracheal injection of zinc oxide dust in guinea pigs. Toxicology 38:197-202.

*Gupta T, Talukder G, Sharma A. 1991. Cytotoxicity of zinc chloride in mice in vivo. Biol Trace Elem Res 30:95-101.

*Guthrie J. 1956. Attempts to produce seminomata in the albino rat by inoculation of hydrocarbons and other carcinogens into normally situated and ectopic testes. Br J Cancer 10:134-144.

*Guy RD, Chakrabarti CL. 1976. Studies of metal-organic interactions in model systems pertaining to natural waters. Can J Chem 54:2600-2611.

Guy RD, Chakrabarti CL, Schramm LL. 1975. The application of a simple chemical model of natural waters to metal fixation in particulate matter. Can J Chem 53:661-669.

*Guzelian PS, Henry CJ, Olin SS, eds. 1992. Similarities and differences between children and adults: Implications for risk assessment. Washington, DC: International Life Sciences Institute Press.

*Gyorffy EJ, Chan H. 1992. Copper deficiency and microcytic anemia resulting from prolonged ingestion of over-the-counter zinc. Am J Gastroenterology 87(8):1054-1055.

Habib FK, Hammond GL, Lee IR, et al. 1976. Metal-androgen interrelationships in carcinoma and hyperplasia of the human prostate. J Endocr 71:133-141. 
9. REFERENCES

*Haines RC. 1984. Environmental contamination-surveys of heavy metals in urban soils and hazard assessment. Trace Substances in Environmental Health 18:450-460.

*Hale JG. 1977. Toxicity of metal mining wastes. Bull Environ Contam Toxicol 17:66-73.

*Hale WE, May FE, Thomas RG, et al. 1988. Effect of zinc supplementation on the development of cardiovascular disease in the elderly. Journal of Nutrition for the Elderly 8(2):49-57.

*Hallbook T, Lanner E. 1972. Serum-zinc and healing of venous leg ulcers. Lancet ii:780-782.

*Hallmans G. 1977. Treatment of burns with zinc tape: A study of local absorption of zinc in humans. Scand J Plast Reconstr Surg 11:155-161.

*Halme E. 1961. On the carcinogenic effect of drinking water containing zinc. Vitalstoffe 6:59-66.

Hambidge M, Krebs NF. 2001. Interrelationships of key variables of human zinc homeostasis:

Relevance to dietary zinc requirements. Annu Rev Nutr 21:429-452.

Hambidge KM, Casey CE, Krebs NF. 1986. Zinc. In: Mertz W, ed. Trace elements in human and animal nutrition. Vol. 2, 5th ed. New York, NY: Academic Press, 1-137.

*Hambidge KM, Hambidge C, Jacobs M, et al. 1972. Low levels of zinc in hair, anorexia, poor growth and hypogeusia in children. Pediatr Res 6:868-874.

*Hambidge M, Hackshaw A, Wald N. 1993. Neural tube defects and serum zinc. Br J Obstet Gynaecol 100:746-749.

*Hamdi EA. 1969. Chronic exposure to zinc of furnace operators in a brass foundry. Br J Ind Med 26:126-134.

*Hamilton DL, Bellamy JEC, Valberg JD, et al. 1978. Zinc, cadmium, and iron interactions during intestinal absorption in iron-deficient mice. Can J Physiol Pharmacol 56:384-389.

Hammock D, Huang CC, Mort G, et al. 2003. The effect of humic acid on the uptake of mercury(II), cadmium(II), and zinc(II) by Chinook salmon (Oncorhynchus tshawytscha) eggs. Arch Environ Contam Toxicol 44:83-88.

*Hammond JW. 1944. Metal fume fever in crushed stone industry. J Ind Hyg Toxicol 26:117-119.

Hanna LA, Peters JM, Wiley LM, et al. 1997. Comparative effects of essential and nonessential metals on preimplantation mouse embryo development in vitro. Toxicology 116(1-3):123-131.

Hansen JDL, Lehmann BH. 1969. Serum zinc and copper concentrations in children with protein calorie malnutrition. S Afr Med J 43:1248-1250.

Hansen M, Samman S, Madsen LT, et al. 2001. Folic acid enrichment of bread does not appear to affect zinc absorption in young women. Am J Clin Nutr 74:125-129.

Hantson P, Lievens M, Mahieu P. 1996. Accidental ingestion of a zinc and copper sulfate preparation. J Toxicol Clin Toxicol 34(6):725-730. 
9. REFERENCES

Hardiman S, Pearson B. 1995. Heavy metals, TBT and DDT in the sydney rock oyster (Saccostrea commercialis) sampled from the Hawkesbury River Estuary, NSW, Australia. Mar Pollut Bull 30:563567.

Harding LE, Harris ML, Elliott JE. 1998. Heavy and trace metals in wild mink (Mustela vison) and river otter (Lontra canadensis) captured on rivers receiving metals discharges. Bull Environ Contam Toxicol 61:600-607.

*Harford C, Sarkar B. 1991. Induction of metallothionein by simultaneous administration of cadmium(II) and zinc(II). Biochem Biophys Res Commun 177(1):224-228.

Harrison RM, Williams CR. 1981. Characterization of airborne heavy metals within a primary zinc-lead smelting works. Environ Sci Technol 15:1197-1204.

Harrison SE, Klaverkamp JF. 1990. Metal contamination in liver and muscle of northern pike (Esox lucius) and white sucker (Catostomus commersoni) from lakes near the smelter at Flin Flon, Manitoba. Environ Toxicol Chem 9:941-956.

Harrison WW, Yurachek JP, Benson CA. 1969. The determination of trace elements in human hair by atomic absorption spectroscopy. Clin Chim Acta 23:83-91.

Hartsfield JK, Lee MY, Morel JG, et al. 1992. Statistical analysis of the effect of cadmium and zinc on hamster teratogenesis. Biochem Med Metab Biol 48(2):159-173.

Hartwell TD, Handy RW, Harris BS, et al. 1983. Heavy metal exposure in populations living around zinc and copper smelters. Arch Environ Health 38:284-295.

Hassan HA, Netchvolodoff C, Raufman JP. 2000. Zinc-induced copper deficiency in a coin swallower. Am J Gastroenterol 95(10):2975-2977.

Hatayama T, Tsukimi Y, Wakatsuki T, et al. 1992. Characteristic induction of 70000-DA-heat shock protein and metallothionein by zinc in HELA-cells. Mol Cell Biochem 112(2):143-153.

*Hayashi M, Yamamoto K, Yoshimura M, et al. 1993. Cadmium, lead, and zinc concentrations in human fingernails. Bull Environ Contam Toxicol 50(4):547-553.

Haynes D, Johnson JE. 2000. Organochlorine, heavy metal and polyaromatic hydrocarbon pollutant concentrations in the Great Barrier Reef (Australia) environment: A review. Mar Pollut Bull 41:267-278.

*HazDat. 2005. HazDat Database: ATSDR's Hazardous Substance Release and Health Effects Database. Atlanta, GA: Agency for Toxic Substances and Disease Registry. www.atsdr.cdc.gov/hazdat.html. April 28, 2005.

*He LS, Yan XS, Wu DC. 1991. Age-dependent variation of zinc-65 metabolism in LACA mice. Int J Radiat Biol 60(6):907-916.

*He XT, Logan TJ, Traina SJ. 1995. Physical and chemical characteristics of selected U.S. municipal solid waste composts. J Environ Qual 24:543-552. 
9. REFERENCES

Headley AD. 1996. Heavy metal concentrations in peat profiles from the high arctic. Sci Total Environ 177:105-111.

*Heaton RW, Rahn KA, Lowenthal DH. 1990. Determination of trace elements, including regional tracers, in Rhode Island precipitation. Atmos Environ 24A:147-153.

Hedges JD, Kornegay ET, Thomas HR. 1976. Comparison of dietary zinc levels for reproducing sows and the effect of dietary zinc and calcium on the subsequent performance of their progeny. J Anim Sci 43:453-463.

Hegsted DM, McKibbin JM, Drinker CK. 1945. U.S. public health report. Washington, DC: U.S. Government Printing Office, Suppl 179.

*Hegstrom LJ, West SD. 1989. Heavy metal accumulation in small mammals following sewage sludge application to forests. J Environ Qual 18:345-349.

*Heijerick DG, De Schamphelaere KAC, Janssen CR. 2002a. Biotic ligand model development predicting $\mathrm{Zn}$ toxicity to the alga Pseudokirchneriella subcapitata: Possibilities and limitations. Comp Biochem Physiol C 133:207-218.

Heijerick DG, De Schamphelaere KAC, Janssen CR. 2002b. Predicting acute zinc toxicity for Daphnia magna as a function of key water chemistry characteristics: Development and validation of a biotic ligand model. Environ Toxicol Chem 21(6):1309-1315.

*Heiny JS, Tate CM. 1997. Concentration, distribution, and comparison of selected trace elements in bed sediment and fish tissue in the South Platte River Basin, USA, 1992-1993. Arch Environ Contam Toxicol 32:246-259.

*Heit M, Klusek CS. 1985. Trace element concentrations in the dorsal muscle of white suckers and brown bullheads from two acidic Adirondack lakes. Water Air Soil Pollut 25:87-96.

*Heit M, Klusek C, Baron J. 1984. Evidence of deposition of anthropogenic pollutants in remote Rocky Mountain lakes. Water Air Soil Pollut 22:403-416.

*Heit M, Schofield C, Driscoll CT, et al. 1989. Trace element concentrations in fish from three Adirondack lakes with different pH values. Water Air Soil Pollut 44:9-30.

*Hellou J, Warren WG, Payne JF, et al. 1992. Heavy metals and other elements in three tissues of cod, Gadus morhua from the Northwest Atlantic. Mar Pollut Bull 24(9):452-458.

*Helmers E, Schrems O. 1995. Wet deposition of metals to the tropical north and the south Atlantic ocean. Atmos Environ 29:2475-2484.

*Helz GR, Huggett RJ, Hill JM. 1975. Behavior of Mn, Fe, Cu, Zn, Cd, and Pb discharged from a wastewater treatment plant into an estuarine environment. Water Res 9:631-636.

*Hempe JM, Cousins RJ. 1991. Cysteine-rich intestinal protein binds zinc during transmucosal zinc transport. Proc Nat Acad Sci 88(121):9671-9674.

*Hempe JM, Cousins RJ. 1992. Cysteine-rich intestinal protein and intestinal metallothionein: An inverse relationship as a conceptual model for zinc absorption in rats. J Nutr 122(1):89-95. 
Henderson LM, Brewer GJ, Dressman JB, et al. 1996. Use of zinc tolerance test and 24-hour urinary zinc content to assess oral zinc absorption. J Am Coll Nutr 15(1):79-83.

Hendriks AJ, Pieters H, Deboer J. 1998. Accumulation of metals, polycyclic (halogenated) aromatic hydrocarbons, and biocides in zebra mussel and eel from the Rhine and Meuse Rivers. Environ Toxicol Chem 17:1885-1898.

*Henkin RI. 1974. Metal-albumin-amino acid interactions: Chemical and physiological interrelationships. In: Friedman M, ed. Chemical and physiological interrelationships in protein-metal interactions. New York, NY: Plenum Press, 299-328.

Henkin RI, Aamodt RL. 1983. A redefinition of zinc deficiency. In: Inglett G, ed. The nutritional bioavailability of zinc. Washington, DC: American Chemical Society, 83-105.

Henkin RI, Aamodt RL, Agarwal RP, et al. 1982. The role of zinc in taste and smell. In: Prasad AS, ed. The clinical, biochemical and nutritional aspects of trace elements. New York, NY: Alan/Liss, 161-188.

*Henkin RI, Mueller CW, Wolf RO. 1975a. Estimation of zinc concentration of parotid saliva by flameless atomic absorption spectrophotometry in normal subjects and in patients with idiopathic hypogeusia. J Lab Clin Med 86:175-180.

*Henkin RI, Patten BM, Re PK, et al. 1975b. A syndrome of acute zinc loss: Cerebellar dysfunction, mental changes, anorexia, and taste and smell dysfunction. Arch Neurol 32:745-751.

*Henkin RI, Schechter PH, Friedewald WT, et al. 1976. A double blind study of the effects of zinc sulfate on taste and smell dysfunction. Am J Med Sci 272:285-299.

*Henry JB, ed. 1984. Clinical diagnosis and management by laboratory methods. Philadelphia, PA: WB Saunders Company, 162-163, 1437, 1442.

Hentz LH, Johnson FB, Baturay A. 1992. Air emission studies of sewage sludge incinerators at the Western Branch wastewater treatment plant. Water Environ Res 64(2):111-119.

Henzel JH, DeWeese MS, Lichti, EL. 1970. Zinc concentrations within healing wounds. Arch Surg 100:349-357.

*Henzel JH, Keitzer FW, Lichti EL, et al. 1971. Efficacy of zinc medication as a therapeutic modality in atherosclerosis: Followup observations on patients medicated over prolonged periods. In: Hemphill DD, ed. Trace Substances in Environmental Health 2:336-341.

Herawati N, Rivai IF, Koyama H, et al. 1998a. Zinc levels in rice and in soil according to the soil types of Japan, Indonesia and China. Bull Environ Contam Toxicol 60:402-408.

Herawati N, Suzuki S, Hayashi K, et al. 2000. Cadmium, copper, and zinc levels in rice and soil of Japan, Indonesia, and China by soil type. Bull Environ Contam Toxicol 64:33-39.

*Hermann R, Neumann-Mahlkau P. 1985. The mobility of zinc, cadmium, copper, lead, iron and arsenic in ground water as a function of redox potential and pH. Sci Total Environ 43:1-12. 
Hermanson MH. 1991. Chronology and sources of anthropogenic trace metals in sediments from small, shallow arctic lakes. Environ Sci Technol 25:2059-2064.

Hermanson MH. 1993. Historical accumulation of atmospherically derived pollutant trace metals in the arctic as measured in dated sediment cores. Water Sci Technol 28(8-9):33-41.

*Hesterberg D, Sayers DE, Zhou W, et al. 1997. X-ray absorption spectroscopy of lead and zinc speciation in a contaminated groundwater aquifer. Environ Sci Technol 31:2840-2846.

*Heth DA, Hoekstra WG. 1965. Zinc-65 absorption and turnover in rats: Part I. A procedure to determine zinc-65 absorption and the antagonistic effect of calcium in a practical diet. J Nutr 85:367-374.

*Hewitt PJ. 1988. Accumulation of metals in the tissues of occupationally exposed workers. Environ Geochem Health 10:113-116.

Hidalgo J, Giralt M, Garvey JS, et al. 1991. Effect of morphine administration on rat liver metallothionein and zinc metabolism. J Pharmacol Exp Ther 259(1):274-278.

Hill CH, Matrone G. 1970. Zinc susceptibility greater in animals fed a low copper diet. Fed Proc Am Soc Exp Biol 29:1474.

*Hill GM, Brewer GJ, Hogikyan ND, et al. 1984. The effect of depot parenteral zinc on copper metabolism in the rat. J Nutr 114:2283-2291.

Hill GM, Miller ER, Stowe HD. 1983. Effect of dietary zinc levels on health and productivity of gilts an sows through two parities. J Anim Sci 57:114-122.

*Hiller R, Seigel D, Sperduto RD, et al. 1995. Serum zinc and serum lipid profiles in 778 adults. Ann Epidemiol 5:490-496.

Hirai M, Nomiyama H, Nomiyama K. 1992. Persistent anorexia in rabbits given a large dose of intravenous zinc sulfate. Biomed Res Trace Elem 3(3):313-318.

*Hirano S, Higo S, Tsukamoto N, et al. 1989. Pulmonary clearance and toxicity of zinc oxide instilled into the rat lung. Arch Toxicol 63:336-342.

Hirose K. 1990. Chemical speciation of trace metals in seawater: Implication of particulate trace metals. Mar Chem 28:267-274.

Hitchcock DR, Thomas BR. 1992. Some trace metals in sediments from Cardiff Bay, UK. Mar Pollut Bull 24:464-466.

*Hjortso E, Quist J, Bud M, et al. 1988. ARDS after accidental inhalation of zinc chloride smoke. Intensive Care Med 14:17-24.

Ho MH, Dillon HK. 1986. Biological monitoring. Environ Sci Technol 20:124-127.

*Hoel DG, Davis DL, Miller AB, et al. 1992. Trends in cancer mortality in 15 industrialized countries, 1969-1986. J Natl Cancer Inst 84(5):313-320. 
9. REFERENCES

*Hoffman HN II, Phyliky RL, Fleming CR. 1988. Zinc-induced copper deficiency. Gastroenterology 94:508-512.

Hogan GR, Cole BS, Lovelaie JM. 1987. Sex and age mortality responses in zinc acetate treated mice. Bull Environ Contam Toxicol 39:156-161.

*Homma S, Jones R, Qvist J, et al. 1992. Pulmonary vascular lesions in the adult respiratory distress syndrome caused by inhalation of zinc chloride smoke: A morphometric study. Hum Pathol 23(1):45-50.

*Honda R, Tawara K, Nishijo M, et al. 2003. Cadmium exposure and trace elements in human breast milk. Toxicology 186(3):255-259.

Hong S, Boutron CF, Edwards R, et al. 1998. Heavy metals in antarctic ice from law dome: Initial results. Environ Res 78:94-103.

*Hooper PL, Visconti L, Garry PJ, et al. 1980. Zinc lowers high-density lipoprotein-cholesterol levels. JAMA 244:1960-1961.

Horng CJ, Lin SR. 1997. Determination of urinary zinc, chromium, and copper in steel production workers. Biol Trace Elem Res 55(3):307-314.

Hortz C, Lowe NM, Araya M, et al. 2003. Assessment of the tract element status of individuals and populations: The example of zinc and copper. J Nutr 133(5):1563S-1568S.

*Houba C, Remacle J, Dubois D, et al. 1983. Factors affecting the concentrations of cadmium, zinc, copper and lead in the sediments of the Vesdre River. Water Res 17:1281-1286.

Houston S, Haggard J, Williford J, et al. 2001. Adverse effects of large-dose zinc supplementation in an institutionalized older population with pressure ulcers. J Am Geriatr Soc 49:1130-1132.

*HSDB. 1986. Hazardous Substances Data Bank. National Library of Medicine, National Toxicology Information Program, Bethesda, MD.

*HSDB. 1990. Hazardous Substances Data Bank. National Library of Medicine, National Toxicology Information Program, Bethesda, MD.

HSDB. 1993. Hazardous Substances Data Bank. National Library of Medicine, National Toxicology Information Program, Bethesda, MD.

*HSDB. 2003. Zinc. Environmental standards and regulations. Bethesda, MD: Hazardous Substances Data Bank. http://toxnet.nlm.nih.gov/cgi-bin/sis/htmlgen?HSDB.htm. June 6, 2003.

*Hsu FS, Krook L, Pond WG, et al. 1975. Interactions of dietary calcium with toxic levels of lead and zinc in pigs. J Nutr 105:112-118.

*Hu HL, Chen RD, Ma LH. 1992. Protective effect of zinc on liver injury induced by D-galactosamine in rats. Biol Trace Elem Res 34(1):27-33.

Huang YJ, Gulson BL. 2002. Selenium in soils, spermatophytes and bryophytes around a $\mathrm{Zn}-\mathrm{Pb}$ smelter, New South Wales, Australia. Sci Total Environ 293:129-141. 
Huerta P, Blanco MD, Olmo R, et al. 1991. Evolution of weight and zinc level in thymus and spleen of rats after zinc treatment. Toxicol Environ Chem 33(3-4):231-237.

*Hunt J. 2003. Bioavailability of iron, zinc and other trace minerals from vegetarian diets. Am J Clin Nutr 78(3):633S-639S.

Hunt CD, West DA, Lewis DA. 1994. Trace metals concentrations in New York/New Jersey harbor. Hazard Ind Wastes 26:691-698.

*Hunt JR, Lykken GI, Mullen Lk. 1991. Moderate and high amounts of protein from casein enhance human absorption of zinc from whole-wheat or white rolls. Nutr Res 11(5):413-418.

Hunt JR, Matthys LA, Johnson LK. 1998. Zinc absorption, mineral balance, and blood lipids in women consuming controlled lactoovovegetarian and omniverous diets for $8 \mathrm{wk}$. Am J Clin Nutr 67:421-430.

*Hutchinson F, Wai CM. 1979. Cadmium, lead, and zinc in reclaimed phosphate mine waste dumps in Idaho. Bull Environ Contam Toxicol 23:377-380.

Hwang S-J, Chang S-C, Lee SC, et al. 1999. Short-and long-term uses of calcium acetate do not change hair and serum zinc concentrations in hemodialysis patients. Scand J Clin Lab Invest 59:83-88.

*ICF. 1986. Development of soil: Water distribution coefficients for LLM inorganic chemicals (draft). Washington, DC.

Igic PG, Lee E, Harper W, et al. 2002. Toxic effects associated with consumption of zinc. Mayo Clin Proc 77:713-716.

*Injuk J, Otten P, Laane R, et al. 1992. Atmospheric concentrations and size distributions of aircraftsampled $\mathrm{Cd}, \mathrm{Cu}, \mathrm{Pb}$ and $\mathrm{Zn}$ over the Southern Bight of the North Sea. Atmos Environ 26A(14):24992508.

Injuk J, Vangrieken R. 1995. Atmospheric concentrations and deposition of heavy metals over the North Sea: A literature review. J Atmos Chem 20:179-212.

*IOM. 2002. Dietary reference intakes for vitamin A, vitamin K, arsenic, boron, chromium, copper, iodine, iron, manganese, molybdenum, nickel, silicon, vanadium, and zinc. Institute of Medicine. Food and Nutrition Board, NRC. Washington, DC: National Academy Press, 442-501.

*IRIS. 2003. Zinc and compounds. Washington, DC: Integrated Risk Information System. http://www.epa.gov/iris/. June 6, 2003.

*Istfan NW, Janghorbani M, Young VR. 1983. Absorption of stable ${ }^{70} \mathrm{Zn}$ in healthy young men in relation to zinc intake. Am J Clin Nutr 38:187-194.

Itoh M, Ebadi M. 1982. The selective inhibition of hippocampal glutamic acid decarboxylase in zincinduced epileptic seizures. Neurochem Res 7:1287-1289.

Jackson BP, Allen PLS, Hopkins WA, et al. 2002. Trace element speciation in largemouth bass (Micropterus salmoides) from a fly ash settling basin by liquid chromatography-ICP-MS. Anal Bioanal Chem 374:203-211. 
Jackson MJ, Lowe NM. 1992. Physiological role of zinc. Food Chem 43(3):233-238.

Jain CK, Ram D. 1997. Adsorption of lead and zinc on bed sediments of the river Kali. Water Res 31(1):154-162.

Jalla S, Westcott J, Steirn M, et al. 2002. Zinc absorption and exchangeable zinc pool sizes in breast-fed infants fed meat or cereal as first complementary food. J Pediatr Gastroenterol Nutr 34:35-41.

*Janghorbani M, Ting BTG, Istfan NW, et al. 1981. Measurement of ${ }^{68} \mathrm{Zn}$ and ${ }^{70} \mathrm{Zn}$ in human blood in reference to the study of zinc metabolism. Am J Clin Nutr 34:581-591.

Jansen RAG, Vanleeuwen HP, Cleven RFMJ, et al. 1998. Speciation of lability of zinc(II) in river waters. Environ Sci Technol 32:3882-3886.

*Janssen RPT, Peijnenburg WJGM, Posthuma L, et al. 1997. Equilibrium partitioning of heavy metals in Dutch field soils. I. Relationship between metal partition coefficients and soil characteristics. Environ Toxicol Chem 16:2470-2478.

Jehan ZS, Motlag DB. 1995. Metal induced changes in the erythrocyte membrane of rats. Toxicol Lett 78(2):127-133.

Jeng MS, Jeng WL, Hung TC, et al. 1999. Mussel watch: a review of cu and other metals in various marine organisms in Taiwan, 1991-98. Environ Pollut 110:1-9.

*Jenkins RA. 1986. Occurrence of selected metals in cigarette tobaccos and smoke. IARC Sci Publ 71:129-141.

*Jenkins KJ, Hidiroglou M. 1991. Tolerance of the preruminant calf for excess manganese or zinc in milk replacer. J Dairy Sci 74:1047-1053.

Jenkins KJ, Kramer JKG. 1992. Changes in lipid composition of calf tissues by excess dietary zinc. J Dairy Sci 75(5):1313-1319.

Jiang QG, Sun JG, Qin XF. 1991. The effects of trinitrotoluene toxicity on zinc and copper metabolism. Toxicol Lett 55(3):343-349.

Jickells TD, Davis TD, Tranter M, et al. 1992. Trace elements in snow samples from the Scottish highlands: Sources and dissolved/particulate distributions. Atmos Environ 26a:393-401.

Jin X, Cheung YY. 1991. Determination of trace manganese, cobalt, nickel, copper, zinc, arsenic, molybdenum and strontium in cabbage, turnip, soya beans and soil by inductively coupled plasma mass spectrometry. Fenxi Huaxue 19(4):430-432.

Johansen P, Hansen MM, Asmund G, et al. 1991. Marine organisms as indicators of heavy metal pollution: Experience from 16 years of monitoring at a lead-zinc mine in Greenland. Chem Ecol 5(12):35-55.

*Johanson CE. 1980. Permeability and vascularity of the developing brain: Cerebellum vs cerebral cortex. Brain Res 190:3-16. 
*John W, Kaifer R, Rahn K, et al. 1973. Trace element concentrations in aerosols from the San Francisco Bay Area. Atmos Environ 7:107-118.

*Johnson PE. 1982. A mass spectrometric method for use of stable isotopes as tracers in studies of iron, zinc, and copper absorption in human subjects. J Nutr 112:1414-1424.

*Johnson A, Norton D, Yake B, et al. 1990. Transboundary metal pollution of the Columbia River (Franklin D. Roosevelt Lake). Bull Environ Contam Toxicol 45:703-710.

*Johnson FA, Stonehill RB. 1961. Chemical pneumonitis from inhalation of zinc chloride. Dis Chest 40:619-624.

*Johnson MA, Flagg EW. 1986. Effects of sucrose and cornstarch on the development of copper deficiency in rats fed high levels of zinc. Nutr Res 6:1307-1319.

Johnson PE, Hunt CD, Milne DB, et al. 1993. Homeostatic control of zinc metabolism in men: Zinc excretion and balance in men fed diets low in zinc. Am J Clin Nutr 57:557-565.

*Johnson PE, Hunt JR, Ralston NV. 1988. The effect of past and current dietary Zn intake on Zn absorption and endogenous excretion in the rat. J Nutr 118:1205-1209.

*Jolly JH. 1988. Zinc: 1988. Minerals yearbook. Vol. 1. Washington, DC: U.S. Bureau of Mines, Department of Interior, 1019-1048.

*Jones R, Burgess MSE. 1984. Zinc and cadmium in soils and plants near electrical transmission (hydro) towers. Environ Sci Technol 18(10):731-734.

Jones R, Prohaska KA, Burgess MSE. 1988. Zinc and cadmium in corn plants growing near electrical transmission towers. Water Air Soil Pollut 37:355-363.

*Jop KM, Biever RC, Hoberg JR, et al. 1997. Analysis of metals in blue crabs, Callinectes sapidus, from two Connecticut estuaries. Bull Environ Contam Toxicol 58:311-317.

*Jürgensen H, Behne D. 1977. Variations in trace element concentrations in human blood serum in the normal state investigated by instrumental neutron activation analysis. Journal of Radioanalytical Chemistry 37:375-382.

*Kabala C, Singh BR. 2001. Fractionation and mobility of copper, lead, and zinc in soil profiles in the vicinity of a copper smelter. J Environ Qual 30:485-492.

*Kada J, Heit M. 1992. The inventories of anthropogenic lead, zinc, arsenic, cadmium, and the radionuclides ${ }^{137} \mathrm{Cs}$ and excess ${ }^{210} \mathrm{~Pb}$ in lake sediments of the Adirondack region, USA. Hydrobiologia 246(3):231-241.

*Kadiiska M, Stoytchev T, Serbinova E. 1985. Effect of some heavy metal salts on hepatic monooxygenases after subchronic exposure. Arch Toxicol Suppl 8:313-315.

Kafka Z, Kuras M. 1997. Heavy metals in soils contaminated from different sources. Ecological issues and environmental impact assessment, 175-180. 
9. REFERENCES

Kalas JA, Ringsby TH, Lierhagen S. 1995. Metals and selenium in wild animals from Norwegian areas close to Russian nickel smelters. Environ Monit Assess 36:251-270.

Kalay M, Ay O, Canli M. 1999. Heavy metal concentrations in fish tissues from the northeast Mediterranean Sea. Bull Environ Contam Toxicol 63:673-681.

*Kalbasi M, Racz GJ, Lewen-Rudgers LA. 1978. Reaction products and solubility of applied zinc compounds in some Manitoba soils. Soil Sci 125:55-64.

*Kaminski MD, Landsberger S. 2000a. Heavy metals in urban soils of east St. Louis, Illinois. Part 1: Total concentration of heavy metals in soils. J Air Waste Manage Assoc 50:1667-1679.

*Kaminski MD, Landsberger S. 2000b. Heavy metals in urban soils of east St. Louis, Illinois. Part II: Leaching characteristics and modeling. J Air Waste Manage Assoc 50:1680-1687.

Karathanasis AD. 1999. Subsurface migration of copper and zinc mediated by soil colloids. Soil Sci Soc Am J 63(4):830-838.

Karvelas M, Katsoyiannis A, Samara C. 2003. Occurence and fate of heavy metals in the wastewater treatment process. Chemosphere 53:1201-1210.

Kashulin NA, Ratkin NE, Pauvalter VA, et al. 2001. Impact of airborne pollution of the drainage area of subarctic lakes and fish. Chemosphere 42:51-59.

*Kasprzak KS, Kovatch RM, Poirier LA. 1988. Inhibitory effect of zinc on nickel subsulfide carcinogenesis in Fischer rats. Toxicology 52:253-262.

*Katya-Katya M, Ensminger A, Mèjean L, et al. 1984. The effect of zinc supplementation on plasma cholesterol levels. Nutr Res 4:633-638.

*Kazacos EA, Van Vleet JF. 1989. Sequential ultrastructural changes of the pancreas in zinc toxicosis in ducklings. Am J Pathol 134:581-595.

Kececi T, Keskin E. 2002. Zinc supplementation decreases total thyroid hormone concentration in small ruminants. Acta Vet Hung 50:93-100.

*Keen CL, Hurley LS. 1977. Zinc absorption through skin: Correction of zinc deficiency in the rat. Am J Clin Nutr 30:528-530.

Keen CL, Uriu-Hare JY, Hawk SN, et al. 1998. Effect of copper deficiency on prenatal development and pregnancy outcome. Am J Clin Nutr 67:1003S-1011S.

Kelland EE, Kelly MD, Toms NJ. 2004. Pyruvate limits zinc-induced rat oligodendrocyte progenitor cell death. Eur J Neurosci 19(2):287-294.

Kelly EJ, Quaife CJ, Froelick GJ, et al. 1996. Metallothionein I and II protect against zinc deficiency and zinc toxicity in mice. J Nutr 126:1782-1790.

Kelly JJ, Tate RL. 1998. Effects of heavy metal contamination and remediation on soil microbial communities in the vicinity of a zinc smelter. J Environ Qual 27:609-617. 
*Ketcheson MR, Barron GP, Cox DH. 1969. Relationship of maternal dietary zinc during gestation and lactation to development and zinc, iron, and copper content of the postnatal rat. J Nutr 98:303-311.

Khan AT, Atkinson A, Graham TC, et al. 2000. A preliminary study on the reproductive capability of rats treated with zinc chloride. Toxicologist 54:369-370.

*Khan AT, Atkinson A, Graham TC, et al. 2001a. A preliminary study on the reproductive capability of mice treated with zinc chloride. Toxicologist 60:110.

*Khan AT, Atkinson A, Graham TC, et al. 2001b. Effects of low levels of zinc on reproductive performance of rats. Environ Sci (Tokyo) 8:367-381.

*Khwaja HA, Brudnoy S, Husain L. 1995. Chemical characterization of three summer cloud episodes at Whiteface Mountain. Chemosphere 31:3357-3381.

Kim BJ, Kim YH, Kim S, et al. 2000. Zinc as a paracrine effector in pancreatic islet cell death. Diabetes 49:367-372.

Kim EY, Goto R, Tanabe S, et al. 1998. Distribution of 14 elements in tissues and organs of oceanic seabirds. Arch Environ Contam Toxicol 35:638-645.

Kim J, Paik HY, Joung H, et al. 2003. Effects of dietary phyate and supplemental zinc on zinc absorption in young Korean women. FASEB J 17(4-5):A301.

King JC. 1986. Assessment of techniques for determining human zinc requirements. J Am Diet Assoc 86(11):1523-1528.

*King JC. 2000. Determinants of maternal zinc status during pregnancy. Am J Clin Nutr 71:1334S$1343 \mathrm{~S}$.

King JC. 2001. Effect of reproduction on the bioavailability of calcium, zinc and selenium. J Nutr 131:1355S-1358S.

*Kinnamon KE. 1963. Some independent and combined effects of copper, molybdenum, and zinc on the placental transfer of zinc-65 in the rat. J Nutr 81:312-320.

Kirby J, Maher W, Krikowa F. 2001. Selenium, cadmium, copper, and zinc concentrations in sediments and mullet (Mugil cephalus) from the southern basin of Lake Macquarie, NSW, Australia. Arch Environ Contam Toxicol 40:246-256.

*Kirchgessner M, Roth HP, Weigand E. 1976. Biochemical changes in zinc deficiency. In: Prasad AS, ed. Trace elements in human health and disease. New York, NY: Academic Press, 1:189-225.

*Klevay LM, Hyg SD. 1973. Hypercholesterolemia in rats produced by an increase in the ratio of zinc to copper ingested. Am J Clin Nutr 26:1060-1068.

Klucik I, Koprda J. 1979. Hypocalcaemia in subjects after long-term exposure to zinc oxide. Prac Lek 31(6):234-237. 
Knudsen E, Jensen M, Solgaard P, et al. 1995. Zinc absorption estimated by fecal monitoring of zinc stable isotopes validated by comparison with whole-body retention of zinc radioisotopes in humans. $\mathrm{J}$ Nutr 125:1274-1282.

Kodavanti UP, Schladweiler MCJ, Ledbetter AD, et al. 2002. Pulmonary and systemic effects of zinccontaining emission particles in three rat strains: Multiple exposure scenarios. Toxicol Sci 70:73-85.

*Komori M, Nishio K, Kitada M, et al. 1990. Fetus-specific expression of a form of cytochrome P-450 in human livers. Biochemistry 29:4430-4433.

Kordas K, Lopez P, Rosado JL, et al. 2003. Effects of iron and zinc supplementation on cognitive function of lead-exposed Mexican children. FASEB J 17(4-5):A1100.

Kosman DJ, Henkin RI. 1981. Erythrocyte zinc in patients with taste and smell dysfunction [Letter]. Am J Clin Nutr 34:118-119.

Koutrakis P, Briggs SLK, Leaderer PB. 1992. Source apportionment of indoor aerosols in Suffolk and Onondaga Counties, New York. Environ Sci Technol 26(3):521-527.

Kowalczyk DF, Gunson DE, Shoop CR, et al. 1986. The effects of natural exposure to high levels of zinc and cadmium in the immature pony as a function of age. Environ Res 40:285-300.

*Kowalska-Wochna E, Moniuszko-Jakoniuk J, Kulikowska E, et al. 1988. The effect of orally applied aqueous solutions of lead and zinc on chromosome aberrations and induction of sister chromatid exchanges in the rat (Rattus sp.) Genetica Polonica 29(2):181-189.

*Kozik MB, Gramza G, Pietrzak M. 1981. Neurosecretion of the hypothalamo-hypophyseal system after intragastric administration of zinc oxide. Folia Histochem Cytochem 19:115-122.

*Kozik MB, Maziarz L, Godlewski A. 1980. Morphological and histochemical changes occurring in the brain of rats fed large doses of zinc oxide. Folia Histochem Cytochem 18:201-206.

*Krebs NF. 1999. Zinc transfer to the breastfed infant. J Mam Gland Biol Neoplasia 4:259-268.

Krebs NF. 2000. Overview of zinc absorption and excretion in the human gastrointestinal tract. J Nutr 130:1374S-1377S.

Krebs NF, Hambidge KM, Westcott JE, et al. 2003. Exchangeable zinc pool size in infants is related to key variables of zinc homeostasis. J Nutr 133(5S1):1498S-501S.

Krebs NF, Reidinger CJ, Miller LV, et al. 2000. Zinc homeostasis in healthy infants fed a casein hydrolysate formula. J Pediatr Gastroenterol Nutr 30:29-33.

Krebs NF, Reidinger CJ, Robertson AD, et al. 1994. Growth and intakes of energy and zinc in infants fed human milk. J Pediatr 124:32-39.

Kress N, Hornung H, Herut B, et al. 1998. Concentrations of Hg, Cd, Zn, Fe and Mn in deep sea benthic fauna from the southeastern Mediterranean sea: A comparison between fauna collected at a pristine area and at two disposal sites. Mar Pollut Bull 36:911-921. 
9. REFERENCES

Kress Y, Gaskin F, Brosnan CF, et al. 1981. Effects on zinc on the cytoskeletal proteins in the central nervous system. Brain Res 220:139-149.

*Krishnan K, Andersen ME. 1994. Physiologically based pharmacokinetic modeling in toxicology. In: Hayes AW, ed. Principles and methods of toxicology. 3rd ed. New York, NY: Raven Press, Ltd., 149188.

*Krishnan U, Hee SSQ. 1992. Ear wax: A new biological monitoring medium for metals? Bull Environ Contam Toxicol 48:481-486.

Krone CA, Harms LC. 2003. Re: Zinc supplement use and risk of prostate cancer. J Natl Cancer Inst 95(20):1556-1557.

Kroneman J, Goedegebuure SA. 1980. [Zinc poisoning in a foal.] Tijdschr Diergeneesk 105:1049-1053. (Dutch)

Kudalkar PR, Brody J, Buccholtz MS. 2004. Zinc induced copper deficiency anemia and leucopenia: A case report. Blood 100(11):17b.

Kumar M. 1992. Accumulation of lead, cadmium, and zinc in aquatic snails from four freshwater sites in Steuben County, Indiana. Bios 62(1-2):2-8.

*Kumar S. 1976. Effect of zinc supplementation on rats during pregnancy. Nutr Rep Int 13:33-36.

*Kuschner WG, D'Alessandro A, Wintermeyer SF, et al. 1995. Pulmonary responses to purified zinc oxide fume. J Investi Med 43(4):371-378.

*Kuschner WG, D'Alessandro A, Wong H, et al. 1997. Early pulmonary cytokine responses to zinc oxide fume inhalation. Environ Res 75:7-11.

*Kynast G, Saling E. 1986. Effect of oral zinc application during pregnancy. Gynecol Obstet Invest 21:117-123.

*L'Abbe MR, Fischer PWF. 1984a. The effects of dietary zinc on the activity of copper-requiring metalloenzymes in the rat. J Nutr 114:823-828.

*L'Abbe MR, Fischer PWF. 1984b. The effects of high dietary zinc and copper deficiency on the activity of copper-requiring metalloenzymes in the growing rat. J Nutr 114:813-822.

Labrenz M, Druschel GK, Thomsen-Ebert T, et al. 2000. Formation of sphalerite (ZnS) deposits in natural biofilms of sulfate-reducing bacteria. Science 290:1744-1747.

LaGoy PK. 1987. Estimated soil ingestion rates for use in risk assessment. Risk Anal 7:355-359.

Lal UB. 1976. Effects of low and high levels of dietary zinc on pathology in rats exposed. Thesis. Cincinnati, OH: Department of Environmental Health, College of Medicine, University of Cincinnati.

*Lam HF, Chen LC, Ainsworth D, et al. 1988. Pulmonary function of guinea pigs exposed to freshly generated ultrafine zinc oxide with and without spike concentrations. Am Ind Hyg Assoc J 49:333-341. 
*Lam HF, Conner MW, Rogers AE, et al. 1985. Functional and morphologic changes in the lungs of guinea pigs exposed to freshly generated ultrafine zinc oxide. Toxicol Appl Pharmacol 78:29-38.

*Lam HF, Peisch R, Amdur MO. 1982. Changes in lung volumes and diffusing capacity in guinea pigs exposed to a combination of sulfur dioxide and submicron zinc oxide mixed in a humidified furnace. Toxicol Appl Pharmacol 66:427-433.

Langini SH, Crane MD, Lazzari A, et al. 2002. Placental iron, zinc and copper concentrations and pregnancy outcome. FASEB J 16:A280.

*Langmyhr FJ, Eyde B, Jonsen J. 1979. Determination of the total content and distribution of cadmium, copper and zinc in human parotid saliva. Anal Chim Acta 107:211-218.

*Lansdown ABG. 1991. Interspecies variations in response to topical application of selected zinc compounds. Food Chem Toxicol 29:57-64.

Lansdown ABG. 1993. Influence of zinc oxide in the closure of open skin wounds. Int J Cosmet Sci 15:83-85.

*Lantzy RJ, MacKenzie FT. 1979. Atmospheric trace metals: Global cycle and assessment of man's impact. Geochim Cosmochim Acta 43:511-526.

La Perriere JD, Wagener SM, Bjerklie DM. 1985. Gold-mining effects on heavy metals in streams, Circle Quadrangle, Alaska. Water Res Bull 21:245-252.

Larsen TS, Kristensen JA, Asmund G, et al. 2001. Lead and zinc in sediments and biota from Maarmorilik, West Greenland: An assessment of the environmental impact of mining wastes on an Arctic fjord system. Environ Pollut 114:275-283.

Larsson M, Rossander-Hulthén L, Sandström B, et al. 1996. Improved zinc and iron absorption from breakfast meals containing malted oats with reduced phytate content. Br J Nutr 76:677-688.

Lasenby DC, Vanduyn J. 1992. Zinc and cadmium accumulation by the opossum shrimp Mysis relicta. Arch Environ Contam Toxicol 23:179-183.

Lasley SM, Gilbert ME. 1999. Lead inhibits the rat $N$-methyl-D-aspartate receptor channel by binding to a site distinct from the zinc allosteric site. Toxicol Appl Pharmacol 159:224-233.

*Lastra MD, Pastelin R, Herrera MA, et al. 1997. Increment of immune responses in mice perinatal stages after zinc supplementation. Arch Med Res 28:67-72.

Lau JC, Joseph MG, Cherian MG. 1998. Role of placental metallothionein in maternal to fetal transfer of cadmium in genetically altered mice. Toxicology 127:167-178.

*Lauenstein GG, Robertson A, O'Connor T. 1990. Comparison of trace metal data in mussels and oysters from a mussel watch programme of the 1970s with those from a 1980s programme. Mar Pollut Bull 21:440-447.

Laurant P, Drozbartholet C, Berthelot A. 1991. Effect of a long-term high magnesium intake on metabolism of zinc in Sprague Dawley male rats. Trace Elements in Medicine 8(2):70-73. 
9. REFERENCES

Leazer TM, Keen CL, Daston GP, et al. 1994. Zn pretreatment, but not co-administration, protects against the developmental toxicity of LPS in the mouse. Teratology 49:369-370.

Leccia MT, Richard MJ, Beani JC, et al. 1993. Protective effect of selenium and zinc on UV-A damage in human skin fibroblasts. Photochem Photobiol 58(4):548-553.

Leeder JS, Kearns GL. 1997. Pharmcogenetics in pediatrics: Implications for practice. Pediatr Clin North Am 44(1):55-77.

*Leitzmann MF, Stampfer MJ, Wu K, et al. 2003. Zinc supplement use and risk of prostate cancer. J Natl Cancer Inst 95(13):1004-1007.

Leonar A, Gerber GB, Leonard F. 1986. Mutagenicity, carcinogenicity and teratogenicity of zinc. Mutat Res 168:343-353.

*Leung H-W. 1993. Physiologically-based pharmacokinetic modelling. In: Ballentine B, Marro T, Turner P, eds. General and applied toxicology. Vol. 1. New York, NY: Stockton Press, 153-164.

*Levine MB, Hall AT, Barrett GW, et al. 1989. Heavy metal concentrations during ten years of sludge treatment to an old-field community. J Environ Qual 18:411-418.

Levy DB, Barbarick KA, Siemer EG, et al. 1992. Distribution and partitioning of trace metals in contaminated soils near Leadville, Colorado. J Environ Qual 21:185-195.

*Lewis MR, Kokan L. 1998. Zinc gluconate: Acute ingestion. J Toxicol Clin Toxicol 36:99-101.

*Lewis RJ. 1997. Hawley's condensed chemical dictionary. New York, NY: John Wiley \& Sons, Inc., 1194-1202.

Li TY, Kraker AJ, Shaw CF III, et al. 1980. Ligand substitution reactions of metallothioneins with EDTA and apo-carbonic anhydrase. Proc Natl Acad Sci U S A 77:6334-6338.

Li X, Christie P. 2001. Changes in soil solution $\mathrm{Zn}$ and $\mathrm{pH}$ and uptake of $\mathrm{Zn}$ by arbuscular mycorrhizal red clover in Zn-contaminated soil. Chemosphere 42:201-207.

Licastro F, Mocchegiani E, Zannotti M, et al. 1992. Zinc affects the metabolism of thyroid hormones in children with Down's Syndrome: Normalization of thyroid stimulating hormone and of reversal triiodothyronine plasmic levels by dietary zinc supplementation. Int J Neurosci 65(1-4):259-268.

*Lievens P, Versieck J, Cornelis R, et al. 1977. The distribution of trace elements in normal human liver determined by semi-automated radiochemical neutron activation analysis. J Radioanal Chem 37:483-496.

Lin AMY, Fan SF, Yang DM, et al. 2003. Zinc-induced apoptosis in substantia nigra of rat brain: Neuroprotection by vitamin D3. Free Radic Biol Med 34(11):1416-1425.

Lind T, Lonnerdai B, Stenlund H, et al. 2004. Single, but not combined iron and zinc supplementation improves growth and development of Indonesian infants. FASEB J 18(4-5):A844.

Lindahl M, Leanderson P, Tagesson C. 1998. Novel aspect on metal fume fever: zinc stimulates oxygen radical formation in human neutrophils. Hum Exp Toxicol 17:105-110. 
9. REFERENCES

Linder N, Statter M, Leibovici V, et al. 1988. An oral zinc loading test in psoriasis. Metabolism 37:807809.

*Lindsay WL. 1979. Chemical equilibria in soils. New York, NY: John Wiley \& Sons, 210-220.

*Linn WS, Kleinman M, Bailey R, et al. 1981. Human respiratory responses to an aerosol containing zinc ammonium sulfate. Environ Res 25:404-414.

*Lioy PJ, Wolff GT, Kneip TJ. 1978. Toxic airborne elements in the New York metropolitan area. J Air Pollut Control Assoc 28:510-512.

Lisk DJ, Gutenmann WH, Rutzke M, et al. 1992. Survey of toxicants and nutrients in composted waste materials. Arch Environ Contam Toxicol 22:190-194.

Liu J, Liu Y, Michalska AE, et al. 1996. Distribution and retention of cadmium in metallothionein I and II null mice. Toxicol Appl Pharmacol 136:260-268.

Liu X, Jin T, Nordberg GF, et al. 1994. Influence of zinc and copper administration on metal disposition in rats with cadmium-metallothionein-induced nephrotoxicity. Toxicol Appl Pharmacol 126:84-90.

*Livingston, AL. 1978. Forage plant estrogens. J Toxicol Environ Health 4:301-324.

*Llobet JM, Colomina MT, Domingo JL, et al. 1989. Comparison of the antidotal efficacy of polyaminocarboxylic acids (CDTA and DTPA) with time after acute zinc poisoning. Vet Hum Toxicol $31: 25-28$.

*Llobet JM, Domingo JL, Colomina MT, et al. 1988a. Subchronic oral toxicity of zinc in rats. Bull Environ Contam Toxicol 41:36-43.

*Llobet JM, Domingo JL, Corbella J. 1988b. Antidotes for zinc intoxication in mice. Arch Toxicol 61:321-323.

*Lloyd TB. 1984. Zinc compounds. In: Grayson M, ed. Kirk-Othmer encyclopedia of chemical technology. 3rd Edition, vol. 24. New York, NY: John Wiley and Sons, 851-863.

*Lloyd TB, Showak W. 1984. Zinc and zinc alloys. In: Grayson M, ed. Kirk-Othmer encyclopedia of chemical technology. 3rd Edition, vol. 24. New York, NY: John Wiley and Sons, 835-836.

Lobel PB, Longerich HP, Jackson SE, et al. 1991. A major factor contributing to the high degree of unexplained variability of some elements concentrations in biological tissue: 27 elements in 5 organs of the mussel Mytilus as a model. Arch Environ Contam Toxicol 21:118-125.

Lobner D, Asrari M. 2003. Neurotoxicity of dental amalgam is mediated by zinc. J Dent Res 82(3):243246.

*Logue JN, Koontz MD, Hattwick MAW. 1982. A historical prospective mortality study of workers in copper and zinc refineries. J Occup Med 24:398-408.

Lohmann RD, Beyesmann D. 1993. Cadmium and zinc mediated changes of the $\mathrm{Ca}^{2+}$-dependent endonuclease in apoptosis. Biochem Biophys Res Commun 190(3):1097-1103. 
9. REFERENCES

*Lombardi-Boccia G, Aguzzi A, Cappelloni M, et al. 2003. Total-diet study: Dietary intakes of macro elements and tracr elements in Italy. Br J Nutr 90(6):1117-1121.

*Lombeck I, Schnippering HG, Ritzl F, et al. 1975. Absorption of zinc in acrodermatitis enteropathica. Lancet i:855.

Lombi E, Hamon RE, McGrath SP, et al. 2003. Lability of $\mathrm{Cd}, \mathrm{Cu}$, and $\mathrm{Zn}$ in polluted soils treated with lime, beringite, and red mud and identification of a non-liable colloidal fraction of metals using isotopic techniques. Environ Sci Technol 37(5):979-984.

Lönnerdal B. 2000. Dietary factors influencing zinc absorption. J Nutr 130:1378S-1383S.

Lönnerdal B, Jayawickrama L, Lien EL. 1999. Effect of reducing the phytate content and of partially hydrolyzing the protein in soy formula on zinc and copper absorption and status in infant rhesus monkeys and rat pups. Am J Clin Nutr 69:490-496.

*Lopez-Artiguez M, Camean AM, Repetto M. 1996. Determination of nine elements in sherry wine by inductively coupled plasma-atomic emission spectrometry. J AOAC Int 79(5):1191-1197.

*Lopez-Artiguez M, Grilo A, Soria L, et al. 1990. Levels of zinc and lead in wines from area south of Seville. Bull Environ Contam Toxicol 45:711-717.

*Loranger S, Tetrault M, Kennedy G, et al. 1996. Manganese and other trace elements in urban snow near an expressway. Environ Pollut 92:203-211.

Lores EM, Pennock JR. 1998. The effect of salinity on binding of $\mathrm{Cd}, \mathrm{Cr}, \mathrm{Cu}$, and $\mathrm{Zn}$ to dissolved organic matter. Chemosphere 37:861-874.

Lowe NM, Green A, Rhodes JM, et al. 1993. Studies of human zinc kinetics using the stable isotope ${ }^{70}$ Zn. Clin Sci 84(1):113-117.

Lowe NM, Woodhouse LR, Matel JS, et al. 2000. Comparison of estimates of zinc absorption in humans by using 4 stable isotopic tracer methods and compartmental analysis. Am J Clin Nutr 71:523-529.

Lowe NM, Woodhouse LR, Wee J, et al. 1999. Short-term zinc kinetics in pregnant rats fed marginal zinc diets. J Nutr 129:1020-1025.

Lowry SF, Goodgame JT Jr, Smith JC Jr, et al. 1979. Abnormalities of zinc and copper during total parenteral nutrition. Ann Surg 189:120-128.

*Lü J, Combs GF Jr, Fleet JC. 1990. Time-course studies of pancreatic exocrine damage induced by excess dietary zinc in the chick. J Nutr 120:389-397.

Luef E, Prey T, Kubicek CP. 1991. Biosorption of zinc by fungal mycelial wastes. Appl Microbiol Biotechnol 34(5):688-692.

Lumsden RB, Weir CD. 1945. Subglottic stenosis after exposure to a high concentration of screening smoke (zinc chloride). Br Med J i:554-555.

Luo YM, Christie P, Baker AJM. 2000. Soil solution $\mathrm{Zn}$ and $\mathrm{pH}$ dynamics in non-rhizosphere soil and in the rhizosphere of Thlaspi caerulescens grown in a $\mathrm{Zn} / \mathrm{Cd}$-contaminated soil. Chemosphere 41:161-164. 
9. REFERENCES

Luo YM, Yan WD, Christie P. 2001. Soil solution dynamics of $\mathrm{Cu}$ and $\mathrm{Zn}$ in a $\mathrm{Cu}$ - and $\mathrm{Zn}$-polluted soil as influenced by $\gamma$-irradiation and $\mathrm{Cu}-\mathrm{Zn}$ interaction. Chemosphere 42:179-184.

*Luterotti S, Zanić-Grubišić T, Juretić D. 1992. Rapid and simple method for determination of copper, manganese and zinc in rat liver by direct flame atomic-absorption spectrometry. Analyst (London) 117(2):141-143.

*Lytle TF, Lytle JS. 1990. Heavy metals in the eastern oyster Crassostrea virginica of the Mississippi Sound. Bull Environ Contam Toxicol 44:142-148.

*Ma LQ, Rao GN. 1997a. Chemical fractionation of cadmium, copper, nickel, and zinc in contaminated soils. J Environ Qual 26:259-264.

Ma LQ, Rao GN. 1997b. Heavy metals in the environment-chemical fractionation of cadmium, copper, nickel, and zinc in contaminated soils. J Environ Qual 26:259-264.

MacDonald RS. 2000. The role of zinc in growth and cell proliferation. J Nutr 130:1500S-1508S.

Macdonald RW, Macdonald DM, O'Brien MC, et al. 1991. Accumulation of heavy metals (lead, zinc, copper, cadmium), carbon and nitrogen in sediments from Strait of Georgia, B.C., Canada. Marine Chemistry 34(1-2):109-135.

Machemer SD. 2004. Characterization of airborne and bulk particulate from iron and steel manufacturing facilities. Environ Sci Technol 38:381-389.

Madden JD, Grodner RM, Feagley SE, et al. 1991. Minerals and xenobiotic residues in the edible tissues of wild and pond-raised Louisiana crayfish. J Food Safety 12:1-15.

*Maessen O, Freedman B, McCurdy R. 1985. Metal mobilization in home well water systems in Nova Scotia. J Am Water Works Assoc 77:73-80.

*Magee AC, Matrone G. 1960. Studies on growth, copper metabolism and iron metabolism of rats fed high levels of zinc. J Nutr 72:233-242.

*Mahaffey KR, Corneliussen PE, Jelinek CF, et al. 1975. Heavy metal exposure from foods. Environ Health Perspect 12:63-69.

*Mahomed K, James DK, Golding J, et al. 1989. Zinc supplementation during pregnancy: A double blind randomized controlled trial. Br Med J 299:826-833.

*Maita K, Hirano M, Mitsumori K, et al. 1981. Subacute toxicity studies with zinc sulfate in mice and rats. J Pest Sci 6:327-336.

Malenky B, Van Grieken R, Vant Dack L, et al. 1983. Atmospheric trace element concentration in Jerusalem, Israel. Atmos Environ 17:819-822.

Malo JL, Cartier A, Dolovich J. 1993a. Occupational asthma due to zinc. J Allergy Clin Immunol 91(1):309.

Malo JL, Cartier A, Dolovich J. 1993b. Occupational asthma due to zinc. Eur Resp J 6:447-450. 
9. REFERENCES

*Malo JL, Malo J, Cartier A, et al. 1990. Acute lung reaction due to zinc inhalation. Eur Res J 3:111114.

Manary MJ, Hotz C, Krebs NF, et al. 2000. Dietary phytate reduction improves zinc absorption in Malawian children recovering from tuberculosis but not in well children. J Nutr 130:2959-2964.

Marco LM, Jimenez E, Hernandez EA, et al. 2001. Determination of Zn/Cu ratio and oligoelements in serum samples by total reflection X-ray fluorescence spectrometry for cancer diagnosis. Spectrochim Acta, Part B 56:2195-2201.

Maret TR, Skinner KD. 2000. Concentrations of selected trace elements in fish tissue and streambed sediment in the Clark Fork-pend Oreille and Spokane river basins, Washington, Idaho, and Montana, 1998. National water-quality assessment program. Boise Idaho: Report 00-4159.

*Marks GE, Moore CE, Kanabrocki EL, et al. 1972. Determination of trace elements in human tissue: I. $\mathrm{Cd}, \mathrm{Fe}, \mathrm{Zn}, \mathrm{Mg}$, and Ca. Applied Spectroscopy 26:523-527.

*Marquart H, Smid T, Heederik D, et al. 1989. Lung function of welders of zinc-coated mild steel: Cross-sectional analysis and changes over five consecutive work shifts. Am J Ind Med 16:289-296.

*Marrs TC, Colgrave HF, Edginton JAG, et al. 1988. The repeated dose toxicity of a zinc oxide/hexachloroethane smoke. Arch Toxicol 62:123-132.

*Martin CJ, Le CXC, Guidotti TL, et al. 1999. Zinc exposure in Chinese foundry workers. Am J Ind Med 35:574-580.

Martin MH, Nickless G, Stenner RD. 1997. Concentrations of cadmium, copper, lead, nickel, and zinc in the alga Fucus serratus in the seven estuary from 1971 to 1995. Chemosphere 34:325-334.

Martincic D, Kwokal Z, Peharec Z, et al. 1992. Distribution of zinc, lead, cadmium and copper between seawater and transplanted mussels (Mytilus galloprovincialis). Sci Total Environ 119:211-230.

Martinez CE, McBride MB. 1999. Dissolved and labile concentrations of $\mathrm{Cd}, \mathrm{Cu}, \mathrm{Pb}$, and $\mathrm{Zn}$ in aged ferrihydrite-organic matter systems. Environ Sci Technol 33:745-750.

Marx G, Krugliak J, Shaklai M. 1991. Nutritional zinc increases platelet reactivity. Am J Hematol 38(3):161-165.

*Marzin DR, Vo Phi H. 1985. Study of the mutagenicity of metal derivatives with Salmonella typhimurium TA102. Mutat Res 155:49-51.

*Matarese SL, Matthews JI. 1966. Zinc chloride (smoke bomb) inhalational lung injury. Chest 89:308309.

Mateus ML, dos Santos APM, Batoreu MC. 2000. Evidence for zinc protection against 2,5-hexanedione toxicity by co-exposure of rats to zinc chloride. J Appl Toxicol 20:211-214.

*Mathur A, Wallenius K, Abdulla M. 1979. Influence of zinc on onset and progression of oral carcinogenesis in rats. Acta Odontologica Scand 37:377-384. 
9. REFERENCES

Matusiewicz H, Sturgeon R, Luong V, et al. 1991. Determination of copper, iron, manganese and zinc in river and estuarine water by atom trapping-flame atomic absorption spectrometry. Fresenius $\mathrm{J}$ Anal Chem 340(1)35-40.

*May TW, Wiedmeyer RH, Gober J, et al. 2001. Influence of mining-related activities on concentrations of metals in water and sediment from streams of the Black Hills, South Dakota. Arch Environ Contam Toxicol 40:1-9.

* Mayer T, Manning PG. 1990. Inorganic contaminants in suspended solids from Hamilton Harbour. J Great Lakes Res 16:299-318.

* Mayr U, Butsch A, Schneider S. 1992. Validation of two in vitro test systems for estrogenic activities with zearalenone, phytoestrogens and cereal extracts. Toxicology 74:135-149.

*McBean LD, Mahloudji M, Reinhold JG, et al. 1971. Correlation of zinc concentrations in human plasma and hair. Am J Clin Nutr 24:506-509.

*McCarthy HT, Ellis PC. 1991. Comparison of microwave digestion with conventional wet-ashing and dry-ashing digestion for analysis of lead, cadmium, chromium, copper, and zinc in shellfish by flame atomic-absorption spectroscopy. J Assoc Off Anal Chem 74(3):566-569.

*McCord CP. 1960. Metal fume fever as an immunological disease. Industr Med Surg 29:101-107.

*McCord CP, Friedlander A, Brown WE, et al. 1926. An occupational disease among zinc workers. Arch Intern Med 37:641-659.

*McGeer J, Brix KV, Skeaff JM, et al. 2003. Inverse relationship between bioconcentration factor and exposure concentration for metals: Implications for hazard assessment of metals in the aquatic environment. Environ Toxicol Chem 22(5):1017-1037.

McGrath D. 1995. Organic micropollutant and trace element pollution of Irish soils. Sci Total Environ 164:125-133.

McKenna IM, Chaney RL, Tao SH, et al. 1992. Interactions of plant zinc and plant species on the bioavailability of plant cadmium to Japanese quail fed lettuce and spinach. Environ Res 57(1):73-87.

McKenna IM, Chaney RL, Williams FM. 1993. The effects of cadmium and zinc interactions on the accumulation and tissue distribution of zinc and cadmium in lettuce and spinach. Environ Pollut 79(2):113-120.

McKinney PE, Brent J, Kulig K. 1994. Acute zinc chloride ingestion in a child: Local and systemic effects. Ann Emerg Med 23(6):1383-1387.

McKinney PE, Brent J, Kulig K. 1995. Zinc chloride ingestion in a child: Exocrine pancreatic insufficiency. Ann Emerg Med 25:562.

McLaughlin MJ, Smolders E. 2001. Background zinc concentrations in soil affect the zinc sensitivity of soil microbial processes--a rationale for a metalloregion approach to risk assessments. Environ Toxicol Chem 20(11):2639-2643. 
9. REFERENCES

*McMichael AJ, Dreosti IE, Ryan P, et al. 1994. Neuroal tube defects and maternal serum zinc and copper concentrations in mid-pregnancy: A case-control study. Med J Aust 161:478-482.

McNall AD, Fosmire GJ. 1996. Zinc status does not affect aluminum deposition in tissues of rats. Biol Trace Elem Res 53:7-18.

McNulty TJ, Taylor CW. 1999. Extracellular heavy-metal ions stimulate $\mathrm{Ca}^{2+}$ mobilization in hepatocytes. Biochem J 339:555-561.

Mehra R, Juneja M. 2003. Adverse health effects in workers exposed to trace/toxic metals at the workplace. Indian J Biochem Biophys 40:131-135.

Mendez-Sanchez N, Roldan-Valadez E, Flores MA, et al. 2001. Zinc salts precipitate unconjugated bilirubin in vitro and inhibit enterohepatic cycling of bilirubin in hamsters. Eur J Clin Invest 31:773-780.

Meng Z. 1998. Age- and sex-related differences in zinc and lead levels in human hair. Biol Trace Elem Res 61:79-87.

Mentasti E, Abollino O, Aceto M, et al. 1998. Distribution and statistical correlations of major, minor and trace metals in lake environments of Antarctica. Int J Environ Anal Chem 71:245-255.

Meo SA, Al-Khlaiwi T. 2003. Health hazards of welding fumes. Saudi Med J 24(11):1176-1182.

Meret S, Henkin RI. 1971. Simultaneous direct estimation by atomic absorption and spectrophotometry of copper and zinc in serum, urine, and cerebrospinal fluid. Clin Chem 17:369-373.

Messer NT. 1981. Tibiotarsal effusion associated with chronic zinc intoxication in three horses. J Am Vet Med Assoc 178:294-297.

*Methfessel AH, Spencer H. 1973. Zinc metabolism in the rat: I. Intestinal absorption of zinc. J Appl Physiol 34:58-62.

*Meurs KM, Breitschwerdt EB, Baty CJ, et al. 1991. Postsurgical mortality secondary to zinc toxicity in dogs. Vet Hum Toxicol 33(6):579-583.

*Mielke HW, Gonzales CR, Smith MK, et al. 1999. The urban environment and children's health: Soils as an integrator of lead, zinc, and cadmium in New Orleans, Louisiana, U.S.A. Environ Res 81:117-129.

*Mielke HW, Gonzales CR, Smith MK, et al. 2000. Quantities and associations of lead, zinc, cadmium, manganese, chromium, nickel, vanadium, and copper in fresh Mississippi delta alluvium and New Orleans alluvial soils. Sci Total Environ 246:249-259.

*Mielke HW, Powell ET, Shah A, et al. 2001. Multiple metal contamination from house paints: Consequences of power sanding and paint scraping in New Orleans. Environ Health Perspect 109:973978.

Migon C. 1993. Riverine and atmospheric inputs of heavy metals to the Ligurian Sea. Sci Total Environ 138:289-299.

Migon C, Caccian JL. 1993. Estimation of anthropogenic and natural heavy metals in the northwestern Mediterranean rainwater and total atmospheric deposition. Chemosphere 27:2389-2396. 
9. REFERENCES

* Miguel AH, Neto FRD, Cardoso JN, et al. 1995. Characterization of indoor air quality in the cities of Sao Paulo and Rio De Janeiro, Brazil. Environ Sci Technol 29:338-345.

Mihelcic G, Surija B, Juracic M, et al. 1996. History of the accumulation of trace metals in sediments of the Saline Rogoznica Lake (Croatia). Sci Total Environ 182:105-115.

Millan J, Calero M, Sampalo A, et al. 1991. Changes in the angiotensin converting enzyme associated with zinc oral overload. Medicina Clinia 96(7):276.

Miller L, Krebs N. 2000. Development of a compartmental model of human zinc metabolism: Identifiability and multiple studies analyses. Am J Physiol Regul Integr Comp Physiol 279:R1671R1684.

Miller LV, Hambidge KM, Naake VL, et al. 1994. Size of the zinc pools that exchange rapidly with plasma zinc in humans: Alternative techniques for measuring and relation to dietary zinc intake. J Nutr $124: 268-276$.

Miller PA, Munkittrick KR, Dixon DG. 1992. Relationship between concentrations of copper and zinc in water, sediment, benthic invertebrates, and tissues of white sucker (Catostomus commersoni) at metalcontaminated sites. Can J Fish Aquat Sci 49(5):978-984.

Miller RM, Stitzerschnabel L, Artiola JF, et al. 1992. Effect of four alcohols on adsorption desorption and movement of cadmium, nickel, and zinc through soils. Chemosphere 24:1855-1866.

*Milliken JA, Waugh D, Kadish ME. 1963. Acute interstitial pulmonary fibrosis caused by a smoke bomb. Can Med Assoc J 88:36-39.

*Milne DB, Davis CD, Nielsen FH. 2001. Low dietary zinc alters indices of copper function and status in postmenopausal women. Nutrition 17:701-708.

Milunsky A, Morris JS, Jick H, et al. 1992. Maternal zinc and fetal neural tube defects. Teratology 46(4):341-348.

*Minear RA, Ball RO, Church RL. 1981. Data base for influent heavy metals in publicly owned treatment works. EPA-600/S2-81-220. 1-5.

Minyard JP Jr, Roberts WE. 1991. State findings on pesticide residues in foods - 1988 and 1989. J Assoc Off Anal Chem 74:438-452.

*Mirenda RJ. 1986. Acute toxicity and accumulation of zinc in the crayfish Orconectes virilis (Hagen). Bull Environ Contam Toxicol 37:387-394.

Mo C, Neilson B. 1991. Variability in measurements of zinc in oysters C. virginica. Mar Pollut Bull 22:522-525.

Monti D, Capri M, Cossarizza A, et al. 1992. Inhibition of apoptosis by zinc: A reappraisal. Biochem Biophys Res Commun 187(3):1256-1261.

*Moore R. 1978. Bleeding gastric erosion after oral zinc sulfate. Br Med J i:754. 
9. REFERENCES

*Morales-Rubio A, Salvador A, de la Guardia M. 1992. Microwave muffle furnace assisted decomposition of vegetable samples for flame atomic spectrometric determination of $\mathrm{Ca}, \mathrm{Mg}, \mathrm{K}, \mathrm{Fe}, \mathrm{Mn}$ and Zn. Fresenius J Anal Chem 342(4-5):452-456.

*Moreno MA, Marin C, Vinagre F, et al. 1999. Trace element levels in whole blood samples from residents of the city of Badajoz, Spain. Sci Total Environ 229:209-215.

Mori T, Akashi S, Nukada A. 1975. Effects of the inhalation of catalytically active metallic oxide fumes on rabbits. Int Arch Occup Environ Health 36:29-39.

Morrison GMP, Revitt DM, Ellis JB. 1990. Metal speciation in separate stormwater systems. Wat Sci Technol 22:53-60.

Morselli L, Zappoli S, Tirabassa T. 1992. Characterization of the effluents from a municipal solid waste incinerator plant and of environmental impact. Chemosphere 24:1775-1784.

*Morselli PL, Franco-Morselli R, Bossi L. 1980. Clinical pharmacokinetics in newborns and infants: Age-related differences and therapeutic implications. Clin Pharmacokin 5:485-527.

*Mueller EJ, Seger DL. 1985. Metal fume fever: A review. J Emerg Med 2:271-274.

Muench D. 1992. Soil contamination beneath asphalt roads by polynuclear aromatic hydrocarbons, zinc, lead and cadmium. Sci Total Environ 126(1-2):49-60.

Mulchi CL, Mastradone PJ, Armbruster JA. 1990. Investigations of trace metal concentrations in crops and soils near a fossil-fuel power plant in Maryland. J Air Waste Manage Assoc 40:185-193.

*Mulhern SA, Stroube WB, Jacobs RM. 1986. Alopecia induced in young mice by exposure to excess dietary zinc. Experientia 42:551-553.

Muller FLL, Kester DR. 1991. Measurement of the different forms of zinc in Narragansett Bay water based on the rate of uptake by a chelating resin. Marine Chemistry 33(1-2):171-186.

*Mumma RO, Raupach DC, Sahadewan K, et al. 1990. National survey of elements and radioactivity in municipal incinerator ashes. Arch Environ Contam Toxicol 19:399-404.

*Mumma RO, Raupach DC, Sahadewan K, et al. 1991. Variation in the elemental composition of municipal refuse incinerator ashes with time of sampling. Chemosphere 23:391-395.

*Mumma RO, Raupach DC, Waldman JP, et al. 1984. National survey of elements and other constituents in municipal sewage sludges. Arch Environ Contam Toxicol 13:75-83.

Murata K, Araki S. 1991. Autonomic nervous system dysfunction in workers exposed to lead, zinc, and copper in relation to peripheral-nerve conduction: A study of R-R interval variability. Am J Ind Med 20(5):663-671.

*Murphy JV. 1970. Intoxication following ingestion of elemental zinc. JAMA 212:2119-2120.

*Murray LM. 1926. An analysis of sixty cases of drug poisoning. Arch Pediat 43:193-196. 
Murray S, Tell LA, Bush M. 1997. Zinc toxicosis in a celebes ape (Macaca nigra) following ingestion of pennies. J Zoo Wild Med 28:101-104.

*Murthy L, Petering HG. 1976. Effect of dietary zinc and copper interrelationships on blood parameters of the rat. J Agric Food Chem 24:808-811.

Murthy RC, Holovack MJ. 1991. Ultrastructural changes in rat lungs exposed to combinations of cadmium, zinc, copper, and nickel. J Submicroscopic Cytol Pathol 23(2):289-293.

Nadakumaran M, Dashti HM, Al-Saleh E, et al. 2003. Transport kinetics of zinc, copper, selenium, and iron in perfused human placental lobule in vitro. Mol Cell Biochem 252(1-2):91-96.

Nagpal NK. 2000. Ambient water quality guidelines for zinc: Overview. GRAI 14:1-14.

Nakamichi N, Chidlow G, Osborne NN. 2003. Effects of intraocular injection of a low concentration of zinc on the rat retina. Neuropharmacology 45(5):637-648.

Nakamoto RJ, Hassler TJ. 1992. Selenium and other trace elements in bluegills from agricultural return flows in the San Joaquin Valley, California. Arch Environ Contam Toxicol 22:88-98.

Namminga H, Wilhm J. 1977. Heavy metals in water, sediments, and chironomids. J Water Pollut Control Fed 1977:1725-1731.

*NAS. 1977. Drinking water and health--inorganic solutes. National Academy of Sciences.

Washington, DC: National Academy Press, 1:205-229, 299-304, 315-316, 447-460.

*NAS. 1980. Drinking water and health. National Academy of Sciences. Washington, DC: National Academy Press, 3:315-321.

*NAS/NRC. 1979. Zinc. Subcommittee on Zinc, Committee on Medical and Biologic Effects of Environmental Pollutants, Division of Medical Sciences, National Academy of Sciences/National Research Council. Baltimore, MD: University Park Press.

*NAS/NRC. 1989a. Biologic markers in reproductive toxicology. National Academy of Sciences/National Research Council. Washington, DC: National Academy Press, 15-35.

*NAS/NRC. 1989b. Recommended dietary allowances. National Academy of Sciences/National Research Council. Washington, DC: National Academy Press, 10th ed., 205-213.

NATICH. 1993. Acceptable ambient concentration guidelines or standards by pollutant. National Air Toxics Information Clearinghouse. Washington, DC: U.S. Environmental Protection Agency, Office of Air Quality Planning and Standards. June 22, 1993.

*Nelson LSJ, Jacobs FA, Brushmiller JG. 1985. Solubility of calcium and zinc in model solutions based on bovine and human milks. J Inorg Biochem 24:255-265.

Nelson LSJ, Jacobs FA, Brushmiller JG. 1987. Coprecipitation modulates the solubility of minerals in bovine milk. J Inorg Biochem 39:173-179.

Neto JB, Vieira JGH, Shuhama T, et al. 1991. Interaction among zinc, glucose, and insulin in normal individuals during glucose and tolbutamide perfusion. Biol Trace Elem Res 28(2):123-133. 
9. REFERENCES

*Neuberger JS, Hollowell JG. 1982. Lung cancer excess in an abandoned lead-zinc mining and smelting area. Sci Total Environ 25:287-294.

Neuhauser EF, Cukic ZV, Malecki MR, et al. 1995. Bioconcentration and biokinetics of heavy metals in the earthworm. Environ Pollut 89(3):293-301.

*Neve J, Hanocq M, Peretz A, et al. 1991. Pharmacokinetic study of orally administered zinc in humans: Evidence for an enteral recirculation. Eur J Drug Metab Pharmacokinet 16(4):315-323.

Neve J, Hanocq M, Peretz A, et al. 1992. Absorption and metabolism of oral zinc gluconate in humans in fasting state, during, and after a meal. Biol Trace Elem Res 32:201-212.

Newman HM, Yang RSH, Magnusson KR. 2002. Effects of developmental exposure to lead, magnesium and zinc mixtures on spatial learning and expression of NMDA receptor subunit mRNA in Fischer 344 rats. Toxicol Lett 126:107-119.

*Ni B, Wang P, Luo Y, et al. 1991. Determination of activable isotopic tracers of zinc by neutronactivation analysis for study of bioavailability of zinc. J Radioanal Nucl Chem 151(2):255-260.

Nielsen NH, Menné T. 1997. Allergic contact dermatitis caused by zinc pyrithione associated with pustular psoriasis. Am J Contact Dermatitis 8:170-171.

*Nielson KK, Mahoney AW, Williams LS, et al. 1991. X-ray fluorescence measurements of Mg, P, S, $\mathrm{Cl}, \mathrm{K}, \mathrm{Ca}, \mathrm{Mn}, \mathrm{Fe}, \mathrm{Cu}$ and $\mathrm{Zn}$ in fruits, vegetables and grain products. J Food Compos Anal 4(1):39-51.

*NIOSH. 1976. National occupational hazard survey (1970). Cincinnati, OH: National Institute for Occupational Safety and Health, Department of Health and Human Services.

*NIOSH. 1984a. NIOSH manual of analytical methods. 3rd ed. Eller PM, ed. Cincinnati, OH: U.S. Department of Health and Human Services, National Institute for Occupational Safety and Health. DHHS (NIOSH) publication no. 84-100.

*NIOSH. 1984b. National occupational exposure survey (1980-83). Cincinnati, OH: National Institute for Occupational Safety and Health, Department of Health and Human Services.

NIOSH. 1987. Registry of toxic effects of chemical substances. 1985-1986 Edition, vol. 5. Sweet DV, ed. National Institute for Occupational Safety and Health. U.S. Government Printing Office, Washington, DC.

*NIOSH. 1990. NIOSH pocket guide to chemical hazards. U.S. Department of Health and Human Services, National Institute for Occupational Safety and Health, Cincinnati, OH.

NIOSH. 1992. Recommendations for occupational safety and health: Compendium of policy documents and statements. Cincinnati, $\mathrm{OH}$ : National Institute for Occupational Safety and Health, Department of Health and Human Services, 1-205.

*NIOSH 1994. NIOSH manual of analytical methods. U.S. Department of Health and Human Services, National Institute for Occupational Safety and Health, Cincinnati, OH. 
9. REFERENCES

*NIOSH. 2003a. NIOSH pocket guide to chemical hazards. Zinc chloride. Washington, DC: National Institute for Occupational Safety and Health. http://www.cdc.gov/niosh/npg/npg.html. June 6, 2003.

*NIOSH. 2003b. NIOSH pocket guide to chemical hazards. Zinc oxide. Washington, DC: National Institute for Occupational Safety and Health. http://www.cdc.gov/niosh/npg/npg.html. June 6, 2003.

NIOSH/OSHA. 1981. Occupational health guidelines for chemical hazards. Government Printing Office, National Institute for Occupational Safety and Health/Occupational Safety and Health Administration, DHHS.

*Nishimura M. 1987. Zinc competitively inhibits calcium-dependent release of transmitter at the mouse neuromuscular junction. Pflugers Archiv 410:623-626.

*Nishioka H. 1975. Mutagenic activities of metal compounds in bacteria. Mutat Res 31:185-189.

Nishiyama S, Nakamura T, Higashi A, et al. 1991. Infusion of zinc inhibits serum calcitonin levels in patients with various zinc status. Calcif Tissue Res 49(3):179-182.

Nolting RF, Helder W. 1991. Lead and zinc as indicators for atmospheric and riverine particle transport to sediments in the Gulf of Lions. Oceanol Acta 14(4):357-367.

*Norrstrom AC, Jacks G. 1998. Concentration and fractionation of heavy metals in roadside soils receiving de-icing salts. Sci Total Environ 218:161-174.

*NRC. 1993. National Research Council. Pesticides in the diets of infants and children. Washington, DC: National Academy Press.

*Nriagu JO. 1989. A global assessment of natural sources of atmospheric trace metals. Nature 338:4749.

*Nriagu JO, Davidson CI. 1980. Zinc in the atmosphere. In: Nriagu JO, ed. Zinc in the environment, Vol. 1: Cycling and characterization. New York, NY: John Wiley and Sons, Inc., 1-15.

*Nriagu JO, Lawson G, Wong HKT, et al. 1996. Dissolved trace metals in lakes Superior, Erie, and Ontario. Environ Sci Technol 30:178-187.

*Nriagu JO, Pacyna JM. 1988. Quantitative assessment of worldwide contamination of air, water and soils by trace metals. Nature 333:134-139.

*Obeck DK. 1978. Galvanized caging as a potential factor in the development of the "fading infant" or "white monkey" syndrome. Lab Anim Sci 28:698-704.

Oberleas D. 1996. Mechanism of zinc homeostasis. J Inorg Biochem 62:231-241.

O'Brien KO, Zavaleta N, Caulfield LE, et al. 2000. Prenatal iron supplements impair zinc absorption in pregnant Peruvian women. J Nutr 130:2251-2255.

O'Connor TP, Ehler CN. 1991. Results from the NOAA national status and trends program on distribution and effects of chemical contamination in the coastal and estuarine United States. Environ Monit Assess 17:33-49. 
9. REFERENCES

*O'Dell BJ. 1969. Effect of dietary components upon zinc availability. Am J Clin Nutr 22:1315-1322.

O'Dell BL. 1968. Trace elements in embryonic development. Fed Proc 27:199-206.

O'Dell BL. 1992. Cysteine-rich intestinal protein (CRIP): A new intestinal zinc transport protein. Nutr Rev 50(8):232-233.

Odland JO, Nieber E, Romanova N, et al. 2003. Intercommunity and temporal variation of eleven essential and five toxic elements in human placentas from deliveries in thirteen Arctic and sub-Arctic areas of Russia and Norway. J Environ Monitor 5(1):166-174.

*Oestreicher P, Cousins RJ. 1985. Copper and zinc absorption in the rat: Mechanism of mutual antagonism. J Nutr 115:159-166.

Ogden L, Graham T, Mahboob M, et al. 2002. Effects of zinc chloride on reproductive parameters of CD-1 mice. Toxicologist 66:33.

*Ogiso T, Ogawa N, Miura T. 1979. Inhibitory effect of high dietary zinc on copper absorption in rats: II. Binding of copper and zinc to cytosol proteins in the intestinal mucosa. Chem Pharm Bull (Tokyo) 27(2):515-521.

*Ohanian EV. 1986. Health effects of corrosion products in drinking water. Trace Substances in Environmental Health 20:122-138.

*Ohnesorge FK, Wilhelm M. 1991. Zinc. Metals and their compounds in the environment. Weihieim, NY: VCH, 1309-1333.

*Ohno H, Doi R, Yamamura K, et al. 1985. A study of zinc distribution in erythrocytes of normal humans. Blut 50:113-116.

Oliver MF. 1988. Reducing cholesterol does not reduce mortality. JACC 12:814-817.

*O’Neil MJ, Smith A, Heckelman PE. 2001. Merck index. 10th ed. Rahway, NJ: Merck \& Co., Inc.

*Ong CN, Chia SE, Foo SC, et al. 1993. Concentrations of heavy metals in maternal and umbilical cord blood. BioMetals 6:61-66.

Onosaka S, Tetsuchikawahara N, Min KS. 2002. Paradigm shift in zinc: Metal pathology. Tohoku J Exp Med 196:1-7.

Oosting JS, Lemmens AG, Vandenberg GJ, et al. 1991. Iron, copper and zinc status in rats fed supplemental nickel. Biol Trace Elem Res 31(1):63-70.

Ordonez A, Loredo J, Demiguel E, et al. 2003. Distribution of heavy metals in the street dusts and soils of an industrial city in northern Spain. Arch Environ Contam Toxicol 44:160-170.

OSHA. 1982. Access to employee exposure and medical records, proposed modification; request for comments and notice of public hearing. U.S. Occupational Safety and Health Administration. Fed Regist 47:30420-30438. 


\section{REFERENCES}

OSHA. 1992. Air contaminants. U.S. Occupational Safety and Health Administration. Code of Federal Regulations. 29 CFR 1910.1000.

*OSHA. 2003a. Occupational safety and health standards. Limits for air contaminants. Washington, DC: U.S. Occupational Safety and Health Administration. 29 CFR 1910.1000, Table Z-1. http://www.osha.gov/comp-links.html. June 6, 2003.

*OSHA. 2003b. Occupational safety and health standards for shipyard employment. Air contaminants. Washington, DC: U.S. Occupational Safety and Health Administration. 29 CFR 1915.1000. http://www.osha.gov/comp-links.html. June 6, 2003.

*OSHA. 2003c. Safety and health regulations for construction. Gases, vapors, fumes, dusts, and mists. Washington, DC: U.S. Occupational Safety and Health Administration. 29 CFR 1926.55, Appendix A. http://www.osha.gov/comp-links.html. June 6, 2003.

Osman K, Akesson A, Berglund M, et al. 2000. Toxic and essential elements in placentas of Swedish women. Clin Biochem 33(2):131-138.

*OTA. 1990. Neurotoxicity: Identifying and controlling poisons of the nervous system. Washington, DC: Office of Technology Assessment, U.S. Congress. OTA-BA-436. April 1990.

Outridge PM, Noller BN. 1991. Accumulation of toxic trace elements by freshwater vascular plants. Rev Environ Contam Toxicol 121:1-63.

*Owen GM, Brozek J. 1966. Influence of age, sex and nutrition on body composition during childhood and adolescence. In: Falkner F, ed. Human development. Philadelphia, PA: WB Saunders, 222-238.

*Pacyna JM, Bartonova A, Cornille P, et al. 1989. Modelling of long-range transport of trace elements: A case study. Atmos Environ 23:107-114.

Paksy K, Varga B, Lazar P. 1996. Zinc protection against cadmium-induced infertility in female rats. Effect of zinc and cadmium on the progesterone production of cultured granulosa cells. BioMetals 10:2736.

*Pal N, Pal B. 1987. Zinc feeding and conception in the rats. Int J Vitam Nutr Res 57:437-440.

Palmer JB, Rand GM. 1977. Trace metal concentrations in two shellfish species of commercial importance. Bull Environ Contam Toxicol 18:512-520.

Palmiter RD. 1994. Regulation of metallothionein genes by heavy metals appears to be mediated by a zinc-sensitive inhibitor that interacts with a constitutively active transcription factor, MTF-1. Proc Natl Acad Sci USA 91:1219-1223.

*Panayi AE, Spyrou NM, Iversen BS, et al. 2002. Determination of cadmium and zinc in Alzheimer's brain tissue using inductively coupled plasma mass spectrometry. J Neurol Sci 195:1-10.

*Paode RD, Sofuoglu SC, Sivadechathep J, et al. 1998. Dry deposition fluxes and mass size distributions of $\mathrm{Pb}, \mathrm{Cu}$, and $\mathrm{Zn}$ measured in southern Lake Michigan during aeolos. Environ Sci Technol 32:1629-1635. 
*Paquin PR, Gorsuch JW, Apte S, et al. 2002. The biotic ligand model: A historical overview. Comp Biochem Physiol C 133:3-35.

Pare CMB, Sandler M. 1954. Smoke-bomb pneumonitis: Description of a case. J Army Med Corp 100:320-322.

Park J, Presley BJ. 1997. Trace metal contamination of sediments and organisms from the Swan Lake area of Galveston Bay. Environ Pollut 98:209-221.

*Parodi A, Priano L, Rebora A. 1991. Chronic zinc deficiency in a patient with psoriasis and alcoholic liver cirrhosis. Int J Dermatol 30:45-47.

Parveen Z, Khuhro MI, Rafiq N. 2003. Market basket survey for lead, cadmium, copper, chromium, nickel, and zinc in fruits and vegetables. Bull Environ Contam Toxicol 71:1260-1264.

*Pascoe GA, Blanchet RJ, Linder G. 1996. Food chain analysis of exposures and risks to wildlife at a metals-contaminated wetland. Arch Environ Contam Toxicol 30:306-318.

Pasqualatto D, Fernandez MC. 2003. N-Acetylcysteine in zinc chloride poisoning. Toxicol Lett 144(suppl 1):s72.

Paterson PG, Mas A, Sarkar B, et al. 1991. The influence of zinc binding ligands in fetal circulation on zinc clearance across the in situ perfused guinea pig placenta. J Nutr 121(3):338-344.

*Patterson JW, Allen HE, Scala JJ. 1977. Carbonate precipitation for heavy metals pollutants. J Water Pollut Control Fed 2397-2410.

*Patterson KY, Veillon C, Moser-Veillon PB, et al. 1992. Determination of zinc stable isotopes in biological materials using isotope dilution inductively coupled plasma mass spectrometry. Anal Chim Acta 258(2):317-324.

*Patterson WP, Winkelman M, Perry MC. 1985. Zinc-induced copper deficiency: Megamineral sideroblastic anemia. Ann Intern Med 103:385-386.

Paulson AJ, Curl HC Jr, Feeley RA. 1989. Estimates of trace metal inputs from non-point sources discharged into estuaries. Mar Pollut Bull 20:549-555.

*Pecoud A, Donzel P, Schelling JL. 1975. Effects of foodstuffs on the absorption of zinc sulfate. Clin Pharmacol Ther 17:469-474.

Pedroli BM, Maasdam WAC, Verstraten JM. 1990. Zinc in poor sandy soils and associated groundwater: A case study. Sci Total Environ 91:59-77.

Pempkowiak J, Sikora A, Biernacka E. 1999. Speciation of heavy metals in marine sediments vs their bioaccumulation by mussels. Chemosphere 39:313-321.

*Pennington JAT, Schoen SA. 1996. Contributions of food groups to estimated intakes of nutritional elements: Results from the FDA total diet studies, 1982-1991. Int J Vitam Nutr Res 66(4):342-349.

*Pennington JAT, Capar SG, Parfitt CH, et al. 1996. History of the food and drug administration's total diet study (part II) 1987-1993. J AOAC Int 79:163-170. 
9. REFERENCES

*Pennington JAT, Young BE, Wilson DB, et al. 1986. Mineral content of foods and total diets: The selected minerals in foods survey, 1982 to 1984. J Am Diet Assoc 86(7):876-891.

*Pennington JAT, Young BE, Wilson D. 1989. Nutritional elements in U.S. diets: Results from the total diet study, 1982 to 1986. J Am Diet Assoc 89(5):659-664.

*Perry DF. 1990. Flame atomic absorption spectrometric determination of serum zinc: Collaborative study. J Assoc Off Anal Chem 73:619-621.

Persson E, Henriksson J, Tallkvist J, et al. 2003. Transport and subcellular distribution of intranasally administered zinc in the olfactory system of rats and pikes. Toxicology 191(2-3):97-108.

Petrie JJB, Row PG. 1977. Dialysis anaemia caused by subacute zinc toxicity. Lancet i:1178-1180.

Pettilä V, Takkunen O, Tukiainen P. 2000. Zinc chloride smoke inhalation: A rare cause of severe acute respiratory distress syndrome. Intensive Care Med 26:215-217.

*Philipp R, Hughes A, Robertson M. 1982. Stomach cancer and soil metal content. Br J Cancer 45:482.

*Piao F, Yokoyama K, Ma N, et al. 2003. Subacute toxic effects of zinc on various tissues and organs of rats. Toxicol Lett 145(1):28-35.

Pimentel JL, Cook ME, Greger JL. 1992a. Anemia induced by ingestion of excess zinc in chicks: Importance of red blood cell turnover. J Nutr Biochem 3(3):146-150.

Pimentel JL, Greger JL, Cook ME, et al. 1992b. Iron metabolism in chicks fed various levels of zinc and copper. J Nutr Biochem 3(3):140-145.

Pinheiro FS, Jorge SM, Martinez FE. 1992. Plasma zinc and copper levels in maternal, placental intervillous space and cord blood. Nutr Res 12(3):367-373.

Piscator M. 1976. Health hazards from inhalation of metal fumes. Environ Res 11:268-270.

Pistorius D. 1976. Early reactions of the rat lung to respiratory air containing zinc oxide. Beitr Silikose Forsch Pneumokoniose 28:69-77.

Pistorius D, Rosmanith J, Breining H. 1976. Intake and distribution of zinc in rat organisms after zinc oxide inhalation in male and female animals. Beitr Silikose Forsch Pneumokoniose 28:92-101.

*Pita FW, Hyne NJ. 1975. The depositional environment of zinc, lead and cadmium in reservoir sediments. Water Res 9:701-706.

Plessi M, Bertelli D, Monzani A. 1997. Determination of aluminum and zinc in infant formulas and infant foods. J Food Comp Anal 10:36-42.

Pluess A, Ferrell RE Jr. 1991. Characterization of lead and other heavy metals in fly ash from municipal waste incinerators. Haz Waste Haz Mat 8:275-292.

Pocino M, Malave I, Baute L. 1992. Mitogenic effect of zinc on lymphocytes from strains of mice that are either high or low-responder to T-cell mitogens. Immunopharmacol Immunotoxicol 14(1-2):295-321. 
9. REFERENCES

Poissant L, Koprivnjak JF, Matthieu R. 1997. Some persistent organic pollutants and heavy metals in the atmosphere over a St. Lawrence River valley site (Villeroy) in 1992. Chemosphere 34:567-585.

Pokorny B, Ribaric-Lasnik C. 2000. Lead, cadmium, and zinc in tissues of roe deer (Capreolus capreolus) near the lead smelter in the Koroska Region (northern Slovenia). Bull Environ Contam Toxicol 64:20-26.

Polissar AV, Hopke PK, Poirot RL. 2001. Atmospheric aerosol over Vermont: Chemical composition and sources. Environ Sci Technol 35:4604-4621.

Pollack SV. 1982. Wound healing: A review. J Dermatol Surg Oncol 8:667-672.

Poole KG, Elkin BT, Bethke RW. 1998. Organochlorine and heavy metal contaminants in wild mink in western Northwest Territories, Canada. Arch Environ Contam Toxicol 34:406-413.

Popko J, Olszewski S, Hukalowicz K, et al. 2003. Lead, cadmium, copper and zinc concentrations in blood and hair of mothers of children with locomotor system malfunctions. Pol J Environ Stud 12(3):375-379.

Porea TJ, Belmont JW, Mahoney DH. 2000. Zinc-induced anemia and neutropenia in an adolescent. J Pediatr 136:688-690.

Pories WH, Strain WH. 1974. Zinc sulfate therapy in surgical patients. In: Pories WJ, Strain WH, Hsu JM, et al., eds. Clinical applications of zinc metabolism. Springfield, IL: C.C. Thomas, 139-157.

*Porter KG, McMaster D, Elmes ME, et al. 1977. Anaemia and low serum-copper during zinc therapy. Lancet ii:774.

*Poswillo DE, Cohen B. 1971. Inhibition of carcinogenesis by dietary zinc. Nature 231:447-448.

*Potter JL. 1981. Acute zinc chloride ingestion in a young child. Ann Emerg Med 10:267-269.

Powell JH, Powell RE. 2001. Trace elements in fish overlying subaqueous tailings in the tropical west Pacific. Water Air Soil Pollut 125:81-104.

Prasad AS. 1979. Zinc in human nutrition. Boca Raton, FL: CRC Press, Inc.

*Prasad AS. 1988. Clinical spectrum and diagnostic aspects of human zinc deficiency. In: Prasad AS, ed. Essential and toxic trace elements in human health and disease. New York, NY: Alan R. Liss, Inc., 3-53.

*Prasad AS. 1991. Discovery of human zinc deficiency and studies in an experimental human model. Am J Clin Nutr 53:403-412.

Prasad AS. 1993. Essentiality and toxicity of zinc. Scand J Work Environ Health 19:134-136.

Prasad R, Nath R. 1993. Zinc transport in monkey renal brush border membrane vesicles and its interaction with cadmium: A kinetic study. J Trace Elem Exp Med 6:95-107. 
9. REFERENCES

*Prasad AS, Brewer GJ, Schoomaker EB, et al. 1978. Hypocupremia induced by zinc therapy in adults. JAMA 240:2166-2168.

*Prasad AS, Miale A Jr, Farid Z, et al. 1963b. Zinc metabolism in patients with the syndrome of iron deficiency anemia, hepatosplenomegaly, dwarfism, and hypogonadism. J Lab Clin Med 61:537-549

* Prasad AS, Schulert AR, Sandstead HH, et al. 1963a. Zinc, iron, and nitrogen content of sweat in normal and deficient subjects. J Lab Clin Med 62:84-89.

Prasad R, Kaur D, Kumar V. 1996. Kinetic characterization of zinc binding to brush border membranes from rat kidney cortex: Interaction with cadmium. Biochim Biophys Acta 1284:69-78.

*Pratt GC, Palmer K, Wu CY, et al. 2000. An assessment of air toxics in Minnesota. Environ Health Perspect 108:815-825.

*Presley BJ, Taylor RJ, Boothe PN. 1990. Trace metals in Gulf of Mexico oysters. Sci Total Environ 97/98:551-593.

*Provost JJ, Munnis P, Morine GH. 1993. Alternate method for determining zinc in hair. Microchemical Journal 47(1-2):28-32.

Przyslawski J, Schlegel-Zawadzka M. 2003. The intake and consumption pattern of selected minerals in daily food rations taken by budgetary and non-budgetary workers in Poland. Trace Elem Electrolytes 20(2):108-112.

Quehee SS. 1994. Availability of elements in leaded/unleaded automobile exhausts, a leaded paint, a soil, and some mixtures. Arch Environ Contam Toxicol 27:145-153.

*Ragaini RC, Ralston HR, Roberts N. 1977. Environmental trace metal contamination in Kellogg, Idaho, near a lead smelting complex. Environ Sci Technol 11:773-781.

Raghunath R, Tripathi RM, Khandekar RN, et al. 1997. Retention times of $\mathrm{Pb}, \mathrm{Cd}, \mathrm{Cu}$ and $\mathrm{Zn}$ in children's blood. Sci Total Environ 207:133-139.

*Raghunath R, Tripathi RM, Sastry VN, et al. 2000. Heavy metals in maternal and cord blood. Sci Total Environ 250:135-141.

Rajaratnam G, Winder C, An M. 2002. Metals in drinking water from new housing estates in the Sydney area. Environ Res 89:165-170.

Ramachandran V, D'Souza TJ. 1998. Plant uptake of cadmium, zinc, and manganese in soils amended with sewage sludge and city compost. Bull Environ Contam Toxicol 61:347-354.

*Ramadurai J, Shapiro C, Kozloff M, et al. 1993. Zinc abuse and sideroblastic anemia. Am J Hematology 42(2):227-228.

*Ramelow GJ, Webre CL, Mueller CS, et al. 1989. Variations of heavy metals and arsenic in fish and other organisms from the Calcasieu River and Lake, Louisiana. Arch Environ Contam Toxicol 18:804818. 
9. REFERENCES

Rath FW, Kortge R, Haase P, et al. 1991. The influence of zinc administration on the development of experimental lung metastases after an injection of tumor cells into the tail vein of rats. Exp Pathol 41(4):215-217.

Ray S, McLeese DW, Waiwood BA, et al. 1980. The disposition of cadmium and zinc in Pandalus montagui. Arch Environ Contam Toxicol 9:675-681.

Reddy KJ, Wang L, Gloss SP. 1995. Solubility and mobility of copper, zinc, and lead in acidic environments. Plant Soil 171:53-58.

Reidiker M, Williams R, Devlin R, et al. 2003. Exposure to particulate matter. Environ Technol 37:2084-2093.

Reimann C, Nishavaara H, Decaritat P, et al. 1996. Regional variation of snowpack chemistry in the vicinity of nickel and Zapoljarnij, Russia, Northern Finland and Norway. Sci Total Environ 182:147-158.

*Reinhold JG, Faradji B, Abadi P, et al. 1991. Decreased absorption of calcium, magnesium, and phosphorous by humans due to increased fiber and phosphorous consumption as wheat bread. Nutr Rev 49(7):204-206.

Repke JT. 1991. Calcium, magnesium, and zinc supplementation and perinatal outcome. Clin Obstet Gynecol 34(2):262-267.

Rhoden CR, Lawrence J, Godleski JJ, et al. 2004. N-Acetylcysteine prevents lung inflammation after short-term inhalation exposure to concentrated ambient particles. Toxicol Sci 79(2):296-303.

*Rice KC. 1999. Trace-element concentrations in steambed sediment across the conterminous United States. Environ Sci Technol 33:2499-2504.

*Richards MP, Cousins RJ. 1975. Mammalian zinc homeostasis: Requirement for RNA and metallothionein synthesis. Biochem Biophys Res Commun 64:1215-1223.

Riffo M, Leiva S, Astudillo J. 1992. Effect of zinc on human sperm motility and the acrosome reaction. Int J Androl 15(3):229-237.

Rijstenbil JW, Poortvliet TCW. 1992. Copper and zinc in estuarine water: Chemical speciation in relation to bioavailability to the marine planktonic diatom Ditylum brightwellii. Environ Toxicol Chem 11(11):1615-1625.

Riley MR, Boesewetter DE, Kim AM, et al. 2003. Effects of metals $\mathrm{Cu}, \mathrm{Fe}, \mathrm{Ni}, \mathrm{V}$, and $\mathrm{Zn}$ on rat lung epithelial cells. Toxicology 190(3):171-184.

Riveros-Rosas H, Pfeifer GD, Lynam DR, et al. 1997. Personal exposure to elements in Mexico City air. Sci Total Environ 198:79-96.

Riviere MR, Chouroulinkov I, Fuerin M. 1959. Testicular tumors in the rat after injection of zinc chloride. Comptes Rendus Hebdomadaires des Seances de 1 Academie Sciences (Paris) 249:2649-2651.

*Rivlin RS. 1983. Misuse of hair analysis for nutritional assessment. Am J Med 75:489-493. 
9. REFERENCES

*Robinson FR, Fulton RM, Martinez M, et al. 1991. Zinc toxicosis in dogs. Canine Practice 16(3):2731.

Rodrigues LEA, Mathias CMD, Orrico M, et al. 1991. Antiulcerative action of zinc ions: Effect on lysosomal stability of gastric mucosa. Trace Elements in Medicine 8(3):109-112.

*Rohrs LC. 1957. Metal-fume fever from inhaling zinc oxide. Arch Ind Health 16:42-47.

Rosman KJR, Kempt NK. 1991. Determination of copper, zinc, cadmium and lead in marine sediments SD-M-2/TM and BCSS-1 and dogfish muscle DORM-1 by isotope dilution mass spectrometry. Geostandards Newsletter 15(1):117-119.

Rossanderhulten L, Brune M, Sandstrom B, et al. 1991. Competitive inhibition of iron absorption by manganese and zinc in humans. Am J Clin Nutr 54(1):152-156.

*Rossowska MJ, Nakamoto T. 1992. Caffeine decreases zinc and metallothionein levels in heart of newborn and adult rats. Pediatr Res 32(3):330-332.

*Roth-Bassell HA, Clydesdale FM. 1991. The influence of zinc, magnesium, and iron on calcium uptake in brush border membrane vesicles. J Am Coll Nutr 10(1):44-49.

*Rowan DJ, Kalff J. 1993. Predicting sediment metal concentrations in lakes without point sources. Water Air Soil Pollut 66:145-161.

*Roy WR. 1994. Groundwater contamination form municipal landfills in the USA. In: Adriano DC, ed. Contamination of groundwaters: Case studies. Northwood, UK: Scientific Review, 411-446.

*Rudd T, Lake DL, Mehrotra I, et al. 1988. Characterization of metal forms in sewage sludge by chemical extraction and progressive acidification. Sci Total Environ 74:149-175.

Ruick G. 1991. Results of a monitoring program for the evaluation of copper, lead, cadmium, zinc, and nickel intakes with food. Z Lebensm Unters Forsch 192(3):249-251.

Sadiq M, Mian AA. 1994. Lead, titanium and zinc in air particulate at Dhahran, Saudi Arabia, during and after Kuwait oil fires. Sci Total Environ 152:113-118.

*Saeed M, Fox RL. 1977. Relations between suspension pH and zinc solubility in acid and calcareous soils. Soil Sci 124:199-204.

Saito S, Okabe M, Yoshida K, et al. 1999. The effect of heavy metal-induced metallothionein on $\mathrm{Zn}, \mathrm{Cu}$ and $\mathrm{Cd}$ accumulation in rat kidney. Pharmacol Toxicol 84:255-260.

Saito S, Yoshida K. 1998. The effect of gold on zinc in liver and in metallothionein. Res Commun Mol Pathol Pharmacol 100(1):83-91.

Saito S, Yoshizu S, Kojima Y. 1995. Relative zinc-binding capacity of metallothionein: Studies in renal cytosols from zinc-injected rats. Res Commun Mol Pathol Pharmacol 90(3):363-371.

Salgueiro MJ, Zubillaga MB, Lysionek AE, et al. 2000. Bioavailability, biodistribution, and toxicity of biozn-aas: A new zinc source. Comparative studies in rats. Nutrition 16:762-766. 
9. REFERENCES

*Saltzman BE, Cholak J, Schafer LJ, et al. 1985. Concentrations of six metals in the air of eight cities. Environ Sci Technol 19:328-333.

*Saltzman BE, Gross SB, Yeager DW, et al. 1990. Total body burdens and tissue concentrations of lead, cadmium, copper, zinc, and ash in 55 human cadavers. Environ Res 52:126-145.

*Salzman MB, Smith EM, Koo C. 2002. Excessive oral zinc supplementation. J Pediatr Hematol Oncol 24(7):582-584.

*Samman S, Roberts DCK. 1987. The effect of zinc supplements on plasma zinc and copper levels and the reported symptoms in healthy volunteers. Med J Australia 146:246-249.

*Samman S, Roberts DCK. 1988. The effect of zinc supplementation on lipoproteins and copper status. Atherosclerosis 70:247-252.

Sandberg AS. 1991. The effect of food processing on phytate hydrolysis and availability of iron and zinc. Adv Exp Med Biol 289:499-508.

*Sanders JR, El Kherbawy MI. 1987. The effect of $\mathrm{pH}$ on zinc adsorption equilibria and exchangeable zinc pools in soils. Environ Pollut 44:165-176.

Sandstead HH. 1973. Zinc nutrition in the United States. Amer J Clin Nutr 26:1251-1260

Sandstead HH. 1978. Zinc interference with copper metabolism. JAMA 240:2188-2189.

*Sandstead HH. 1981. Zinc in human nutrition. In: Bronner F, Coburn JW, eds. Disorders of mineral metabolism. New York, NY: Academic Press, 94-159.

Sandstead HH. 1994. Understanding zinc: Recent observations and interpretations. J Lab Clin Med 124:322-327.

Sandstead HH, Frederickson CJ, Penland JG. 2000. History of zinc as related to brain function. J Nutr 130(2S):496S-502S.

Sandstead HH, Penland JG, Alcock NW, et al. 1998. Effects of repletion with zinc and other micronutrients on neuropsychologic performance and growth of Chinese children. Am J Clin Nutr 68(2):470S-475S.

*Sandstead HH, Wallwork JC, Halas ES, et al. 1983. Zinc and central nervous function. In: Sarkar B, ed. Biological aspects of metals and metal related diseases. New York, NY: Raven Press, 225-241.

Sandström B. 1992. Dose dependence of zinc and manganese absorption in man. Proc Nutr Soc 51(2):211-218.

Sandström B. 1995. Considerations in estimates of requirements and critical intake of zinc. Adaption, availability and interactions. Analyst 120:913-915.

*Sandström B, Abrahamson H. 1989. Zinc absorption and achlorhydria. Eur J Clin Nutr 43:877-879.

*Sandström B, Cederblad A. 1980. Zinc absorption from composite meals: II. Influence of the main protein source. Am J Clin Nutr 33:1778-1783. 
9. REFERENCES

*Sandström B, Sandberg AS. 1992. Inhibitory effects of isolated inositol phosphates on zinc absorption in humans. Journal of Trace Elements and Electrolytes in Health and Disease 6(2):99-103.

Sanfilippo DJ, Eisenga BH, Kuslikis BI. 2001. Acute zinc toxicity in a child receiving total peripheral nutrition (TPN). J Toxicol Clin Toxicol 39:553.

Santon A, Giannetto S, Sturniolo GC, et al. 2002. Interactions between $\mathrm{Zn}$ and $\mathrm{Cu}$ in LEC rats, an animal model of Wilson's disease. Histochem Cell Biol 117:275-281.

Santore RC, Mathew R, Paquin PR, et al. 2002. Application of the biotic ligand model to predicting zinc toxicity to rainbow trout, fathead minnow, and Daphnia magna. Comp Biochem Physiol C 133:271-285

*Sanudo-Wilhelmy SA, Gill GA. 1999. Impact of the clean water act on the levels of toxic metals in urban estuaries: The Hudson River Estuary revisited. Environ Sci Technol 33:3477-3481.

Sax NI. 1984. Dangerous properties of industrial materials. 6th ed. New York, NY: Van Nostrand Reinhold, 2751-2757.

Saxena R, Bedwal RS, Mathur RS. 1989. Zinc toxicity and male reproduction in rats: A histological and biochemical study. Trace Elem Med 6:119-133.

*Schalscha EB, Morales M, Vergara I, et al. 1982. Chemical fractionation of heavy metals in wastewater-affected soils. J Water Pollut Control Fed 54:175-180.

*Schenker MB, Speizer FE, Taylor JO. 1981. Acute upper respiratory symptoms resulting from exposure to zinc chloride aerosol. Environ Res 25:317-324.

*Schiffer RB, Sunderman FW Jr, Baggs RB, et al. 1991. The effects of exposure to dietary nickel and zinc upon humoral and cellular immunity in SJL mice. J Neuroimmunol 34:229-239.

*Schlicker SA, Cox DH. 1968. Maternal dietary zinc, and development and zinc, iron, and copper content of the rat fetus. J Nutr 95:287-294.

*Schmitt CJ, Brumbaugh WG. 1990. National contaminant biomonitoring program: Concentrations of arsenic, cadmium, copper, lead, mercury, selenium, and zinc in U.S. freshwater fish, 1976-1984. Arch Environ Contam Toxicol 19:731-747.

*Schock MR, Neff CH. 1988. Trace metal contamination from brass fittings. J Am Waterworks Assoc 80:47-56.

Schroder JJ, Cousins RJ. 1991. Metallothionein and zinc metabolism in hepatocytes. Methods Enzymol 205:575-584.

*Schroeder HA, Nason AP, Tipton IH. 1967. Essential trace metals in man: Zinc: Relation to environmental cadmium. J Chronic Dis 20:179-210.

Schuhmacher M, Domingo JL, Corbella J. 1993. Chromium, copper, and zinc concentrations in edible vegetables grown in Tarrogona Province, Spain. Bull Environ Contam Toxicol 50:514-521. 
9. REFERENCES

Schuhmacher M, Domingo JL, Llobet JM, et al. 1993. Dietary intake of copper, chromium and zinc in Tarragona Province, Spain. Sci Total Environ 132:3-10.

Schuhmacher M, Domingo JL, Lllobet JM, et al. 1994. Cadmium, chromium, copper, and zinc in rice and rice field soil from southern Catalonia, Spain. Bull Environ Contam Toxicol 53:54-60.

*Schuhmacher M, Meneses M, Granero S, et al. 1998. Trace metals in vegetation grown near to an old municipal solid waste incinerator from Catalonia, Spain. Fresenius Environ Bull 7:42-50.

*Scudlark JR, Conko KM, Church TM. 1994. Atmospheric wet deposition of trace elements to Chesapeake Bay: CBAD study year 1 results. Atmos Environ 28(8):1487-1498.

*Seal CJ, Heaton FW. 1983. Chemical factors affecting the intestinal absorption of zinc in vitro and in vivo. Br J Nutr 560:317-324.

Serfaty-Lacrosniere C, Wood RJ, Voytko D, et al. 1995. Hypochlorhydria from short-term omeprazole treatment does not inhibit intestinal absorption of calcium, phosphorus, magnesium or zinc from food in humans. J Am Coll Nutr 14(4):364-368.

Serjeant BR, Galloway RE, Gueri MC. 1970. Oral zinc sulphate in sickle cell ulcers. Lancet ii:891-893.

*Setchell BP, Waites GMH. 1975. The blood-testis barrier. In: Creep RO, Astwood EB, Geiger SR, eds. Handbook of physiology: Endocrinology V. Washington, DC: American Physiological Society.

Shabalina LP, Spiridonova VS. 1988. Toxicity and character of the effect of some zinc compounds. J Hyg Epidemiol Microbiol Immunol 32:397-405.

Shabanzadeh AP, Shuaub A, Yang T, et al. 2004. Effect of zinc in ischemic brain injury in an embolic model of stroke in rats. Neurosci Lett 356(1):69-71.

Shacklette HT. 1980. Elements in fruits and vegetables from areas of commercial production in the conterminous United States. Geological survey professional paper 1178. Washington, DC: United States government printing office.

*Shacklette HT, Boerngen JG. 1984. Element concentrations in soils and other surficial materials of the conterminous United States. A U.S. geological survey professional paper 1270. Washington, DC: United States government printing office.

Shafey TM, McDonald MW, Dingle JG. 1991. Effects of dietary calcium and available phosphorus concentration on digesta $\mathrm{pH}$ and on the availability of calcium, iron, magnesium and zinc from the intestinal contents of meat chickens. Br Poult Sci 32(1):185-194.

*Shah DR, Singh PP, Gupta RC, et al. 1988. Effect of oral zinc sulphate on serum lipids and lipoproteins in human subjects. Indian J Physiol Pharmacol 32:47-50.

*Shahin U, Yi SM, Paode RD, et al. 2000. Long-term elemental dry deposition fluxes measured around Lake Michigan with an automated dry deposition sampler. Environ Sci Technol 34:1887-1892.

*Sharrett AR, Carter AP, Orheim RM, et al. 1982a. Daily intake of lead, cadmium, copper, and zinc from drinking water: The Seattle study of trace metal exposure. Environ Res 28:456-475. 
9. REFERENCES

*Sharrett AR, Orheim RM, Carter AP, et al. 1982b. Components of variation in lead, cadmium, copper, and zinc concentration in home drinking water: The Seattle study of trace metal exposure. Environ Res 28:476-498.

*Shaw JCL, Bury AJ, Barber A, et al. 1982. A micromethod for the analysis of zinc in plasma or serum by atomic absorption spectrophotometry using graphite furnace. Clin Chim Acta 118:229-239.

Sheffet A, Thind I, Miller A, et al. 1982. Cancer mortality in a pigment plant utilizing lead and zinc chromates. Arch Environ Health 37:44-52.

*Shiller AM, Boyle E. 1985. Dissolved zinc in rivers. Nature 317:49-52.

*Sibley PK, Ankley GT, Cotter AM, et al. 1996. Predicting chronic toxicity of sediments spiked with zinc: An evaluation of the acid-volatile sulfide model using a life-cycle test with the midge Chironomus tetans. Environ Toxicol Chem 15(12):2102-2112.

Siddiq MM, Tsirka SE. 2004. Modulation of zinc toxicity by tissue plasminogen activator. Mol Chem Neuropathol 25(1):162-171.

Sidle RC, Chambers JC, Amacher MC. 1991. Fate of heavy metals in an abandoned lead-zinc tailing pond: II. Sediment. J Environ Qual 20:752-758.

Sileo L, Beyer WM. 1985. Heavy metals in white-tailed deer living near a zinc smelter in Pennsylvania. J Wildlife Dis 21:289-296.

*Simmer K, Lort-Phillips L, James C, et al. 1991. A double-blind trial of zinc supplementation in pregnancy. Eur J Clin Nutr 45:139-144.

Simons TJB. 1995. The affinity of human erythrocyte porhobilinogen synthase for $\mathrm{Zn}^{2+}$ and $\mathrm{Pb}^{2+}$. Eur J Biochem 234:178-183.

Sinex SA, Wright DA. 1988. Distribution of trace metals in the sediments and biota of Chesapeake Bay. Mar Pollut Bull 19:425-431.

Singh KP, Zaidi SIA, Raisuddin S, et al. 1992. Effect of zinc on immune functions and host resistance against infection and tumor challenge. Immunopharmacol Immunotoxicol 14(4):813-840.

Smith R. 1984. NIWR interlaboratory comparison study No. 83/A: Determination of trace metals in river sediment. Pretoria, South Africa: Council for Scientific and Industrial Research, National Institute for Water Research. Research report No. 602, 1-33.

Smith DJT, Harrison RM, Luhana L, et al. 1996. Concentrations of particulate airborne polycyclic aromatic hydrocarbons and metals collected in Lahore, Pakistan. Atmos Environ 30:4031-4040.

*Smith SE, Larson EJ. 1946. Zinc toxicity in rats: Antagonistic effects of copper and liver. J Biol Chem 163:29-38.

Smith JW, Tokach MD, Goodband RD, et al. 1997. Effects of the interrelationship between zinc oxide and copper sulfate on growth performance of early-weaned pigs. J Anim Sci 75:1861-1866. 
9. REFERENCES

*Smolders E, Degryse F. 2002. Fate and effect of zinc from tire debris in soil. Environ Sci Technol 36:3706-3710.

*Sohler A, Wolcott P, Pfeiffer CC. 1976. Determination of zinc in fingernails by non-flame atomic absorption spectroscopy. Clin Chim Acta 70:391-398.

*Song MR, Adham NF. 1979. Evidence for an important role of prostaglandin-E2 and prostaglandin-F2 in the regulation of zinc transport in the rat. J Nutr 109:2152-2159.

*Song MK, Kim YY, Heng MCY, et al. 1992. Prostaglandin interacts with steroid sex hormones in the regulation of intestinal zinc transport. Comp Biochem Physiol 101A(3):477-481.

Soto-Ferreiro RM, Casais Laino C, Bermejo-Barrera P. 1991. Comparative study of sample preparation methods for zinc, iron and copper determination in mussels by flame atomic-absorption spectrometry. Anal Lett 24(12):2277-2292.

*Soto-Jimenez M, Paez-Osuna F. 2001. Cd, Cu, Pb, and Zn in lagoonal sediments from Mazatlan Harbor (se Gulf of California): Bioavailability and geochemical fractioning. Bull Environ Contam Toxicol 66:350-356.

*Spencer H, Kramer L, Osis D. 1985. Zinc metabolism in man. J Environ Pathol Toxicol Oncol 5:265278.

*Spencer H, Norris C, Osis D. 1992. Further studies of the effect of zinc on intestinal absorption of calcium in man. J Am Coll Nutr 11(5):561-566.

*Spencer H, Osis D, Kramer L, et al. 1976. Intake, excretion, and retention of zinc in man. In: Prasad AS, ed. Trace elements in human health and disease. Vol. 1: Zinc and copper. New York, NY:

Academic Press, 345-361.

*Spencer H, Rosoff B. 1966. Effect of chelating agents in the removal of zinc-65 in man. Health Phys 12:475-480.

Spencer H, Rosoff B, Feldstein A, et al. 1965b. Metabolism of zinc-65 in man. Radiat Res 24:432-445.

Spencer H, Vankinscott V, Lewin I, et al. 1965a. Zinc-65 metabolism during low and high calcium intake in man. J Nutr 86:169-177.

*Spicer CW, Buxton BE, Holdren MW, et al. 1996. Variability of hazardous air pollutants in an urban area. Atmos Environ 30:3443-3456.

*Sprenger MD, McIntosh AW, Hoenig S. 1988. Concentrations of trace elements in yellow perch (Perca flavescens) from six acidic lakes. Water Air Soil Pollut 37:375-388.

*Sprenger M, McIntosh A, Lewis T. 1987. Variability in concentrations of selected trace elements in water and sediment of six acidic lakes. Arch Environ Contam Toxicol 16:383-390.

Stabile A, Pesaresi MA, Stabile AM, et al. 1991. Immunodeficiency and plasma zinc levels in children with downs syndrome: A long-term follow-up of oral zinc supplementation. Clin Immunol Immunopathol 58(2):207-216. 
9. REFERENCES

Stanley JS, Stockton RA. 1986. Broad scan analysis of the fy82 national human adipose tissue survey specimens, V. Trace elements. Washington, DC: U.S. Environmental Protection Agency, 72. EPA560586039.

Steffensen IL, Mesna OJ, Melhuus A, et al. 1991. Mitogenicity and metallothionein induction: Two separate effects of zinc ions on human mononuclear blood cells. Pharmacol Toxicol 68(6):445-449.

Steimle FW, Zdanowicz VS, Gadbois DF. 1990. Metals and organic contaminants in Northwest Atlantic deep-sea tilefish tissues. Mar Pollut Bull 21:530-535.

Stein A, Varekamp C, Vanegmond C, et al. 1995. Zinc concentrations in groundwater at different scales. J Environ Qual 24:1205-1214.

Steinbach OM, Wolterbeek HT. 1993. Effects of zinc on rat hepatoma HTC cells and primary cultured rat hepatocytes. Toxicol Appl Pharmacol 118(2):245-254.

Stewart FM, Monteiro LR, Furness RW. 1997. Heavy metal concentrations in Cory's Shearwater, Calonectris diomedea, fledglings from the Azores, Portugal. Bull Environ Contam Toxicol 58:115-122.

Stewart FM, Thompson DR, Furness RW. 1994. Seasonal variation in heavy metal levels in tissue of common guillemots, Uria aalge from Northwest Scotland. Arch Environ Contam Toxicol 27:168-175.

Stillman MJ. 1995. Metallothioneins. Coordination Chemistry Reviews 144:461-511.

*Stocks P, Davies RI. 1964. Zinc and copper content of soils associated with the incidence of cancer of the stomach and other organs. Br J Cancer 18:14-24.

*Stokinger HE. 1981. The metals: Zinc, Zn. In: Clayton GD, Clayton FE, eds. Patty's industrial hygiene and toxicology. Vol. 2A: Toxicology. 3rd ed. New York, NY: John Wiley and Sons, 20332049.

*Stoner GD, Shimkin MB, Toxell MC, et al. 1976. Test for carcinogenicity of metallic compounds by the pulmonary tumor response in strain A mice. Cancer Res 36(5):1744-1747.

Storelli MM, Marcotrigiano GO. 2000. Environmental contamination in bottlenose dolphin (Tursiops truncatus): Relationship between levels of metals, methylmercury, and organochlorine compounds in an adult female, her neonate, and a calf. Bull Environ Contam Toxicol 64:333-340.

*Storm GL, Fosmire GJ, Bellis ED. 1994. Persistence of metals in soil and selected vertebrates in the vicinity of the Palmerton zinc smelters. J Environ Qual 23:508-514.

*Straube EF, Schuster NH, Sinclair AJ. 1980. Zinc toxicity in the ferret. J Comp Pathol 90:355-361.

*Stroud S. 1991. Too much zinc has a domino effect. Am J Nurs 91(2):61.

Struyf H, Vangrieken R. 1993. An overview of wet deposition of micropollutants to the North Sea. Atmos Environ 27a:2669-2687.

*Sturgis CC, Drinker P, Thomson RM. 1927. Metal fume fever: I. Clinical observations on the effect of the experimental inhalation of zinc oxide by two apparently normal persons. J Ind Hyg 9:88-97. 
9. REFERENCES

*Sturniolo GC, Montino C, Rossetto L, et al. 1991. Inhibition of gastric acid secretion reduces zinc absorption in man. J Am Coll Nutr 10(4):372-375.

*Stutz DR, Janusz SJ, eds. 1988. Hazardous materials injuries. A handbook for pre-hospital care. 2nd ed. Beltsville, MD: Bradford Communications Corporation, 412-413.

Subcommittee on Mineral Toxicity in Animals. 1980. Zinc: Mineral tolerance of domestic animals. Washington, DC: National Academy of Sciences, Subcommittee on Mineral Toxicity in Animals, 553577.

*Suber RL. 1989. Clinical pathology for toxicologists. In: Hayes AW, ed. Principles and methods of toxicology. 2nd ed. New York, NY: Raven Press, Ltd., 485-519.

Subramanian KS. 1988. Determination of trace elements in biological fluids other than blood by graphite furnace atomic absorption spectrometry. Prog Anal Spectrosc 11:511-608.

Subramanian KS, Connor JW, Meranger JC. 1991. Leaching of antimony, cadmium, copper, lead, silver, tin and zinc from copper piping with non-lead-based soldered joints. J Environ Sci Health A26(6):911929.

Sukumar A. 2002. Factors influencing levels of trace elements in human hair. Rev Environ Contam Toxicol 175:45-78.

Summer W, Haponik E. 1981. Inhalation of irritant gases. Clin Chest Med 2:273-287.

*Summerfield AL, Steinberg FU, Gonzalez JG. 1992. Morphological findings in bone marrow precursor cells in zinc induced copper deficiency anemia. Am J Clin Pathol 97(5):665-668.

Sunanda BS, Rao S, Raju TR. 1998. Corticosterone attenuates zinc-induced neurotoxicity in primary hippocampal cultures. Brain Res 791:295-298.

Sundelin B, Eriksson AK. 2001. Mobility and bioavailability of trace metals in sulfidic coastal sediments. Environ Toxicol Chem 20:748-756.

Sung W. 1995. Some observations on surface partitioning of $\mathrm{Cd}, \mathrm{Cu}$, and zinc in estuaries. Environ Sci Technol 29:1303-1312.

*Sutomo FX, Woutersen RA, Vandenhamer CJA. 1992. Effects of elevated zinc intake on the copper metabolism and the pancreas of the mouse. J Trace Elem Electrolytes Health Dis 6(2):75-80.

*Sutton WR, Nelson VE. 1937. Studies on zinc. Proc Soc Exp Biol Med 36:211-213.

*Sweet CW, Vermette SJ, Landsberger S. 1993. Sources of toxic trace elements in urban air in Illinois. Environ Sci Technol 27:2502-2510.

Szefer P, Pempkowiak J, Skwarzec B, et al. 1993. Concentration of selected metals in penguins and other representative fauna of Antarctica. Sci Total Environ 138:281-288.

*Szpunar CB, Lambert JB, Buikstra JE. 1978. Analysis of excavated bone by atomic absorption. Am J Phys Anthrop 48:199-202. 
9. REFERENCES

Szuster-Ciesielska A, Stachura A, Slotwinska M, et al. 2000. The inhibitory effect of zinc on cadmiuminduced cell apoptosis and reactive oxygen species (ROS) production in cell cultures. Toxicology 145:159-171.

*Szymanska JA, Swietlicka EA, Piotrowski JK. 1991. Protective effect of zinc in the hepatotoxicity of bromobenzene and acetaminophen. Toxicology 66(1):81-91.

*Tacnet F, Watkins DW, Ripoche P. 1990. Studies of zinc transport into brush-border membrane vesicles isolated from pig small intestine. Biochim Biophys Acta 1024:323-330.

Takagi Y, Matsuda S, Imai S, et al. 1986. Trace elements in human hair: An international comparison. Bull Environ Contam Toxicol 36:793-800.

*Takagi Y, Matsuda S, Imai S, et al. 1988. Survey of trace elements in human nails: An international comparison. Bull Environ Contam Toxicol 41:690-695.

Tamura T. 2003. Relationship between plasma zinc levels and body-mass index (BMI) in pregnancy. FASEB J 17(4-5):A302.

Tan BKH, Bay BH, Sit KH, et al. 1995. Acute zinc administration prolongs hexobarbitone-induced sleeping time in C57/6J mice. Pharmacol Res 32(4):233-236.

*Taper LJ, Hinners ML, Ritchey SJ. 1980. Effects of zinc intake on copper balance in adult females. Am J Clin Nutr 33:1077-1082.

Taubeneck MW, Daston GP, Rogers JM, et al. 1995. Tumor necrosis factor- $\alpha$ alters maternal and embryonic zinc metabolism and is developmentally toxic in mice. J Nutr 125:908-919.

*Taylor HE, Antweiler RC, Roth DA, et al. 2001. The occurrence and distribution of selected trace elements in the upper Rio Grande and tributaries in Colorado and northern New Mexico. Arch Environ Contam Toxicol 41:410-426.

Teillet L, Tacnet F, Ripoche P, et al. 1995. Effect of aging on zinc and histidine transport across rat intestinal brush-border membranes. Mech Ageing Dev 79:151-167.

Telisman S, Cvitkovic P, Jurasovic J, et al. 2000. Semen quality and reproductive endocrine function in relation to biomarkers of lead, cadmium, zinc, and copper in men. Environ Health Perspect 108:45-53.

Terse PS, Komiskey HL. 1997. Modulation of a competitive $N$-methyl-D-aspartate receptor antagonist binding by zinc oxide. Brain Res 744:347-350.

Terytze K. 1993. Enrichment and distribution of heavy meals and other elements in surface sediments of Berlin waters (Germany) and their surroundings. Acta Hydrochim Hydrobiol 21:8-20.

Tessier A, Fortin D, Belzile N, et al. 1996. Metal sorption to diagenetic iron and manganese oxyhydroxides and associated organic matter: Narrowing the gap between field and laboratory measurements. Geochim Cosmochim Acta 60:387-404.

Thomas DJ, Winchurch RA, Adler WH. 1989. Influence of age upon the metabolism of zinc in livers of C57BL/6J mice. Mech Ageing Dev 47:241-251. 
9. REFERENCES

Thomas EA, Bailey LB, Kauwell GA, et al. 1992. Erythrocyte metallothionein response to dietary zinc in humans. J Nutr 122(12):2408-2414.

*Thompson ED, McDermott JA, Zerkle TB, et al. 1989. Genotoxicity of zinc in 4 short-term mutagenicity assays. Mutat Res 233:267-272.

Thrush PW, ed. 1968. A dictionary of mining and terms. Washington, DC: U.S. Department of Interior.

Torre M, Rodriguez AR, Saura-Calixto F. 1991. Effects of dietary fiber and phytic acid on mineral availability. Crit Rev Food Sci Nutr 30(2):1-22.

Towers NR, Young PW, Wright DE. 1981. Effect of zinc supplementation on bovine plasma copper. N Z Vet J 29:113-114.

Travaglini P, Mocchegiani E, Demin C, et al. 1992. Modifications of thymulin titers in patients affected with prolonged low or high zinc circulating levels are independent of patients age. Arch Gerontol Geroatr S3:349-357.

Treble RG, Thompson TS. 1998. Trace metals in moose (Alces alces) liver. Bull Environ Contam Toxicol 60:531-537.

*TRI02. 2004. TRI explorer: Providing access to EPA's toxics release inventory data. Washington, DC: Office of Information Analysis and Access. Office of Environmental Information. U.S.

Environmental Protection Agency. Toxics Release Inventory. http://www.epa.gov/triexplorer/.

December 28, 2004.

*Tripathi RM, Raghunath R, Mahapatra S, et al. 2001. Blood lead and its effect on Cd, Cu, Zn, Fe and hemoglobin levels of children. Sci Total Environ 277:161-168.

*Trocine RP, Trefry JH. 1996. Metal concentrations in sediment, water and clams from the Indian River Lagoon, Florida. Mar Pollut Bull 32(10):754-759.

Troskot B, Simicevic VN, Dodig M, et al. 1997. The protective effect of zinc sulphate pretreatment against duodenal ulcers in the rat. BioMetals 10:325-329.

*Tsuda T, Inoue T, Kojima M, et al. 1995. Market basket and duplicate portion estimation of dietary intakes of cadmium, mercury, arsenic, copper, manganese, and zinc by Japanese adults. J AOAC Int 78(6):1363-1367.

Turecki T, Ewan RC, Stahr HM. 1995. Effect of dietary phytic acid and cadmium on the availability of cadmium, zinc, copper, iron, and manganese to rats. Bull Environ Contam Toxicol 54:760-767.

Turgeon-O'Brien H, Ferland S. 1996. The relationship between maternal zinc (Zn) intake and neonatal anthropometric measurements in newborn infants. FASEB J 10:A517.

Turnbull AJ, Wood RJ, Russell RM. 1992. Hypochlorhydria does not inhibit zinc absorption in the rat. Nutr Res 12(8):999-1008.

*Turner JA. 1921. An occupational dermatoconiosis among zinc oxide workers. Public Health Rep $36: 2727-2732$. 
9. REFERENCES

Turnlund JR, Keyes WR, Hudson CA, et al. 1991. A stable isotope study of zinc, copper, and iron absorption and retention by young women fed vitamin B6 deficient diets. Am J Clin Nutr 54(6):10591064.

*Tyler LD, McBride MB. 1982. Mobility and extractability of cadmium, copper, nickel, and zinc in organic and mineral soil columns. Soil Science 134:198-205.

Udom AO, Brady FO. 1980. Reactivation in vitro of zinc-requiring apo-enzymes by rat liver zincthionein. Biochem J 187:329-335.

Uenlue E, Guemguem B. 1993. Concentrations of copper and zinc in fish and sediments from the Tigris River in Turkey. Chemosphere 26:2055-2061.

*Underwood EJ. 1977. Trace elements in human and animal nutrition. 4th ed. New York, NY: Academic Press.

*Uriu-Hare JY, Stern JS, Keen CL. 1989. Influence of maternal dietary Zn intake on expression of diabetes-induced teratogenicity in rats. Diabetes 38:1282-1290.

*USGS. 2000b. Concentrations of selected trace elements in fish tissue and Concentrations of selected trace elements in fish tissue and streambed sediment in the Clark Fork-Pend Oreille and Spokane River Basins, Washington, Idaho, and Montana, 1998. Boise, Idaho: U.S. Geological Survey. WaterResources Investigation Report 00-4159.

*USGS. 2000a. Organic compounds and trace elements in fish tissue and bed sediment from streams in the Yellowstone River Basin, Montana and Wyoming, 1998. Cheyenne, WY: U.S. Geological Survey. Water-Resources Investigations Report 00-4190.

*USGS. 2001. Zinc. U.S. Geological Survey, Mineral Commodity Summaries. http://minerals.usgs.gov/minerals/pubs/commodity/zinc. June 5, 2003.

*USGS. 2002. Trace elements and organic compounds in streambed sediment and fish tissue of coastal New England streams, 1998-99. Denver, CO: U.S. Geological Survey. Water-Resources Investigations Report 02-4179.

*USGS. 2003. Zinc. U.S. Geological Survey, Mineral Commodity Summaries. http://minerals.usgs.gov/minerals/pubs/commodity/zinc. June 5, 2003.

Uzzo RG, Leavis P, Hatch W, et al. 2002. Zinc inhibits nuclear factor-kappa B activation and sensitizes prostate cancer cells to cytotoxic agents. Clin Cancer Res 8(11):3579-3583.

Vallee BL. 1959. Biochemistry, physiology and pathology of zinc. Physiol Rev 39:443-490.

Vallee BL, Falchuk KH. 1993. The biochemical basis of zinc physiology. Physiol Rev 73(1):79-118.

Valverde M, Rojas E, Sordo M, et al. 1996. Genotoxic effects of zinc chloride and aluminum chloride in human leukocytes and lymphocytes assessed by the alkaline single cell gel electrophoresis assay. Environ Mol Mutagen 27:70.

Van Campen DR, Scaife PU. 1967. Zinc interference with copper absorption in rats. J Nutr 91:473-476. 
*van den Berg C. 1986. The determination of trace metals in sea-water using cathodic stripping voltammetry. Sci Total Environ 49:89-99.

van den Berg CMG. 1991. Monitoring of labile copper and zinc in estuarine waters using a cathodicstripping chronopotentiometry. Marine Chemistry 34(3-4):211-223.

Vas P. 1991. Trace metal levels in sharks from British and Atlantic waters. Mar Pollut Bull 22:67-72.

Vas P, Steven JD, Bonwick GA, et al. 1990. Cd, Mn, and Zn concentrations in vertebrae of blue shark and shortfin Mako in Australian coastal waters. Mar Pollut Bull 13:217-218.

Vasconcelos MTSD, Taveres HMF. 1998. Atmospheric metal pollution (Cr, $\mathrm{Cu}, \mathrm{Fe}, \mathrm{Mn}, \mathrm{Ni}, \mathrm{Pb}$ and $\mathrm{Zn}$ ) in Oporto City derived from results for low-volume aerosol samplers and for the moss Sphagnum auriculatum bioindicator. Sci Total Environ 212:11-20.

*Vasikaran SD, Patel S, O'Gorman P. 1992. Zinc and copper status of lead workers. Trace Elem Med 9(2):103-104.

Vazquez F, Aguilera G, Delgado D, et al. 1990. Trace and heavy metals in the oyster Crassostrea virginica, San Andreas Lagoon, Tamaulipas, Mexico. Bull Environ Contam Toxicol 45:907-914.

*Vazquez FG, Aguilera LG, Sharma VK. 1994. Metals in sediments of San Andres Lagoon, Tamaulipas, Mexico. Bull Environ Contam Toxicol 52:382-387.

*Vazquez FG, Sharma VK, Alexander VH, et al. 1995. Metals in some lagoons of Mexico. Environ Health Perspect Suppl 103:33-34.

Vedagiri U, Ehrenfeld J. 1991. Effects of Sphagnum moss and urban runoff on bioavailability of lead and zinc from acidic wetlands of the New Jersey pinelands. Environ Pollut 72(4):317-330.

*Veeken A, Hamelers B. 2002. Sources of Cd, Cu, Pb and Zn in biowaste. Sci Total Environ 300:87-98.

Veinott G, Perroncashman S, Anderson MR. 2001. Baseline metal concentrations in coastal Labrador sediments. Mar Pollut Bull 42:187-192.

Velie E, Shaw G, Block G, et al. 1996. Maternal supplement and dietary zinc intake and the occurrence of neural tube defects in California. Am J Epidemiol 143:S1.

*Venitt S, Levy LS. 1974. Mutagenicity of chromates in bacteria and its relevance to chromate carcinogenesis. Nature 250:493-495.

Versiek J, Cornelis R. 1980. Normal levels of trace elements in human blood plasma or serum. Anal Chem Acta 116:217-254.

Veysseyre A, Moutard K, Ferrari C, et al. 2001. Heavy metals in fresh snow collected at different altitudes in the Chamonix and Maurienne Valleys, French Alps: Initial results. Atmos Environ 35:415425.

*Vieira I, Sonnier M, Cresteil T. 1996. Developmental expression of CYP2E1 in the human liver: Hypermethylation control of gene expression during the neonatal period. Eur J Biochem 238:476-483. 
9. REFERENCES

*Vilkina GA, Pomerantseva MD, Romaiia LK. 1978. [Lack of mutagenic activity of cadmium and zinc salts in somatic and germ mouse cells.] Genetika (Moscow) 14:2212-2214. (Russian)

*Villaescusa-Celaya JA, Gutierrez-Galindo EA, Flores-Munoz G. 2000. Heavy metals in the fine fraction of coastal sediments from Baja California (Mexico) and California (USA). Environ Pollut 108:453-462.

*Villanueva S, Botello AV. 1998. Metal pollution in coastal areas of Mexico. Rev Environ Contam Toxicol 157:53-94.

Villarreal-Trevino CM, Obregon-Morales ME, Lozano-Morales JF, et al. 1986. Bioaccumulation of lead, copper, iron, and zinc by fish in a transect of the Santa Catarina River in Cadereyta Jimenez, Nuevo Leon, Mexico. Bull Environ Contam Toxicol 37:395-401.

*Vogelmeier C, Konig G, Bencze K, et al. 1987. Pulmonary involvement in zinc fume fever. Chest 92:946-949.

Volmer PA, Roberts J, Meerdink RJ. 2004. Canine zinc toxicosis from ingestion of a decorative bathroom fixture. J Toxicol Clin Toxicol 41(5):741.

*Voroshilin SI, Plotko EG, Fink TV, et al. 1978. [Cytogenetic effects of inorganic and acetate compounds of tungsten, zinc, cadmium, and cobalt in animal and human somatic cells.] Tsitol Genet 12(3):241-243. (Russian)

*Waalkes MP, Rehm S, Riggs CW, et al. 1989. Cadmium carcinogenesis in male Wistar [Crl:(WI)BR] rats: Dose-response analysis of effects of zinc on tumor induction in the prostate, in the testes, and at the injection site. Cancer Res 49:4282-4288.

*Wagner HP, Dalglish K, McGarrity MJ. 1991. Determination of zinc in wort and beer by graphitefurnace atomic absorption spectrometry. J Am Soc Brew Chem 49(1):28-30.

*Wallenius K, Mathur A, Abdulla M. 1979. Effect of different levels of dietary zinc on development of chemically induced oral cancer in rats. Int J Oral Surg 8:56-62.

Walsh CT, Sandstead HH, Prasad AS, et al. 1994. Zinc: Health effects and research priorities for the 1990s. Environ Health Perspect 102(Suppl. 2):5-46.

*Walters M, Roe F. 1965. A study of the effects of zinc and tin administered orally to mice over a prolonged period. Food Cosmet Toxicol 3:276-321.

Walther SC, Walther UI, Siagian II, et al. 2003. Effectivity of antioxidative vitamins on zinc-induced toxicity in doxorubicin pretreated lung cells. Naunyn-Schmiedebergs Arch Pharmacol 367(Supp. 1):R157.

Waner T, Nyska A. 1991. The toxicological significance of decreased activities of blood alanine and aspartate-aminotransferase. Vet Res Commun 15(1):73-78.

Wang Z, Atkinson SA, Bertolo RFP, et al. 1993. Alterations in intestinal uptake and compartmentalization of zinc in response to short-term dexamethasone therapy or excess dietary zinc in piglets. Pediatric Res 33(2):118-124. 
9. REFERENCES

*Wapnir RA, Balkman C. 1991. Inhibition of copper absorption by zinc: Effect of histidine. Biol Trace Elem Res 29(3):193-202.

*Wapnir RA, Stiel L. 1986. Zinc intestinal absorption in rats: Specificity of amino acids as ligands. J Nutr 116:2171-2179.

*Warwick P, Hall A, Pahley V, et al. 1998. Zinc and cadmium mobility in sand: Effects of pH, speciation, cation exchange capacity (CEC), humic acid and metal ions. Chemosphere 36(10):2283-2290.

*Wasowicz W, Gromadzinska J, Szram K, et al. 2001. Selenium, zinc, and copper concentrations in the blood and milk of lactating women. Biol Trace Elem Res 79(3):221-233.

*Wastney ME, Aamodt RL, Rumble WF, et al. 1986. Kinetic analysis of zinc metabolism and its regulation in normal humans. Am J Physiol 251:R398-R408.

Wastney ME, Ahmed S, Henkin RI. 1992. Changes in regulation of human zinc metabolism with age. Am J Physiol 263(5):1162-1168.

Wastney ME, Gokmen IG, Aamodt RL, et al. 1991. Kinetic analysis of zinc metabolism in humans after simultaneous administration of Zn-65 and Zn-70. Am J Physiol 260(1):R134-R141.

Watanabe T, Iwami O, Nakatsuka H, et al. 1991. Correlation of cadmium, copper, manganese, and zinc levels in the urine of people in nonpolluted areas. J Toxicol Environ Health 33(3):263-272.

Watjen W, Haase H, Biagioli M, et al. 2002. Induction of apoptosis in mammalian cells by cadmium and zinc. Environ Health Perspect Suppl 110:865-867.

Watkins KL, Southern LL. 1993. Effect of dietary sodium zeolite-A on zinc utilization by chicks. Poult Sci 72(2):296-305.

*Watson WS, Mitchell KG, Lyons TDB, et al. 1987. A simple blood sample method for measuring oral zinc absorption in clinical practice. Clin Phys Physiol Meas 8:173-178.

Watson WS, Mitchell KG, Lyon TDB, et al. 1999. A two-compartment model for zinc in humans. J Trace Elem Med Biol 13:141-149.

Wax PM, Becker CE, Curry SC. 2003. Unexpected "gas" casualties in Moscow: A medical toxicology perspective. Ann Emerg Med 41:700-705.

*Weast RC, ed. 1988. CRC handbook of chemistry and physics. 69th ed. Boca Raton, FL: CRC Press, B-143, B-145.

Weathers KC, Likens GE, Barmann FH. 1988. Cloudwater chemistry from ten sites in North America. Environ Sci Technol 22:1018-1026.

*Weigand E, Kirchgessner M. 1992. Absorption, endogenous excretion, and balance of zinc in growing rats on diets with various sugars replacing starch. Biol Trace Elem Res 34:67-77.

*Weigert P. 1991. Metal loads of food of vegetable origin including mushrooms. In: Merian E, ed. Metals and their compounds in the environment. Weinheim, Federal Republic of Germany: VCH, 449468. 
9. REFERENCES

Weinberger RP, Rostas JAP. 1991. Effect of zinc on calmodulin-stimulated protein kinase-II and protein phosphorylation in rat cerebral cortex. J Neurochem 57(2):605-614.

*Weiss G, ed. 1986. Hazardous chemicals data book. 2nd ed. Park Ridge, NJ: Noyes Data Corp., 1028-1048.

Weiss JH, Hartley DM, Koh JY, et al. 1993. AMPA receptor activation potentiates zinc neurotoxicity. Neuron 10(1):43-49.

Wellinghausen N, Rink L. 1998. The significance of zinc for leukocyte biology. J Leuk Biol 64:571577.

Wenk GL, Stemmer KL. 1983. Suboptimal dietary zinc intake increases aluminum accumulation into the rat brain. Brain Res 288:393-395.

Wenning RJ, Bonnevie NL, Huntley SL. 1994. Accumulation of metals, polychlorinated biphenyls, and polycyclic aromatic hydrocarbons in sediments from the Lower Passaic River, New Jersey. Arch Environ Contam Toxicol 27:64-81.

Wesselkamper SC, Chen LC, Gordon T. 2001. Development of pulmonary tolerance in mice exposed to zinc oxide fumes. Toxicol Sci 60:144-151.

*West JR, Smith HW, Chasis H. 1948. Glomerular filtration rate, effective renal blood flow, and maximal tubular excretory capacity in infancy. J Pediatr 32:10-18.

*Wetter L, Agren MS, Hallmans G, et al. 1986. Effects of zinc oxide in an occlusive, adhesive dressing on granulation tissue formation. Scand J Plast Reconstr Surg 20:165-172.

White CW, Avraham KB, Shanley PF, et al. 1991. Transgenic mice with expression of elevated levels of copper-zinc superoxide dismutase in the lungs are resistant to pulmonary oxygen toxicity. J Clin Invest 87(6):2162-2168.

White DH, Cromartie E. 1985. Bird use and heavy metal accumulation in waterbirds at dredge disposal impoundments, Corpus Christi, Texas. Bull Environ Contam Toxicol 34:295-300.

*White JR, Driscoll CT. 1987. Zinc cycling in an acidic Adirondack Lake. Environ Sci Technol 21:211216.

Whittaker PH. 1945. Radiological appearances of the chest following partial asphyxiation by a smoke screen. Br J Radiol 18:396.

*WHO. 1996. Zinc. Trace elements in human nutrition and health. World Health Organization,72-104.

*WHO. 2001. Zinc. Environmental Health Criteria 221. Geneva, Switzerland: World Health Organization. http://www.inchem.org/documents/ehc/ehc/ehc221.htm. June 11, 2003.

*Widdowson EM, Dickerson JWT. 1964. Chemical composition of the body. In: Comar CL, Bronner F, eds. Mineral metabolism: An advanced treatise. Volume II: The elements Part A. New York: Academic Press. 
*Wilde C. 1975. Aerosol metallic paints: Deliberate inhalation: A study of inhalation and/or ingestion of copper and zinc particles. Int J Addict 10:127-134.

Wilhelm B, Walther UI, Fichtl B. 2001. Effects of zinc chloride on glutathione and glutathione synthesis rates in various lung cell lines. Arch Toxicol 75:388-394.

*Wilhelm M, Hafner D, Lombeck I, et al. 1991. Monitoring of cadmium, copper, lead and zinc status in young children using toenails: Comparison with scalp hair. Sci Total Environ 103:199-207.

Willis JB. 1962. Determination of lead and other heavy metals in urine by atomic absorption spectroscopy. Anal Chem 35:614-617.

Willoughby RA, MacDonald E, McSherry BJ, et al. 1972. Lead and zinc poisoning and the interaction between $\mathrm{Pb}$ and $\mathrm{Zn}$ poisoning in the foal. Can J Comp Med 36:348-359.

Wilson BL, Mitchell DL. 1991. Trace metal study of sediment samples near electrical generating facility. J Environ Sci Health A26:493-509.

*Windholz M. 1983. Merck index. 10th ed. Rahway, NJ: Merck \& Co., Inc., 1455-1458.

*Windom HL, Byrd JT, Smith RG Jr, et al. 1991. Inadequacy of NASQAN data for assessing metal trends in the nation's rivers. Environ Sci Technol 25:1137-1142.

*Witschi HR, Last JA. 2001. Toxic responses of the respiratory system. In: Klaassen CD, ed. Casarett \& Doull's toxicology: The basic science of poisons. 6 ed. New York, NY: McGraw-Hill,515-534.

Wolnik KA, Fricke FL, Capar SG, et al. 1983a. Elements in major raw agricultural crops in the United States: 1. Cadmium and lead in lettuce, peanuts, potatoes, soybeans, sweet corn, and wheat. J Agric Food Chem 31:1240-1244.

Wolnik KA, Fricke FL, Capar SG, et al. 1983b. Elements in major raw agricultural crops in the United States: 2. Other elements in lettuce, peanuts, potatoes, soybeans, sweet corn, and wheat. J Agric Food Chem 31:1244-1249.

Wolnik KA, Fricke FL, Capar SG, et al. 1985. Elements in major raw agricultural crops in the United States: 3. Cadmium, lead, and eleven other elements in carrots, field corn, onions, rice, spinach, and tomatoes. J Agric Food Chem 33:807-811.

*Wong PK. 1988. Mutagenicity of heavy metals. Bull Environ Contam Toxicol 40:597-603.

Wong WY, Merkus HMWM, Thomas CMG, et al. 2002. Effects of folic acid and zinc sulfate on male factor subfertility: A double-blind, randomized, placebo-controlled trial. Fertil Steril 77:491-498.

*Woo W, Gibbs DL, Hooper PL, et al. 1983. The effect of dietary zinc on high-density lipoprotein synthesis. Nutr Rep Int 27:499-502.

Wood JPM, Osborne NN. 2003. Zinc and energy requirements in induction of oxidative stress to retinal pigmented epithelial cells. Neurochem Res 28(10):1525-1530.

Wormser U, Benzakine S. 1991. Increased levels of hepatic and renal metallothionein in the rat and guinea-pig after percutaneous application of zinc chloride. Bull Environ Contam Toxicol 46(2):249-254. 
9. REFERENCES

Xu B, Chia S-E, Ong C-N. 1994. Concentrations of cadmium, lead, selenium, and zinc in human blood and seminal plasma. Biol Trace Elem Res 40(1):49-57.

Xu P, Price J, Wise A, et al. 1992. Interaction of inositol phosphates with calcium, zinc and histidine. J Inorg Biochem 47(2):119-130.

*Yadrick MK, Kenney MA, Winterfelt EA. 1989. Iron, copper, and zinc status: Response to supplementation with zinc or zinc and iron in adult females. Am J Clin Nutr 49:145-150.

Yamaguchi M. 1993. Regulatory effects of zinc and copper on the calcium transport system in rat liver nuclei: Relation to SH-groups in the releasing mechanism. Biochem Pharmacol 45(4):943-948.

*Yamaguchi M, Takahashi K, Okada S. 1983. Zinc-induced hypocalcemia and bone resorption in rats. Toxicol Appl Pharmacol 67:224-228.

Yamataka A, Pringle KC, Wyeth J. 1998. A case of zinc chloride ingestion. J Pediatr Surg 33(4):660662.

*Yang CL, Du XH, Zou WZ, et al. 1991. Protective effect of zinc induced metallothionein synthesis on gentamicin nephrotoxicity in rats. Ren Fail 13(4):227-232.

Yap CK, Ismail A, Tan SG, et al. 2002. Correlations between speciation of $\mathrm{Cd}, \mathrm{Cu}, \mathrm{Pb}$ and $\mathrm{Zn}$ in sediment and their concentrations in total soft tissue of green-lipped mussel Perna viridis from the west coast of Peninsular Malaysia. Environ Int 28:117-126.

Yasui M, Ota K, Garruto RM. 1991. Aluminum decreases the zinc concentration of soft-tissues and bones of rats fed a low calcium magnesium diet. Biol Trace Elem Res 31(3):293-304.

*Yatsuyanagi J, Iwai K, Ogiso T. 1987. Suppressive effect of zinc on some functions of neutrophils: Studies with carrageenan-induced inflammation in rats. Chem Pharm Bull (Tokyo) 35:699-704.

*Yeats PA. 1988. The distribution of trace metals in ocean waters. Sci Total Environ 72:131-149.

Yeung GS, Schauer CS, Zlotkin SH. 2001. Fractional zinc absorption using a single isotope tracer. Eur J Clin Nutr 55:1098-1103.

Yim WW-S. 1976. Heavy metal accumulation in estuarine sediments in a historical mining of Cornwall. Mar Pollut Bull 7:147-150.

Yokoi K, Egger NG, Ramanujam VMS, et al. 2003. Association between plasma zinc concentration and zinc kinetic parameters in premenopausal women. Am J Physiol Endocrinol Metab 285:E1010-E1020.

*Yokoyama M, Koh J, Choi DW. 1986. Brief exposure to zinc is toxic to cortical neurons. Neurosci Lett 71:351-355.

Yoon J-S, Yoon J-Y, Oh H-M. 2004. Effect of zinc supplementation on iron status in Type II diabetes mellitus patients. FASEB J 18(4-5):120. 
9. REFERENCES

*Yoshida M, Fumukmoto M, Kishimoto T, et al. 1993. Effects of zinc, selenium, and calcium on the nephrotoxicity of cadmium in primary cultures of rat renal proximal epithelial cells. Biol Trace Elem Res 36(3):219-227.

Young LB, Harvey HH. 1991. Metal concentrations in chironomids in relation to the geochemical characteristics of surficial sediments. Arch Environ Contam Toxicol 21:202-211.

Yousef YA, Yu LL. 1992. Potential contamination of groundwater from copper, lead, and zinc in wet detention ponds receiving highway runoff. J Environ Sci Health 27A(4):1033-1044.

Yukawa M, Suzuki-Yasumota MS, Amano K, et al. 1980. Distribution of trace elements in the human body determined by neutron activation analysis. Arch Environ Health 35:36-44.

*Zachwieja Z, Chlopicka J, Schlegel-Zawadzka M, et al. 1995. Evaluation of zinc content in children's hair. Biol Trace Elem Res 47:141-145.

Zadorozhnaja TD, Little RE, Miller RK, et al. 2000. Concentrations of arsenic, cadmium, copper, lead, mercury, and zinc in human placentas from two cities in Ukraine. J Toxicol Environ Health A 61:255263.

*Zaporowska H, Wasilewski W. 1992. Combined effect of vanadium and zinc on certain selected hematological indices in rats. Comp Biochem Physiol 103C(1):143-147.

Zarcinas BA, Rogers SL. 2002. Copper, lead and zinc mobility and bioavailability in a river sediment contaminated with paint stripping residue. Environ Geochem Health 24:191-203.

Zavaleta N, Abrams S, Lonnerdal B. 2002. Iron (Fe) and zinc (Zn) absorption in 1-yr-old Peruvian children consuming a diet based on wheat flour fortified with Fe with/without $\mathrm{Zn}$ and/or vitamin A.

FASEB J 16:A749.

*Zerahn B, Kofoed-Enevoldsen A, Jensen BV, et al. 1999. Pulmonary damage after modest exposure to zinc chloride smoke. Resp Med 93:885-890.

Zhang H. 2004. In-situ speciation of $\mathrm{Ni}$ and $\mathrm{Zn}$ in freshwaters: Comparison between DGT measurements and speciation models. Environ Sci Technol 38(5):1421-1427.

Zheng M, Fang M. 2000. Correlations between organic and inorganic species in atmospheric aerosols. Environ Sci Technol 34:2721-2726.

Zhou JR, Fordyce CJ, Raboy V, et al. 1992. Reduction of phytic acid in soybean products improves zinc bioavailability in rats. J Nutr 122(12):2466-2473.

*Ziegler EE, Edwards BB, Jensen RL, et al. 1978. Absorption and retention of lead by infants. Pediatr Res 12:29-34.

Zirschky J, Crawford D, Norton L, et al. 1989. Metals removal in overland flow. J Water Pollut Control Fed 61:470-475.

Zodl B, Zeiner M, Sargazi M, et al. 2003. Toxic and biochemical effects of zinc in Caco-2 cells. J Inorg Biochem 97(4):324-330. 
9. REFERENCES

*Zoller WH, Gladney ES, Duce RA. 1974. Atmospheric concentrations and sources of trace metals at the South Pole. Science 183:198-200.

Zyleski RA, Siddiqui MS, Mayhew JF, et al. 2004. Zinc pennies in the esophagus. Pediatrics 113(1):176-177. 



\section{GLOSSARY}

Absorption-The taking up of liquids by solids, or of gases by solids or liquids.

Acute Exposure-Exposure to a chemical for a duration of 14 days or less, as specified in the Toxicological Profiles.

Adsorption-The adhesion in an extremely thin layer of molecules (as of gases, solutes, or liquids) to the surfaces of solid bodies or liquids with which they are in contact.

Adsorption Coefficient $\left(\mathbf{K}_{\mathbf{o c}}\right)$ - The ratio of the amount of a chemical adsorbed per unit weight of organic carbon in the soil or sediment to the concentration of the chemical in solution at equilibrium.

Adsorption Ratio (Kd) - The amount of a chemical adsorbed by sediment or soil (i.e., the solid phase) divided by the amount of chemical in the solution phase, which is in equilibrium with the solid phase, at a fixed solid/solution ratio. It is generally expressed in micrograms of chemical sorbed per gram of soil or sediment.

Anthropogenic — Caused by human activities.

Benchmark Dose (BMD) - Usually defined as the lower confidence limit on the dose that produces a specified magnitude of changes in a specified adverse response. For example, a BMD 10 would be the dose at the $95 \%$ lower confidence limit on a $10 \%$ response, and the benchmark response (BMR) would be $10 \%$. The BMD is determined by modeling the dose response curve in the region of the dose response relationship where biologically observable data are feasible.

Benchmark Dose Model—A statistical dose-response model applied to either experimental toxicological or epidemiological data to calculate a BMD.

Bioconcentration Factor (BCF) - The quotient of the concentration of a chemical in aquatic organisms at a specific time or during a discrete time period of exposure divided by the concentration in the surrounding water at the same time or during the same period.

Biomarkers-Broadly defined as indicators signaling events in biologic systems or samples. They have been classified as markers of exposure, markers of effect, and markers of susceptibility.

Cancer Effect Level (CEL) - The lowest dose of chemical in a study, or group of studies, that produces significant increases in the incidence of cancer (or tumors) between the exposed population and its appropriate control.

Carcinogen-A chemical capable of inducing cancer.

Case-Control Study-A type of epidemiological study that examines the relationship between a particular outcome (disease or condition) and a variety of potential causative agents (such as toxic chemicals). In a case-controlled study, a group of people with a specified and well-defined outcome is identified and compared to a similar group of people without outcome. 
Case Report-Describes a single individual with a particular disease or exposure. These may suggest some potential topics for scientific research, but are not actual research studies.

Case Series-Describes the experience of a small number of individuals with the same disease or exposure. These may suggest potential topics for scientific research, but are not actual research studies.

Ceiling Value-A concentration of a substance that should not be exceeded, even instantaneously.

Chronic Exposure-Exposure to a chemical for 365 days or more, as specified in the Toxicological Profiles.

Cohort Study-A type of epidemiological study of a specific group or groups of people who have had a common insult (e.g., exposure to an agent suspected of causing disease or a common disease) and are followed forward from exposure to outcome. At least one exposed group is compared to one unexposed group.

Cross-sectional Study-A type of epidemiological study of a group or groups of people that examines the relationship between exposure and outcome to a chemical or to chemicals at one point in time.

Data Needs-Substance-specific informational needs that if met would reduce the uncertainties of human health assessment.

Developmental Toxicity-The occurrence of adverse effects on the developing organism that may result from exposure to a chemical prior to conception (either parent), during prenatal development, or postnatally to the time of sexual maturation. Adverse developmental effects may be detected at any point in the life span of the organism.

Dose-Response Relationship-The quantitative relationship between the amount of exposure to a toxicant and the incidence of the adverse effects.

Embryotoxicity and Fetotoxicity-Any toxic effect on the conceptus as a result of prenatal exposure to a chemical; the distinguishing feature between the two terms is the stage of development during which the insult occurs. The terms, as used here, include malformations and variations, altered growth, and in utero death.

Environmental Protection Agency (EPA) Health Advisory-An estimate of acceptable drinking water levels for a chemical substance based on health effects information. A health advisory is not a legally enforceable federal standard, but serves as technical guidance to assist federal, state, and local officials.

Epidemiology-Refers to the investigation of factors that determine the frequency and distribution of disease or other health-related conditions within a defined human population during a specified period.

Genotoxicity-A specific adverse effect on the genome of living cells that, upon the duplication of affected cells, can be expressed as a mutagenic, clastogenic, or carcinogenic event because of specific alteration of the molecular structure of the genome.

Half-life-A measure of rate for the time required to eliminate one half of a quantity of a chemical from the body or environmental media. 
Immediately Dangerous to Life or Health (IDLH) - The maximum environmental concentration of a contaminant from which one could escape within 30 minutes without any escape-impairing symptoms or irreversible health effects.

Immunologic Toxicity-The occurrence of adverse effects on the immune system that may result from exposure to environmental agents such as chemicals.

Immunological Effects—Functional changes in the immune response.

Incidence-The ratio of individuals in a population who develop a specified condition to the total number of individuals in that population who could have developed that condition in a specified time period.

Intermediate Exposure-Exposure to a chemical for a duration of 15-364 days, as specified in the Toxicological Profiles.

In Vitro-Isolated from the living organism and artificially maintained, as in a test tube.

In Vivo-Occurring within the living organism.

Lethal Concentration( $\left.\mathrm{Lo}_{0}\right)\left(\mathbf{L C}_{\mathbf{L o}}\right)$ - The lowest concentration of a chemical in air that has been reported to have caused death in humans or animals.

Lethal Concentration( $\left.{ }_{50}\right)\left(\mathbf{L C}_{50}\right)$ - A calculated concentration of a chemical in air to which exposure for a specific length of time is expected to cause death in $50 \%$ of a defined experimental animal population.

Lethal Dose( $\left(_{\text {Lo }}\right)\left(\mathbf{L D}_{\mathbf{L O}}\right)$ - The lowest dose of a chemical introduced by a route other than inhalation that has been reported to have caused death in humans or animals.

Lethal Dose $\left.{ }_{50}\right)\left(\mathbf{L D}_{50}\right)$ - The dose of a chemical that has been calculated to cause death in $50 \%$ of a defined experimental animal population.

Lethal Time $\left.{ }_{50}\right)\left(\mathbf{L T}_{50}\right)$ - A calculated period of time within which a specific concentration of a chemical is expected to cause death in $50 \%$ of a defined experimental animal population.

Lowest-Observed-Adverse-Effect Level (LOAEL) - The lowest exposure level of chemical in a study, or group of studies, that produces statistically or biologically significant increases in frequency or severity of adverse effects between the exposed population and its appropriate control.

Lymphoreticular Effects-Represent morphological effects involving lymphatic tissues such as the lymph nodes, spleen, and thymus.

Malformations-Permanent structural changes that may adversely affect survival, development, or function.

Minimal Risk Level (MRL) — An estimate of daily human exposure to a hazardous substance that is likely to be without an appreciable risk of adverse noncancer health effects over a specified route and duration of exposure. 
Modifying Factor (MF)—A value (greater than zero) that is applied to the derivation of a Minimal Risk Level (MRL) to reflect additional concerns about the database that are not covered by the uncertainty factors. The default value for a MF is 1 .

Morbidity-State of being diseased; morbidity rate is the incidence or prevalence of disease in a specific population.

Mortality-Death; mortality rate is a measure of the number of deaths in a population during a specified interval of time.

Mutagen-A substance that causes mutations. A mutation is a change in the DNA sequence of a cell's DNA. Mutations can lead to birth defects, miscarriages, or cancer.

Necropsy-The gross examination of the organs and tissues of a dead body to determine the cause of death or pathological conditions.

Neurotoxicity-The occurrence of adverse effects on the nervous system following exposure to a chemical.

No-Observed-Adverse-Effect Level (NOAEL) - The dose of a chemical at which there were no statistically or biologically significant increases in frequency or severity of adverse effects seen between the exposed population and its appropriate control. Effects may be produced at this dose, but they are not considered to be adverse.

Octanol-Water Partition Coefficient $\left(\mathbf{K}_{\mathbf{0 w}}\right)$ - The equilibrium ratio of the concentrations of a chemical in $n$-octanol and water, in dilute solution.

Odds Ratio (OR) - A means of measuring the association between an exposure (such as toxic substances and a disease or condition) that represents the best estimate of relative risk (risk as a ratio of the incidence among subjects exposed to a particular risk factor divided by the incidence among subjects who were not exposed to the risk factor). An OR of greater than 1 is considered to indicate greater risk of disease in the exposed group compared to the unexposed group.

Organophosphate or Organophosphorus Compound-A phosphorus-containing organic compound and especially a pesticide that acts by inhibiting cholinesterase.

Permissible Exposure Limit (PEL) — An Occupational Safety and Health Administration (OSHA) allowable exposure level in workplace air averaged over an 8-hour shift of a 40-hour workweek.

Pesticide-General classification of chemicals specifically developed and produced for use in the control of agricultural and public health pests.

Pharmacokinetics-The dynamic behavior of a material in the body, used to predict the fate (disposition) of an exogenous substance in an organism. Utilizing computational techniques, it provides the means of studying the absorption, distribution, metabolism, and excretion of chemicals by the body.

Pharmacokinetic Model-A set of equations that can be used to describe the time course of a parent chemical or metabolite in an animal system. There are two types of pharmacokinetic models: data-based and physiologically-based. A data-based model divides the animal system into a series of compartments, which, in general, do not represent real, identifiable anatomic regions of the body, whereas the physiologically-based model compartments represent real anatomic regions of the body. 
Physiologically Based Pharmacodynamic (PBPD) Model—A type of physiologically based doseresponse model that quantitatively describes the relationship between target tissue dose and toxic end points. These models advance the importance of physiologically based models in that they clearly describe the biological effect (response) produced by the system following exposure to an exogenous substance.

Physiologically Based Pharmacokinetic (PBPK) Model-Comprised of a series of compartments representing organs or tissue groups with realistic weights and blood flows. These models require a variety of physiological information: tissue volumes, blood flow rates to tissues, cardiac output, alveolar ventilation rates, and possibly membrane permeabilities. The models also utilize biochemical information, such as air/blood partition coefficients, and metabolic parameters. PBPK models are also called biologically based tissue dosimetry models.

Prevalence-The number of cases of a disease or condition in a population at one point in time.

Prospective Study - A type of cohort study in which the pertinent observations are made on events occurring after the start of the study. A group is followed over time.

$\mathbf{q}_{1}{ }^{*}$ - The upper-bound estimate of the low-dose slope of the dose-response curve as determined by the multistage procedure. The $\mathrm{q}_{1} *$ can be used to calculate an estimate of carcinogenic potency, the incremental excess cancer risk per unit of exposure (usually $\mu \mathrm{g} / \mathrm{L}$ for water, $\mathrm{mg} / \mathrm{kg} / \mathrm{day}$ for food, and $\mu \mathrm{g} / \mathrm{m}^{3}$ for air).

Recommended Exposure Limit (REL) - A National Institute for Occupational Safety and Health (NIOSH) time-weighted average (TWA) concentration for up to a 10-hour workday during a 40-hour workweek.

Reference Concentration (RfC)—An estimate (with uncertainty spanning perhaps an order of magnitude) of a continuous inhalation exposure to the human population (including sensitive subgroups) that is likely to be without an appreciable risk of deleterious noncancer health effects during a lifetime. The inhalation reference concentration is for continuous inhalation exposures and is appropriately expressed in units of $\mathrm{mg} / \mathrm{m}^{3}$ or $\mathrm{ppm}$.

Reference Dose (RfD) — An estimate (with uncertainty spanning perhaps an order of magnitude) of the daily exposure of the human population to a potential hazard that is likely to be without risk of deleterious effects during a lifetime. The RfD is operationally derived from the no-observed-adverse-effect level (NOAEL, from animal and human studies) by a consistent application of uncertainty factors that reflect various types of data used to estimate RfDs and an additional modifying factor, which is based on a professional judgment of the entire database on the chemical. The RfDs are not applicable to nonthreshold effects such as cancer.

Reportable Quantity (RQ) - The quantity of a hazardous substance that is considered reportable under the Comprehensive Environmental Response, Compensation, and Liability Act (CERCLA). Reportable quantities are (1) 1 pound or greater or (2) for selected substances, an amount established by regulation either under CERCLA or under Section 311 of the Clean Water Act. Quantities are measured over a 24-hour period. 
Reproductive Toxicity-The occurrence of adverse effects on the reproductive system that may result from exposure to a chemical. The toxicity may be directed to the reproductive organs and/or the related endocrine system. The manifestation of such toxicity may be noted as alterations in sexual behavior, fertility, pregnancy outcomes, or modifications in other functions that are dependent on the integrity of this system.

Retrospective Study-A type of cohort study based on a group of persons known to have been exposed at some time in the past. Data are collected from routinely recorded events, up to the time the study is undertaken. Retrospective studies are limited to causal factors that can be ascertained from existing records and/or examining survivors of the cohort.

Risk-The possibility or chance that some adverse effect will result from a given exposure to a chemical.

Risk Factor-An aspect of personal behavior or lifestyle, an environmental exposure, or an inborn or inherited characteristic that is associated with an increased occurrence of disease or other health-related event or condition.

Risk Ratio-The ratio of the risk among persons with specific risk factors compared to the risk among persons without risk factors. A risk ratio greater than 1 indicates greater risk of disease in the exposed group compared to the unexposed group.

Short-Term Exposure Limit (STEL) - The American Conference of Governmental Industrial Hygienists (ACGIH) maximum concentration to which workers can be exposed for up to 15 minutes continually. No more than four excursions are allowed per day, and there must be at least 60 minutes between exposure periods. The daily Threshold Limit Value-Time Weighted Average (TLV-TWA) may not be exceeded.

Standardized Mortality Ratio (SMR) - A ratio of the observed number of deaths and the expected number of deaths in a specific standard population.

Target Organ Toxicity-This term covers a broad range of adverse effects on target organs or physiological systems (e.g., renal, cardiovascular) extending from those arising through a single limited exposure to those assumed over a lifetime of exposure to a chemical.

Teratogen-A chemical that causes structural defects that affect the development of an organism.

Threshold Limit Value (TLV)—An American Conference of Governmental Industrial Hygienists (ACGIH) concentration of a substance to which most workers can be exposed without adverse effect. The TLV may be expressed as a Time Weighted Average (TWA), as a Short-Term Exposure Limit (STEL), or as a ceiling limit (CL).

Time-Weighted Average (TWA) —An allowable exposure concentration averaged over a normal 8-hour workday or 40-hour workweek.

Toxic Dose $\left(_{50}\right)\left(\mathbf{T D}_{50}\right)$ - A calculated dose of a chemical, introduced by a route other than inhalation, which is expected to cause a specific toxic effect in $50 \%$ of a defined experimental animal population.

Toxicokinetic-The absorption, distribution, and elimination of toxic compounds in the living organism. 
Uncertainty Factor (UF)—A factor used in operationally deriving the Minimal Risk Level (MRL) or Reference Dose (RfD) or Reference Concentration (RfC) from experimental data. UFs are intended to account for (1) the variation in sensitivity among the members of the human population, (2) the uncertainty in extrapolating animal data to the case of human, (3) the uncertainty in extrapolating from data obtained in a study that is of less than lifetime exposure, and (4) the uncertainty in using lowestobserved-adverse-effect level (LOAEL) data rather than no-observed-adverse-effect level (NOAEL) data. A default for each individual UF is 10; if complete certainty in data exists, a value of 1 can be used; however, a reduced UF of 3 may be used on a case-by-case basis, 3 being the approximate logarithmic average of 10 and 1 .

Xenobiotic-Any chemical that is foreign to the biological system. 



\section{APPENDIX A. ATSDR MINIMAL RISK LEVELS AND WORKSHEETS}

The Comprehensive Environmental Response, Compensation, and Liability Act (CERCLA) [42 U.S.C. 9601 et seq.], as amended by the Superfund Amendments and Reauthorization Act (SARA) [Pub. L. 99499], requires that the Agency for Toxic Substances and Disease Registry (ATSDR) develop jointly with the U.S. Environmental Protection Agency (EPA), in order of priority, a list of hazardous substances most commonly found at facilities on the CERCLA National Priorities List (NPL); prepare toxicological profiles for each substance included on the priority list of hazardous substances; and assure the initiation of a research program to fill identified data needs associated with the substances.

The toxicological profiles include an examination, summary, and interpretation of available toxicological information and epidemiologic evaluations of a hazardous substance. During the development of toxicological profiles, Minimal Risk Levels (MRLs) are derived when reliable and sufficient data exist to identify the target organ(s) of effect or the most sensitive health effect(s) for a specific duration for a given route of exposure. An MRL is an estimate of the daily human exposure to a hazardous substance that is likely to be without appreciable risk of adverse noncancer health effects over a specified duration of exposure. MRLs are based on noncancer health effects only and are not based on a consideration of cancer effects. These substance-specific estimates, which are intended to serve as screening levels, are used by ATSDR health assessors to identify contaminants and potential health effects that may be of concern at hazardous waste sites. It is important to note that MRLs are not intended to define clean-up or action levels.

MRLs are derived for hazardous substances using the no-observed-adverse-effect level/uncertainty factor approach. They are below levels that might cause adverse health effects in the people most sensitive to such chemical-induced effects. MRLs are derived for acute (1-14 days), intermediate (15-364 days), and chronic (365 days and longer) durations and for the oral and inhalation routes of exposure. Currently, MRLs for the dermal route of exposure are not derived because ATSDR has not yet identified a method suitable for this route of exposure. MRLs are generally based on the most sensitive chemical-induced end point considered to be of relevance to humans. Serious health effects (such as irreparable damage to the liver or kidneys, or birth defects) are not used as a basis for establishing MRLs. Exposure to a level above the MRL does not mean that adverse health effects will occur. 
MRLs are intended only to serve as a screening tool to help public health professionals decide where to look more closely. They may also be viewed as a mechanism to identify those hazardous waste sites that are not expected to cause adverse health effects. Most MRLs contain a degree of uncertainty because of the lack of precise toxicological information on the people who might be most sensitive (e.g., infants, elderly, nutritionally or immunologically compromised) to the effects of hazardous substances. ATSDR uses a conservative (i.e., protective) approach to address this uncertainty consistent with the public health principle of prevention. Although human data are preferred, MRLs often must be based on animal studies because relevant human studies are lacking. In the absence of evidence to the contrary, ATSDR assumes that humans are more sensitive to the effects of hazardous substance than animals and that certain persons may be particularly sensitive. Thus, the resulting MRL may be as much as 100-fold below levels that have been shown to be nontoxic in laboratory animals.

Proposed MRLs undergo a rigorous review process: Health Effects/MRL Workgroup reviews within the Division of Toxicology, expert panel peer reviews, and agency-wide MRL Workgroup reviews, with participation from other federal agencies and comments from the public. They are subject to change as new information becomes available concomitant with updating the toxicological profiles. Thus, MRLs in the most recent toxicological profiles supersede previously published levels. For additional information regarding MRLs, please contact the Division of Toxicology, Agency for Toxic Substances and Disease Registry, 1600 Clifton Road NE, Mailstop F-32, Atlanta, Georgia 30333. 


\section{MINIMAL RISK LEVEL (MRL) WORKSHEET}

$\begin{array}{ll}\text { Chemical name: } & \text { Zinc and compounds } \\ \text { CAS number: } & \\ \text { Date: } & \text { May 6, 2005 } \\ \text { Profile status: } & \text { Final Draft Post-Public } \\ \text { Route: } & \text { [ ] Inhalation [X] Oral } \\ \text { Duration: } & \text { [ ] Acute [X] Intermediate [ ] Chronic } \\ \text { Key to figure: } & 25 \\ \text { Species: } & \text { Human } \\ \text { MRL: } & 0.3[\mathrm{X}] \mathrm{mg} / \mathrm{kg} / \text { day [ ] } \mathrm{ppm} \mathrm{[} \mathrm{]} \mathrm{mg} / \mathrm{m}^{3}\end{array}$

Reference: Yadrick MK, Kenney MA, Winterfelt EA. 1989. Iron, copper, and zinc status: Response to supplementation with zinc or zinc and iron in adult females. Am J Clin Nutr 49:145-150.

Experimental design: Eighteen healthy women, ages 25-40 years, were given zinc gluconate supplements twice daily (50 mg supplemental zinc/day, or $0.83 \mathrm{mg}$ supplemental zinc/kg/day assuming a 60-kg mean body weight for healthy women) for a 10-week period (Yadrick et al. 1989). Blood was drawn from each subject prior to treatment for use as a referent. Erythrocyte superoxide dismutase (ESOD) activity declined over the 10-week supplementation period and, at 10 weeks, was significantly $(\mathrm{p}<0.05)$ lower $(47 \%$ decrease) than pretreatment values; a decrease at 6 weeks of exposure $(15 \%)$ was not statistically significant. ESOD levels are considered to be a sensitive indicator of systemic copper status. Ceruloplasmin levels were not altered. Serum zinc was significantly increased at both 6 and 10 weeks. There was also a significant decline in serum ferritin $(23 \%)$ and hematocrit (4\%) values at 10 weeks. In women similarly-exposed but also receiving $0.42 \mathrm{mg}$ supplemental iron/day, serum ferritin was increased at both 6 and 10 weeks of exposure, while serum ESOD levels were significantly decreased at 6 weeks $(24 \%)$ and 10 weeks $(47 \%)$.

Effects noted in study and corresponding doses: Statistically significant decreases in erythrocyte SOD and serum ferritin levels at $0.83 \mathrm{mg}$ supplemental zinc/kg/day. Since these effects were subclinical, they were designated as non-adverse, as described below.

Dose end point used for MRL derivation: Yadrick et al. (1989) reported a significant decrease in ESOD, which is considered to be a sensitive indicator of body copper status, in women exposed to $50 \mathrm{mg}$ supplemental zinc/day. Because the observed effect is considered to be a precursor event to the more severe symptoms seen with zinc-induced copper deficiency, rather than a toxic effect of itself, the $50 \mathrm{mg}$ supplemental zinc/day value is considered to be NOAEL. At the same exposure level, serum ferritin levels decreased from 36.6 to $28.2 \mu \mathrm{g} / \mathrm{L}$ (23\% decrease), which was statistically significant. According to the most recent NHANES data (cited in IOM 2000), the median range for serum ferritin levels in menstruating women is $36-40 \mu \mathrm{g} / \mathrm{L}$, while a value of $<12 \mu \mathrm{g} / \mathrm{L}$ represents depleted iron stores. Thus, the subjects dropped below the median range for women of their age group, but were still considerably above the level that would represent a depletion of iron stores; in the absence of other effects indicating changes in iron status, this subclinical effect was also designated as a NOAEL. Assuming a reference female body weight of $60 \mathrm{~kg}$, this represents $0.83 \mathrm{mg}$ zinc/ $\mathrm{kg} / \mathrm{day}$.

\section{[X] NOAEL [ ] LOAEL}


Uncertainty factors used in MRL derivation:

[ ] 1 [ ] 3 [ ] 10 (for use of a LOAEL)

[ ] 1 [ ] 3 [ ] 10 (for extrapolation from animals to humans)

[ ] 1 [X] 3 [ ] 10 (for human variability)

The intermediate oral MRL for zinc is derived as follows:

$$
\begin{aligned}
& \mathrm{MRL}=\mathrm{NOAEL} \div \mathrm{UF} \\
& \mathrm{MRL}=0.83 \mathrm{mg} \text { zinc/kg/day } \div 3 \\
& \mathrm{MRL}=0.3 \mathrm{mg} \text { zinc/kg/day }
\end{aligned}
$$

Was a conversion factor used from $\mathrm{ppm}$ in food or water to a $\mathrm{mg} /$ body weight dose? No.

Was a conversion used from intermittent to continuous exposure? If so, explain: No.

If an inhalation study in animals, list conversion factors used in determining human equivalent dose: Not applicable.

Other additional studies or pertinent information that lend support to this MRL:

It should be noted that the MRL is calculated based on the assumption of healthy dietary levels of zinc (and copper), and represents the level of exposure above and beyond the normal diet that is believed to be without an appreciable risk of toxic response.

Fischer et al. (1984) gave groups of 13 healthy adult male volunteers (ages not specified) 0 (cornstarch) or $25 \mathrm{mg}$ supplemental zinc (as zinc gluconate) twice daily for 6 weeks ( 0 or $0.71 \mathrm{mg}$ supplemental zinc/kg/day). Nonfasting blood samples were taken at the beginning and at biweekly intervals and tested for measures of copper status. ESOD activity decreased after 4 weeks in the supplement group and was significantly lower than controls by 6 weeks. An inverse correlation between plasma zinc levels and erythrocyte superoxide dismutase activity was also observed at 6 weeks. Plasma copper levels and levels of ferroxidase activity did not change during the course of the study.

Groups ( $\mathrm{n}=10-13)$ of postmenopausal women (mean age $64.9 \pm 6.7$ years) with an average body weight of $65.1 \pm 9.5 \mathrm{~kg}$ were evaluated for the effects of excess zinc exposure (Davis et al. 2000; Milne et al., 2001). After an initial equilibration period during which they received $2 \mathrm{mg} \mathrm{Cu}$ and $9 \mathrm{mg}$ zinc/day (the RDA for women of that age is $8 \mathrm{mg}$ zinc/day) for 10 days, subjects received either low (1 mg) or high ( $3 \mathrm{mg})$ copper diets, and either low $(3 \mathrm{mg})$ or high $(56 \mathrm{mg})$ zinc for 90 days; it is noteworthy that the "low copper" subjects were still receiving copper levels greater than the current RDA for copper. After a 10-day equilibration period, the study was repeated with the same copper level in the diet, such that each subject received both low and high zinc throughout the course of the study. Blood was drawn during each equilibration period, and twice monthly during the exposure periods. Levels during the equilibration periods were used as the referent for the exposure periods. Zinc supplementation resulted in significant increases in plasma and platelet zinc levels. In high-zinc subjects, increases were seen in bone-specific alkaline phosphatase levels ( 25\%) and extracellular superoxide dismutase ( 15\%), while significant decreases were seen in mononuclear white cell 5'-nucleotidase $(\sim 30 \%)$ and plasma 5'-nucleotidase activity $(\sim 36 \%)$. Slight $(<10 \%)$ changes were also seen in erythrocyte copper/zinc SOD and plasma free thyroxine. Other evaluated end points were not significantly modified by zinc supplementation. Copper status indicators were decreased by supplementation with zinc, including copper balance (total intake-total eliminated in urine and feces), serum-immunoreactive ceruloplasmin, platelet 
cytochrome-c oxidase activity, total cholesterol, glutathione, and glutathione peroxidase activity. No effect was seen on concentration of zinc in red blood cells or on indicators of iron status.

Groups of 9,13 , or 9 healthy white men were administered 0,50 , or $75 \mathrm{mg} /$ day supplemental zinc as zinc gluconate (total zinc intakes were $0.16,0.85$, and $1.10 \mathrm{mg}$ supplemental zinc/kg/day, respectively, based on mean group body weights) for 12 weeks (Black et al. 1988). The subjects were given instructions to avoid foods high in calcium, fiber, and phytic acid, dietary constituents that are known to decrease zinc absorption. Subjects were also told to restrict their intake of zinc-rich foods in order to minimize the variation in daily dietary zinc. There was a general decline in the mean serum HDL-cholesterol for the 75 -mg supplement group between weeks 6 and 12. HDL values for this group were significantly lower than those for the placebo group at weeks 6 and $12(\mathrm{p}<0.05)$. There was also a decline in the HDL values for the 50-mg group between weeks 8 through 12; however, this decline was not significantly different from that for the controls until the 12th week of treatment. Serum zinc, copper, total cholesterol, LDLcholesterol, and triglycerides did not appear to be affected by treatment.

Freeland-Graves et al. (1982) exposed groups of eight healthy women to $0,15,50$, or $100 \mathrm{mg}$ supplemental zinc as zinc acetate (approximately 0, 0.25, 0.83, or $1.7 \mathrm{mg}$ supplemental zinc/kg/day, assuming a reference female body weight of $60 \mathrm{~kg}$ ) daily for 60 days. In the highest exposure group only, plasma HDL-cholesterol was significantly reduced at 4 weeks of exposure, but not at any other timepoint examined. A correlation between dietary zinc and whole-blood copper was observed in treated subjects. In the 50 and $100 \mathrm{mg}$ groups, some bloating, nausea, and abdominal cramps were reported unless the supplement was taken with a large glass of water at mealtime.

Prasad et al. (1978) fed a patient with sickle cell anemia supplements of 150-200 mg supplemental zinc/day for 2 years. The supplement resulted in copper deficiency; serum copper and plasma ceruloplasmin levels were decreased. When copper was administered, the plasma ceruloplasmin levels became normal. In a follow-up study, of 13 patients on zinc therapy (similar treatment levels assumed), 7 patients had ceruloplasmin levels at the lower limit of normal after 24 weeks of dosing.

Agency Contact (Chemical Managers): Nickolette Roney, M.S.; Cassandra V. Smith, M.S.; Malcolm Williams, D.V.M., Ph.D. 



\section{APPENDIX B. USER'S GUIDE}

\section{Chapter 1}

\section{Public Health Statement}

This chapter of the profile is a health effects summary written in non-technical language. Its intended audience is the general public, especially people living in the vicinity of a hazardous waste site or chemical release. If the Public Health Statement were removed from the rest of the document, it would still communicate to the lay public essential information about the chemical.

The major headings in the Public Health Statement are useful to find specific topics of concern. The topics are written in a question and answer format. The answer to each question includes a sentence that will direct the reader to chapters in the profile that will provide more information on the given topic.

\section{Chapter 2}

\section{Relevance to Public Health}

This chapter provides a health effects summary based on evaluations of existing toxicologic, epidemiologic, and toxicokinetic information. This summary is designed to present interpretive, weightof-evidence discussions for human health end points by addressing the following questions:

1. What effects are known to occur in humans?

2. What effects observed in animals are likely to be of concern to humans?

3. What exposure conditions are likely to be of concern to humans, especially around hazardous waste sites?

The chapter covers end points in the same order that they appear within the Discussion of Health Effects by Route of Exposure section, by route (inhalation, oral, and dermal) and within route by effect. Human data are presented first, then animal data. Both are organized by duration (acute, intermediate, chronic). In vitro data and data from parenteral routes (intramuscular, intravenous, subcutaneous, etc.) are also considered in this chapter.

The carcinogenic potential of the profiled substance is qualitatively evaluated, when appropriate, using existing toxicokinetic, genotoxic, and carcinogenic data. ATSDR does not currently assess cancer potency or perform cancer risk assessments. Minimal Risk Levels (MRLs) for noncancer end points (if derived) and the end points from which they were derived are indicated and discussed.

Limitations to existing scientific literature that prevent a satisfactory evaluation of the relevance to public health are identified in the Chapter 3 Data Needs section.

\section{Interpretation of Minimal Risk Levels}

Where sufficient toxicologic information is available, ATSDR has derived MRLs for inhalation and oral routes of entry at each duration of exposure (acute, intermediate, and chronic). These MRLs are not 
meant to support regulatory action, but to acquaint health professionals with exposure levels at which adverse health effects are not expected to occur in humans.

MRLs should help physicians and public health officials determine the safety of a community living near a chemical emission, given the concentration of a contaminant in air or the estimated daily dose in water. MRLs are based largely on toxicological studies in animals and on reports of human occupational exposure.

MRL users should be familiar with the toxicologic information on which the number is based. Chapter 2, "Relevance to Public Health," contains basic information known about the substance. Other sections such as Chapter 3 Section 3.9, "Interactions with Other Substances," and Section 3.10, "Populations that are Unusually Susceptible" provide important supplemental information.

MRL users should also understand the MRL derivation methodology. MRLs are derived using a modified version of the risk assessment methodology that the Environmental Protection Agency (EPA) provides (Barnes and Dourson 1988) to determine reference doses (RfDs) for lifetime exposure.

To derive an MRL, ATSDR generally selects the most sensitive end point which, in its best judgement, represents the most sensitive human health effect for a given exposure route and duration. ATSDR cannot make this judgement or derive an MRL unless information (quantitative or qualitative) is available for all potential systemic, neurological, and developmental effects. If this information and reliable quantitative data on the chosen end point are available, ATSDR derives an MRL using the most sensitive species (when information from multiple species is available) with the highest no-observed-adverse-effect level (NOAEL) that does not exceed any adverse effect levels. When a NOAEL is not available, a lowest-observed-adverse-effect level (LOAEL) can be used to derive an MRL, and an uncertainty factor (UF) of 10 must be employed. Additional uncertainty factors of 10 must be used both for human variability to protect sensitive subpopulations (people who are most susceptible to the health effects caused by the substance) and for interspecies variability (extrapolation from animals to humans). In deriving an MRL, these individual uncertainty factors are multiplied together. The product is then divided into the inhalation concentration or oral dosage selected from the study. Uncertainty factors used in developing a substance-specific MRL are provided in the footnotes of the levels of significant exposure (LSE) tables.

\section{Chapter 3}

\section{Health Effects}

\section{Tables and Figures for Levels of Significant Exposure (LSE)}

Tables and figures are used to summarize health effects and illustrate graphically levels of exposure associated with those effects. These levels cover health effects observed at increasing dose concentrations and durations, differences in response by species, MRLs to humans for noncancer end points, and EPA's estimated range associated with an upper- bound individual lifetime cancer risk of 1 in 10,000 to 1 in 10,000,000. Use the LSE tables and figures for a quick review of the health effects and to locate data for a specific exposure scenario. The LSE tables and figures should always be used in conjunction with the text. All entries in these tables and figures represent studies that provide reliable, quantitative estimates of NOAELs, LOAELs, or Cancer Effect Levels (CELs).

The legends presented below demonstrate the application of these tables and figures. Representative examples of LSE Table 3-1 and Figure 3-1 are shown. The numbers in the left column of the legends correspond to the numbers in the example table and figure. 


\section{LEGEND}

\section{See Sample LSE Table 3-1 (page B-6)}

(1) Route of Exposure. One of the first considerations when reviewing the toxicity of a substance using these tables and figures should be the relevant and appropriate route of exposure. Typically when sufficient data exist, three LSE tables and two LSE figures are presented in the document. The three LSE tables present data on the three principal routes of exposure, i.e., inhalation, oral, and dermal (LSE Tables 3-1, 3-2, and 3-3, respectively). LSE figures are limited to the inhalation (LSE Figure 3-1) and oral (LSE Figure 3-2) routes. Not all substances will have data on each route of exposure and will not, therefore, have all five of the tables and figures.

(2) Exposure Period. Three exposure periods - acute (less than 15 days), intermediate (15364 days), and chronic (365 days or more) — are presented within each relevant route of exposure. In this example, an inhalation study of intermediate exposure duration is reported. For quick reference to health effects occurring from a known length of exposure, locate the applicable exposure period within the LSE table and figure.

(3) Health Effect. The major categories of health effects included in LSE tables and figures are death, systemic, immunological, neurological, developmental, reproductive, and cancer. NOAELs and LOAELs can be reported in the tables and figures for all effects but cancer. Systemic effects are further defined in the "System" column of the LSE table (see key number 18).

(4) Key to Figure. Each key number in the LSE table links study information to one or more data points using the same key number in the corresponding LSE figure. In this example, the study represented by key number 18 has been used to derive a NOAEL and a Less Serious LOAEL (also see the two "18r" data points in sample Figure 3-1).

(5) Species. The test species, whether animal or human, are identified in this column. Chapter 2, "Relevance to Public Health," covers the relevance of animal data to human toxicity and Section 3.4, "Toxicokinetics," contains any available information on comparative toxicokinetics. Although NOAELs and LOAELs are species specific, the levels are extrapolated to equivalent human doses to derive an MRL.

(6) Exposure Frequency/Duration. The duration of the study and the weekly and daily exposure regimens are provided in this column. This permits comparison of NOAELs and LOAELs from different studies. In this case (key number 18), rats were exposed to "Chemical x" via inhalation for 6 hours/day, 5 days/week, for 13 weeks. For a more complete review of the dosing regimen, refer to the appropriate sections of the text or the original reference paper (i.e., Nitschke et al. 1981).

(7) System. This column further defines the systemic effects. These systems include respiratory, cardiovascular, gastrointestinal, hematological, musculoskeletal, hepatic, renal, and dermal/ocular. "Other" refers to any systemic effect (e.g., a decrease in body weight) not covered in these systems. In the example of key number 18, one systemic effect (respiratory) was investigated.

(8) NOAEL. A NOAEL is the highest exposure level at which no harmful effects were seen in the organ system studied. Key number 18 reports a NOAEL of 3 ppm for the respiratory system, 
which was used to derive an intermediate exposure, inhalation MRL of $0.005 \mathrm{ppm}$ (see footnote "b").

(9) LOAEL. A LOAEL is the lowest dose used in the study that caused a harmful health effect. LOAELs have been classified into "Less Serious" and "Serious" effects. These distinctions help readers identify the levels of exposure at which adverse health effects first appear and the gradation of effects with increasing dose. A brief description of the specific end point used to quantify the adverse effect accompanies the LOAEL. The respiratory effect reported in key number 18 (hyperplasia) is a Less Serious LOAEL of $10 \mathrm{ppm}$. MRLs are not derived from Serious LOAELs.

(10) Reference. The complete reference citation is given in Chapter 9 of the profile.

(11) CEL. A CEL is the lowest exposure level associated with the onset of carcinogenesis in experimental or epidemiologic studies. CELs are always considered serious effects. The LSE tables and figures do not contain NOAELs for cancer, but the text may report doses not causing measurable cancer increases.

(12) Footnotes. Explanations of abbreviations or reference notes for data in the LSE tables are found in the footnotes. Footnote "b" indicates that the NOAEL of 3 ppm in key number 18 was used to derive an MRL of $0.005 \mathrm{ppm}$.

\section{LEGEND}

\section{See Sample Figure 3-1 (page B-7)}

LSE figures graphically illustrate the data presented in the corresponding LSE tables. Figures help the reader quickly compare health effects according to exposure concentrations for particular exposure periods.

(13) Exposure Period. The same exposure periods appear as in the LSE table. In this example, health effects observed within the acute and intermediate exposure periods are illustrated.

(14) Health Effect. These are the categories of health effects for which reliable quantitative data exists. The same health effects appear in the LSE table.

(15) Levels of Exposure. Concentrations or doses for each health effect in the LSE tables are graphically displayed in the LSE figures. Exposure concentration or dose is measured on the log scale "y" axis. Inhalation exposure is reported in $\mathrm{mg} / \mathrm{m}^{3}$ or $\mathrm{ppm}$ and oral exposure is reported in $\mathrm{mg} / \mathrm{kg} / \mathrm{day}$.

(16) NOAEL. In this example, the open circle designated $18 \mathrm{r}$ identifies a NOAEL critical end point in the rat upon which an intermediate inhalation exposure MRL is based. The key number 18 corresponds to the entry in the LSE table. The dashed descending arrow indicates the extrapolation from the exposure level of $3 \mathrm{ppm}$ (see entry 18 in the table) to the MRL of $0.005 \mathrm{ppm}$ (see footnote "b" in the LSE table).

(17) CEL. Key number 38m is one of three studies for which CELs were derived. The diamond symbol refers to a CEL for the test species-mouse. The number 38 corresponds to the entry in the LSE table. 
(18) Estimated Upper-Bound Human Cancer Risk Levels. This is the range associated with the upperbound for lifetime cancer risk of 1 in 10,000 to 1 in 10,000,000. These risk levels are derived from the EPA's Human Health Assessment Group's upper-bound estimates of the slope of the cancer dose response curve at low dose levels $\left(\mathrm{q}_{1}{ }^{*}\right)$.

(19) Key to LSE Figure. The Key explains the abbreviations and symbols used in the figure. 


\section{SAMPLE}

$1 \rightarrow \quad$ Table 3-1. Levels of Significant Exposure to [Chemical $x$ ] - Inhalation

\begin{tabular}{|c|c|c|c|c|c|c|c|c|c|}
\hline & & \multirow[b]{2}{*}{$\begin{array}{l}\text { Key to } \\
\text { figure }^{a}\end{array}$} & \multirow{2}{*}{\multicolumn{2}{|c|}{$\begin{array}{c}\text { Exposure } \\
\text { frequencyl } \\
\text { Species duration }\end{array}$}} & \multirow[b]{2}{*}{ System } & \multirow[b]{2}{*}{$\begin{array}{l}\text { NOAEL } \\
(p p m)\end{array}$} & \multicolumn{2}{|l|}{ LOAEL (effect) } & \multirow[b]{2}{*}{ Reference } \\
\hline & & & & & & & $\begin{array}{l}\text { Less serious } \\
(\mathrm{ppm})\end{array}$ & Serious (ppm) & \\
\hline \multirow[t]{2}{*}{2} & \multirow[t]{2}{*}{$\rightarrow$} & \multicolumn{8}{|c|}{ INTERMEDIATE EXPOSURE } \\
\hline & & & 5 & 6 & 7 & 8 & 9 & & 10 \\
\hline 3 & $\rightarrow$ & Systemic & $\downarrow$ & $\downarrow$ & $\downarrow$ & $\downarrow$ & $\downarrow$ & & $\downarrow$ \\
\hline \multirow[t]{7}{*}{4} & $\rightarrow$ & 18 & Rat & $\begin{array}{l}13 \mathrm{wk} \\
5 \mathrm{~d} / \mathrm{wk} \\
6 \mathrm{hr} / \mathrm{d}\end{array}$ & Resp & $3^{b}$ & 10 (hyperplasia) & & Nitschke et al. 1981 \\
\hline & & CHRONIC & KPOSURE & & & & & & \\
\hline & & Cancer & & & & & 11 & & \\
\hline & & & & & & & $\downarrow$ & & \\
\hline & & 38 & Rat & $\begin{array}{l}18 \mathrm{mo} \\
5 \mathrm{~d} / \mathrm{wk} \\
7 \mathrm{hr} / \mathrm{d}\end{array}$ & & & 20 & $\begin{array}{l}\text { (CEL, multiple } \\
\text { organs) }\end{array}$ & Wong et al. 1982 \\
\hline & & 39 & Rat & $\begin{array}{l}89-104 \mathrm{wk} \\
5 \mathrm{~d} / \mathrm{wk} \\
6 \mathrm{hr} / \mathrm{d}\end{array}$ & & & 10 & $\begin{array}{l}\text { (CEL, lung tumors, } \\
\text { nasal tumors) }\end{array}$ & NTP 1982 \\
\hline & & 40 & Mouse & $\begin{array}{l}79-103 \mathrm{wk} \\
5 \mathrm{~d} / \mathrm{wk} \\
6 \mathrm{hr} / \mathrm{d}\end{array}$ & & & 10 & $\begin{array}{l}\text { (CEL, lung tumors, } \\
\text { hemangiosarcomas) }\end{array}$ & NTP 1982 \\
\hline 12 & $\rightarrow$ & $\begin{array}{l}\mathrm{a} \text { The numb } \\
\mathrm{b} \text { Used to de } \\
\text { by an uncer }\end{array}$ & rrespond & diate inhala & $\begin{array}{l}\text { are 3-1. } \\
\text { Minimal }\end{array}$ & s. & $\mathrm{LO}^{-3} \mathrm{ppm} ; \mathrm{c}$ & adjusted for intermitte & exposure and divided \\
\hline
\end{tabular}




\section{SAMPLE}

13

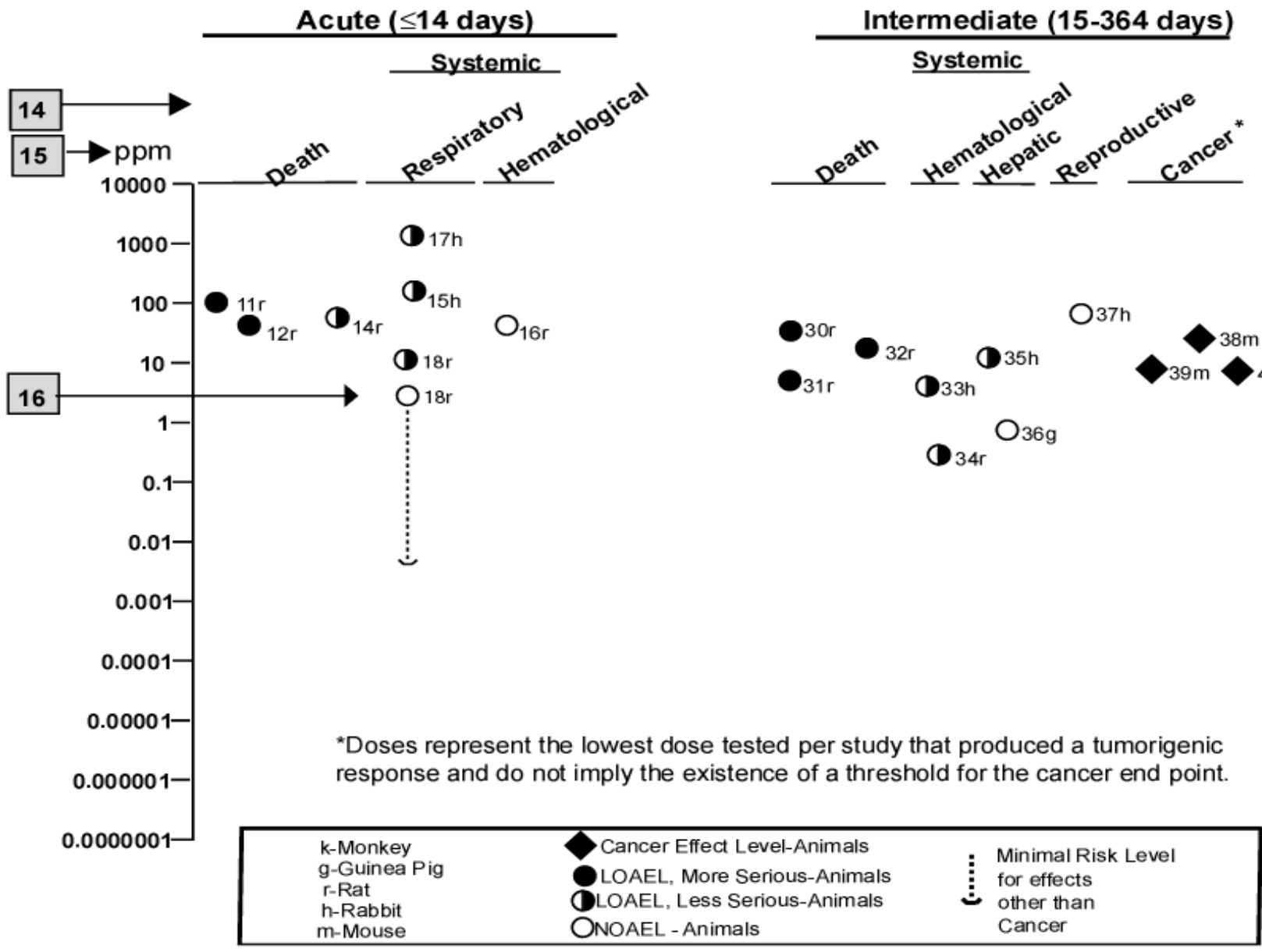

Figure 3-1. Levels of Significant Exposure to [Chemical X] - Inhalation

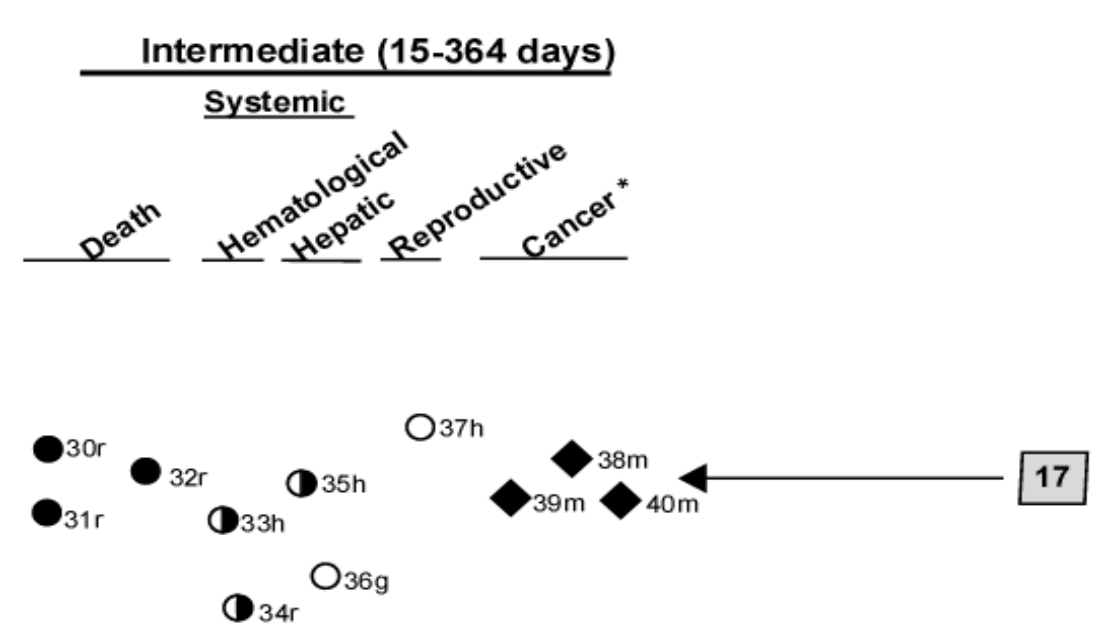





\section{APPENDIX C. ACRONYMS, ABBREVIATIONS, AND SYMBOLS}

\begin{tabular}{|c|c|}
\hline ACGIH & American Conference of Governmental Industrial Hygienists \\
\hline ACOEM & American College of Occupational and Environmental Medicine \\
\hline ADI & acceptable daily intake \\
\hline ADME & absorption, distribution, metabolism, and excretion \\
\hline AED & atomic emission detection \\
\hline AFID & alkali flame ionization detector \\
\hline AFOSH & Air Force Office of Safety and Health \\
\hline ALT & alanine aminotransferase \\
\hline AML & acute myeloid leukemia \\
\hline $\mathrm{AOAC}$ & Association of Official Analytical Chemists \\
\hline AOEC & Association of Occupational and Environmental Clinics \\
\hline $\mathrm{AP}$ & alkaline phosphatase \\
\hline APHA & American Public Health Association \\
\hline AST & aspartate aminotransferase \\
\hline $\mathrm{atm}$ & atmosphere \\
\hline ATSDR & Agency for Toxic Substances and Disease Registry \\
\hline AWQC & Ambient Water Quality Criteria \\
\hline BAT & best available technology \\
\hline $\mathrm{BCF}$ & bioconcentration factor \\
\hline BEI & Biological Exposure Index \\
\hline BMD & benchmark dose \\
\hline BMR & benchmark response \\
\hline BSC & Board of Scientific Counselors \\
\hline $\mathrm{C}$ & centigrade \\
\hline CAA & Clean Air Act \\
\hline $\mathrm{CAG}$ & Cancer Assessment Group of the U.S. Environmental Protection Agency \\
\hline CAS & Chemical Abstract Services \\
\hline $\mathrm{CDC}$ & Centers for Disease Control and Prevention \\
\hline CEL & cancer effect level \\
\hline CELDS & Computer-Environmental Legislative Data System \\
\hline CERCLA & Comprehensive Environmental Response, Compensation, and Liability Act \\
\hline CFR & Code of Federal Regulations \\
\hline $\mathrm{Ci}$ & curie \\
\hline $\mathrm{CI}$ & confidence interval \\
\hline $\mathrm{CL}$ & ceiling limit value \\
\hline CLP & Contract Laboratory Program \\
\hline $\mathrm{cm}$ & centimeter \\
\hline CML & chronic myeloid leukemia \\
\hline CPSC & Consumer Products Safety Commission \\
\hline CWA & Clean Water Act \\
\hline DHEW & Department of Health, Education, and Welfare \\
\hline DHHS & Department of Health and Human Services \\
\hline DNA & deoxyribonucleic acid \\
\hline DOD & Department of Defense \\
\hline DOE & Department of Energy \\
\hline DOL & Department of Labor \\
\hline DOT & Department of Transportation \\
\hline
\end{tabular}




\begin{tabular}{|c|c|}
\hline $\begin{array}{l}\text { DOT/UN/ } \\
\text { NA/IMCO }\end{array}$ & $\begin{array}{l}\text { Department of Transportation/United Nations/ } \\
\text { North America/International Maritime Dangerous Goods Code }\end{array}$ \\
\hline DWEL & drinking water exposure level \\
\hline ECD & electron capture detection \\
\hline ECG/EKG & electrocardiogram \\
\hline EEG & electroencephalogram \\
\hline EEGL & Emergency Exposure Guidance Level \\
\hline EPA & Environmental Protection Agency \\
\hline $\mathrm{F}$ & Fahrenheit \\
\hline $\mathrm{F}_{1}$ & first-filial generation \\
\hline FAO & Food and Agricultural Organization of the United Nations \\
\hline FDA & Food and Drug Administration \\
\hline FEMA & Federal Emergency Management Agency \\
\hline FIFRA & Federal Insecticide, Fungicide, and Rodenticide Act \\
\hline FPD & flame photometric detection \\
\hline $\mathrm{fpm}$ & feet per minute \\
\hline FR & Federal Register \\
\hline FSH & follicle stimulating hormone \\
\hline $\mathrm{g}$ & gram \\
\hline GC & gas chromatography \\
\hline $\operatorname{gd}$ & gestational day \\
\hline GLC & gas liquid chromatography \\
\hline GPC & gel permeation chromatography \\
\hline HPLC & high-performance liquid chromatography \\
\hline HRGC & high resolution gas chromatography \\
\hline HSDB & Hazardous Substance Data Bank \\
\hline IARC & International Agency for Research on Cancer \\
\hline IDLH & immediately dangerous to life and health \\
\hline ILO & International Labor Organization \\
\hline IRIS & Integrated Risk Information System \\
\hline $\mathrm{Kd}$ & adsorption ratio \\
\hline $\mathrm{kg}$ & kilogram \\
\hline $\mathrm{kkg}$ & metric ton \\
\hline $\mathrm{K}_{\mathrm{oc}}$ & organic carbon partition coefficient \\
\hline $\mathrm{K}_{\mathrm{ow}}$ & octanol-water partition coefficient \\
\hline $\mathrm{L}$ & liter \\
\hline LC & liquid chromatography \\
\hline $\mathrm{LC}_{50}$ & lethal concentration, $50 \%$ kill \\
\hline $\mathrm{LC}_{\mathrm{Lo}}$ & lethal concentration, low \\
\hline $\mathrm{LD}_{50}$ & lethal dose, $50 \%$ kill \\
\hline $\mathrm{LD}_{\mathrm{Lo}}$ & lethal dose, low \\
\hline LDH & lactic dehydrogenase \\
\hline LH & luteinizing hormone \\
\hline LOAEL & lowest-observed-adverse-effect level \\
\hline LSE & Levels of Significant Exposure \\
\hline $\mathrm{LT}_{50}$ & lethal time, $50 \%$ kill \\
\hline $\mathrm{m}$ & meter \\
\hline MA & trans,trans-muconic acid \\
\hline MAL & maximum allowable level \\
\hline $\mathrm{mCi}$ & millicurie \\
\hline MCL & maximum contaminant level \\
\hline
\end{tabular}




\begin{tabular}{|c|c|}
\hline MCLG & maximum contaminant level goal \\
\hline MF & modifying factor \\
\hline MFO & mixed function oxidase \\
\hline $\mathrm{mg}$ & milligram \\
\hline $\mathrm{mL}$ & milliliter \\
\hline $\mathrm{mm}$ & millimeter \\
\hline $\mathrm{mmHg}$ & millimeters of mercury \\
\hline $\mathrm{mmol}$ & millimole \\
\hline mppcf & millions of particles per cubic foot \\
\hline MRL & Minimal Risk Level \\
\hline MS & mass spectrometry \\
\hline NAAQS & National Ambient Air Quality Standard \\
\hline NAS & National Academy of Science \\
\hline NATICH & National Air Toxics Information Clearinghouse \\
\hline NATO & North Atlantic Treaty Organization \\
\hline NCE & normochromatic erythrocytes \\
\hline $\mathrm{NCEH}$ & National Center for Environmental Health \\
\hline NCI & National Cancer Institute \\
\hline ND & not detected \\
\hline $\begin{array}{l}\text { NFPA } \\
\text { ng }\end{array}$ & $\begin{array}{l}\text { National Fire Protection Association } \\
\text { nanogram }\end{array}$ \\
\hline NHANES & National Health and Nutrition Examination Survey \\
\hline NIEHS & National Institute of Environmental Health Sciences \\
\hline NIOSH & National Institute for Occupational Safety and Health \\
\hline NIOSHTIC & NIOSH's Computerized Information Retrieval System \\
\hline NLM & National Library of Medicine \\
\hline $\mathrm{nm}$ & nanometer \\
\hline nmol & nanomole \\
\hline NOAEL & no-observed-adverse-effect level \\
\hline NOES & National Occupational Exposure Survey \\
\hline NOHS & National Occupational Hazard Survey \\
\hline NPD & nitrogen phosphorus detection \\
\hline NPDES & National Pollutant Discharge Elimination System \\
\hline NPL & National Priorities List \\
\hline NR & not reported \\
\hline NRC & National Research Council \\
\hline NS & not specified \\
\hline NSPS & New Source Performance Standards \\
\hline NTIS & National Technical Information Service \\
\hline NTP & National Toxicology Program \\
\hline ODW & Office of Drinking Water, EPA \\
\hline OERR & Office of Emergency and Remedial Response, EPA \\
\hline OHM/TADS & Oil and Hazardous Materials/Technical Assistance Data System \\
\hline OPP & Office of Pesticide Programs, EPA \\
\hline OPPT & Office of Pollution Prevention and Toxics, EPA \\
\hline OPPTS & Office of Prevention, Pesticides and Toxic Substances, EPA \\
\hline OR & odds ratio \\
\hline OSHA & Occupational Safety and Health Administration \\
\hline OSW & Office of Solid Waste, EPA \\
\hline OTS & Office of Toxic Substances \\
\hline OW & Office of Water \\
\hline
\end{tabular}




$\begin{array}{ll}\text { OWRS } & \text { Office of Water Regulations and Standards, EPA } \\ \text { PAH } & \text { polycyclic aromatic hydrocarbon } \\ \text { PBPD } & \text { physiologically based pharmacodynamic } \\ \text { PBPK } & \text { physiologically based pharmacokinetic } \\ \text { PCE } & \text { polychromatic erythrocytes } \\ \text { PEL } & \text { permissible exposure limit } \\ \text { pg } & \text { picogram } \\ \text { PHS } & \text { Public Health Service } \\ \text { PID } & \text { photo ionization detector } \\ \text { pmol } & \text { picomole } \\ \text { PMR } & \text { proportionate mortality ratio } \\ \text { ppb } & \text { parts per billion } \\ \text { ppm } & \text { parts per million } \\ \text { ppt } & \text { parts per trillion } \\ \text { PSNS } & \text { pretreatment standards for new sources } \\ \text { RBC } & \text { red blood cell } \\ \text { REL } & \text { recommended exposure level/limit } \\ \text { RfC } & \text { reference concentration } \\ \text { RfD } & \text { reference dose } \\ \text { RNA } & \text { ribonucleic acid } \\ \text { RQ } & \text { reportable quantity } \\ \text { RTECS } & \text { Registry of Toxic Effects of Chemical Substances } \\ \text { SARA } & \text { Superfund Amendments and Reauthorization Act } \\ \text { SCE } & \text { sister chromatid exchange } \\ \text { SGOT } & \text { serum glutamic oxaloacetic transaminase } \\ \text { SGPT } & \text { serum glutamic pyruvic transaminase } \\ \text { SIC } & \text { standard industrial classification } \\ \text { SIM } & \text { selected ion monitoring } \\ \text { SMCL } & \text { secondary maximum contaminant level } \\ \text { SMR } & \text { standardized mortality ratio } \\ \text { SNARL } & \text { suggested no adverse response level } \\ \text { SPEGL } & \text { Short-Term Public Emergency Guidance Level } \\ \text { STEL } & \text { short term exposure limit } \\ \text { STORET } & \text { Storage and Retrieval } \\ \text { TD } & \text { toxic dose, } 50 \% \text { specific toxic effect } \\ \text { TLV } & \text { threshold limit value } \\ \text { TOC } & \text { total organic carbon } \\ \text { TPQ } & \text { threshold planning quantity } \\ \text { TRI } & \text { Toxics Release Inventory } \\ \text { TSCA } & \text { Toxic Substances Control Act } \\ \text { TWA } & \text { time-weighted average } \\ \text { UF } & \text { uncertainty factor } \\ \text { U.S. } & \text { United States } \\ \text { USDA } & \text { United States Department of Agriculture } \\ \text { USGS } & \text { United States Geological Survey } \\ \text { VOC } & \text { volatile organic compound } \\ \text { WBC } & \text { white blood cell } \\ \text { WHO } & \text { World Health Organization } \\ & \end{array}$




$\begin{array}{ll}> & \text { greater than } \\ \geq & \text { greater than or equal to } \\ = & \text { equal to } \\ < & \text { less than } \\ \leq & \text { less than or equal to } \\ \% & \text { percent } \\ \alpha & \text { alpha } \\ \beta & \text { beta } \\ \gamma & \text { gamma } \\ \delta & \text { delta } \\ \mu \mathrm{m} & \text { micrometer } \\ \mu \mathrm{g} & \text { microgram } \\ \mathrm{q}_{1}{ }^{*} & \text { cancer slope factor } \\ - & \text { negative } \\ + & \text { positive } \\ (+) & \text { weakly positive result } \\ (-) & \text { weakly negative result }\end{array}$





\section{APPENDIX D. INDEX}

absorbed dose

active transport

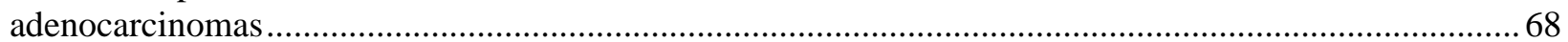

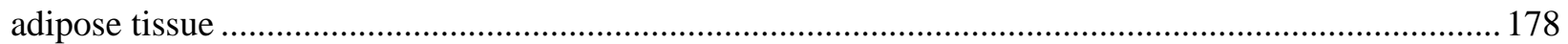

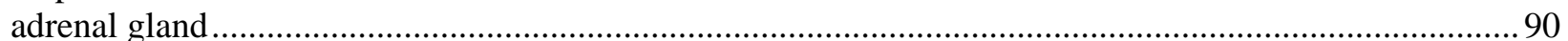

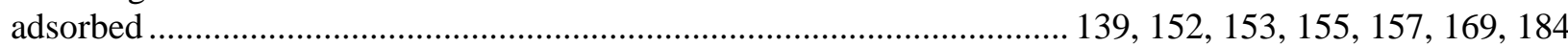

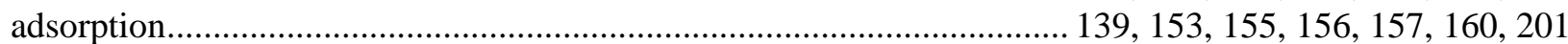

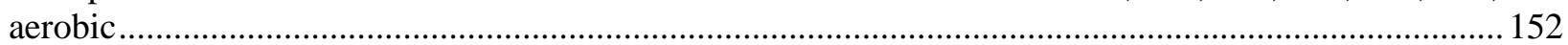

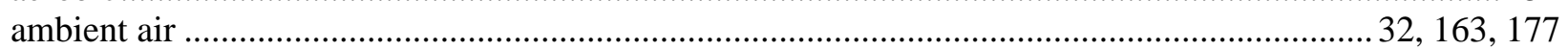

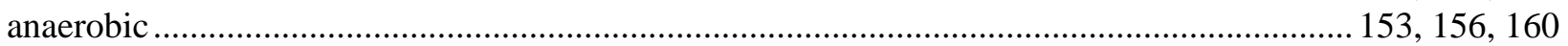

anemia ............................... 5, 13, 15, 17, 19, 34, 58, 59, 69, 88, 95, 98, 102, 107, 110, 111, 113, 202

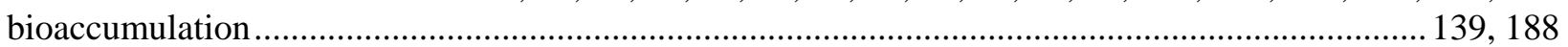

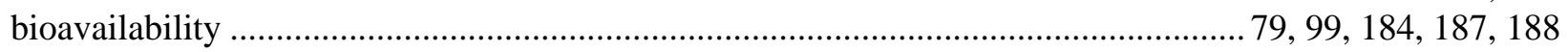

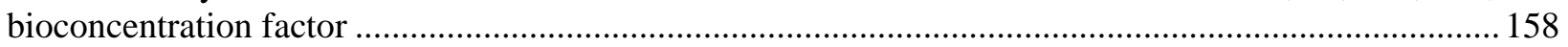

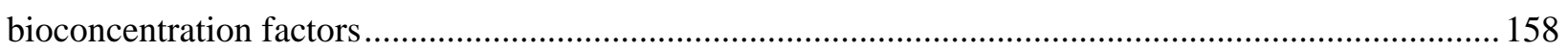

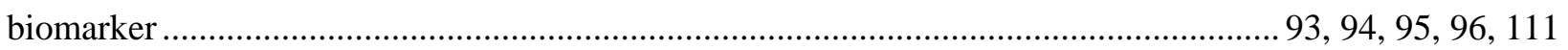

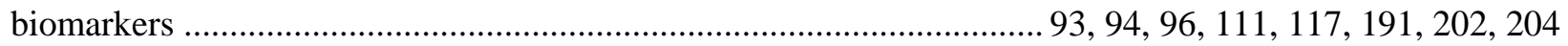

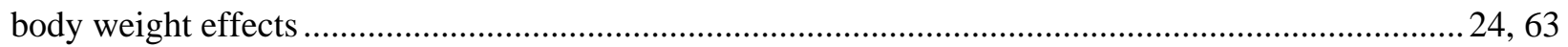

breast milk

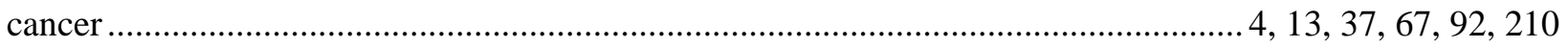

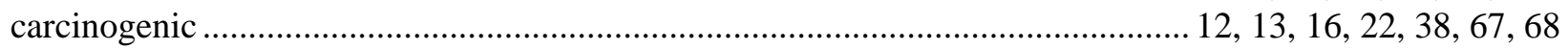

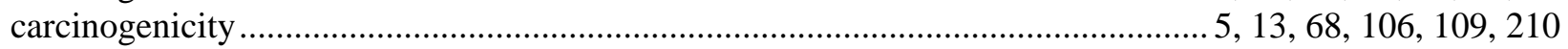

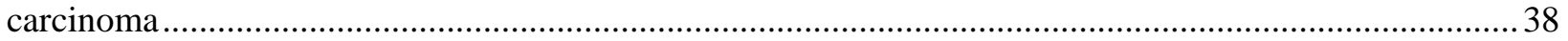

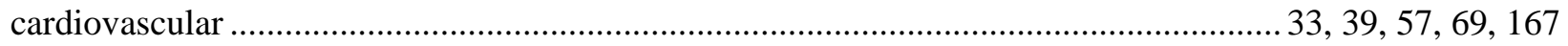

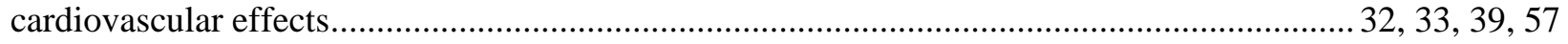

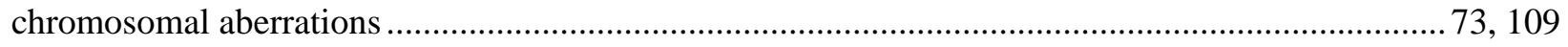

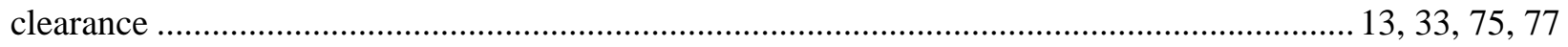

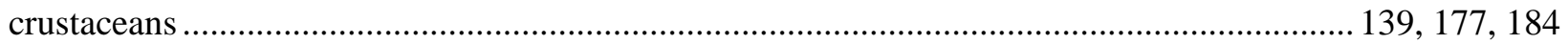

death

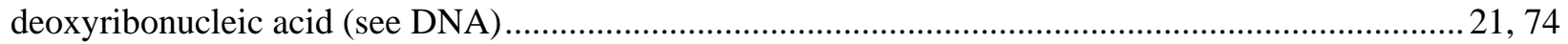

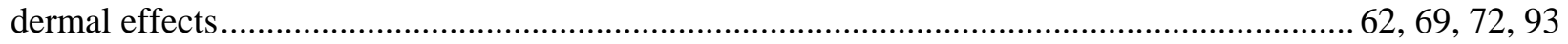

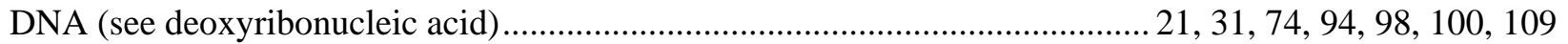

dopamine

endocrine

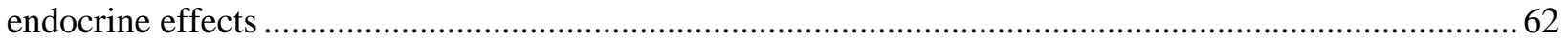

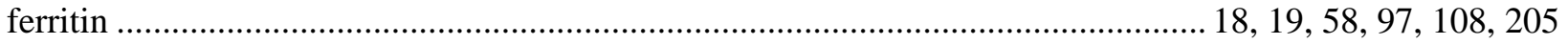

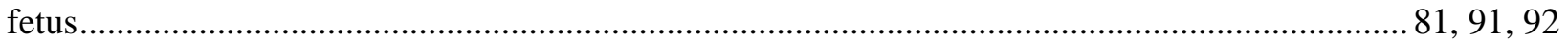

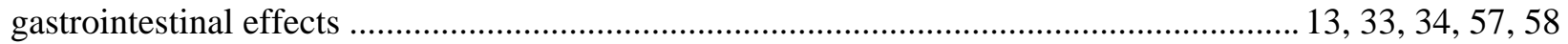

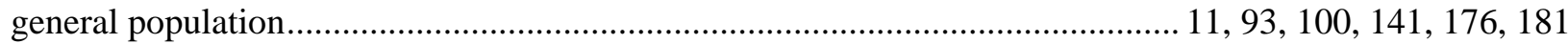

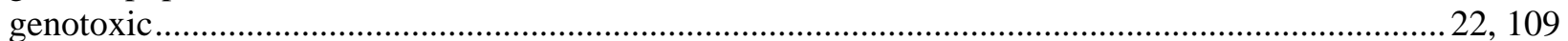

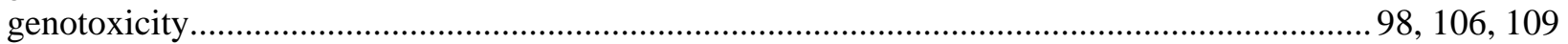

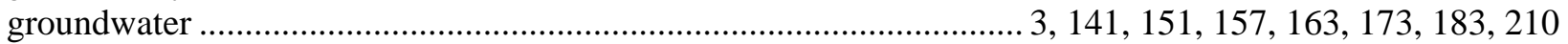

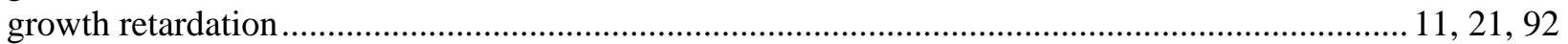

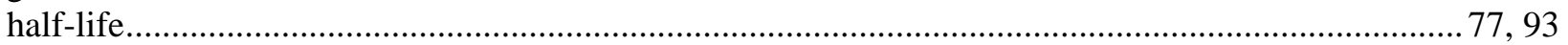

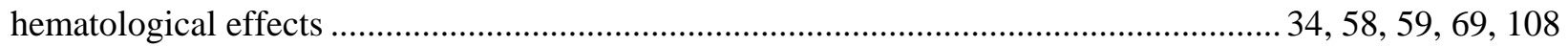

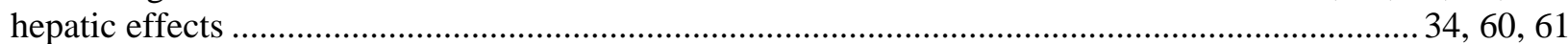

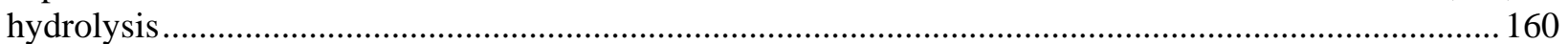

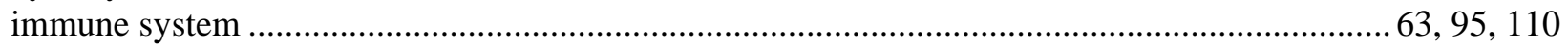




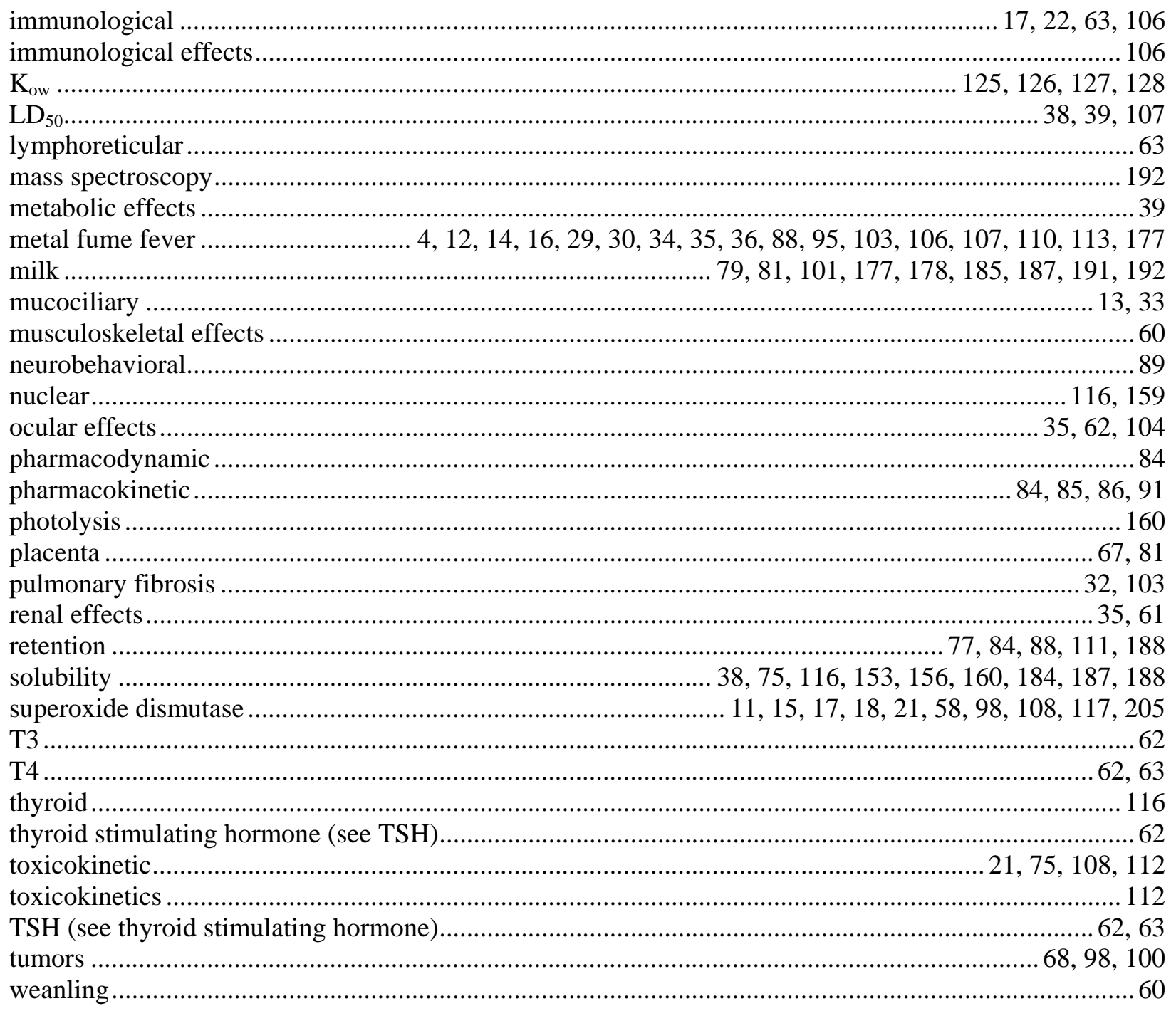


